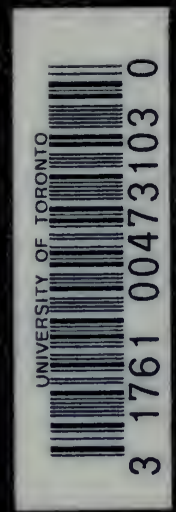







\title{
ONOIATOLOGIA ANATOMICA.
}

\author{
GESCHICHTE UND KRITIK
}

DER

\section{NA'TOMISCHEN SPRACHE DER GEGENWART,}

MIT BESONDERER BERÜCKSICHTIGUNG

IHRER BARBARISMEN, WIDERSINNIGKEITEN, TROPEN, UND GRAMMATIKALISCHEN FEHLER.

VON

\section{JOSEPH HYRTL,}

EMER. PROFESSOR DER ANATOMIE AN DER WIENER UNIVERSITÄT.

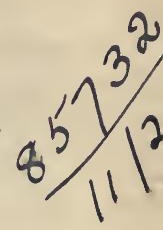

Barbarismis et soloecismis obsitae sunt res vestrae, et vitiorum deformitate pollutae.

Arnobius, adversus gentes, Lib. I., Cap. 59.

WIEN, 1880.

W I L H E L M B R A U M Ü L L E R

K. K. HOF- UND UNIVELSITÄTSBUCHHÄNDLER. 
QM

81
$H 82$ 


\section{VORWORT.}

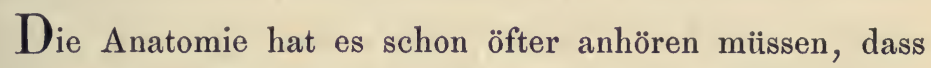
sie eine arbiträre und prinziplose Sprache spricht. Als die Naturwissenschaften im vorigen Jahrhundert ihre Sprache reformirten, unterliess es die Anatomie, ein Gleiches zu thun. Die Anatomen waren vollauf mit den Aufgaben ihrer Wissenschaft beschäftigt, und fanden keine Zeit, oder fühlten sich nicht aufgelegt, ihre Terminologie einer wissenschaftlichen Kritik zu unterziehen, um an die Stelle des Veralteten, Fehlerhaften, und Widersinnigen, Besseres zu setzen. Die fast gänzlich unbeachtet gelassenen, und nur für Spielereien gehaltenen Versuche von Dumas, Schreger, und Chaussier, die Nomenclatur der Muskeln nach einem einheitlichen Grundsatz neu zu gestalten, wirkten nicht ermuthigend für Arbeiten dieser Art, und die häufig missrathenen Bestrebungen Einzelner, statt der unwissenschaftlichen und albernen anatomischen Namen, passendere einzuführen, dienten nur dazu, das bunte Gewirre der anatomischen Kunstausdrücke zu vermehren, zu dessen Bewältigung Schreger, Pierer, und F. C. Lorenzo, eine eigene Wissenschaft - die anatomische Synonymik erschaffen mussten. Alte Angewöhnungen werden nicht blos 
im Leben, sondern auch in der Sprache ungern aufgegeben, denn das

$$
\text { "- - - parere minoribus, et quae }
$$

„Imberbes didicere, senes perdenda fateri,"

fällt uns Allen schwer.

So ist es denn vor der Hand beim Alten geblieben.

Wir können die von den griechischen und römischen Aerzten ererbten anatomischen Ausdrücke, welche auf physiologischen Vorstellungen unserer Vorfahren beruhen, wie z. B. Arteria, Parenchy̆ma, Anastomōsis, Aponeurōsis, Glandula pinealis, Cardia, Bronchus, Torcŭlar, aus Pietät gegen das Alterthum noch ferner dulden, wenngleich diese Vorstellungen schon lange ganz andere geworden sind, und die betreffenden Worte, bei dem jetzigen Zustand unserer Kenntnisse, gar keinen Sinn mehr haben. Aber wir können nicht gleichgiltig zusehen, wenn die jüngere Generation, von dem in der französischen und

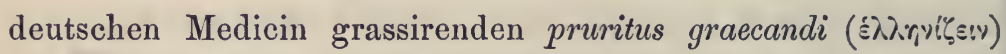
angesteckt wird, und sich darin gefällt, für unbedeutende anatomische Wahrnehmungen, lange griechische Worte zu schmieden, um dadurch ihren Abhandlungen einen gelehrten und interessanten Anstrich zu geben. Und was für Worte! Die meisten derselben werden zwar, ausser von ihren Erfindern, von Niemand gebraucht. Sie blieben deshalb auch in diesem Buche unberücksichtigt, indem ich nur jene auf's Korn nahm, welche eine weitere Verbreitung gefunden haben. Ist denn unsere Muttersprache, welche in der Wahl der anatomischen Benennungen immer das Richtigste zu treffen wusste, nicht reich und bildbar genug, um allen anatomischen Beobachtungen zu bezeichnenden Namen zu verhelfen, und die zur leidigen Ziererei gewordene Sucht nach Fremdwörtern, als gänzlich 
unberechtigt und überflüssig erscheinen zu lassen? Quid enim ineptius et magis ridiculum cogitari potest, quam vocibus graecis, contra omnes linguae regulas et usum efformatis, ad significandas res uti, quae eodem, quo scribitur, sermone, sive is latinus sit, sive vernaculus, aeque commode et breviter, multoque aptius ad intelligendum exprimi possunt (C. G. Kühn, De inepta cognitionis graeci sermonis simulatione, in Opusc. acad. Vol. II, pag. 269).

Die Anatomie scheint es ferner nicht zu wissen, dass sie eine Menge Worte in einem ganz anderen Sinne gebraucht, als ihnen im guten Latein zukommt. So sind z. B. die Nervi cardiaci nicht Nerven des Herzens, sondern herzkranke Nerven, - das Epigastrium nicht Magengegend, sondern Ba uchwand, - die Vesica fellea nicht Gallenblase, sondern gallbittere Blase, - die Glandulae sebaceae nicht talgbereitende, sondern aus Talg gemachte Drüsen, - die Sutura mendosa nicht falsche Naht, sondern fehlerreiche Naht, - die Vasa lymphatica nicht Lymphgefässe, sondern wahnsinnige Gefässe, - die Vasa serosa nicht Wassergefässe, sondern wässerige Gefüsse, - der Canalis tubarius nicht Tubenkanal, sondern trompetenmachender Kanal, - der Vermis bombycinus cerebelli nicht Seidenwurm, sondern seidener Wurm, - der Thalamus opticus nicht Sehhügel, sondern Sehkammer, das Os cribrosum nicht Siebbein, sondern siebreiches Bein, - das Os palatinum nicht Gaumenbein, sondern das zum Berg Palatium gehörige, auch kaiserliche Bein, - der Musculus risorius nicht Lachmuskel, sondern lächerlicher Muskel, - der Musculus complexus und vastus nicht durchflochtener und dicker Muskel, sondern umarmter und verödeter Muskel, - der Flexor sublimis und profundus nicht oberflächlicher und tiefliegender Beuger, sondern in die L uft 
ragender und bodenlos tiefer Beuger, - das Neurilema nicht Nervenscheide, sondern Nervenwille, - der Nervus patheticus nicht der Leidenschaftsnerv, sondern der leidende, der gefühlvolle Nerv, - das Endothel nicht inneres Epithel, sondern Innenwarze, - die Orbita nicht Augenhöhle, sondern Wagengeleise, - Cilia nicht Wimperhaare, sondern Augenlider, - die Articulatio trochilodes nicht Radgelenk, sondern zaunkönigähnliches Gelenk, - die Vulva (richtig Volva) nicht äussere weibliche Scham, sondern Gebärmutter des Sclıweines, u. m. a. Die anatomische Sprache darf zwar, in der Wahl der Worte für neue Begriffe und Auffassungen, ihre Launen haben, weil sie jede Sprache hat; aber diese Launen dürfen nicht mit den unverbrüchlichen Regeln der Grammatik und Etymologie in Conflict gerathen, "quas penes arbitrium est, et jus, et norma dicendi“.

Noch grösser ist das Heer der neulateinischen und neugriechischen Barbarismen, mit welchen schon die älteren Anatomen, ohne es $\mathrm{zu}$ wissen, ihre Sprache verunstaltet haben, und mit deren Aufgeben die jüngeren sicher nichts verlieren würden. Ich erwähne: Albuginea, Antibrachium, Arciformis, Articulatio, Basilaris, Cavitas, Cerumen, Colatorium, Cytoblasten (für Zellenkerne, vi nominis aber Zellensprossen), Digitationes, Disdiaclasten, Duodenum, Ejaculatorius, Embryo, Plur. Embryones (statt des richtigen Embryon, Plur. Embrya), Endosmosis und Exosmosis (richtig Eisothesis und Exothesis), Excrescentia (richtig Exstantia, Cic.), Excretorius, Fibrosus (statt Fibratus), Fontanella, Hallux, Imbibitio, Interosseus, Interscapulium, Lacrimalis, Neurhymen (Nervenscheide), Nucha, Ovarium (richtig Oophoron), Ossa rapho-geminantia, Pedunculus, Perilympha, Pia und dura mater, Plica, Pneumogastricus, Promontorium (richtig Promun- 
turium, von promineo), Protuberantia, Pulmonalis und Lumbalis (sprachrichtig Pulmonarius und Lumbaris), Pyriformis, Ramificatio, Retina, Rotula, Salvatella, Sclerotica, Secundinae, Semitendinosus und Semimembranosus, Supra- und Infraspinatus, Suspensorius, Synciput, Trachea (richtig Trachīa), Tractus foraminulentus (richtig foraminatus), Tricuspidalis (statt Tricuspis), Trochiter und Trochantin, Tuberositas, Urinaculum (statt Urachus), Urinarius (statt Urinalis), Uropoeticus, Uvea, Vacuolae, Valvula (richtig Valvola), Vernix (gar nicht lateinisch, sondern neugriechisch $\beta$ epvixn, spanisch berniz), wie auch alle Muskel- und Nervennamen in glossus, fast alle Muskelnamen in ideus, und eine bedauerliche Menge anderer. Wer dieses sehr unvollständige Register leichter und schwerer Sprachvergehen überblickt, sollte er nicht daran gemahnt werden, dass es Zeit wäre, an eine vorzunehmende Läuterung und Verbesserung des anatomischen Vocubulars zu denken?

Die anatomische Sprache reformiren zu wollen, konnte mir nicht in den Sinn kommen. Dazu gehört ein ad hoc gewählter Ausschuss sprachkundiger Anatomen, mit philologischer Assistenz, - eine Academia della crusca anatomica. Ich hatte nur die Absicht, die Nothwendigkeit einer Reform Jenen anschaulich zu machen, welche sich die Mühe nehmen wollen, dieses Buch zu durchblättern. Sie werden, so hoffe ich, ihm die Anerkennung nicht versagen, eine nothwendige Vorarbeit für jene Reform, wenn sie je unternommen werden sollte, geliefert zu haben, indem es zeigt, wo das Verbessern zu beginnen hätte. Die Reinigung der anatomischen Sprache würde unausbleiblich auch jene der medicinischen anregen, welche noch viel schlechter ist, als die anatomische, da sie nicht für das Wesen, sondern nur für allerlei Zeichen und Erscheinungen 
der Krankheiten, figürliche Namen besitzt. Entzündung ohne Flamme, Brand ohne Feuer, und tausend andere Absurditäten kennt nur die Medicin.

Was ich nebenbei über Benennungen der Organe nach ihren vermeintlichen Entdeckern, über Ursprung, Schicksale und Verwandtschaften, über Etymologie, Synonymik und Orthographie der anatomischen Kunstworte angeführt habe, wird den Anatomen, welchen an der Correctheit ihrer Sprache und an der geschichtlichen Entwicklung derselben, etwas gelegen ist, zur unterhaltenden Belehrung dienen. Einiges davon dürfte auch den Sprachforschern nicht unwillkommen sein. Von den prosodischen Fehlern wurden nur die ärgsten gerügt, da diesen Gegenstand bereits J. S. Löwenstein (Die medicinische Prosodie, Berlin, 1838) ausführlich behandelt hat.

Ich weiss, dass Schriften solchen Inhalts, nicht das Los beschieden ist, so viel und so aufmerksam gelesen zu werden, wie confiscirte politische Brochuren. Dieses jedoch glaube ich von der Onomatologia anatomica erwarten zu dürfen, dass, auf ihre Anregung hin, wenigstens die von jedem anatomischen Autor leicht anzubringenden Correcturen grammatikalischer Fehler und sprachlichen Unsinnes nicht ausbleiben werden. Mit dem Object meiner ehemaligen Berufswissenschaft, kann ich mich, in der Zurückgezogenheit meines jetzigen Lebens, nicht mehr beschäftigen. So habe ich mich denn an die Worte gemacht, auf welche das Horazische „cadentque, quae nunc sunt in honore vocabula", Anwendung findet.

Perchtoldsdorf bei Wien, im März, 1880.

Jos. Hyrt1. 


\section{INHALTSVERZEICH NISS.}

1. Abdomen

2. Acetabulum und Acceptabulum ..... 3

3. Acromium . . . . . 4

4. Adiposus . . . . . . 6

5. Adnata und Agnata . . 7

6. Aëreus . . . . . . 9

7. Aeus und eus . . . 10

8. Ala und ihre Arten. 12

9. Albuginea . . . . 15

10. Allantois . . . . . 17

11. Alvus, Alveus, und Alveolus . . . . . 19

12. Amnios oder Amnion?. 21

13. Ampulla . . . . . 22

14. Amygdalae . . . . 25

15. Anastomōsis . . . . 27

16. Ancon und Anconaeus quartus . . . . . 30

17. Angiologia . . . . . 31

18. Aniscalptor . . . . 33

19. Antibrachium . . . . 34

20. Antihelix . . . . . 36

21. Anus und Annulus . 37

22. Aorta und Arcus aortae 39
23. Aponeurosis . . . 41

24. Apophysis und Epiphysis 43

25. Aquula Cotunnii und $\mathrm{Hu}$ mor aqueus. . . . . 44

26. Arachnoidea, alt und neu 46

27. Arbor vitae und Palma plicata . . . . . 48

28. Area und Areola . . 49

29. Arteria und Vena. . . 51

30. Arthrodia. . . . .. 52

31. Articulatio . . . . 53

32. Arytaenoideus. . . . 57

33. Astragalus . . . . 59

34. Atlas und Epistropheus -

35. Atrabiliarius . . . . 62

36. Atrium . . . . . 63

37. Auriculae cordis . . 64

38. Azygos . . . . . . 66

39. Basilaris . . . . 68

40. Basilica. . . . . . -

41. Blastema und Cytoblastema . . . . . . 69

42. Bregma und Bregmaticus 70

43. Bronchus . . . . . 71

44. Bursae mucosae. 
45. Calamus seriptorius. .

Seite

46. Calcaneus oder Calcaneum?

47. Calcar avis

48. Calix oder Calyx? .

49. Callosus .

50. Calva und Calvaria.

51. Camera und Fornix

52. Canalis und Foramen, - Hiatus und Trajectus

53. Canthus und Encanthis

54. Capillitium und Verwandtes

55. Capsulae.

56. Caput gallinaginis

57. Cardiacus

58. Caro und Caruncula

59. Carotis . . . . .

60. Carpus und Metacarpus

61. Cartilago .....

62. Cauda equina . . .

63. Cava . . . . .

64. Cavitas und ihre Verwandten .... 100

65. Cella und Cellula . 101

66. Cephalica .... 103

67. Cerumen

68. Chiasma .

69. Choana, alt und neu

70. Choledochus und Cholecystis

71. Chorda

72. Chorion

73. Choroidea oder Chorioidea?

74. Chymificatio und Chylificatio

100

105

107

108 109

111

113

114
75. Cilia . . . . 116

76. Cisterna . . . 119

77. Clavicula . . . . 120

78. Clitoris. . . . 122

79. Соссух . . . . 123

80. Cochlea . . . . 125

81. Coecum . . . . 128

82. Coeliaca . . . . 130

83. Coleus . . . . . 132

84. Colon . . . . 134

85. Columella cochleae . 135

86. Communicans faciei . -

87. Complexus .... - -

88. Conarium s. Glandula pinealis . . . . 136

89. Conchae narium und andere Conchae. . 138

90. Condylus. . . . 141

91. Confluens . . . 144

92. Conjugata . . . 145

93. Conjunctiva. . . 146

94. Coracoideus. . . 147

95. Cornu Ammonis . 148

96. Cornua limacum . . 149

97. Coronoideus . . . 150

98. Cotyle und Cotyledones . . . . . 151

99. Coxa, Coxendix, und Anchae . . . 153

100. Cranium . . . 156

101. Cremaster einst und jetzt. . . . . 157

102. Cribrosus und Cribrum 160 103. Cricoideus . . . 163 104. Crista galli. . . 164 105. Crotaphiticus . . 165 106. Crureus und Cruralis . 165 
107. Cryptae . . . 166

108. Cubitus und Cubitaeus 168

109. Cucularis oder Cucullaris? . . . . . 169

110. Cunnus. . . . 171

111. Cupula .

112. Dartos, Erythroides, und Elytroides.. . . 172

113. Decidua . . . . 173

114. Deferens vas . . . 175

115. Dentes canini s. angulares, sapientiae, caysales .

116. Diaphragma . . 178

117. Diaphysis . . . 179

118. Digitationes hippocampi . . . . 180

119. Diploëticus oder Diploicus? - Diploë . 184

120. Disdiaclasten . . 186

121. Diverticulum . . . 187

122. Ductus, Aquaeductus, Meatus und Porus . 188

123. Ductus arteriosus Botalli .

124. Duodenum . . . 192

125. Dura und pia mater . 194

126. Embryo . . . . 195

127. Eınissaria . . . 196

128. Emulgentes. . . 198

129. Encauston dentis . . 199

130. Ependyma . . . 200

131. Ephippium und Sella turcica

132. Epicondylus und Epitrochlea

133. Epididymis .
134. Epistropheus . . . 204

135. Epiploon .

136. Epithelium und Endothelium . . . . 205

137. Extremitates . . 207

138. Fascia, Taenia, Vitta. 208

139. Fel und felleus. . 211

140. Femur und Femen. 212

141. Fibella und Fibula . 213

142. Fibra, fibrosus, und fibrina..... 215

143. Filamentum und Filum . . . . . 216

144. Fimbria . . . 217

145. Foetus oder Fetus? - 219

146. Folliculus

147. Fontanella

148. Foramen coecum . 221

149. Foramen obturatorium . . . . 223

150. Fornix tricuspidalis : 224

151. Fossa und Fovea . -

152. Frenulum. . . . 225

153. Furcula sterni . . 226

154. Galea . . . . 227

155. Ganglion . . . . 230

156. Gaster und Gastrula . 231

157. Gastrocnemius . . 232

158. Gelasinus . . . . 233

159. Gena, Geneion, und Mentum .... 235

160. Genu und geniculatum corpus . . . . 237

161. Gingiva . . . 238

162. Ginglymus . . . . -

163. Glabella . . . . 239

164. Glandula . . . 240 
Seite

165. Glenoidalis . . . 243

166. Glomer und Glomerulus ...... 244

167. Glottis . . . . 244

168. Glutaei. . . . 247

169. Gomphosis . . . . -

170. Habenula. . . 248

171. Hallux . . . . -

172. Helicotrema . . 249

173. Hepar und Jecur . -

174. Hilus renis . . . 250

175. Hircus, Hirquus • 251

176. Histo-oder Histiologie 253

177. Humerus . . . . -

178. Hyaloidea . . . 254

179. Hydroperione . . 255

180. Hymen. . . . 256

181. Hypoglossus . . 258

182. Hypophysis . . . 259

183. Ideus, eides, und odes als Endsilben anatomischer Beiwörter . . 260

184. Ideus, als Ausgang von Muskel-, Bänder- und Gelenksnamen . . 263

185. Ileum : . . . 265

186. Ilium, Ileum, Ilei, oder Ilii? . . . 266

187. Incus . . . . 267

188. Infundibulum . . 268

189. Innominatus s. Anonymus . . . . . -

190. Inguinalis . . . 272

191. Inscriptiones tendineae. . . . . 274

192. Interfemineum . . 275

193. Internodia . . . 276
194. Interosseus . . . . 276

195. Intestinum . . . 277

196. Iris . . . . 278

197. Ischiaticus oder Ischiadicus?.

198. Ischium der Alten und Neueren . . . . 279

199. Isthmus faucium und Fauces . . . 2 280

200. Jejunum . . . . 282

201. Jugum, Jugulum, Jugularis . . . . . 283

202. Labium und Labrum 285

203. Labyrinthus . . . 286

204. Lacertus . . . . 287

205. Lacinia.

206. Lacuna. . . . 289

207. Lacunar und Parimentum .... . 291

208. Laminae und Lamina spiralis. . . . . 292

209. Larynx . . . . 293

210. Lema und Gramia . 294

211. Lemniscus und La. queus .. . . . 295

212. Lien und Splen . . 296

213. Ligamentum . . . . -

214. Ligula und Lingula . 299

215. Linea alba abdominis 300

216. Lympha und lymphatica vasa. . . . . -

217. Lyra und Psalterium 302

218. Magma . . . 304

219. Mala . . . . 305

220. Malleus . . . 306

221. Malleolus . .. . . 309

222. Mandibula u. Maxilla 310 
223. Manubrium sterni. $\begin{array}{r}\text { Seite } \\ 312\end{array}$

224. Masseter . . . . 314

225. Mastoideus und Mamillaris . . . . 315

226. Matrix . . . . . 316

227. Meconium . . . 318

228. Mediana . . . . 319

229. Mediastinum . . . 320

230. Medulla oblongata. . 323

231. Meninx und Myrinx 324

232. Menisci . . . 325

233. Mesenterium und Mesaraion

234. Metacarpus

235. Metatarsus

236. Mitralis

237. Modiolus und Columella cochleae . . 331

238. Morsus diaboli und Morsus Adami . . 332

239. Motorius und Sensitivus.

240. Musculus und Lacertus ..... 335

241. Musculorum denominationes insolitae . . 337

242. Nares, Naris, Nasus.

243. Nervus, Nervosus, und Neurula . . . 352

244. Neurilema und Neurhymen . . . 353

245. Neuriorhabdia . . 355 246. Nucha . . . . . 356 247. Nucleus und Cytoblast 248. Nymphae und Myrtiformis . . . . . 359 249. Oesophagus. . . 361
250. Olecranon ... 361

251. Omentum. . . . 363

252. Orbita . . . . 365

253. Os tincae. . . 367

254. Ovarium . . . 368

255. Palatum durum und molle . . . . . 369

256. Palma und Vola manus 371

257. Palpebra . . . 373

258. Pampiniformis plexus

259. Pancreas . . . . 375

260. Panniculus, Pellicula, Membrana, Tunica . 378

261. Papilla. . . . . 379

262. Parenchyma, Prosenchyma, und Enchyma 380

263. Parotis und Ductus Stenonianus . . . 383

264. Patella und Rotula . 385 265. Patheticus . . . 386 266. Pectineus. . . 387 267. Pedunculus . . . . 388 268. Pelvis . . . . 389 269. Penis . . . . 391

270. Pennatus und Semipennatus . . . 396

271. Perilympha. . . 397

272. Perineum. . . . 398

273. Periosteum oder Periostium?

274. Peritoneum oder Peritonaeum? . . 400

275. Perone..... 401

276. Pes anserinus ... -

277. Pes hippocampi s. hippopotami major et minor ......4403 
5eite

278. Phalanges . . . 403

279. Philtrum . . . . 405

280. Pharynx . . . . 407

281. Phrenicus .... -

282. Placenta . . . . 409

283. Planta und Plantaris 411

284. Platysma myoides . . 412

285. Pleura. . . . . 414

286. Plica . . . . . 415

287. Pomum Adami, und Pomum s. Malum granatum : . . . . 416

288. Praecordia . . . . 418

289. Praeparantes Venae et Arteriae

290. Praeputium .

420

291. Processus Folii oder Processus Ravii . . . 422

292. Promontorium . . 423

293. Pronaus . . . . 424

294. Prostata und Parastata . . . . . 425

295. Protuberantia. . . 428

296. Psoas . . . . . 430

297. Pulmo oder Pulmones? 431

298. Pulpa . . . . . 433

299. Pupillae . . . . . 434

300. Pylorus . . . . 435

301. Pyriformis oder piriformis?

302. Quadrigeminus 303. Radius . 439

304. Ramificatio . . . . 440

305. Raninae..... 441

306. Raphe . . . . . 442

307. Rectum . . . . 446

308. Restiformis . . . 447
309. Retia, und Rete mirabile ..... . 448

310. Retina . . . . . 452

311. Retinaculum . . . 454

312. Risorius . . . . . 456

313. Rostrum cochleare. . 457

314. Sacrum und Kreuzbein

315. Salvatella . . . 458

316. Saphena . . . . 459

317. Scala tympani und Scala vestibula . . 460

318. Scaleni . . . . 462

319. Scaphoideus. . . . 463

320. Scapula, Spathula, Scoptula

321. Schindylesis . . . 465

322. Sclera oder Sclerotica? .

323. Scortum oder Scrotum?. . . . . . 467

324. Scrobiculus cordis und Praecordia . . . . 469

325. Scyphus Vieussenii • 470 326. Sebaceus . . . . 471

327. Secundinae... . 472

328. Semimembranosus und Semitendinosus . 474

329. Sesamoideus . . . 475

330. Sigmoideus und semilunaris . . . . . 476

331. Sinus . . . . . 478

332. Smegma . . . . 479

333. Soleus, Sohlenmuskel 481

334. Sphenoideus oder Sphecoideus? . . . 483

335. Sphincter . . . . 484 
Seite 336. Spina dorsi . . . . 485 337. Spina scapulae . . 488 338. Spinosus . . . . . 489 339. Splenius . . . . . 491 340. Stapes . . . . . 492 341. Sternum . . . . 495 342. Stomachus ... . . . 343. Stria und striatus. . 496 344. Stroma. . . . . 497 345. Stylus oder Stilus? . 499 346. Sublimis . . . . 500 347. Supra-et infraspinatus 501 348. Sura und suralis . . 503 349. Suspensorius . . . . 504 350. Sutura arcualis und arcuata. . . . . 505

351. Sutura coronalis und coronaria. . . . 507

352. Sutura lambdoidea, nicht lamdoidea . . 509

353. Sutura sagittalis . . 510 354. Sutura squamosa . . 511 355. Suturae verae et spuriae . . . . . 512

356. Sympathicus . . . 514 357. Symphysis , . . 517 358. Synciput und Occiput 518 359. Syndesmos oder Desmos . . . . 519

360. Synhymensis . . . 520 361. Synovia . . . 521 362. Talus . . . . 524

363. Tarsus und Metatarsus des Fusses, - Tarsus als Augenlidknorpel . 526 364. Tela. . . . . 530 365. Tendo Achillis . . 531
366. Teres . . . . . 533

367. Testa . . . . 535

368. Textus cellularis, Textura, und Structura . 537

369. Thalami nervorum opticorum . . . 539

370. Thenar, Hypothenar, Mesothenar, Opisthenar, und Parathenar . 541

371. Thorax. . . . . 543

372. Thymus . . . . 544

373. Thyreoidea . . . 547

374. Tibia . . . . . 549

375. Tonsillae . . . . 551

376. Torcular Herophili . 552

377. Trabs cerebri. . . 554

378. Trachea . . . . 555

379. Tractus . . . . 557

380. Tragusund Antitragus 558

381. Trapezius. . . . 560 .

382. Triangulus, trigōnus, und triquetrus . . 562

383. Tricuspidalis . . . 564

384. Trigeminus und Trifacialis. . . . . 566

385. Trochanter, Trochiter, und Trochantin . . 567

386. Trochlea, Musculus u. Nervus trochlearis. . 569 387. Tuba Eustachii . . 571 388. Tubae Fallopianae . . 573 389. Tuber, Tuberculum, Tuberositas . . . 577 390. Tympanum und Membrana tympani . . 579 391. Ulna . . . . . . 581 392. Umbo und Umbilicus. 
Seite 393. Urachus . . . . . 584

394. Urethra und Ureteres . . . . 585

395. Urocystis . . . . 586

396. Uterus . . . . . . -

397. Uvea und Iris . . 588

398. Uvula und Uva . . 591

399. Vacuolen . . . . 594

400. Vagus . . . . . -

401. Valvulae . . . . 596

402. Valvula cerebri magna . . . . . 598

403. Valvulae conniventes Kerkringii . . . . 599

404. Valvula Bauhini, Tulpii, oder Fallopiae? . 600

405. Vasa vorticosa Stenonis ...... 602

406. Vastus . . . . . 604
407. Vena portae oder Vena portarum?. . . . 605

408. Vermis cerebri vor Alters, und jetzt . . 607 409. Vernix caseosa . . 610 410. Verpa und Verpus. . 611 411. Vertebra . . . 612 412. Veru montanum . 614 413. Vesiculae seminales . 615 414. Vestibulum . . . 616 415. Vibrissae. . . . 617 416. Villi alt und neu. . 417. Vomer . . . . . 618 418. Vulva, Cunnus, und deren Synonyme . 620 419. Xiphoideus . . . . 623 420. Zona orbicularis. . - 421. Zygoma und Zygomaticus . . . . 625

\section{Ad notam lectoris.}

Von den zwei sehr häufig vorkommenden Abkürzungen LB und HL, bezieht sich die erstere auf die Schreibarten der Latino-Barbari im Mittelalter, die zweite auf $\mathrm{Hyrtl}$, Das Arabische und Hebräische in der Anatomie, Wien, 1879. 


\section{Abdomen.}

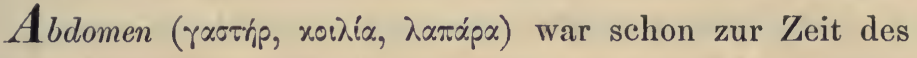
Plinius, ein veraltetes Wort. Es wurde nur auf den Unterleib trïchtiger Schweine angewendet, welcher, seiner strotzenden Milchdrüsen wegen, den Feinschmeckern als ein Leckerbissen ralt: porcae sumen optimum, si modo foetus non hauserit; antiqui "abdomen" vocabant $\left.{ }^{1}\right)$. Cicero und die Comödiendichter übertrugen Abdomen, vom Schweine auf den Menschen, jedoch nur im verächtlichen Sinne, als Wanst eines Schlemmers: wie in natus abdomini, und insatiabile abdomen. Venter und Alvus waren die einzigen anständigen Namen für Bauch, - der letztere aber in der Anatomie fast gar nicht gebraucht. Jetzt ist es anders geworden. Abdomen herrscht, mit dem von ihm gebildeten Eigenschaftswort: abdominalis, ganz allein in der Sprache der Anatomie und Medicin. Celsus war es, welcher in zwei Stellen seines Buches, das uralte Abdomen wieder zu Ehren brachte: a pube abdomen, sursum versus, ad praecordia pervenit ${ }^{2}$ ), und interdum vel ex ictu, vel retento diutius spiritu, interior abdominis membrana (Bauchfell) rumpitur ${ }^{3}$ ). Bauhinus und Spigelius wollten vom Abdomen nichts wissen:

1) Plinius, Hist. nat., Lib. 1I, Cap. 37, Sect. 84.

2) De medicina, Lib. IV, Cap. 1.

3) Lib. VII, Cap. 17.

Hyrt. Onomatologia anatomica. 
quia male ita vocatur ${ }^{1}$ ). Sie blieben, wie Vesal, steif und fest bei Venter.

Ueber die bei den Arabisten und Restauratoren der Anatomie im 14. und 15. Jahrhundert vorkommenden Ausdrücke für Unterleib, als: Mirach, Aqualiculus, Sumen, Ficteris, Specile und Itrum, sieh' HL, §. LXXIX, Mirach.

Zwei Ausdrücke, welche im erwähnten Paragraph nicht angeführt werden, weil sie mir erst nạchträglich unterkamen, will ich hier anreihen:

1. Physcon, meistens nur für einen fetten Unterleib, oder für das Hypogastrium. Фúc\%n treffen wir im Aristophanes, als dickes Gedärm und als Wurst, und Physcon = Dickwanst, war ein Spottname für Ptolemäus V., welcher seinen Bauch in einer Schlinge tragen musste. Die Aerzte bildeten in neuerer Zeit ihre Physconia daraus (Anschoppung des Unterleibes). Die Wurzel dieser Worte ist quó́w, aufblasen und blasen. Von ihr heisst der wasserblasende Walfisch, welcher uns das Spermacet liefert: Physeter.

2. Pantex im Valescus und Savonarola, ist ein Wort von gutem alten Adel. Es fällt ihm, gewöhnlich im Plural als pantices, im Plautus ${ }^{2}$ ) und Martial ${ }^{3}$ ) die Bedeutung als Dickdarm und Wurst zu. Unverkennbar wurde dieser pantex der Vater der italienischen pancia, der französischen panse, sowie des altdeutschen "Panzier" $=$ Panzer, ehemals jener Theil einer Rüstung, welcher den Unterleib. bedeckte, und zugleich als Brustharnisch diente.

Ueber die griechischen Benennungen des Unterleibes, sieh' die Artikel Gaster, Coeliaca, und Cava, in diesem Buche.

1) Anspielung auf die Schweine, im Theatrum anat. Bauhini Lib. I, Cap. 1, sub initio.

2) Pseudolus, Act. I, Sc. 2, Vers 50 .

3) Epigramm. VI, 64, 19. 


\section{Acetabulum und Acceptabulum.}

Acetabulum, Pfanne des Hüftbeins, schrieben die LatinoBarbari als Acceptabulum, "quia accipit caput femoris". Das ganze Mittelalter blieb beim Acceptabulum. Das Studium der Classiker lag damals im Argen; sonst hätte das echte Acetabulum, nicht durch eine vermeintliche Correctur entstellt werden können. Selbst die Codices des Plinius und Cato aus dieser Zeit, enthalten das Acceptabulum, statt Acetabulum (Forcell.). Die Verwandtschaft von Acetabulum mit Acetum, Essig, mag den Mönchen, welchen wir die ersten lateinischen Uebersetzungen der Hauptwerke arabischer und griechischer Aerzte zu verdanken haben, befremdlich vorgekommen sein. Sie existirt jedoch, und erklärt uns das Acetabulum ganz befriedigend. Nach Isidorus (Origines, $X X, 4$ ) und Apicius (De re culinaria, VIII, 7) ist Acetabulum ein Gefäss, in welchem aromatischer Essig auf die Tafel gestellt wurde, um das Brot

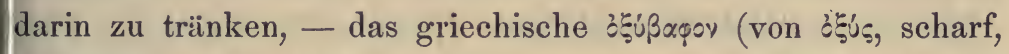
und $\rho \dot{\alpha} \pi \tau \omega$, eintauchen, woher auch Baptisma, die Taufe). Im Museum zu Neapel befindet sich ein solches Acetabulum aus feinem rothen Thon, welches an seinem Fuss das Wort $3 \xi$ Bapor eingebrannt zeigt $\left.{ }^{1}\right)$. Mit diesem Acetabulum, welches ziemlich gross ist, und zwei Henkel besitzt, hat die Pfanne des Hüftbeins sicher keine Aehnlichkeit, eher noch mit dem Acetabulum des Plinius, als Mass für den vierten Theil einer Hemina. Aber auch kleine, halbkugelige Schälchen, wie die türkischen Kaffeeschalen sind, hiessen Acetabula. Die Taschenspieler und Gaukler bedienten sich derselben zu allerlei Kunststïcken. Alciphron ${ }^{2}$ ) hat uns davon Kunde gegeben. Die Taschenspieler legten unter eines von mehreren umgestürzten Acetabulis ein Steinchen, oder eine Kugel, und eskamotirten

1) Abgebildet in Anthony Rich, Römische Alterthümer, pag. 7.

2) Epist. III, 20. 
sie von dem einen Näpfchen unter das andere: manuum dexteritate ita tractant, ut, cum credis, sub uno acetabulo esse, sub altero inveniatur (Forcell.). Seneca erwähnt die Acetabula et calculi praestigiatorum (Taschenspieler), in quibus fallacia ipsa delectat. Bei den modernen Kunstreitern sieht man es öfters, dass sie in die Luft geworfene Kugeln, während des schnellsten Reitens, mit Schälchen auffangen, welche nicht grösser als die Kugeln sind. Diese kleinen und halbsphärischen Schalen, sind das Vorbild des anatomischen Acetabulum, welches sich für immer, statt dem barbarischen Acceptabulum, in unserer Sprache installirt hat. Auch die. Blumenkelche werden im Plinius, metaphorisch Acetabula genannt.

Statt Acetabulum finden wir im Cels us s ${ }^{\text {) }}$ auch Sinus coxae, und bei den Arabisten sehr oft Pisside, seltener Bucella. Mehr hierüber bietet HI, §. LXX, Harcasach und Acceptabulum, und der Artikel Cotyle in diesem Buche. Bucella wird, höchst auffallender Weise, von den Arabisten sowohl für Gelenksgrube, als für kleine Gelenksköpfe gebraucht, z. B. für die Processus condyloidei des Hinterhauptbeins. Bucella kann nicht die Buccella des Martial sein, denn diese bedeutet "kleiner Mund". Eher wäre, als Wurzel, an das italienische bucare, aushöhlen, und buco, Loch, zu denken.

\section{Acromium,}

Die zwischen der seitlichen Halsgegend und dem Oberarm befindliche, eine weiche und gerundete Wölbung bildende Region des Oberleibes, hiess bei den Griechen $\tilde{\omega} \mu 0 s$, bei den Römern Humerus. Unmittelbar über der weichen Wölbung, fühlt man eine harte Stelle - die höchstgelegene an der Schulter. Sie entspricht der Verbindung des Schlüsselbeins mit dem Schulterblatt, und wurde axpóputov genannt, von žxpos,

1) De medicina, Lib. IX, Cap. 1. 
das äusserste, und ڤँ..oร, Schulter: extremum spinae scapulae cum jugulo (Schlüsselbein) connectitur, quem locum nonnulli anatomici acromion vocant ${ }^{1}$ ). In derselben Weise definirt Rufus das Acromion, als juguli scapularumque ossis copula ${ }^{2}$ ). Gal en nimmt aber Acromion noch in einem anderen Sinne: quidam, praeter ambo ossa, quae conjunguntur (clavicula und scapula), tertium os adesse inquiunt, quod in solis hominibus reperitur, idque

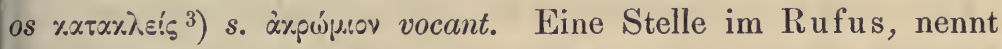
den vor-Galenischen Anatomen, Eudemus, als den Erfinder dieses selbstständigen $O s$ acromii $\left.{ }^{4}\right)$. Wir wissen, dasș das Acromion, als äusserstes Ende der Spina scapulae, zuweilen als ein besonderer, mit der Spina scapulae durch Knorpel zusammengelötheter Knochen auftritt. Sollte Eudemus diesen seltenen Fall gesehen, und denselben für den regelmässigen Zustand des Acromion gehalten haben? Möglich wäre es.

Auch bei der Galenischen Anschaunng des Acromion, als Verbindung des Schlüsselbeins mit der Spina scapulae, verblieb es nicht. Galen nannte selbst an mehreren Stellen, z. B. im 10. Capitel der Introductio s. Medicus, das äusserste Ende der Spina allein: Acromion. Die Nachwelt hielt an dieser Auffassung des Acromion für immer fest, und so haben wir es jetzt, als äusseres und breites Ende des Schulterblattgrates. Vesal führte, als Todfeind des Galen, seinen Summus humerus statt acromion ein, neben welchem es jetzt noch häufig erwähnt wird. Die deutsche Schulterhöhe und Grätenecke (Gratecke) besagen dasselbe. - Mit einem Schweinsrüssel hat das Acromion gar keine Aehnlichkeit. Das Rostrum porcinum (Pierer und Schreger) konnte nur durch eine Verwechslung des Acromion mit dem Processus coracoideus entstanden sein,

1) Oribasius, Anatomica ex Galeno, pag. 155.

2) De partibus hominis, pag. 29.

3) Im Pollux und Hesychius, finden wir $\alpha \alpha \tau \alpha \lambda \lambda$ sis, als Brustbeinende des Schlüsselbeins.

4) Op. cit., pag. 29. 
welcher bei den Latino-Barbari zuweilen, aber auch nur als Rostrum und Processus rostriformis (ohne Schwein) dazwischenkommt.

\section{Adiposus.}

Die Anatomie hat einen Panniculus adiposus, eine Capsula adiposa renum, mehrfache Strata adiposa, Lobuli adiposi, und Vesiculae adiposae (Fettlappen und Fettbläschen), eine Massa adiposa acetabuli, und eine Arteria und Vena adiposa' '), aber das römische Latein hat kein Adjectiv adiposus. Ein solches wurde erst von den Uebersetzern des Avicenna erfunden, und ist somit barbarisch.

Was die Anatomen mit adiposus sagen wollen, drückten die Römer mit adipatus, spät auch mit adipeus aus, wie z. B. cervix tauri adipea, der fette Nacken des Stieres, im Hieronymus zu lesen ist. Beide besagen: adipe onustus, und könnten das angemasste adiposus, mit Recht ausser Gebrauch setzen. - Nicht besser als adiposus, ist adipinus, welches gleichfalls von den Arabisten stammt, und ausschliesslich als Prädicat des fettreichen Netzes, Zirbus adipinus, gebraucht wurde.

Nur das weiche Fett wohlgenährter Thiere und Menschen, hiess Adeps. Das spisse Fett (quae concrescit) hiess Sebum, auch Sevum. Das aus Sebum gebildete sebaceus der Anatomie (Glandulae sebaceae), ist der lateinischen Sprache ebenso fremd, wie adiposus. Adeps wurde von den Römern, welche mehr auf die äusserlichen Heilmittel hielten, als auf die innerlichen, als Salbe gegen verschiedene Leiden verwendet. Es war ihnen nicht gleichgiltig, von welchem Thiere das Fett genommen

1) Die Ductus adiposi des Malpighi (De omento et adiposis ductibus, Bonon. 1665, Cap. C), welche das schon im Blute vorhandene Fett, aus den Capillargefässen in die Fettbläschen überführen, sind längst verschollen. 
wurde. Wir finden im Plinius ${ }^{1}$ ) Adeps suillus, vitulinus, aprugnus (Eberfett), vulpinus, ursinus, lupinus, anserinus, in bestimmten Krankheiten empfohlen, und im Vegetius²) auch

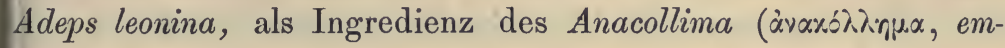
plastrum conglutinans). Wie Vegetius, gebraucht auch Celsus Adeps mit dem genus femininum, - alle anderen Classiker immer nur männlich. Thierisches und pflanzliches Fett (Oel), wurden als pinguedo zusammengefasst, und selbst der fruchtbare Acker campus pinguis (fetter Boden) genannt. Das jetzt noch officinelle Schweinschmalz, Axungia porci, führt seinen Namen von einem nicht medicinischen Gebrauch: $a b$ unguendis axibus. Alles Fett zum Einschmieren verschiedener Gegenstände, heisst deshalb unguen, und die Form desselben Unguentum (Salbe). Das Sch m e e r der Deutschen, ging ja auch aus schmieren hervor. Die

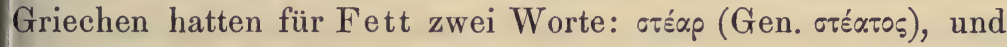
$\pi \varphi \varepsilon_{i} r_{\text {. }}$. Von letzterem haben wir die Pimelosis, Fettsucht, und von ersterem will ich sagen, dass es dem'ganz unrichtigen Stearin den Ursprung gab, welches richtig nur Steatin genannt werden darf, da, nach allgemein giltiger Regel, das von oréap zu formirende Adjectiv, aus dem Stamme, welcher im Genitiv zu 'lage tritt, nicht aus dem Nominativ dieses Wortes gebildet werden muss. Der Genitiv lautet aber otśatos, nicht oтéapos.

\section{Adnata und Agnata.}

Adnata und Agnata sind ältere Bezeichnungen der Bindehaut des Auges. Obwohl lautähnlich, und aus ad-nascor entstanden, sind beide Worte doch verschiedenen Sinnes, und können nicht einander substituirt werden. Während adnatus, als angewachsen, sich für die fragliche Haut des Auges brauchen lässt (adnata, quia oculo adnascitur), kann agnatus

1) Hist. nat., Lib. XXVIII, Cap. 11.

2) Ars veterinaria, Lib. III, Cap. 22. 
keineswegs dafür verwendet werden. Agnatus (adgnatus) hiess bei den römischen Juristen, ein nachgeborner Sohn, wenn schon ein rechtmässiger Erbe in der Familie vorhanden war. Auch die Anverwandten von väterlicher Seite, hiessen Agnati, und im Plinius werden Auswüchse des Pflanzenstengels, die Paraphyades des 'Theophilus, und überzählige Gliedmassen, als Agnata erwähnt: membra animalibus agnata, inutilia sunt, sicut sextus homini semper digitus ${ }^{1}$ ). Die Harre, welche die Neugebornen mit sich auf die Welt bringen, hiessen pili congeniti, die später wachsenden aber agnati: libidinosis congeniti pili maturius defluunt, agnati celerius crescunt ${ }^{2}$ ).

Aus dem Gesagten folgt, dass. Agnata für die Bindehaut nicht anwendbar ist, Adnata aber ganz gut passt, als Uebersetzung des von Galen gebrauchten Wortes \%xгx́quats (gíu, produco, фíopuxt, nascor). Galen erwähnt die Bindehaut, als eine Fortsetzung des Periosts der Augenhöhle: septima est

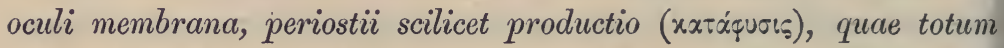
oculum cum ossibus colligat, simulque moventes ipsum musculos operit ${ }^{3}$ ). Ein anderer Galenischer Ausdruck für Bindehaut:

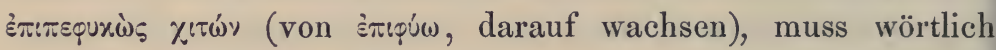
mit angewachsene Haut, d. i. adnata membrana, übersetzt werden. Gorraeus bemerkt hiezu: sic dicta, quod aliis, oculum constituentibus tunicis, forinsecus sit adnata ${ }^{4}$ ). Vesal, welcher keine griechischen Worte in der Anatomie dulden wollte, gab zuerst die Cataphysis des Galen, mit dem Worte Adnata zurück, welches richtiger und besser ist, als der viel ältere Name Conjunctiva, von welchem später. Seit Vesal ist die Adnata in der Anatomie, nur als Synonymon von Conjunctiva verblieben.

Vergleiche Artikel Conjunctiva.

I) Hist. nat., Lib. XI, Cap. 52, Sect. 113.

2) Plinius, Op. cit., Lib. XI, Cap. 40, Sect. 94.

3) De usu partium, Lib. V, Cap. 2, ad finem.

4) Definitiones medicae, pag. 152. 


\section{Aëreus.}

Während der Entdecker der bläschenförmigen Enden der Luftwege in den Lungen, M. Malpighi, dieselben Cellulae und Vesiculae pulmonales nannte ${ }^{1}$ ), schien es den Neueren besser, sie Vesiculae cëreae $\mathrm{zu}$ nennen, weil sie Luft enthalten. Um das Ungereimte dieser Benennung anschaulich zu machen, berufe ich mich auf die Anwendungen, welche aëreus (besser aërius) bei den Classikern gefunden hat. Aërius heisst 1., was sich in der Luft befindet: genus pennigerum et aërium, die Vögel im Plinius, aëriae nubes und aëria domus, Himmelsraum im Cicero, mel aërium im Virgil, der Honig, nach dem damaligen Glauben, dass der Honig mit dem Thau vom Himmel falle, und von den Bienen nur aufgesammelt, aber nicht erzeugt werde. 2. ist aërius ein Beiwort für hoch aufragende Bäume, Eichen und Cypressen, bei den Dichtern Catull und Virgil. 3. bezeichnet es die himmelblaue Farbe, und 4. alles Eitle und Luftige, wie spes aëria im Arnobius. Die Luft, für sich allein, kann keine Bläschen bilden. Vesiculae aëreae sind undenkbar. Zum Bläschen gehört vor Allem eine Membran in Bläschenform. Die Luftbläschen der Lunge sind also keine Vesiculae aëreae, sondern membranaceae. Dass diese Vesiculae Luft enthalten, könnte nur durch aëriferae ausgedrückt werden, welches sich auch als aërophorae nicht schlecht ausnehmen würde. Alveoli, für Luftbläschen der Lunge, gehört der neuesten Zeit an und ist verwerflich, da das Wort mit den Alveoli der Lymphdrüsen in Conflict geräth, und die zum Alveolus, Bienenzelle, gehörige Tiefe, wie sie an den Zahnfächern sich zeigt, den Luftzellen der Lunge abgeht. Warum man die traubig aggregirten Luftbläschen der Lunge, nicht Acini nennt, fällt Allen auf; die Lunge ist doch nach dem Typus einer acinösen Drüse gebaut. Die Spiramenta und Foraminula der Latino-

1) De pulmonibus, epistolae duae ad Borellum. Romae, 1661. 
Barbari, sind schon längst verschollen, wie auch ihre Fistulae (unsere Bronchien). Sie stellten sich das Ende der Luftwege in den Lungen, als eine Menge von Röhrchen vor, welche in die Wurzeln der Vena pulmonalis, damals Arteria venosa genannt, einmünden : ut aërem transmittant ad arteriam venosam, quae eum portat ad $\operatorname{cor}^{1}$ ), wo die Luft sich mit dem durch die Scheidewand der Kammern, aus dem rechten in den linken Ventrikel transsudirten Blute vermischt, und per effervescentiam, den Spiritus vitalis erzeugt, welchen die Aorta durch den ganzen Leib versendet. Präciser als im Berengarius, hat diese Ansicht nirgends verlautet: Inter istos sinus (Herzkammern), est paries densus et spissus (unser Septum ventriculorum), a Galeno diaphragma dictus, in quo sunt foramina plura parva; a dextro sinu in sinistrum tendentia, hinc sanguis subtiliatus a dextro in sinistrum meat, ubi in spiritum vitalem complete mutatur ${ }^{2}$ ).

\section{Aeus und eus.}

In dem Gebrauch der in aeus und eus endigenden Beiwörter, welche zur näheren Bezeichnung gewisser Muskeln, Gefässe, Nerven, und Bänder dienen, herrscht grosse Willkür. Wo der Eine aeus schreibt, schreibt ein Anderer euś, z. B. glutaeus und gluteus, peronaeus und peroneus, u. v. a. Soll Ordnung hierin geschafft werden, muss eine Regel für die beiden Schreibarten aufgestellt werden. Sie ist leicht zu finden.

Ist das betreffende Beiwort griechischen Ursprungs, und wurde es aus einem griechischen Hauptworte, durch Umwandlung der Endsilbe desselben in a.os, gebildet, wie riou-

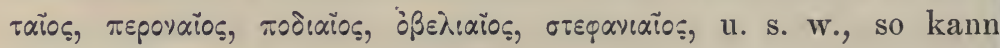
und darf es im Lateinischen nur als glutaeus, peronaeus,

1) Mundini Anathomia emendata, in capite: de anathomia pulmomum.

2) Isagogae breves, in capite: de corde (beiläufig in der Mitte des nicht paginirten Textes). 
podiaeus, obeliaeus (sagittalis), stephaniaeus (coronalis), geschrieben werden. Ist aber das Hauptwort, aus welchem ein anatomisches Adjectiv gebildet wird, ein urlateinisches, wie pecten, brachium, poples, femur, tibia, crus, solea, und cubitus, so darf auf keinen Fall pectinaeus, brachiaeus, poplitaeus, femoraeus, tibiaeus, cruraeus, solaeus, und cubitaeus, welche Worte besonders in der Myographia von Jac. Douglas auffallen ${ }^{1}$ ), sondern es muss pectiněus, brachialis, poplitěus, femoralis, tibialis, cruralis, solěus, und cubitalis gemacht werden, wie es Albinus ${ }^{2}$ ) gethan hat. Bei allen Adjectiven in eus, ist das e kurz, quia vocalis ante vocalem corripitur. Schreibt man also pectineus und soleus, so muss man auch pectinĕus und solěus, nicht pectinēus und solēus sagen, wie es zur Unsitte im anatomischen Sprechen geworden. Uebrigens will ich nicht übergehen, dass alle anatomischen Adjective in alos, mit einziger Ausnahme von tooıaiog ${ }^{3}$ ), im guten Griechisch nicht bekannt waren, und Neubildungen sind, deren sich nur die mittelalterliche Anatomie zu rühmen hat.

Auch das Hauptwort Peritoneum, muss unbedingt Peritonaeum geschrieben werden, da Galenus und Oribasius, und mit ihnen alle griechischen Aerzte, nur von einem $\pi$ eptróralos

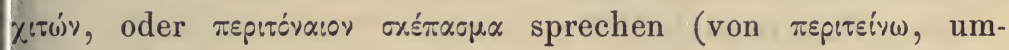

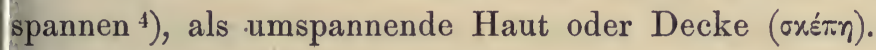

1) Schreger (Synonymia anatomica) benannte den Levator auriculae, als Musculus aponeurotico-helicaeus, und Dumas (Système de nomenclature) als temporo-conchinaeus!

2) Es lohnt sich der Mühe, in dieser orthographischen Beziehung, die Synonyma durchzugehen, welche in der Historia musculorum hominis von Albinus zusammengestellt sind.

3) Welches Wort aber nicht im Sinne von Zugehörigkeit zum Fuss, sondern in jenem von fussbreit und fusslang angewendet wird, wie im Plato und Lucian.

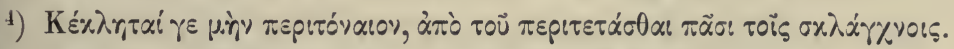
Galenus, De naturalibus facultatibus, Lib. VI, Cap. 4. 
Anders verhält es sich mit dem griechischen Wort für Mittelfleisch. Wir finden bei den griechischen Classikern $\pi \varepsilon p^{\prime} v$ vov und $\pi$ epivalov, dürfen also, nach Wahl, Perineum oder Perinaeum schreiben.

Die latinisirten Beiwörter: laryngeus, plaryngeus, hyoideus, etc., dürfen absolut nie mit ae geschrieben werden, da im

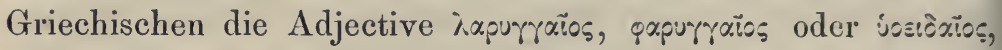
etc., fehlen, und der lateinische Ausgang eus, nur von Jenen, welche sich so Vieles im Sprachverderben erlaubten, auch einem griechischen Hauptworte angehängt werden konnte. Diese Worte gehören alle in den Kram der Barbarismen. Man hätte sie ganz gewiss nicht erfunden, wenn es für Kehlkopf, Schlundkopf, Zungenbein, ein einfaches Wort im Lateinischen gäbe. So aber gibt es nur ein Caput fistulae, Caput gulae, Os lambdae, aus welchen keine Adjective möglich sind.

\section{Ala und ihre Arten.}

Ala wird in der Anatomie in zweifachem Sinne angewendet: 1. als Flügel, 2. als Achsel.

1. Als Flügel.

Grammatikalisch bezieht sich Ala nur auf den Flügel, als Bewegendes. Der ruhende Flügel, als gefiederter Bestandtheil des Vogelleibes, heisst Penna, wie die Feder selbst. Movere alas, alas explicare, alis plaudens columba (Virgil), galli plausu premunt alas (Cicero), und viele andere Redensarten, sprechen für Ala, als Bewegungsorgan. Poetisch werden deshalb auch die Ruder, und die Segel der Schiffe, alae genannt, wie im Propertius: classis centenis remiget alis, und velorum pandimus alas, im Virgil. Auch die Schwadronen leichter Reiterei, welche die Flanken der Legionen umschwärmten und deckten, hiessen alae und equites alarii (Livius). Von dieser Ala, als Flügel, hat die lateinische Anatomie viele Anwendungen bewahrt, wie die griechische von $\pi \tau \hat{p}$ pug. Hieher gehören die 
Alae narium (Pinnae narium im Bauhin, Alulae und Fibrae ') narium bei den Arabisten), - die Alae diaphragmatis (nach Haller, die Seitentheile des Centrum tendineum des Zwerchfells), - die Alae ossis sphenoidei (Flügelfortsätze, Processus pterygoidei), - die Ala parva Ingrassiae, - die Alae vomeris, welche die Crista sphenoidalis zwischen sich nehmen, - die Alae cristae galli, - bei älteren Anatomen auch die Ala major et minor omenti (grosses und kleines Netz), - die Alae pelvis (Ossa ilei), - die Alae majores et minores pudendi muliebris (grosse und kleine Schamlefzen), - und die Alae vespertilionum, unter welchen Winslow die breiten Mutterbänder verstanden wissen wollte, während Andere sie nur auf die, zwischen Ovarium und Tuba befindlichen Abschnitte derselben, restringirten ${ }^{2}$ ), welche im Winslow blos als ailerons, oder feuillets, angeführt werden. Die breiten Mutterbänder Alae vespertilionum zu nennen, passt nicht gut, da sie keinen freien und gezackten Rand haben, wie er dem Flügel einer Fledermaus zukommt. Dagegen kann der zwischen Eierstock und Tuba ausgespannte Antheil der Ligamenta lata uteri, seines freien und bogenförmigen Randes wegen, immerhin eine $A l a$, wenn auch nicht gerade eine Ala vespertilionis genannt werden.

Mehrfältige Anwendung hat auch das Adjectiv alaris, flügelförmig, aufzuweisen: in den Ligamentis alaribus des Kniegelenks, des Zahnfortsatzes, der Leber, und in den

1) Fibra, ein den Classikern entlehnter Ausdruck für Lappen: Fibrae hepatis (Cicero), Fibrae pulmonis (Celsus). Metaphorisch wird Fibra auch für Eingeweid gesetzt:

„Protinus ereptas viventi corpori fibras

"Inspiciunt, mentemque Deâm scrutantur in illis."

Mundinus und seine Anbänger, substituiren dær Fibra als Lappen, die Penula oder Pennula, welche auch zu Premula metamorphosirt wurde.

2) Haller, Elem. physiol., T. VII, pag. 100. 
Processus und Canales alares des Keilbeins (Processus und Canales pterygoidei).

2. Als Achsel.

Hier haben wir eine Ala, als Reproduction der Ala des Vogels, von einer $A l a$, als Contraction von Axilla, zu unterscheiden. Der Vogelflügel hat sein Analogon, in dem mit der Schulter verbundenen Arm. Ala wird deshalb bei den Arabisten für die Schulter und für den Oberarm verwendet, wie denn Ala ossis humeri, zuweilen für Oberarmkopf bei ihnen angetroffen wird. Im Schylhans finde ich das Schulterblatt, als "Axelbein", und im besten Deutsch, steht Achsel für Schulter. Man denke an die hohe Achsel, an den Achselgurt und Achselriemen, an den Achselträger (Heuchler), an Achselzucken, und etwas auf die leichte Achsel nehmen, an das Achselstück der alten Rüstungen, aus welchem die jetzigen "Epauletten" hervorgingen, an die Achselbänder der Livréebedienten, und die Achselschnüre der Uhlanen ${ }^{1}$ ). Auch in den Classikern gerathen wir auf ala, für die ganze Schulter: umbonibus, incussaque ala, sternere hostes, mit Schild und vorgedrängter Schulter den Feind niederwerfen (Livius). Von der "ganzen Schulter", sank die Ala zur "Grube der Schulter" = Achselhöhle herab, und wird in dieser Verwendung, für eine Synkope von Axilla gehalten. Ita vestra axilla, ala facta est, elisione literae vastioris (Cicero). Die Litera vasta ist das scharf tönende $x$, welches die Römer, mit

1) Dieses schmucke Stück der Reiteruniform, leitet seine Entstehung von den Stricken her, welche die wallonischen Reiter, im Freiheitskriege der Niederländer, sich um den Hals banden, um die spanischen Proclamationen zu verhöhnen, welche jeden mit den Waffen Gefangenen, zum Tod durch den Strang verurtheilten. Grimmer und trotziger Humor liegt darin, den Strick sich gleich selbst um den Nacken zu werfen. Dieser Galgenstrick der wallonischen Reiter, hat es wohl verdient, eine Zierde der militärischen Kleidung geworden zu sein. 
dem zugehörigen Vocal, öfter, euphoniae causa, aus der Mitte gewisser Worte wegliessen, wie in: velum statt vexillum, mala statt maxilla, palus statt paxillus (Pfahl), talus für taxillus (Würfel, os tali), paullum für pauxillum (wenig), tela für texilla (Gewebe), filum für fixillum (Faden), u. m. a. Durch Celsus wurde $A l a$, als Achselgrube, auch in die medicinische Sprache eingeführt (abscessus alarum), konnte aber die anatomische Axilla nicht aus dem Verkehr bringen. Nur ein aus ala gebildetes Adjectiv, ist bei den Anatomen gangbar: alaris. Wir verfügen über Pili alares, welche sich die Römer auszurupfen pflegten (alas vellere, im Juvenal), über Glandulae alares, Achseldrüsen, und über die kleinen Arteriae und Venae alares.

Ich erwähne noch, dass die Griechen eine ähnliche Abkürzung mit ihrer $\mu \alpha \sigma \% \alpha \dot{\lambda} \eta$ (Achsel) vornahmen. Sie sagten $\dot{\pi} \pi \dot{\delta}$ $\mu \alpha \dot{\lambda} \lambda$ rs, wenn sie etwas unter die Achsel nahmen, wie Horaz: sub ala portare fasciculum librorum. - Der Winkel, unter welchem ein Ast, ein Zweig, ein Blattstiel abtritt, hiess bei

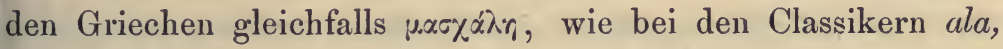
und ebenso bekannt ist die Blattaxel in der Botanik.

Axilla finde ich in den Origines von Isidorus, zu Ascilla verändert. - Diese Ascilla wurde die Mutter der italienischen Ascella, welche der provençalischen aissela, dem altfranzösischen aisselle, und dem neufranzösischen aiselle, ihr Dasein gab. Die Lateiner des Mittelalters, machten aus Ascella ihre Ascellata, welche bei den Uebersetzern des Avicenna, für Achselvene verwendet wird, auch mit der Verdrehung: Asfellata.

\section{Albuginea,}

Die Anatomie spricht von einer Albuginea oculi (Sclerotica), und von einer Albuginea testis. Beide sind dichte und starke Faserhäute von weisser Farbe - inde nomen. Aber dieses Nomen ist nicht römisch. Es giebt in der römischen Sprache kein Adjectiv albugineus. Dasselbe wurde erst von 
den lateinischen Uebersetzern des Rases und Avicenna gebildet, und zwar nicht für die Sclerotica, sondern für den Humor aqueus, welcher nicht unter diesem Namen, sondern als Humor albugineus und albumineus bei diesen Männern erscheint. Albugineus und albumineus sind aber zwei, nicht gleichsinnige Worte. Sie haben nichts mit einander gemein, als dass sie beide Neubildungen sind. Albumineus kommt von Albumen,

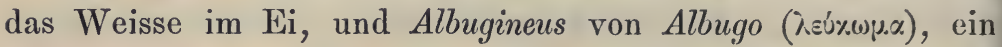
weisser, das Sehen störender Fleck in der Hornhaut. Der Humor aqueus ist aber nicht weiss, sondern wasserhell, wie das Eiklar, und deshalb Humor albumineus noch immer besser als albugineus.

Was am Auge, bei äusserer Ansicht desselben, weiss erscheint, nannten die Griechen: to $\lambda$ suxòy (A ristoteles). Die Uebersetzer des Aristoteles, nennen es Album oculi. Dieses Album oculi ist jedoch nur der vordere Abschnitt der Sclerotica, auf welchem die Conjunctiva scleroticae haftet. So wurde also auch die Sclerotica "weisse Augenhaut" genannt, und statt alba tunica oculi, die barbarische Albuginea eingefühṛt, von welcher aber die Anatomen unserer Zeit nur wenig Gebrauch machen. Da alle weissen, faserigen Gebilde, Sehnen und sehnige Bänder, vor Alters als veüpa zusammengefasst wurden, erklärt sich die im Julius Pollux enthaltene Benennung der

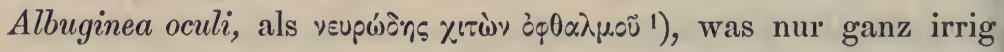
als Netzhaut ausgelegt werden konnte. Vielfältig stösst man in den Schriften der alten Anatomen, auf die Faserhäute, als Tunicae nerveae.

Die Albuginea testis gehört, wie die Albuginea oculi, zu den fibrösen Häuten. An Farbe und Dichtheit, stimmt sie mit der Albuginea oculi ganz überein.

Indem das vordere Segment der Sclerotica, mit der Conjunctiva bulbi verwachsen ist, wurde Albuginea sehr häufig in vor-Vesal'scher Zeit, auch für Conjunctiva gebraucht, welche

1) Onomasticon, Lib. II, Cap. 70 . 
unter den Latino-Barbari, selbst zum Albamentum oculi herabsank. Wer in dem Gedanken lebt, dass Albuginea nur die Sclerotica sein kann, versteht die alten Beschreibungen der Conjunctiva ganz gewiss nicht. Noch im Bartholinus lesen wir Adnata alba, für Bindehaut des Augapfels 1), obwohl nicht sie, sondern die darunter liegende Sclerotica weiss ist. Sieh' den Artikel Conjunctiva.

\section{Allantois,}

Die Kunde von der Allantois reicht weit in das entlegenste Alterthum zurück. In der letzten Auflage meines anatomischen Lehrbuches, habe ich Allantois als ein verstümmeltes Wort

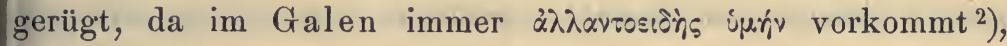
welcher Ausdruck sich nur als Allantoidea latinisiren lässt, nach Art so vieler anderer anatomischer Worte: Hyaloidea, Arachnoidea, etc. Die Form der Allantois, gleicht nämlich jener einer Wurst: $\dot{\alpha} \lambda \lambda \tilde{\alpha}_{5}$, Gen. $\left.\alpha \lambda \lambda \tilde{\alpha}_{\text {vros }}{ }^{3}\right)$. Diese Aehnlichkeit drückt der Ausgang siòrs aus, von siòos, Ansehen, oder Gestalt. Ich bin aber von meiner Verstimmung gegen Allantois zurückgekommen, da ich bei meinem näheren Bekanntwerden mit classischen griechischen Autoren, den Ausgang siòns öfter durch

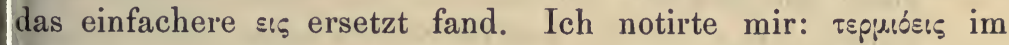

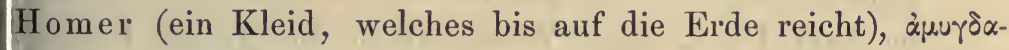

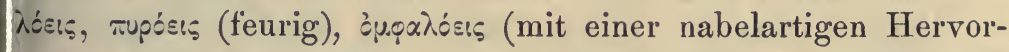
ragung versehen) im $\mathrm{Homer}$, трo\%ósıs (rundlich), póósıs (rissig),

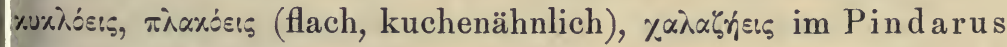

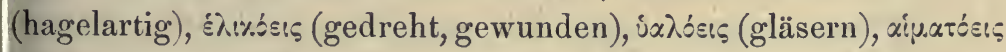

1) Institutiones anat., Lib. III, Cap. 8, de oculis.

2) De uteri dissectione, Cap. 10 zuerst, und später noch an mehreren Orten.

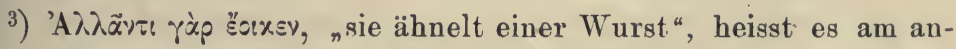
gegebenen Orte.

Hyrtl. Onomatologia anatomica. 
(blutig) im Homer, or,oxuśsıs (ein mit Sesamkörnern gefüllter

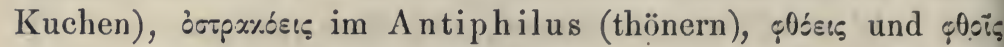
(Pille), oxxpuósıs (thränenreich), und einige mehr. Da nun Allantois sprachlich richtig ist, können wir auch Hyois = "Zungenbein", und Stylois = "Griffelfortsatz", welche uns bei den Restauratoren der Anatomie unterkommen, anstandslos passiren lassen. Insofern unterliegt auch die Arteria gastroepiplois des Spigelius ${ }^{1}$ ), keinem Tadel.

Allantois wäre sofort ganz correct, als wurstähnliche Haut - die Membrana farciminalis ${ }^{2}$ ) des Vesal. Anständiger repräsentirt sich Harnhaut und Harnsack, da die Allantois durch die Ausführungsgänge der Wolff'schen Körper (Primordialnieren), die stickstoffhältigen Zersetzungsproducte des embryonischen Stoffwechsels zugeführt erhält. Dass Allantois zu Alamois und Alantois verfälscht wurde, lässt sich von der geringen Kenntniss der griechischen Sprache bei unseren anatomischen Vorfahren, erwarten. - Harvey verwechselt die Allantois mit dem Chorion! ${ }^{3}$ )

1) De corp. hum. fabrica, Lib. VI, Cap. 4.

2) Isidorus definirt Farcimen als: Caro concisa, qua intestinum farcitur, hoc est, impletur, cum aliarum rerum commixtione. Dadurch unterscheidet sich Farcimen von Botulus. Botulus hiess eigentlich eine mit Blut gefüllte Wurst: botulus cruore distentus, im Tertullian. Diese Würste waren von grossem Umfang; kleine Gattungen hiessen Hillae und Fonticula. Nach Verschiedenheit des Inhaltes, erhiélten die Würste einen verschiedenen Namen. Da die Römer grosse Freunde ron Würsten waren, liesse sich aus diesen zahlreichen Namen, ein langer Speisezettel zusammenstellen. Von Longano, Lucanica, Isicium, Pantex, Apexabo, Tomaculum, liest man bei den Comödienschreibern, Satyrikern, und späteren Prosaisten.

3) De generatione animalium, Addit. 4. 


\section{Alvus, Alveus, und Alveolus.}

Diesen Drillingen war ein verschiedenes Loos bescheert. Nur der dritte lebt gegenwärtig noch in der Anatomie. Der mittlere, Alveus als längliche Vertiefung, starb frühzeitig, und hat nur im Alveus communis ductuim semicircularium, ein fast schon erloschenes Andenken hinterlassen. Scarpa bediente sich dieses langen Ausdruckes, zur Bezeichnung jenes Vorhofsäckchens, welches mit den häutigen Bogengängen in Höhlenverbindung steht ${ }^{1}$ ). Wir ziehen die kürzeren Benennungen Sacculus oblongus oder ellipticus vor. - Der erste war nie in der Anatomie zu Hause, wohl aber in den Schriften der lateinschreibenden Aerzte aller Zeiten, und zwar entweder als Unterleib, insofern derselbe den sich periodisch entleerenden Nahrungsschlauch enthält, oder als Excremente desselben; wie Alvus nigra, foetens, pallida, sicca, dura, und fuida, im Celsus. Hierauf gründen sich sehr viele, seit Celsus, in der Medicin gebräuchliche Ausdrücke: alvum purgare, exonerare, inanire, subducere, sowie Alvus fluens, stricta, reserata, obstipata, u. v. a. Am Durchfall Leidende, heissen im Plinius: Alvini. Festus lässt nur die Weiber einen alvus (ab alendo) = uterus besitzen, in welchem engeren Sinne etwas auch im Plautus zu finden

1) Disquisitiones anat. de auditu et olfactu, S. II, Cap. 2, §. 10. Pecquet hat auch einen verschollenen Alveus ampullosus, als paarige, aus der Cisterna lumbalis hervortretende, und sich zum Ductus thoracicus vereinigende Gänge, welche jedoch im Menschen nicht vorkommen, und nur am Hunde beobachtet wurden (Experimenta nova anat., Parisiis, 1631). - Bei den Classikern begegnen wir Alveus als Flussbett, und translate auch als Badewanne, als Bienenstock, und als einen, aus Einem Baumstamme gehauenen Kahn ("Anbamler" in ober-österreichischer Mundart). In dem Sinne von Alveus, als Flussbett, nennt Haller den Aquaeductus Sylvii, auch Alveus Sylvii. 
ist: me illa in alvo menses gestavit decem. Abdomen und Venter imus s. infimus, haben den Alvus aus der Anatomie gänzlich verdrängt. Desto vielfältigere Anwendung machen wir von Alveolus, indem Alles, was zu den Zahnzellen, Alveoli, in irgend einer Beziehung steht, alveolar genannt wird, wie die Processus und Limbi alveolares der beiden Kiefer, die Foramina und Juga alveolaria, die Nervi, Arteriae und Venae alveolares, zu welchen in neuester Zeit noch die Alveolen der Lunge und der Lymphdrüsen hinzukamen. Alle diese Ausdrücke erfreuen sich einer vollen und wohlbegründeten Berechtigung. Denn Alveolus ist Zahnzelle, nicht Zahnlücke, worunter die durch Verlust eines Zahnes entstandene Bresche in der Zahnreihe (Ordo, Series, Sepes, s. Maceria dentium ${ }^{1}$ ) verstanden wird. Vesal gab der Anatomie dieses Wort, während vor ihm die Ausdrücke Mortariola und Praesepiola für "Zahnzellen" gebraucht wurden. Mortariolum ${ }^{2}$ ), Mörserchen, äquivalirt dem

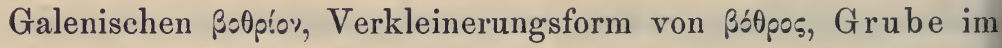
Homer, und Praesepiola ${ }^{3}$ ), Krippchen, ist die wörtliche Uebersetzung von den $\varphi x \tau v i \alpha$ des $R$ ufus $^{4}$ ), denen die Homerische 甲̣́́㇒v sowie Alvarium und Alvearium, als Bienenstock, sind uns aus Virgil's Georgicon bekannt. Hieraus formte Vesal seine Alveoli, vielleicht im Gedanken an apium cellulae, denn die

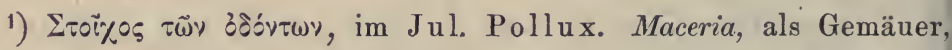
findet sich auch im Cicero: nullo aprico horto, nulla casa, nulla emissaria, nulla maceria.' Ad famil. XVI, 18.

2) Mortaria heissen im Vitruvius, die Mörtelpfannen der Maurer, im Plinius, die Mörser.

3) Die Praesepiola sollen richtiger Praesaepiola geschrieben werden, da sie von praesaepis, Krippe, stammen, und diese von praesaepio, umzäunen.

4) Ф人́⿰习ท wird im Jul. Pollux als ein hölzerner, in Fächer getheilter Trog erwähnt, in welchen das Futter der Hausthiere geschüttet wird. 
Römer kannten Alveolus als Bienenzelle nicht. Ihnen war dieses Wort jede Art von kleiner Mulde, besonders aber das mit einem hohen Rande eingefasste Spielbrett, auf welches die Würfel aus dem Becher hingeworfen wurden (Cicero). Alveolus, als Mulde oder Bucht, gab den Alveoli pulmonum ihre Entstehung, unter welchen Rossignol') dasjenige verstand, was man bisher, nach Malpighi, Vesiculae und Cellulae pulmonales genannt hat. - Die mit einem feinfaserigen Fachwerk durchzogenen Raumabtheilungen einer Lymphdrüse, Alveoli zu nennen, wie es in den äusserst zahlreichen Schriften über diesen Gegenstand allgemein geschieht, war gar nicht nöthig, da die alten Loculamenta in jeder Hinsicht besser waren. Neue Namen werden nur dann benöthigt, wenn die alten schlecht sind, was man von den Loculamentis nicht sagen kann. Die Loculamenta testis wurden nicht zu Alveoli modernisirt.

\section{Amnios oder Amnion?}

Man kann in der Wahl nicht fehlen, denn Beides ist recht. Amnios wird diese Eihaut nach Galen benannt, welcher àjusios schrieb ${ }^{2}$ ), und zwar als Adjectiv zu úuń (Haut). Demzufolge muss man Amñ̄os, nicht Amnı̌os sagen, und als Geschlechtşwort der, nicht das vorsetzen, denn àjveios ist generis masculini. Allenfalls könnte man noch die Amnios erlauben, wenn man sich "Haut" dazudenkt. Aber das Amnios muss mit dem strengsten Interdict belegt werden.

Julius Pollux, Lehrer der Redekunst in Athen und später in Rom (2. Jahrhundert n. Chr.), welcher in seinem Onomasticon, das vollständigste Inventar aller anatomischen Kunstwörter zusammenstellte, schreibt to àuviov ${ }^{3}$ ), woraus uns

1) Recherches sur la structure du poumon. Bruxelles, 1846.

2) De Hippocratis et Platonis decretis, Lib. VI, Cap. 6.

3) In Lib. II, Cap. 4, Sect. 223, heisst es: interius foetus velamen, Empedocles auvíov vocat. 
das Recht erfliesst, statt der oder die Amnios, auch das Amnion sagen zu können. Das Etymon von beiden ist àjuvós, Schaf, agnus. 'Apjveios heisst, was zum Schafe gehört, oder vom Schafe kommt. Vesal führte deshalb, statt Amnios, seine Membrana agnina, unsere Schafhaut, ein. Bei dem Opfern trächtiger Schafe, hat man unstreitig diese Haut zuerst beobachtet. Sie musste auffallen, weil, ihrer Zartheit und Durchsichtigkeit wegen, der Schafembryo durch sie hindurch, ganz gut und genau gesehen wird. Deshalb ist die Benennung Schafhaut, obwohl etwas unpassend für das menschliche Weib, doch bezeichnend für die Sache. Wenn noch Zweifel obwaltet, ob man sich für Amnios oder Amnion entscheiden soll, möge man lieber bei Amnios bleiben, weil Amnion noch einen Nebenbegriff hat. In der Odyssee ${ }^{1}$ ) heisst die Schale, in welcher das Blut der Opferthiere aufgesammelt wird, ג̇uíov.

Ueber die Synonyma von Amnios, habe ich im ersten Paragraph meiner Schrift: Das Arabische und Hebräische in der Anatomie, ausführlich gehandelt.

\section{Ampulla.}

- Ampulla hat nur den Werth eines Beqüemlichkeitswortes. Es entstand sicher nicht als Diminutiv von Amphora, wie die Lexica glaublich machen wollen, sondern per syncopen aus ampla bulla. Bevor wir seine anatomischen Anwendungen anführen, beginnen wir mit Bulla. Bullae (von bullire, sieden), hiessen die im siedenden Wasser aufsteigenden, schnell platzenden Luftblasen: offensae bulla tumescit aquae (Martial). Die runde Form dieser Bullae, bedingte ihre figürliche Uebertragung auf mancherlei andere Gegenstände, worunter nur die Bulla aurea und scortea, hier erwähnt werden soll. Bulla aurea, war ein aus zwei halbkugeligen, concaven Goldplatten

1) Lib. III, Vers 444 . 
bestehender Schmuckgegenstand, welchen die Kinder vornehmer Römer, um den Hals trugen, als signum ingenuitatis (guter Geburt ${ }^{1}$ ). Die Kinder der Freigelassenen, und der unteren Volksklassen, durften nur solche Bullae aus Leder (scortum) tragen ${ }^{2}$ ). Die Bullae umschlossen Amulette. Sie wurden nur bis zum Beginn der Mannbarkeit getragen,. dann aber mit dem Kinderkleid (praetexta) bei Seite gelegt, und den Schutzgottheiten des Hauses geweiht ${ }^{3}$ ). In der Anatomie finde ich die Bullae, nur in Haller's Primae lineae physiologiae, pag. 772, erwähnt, mit dem überflüssigen Zusatz: rotundae. Es sind damit die Graaf'schen Bläschen des Eierstockes gemeint. Sonst giebt es nur noch eine Bulla ossea, als blasig aufgetriebenes Os tympanicum der Raubthiere.

Ampulla war ein Gefäss aus Thon oder Glas, mit engem Hals und blasig aufgetriebenem Bauch ${ }^{4}$ ). Figürlich wandte Horaz das Wort auch für den Schwulst der Rede an: ampullas projicere.

Dass ein Gegenstand von solcher Form, wie er der Ampulla zukommt, in der Anatomie Anwendung finden musste, war zu erwarten. Er fand sie auch, und zwar: 1. in den bekannten Ampullae canalium semicircularium des Gehörlabyrinths, sowohl für die knöchernen, als für die häutigen Canäle, 2. in den Ampullae Lieberkiuhnii, als die in neuerer Zeit wieder zu Ehren gekommenen Höhlungen im Innern der Darmzotten $\left.{ }^{5}\right),-3$. in der Ampulla chylifera, als ein von Haller

1) Plinius, Hist. nat., XXXIII, 4.

2) Cicero, Verres, V, 58.

3) Macrobius, Saturnalia, Lib. II, Cap. 10, und Persius, Sat. $V, 31$ :

"Bullaque succinctis laribus donata pependit."

4) Abbildungen aller Formen von Ampullae, in Anthony Rich, Römische Alterthümer, pag. 28, - meistens bauchige Formen.

$\left.{ }^{5}\right)$ Lieberkühn, De fabrica et actione villorum intest., N. 3, pag. 4 und 5 . 
gebrauchtes Synonym, für Cisterna lumbaris, s. Receptaculum chyli, - 4. in dem Alvus ampullaceus, worunter Pecquet die beiden, aus der Cisterna lumbaris herauștretenden, und sich zum Ductus thoracicus s. Pecquetianus ${ }^{1}$ ), verbindenden Wurzeln

1) Der Schwede Olaus Rudbeck, hat mehr Anspruch auf die Ehre, dem Ductus thoracicus seinen persönlichen Namen zu geben, als Jean Pecquet. Obwohl Rudbeck's Buch: De circulatione sanguinis, um ein Jahr jünger ist (1652), als jenes von Pecquet (1651), so wird doch in ersterem gesagt, dass Rudbeck diesen Gang schon im Jahre 1650 auffand, die Bewegung des Chylus in ihm, durch Unterbindungen (vinculis injectis) sicherstellte, und den Gang, sowie das Receptaculum chyli an der Lendenwirbelsäule, der Tochter Gustav Adolph's, der Königin Christine, zu demonstriren die Ehre hatte. Haller sagt mit Entschiedenheit: (luctum thoracicum detexit (Bibliotheca anat., Tom. I, pag. 447). Pecquet konnte von den Arbeiten Rudbeck's selbstverständlich nichts gewusst haben. Er entdeckte offenbar denselben Gang, ganz auf eigene Faust, und da er besser schrieb, als Rudbeck, auch näher der gelehrten Welt stand, als der Anatom im hohen Norden, trug er den Preis des anatomischen Fundes davon, kurz bevor er, durch unmässigen Genuss von Cognac, sich um's Leben brachte. - Von Rechtswegen sollte der Milchbrustgang, Ductus Eustachii genannt werden. Der durch seine grossen und zahlreichen Entdeckungen berühmte Anatom in Rom, beschrieb den Anfang, den Verlauf, und das Ende des Ductus thoracicus im Pferde. Er kannte aber seine Beziehungen zum lymphatischen Gefässsystem nicht, weil dieses im 16. Jahrhundert, noch eine terra incognita war. Der betreffende Text. sagt: $A b$ insigni trunco jugulari sinistro (linke Schlüsselbeinvene), qua posterior sedes radicis venae jugularis internae spectat, magna quaedam propago germinat, alba, et aqueo humore plena, nec longe $a b$ ortu, in duas partes scinditur, paullo post rursus coeuntes, quae nullos ramos diffundens, juxta sinistrum vertebrarum latus, penetrato septo transverso, deorsum ad medium 
des Milchbrustganges verstand 1), welche aber nur eine Varietät darstellen, da der Ductus thoracicus im Menschen und bei den Thieren, in der Regel einfach aus der Cisterna hervortritt, 5. in den Ampullae ureterum, bei verschiedenen älteren und neueren Anatomen, rundliche Erweiterungen der Harnleiter, an ihrer Einmündungstelle in die Harnblase, - und 6. noch in der Ampulla Henlei ${ }^{2}$ ), als Erweiterung der äusseren Hälfte der Tuba Fallopiae, im Gegensatz zum Isthmus derselben.

\section{Amygdalae.}

Die Amygdalae, Mandeln, sind ein anatomisches Vermächtniss der Araber.

Gesunde Mandeln lassen, im Halse des Lebenden, von sich sehr wenig sehen; desto mehr, wenn sie entzündet oder angeschwollen sind. Daher kommt es, dass die meisten Benennungen der Mandeln, nur der krankhaften Vergrösserung derselben gelten. Kein Mensch weiss etwas von seinen gesunden Mandeln, denn er sieht sie nicht, und fühlt sie nicht. Er merkt ihre Gegenwart erst, wenn sie durch Entzündung anschwellen, den Racheneingang verengern, Schlingen und Sprechen erschweren, und selbst Erstickungsgefahr veranlassen. Dieser Anschwellung verdanken die Mandeln ihren

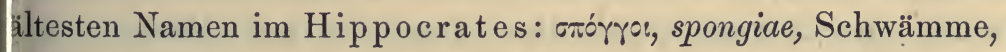
neben welchen auch die von Galen angenommenen Paristhmia

usque lumborum fertur, qua latior effecta (offenbar das Receptaculum s. Cisterna chyli des Pecquet damit gemeint), finem mihi adhuc non bene perceptum obtinet. Wer den Anfang, den Verlauf, und den äusseren Habitus des Ductus thoracicus, so genau angiebt, wie hier Eustachius, der hat ihn, Dii per vostram fidem! doch gewiss entdeckt.

1) Experimenta nova anatomica, etc. Parisiis, 1651.

2) Eingeweidelehre, Oviduct, pag. 466. 
vorkommen, als Mandeln im angeschwollenen, aber auch im natürlichen Zustande ${ }^{1}$ ). Derselbe Doppelsinn kommt den

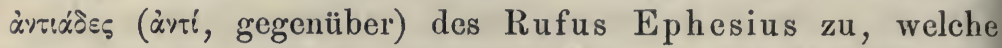
Paulus Aegineta als Paristhmia inflammata, und Celsus als Tonsillae inflammatae definirt. Nur der Galen'sche Ausdruck:

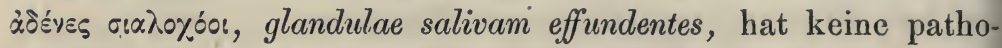
logische Nebenbedeutung. Würde Julius Pollux von gesunden Mandeln gesprochen haben, würde er sie nicht $\mu . \tilde{r}_{7} \lambda \alpha$, Aepfel, genannt haben, denn nur stark angeschwollene Mandeln, liessen sich allenfalls mit Aepfeln vergleichen.

Der Ausdruck Amygdalae für diese Drüsen, findet sich weder in griechischen, noch lateinischen Schriftstellern. Er rührt, wie ich bewiesen habe ${ }^{2}$ ), von den Uebersetzern der Araber her. Avicenna nannte die gesunden, und Albucasis die angeschwollenen Mandeln: al lauzatain (der Dual von lauz, Amygdala). Entzündete und abscedirende Mandeln, konnten ganz gut von den Arabern mit den Kernen des Pfirsichs, Amygdalus persica, einer in Arabien und Persien indigenen Frucht, verglichen werden, welchen sie durch ihre Grösse und Form, und durch die Grübchen an ihrer Oberfläche, ähnlich sehen. Im Avicenna lese ich: duae amygdalae sunt duae carnes nervosae, sicut duae glandulae ${ }^{3}$ ), und im Albucasis: quandoque in gutture accidunt glandulae (Drüsenanschwellungen), et vocantur Amygdalae $\left.{ }^{4}\right)$. Hans von Gersdorf, der erste deutsche Schriftsteller über Anatomie, gab diese Amygdalae mit "Knoden“. Im gemein Wienerischen, hört man die geschwollenen Mandeln "Halsknödel" nennen. So kamen also die Mandeln in die Anatomie! Die Spanier zogen die Galläpfel den Mandeln vor, und nannten die gesunden und die aufgeschwollenen Amygdalae: las agallas, woher es sich ergiebt, warum das Zäpfchen, welches

1) Aphorism. III, 26.

2) HL, Zusätze, pag. 253.

3) Canon, Lib. III, Fen 9, Tr. 1, Cap. 1.

4) De Chirurgia, Edit. Channing, Lib. II, Sect. 36, pag. 199. 
zwischen den agallas hängt, im Spanischen el galluelo heisst. Die italienische gavigna, für Mandel, bekundet durch die sardische ganga und gangula, ihre Verwandtschaft mit der lateinischen glandula, welche Plinius für die Mandel des Schweines gebraucht: in homine tonsillae, in sue glandulae ${ }^{1}$ ).

Der Aehnlichkeit mit geschwollenen Mandeln wegen, erhielten zwei eiförmige Körper an der unteren Fläche des kleinen Gehirns, welche den Raum zwischen Unterwurm, verlängertem Mark, und Hinterlappen des Cerebellum einnehmen, den Namen Amygdalae oder Tonsillae (Malacarne), sowie der Theil des Unterwurms, welcher zwischen ihnen zu liegen kommt, jenen der Uvula.

Vergleiche den Artikel Tonsillae.

\section{Anastomōsis.}

Anastomosis, àvartópwoเs, zählt zu den ältesten Kunstausdrücken der Anatomie. Der Alexandriner Erasistratus, welcher im Jahre 280 v. Chr. starb, ersann sich dieses Wort, zwar nicht als Anastomosis, sondern als Synanastomosis, welcher Ausdruck eigentlich nicht mehr sagt, und von Galen ${ }^{2}$ ) zu Anastomosis abgekürzt wurde. Er wurde, wie das tägliche Brot, den Anatomen unentbehrlich. Galen und Caelius Aurelianus haben uns Bruchstücke aus dem schon früh verloren gegangenen

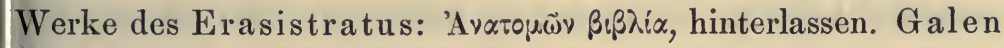
schrieb selbst ein Buch über die Anatomie des Erasistratus, welches wir noch besitzen. Erasistratus war nicht blos Arzt und Anatom; - er war auch ein Denker. Es fiel ihm auf, dass die Arterien, welche, nach den Ansichten seiner Zeit, nur das luftige Wesen des Pneuma enthalten, Blut geben, wenn sie verwundet werden; und durch Verblutung tödten können. Um

1) Hist. nat., Lib. XI, Cap. 37, Sect. 66.

2) De usu partium, Lib. VI, Cap. 17. 
diese Erscheinung zu erklären, erdachte er sich die Synanastomosis der Venen mit den Arterien, welche er natürlich niemals sehen konnte, da man damals das Mikroskop noch nicht kannte. Aber was er sich dachte, hat die Nachwelt factisch festgestellt, indem Malpighi, welcher in der Froschlunge den Uebergang der Arterien in Venen zuerst demonstrirte, eben dadurch zum eigentlichen Begründer der Harvey'schen Kreislaufslehre wurde. Erasistratus konnte seine Synanastomosis, nicht als Uebergang der Arterien in die Venen, sondern umgekehrt, nur als Uebergang der Venen in die Arterien aufstellen. Die Venen führten ja allein Blut, - die Arterien Luft. Diese Uebergänge sind aber nicht immer offen; im gesunden Leibe sind sie geschlossen. Wird aber die Arterie verletzt, und entweicht ihre Luft durch die Wunde, so öffnen sich die bis nun geschlossenen Synanastomoses der Venen mit den Arterien, und lassen das Blut aus jenen in diese überströmen, so dass es zuletzt durch die Arterienwunde sich nach aussen ergiesst. Auch das Fieber öffnet die Synanastomosen, und lässt Blut aus den Venen in die Arterien eįn, welche gegen diesen Eindringling heftig reagiren, durch starken und schnellen Puls. Man kann nicht läugnen, dass Verstand aus diesem Unsinn spricht. Schon das 'Wort Anastomosis (von

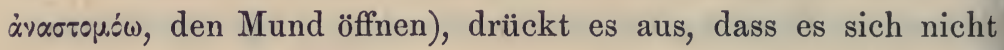
um das beständige Offensein der Verbindung zwischen den Venen und Arterien, sondern nur um ein zeitweilig eintretendes handelt. - Galenus modificirte den Begriff der Anastomosis dadurch, dass er ihn auf jene Laesiones continui der feineren Blutgefässe übertrug, welche den Blutungen zu Grunde liegen, wie dem Nasenbluten, den Hämorrhoiden, und der Menstruation 1). Diese Art von Anastomosis, nannte die lateinische Pathologie: Reseratio, Aufschliessung der Gefässe. Sie verstand darunter ein spontan eintretendes, nicht durch Gewalt erzwungenes sich Oeffnen der Gefässwand,

1) Methodus medendi, Lib. V, Cap. 2. 
zum Unterschied von Rhexis, Riss. - Die späteren Anatomen erweiterten den Begriff der Anastomose noch dadurch, dass sie die Verbindung von Venen mit Venen durch Queräste, von Arterien mit Arterien durch Queräste, oder durch unmittelbare Verschmelzung, und den bleibenden Uebergang der feinsten Arterien in die Anfänge der Venen, sowie auch die eine lange Zeit hindurch festgehaltene Einmündung der Capillararterien in die Anfänge der Drüsenausführungsgänge, in Fettzellen, und in die Lymphgefässe, Anastomosis nannten. Auch die Heilmittel, welche die supponirten Oeffnungen der feinsten Arterien in der Haut aufthun, und dadurch reichliche Schweissabsonderung zu Stande bringen, hiessen Anastomotica, i. e. aperientia osculorum. Sie kommen schon im Hippocrates als Anastomoteria vor '). Die Pathologen machten ihre Deobstruentia daraus.

Die lateinischen Aequivalente für Anastomosis (als Gefässverbindung überhaupt), sind: 1. Conjunctio vasorum per oscula und Exosculatio, im Spigelius 2). Hätte Spigelius den Plinius gelesen, würde er gewusst haben, dass Exosculatio nur für Abküssen, und Schnäbeln der Tauben, von den Römern gebraucht wurde. 2. Inosculatio im $\mathrm{Haller}^{3}$ ), ein neugeschmiedetes, den Römern unbekanntes Wort. 3. Conjunctio und Unio vasorum, im Bartholinus ${ }^{4}$ ), welche Worte aber einen mehr allgemeinen und vieldeutigeren Sinn haben, als Anastomosis. 4. Osculatio schlechtweg, wie im Caelius Aurelianus (nur als küssen im Cicero und Catullus bekannt). Aurelianus sagt es aber klar und deutlich genug: osculatio, quam Graeci anastomosin vocant. - Im Athenaeus ${ }^{5}$ ) stossen wir auf Anastomosis, als Reizung des Appetits, und

1) De natura mulieris, Lib. CX, Cap. 24.

2) Op. cit., Lib. V, Cap. 4.

3) Elementa physiol., Tom. I, Lib. II, Sect. 2, §. 21.

4) Institutiones anat., Lib. I, Cap. 14, de hepate.

5) De morbis chronicis, Lib. II, Cap. 10, in initio. 
bei späteren griechischen Autoren erleben wir die Anastomosis selbst als Gefässverengerung. Sysstomosis führt Aristoteles als zugespitzten Mund, und Strabo, als Einmündung eines Flusses an. - Anastomosis mit Ein-oder Zusammenmündung zu übersetzen, wie es in deutschen Anatomien oft geschieht, widerstreitet dem Sinn des griechischen Wortes, denn $\alpha$ $\nu \alpha$ enthält hier den Begriff von auf, nicht von ein oder zusammen.

\section{Ancon und Anconaeus quartus.}

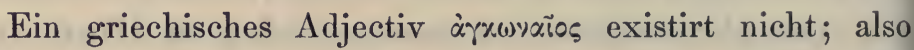

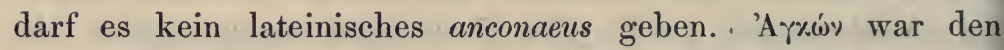
Griechen $=$ Armbug, und mancherlei anderes Eingebogenes. Dass sie das vorspringende Olecranon, auch $\alpha_{\gamma}\langle\dot{\omega}\rangle$ nannten, wie Galen und Rufus bezeugen '), mag daraus zu erklären sein, dass das Olecranon, am gebleichten Knochen, eine tiefe Concavität (Cavitas sigmoidea s. lunata major) zeigt ${ }^{2}$ ). $\mathrm{Da}$ nun das Olecranon $=$ Ancon ist, nannte Winslow den dreiköpfigen Armmuskel, welcher am Olecranon endigt: $A n$ coné, und zwar le grand Anconés), zum Unterschied des petit Anconé, unseres jetzigen Anconaeus quartus. Dass man diesen Anconaeus (nur in Wien) als quartus bezeichnet, ergiebt sich daraus, dass der Wiener Anatom und Chirurg, Ferdinand Leber, in seinen Praelectionibus anatomicis (1778), den langen, mittleren, und kurzen Kopf des Triceps, als Anconaeus longus, externus, und internus beschrieb, somit drei Anconaei legitimi vorhanden waren, denen der alte Anconaeus des Cowper, als Anconaeus quartus sich hinzugesellte. Anconaeus ist zwar besser

1) Articuli angulus, quo nitimur, Ancon est, sive Olecranon, im Rufus, De partibus hominis, pag. 50.

2) Vergleiche den Artikel Olecranon.

$\left.{ }^{3}\right)$ Traité des muscles, pag. 239 und 379. 
als Angoneus im Riolan 1), und Angonaeus im Douglas 2) aber dennoch ein Barbarismus, weil, wie gesagt, ein griechisches żrowraios niemals bestanden hat. Wollte mán, wie es ganz richtig wäre, den Triceps mit dem Anconaeus quartus, zu einem Extensor cubiti quadriceps vereinigen, wie wir einen Extensor sruris quadriceps bereits besitzen, so würde der barbarische Anconaeus quartus, zum vierten Kopf dieses Quadriceps veredelt werden können.

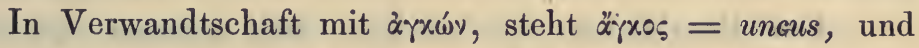
uncus wieder mit Anker. Uncus ist Haken, besonders jener, mit welchem die Leichen der hingerichteten Verbrecher an die Gemonische Treppe geschleift, und in die Tiber geworfen wurden. Daher uncum et. Gemonias minari im Suetonius. Von diesem uncus nannte Vesal das Olecranon, auch Additamentum uncatum ulnae.

\section{Angiologia.}

Von Angiologia, als Gefässlehre, wusste das Alterthum nichts. Ihm war Angiologia eine chirurgische Operation, welche

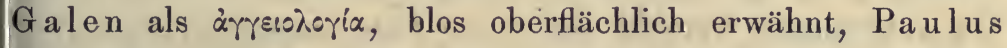
A gineta aber genauer beschreibt ${ }^{3}$ ). Es wird, um hartnäckigen Kopf- und Augenleiden Hilfe zu schaffen, die Stirnoder Schläfearterie in ziemlicher Länge blosgelegt, und so von ihrer Umgebung abgelöst, dass sie mit zwei, an den Enden des freiliegenden Gefässstückes unter ihr durchgeführten Fäden, aufgehoben werden kann. Dann wird das blossgelegte Gefäss in der Mitte entzweigeschnitten, um es genügend lange Zeit bluten zu lassen, worauf die beiden Ligaturen zugebunden, und das zwischen ihnen befindliche Stück des Gefässes

1) Anthropographia, Lib. V, Cap. 25.

2) Myographia, Cap. 31 .

3) Epitome, Lib. VI, Cap. 5. 
exstirpirt wird. Paulus wendete die Angiologia, auch auf varicöse Venen an.

Erst durch Heister kam Angiologia, als Gefässlehre, in Gesellschaft der Myo-, Splanchno- und Neurologia, in die Anatomie, um für immer bei ihr zu bleiben $\left.{ }^{1}\right)$. Das $\lambda \varepsilon \xi(\omega)$ in der "Angiologie" der Chirurgen, bedeutet "aufsuchen", wie das lateinische legere in colligere und legumen, - in der anatomischen Anwendung aber "von etwas handeln".

Der Begriff von àrøsio\%, hat einen grossen Spielraum. Behälter zum verschiedensten Gebrauch, wurden bei den

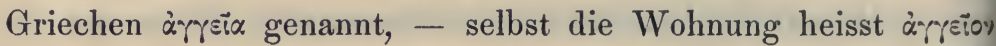
im Xenophon. Auch alle Arten von Gefässen im thierischen Körper, was immer für eine Flüssigkeit enthaltend oder führend, z. B. die Gallen-, Samen-, Luft- und Speichelgefässe, hiessen $\alpha_{\gamma} \gamma \varsigma i \alpha$. Bei den Deutschen verhält es sich mit dem Worte Gefäss, und bei den Lateinern mit dem Worte Vas - ebenso. Jedes Geschirr oder Gefäss, hiess Vas. Die Samenkapseln heissen im Plinius, die Bienenstöcke im Columella: Vasa und Vascula, - die Harn- und Gallenblase, selbst das männliche Glied, insofern es den Samen- und Harnschlauch enthält, kommen als Vas bei bewährten Schriftstellern vor. Die anatomische Sprache hat es mit Vasa sanguifera, seminifera, urinifera, lactifera, bilifera u. dgl. zu thun, sämmtlich neugebildete Worte! Angiologia würde demnach nicht blos die Lehre von den Blutgefässen, sondern von allen möglichen Gefässen sein, wird aber, durch stillschweigendes Uebereinkommen, immer nur im Sinne Heister's, als Lehre von den Blutgefässen, aufgefasst.

Die neuere Medicin verfügt über eine Menge von $\mathrm{Zu}$ -

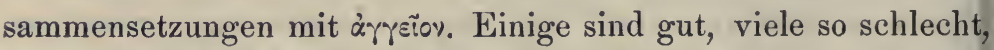
dass ihnen die Tramwaywagen ausweichen. Unter den letzteren, nehmen Angiolymphitis (Piorry), Angiohydrotomie

1) Angiologia vocatur doctrina de vasis sanguiferis, in Compendio anat., Num. 290. 
(Bégin), und die Teleangiectasie bei den Aerzten der ganzen Welt, den Ehrenplatz ein. Wir wollen sie nicht mit der Schusterale sticheln, sondern mit der Keule todtschlagen. Ad 1: Nicht das Wasser der Gefässe, sondern die wasserhältigen (lymphatischen) Gefässe, können sich entzünden. Ad 2: Nicht das Wasser der Gefässe wird eingeschnitten, sondern die Gefässe, welche Wasser enthalten. Ad 3: Nicht die Gefässe der Enden, sondern die Enden der Gefässe sind erweitert, woraus sich ergiebt, als richtiggestellte Trias: Lymphangioitis, Hydrangiotomie, und Angiotelectasie, bei welchen man seine gute Laune nicht verlieren kann.

\section{Aniscalptor.}

Hätte die Anatomie eine Muse, sie müsste weinen über ein so schmutziges Wort. Keine Entschuldigung für dasselbe, als der derbe Humor, welcher es sich nicht nehmen liess, in die ernsteste aller Wissenschaften dareinzureden, und, wie er seinen Anus, seinen Penïs, seine Nates, Testes, Mammae, und seine Vulva, in der Gehirnanatomie anbrachte, so auch den Musculus latissimus dorsi, weil er den Ar'm nach hinten, somit die Hand gegen den After bewegt, als Aniscalptor anzustellen. Vesal bringt diesen Ausdruck zuerst, und hatte so viel Anstandsgefühl, denselben nicht in den Text aufzunehmen, sondern in einer Randnote bei dem Latissimus dorsi delitesciren zu lassen 1). Riolan, welcher das Sprichwort seiner Landsleute vergessen zu haben scheint: qu'il é des choses, qu'on ne doit dire, qu'à soi-même, that ein Uebriges dazu, und brachte uns den noch mehr sagenden Anitersor ${ }^{2}$ ). Die Deutschen, welche sonst nicht Feinde massiver Ausdrücke sind, enthielten

1) De corp. hum. fabrica, Lib. II, Cap. 23.

2) Anthropographia, Lib. V, Cap. 24.

Hyrtl. Onomatologia anatomica. 
sich der Uebersetzung dieser Worte. Wir finden in allen deutschen Anatomien, nur den breiten und breitesten Rückenmuskel.

\section{Antibrachium.}

Allen guten Lateinern ist Antibrachium wildfremd. Es gehört ganz und gar dem verderbten medicinischen Latein der Neuzeit an, und ist, seit dem Anfang des vorigen Jahrhunderts, durch $\mathrm{Heister,} \mathrm{in} \mathrm{der} \mathrm{Anatomic} \mathrm{heimisch} \mathrm{ge-}$ worden. Das griechische $\dot{\alpha} v i$, und das lateinische brachium, haben keine Neigung zur Verbindung, und können dieselbe nur gezwungen eingehen. Gäbe es ein griechisches $\alpha v \tau \iota \beta \rho \alpha / \omega \nu$, so könnte dasselbe zu Antibrachium latinisirt worden sein. Allein die Griechen hatten mehr als genug Ausdrücke für Vorderarm, und fanden es nicht nöthig, einen neuen noch hinzuzufügen, obwohl Antibrachion sich ebenso gut hätte bilden lassen, wie Anticnemion, Anticardion, und Antilobion, von welchen das erste im Aristoteles die vordere Seite des Unterschenkels

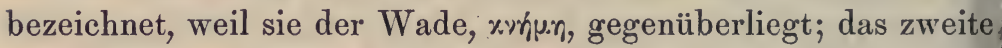
aber im Julius Pollux für Herzgrube steht, und im Latein als Praecordium, jedoch nur im Plural: praecordia, Aufnahme fand. Antilobion (Antilobis) nennt Rufus Ephesius den über dem Ohrläppchen befindlichen Anfang der Windung des Ohres (Helix).

Viel älter als das von den deutschen Anatomen des vorigen Jahrhunderts erfundene Antibrachium, ist Antebrachium. Obwohl dem guten Latein gänzlich unbekannt, wurde es doch im Mittelalter, wenn auch nicht als anatomische Bezeichnung gebraucht. Du Cange und ältere Glossisten, erwähnen die Antebrachia, als jenen Theil einer Rüstung, welcher die Vorderarme zu decken hatte: armaturae genus, quo lacerti (Vorderarme) teguntur. Die Composita mit der lateinischen Präposition ante, drücken immer etwas aus, was in Raum oder Zeit vorher ist, während das griechische ג̌ví nicht blos den Begriff vor, sondern vie] 
häufiger jenen des gegenüber enthält, wie z. B. in Antipodes, Antistates (Gegner), Antithenar, und im griechischen Ausdruck

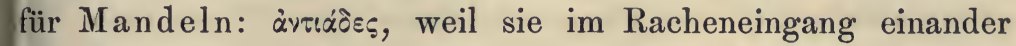

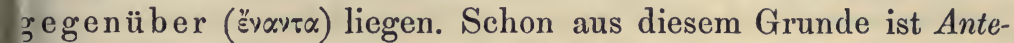
rachium richtiger, als das moderne Antibrachium. Man beliebe, oei ihm zu bleiben, da der Vorderarm dem Arme nicht gege niber, sondern vor ihm sich befindet.

Die Römer hatten für Vorderarm zwei Worte: Cubitus and Brachium. Brachium wird zwar auch für Oberarm gerraucht, aber die medicinische Autorität des Celsus vindicirt hm die Bedeutung Vorderarm durch die Worte: brachium :onstat ex ossibus duobus, quae sunt radius et cubitus ${ }^{1}$ ). Hier rersteht Celsus unter Cubitus unsere jetzige Ulna, während n der gewöhnlichen, d. h. nicht medicinischen Sprache der Römer, unter Cubitus der ganze Vorderarm, zusammt dem allbogen, gedacht wird. Cubitus erhielt seinen Namen von ubare, liegen, da man sich beim Niederlegen auf den Vorderurm und Ellbogen stützt, durch deren Hülfe man sich auch rom Liegen, a cubando, erhebt. Auf den linken Vorderarm ;estützt, lagen die Römer beim Mahle; daher cubitum ponere, o viel als sich zur Tafel setzen, und in cubitum erigi, von der [afel aufstehen. Das griechische xúßtтov, ist die Mutter des talienischen gombito. Das spanische codo (cobido), und das portugiesische covado, sind Verwandte von Cubitus.

Die Griechen bedienten sich für Vorderarm, ver-

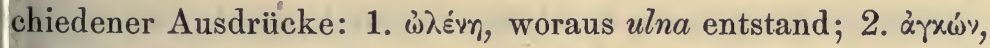
romit auch der Winkel des Ellbogens und das Olecranon

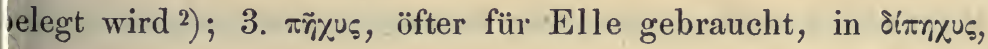

1) De medicina, Lib. VIII, Cap. 1.

$\left.{ }^{2}\right)$ So in der Ilias und Odyssee an vielen Stellen. Bergeinschnitte und Buchten des Meeresufers, kommen auch als $\dot{\alpha} \gamma x \tilde{\omega} y s \varsigma$ vor. Die an einem winkeligen Einbug der Küste des Adriatischen Meeres, von den Syracusanern erbaute Stadt, trägt heute noch, von àrrís, deu Namen Ancona. Das deutsche Enkel 


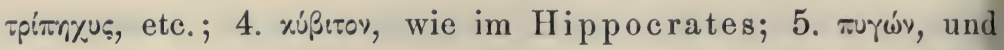
sehr selten $\pi$ uүu mass ausdrückt, und zwar die Länge vom Ellbogen bis zur geschlossenen Faust, während $\pi \tilde{r}_{i}$ 牲, als Längenmass, vom Ellbogen bis zur Spitze des Mittelfingers reicht. Von der $\pi\lrcorner \gamma \mu t_{1}$ (pugnus), als verkürztes Ellenmass, stammen die Pygmäen des Aristoteles und Plinius.

\section{Antihelix.}

So heisst in den anatomischen Handbüchern, die mit dem Helix parallele Gegenleiste des äusseren Ohres, welche im Antitragus endet. Antihelix muss für barbarisch erklärt werden, weil alle mit dem Spiritus asper anlautenden griechischen Worte,

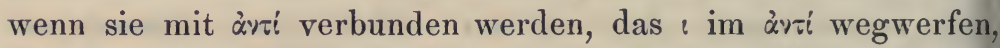
und das $\tau$ als $\theta$ schreiben, man also nicht Antihelix, sondern Anthelix zu sagen hat.

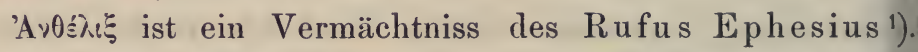
Zu Aristoteles' Zeiten, hatten die verschiedenen Erhaben-

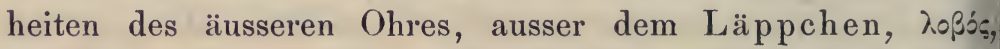
noch keine Namen erhalten. Als Julius Pollux sein Onomasticon schrieb, waren sie schon damit versehen, und wurden

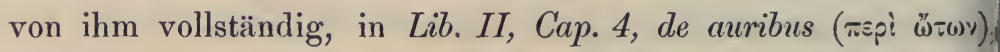
zusammengestellt. Darunter finden wir Anthelix definirt, als *:

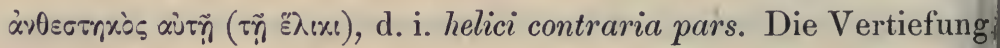
welche der Anthelix umsäumt, hiess *óryn, unsere Concha auris Bartholin nannte den Helix: Capreolus, wahrscheinlich seinex

(Aenkel), als Einbug am Fussrüst, sowie Uncus, Angulus, uni Angel, gehören demselben Stammwort an. Enkel ist abe jetzt nur in der Volkssprache üblich, und zwar für Knöche (das englische ankle), wie z. B. "enkeltief im Schnee ode Koth waten".

1) De partibus corp. hum., Edit. Clinch, pag. 26. 
Biegung wegen, welche mit einem 'Ziegenhorn zu vergleichen' wäre. Wio er aber den Anthelix: Scapha nennen konnte, ist inbegreiflich, da der Anthelix eine Erhabenheit, und Scapha Kahn) eine Vertiefung ist '). Die neuere Anatomie bewahrt 10ch das Andenken an die Scapha des Bartholin, aber nicht Is Gegenleiste, sondern als Fossa scaphoidea, zwischen Leiste and Gegenleiste (Helix und Anthelix).

\section{Anus und Annulus.}

Den drei Worten Anus, Annulus, und Annus, liegt die Idee des in sich selbst Zurückkehrenden, also eines Ringes, u Grunde. Der After, Anus, ist ein Ring, die Fingerringe sind annuli, und das Jahr, d. i. der Zeitraum, welchen nach alter Vorstellung die Sonne braucht, um bei demselben Zeichen les Zodiacus anzulangen, von welchem sie ausging, wird symbolisch als Kreis, und hieroglyphisch als eine im Kreis gekrümmte Schlange dargestellt, welche die Spitze ihres Schweifes im Munde hält. Annus circulus est, heisst es im Varro, De lingua latina, Lib. V, Cap. 2. Den Unterschied macht nur das einfache oder doppelte $n$. Und dieser Unterschied ist sehr unwesentlich, wie die alte Schreibart von Annus, als Anus, und von Annulus, als Anulus, beweist.

Anus, als After, war für die Römer ein Fremdwort, vielleicht vom griechischen Ěvos, id quod in se redit (Forcell.). Cicero sagt: anum appellas alieno no mine; cur non suo potius ${ }^{2}$ ). Dieses Nomen suum ist podex, welchem in der Schriftsprache, das euphemistische anus substituirt wurde. Durch Celsus wurde Anus in die anatomische Sprache eingeführt, um für immer bei ihr zu bleiben: ani vitia, ubi medicamentis non

1) Institutiones anat., Lib. III, Cap. 9, de auribus.

2) Ad famil. $I X, 22$. 
vincuntur, manuum auxilium desiderant ${ }^{1}$ ). Den Aquaeductus Sylvii im Gehirn, oder nur seine Endöffnung unter der hinteren Commissur, Anus cerebri zu nennen ${ }^{2}$ ), sagte dem Geschmack unserer Voreltern besser zu, als dem unseren. Podex, von welchem in der Anatomie nie etwas gehört wird, war selbst den Latino-Barbari so zuwider, dass sie sich lieber ihr Podar und Podarium bildeten. Nur Horaz und Juvenal scheuten sich vor diesem Worte nicht:

$$
\text { "Caeduntur tumidae, medico ridente, mariscae." }
$$

(Juvenal, Sat. II, 12.)

Zahlreicher als die bekannten Anwendungen von Anus, sind jene von Annulus, als Ring. Goldene Ringe zu tragen, war in der Zeit der Republik ein Vorrecht der Equites, Ritter, daher annulo aureo donari, und jus annuli obtinere, im Suetonius, so viel bedeutet, als "zum Ritter geschlagen werden". Die anatomischen Annuli sind der Annulus inguinalis = äusserer Oeffnung des Leistenkanals, der Annulus osseus membranae tympani beim Embryo, die Annuli fibro-cartilaginei cordis, die Protuberantia annularis $=$ Pons Varolii, und eine Schar von Ligamenta annularia, welche jedoch sämmtlich diesen Namen nicht verdienen, da sie keine wahren und vollständigen Ringbänder, sondern nur Semiannuli sind, wie die Ligamenta annularia der Beugesehnen der Finger und Zehen, das Ligamentum anmulare radii, und einige andere.

Dass auch ein altes Weib Anus heisst, wie der After, wollte man von den Runzeln ableiten, welehe im Gesichte alter Weiber, wie am eingezogenen After, vorhanden sind. Diese Ableitung ist mehr possirlich, als gut getroffen. $A b$ annorum multitudine, wie Festus sagt, sieht sich besser an, denn Anus, als altes Weib, wurde auch Annus geschrieben

1) De medicina, Lib. VII, Cap. 30 .

2) Th. Bartholini Institutiones anat., Lib. III, Cap. 6. 
(Forcell.). Ein altes Weib heisst auch Vetula. Daher schreibt sich ein äusserst komischer Lapsus unserer anatomischen Voreltern, in der Benennung des Kreuz- und Steissbeins. Die Uebersetzer der Araber, gaben das arabische al-'us $u \underline{\text { s }}$ (Steissbein) mit Os ani, welches sie auch zu Osanum und Osanium verbildeten. Da nun Anus auch, „altes Weib" bedeutet, und dieses, in Vetula, ein bekanntes Synonym besitzt, haben die Latino-Barbari, für $O s$ ani, kurzweg ihre Vetula hingesetzt. Sie wussten in der Unschuld ihrer sprachlichen Unwissenheit nicht, dass die Römer zwar für Anus, als altes Weib, aber nie für Anus, als After, Vetula gebrauchten. Letzteres war nur den lateinischen Sprachbarbaren möglich.

\section{Aorta, und Arcus aortae.}

\section{Aorta.}

Aorta (גoptŕ) ist ein Hippocratisches Wort. Es diente jedoch dem Pater médicinae nicht als das, was wir heute darunter verstehen, sondern als Luftröhrenast. 'Aoptŕ kommt von àsípw, etwas in die Höhe heben, um es zu tragen. Die

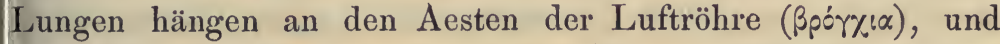
werden von ihnen getragen. Wie Homer den Riemen, an welchem die Waffe hängt, das Wehrgehenk, ḋoptŕp, nennen konnte, so konnte Hippocrates den Luftröhrenast doptń nennen. Aristoteles transferirte das Wort auf die grosse Schlagader, an welcher das Herz hängt '). Galen scheint für die Aorta des Aristoteles, keine Vorliebe gehabt zu haben,

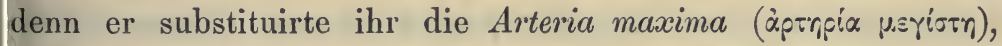

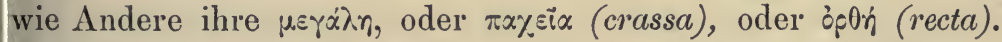
Diese $\partial \rho \theta \dot{y}$ wird uns dadurch interessant, dass sie, mit neugriechischer Aussprache, oft als Orthi bei den Latino-Barbari auftritt, und durch einen lapsus calami, zu Crithi und Chrithi

1) De partibus animalium, Lib. III. 
degenerirte: Arteria major, quae omnium fons est, Chrithi vocatur 1). Offenbar war der ursprüngliche Schreibfehler: Crthi (c für o). Crthi kann nur eine ezechische Zunge pronuneiren. Deshalb schalteten die Italiener ein $i$ nach dem $r$ ein, und schrieben Crithi, welches der Benedictiner Constantinus, als Chrithi und Christi, dem Heiland näher zu bringen wusste.

Adorti, Ahorti, und Orithi, welche ebenfalls bei den LatinoBarbari zu finden sind, ergeben sich leicht als Verunstaltungen von Aorta (גoprí). Dem Bartholinus ist die Aorta, die Mater arteriarum. Näheres über Orthi und Orithi, in HL, §. LXXXIII.

2. Arcus aortae.

Bis zum Anfang des 18. Jahrhunderts, hörte man nichts von einem Arcus aortae. Galen gab seine Beschreibung der Aorta, nur nach Thiermustern (Wiederkäuer). Er kennt blos

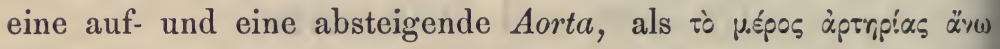

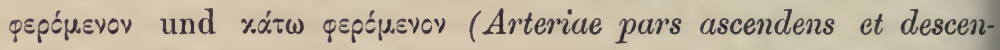
dens). Selbst als im Mittelalter menschliche Leichen unter das Messer kamen, blieb die Aorta ascendens und descendens unbehelligt. Im Carpus${ }^{2}$ ) wird zuerst eines Girgilus Erwähnung gemacht. Die Stelle war mir anfangs nicht ganz verständlich. Ich bezog sie auf das Umgriffenwerden des Aortabogens, durch die rüickläufige Schlinge des Nervus laryngeus inferior. Bei wiederholtem Nachlesen stellte es sich heraus, dass dieser Girgilus (Bacham der Araber) die Krümmung der Aorta ist. Das Wort Girgilus, auch Girgillus, ist schlecht gewählt; denn Girgilus drückt nicht einen.Bogen aus, sondern nach Isidorus, ein lignum, quod in gyrum vertitur. Noch sehlimmer als Girgilus, ist der Dyablus des Carpus. Carpus hätte, als Anatom, den Hippocrates und Galen besser

1) Constantinus Afer, De communibus medico necessariis locis, Lib. II, Cap. 21, - das an unverbesserten Abschreibfehlern reichste Buch, welches ich je zur Hand bekam.

$\left.{ }^{2}\right)$ Isagogae breves, in cap. de nervis reversivis (unsere laryngei recurrentes). 
gekannt haben sollen, als den Teufel, Diavolo und Diablo. Ich kann unter Dyablus nur das griechische siaù.os vermuthen, welches einen Doppellauf, hin und zurück, mit einer Biegung oder Windung dazwischen, bei Hippocrates ausdrückt ${ }^{1}$ ).

Bauhin ahnte wohl, dass es mit Galen's Aorta ascendens und descendens nicht ganz geheuer ist, wagte aber dennoch nicht, der herrschenden Autorität durch eine bestimmte Aussage entgegenzutreten, indem er blos sagt: truncus descendens, ad quintam thoracis vertebram detorquetur, et sinistrorsum paululum descendit ${ }^{2}$ ). Erst im Heister tritt der Aortabogen in seine vollen Rechte: truncus aortae, ad similitudinem arcus inflexus ${ }^{3}$ ). Boerhave und Haller sicherten sein Verbleiben in der Anatomie.

Ueber Girgilus 'und die Nervi reversivi, findet der Leser mehr in HL, §. XXXVI.

\section{Aponeurosis.}

Die jetzige Anatomie, welche veujpov nur als Nerv gelten lässt, muss stutzig werden, wenn sie die fibrösen Häute, als Aponeurōses benannt sieht. Bevor Aristoteles die Nerven veüpa nannte, war veüpov Alles, was wir jetzt fibrös nennen: die Sehnen der Muskeln, und die Bänder der Gelenke. Schon Hippocrates gebraucht, in dem unächten Buch: IIspi äp0pwv,

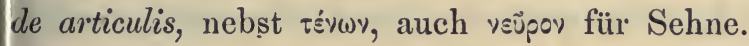

Im Galen gerathén wir auf àtovsúpwsts, in doppelter Bedeutung: 1. als Uebergang des Muskelfleisches in die Sehne, von àmoveupów, in eine Sehne verwandeln, und 2. als Sehne

1) Lib. I, de diaeta, XXXIV, Cap. 12, und Lib. II, XLI, Cap. 12. Im Galen zeigt sich dasselbe Wort in De usu partium, Lib.VII, Cap. 14.

2) Theatrum anat., Lib. II, Cap. 25.

3) Compendium anat., Norimbergae, 1732, pag. 157. 
selbst: musculi in aponeuroses finiuntur $\left.{ }^{1}\right)$. Da nicht alle Muskeln in strangartige Sehnen übergehen, sondern mehrere derselben an ihrer Insertionsstelle theils sehnig, theils noch fleischig sind, wurden von Galen zwei Arten von Aponeurosis aufgestellt: die veupẃôns, als eigentliche oder Strangsehne, und die oxprwórs, als mit Fleisch gemischte Sehne. - Im Oribasius erscheint Aponeurosis zuerst, als latus tenuisque tendo ${ }^{2}$, und dieser Begriff ist bei dem Worte fortan geblieben, bis auf die neueste Zeit, welche auch die Fasciae unter die Aponeuroses aufnahm.

Am liebsten wird Aponeurosis für die breiten Sehnen breiter Muskeln, oder für plötzlich sich verbreiternde Muskelsehnen angewendet, wie die Aponeurose der breiten Bauchmuskeln, die Aponeurose des Zwerchfells (Centrum tendineum), und die Aponeurosis palmaris. Man kam davon ab, die Fascien Aponeuroses zu nennen, mit Ausnahme der Fascia des Plattfusses, welche, schon der analogen Aponeurosis palmaris zu Liebe, Aponeurosis, nicht Fascia plantaris, genannt zu werden pflegt.

Die lateinischen Uebersetzungen von Aponeurosis, selbst die Vesal'sche, missglückten alle, wie die Pronervatio, Enervatio, und Denervatio der anatomischen Synonymien. Nur Membrana tendinosa im Douglas, und ihre Verkehrung in Tendo membranaceus im Verheyen, könnten als Surrogate für Aponeurosis dienen, wenn man sich je entschliessen würde, die in unserer Zeit wirklich sinnlose Aponeurose abzuschaffen. Dass sie bis jetzt geschont wurde, verdankt sie nur ihrem Wohllaut (vox dulce sonat). - Das Adjectiv aponeuroticus, hält allein noch an der Galea cranii fest. Die Expansiones aponeuroticae werden besser und kürzer Fasciae genannt. Aponevrosis statt Aponeurosis zu schreiben, ist Reuchlinische Mode.

1) De motu musculorum, Lib. I, Cap. 1.

2) Anatomia ex Galeno, pag. 105. 


\section{Apophysis und Epiphysis.}

Alle Arten von Knochenfortsätzen, gerade und krumme, stumpfe und spitzige, dicke und dünne, lange und kurze, rauhe, glatte, und überknorpelte, werden im Galen und Oribasius Apophyses (ànoqúrsıs), von uns Processus genannt; -

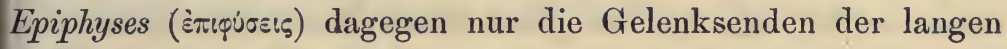
Röhrenknochen (die Appendices ossium im Vesal). Der Unterschied beider beruht aber nicht allein auf dem Standorte derselben, sondern auch auf ihrer Entwicklung. Die Apophysis, der Processus, war, so lange er existirt, immer Eins mit dem

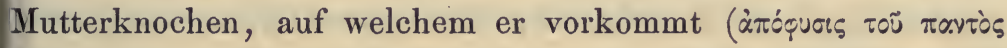

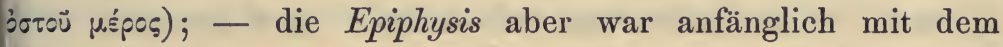
Mittelschafte des Knochens nicht verschmolzen, sondern nur

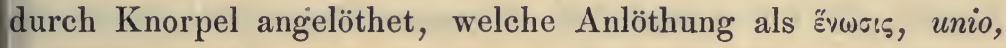
erwähnt wird. Der sonst so genaue Beschreiber der Knochen, Rufus, erwähnt weder Apophysis, noch Epiphysis. Dagegen spricht sich das Lexicon medicum Blancardi 1); über beide sehr treffend mit den Worten aus: Apophysis est pars ossis, non ope cartilaginis adnata, uti epiphysis, sed cum osse continua, et ultra protuberans, tutandis articulis, musculisque firmandis inserviens. Noch in Vesal's grosser Anatomie, werden die Epiphysen für knöcherne Deckel angesehen, welche die Markhöhle der Röhrenknochen oben und unten zu verschliessen haben, damit die Medulla ossium nicht auslaufe. Galen, welcher es als Regel aufstellte, dass die Epiphysen immer grösseren Umfang haben, als der Körper des Knochens, verglich die beiden Epiphysen eines Knochens, ganz riçhtig mit den Epistylen und Basen einer Säule, welche ebenfalls umfänglicher sind als der Säulenschaft, und lässt daraus eine Vermehrung der Tragkraft eines Knochens resultiren: amplificantur epiphyses, ad sustinendi securitatem. Er bemerkte es 
zugleich, dass der Gelenkskopf des Unterkiefers, gegen die Regel anderer Gelenksköpfe, keine Epiphyse, sondern eine Apophyse sei, weil er nie durch Agglutinatio mit dem Kieferast verbunden ist, sondern vom ersten Entstehen des Kiefers an, einen integrirenden Bestandtheil desselben ausmacht. Zwei deutsche Worte: Knochenauswuchs und Knochenanwuchs, würden den Sinn von Apophysis und Epiphysis besser treffen, als ihn die griechischen Ausdrücke entnehmen lassen.

Ich will nicht -übergehen, dass Apophysis und Epiphysis im Hippocrates ganz andere Dinge sind, als im Galen und seinen Nachfolgern. Epiphyses heissen bei ihm knötchenartige Auftreibungen an den Rändern der Augenlider, ex crassioribus quibusdam humoribus excrementitiis obortae ${ }^{1}$ ), und Apophyses sind ihm excrescentiae carneae in foetu feminino apparentes, quasi exortus membrorum. Ich verstehe die letzteren Worte, als "Stummeln der Extremitäten". Warum er sie gerade nur bei weiblichen Embryonen so nennt, weiss ich nicht zu sagen, und der gelehrte Interpietator des Hippocrates: Foësius, wusste es auch nicht. Wahrscheinlich hat er diese Stummeln nur einmal, und zufällig, an einem weiblichen Fötus gesehen: Man hob zu Zeiten des Hippocrates, die Embryonen nicht in Spiritus auf.

\section{Aquula Cotunnii und Humor aqueus.}

\section{Aquula Cotunnii.}

Man könnte Aquula, welches auch Aquola geschrieben wird, leicht für cinen Barbarismus halten, wenn man bedenkt, dass Wasser und Wein, als solche, kein Diminutiv ihres Wesens vertragen. Ihre Menge aber ist verringerbar, so dass

1) Epidemicorum, Lib. III, Sect. 3. 
Aquula ebensogut gesagt werden kann, wie wir Wässerchen zu sagen pflegen.

Die häutigen Säckchen im Vorhof des Gehörlabyrinths, füllén die Höhle des Vorhofs nicht vollkommen aus. Es bleibt zwischen den beiden Säckchen, und der Vorhofswand, stellenweise ein freier Zwischenraum übrig, welcher von einer serösen Flüssigkeit - dem Gehörwasser - eingenommen wird. Diese Flüssigkeit führt, seit sie von Domenico Cotugno ${ }^{1}$ ) zuerst beobachtet wurde, den Namen Aquula Cotunnii, besser Cotunni, da Cotugno zu Cotugnus oder Cotunnus, nicht aber zu Cotunnius, latinisirt werden muss.

Im guten Latein bedeutet Aquula so viel als pauca oder parca aqua, und wurde, mit diesem Sinn, von Cicero ${ }^{2}$ ) und von Plautus ${ }^{3}$ ) gebraucht. Im medicinischen Latein erhält aber Aquula eine andere Verwendung, und steht in den lateinischen Uebersetzungen der Griechen immer für Hydatis. So im Galenus und Paulus Aegineta, und die medicinischen Lexica geben ohne.Ausnahme, Hydatis und Hydroa als Aquula wieder. Galen nennt insbesondere die Wasserbläschen an den Augenlidein Hydatides ${ }^{4}$ ), und die beste Uebersetzung des Galen, von C. G. Kühn, bietet uns diese Hydatides als Aquulae dar. Um also dem anatomischen Latein, welches doch ein medicinisches ist, keine Missverständnisse zu bereiten, haben die Neueren für die Aquula Cotunni, ihre Perilympha substituirt, welche leider viel schlechter ist, als jene. Sieh' Perilympha.

Cotugno bediente sich des Ausdruckes Aquula nicht, sondern spricht von einem vapor in humorem collectus, wie

1) De aquaeductibus auris humanae, Neapoli, 1761, pag. 22.

2) "Non seclusa aliqua aquula, sed universum flumen erumpit," in Orat. $I I, 39$.

3) "Suffundere aquulam," im Curculio, Act. I, Sc. 3, Vers 3.

4) Methodus medendi, Lib. XIV, Cap. 19: "Aquularum, quae magnae sunt, chirurgiâ curabis, quae parvae sunt, siccantibus medicamentis juvantur." 
auch Haller'). Vor Cotugno liess man die, dureh die Auflösung des Gehörnerven gebildete Pulpa, nur von Luft umgeben sein (Vieussens, Valsalva).

2. Humor aqueus.

Bevor der Humor aqueus des Auges zu diesem Namen kam, hiess er bei den Uebersetzern der Araber: Humor aquae

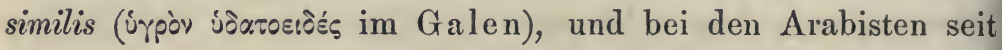

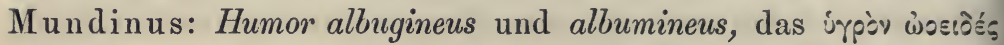
des Aëtius. Lange hielt ich den Humor evagaidos des Constantin Africanus ${ }^{2}$ ) für unerklärbar. Aber die Muse der griechischen Dichter, wies mit goldenem Finger auf suxrris, "rein" (im moralischen Sinne, und von der Sonne und den Sternen gebraucht). An diesem evarris, vergriff sich der ehrwürdige Mönch des Monte Cassino ( $\dagger$ 1087), wollte vermuthlich ein ejaysıò, daraus machen, um den klaren Humor aqueus damit $\mathrm{zu}$ beschenken, schrieb aber neugriechisch und schlecht lateinisch: evagaidos, welches kein Wörterbuch bisher aufzuklären im Stande war. Sie liessen es deshalb lieber weg.

\section{Arachnoidea, alt und neu.}

Im griechischen Alterthum wurde mit Arachnoidea, Retina, und Hyaloidea, die dritte Haut des Auges bezeichnet. Diese Worte waren also Synonyme, wie sich aus folgender Stelle des Rufus ergiebt: tertia oculi tunica, humorem vitreum continens, propter tenuitatem arachnoidea (àpayyosiòr $5^{3}$ ) appellata est, nonnulli, quia Herophilus reti contracto assimilat, veticularem

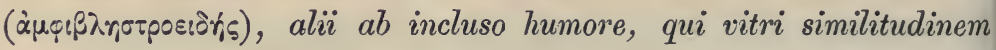

1) Elem. physiol., Tom. V, §. 28.

2) De communibus medico cognitu necessariis locis, im zweiten Bande der Opera omnia, Basil., 1536, Cap. 13.

3) 'Apóxy ist "Spinne", aber auch "Spinnengewebe". 


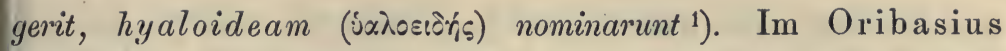
finden wir die Arachnoidea nicht als Synonym der Retina, sondern als Benennung der Ciliarfortsätze der Choroidea: ex ipsa choroide tunica, quae reticularem continet, tenues, et araneis

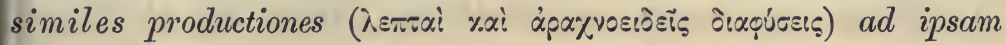
reticularem extensae, ligamenta illi sunt, simulque alimentum afferunt ${ }^{2}$ ). Auch dabei blieb es nicht für immer. Im Celsus erscheint die Arachnoidea, als unsere jetzige Zonula Zinnii, welche für einen Theil der Retina gehalten, und ihres strahligen Ansehens wegen (Corona und Zona radiata im Zinn ${ }^{3}$ ), schon von Herophilus mit den Radiärfasern eines Spinnennetzes verglichen wurde ${ }^{4}$ ). Die Araber, und ihre Uebersetzer, hielten an diesem Begriff der Arachnoidea fest; die Restauratoren der Anatomie aber, gebrauchen Arachnoidea bald für die ganze Retina, bald für die Corona ciliaris, welche sie für den vorderen Abschnitt der Retina hielten, z. B.: duae aliae oculi tunicae accedunt, una anterior aranea, altera posterior retina ${ }^{5}$ ). Mit jedem neuen Schriftsteller, wurde die Verwirrung über die Arachnoidea oculi ärger, so dass der Jammerschrei des Fallopia, ganz begründet erscheint: omnia ita confusa, ut nihil, quod solidum sit et distinctum, conjici possit $\left.{ }^{6}\right)$. Die Verwirrung hörte erst dann auf, als eine ganz neue Membran, mit dem Namen Arachnoidea belegt wurde - die Arachnoidea cerebri. Seit diese, durch die Societas anatomica Amstelodamensis, anno 1664 und $1665^{7}$ ), in ihre Rechte, als eine continuirliche Hülle

1) De appellatione partium corp. hum., pag. 36 und 37.

2) Anatomica ex Galeno, pag. 35.

3) Descriptio oculi humani, Lib. I, Cap. 3, §. 3.

4) Celsus, De medicina, Lib. VII, Cap. 7, §. 13.

5) Carpus, Isagogae breves, in cap. de anatomia oculorum.

6) Observationes anatomicae, in Tomo II operum Vesalii, Edit. Lugd., pag. 756.

7) F. Ruyschii Epistol. IX, und Ger. Blasii Anatome medullae spinalis, pag. 21. 
des Gehirns und Rückenmarkes, eingesetzt wurde, war die Arachnoidea oculi aufgegeben und verlassen. Wenngleich es nicht unbeanständet gelassen werden darf, eine Haut, welche keine Lücken und Oeffnungen hat, wie das Spinnengewebe, Arachnoidea zu nennen, mag doch die Benennung, als Tropus, mit Rücksicht auf die Dünnheit und Zartheit dieser Membran, so lange hingehen, bis nicht die Meninx serosa ihn zu ersetzen berufen sein wird. Wir wünschen, dass es bald geschehen möge. Die Meninx mucosa, welche ich in Hildebrandt's Anatomie noch angeführt finde, hätte füglich in der Weberschen Ausgabe wegbleiben können, statt in Schutz genommen zu werden. Der Meninx media des Bidloo, statt Arachnoidea, lässt sich nichts anhaben.

\section{Arbor vitae und Palma plicata.}

Die alte Chemie hatte ihren Arbor Dianae s. philosophorum, und ihren Arbor Martis, als baumartige Crystallisationsformen von Silber und Eisen. Im Meere wuchsen die Arbores maris $=$ Corallen, und in der Medicin gab es einen Arbor vitae, worunter van Helmont ein Universal-Macrobioticum verstand, welches er aus dem aromatischen Cedernholz bereitete. Die Ceder erreicht bekanntlich ein sehr hohes Alter. Mit der Ceder verwandt ist die Thuya, deren resinöses und subaromatisches $\mathrm{Holz}$ nicht so kostspielig ist, wie jenes der Ceder, und deshalb zur Bereitung eines billigeren Helmontschen Balsamus longae vitae herhalten musste. So erhielt auch die Thuya ihren Namen Arbor vitae. Die Blättchen der immer grünenden Thuya, haben eine ganz eigenthümliche schönє Gruppirung, deren Bild man am Durchschnitt der Hemi sphären des kleinen Gehirns wiedererkennen wollte, wo dif von grauer Substanz eingefassten Strahlungen des weisser Markes, sich wie die Aeste, Zweige, Blätter und Blättcher der Thuya ansehen. Winslow verpflanzte die Thuya in di 
Inatomie 1), wo sie noch immer grünt, als Arbor vitae cerebelli, nd als Arbor vitae uteri, welchen letzteren man sogar zum 1.bor vivificans erhob (Lieutaud ${ }^{2}$ ). Die Schleimhaut des analis cervicis uteri, bildet nämlich an der vorderen und interen Wand des Canals, je einen longitudinalen Aufwurf der Kamm, von welchem seitlich kleinere Kämme oder "ältchen der Schleimhaut abtreten, deren zierliche Anordung, ihrer Aehnlichkeit mit den Folïs palmatis der Palme regen, von Haller mit dem ganz verfehlten Namen Palma licata belegt wurde ${ }^{3}$ ). Wir haben in diesem Buche, dem ;rossen $\mathrm{Haller}$ viel Weihrauch gestreut; jetzt müssen wir hm aber einmal das Rauchfass an den Kopf werfen. Die rwähnten Falten gleichen einem Palmblatt, und sollten desalb Plicae palmatae oder palmiformes genannt werden, nicht ber Palmae plicatae, "gefaltete Palmen", was gar keinen inn hat. Suo quisque abundat sensu.

\section{Area und Areola.}

Area wird nur sehr wenig, das Diminutiv Areola aber, ehr häufig in der Anatomie verwendet. Area hiess bei den \}ömern, ein leerer Platz in einer Stadt. In urbe area, in ure autem ager. Nebst dieser gewöhnlichen Bedeutung von Area, finden sich noch zwei seltenere. 1. Area als $\mathrm{H}$ of um jonne und Mond, sonst Corona genannt, - das griechische

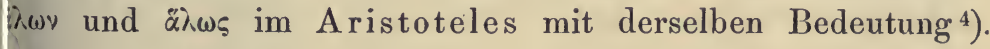

1) Exposition anat., T. IV, Tête, n. 108, Arbre de vie.

2) Zergliederungskunst, $I I . B d .$, pag. 668 , der , le be ndig ma chende Baum" des deutschen Uebersetzers, auf welchem die Ovula Nabothi wachsen.

3) Elem. physiol., T. VII, Lib. 28, Sect. 2, §. 13.

4) Die Lateiner bildeten darnach ihren Halo, onis, welchen S e u eca definirt als : circa solem circulus, quem aptissime coronam dicimus. 
Diese Area wurde von Bauhin, als Areola mammae, auf den Warzenhof übertragen, ihrer relativen Kleinheit wegen. Chausier, welcher an den goldenen Heiligenschein auf alten Gemälden dachte, glaubte Areola durch Auréole verbessern zu müssen. Obwohl man aureolus nur als kleine Goldmünze (aureus) kennt (Martial), gefiel doch die auréole den französischen Pathologen so sehr, dass sie auch andere Höfe, wie den entzündlichen Hof um die Blattern, um die Impfpustel, oder um ein Geschwür, auréole zu nennen pflegen. 2. Area als locus pilis nudatus am Kopf $=$ Glatze. Celsus gedenkt zweierlei Formen dieser Area: als Alopecia und Ophiasis ${ }^{1}$ ), erstere von rundem Umfang, letztere länglich oder unregelmässig. Martial sagt von einem Kahlkopf: nec ullus in longa area pilus notatur.

Wenn also, wie aus dem Gesagten einleuchtet, Area eine grössere, und Areola eine kleinere Fläche ${ }^{2}$ ) ausdrückt, so ist es ein grammatikalischer Fehler, welcher sich seit Haller ${ }^{3}$ ) fortgeerbt hat, die Luicken und Hohlräume eines Gewebes, welche durch Kreuzung seiner faserigen Elemente gebildet werden, Areolae zu nennen, und von einem areolaren Gewebe, einem Areolarkrebs, einer areolaren Knochensubstanz; u. m. a., zu reden, wie es in allen deutschen Anatomien ohne Ausnahme geschieht. Die der Anatomie altangestammter Cellulae und Cavernulae, würden sachgemäss das Wahre aus drücken: "kleine Höhlungen", und von etymologischer Bedenken nichts zu leiden haben. Aber die Worte sind alt nicht mehr in der Mode, und darum mussten sie zurück gesetzt werden, um den missverstandenen Areolae ihren Plat zu überlassen.

1) De medicina, Liz. VI, Cap. 4.

2) Blumen- und Gemüsebeete in den Gärten, heissen im Colv mella: areolae.

3) Primae 'lineae physiologiae, §. 25. 


\section{Arteria und Vena.}

Seit zweitausend Jahren weiss man, dass die Arterien veder Luft, noch das aus Blut und Luft sublimirte Wesen les Spiritus vitalis enthalten, und doch perennirt der uralte

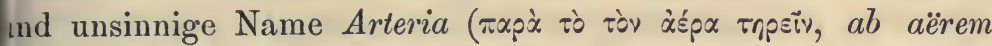
ontinendo, deshalb ḋsporñpss im Erotianus), über dessen erste Inwendung als Luftröhre, der Artikel Trachea in diesem Buche lachgesehen werden mag. Wie die Luftröhre, ihres geringelten Insehens wegen, Arteria aspera genannt wurde, fasste man lie arteriellen Blutgefässe als Arteriae laeves ( $\lambda \varepsilon i$ : $)$ auf. Wenn nan Vena, und die griechische ọ $\lambda \dot{\psi} \psi$, nicht blos für Blutader, ondern auch für Schlagader bei den medicinischen Classikern ; ebraucht sieht (tangere venam, den Puls fühlen, im Suetonius, Venae concidunt, der Puls wird schwach, und Venae moventur, ler Puls schlägt stark, im Celsus), wenn man ferner Vena ür Canal oder Gefäss überhaupt angewendet findet, wie ie denn im Alterthum diese Geltung ununterbrochen bewahrt Iaben '), so muss man sagen, dass die Arabisten eigentlich den frterien den schicklichsten Namen gaben, in ihren Venae pulsailes, micantes, elevabiles, und saltantes, zum Unterschied von len Venae quietae $=$ nicht pulsirende Blutgefässe. Unsere jchlagadern sind eine wörtliche Uebersetzung des arabichen Terminus Venae pulsatiles. Keine andere Sprache hat in so passendes Wort für Arteriae. Leider sind unsere Blut-

1) Ich verweise auf die Vena alba des Celsus = Ureter, auf die Vena uritis der Arabisten = Harnleiter, - auf die Vena audax = Aorta, - auf die Vena genitalis (Yovip.n $\varphi \lambda \varepsilon^{\prime} \psi$ ) $=$ Harnröhre, als Entleerungsgang des Samens, - auf die Venae albae oder lacteae, welche noch ror zwei Jahrhunderten für die Lymphgefässe im Gebrauch standen, - auf die Vena organalis $=$ Luftröhre, - und auf die Vena cibaria $=$ Speiseröhre, möglich verschrieben für Via cibaria im Aurelian. 
adern (Venen) dieses Lobes nicht würdig, denn auch eine Schlagader ist eine Blutader, weil sie Blut enthält, und Blutader für Vene allein, somit eine vox incongrua.

Eine seltsame Verbindung der Begriffe von Vena und Arteria, hat sich in der Vena arteriosa und Arteria venosa, bis zur Entdeckung des Kreislaufes, unangefochten erhalten. Vena

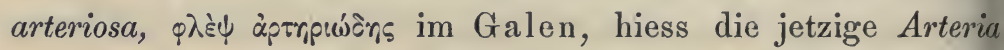
pulmonalis, weil sie venöses Blut in die Lunge führt, und die Wanddicke einer Arterie besitzt. Arteriae venosae dagegen hiessen die Lungenvenen, weil sie mit dem linken Herzen, aus welchem die Arterien entspringen, zusammenhängen, aber nicht die Wanddicke einer Arterie, sondern jene einer Vene haben.

\section{Arthrodia.}

Arthrodia, die Galenische àpopuòía, ist bei uns die generelle Bezeichnung eines freien Gelenks. Galen bestimmt

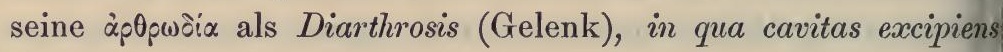
(Gelenksgrube) superficiaria est, caput vero humile et depressum 1). Er führt als Beispiele die Gelenke zwischen Hinterhaupt und Atlas, und zwischen Unterkiefer und Schläfebein an. Die Anatomie der Jetztzeit, nennt jedes Gelenk mit allseitig ge statteter Beweglichkeit, eine Arthrodie, und nimmt zwei Unter arten derselben an: 1. vollkommen freie Arthrodie, wie in Schulter- und Hüftgelenk, und 2. beschränkte Arthrodie zwischen Carpus und Vorderarm, zwischen den Ossa scaphoidec der Hand- und Fusswurzel, und den dazu gehörigen Capitulis zwischen den Köpfen der Mittelhand- und Mittelfussknochen und den ersten Phalangen der Finger und Zehen, etc. 'Ap0pwôt mit Adarticulatio zu übersetzen (van der Linden), ist gan sinnlos. Articulatio libera entspricht dem Begriff der Arthrodi am besten. Höchstens könnte noch eine Arthrodia plana un

1) De ossibus, ad tirones, in procemio. 
ofunda zulässig erscheinen, wie sie Vesling unterschied, iit dem Schultergelenk, als Repräsentant der ersten Form, nd dem Hüftgelenk, als Prototyp der zweiten (Enarthrosis aleni, Pfannengelenk). Arthrodia mit Drehgelenk zu übertzen, geht deshalb nicht an, weil in jedem Gelenk, auch im Vinkel- und Radgelenk, sich etwas dreht.

Sieh' den folgenden Artikel: Articulatio.

\section{Articulatio.}

Ein sehr beliebt gewordener, in Wort und Schrift aller manischen Sprachen allgemein verbreiteter Barbarismus, ist rticulatio. Nicht das Wort ist barbarisch, sondern seine Anendung für Gelenk. Sein Vorkommen im classischen Latein, eschränkt sich nur auf einige Stellen im Plinius. Der Sinn, I welchem es dort gebraucht wird, ist Schössling, Aba eilung, oder Gliederung. Als Gelenk erscheint es nie. las schubweise Wachsen des Stammes und der Aeste eines aumes, wird im Plinius als Articulatio arboris ') erwähnt, ie auch an einer anderen Stelle: clare tunc cernitur excrescenum cacuminum articulatio ${ }^{2}$ ). Plinius erklärt zugleich sich lbst, indem er für Articulatio, auch incrementum geniculatum ibstituirt. Zweitens stossen wir im Plinius auf Articulatio, Is eine Krankheit des Weinstockes, welche sich durch hlechtes Wetter, Reif und Hagel, oder durch ungeschicktes eschneiden, an den jungen Trieben einstellt, als vitibus morbus eculiaris articulatio.

Die Gelenke der Knochen werden in den Classikern, und on unserer höchsten medicinischen Sprachautorität, Cornelius elsus, immer nur als Juncturae, oder Articuli, seltener auch Is Nodi, erwähnt, gar niemals als Articulationes.

1) Hist. nat., Lib. XVII, Cap. 21, Sect. 163.

2) Op. id., Lib. XVI, Cap. 25, Sect. 41. 
Junctura drückt, wie Commissura im Celsus, jede Art von Knochenverbindung aus, nicht blos ein Gelenk. Deshalb werden auch die Nähte des Schädels, Juncturae serratae genannt. Im Ovid finden wir junctura genuum (Kniegelenk), und juncturae verticis (Halsgelenke). Die Uebersetzer der Araber, und die Arabisten im Mittelalter, kennen kein anderes Wort für Gelenk, als Junctura.

Nodus, für Gelenk, wird eigentlich nur in der Umgangssprache angetroffen. Da die Gelenkenden der Knochen dicker sind als ihre Schäfte, erscheint ein Gelenk am Skelet, immer als eine Auftreibung. Diese Auftreibung wird zwar am Lebenden minder merklich, weil das Fleisch der Muskeln, welche den Knochenschaft umgeben, ausgleichend wirkt. Aber an den Fingern, wo es kein Muskelfleisch giebt, besonders an mageren Händen, fallen die Gelenke wie Knoten in's Auge, was auch, obwohl in minderem Grade, am Kniegelenk der Fall ist. Diese Nodi erinnern an die Knoten der Rohrgewächse, und erhielten deshalb von ihnen ihren Namen. So erklärt sich die Redensart: crura sine nodis, steife (ankylotische) Kniee.

Am meisten von den drei genannten Ausdrücken für Gelenk, steht bei den Classikern Articulus in Gebrauch. Seine Etymologie versteht sich leicht. Die Gliedmassen hiessen Artus (seltener Membra). Die kleineren Abtheilungen der Artus, wie Vorder- und Oberarm, Unter- und Oberschenkel, wurden natürlich Articuli genannt, und weil diese Theile durch Gelenke untereinander beweglich verbunden sind, erhielt auch das Gelenk, durch eine Laune des nicht controlirbaren Sprachgebrauchs, den Namen Articulus ${ }^{1}$ ), welcher also nur figürlich zu nehmen ist. Ganz treffend bemerkt das Lexicon totius latinitatis von Forcellini hierïber: articulus non est junctura, sed os, quod in junctura, alteri ossi adnectitur. - Nicht blos dic Gelenke zwischen den Abtheilungen der Gliedmassen, auch

1) Hominis digiti articulos habent ternos, pollex binos, heisst es in Plinius. 
ie Theile eines Ganzen überhaupt, wurden Articuli genannt. o die Silben, als Theile der Worte, - die Absätze in einer :ede oder Abhandlung, - die Punkte eines Gesetzes oder ertrages, - selbst die Zeitabschnitte, wie die Sterbestunde: 2 articulo mortis.

Möge also die Anatomie ihre Articulationes gegen Articuli mtauschen, wenn sie gut latein schreiben und reden will.

Galen, und sein treuer Anhänger Oribasius, welche ie Gliedmassen $x \tilde{\omega} \lambda \alpha$ nennen, sprechen von den Gelenken,

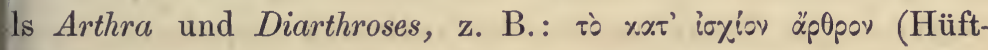

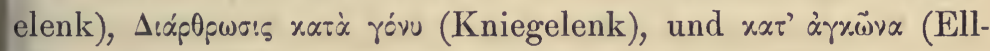
ogengelenk). Hippocrates bedient sich wohl auch des Vortes äpopoy, versteht aber darunter nicht ein Gelenk, sonern den Kopf eines Knochens, welcher von einer Gelenksfanne aufgenommen wird. Ein Gelenk selbst nannte er 1parthrosis, von $\dot{\alpha} \pi \alpha \theta_{\rho} \rho \dot{\omega} \omega$, in Glieder theilen. Die von den Jebersetzern des Hippocrates gebildete Abarticulatio, ist Iso keine besondere Gelenksart, sondern ein Gelenk überraupt 1). Da Arthrosis und Diarthrosis zwei vollkommen gleichinnige Worte sind, war es unnöthig, für das zweite derselben len lateinischen Namen Dearticulatio zu schaffen, wie von Realdus Columbus geschah ${ }^{2}$ ). Er ist ebenso barbarisch, vie die Perarticulatio von Th. Bartholinus ${ }^{3}$ ), und die $A d$ wriculatio von Ingrassias ${ }^{4}$ ).

Leider wurde Articulatio, als Gelenk, von dem besten Lateiner unter allen Anatomen, Vesal ${ }^{5}$ ), zuerst in Verkehr gebracht. Er verwendete dasselbe, wenn er überhaupt von einem Gelenke sprach, während er ein bestimmtes Gelenk mmer als Articulus behandelt.

1) Commentaria Galeni in Hippocratis librum de articulis, I:

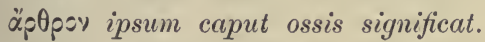

2) De re anatomica, Lil. I, Cap. 3.

3) Institutiones anat., Lib. IV, Cap. 1.

4) Commentaria in Galeni librum de ossibus, pag. 26.

$\left.{ }^{5}\right)$ De corp. hum. fabrica, Lib. I, Cap. 3. 
Wer Articulus sagt, darf auch articularis sagen, als Beiwort für Alles, was zu einem Gelenk gehört. Wer aber Articulatio sagt, müsste consequent auch articulationaris sagen, was noch Niemandem eingefallen ist.

Das deutsche Gelenk fällt uns durch seine Aehnlichkeit mit dem ezechischen članek auf, und mit dem englischen link (verbinden). - Das gemeine Volk nennt die Gelenke, wie auch die Knoten am Rohr und am Strohhalm, Gleichen. Die Anatomie hat sich daraus die Gleichbeine gebildet, welche in der Schriftsprache Sesambeine heissen.

Von dem griechischen äpopor, hat die Anatomie und die Pathologie mehr als hundert Composita aufzuweisen, bei welchen äpopov das erste Wort bildet. An ebenso vielen hängt der Grieche hinten an. Einige davon sind alt und gut; viele neugebacken, schlecht und widersinnig. Was sagt man z. B. dazu, wenn ein berühmter Chirurg seinem Buch über die spontanen Verrenkungen der Gelenke, den Titel Arthrocacologia giebt (Rust)? Wir wollen Arthrokake zugeben, als übler $\mathrm{Zu}$ stand eines Gelenkes, und protestiren nur gegen die französische Aussprache derselben: Arthrocase. Arthrocacologia aber, wird jeder Grieche sagen, ist die üble Nachrede, das Schimpfen ! über die Gelenke!') Wer sich ein parr heitere Stunden bereiten will, der lese, was C. G. Kühn, vor fünfzig Jahren, de inepta cognitionis sermonis graeci simulatione, in seinen Opusculis academicis geschrieben hat ${ }^{2}$ ). Nichtsdestoweniger hat die Manie, griechische Worte, invita Minerva, zusammenzustoppeln, unter Aerzten und leider ganz auffallend bei den Anatomen, gerade einen endemischen Charakter angenommen.

1) Sieh' Julii Pollucis Onomasticon, Lib. II, III, V, und VIII.

2) Vol. II, pag. 260-297. 


\section{Arytaenoideus.}

Es handelt sich hier um Geschichtliches über die Cartilagines arytaenoideae.

Galen und Oribasius sprechen immer nur von einer Cartilago arytaenoidea, niemals von zweien. Dass die Cartilago arytaenoidea ein paariger Knorpel sei, ahnten sie nicht, obgleich es ein Leichtes gewesen wäre, durch Entfernung ihres Schleimhautüberzuges, und der sie zusammenhaltenden Muskeln, ihre Duplicität darzustellen. Nur diesem Galen'schen Irrthum verdanken die Giessbeckenknorpel ihren Namen. Jeder einzelne Knorpel hat, wie wir wissen, eine dreikantig-pyramidale Gestalt. Die Spitzen der beiden Pyramiden, sind etwas nach hinten umgebogen, und bilden durch ihre Aneinanderlagerung, eine mit der Kehlkopfschleimhaut ausgekleidete Rinne, welche dem Schnabel eines Giessbeckens gleicht. Solche durch die umgelegten Spitzen der Cartilagines arytaenoideae gebildete Rinnen, trifft man besonders ausgesprochen bei den Wiederkäuern an, wo sie die Aufmerksamkcit des Galen gefesselt haben müssen. Giessbecken oder Giesskanne heisst àoúratva, und ג̇pura:vos:ò sagt: ora superior hujus cartilaginis tertiae laryngis, figuram arytaence (situlae s. gutturnii) repraesentat. Dass zwei einander gleiche, aber von einander vollkommen unabhängige Knorpel vorhanden sind, erkannte man crst zu Ende des 15. Jahrhunderts, durch Berengarius: haec tertia cartilago laryngis, non est una sola, sed meo judicio duae, unitae taliter, ut una esse videantur 1). Den Namen arytaenoides, welcher sich nur auf den, von Galen für einfach gehaltenen Knorpel schickt, liess man den beiden, obwohl keiner derselben ihn verdient.

Die bei unseren Vorfahren üblichen Benennungen der Cartilagines arytaenoideae, als: Cartilagines guttales (B artholin),

1) Isagogae breves, Cap. de capite gutturis (Kehlkopf). 
gutturninae und gutturniformes (Vesling), stammen von guttus und gutturnium her, welche jedoch nicht dasselbe ausdrücken. Denn guttus ist im Juvenal und Varro, ein Oel- oder Weinkrug, mit sehr engem Hals, welcher den Inhalt nur tropfenweise herausliess (gutta, Tropfen), während das augmentative gutturnium, einen Krug mit weitem Schnabel anzeigt, wie es die Kannen auf unseren Waschtischen sind. Die Cartilago gutturalis der Latino-Barbari, ist nichts weiter als ein Schreibfehler für gutturnalis, bei welchem an guttur, Kehle, nicht gedacht werden kann. Der Schnabel der Giesskanne zeigt sich so breit, und zugleich so kurz, dass die von Sömmerring angeführte Benennung: Schnepfenknorpel 1) des Kehlkopfs, höchst ungeschickt erscheinen muss. Die Schnepfen haben sehr lange und dünne Schnäbel. Sömmerring machte seinen Lapsus dadurch wieder gut, dass er die Schnepfenknorpel auch dreiseitige nennt, obgleich auch diese Benennung nicht ganz tadelfrei ausgeht, da nicht blos eine Pyramide, sondern auch ein Prisma dreiseitig sein kann. Die Duplicität der Giesskannenknorpel, mussten schon die Araber geahnt haben, denn der Uebersetzer des Avicenna lässt sie wie Cymbeln aneinanderschlagen, wenn ein Ton zu erzeugen oder zu verstärken ist, und nennt sie nur aus diesem Grunde Cartilago cymbalaris. Mehr iiber die Giessbeckenknorpel in HL, §. LXXI, Haugena, Larynx. - Ich besorge, dass man die fehlerhaften Cartilagines arytaenoideae, gegen die richtigen pyramidales schwerlich fallen lassen wird.

Wenn die Muskeln der Giesskannenknorpel seit Riolan Arytaenoidei, oder gar nach Douglas Arytaenoidaei genannt wurden, hat man nicht bedacht, dass diese Muskeln keinen Giesskannen ähnlich sehen, und wenn die zwischen den beiden Cartilagines arytaenoideae befindlichen Muskeln ary-arytaenoidei heissen, möge man bedenken, dass man, bequemer Kürze wegen, ein Wort ary gebraucht, welches gar nichts bedeutet.

1) Eingeweidelehre, §. 31. 
Die Musculi ary-arytaenoidei und ary-epiglottici des Santorini, müssen, bei Bedachtnahme auf richtige Ausdrucksweise, heissen: Arytaenici obliqui et transversi, und Epiglottico-arytaenici. Die Neuheit dieser Benennungen ist ihr einziger Feind, welcher die Anatomen hindern wird, den bis nun eingewöhnten Schlendriansnamen den Laufpass zu geben.

\section{Astragalus.}

Sieh' den Artikel: Talus.

\section{Atlas und Epistropheus.}

Den ersten Halswirbel Atlas zu nennen, war ein poetischer Einfall. Er kam sehr spät. Galen und seine

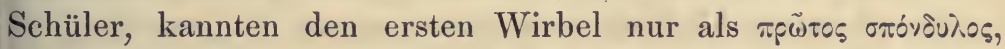

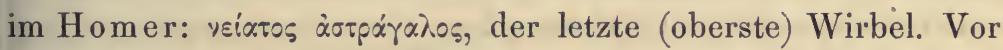
Galen, war er auch als Epistropheus benannt, und zwar ganz richtig, da er es ist, welcher sich um den Zahnfortsatz des

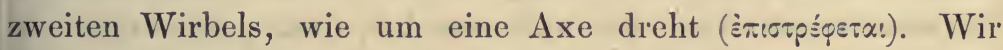
finden den ersten Halswirbel, als Epistropheus, noch im Julius

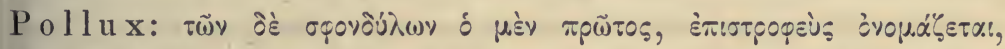
vertebra prima Epistropheus vocatur ${ }^{1}$ ), und im Golraeus heisst es: epistropheus fuit, apud antiquos medicos, nomen primae vertebrae ${ }^{2}$. Dass diese Benennung ihre volle Berechtigung hat, zeigt der Artikel: Vertebra.

Der Erste, welcher den Himmelsträger Atlas in die Anatomie einführte, war Vesal. Er verunstaltete ihn aber ein wenig, indem er ihn Athlas schrieb ${ }^{3}$ ). Die Vesalianer

1) Onomasticon, Lib. II, Cap. 28.

2) Definitiones medicae, pag. 153.

3) De corp. hum. fabrica, Edit. Lugd., pag. 142. 
verschmähten das Wort, blieben bei der Vertebra prima, und machten, wie es schon Julius Pollux gethan '), den siebenten Halswirbel zum Atlas, tum quia reliquas colli vertebras sustinet, tum quia (seines langen Dornfortsatzes wegen) ferendis oneribus potissimum laboret ${ }^{2}$ ). Die Benennung Vertebra magna (Realdus) für den Atlas, stammt aus der Thieranatomie. Die Fleischfresser besitzen einen Atlas, welcher, zufolge der starken Entwicklung seiner Querfortsätze, alle übrigen Halswirbel an Grösse übertrifft. Die Niederländer van Horne ${ }^{3}$ ) und Paulus Barbette, wiesen dem Atlas, als ersten Halswirbel, seinen bleibenden Platz in der Osteologie an ${ }^{4}$ ). Der Bajulus (Lastträger) des A. Laurentius, erzeugte den deutschen Träger, während der Umdreher aus der Zopfzeit des Kulmus und Loder, eigentlich der umzudrehende, oder der drehbare Wirbel heissen sollte. In allen Sprachen hat sich der Atlas sesshaft gemacht.

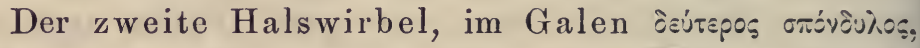
im Vesal immer als Vertebra secunda, musste in jener Zeit, in welcher der erste als Epistropheus bezeichnet wurde, einen anderen Namen geführt haben. Dieser war, entsprechend dem richtigen Sachverhalt, dass der erste Wirbel sich um einen

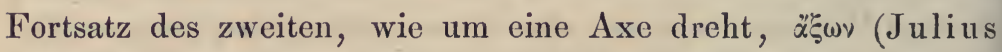
Pollux), und óooús (Hippocrates ${ }^{5}$ ), Zahn. Der Hippocratische j̇oús, ist eine Synecdoche, als Pars pro toto, denn nur der zahnförmige Fortsatz des zweiten Wirbels führte, $a$ similitudine formae, den Namen óooús, Zahn, oder Apophysis odontoides, zahnähnlicher Fortsatż. Dieses Zahnfortsatzes wegen, nannten die Restauratores anatomiae den zweiten Wirbel, ausser

1) Ultimus cardo (letzter Halswirbel), tamquam onera ferens, Atlas vocatur. Onomasticon, Cap. 28, Sect. 132.

2) Gorraeus, Op. cit., pag. 61 .

3) Microcosmus, Leidae, 1660, §. 31 .

4) Chirurgica et anatomica, Leidae, 1672, P. III, Lib. I, Cap. 3.

5) Epidem., Lib. II, Sect. 2, num. 69. 
Axis, auch Vertebra dentata und dentigera. Der ganz unrichtige Name Epistropheus, ist für ihn erst seit Heister allgemein angenommen. - Bei den alten Anatomen, finden wir den Processus odontoideus mitunter als nucleiformis, conicus, und turbinatus angeführt. Diese Worte sind Uebersetzungen griechischer Ausdrücke, und zwar conicus und turbinatus ${ }^{1}$ ) =

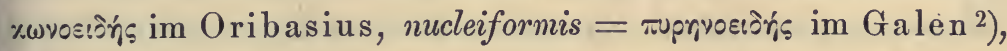
bei den Latino-Barbari pyrinoides, was einen ganz anderen Sinn hat, und auf "Feuer" hindeutet.

Unsere deutsche Anatomie scheint sich den Epistropheus, als zweiten Halswirbel, für immer angeeignet zu haben. Der Zahnwirbel, oder zahntragende Wirbel, wie er in der deutschen Uebersetzung von Lieutaud's Zergliederungskunst (I. Bd., pag. 141) genannt wird, wäre ungleich besser. Nach dem früher Gesagten, sind die Worte Umdreher, Dreher, und der zweideutige Umtreiber im Kulmus, wenn sie überhaupt zulässlich ersçheinen möchten, nur auf den ersten Halswirbel anwendbar, weil der zweite Wirbel die ruhende Axe abgiebt, um welche sich der erste dreht. Warum aber wollen wir nicht mit einem ersten und zweiten. Halswirbel Vorlieb nehmen, statt Atlas und Epistropheus zu sagen, von welchen der erste eine Ueberschwenglichkeit, und der zweite ein offenbarer Unsinn ist, da man eine Sache nicht nach dem benennen kann, was sie nicht ist. Der zweite Halswirbel ist kein Umdreher (Epistropheus), wohl aber dreht sich der erste um seinen Zahnfortsatz, wie das Rad um eine excentrische Axe. Eine andere Erklärung des Wortes Epistropheus, als Atlas, findet der Leser bei otpop̧ús, im Artikel: Vertebra.

1) Zwei Geschlechter der Conchylien, mit kegelförmigem Gehäuse, heissen im zoologischen System heute noch Conus und Turbo.

2) Von $\pi$ upri", harter Kern des Steinobstes. 


\section{Atrabiliarius.}

Kein Anatom hat sich durch so viele Entdeckungen berühmt gemacht, wie Barth. Eustachius. Die Geschichte unserer Wissenschaft, gab $\cdot \mathrm{ihm}$ deshalb den Ehrentitel: vir, ad inveniendum natus. $\mathrm{Zu}$ seinen Entdeckungen zählen auch die Nebennieren. Er nannte sie in der kleinen Schrift: Libellus de renibus, welche 1563 zu Rom erschien, Glandulae renibus incumbentes. Als Renes succenturiati (Nebennieren), kommen sie im Casserius ${ }^{1}$ ) und Spigelius ${ }^{2}$ ) vor. Man hielt sie anfänglich für abgelöste und eingegangene Nierenlappen, welche nur das Vacuum zwischen dem oberen Ende der Niere, und dem Zwerchfell auszufüllen haben. Durch Thomas Bartholinus erhielten sie den Namen Capsulae atrabiliariae $\left.{ }^{3}\right)$. Ihre dichtere und zähere Rindensubstanz, schliesst nämlich ein weiches und sehr gefässreiches Mark ein, in welchem die Venen über die Arterien weitaus prävaliren, so dass dieses dunkelgefärbte Mark (humor faeculentus et niger) leicht für atra bilis genommen werden konnte, welehe von der Rindensubstanz wie von einer Kapsel umgeben wird.

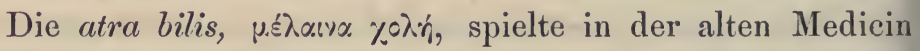
eine sehr bedeutende Rolle, während heutzutage nichts mehr von ihr erübrigt, als der Krankheitsname Melancholie. Die atra bilis war ein, bei der Blutbereitung in der Leber erzeugter Auswurfsstoff, welcher durch die Vena splenica zur Milz geführt wird, um dort verarbeitet und unschädlich gemacht zu werden. Geschah diese Verarbeitung nur unvollständig, so gelangte eine Quantität schwarzer Galle in das Blut, wodurch ein Heer von

1) Tab. anat. $X X$, lit. FF.

$\left.{ }^{2}\right)$ De corp. lum. fabrica, Lib. VIII, Cap. 15, pag. 243: figuram habent semilunarem, fere renibus similem, unde renes succenturiati dicuntur.

3) Institutiones anat., Lib. I, Cap. 18, de capsulis atrabiliariis. 
Krankheiten ausgeheckt werden konnte. Ein klein wenig schwarze Galle, fand aber auch in die Höhle der Capsulae atrabiliariae ihren Weg, und verhalf diesen zu ihrem absurden, aber jetzt noch in den anatomischen Schriften anzutreffenden Namen. Die atra bilis in den Nebennieren, hatte insonderheit die Bestimmung, auf das Blut in den Nieren wie ein Ferment (coaguli instar) einzuwirken, und die leichtere Abscheidung seines Serums als Harn zu ermöglichen (tractum serosae humiditatis, et seri a sanguine separationem, in renibus adjuvant) ${ }^{1}$ ). Unsere Vorältern hatten sonach eine, ihren physiologischen Vorstellungen entsprechende Idee von der Leistung dieser Organe; - für uns, die wir ihren Bau bis in die Atome kennen, sind sie ungelöste, und sicher auch unlösbare Räthsel.

Nun aber endlich auch ad vocem: atrabiliarius. Atrabiliarius wird von keinem Prosaiker oder Dichter erwähnt, und ist in keinem Lexikon zu finden. Ja selbst das einfache biliarius kannten die Römer nicht, und ebensowenig unsere Ductus biliarii der Leber, welche sie gewiss anders, etwa Ductus biliferi genannt haben würden. Biliarius und Atrabiliarius gehören also zu den lateinischen," aber nicht zu den römischen Worten. Sie entstanden als Schöpfungen des medicinischen Neulateins, und sind, was dieses meistens ist, Barbarismen milderer Art.

\section{Atrium.}

Ueber den eigentlichen Sinn von Atrium, sieh' die Artikel: Auriculae cordis, Fauces und Isthmus faucium.

1) Joh. Vesling, Syntagma anatomicum, Cap. III, pag. 36 (Edit. Gerardi Blasii). 


\section{Auriculae cordis,}

Bis in das 18. Jahrhundert, wurden die beiden Vorhöfe des Herzens, nicht aber ihre jetzt als Herzohren bekannten Anhängsel, Aures s. Auriculae cordis genannt. Bei den französischen Anatomen, heissen die Herzvorkammern immer noch: oreillettes, und bei den Engländern: ears of the heart. Galen

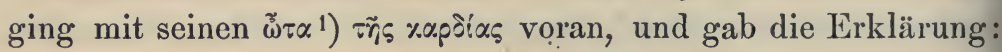
non a forma, sed quia ut aures capiti, ita cordi annexae sunt ${ }^{2}$ ). Im Rufus Ephesius, Julius Pollux, und Oribasius,

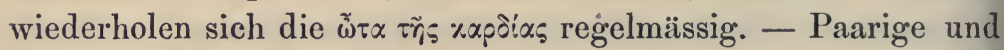
symmetrisch an den Seiten eines Körpers hervorragende Anhängsel, wurden von den Griechen gerne $\tilde{\omega} \tau \alpha$ genannt, so auch die Henkel an Krügen, Vasen, und Amphoren. Die Römer nannten die beiden Bretter, welche sie rechts und links an dem Eisen des Pfluges anbrachten, um die aufgewühlte Erde seitwärts abzuschieben, und die Furche breiter zu machen, Aures aratri:

"Binae aures, duplici aptantur dentalia dorso."

(Virgil, Georg., Lib. I, 172.)

Vesalius übersetzte die Galenischen $\tilde{\omega} \tau \alpha$, mit Aures und Auriculae ${ }^{3}$ ), von welchen die letzteren erst durch Haller, an die konischen Anhängsel der Vorkammern abgegeben wurden. Haller nannte die rechte Vorkammer: Sinus venarum cavarum, und die linke: Sinus venarum pulmonalium. Die Anhängsel der beiden Vorkammern Auriculae zu nennen, war ihm kein missglückter Tropus, da sie wirklich durch Form und hängende Lage, mit den Ohren eines Jagdhundes Aehnlichkeit haben.

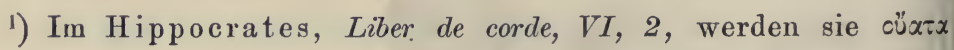
genannt.

2) Administrationes anat., Lib. VII, Cap. 9.

3) Op. cit., Lib. VI, Cap. 14, de cordis auriculis. 
Die Arabisten behandeln die Vorkammern als Appendices, Processus, Alae 1), Membranae auriculares, oder Sinus. Der Name Atrium, kam erst im vorigen Jahrhundert bei den deutschen Anatomen auf, und verblieb in anderen Sprachen bei ihnen, da das Wort Atrium weder französischen, noch englischen Zuschnitt annimmt. Uebrigens ist es schlecht gewählt. Atria sollten von rechtswegen die Herzkammern heissen, als Haupträume im Herzen, wie das eigentliche Wohnzimmer in einem römischen Hause Atrium hiess. Diese Benennung schreibt sich aus den ersten Zeiten der Republik her, wo das sehr einfache, aus Holz gebaute Wohnhaus eines Civis romanus, nur aus zwei Zimmern bestand, deren zweites der gewöhnliche Aufenthaltsort der Familie war, wo auch geschlafen, gearbeitet, gewebt, und gekocht wurde. Dieses Atrium hatte kein Fenster, sondern eine Oeffnung im Plafond, durch welche der Rauch hinauszog, nachdem er die Wände des Atrium hinreichend mit Rauch geschwärzt hatte - ater, schwarz. Die weisse Toga, auf deren Sauberkeit der römische Bürger etwas hielt, behielt er im Atrium nicht an, sondern legte sie im Vorzimmer ab, welches dadurch zu seinem Namen Vestibulum kam, von Vestis, Kleid. Will man die Räume des Herzens mit den zwei Räumen eines solchen Hauses vergleichen, so müsste die Vorkammer Vestibulum, die Kammer aber Atrium genannt werden.

In der Conchyliologie giebt es eine Auricula Midae, in der Botanik eine Auricula Judae (Peziza auricula, Linn.), eine Auricula leporis (Bupleurum), und eine Auricula ursi (Verbascum Myconi, Linn.). Eine rara avis in der Anatomie, ist Cicero's auricula, als Ohrläppchen, mit der Corruption oricilla (auricilla) und avicula, in den Commentarien des Carpus.

1) Nach den $\pi \tau \varepsilon p^{\prime} y(\alpha$ xoĩ $\alpha$, alae cavae, des Rufus. 


\section{Azygos,}

Wer es genau nimmt mit dem Wesen einer Sache, und seinem Ausdruck, findet auch an Azygos etwas auszustellen. Azygos, hervorgegangen aus a priv. und కuyór, Joch (nicht ¿ưbs, Wagebalken, Thürriegel, auch Querreihe), drückt etwas

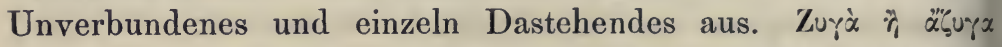
war bei den Griechen: Paar- und Unpaarspielen, und $\alpha^{\prime}$ unvermählt, lesen wir im Euripides.

Galen erborgte sich den Namen Azygos, für die bekannte Vene im Thorax, welche nur auf der rechten Seite vorkommt, und alle rechten Intercostalvenen aufsammelt $\left.{ }^{1}\right)$. Das griechische Wort Azygos, wurde von Vesal ${ }^{2}$ ) mit absque conjuge, oder mit conjugis expers, und von C. Hofmann ${ }^{3}$ ), als sine pari übersetzt, was jetzt noch üblich ist, und von den Deutschen, Engländern, und Holländern, als "unpaare Blutader", Vein without a pair, und Ader sonder paar of weerga, aufgenommen wurde. In der besten lateinischen Uebersetzung des $\mathrm{G}$ ale $\mathrm{n}$, von C. G. Kühn, werden wir durch Vena caelebs (unverheiratete, hagestolze Vene) erheitert 4). Azyga, statt Azygos, zu sagen, konnte sich nur ein Haller erlauben.

Galen konnte unmöglich seine Vene deshalb Azygos genannt haben, weil ihr im Menschen kein Gespan auf der linken Seite entspricht. Galen hat ja keine Menschenleiche

1) De dissectione venarum, Cap. 2, - auch De locis affectis, Lib. I, Cap. 2, - De usu partium, Lib. III, versus finem, - und De administrationibus anat., Lib.VII, Cap. 9, wo er die Azygos in den Herzbeutel eintreten lässt, um sich mit der Cava superior zu verbinden, - eine Anordnung, welche bei den Affen, obwohl nicht als Regel, vorkommt.

2) De corp. hum. fabrica, Lib. III, Cap. 7.

3) Commentaria in Galeni librum: De usu partium, XVI, n. 1114.

4) Galeni Opera omnia, T. XV, pag. 529. 
sergliedert, und bei Thieren, insbesondere bei einzelnen Tattungen der Nager, Insectivoren und Wiederkäuer, wie wch beim Schwein, ist die Azygos auf beiden Seiten vorranden, also keine Azygos mehr. Vom Menschen ist dieses, Paarigwerden der unpaarigen Vene, als Varietät nur zu bezannt, und in allen Schriften über Anomalien der Venen erwähnt. Ich glaube annehmen zu können, dass das Wort Azygos von Galen gewählt wurde, um das Unbegleitetsein lieser Vene von einer anliegenden Arterie auszudrücken, velches ihm auffallen musste, da alle tiefliegenden Venen, uur die Azygos nicht, von Arterien begleitet werden, oder loch, wie die Cava superior und inferior, Arterienstämme in hrer unmittelbaren Nähe haben. Sei dem wie immer, so muss ch noch auf einen Umstand aufmerksam machen, welcher es wünschenswerth erscheinen lässt, die Azygos passender zu beıennen. Die untere Hälfte (beiläufig) der Azygos, ist keine Azygos, da sie eine congruente Gefährtin, als Hemiazygos, auf ler linken Seite besitzt. Dadurch widerspricht auch die Hemiazygos ihrem Namen; sie ist ja mit der unteren Hälfte der Azygos gepaart. Bezieht sich aber das Hemi auf die Länge dieses Gefässes, welche beiläufig die Hälfte der Länge der Azygos beträgt, so müsste auch die obere, ungepaarte Hälfte der Azygos, Hemiazygos genannt werden. Diese Wortsubtilitäten setzen Verwirıung ab. Es wäre deshalb gleich besser, die Azygos in Vena intercostalis communis dextra, und die Hemiazygos in Vena intercostalis communis sinistra inferior umzutauschen. Eine Intercostalis communis sinistra superior, haben wir ohnedies schon. Man könnte sich nur an der Länge dieser anatomischen Termini stossen. - Das Wort Hemiazygos fehlt übrigens der griechischen Sprache. Ich finde es zuerst im Haller'). Die älteren Anatomen sprechen nur von einem alter oder sinister ramus der Azygos.

1) Elem. physiol., T. III, Sect. 1, §. 45, pag. 109. 


\section{Basilaris,}

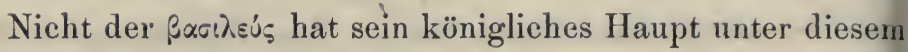
argen Barbarismus beugen müssen, sondern die $\beta$ x́cı૬, der Grund, worauf etwas steht - die Basis. Weder die Griechen, noch die Lateiner verfügen über ein, aus basis gebildetes Beschaffenheits. wort. Basilaris, basalis, und basicus, sind lauter Barbarismen, der erste der schlimmste. Die Anatomie hat ihn zur Zeit der Latino-Barbari, für ihren Bedarf gebildet, um etwas auszudrücken, was am Grunde eines Organs oder eines Knochens sich befindet. So schuf sie sich ihre Protuberantia basilaris für den späteren Pons Varoli, und ihre Pars basilaris ossis occipitis. Die Arteria basilaris, und einiges Andere, alles gleich verwerflich, kam erst später hinzu, als Nachahmung des von Winslow öfters gebrauchten französischen Adjectivs basilaire. - Trotz diesem harten, aber verdienten Urtheil, wird die Arteria basilaris doch ihre Stellung behaupten, da dieser Name kürzer ist als der Haller'sche Truncus communis arteriarum vertebralium ${ }^{1}$ ). Arteria pontis wäre ebenso kurz, als verständlich.

\section{Basilica.}

Ich habe an einem anderen Orte ausführlich, und mit aller Schärfe, deren eine kritische Untersuchung fähig ist bewiesen, dass die Vena basilica weder von den griechischen noch won den römischen Aerzten, je so benannt wurde ${ }^{2}$ ). Die

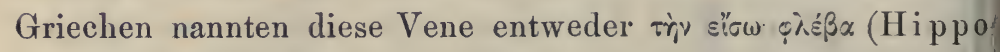

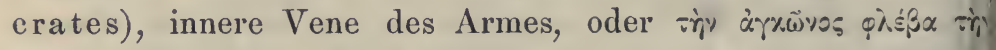
Eัyòov (Galen), d. i. Vena cubiti interna. Da man aus ihr an rechten Arme bei Leberkrankheiten, am linken Arme be

1) Icones anat., Fasc. VII, pag. 10.

2) HL, §. XXXIX, pag. 74-77. 
Milzkrankheiten Blut liess, kommt Ind $9 \lambda \dot{\varepsilon}$ '̦ $\sigma \pi \lambda \varepsilon v i \tau \iota s$ für die linke Basilica, bei den griechischen lerzten vor. Paulus Acgineta nennt sie $\mu \alpha \sigma \alpha \lambda i \alpha^{1}$ ), weil

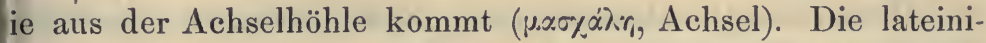
chen Uebersetzungen des Paulus, bringen deshalb ihre Vena laris $=$ axillaris.

Eine Vena basilica fand ich nur im lateinischen Avicenna, Is Uebersetzung des arabischen Ausdrucks: al-basilik ${ }^{2}$ ). Wenn uso C. G. Kühn die Vena basilica von ßacìsús, König, deduirt, und meint, dass ihre Eröffnung am rechten Arm bei Ercrankungen der Leber, dem princeps organon sanguificationis, hr den Namen basilica, die königliche, zuwege brachte, so st dieses nicht mehr als eine gelehrte Spielerei, denn eine Vena basilica hat es bei den Griechen nie gegeben. Sie kam rst dureh den Uebersetzer des Canon, Gerardus, als Nachthmung des arabischen basilik, die innere Vene, in die Anaomie. Hätten aber die Araber etwas königliches an dieser Vene gefunden, so würden sie ihr nicht den Namen al-basilik, ;ondern irgend einen, auf malik (König) hinweisenden Namen ;egeben haben.

\section{Blastema und Cytoblastema.}

Blastema (io $\beta \lambda \dot{\sigma} \sigma \tau \eta \alpha$ ), von $\beta \lambda \alpha \dot{\sigma \tau \alpha \nu s เ \nu, ~ g e r m i n a r e ~ u n d ~ e f f l o-~}$ escere, wurde von den Anatomen, der Sprache des Hipposrates (Epidem., XIV, 8, und De ulceribus, $V, 3$ ) entführt, welcher damit eine efflorescentia cutanea, einen Hautausschlag, versteht. Eine neue Wissenschaft braucht neue Worte. So hat sich die Entwicklungsgeschichte mehrere neue Ausdrücke bilden müissen, wie z. B. Blastoderm, Cytoblast, Neurula, Gastrula, u. m. a., oder sie hat alte Worte in einem neuen

1) Epitome, Lib. VI, Cap. 40.

$\left.{ }^{2}\right)$ Canon, Lib. I, Fen 1, Doctr. 5, Summa 5, Cap. 4. 
Sinn gebraucht, wie Blastema, unter welchem die Botaniker, nach Mirbel, den Pflanzenkeim, die Anatomen den Grund und Boden der Zellenbildung, das Keimlager, verstehen, und deshalb auch als Cytoblastema (жúro:, Zelle) benennen. Pander's Blastoderma, Membrana germinativa, Keimhaut, und R. Wagner's Blastocēlis (*ini

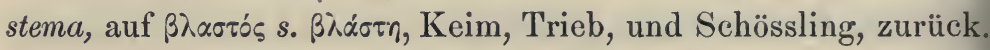

\section{Bregma und Bregmaticus.}

Ein uraltes, aber nicht veraltetes Wort! weil die Ossa parietalia noch immer auch Ossa bregmatica heissen. Die Stelle

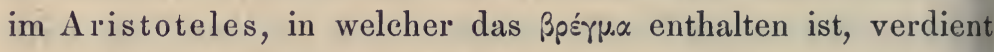
angeführt $\mathrm{zu}$ werden: anterior capitis pars, quae post natum

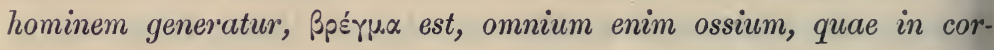
pore sunt, postremum concrescit (Andeutung der Stirnfontanelle 1). In demselben Sinne gebrauchen Homer ${ }^{2}$ ) und Hippocrates ${ }^{3}$ ) ihr Bpe\%pós. Die Commentarien über Aristoteles sagen: Bregma est pars anterior capitis, supra frontem sita ${ }^{4}$ ). Demzufolge nannte Realdus Columbus ${ }^{5}$ ) die Seitenwandbeine, weil sie an Vorderkopf, über der Stirne, liegen: Ossa bregmatica nicht ganz recht,

1) Historia animalium, Lib. I, Cap. 7.

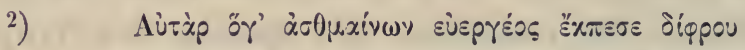

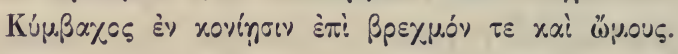

„Und er entsank aufröchelnd dem schön gebildeten Stuhle

„Häuptlings herab in den Staub, auf Scheitel fallend und Schultern."

(Il., $V, 585,586$.

3) De vulneribus capitis, Lib. III, Cap. 1, §. 5.

4) Gorracus, Definitiones medicae, pag. 80 .

5) De re anatomica, Lib. I, Cap. 5. 


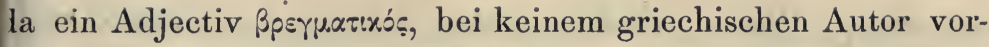
iegt. Vesal nannte sie Ossa verticis, - die Arabisten Ossa rcualia, weil sie einen Bogen zwischen den beiden Schläfen jilden.

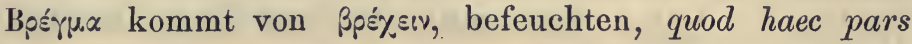
iumidissima sit, praesertim in infantibus ( $\mathrm{G}$ or rae us). Der jcholiast des Homer, Eustathius ${ }^{1}$ ), bezieht sich bei der Erklärung von Bregma ebenfalls auf $\beta p \varepsilon ́ \% \omega$, madefacere; quia iaec ossa infantibus, et saepe adultis, humida et tenera sunt. Die u Borken erhärtenden Absonderungen auf dem noch unoehaarten Kinderschädel, hielt man für tenvia et halituosa exsrementa cerebri, welche durch das dünnknöcherne Bregma

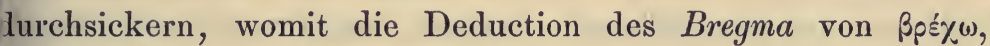
hinlänglich begründet wird. Im Galen wird $\beta p \varepsilon ́ \gamma \mu \alpha$ auch durch ropup̣n (vertex) vertreten, woher der Vesal'sche Ausdruck: Ossa verticis, für bregmatica, sich erklärt. Das eingangs

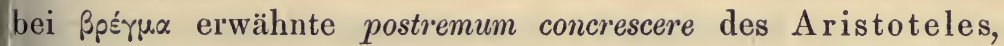
führte es herbei, dass die letztverwachsende Stelle des kindlichen Kopfes, die Stirnfontanelle, hin und wieder von den alten Aerzten Bregma genannt wird.

Vergleiche die Artikel: Fontanella und Synciput.

\section{Bronchus.}

Sieh' den Artikel: Trachea.

\section{Bursae mucosae.}

Der Ausdruck Bursae mucosae muss schon deshalb für einen missglückten erklärt werden, weil diese Bursae keinen Schleim, sondern eine synoviale oder eine seröse Flüssigkeit

1) Ad Iliadis Lib. V, pag. 586 der Edit. Romana. 
absondern. Bursa, als Eigenname, kommt im Cicero vor: Munatius Plancus Bursa ${ }^{1}$ ). Als Beutel war Bursa den Römern nicht bekannt. Das frühe Mittelalter gab dem Worte diesen Sinn, nach dem verwandten griechischen Bípec, Fell, auch Schlauch. Ueber diese mittelalterliche Bursa handelt ausführlich und gelehrt das Glossarium von Dufresne (Du Cange), T. I, pag. 1368 und 1369. Die Latino-Barbari eigneten sich die Bursa, als Beutel, an, und verwertheten sie zuerst als Bursa cordis = Pericardium. Auch im 16. Jahrhundert finden wir die Gallenblase, als Bursa cholerae citrinae, im Bauhin 2). Albinus bediente sich später der Bursae mucosae (richtiger synoviales oder muciparae), zur Bezeichnung der Schleimbeutel der Sehnen ${ }^{3}$ ), welche vor ihm nur als Thecae, Capsae, Capsulae, Vaginae mucilaginosae cursirten. Der Albinische Name ist seither allgemein geworden, und prangt auf den Titeln der Specialwerke über Schleimbeutel, von A. Monro, Rosen: müller, und Schreger.

Als Bursa virilis wird der Hodensack in den alten Uebersetzungen des Aristoteles (für čo\%sos) angetroffen. Mehr davon im Artikel: Scortum oder Scrotum.

\section{Calamus scriptorius.}

Das Alter des Calamus scriptorius Herophili, uibersteigt bereits zweitausend Jahre. Nicht mit einer Schreibfeder, son-

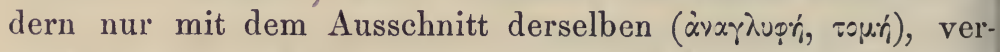
gleicht er den vom Wurm des kleinen Gehirns nicht bedeckten, hinteren Winkel des Bodens der vierten Gehirnkammer (Fossa rhomboidea). Im Sinne des Herophilus, sollte die Anatomic nur von einer Excisura calami scriptorii, nicht von einem

1) Ad Famil., VII, 2.

2) Theatrum anat., Lib. I, Cap. 45, nota C.

3) Historia musculorum hominis, pag. 695. 
anzen Calamus scriptorius sprechen. Nur Ein Anatom hat die ;ache so aufgefasst: Laurentius, weleher sich des richtigen lusdruckes Crena calami bedient. Da die Schriften des Hero, hilus sehr früh verloren gingen, können wir uns nur auf en Galenischen Text berufen, welcher vom Calamus handelt 1): la pars ventriculi quarti nobis apparet, quam Herophilus comuravit cavitati calami, quo scribimus, und etwas später: caviatis latus utrimque attollitur (unseré Stiele des kleinen Gehirns), uantum in calamis a media linea elatius exsurgit, unde Herohilus, imaginis similitudine adductus, rem sic appellavit. Nicht Iso die Schreibfeder, sondern der Schreibfederausschnitt, nit seiner gespaltenen Spitze, wurde von Herophilus unter

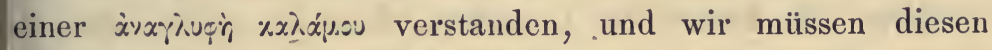
Terminus ebenso ver'stehen.

\section{Calcaneus oder Calcaneum?}

Für beide Schreibarten lassen sich gute Zeugenschaften unfiihren, - die besseren darunter sprechen für Calcaneum, . B. Calcanea camelorum im Lampridius (Heliogabalus, $X X, 5$ ), and Virgil:

"Continuis rivis calcanea fissa vigebant."

(In Moreto, Vers 36.)

Für Calcaneus besitzen wir nur eine kirchliche Autorität, den Ambrosius (Psalm. 48). Die Anatomen des Mittelalters waren ;eistlichen Standes. Sie hielten es also mit dem Kirchenvater, and schrieben Calcaneus. Wenige, wie Laurentius, zogen Calcaneum vor. Celsus, als der beste Gewährsmann für gute anatomische Latinität, kennt nur ein $O s$ calcis ${ }^{2}$ ), welches Einigen noch zu lang schien, und zum Calx einging (Vesal,

1) De administrationibus anat., Lib. IX, Cap. 5, ad finem.

2) De medicina, Lib. VIII, Cap. 1. 
und seine Schüler). Die Sporen werden an dem Fersenabsatz des Stiefels befestigt, weshalb Eustachius ') das Fersenbein Os calcaris nannte, und Bauhinus ${ }^{2}$ ) diesen Knochen zum $\mathrm{O}_{8}$ calcaris (Sporenbein der deutschen Uebersetzung) machte.

Woher kommt aber Calcaneum oder Calcaneus? Im Anat.physiol. Realwörterbuch von Pierer und Choulant, wird dem Worte eine griechische Abstammung zugemuthet, und Galen's

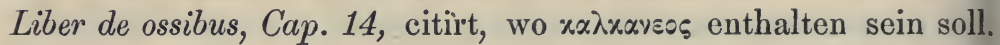
Ich habe weder in dem citirten Capitel, welches übrigens nur vom Schulterblatt handelt, noch an irgend einer anderen Stelle der Opera Galeni (Edit. Kühnii), welche ich, nach dem handlichen Index von F. G. Assmann, auf Calcaneus

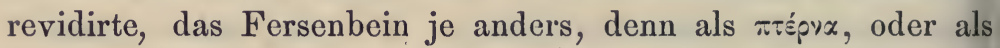

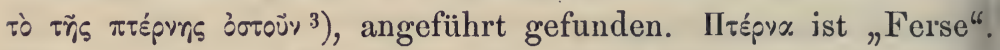
Ebensowenig war in dem, neben Galen citirten Syntagma anatomicum von Vesling, Cap. 17, eine Andeutung über einen griechischen Calcaneus zu finden. Gewissenlos ist es, Citate anzuführen, welche nicht aufzufinden sind.

So bleibt denn nur Calx, Ferse, als Mutter des Calcaneum übrig. Wieso Calx, Kalk, auch Ferse sein kann, habe ich anderswo gezeigt. Sieh' HL, §. II, wo auch über das Achib des Alpagus Bellunensis, ein Synonym des Fersenbeins bei den Arabisten, eingehend gehandelt wird.

Die Perna. (Ferse) des Galen, verschwand nicht gänz-1 lich aus der Anatomie. Es giebt einen Riolan'schen Muskelnamen Perno-dactyleus, für den kurzen, am Fersenhöcker entspringenden Zehenbeuger ${ }^{4}$ ).

1) Opuscula anatomica, pag. 187.

2) Theatrum anat., Lib. IV, Cap. 43.

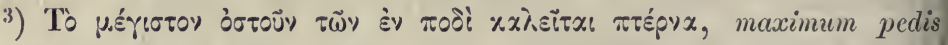
os vocatur $\pi$ répvx. Galenus, De ossibus, Cap. 24.

4) Anthropographia, Lib. V, Cap. 214. 


\section{Calcar avis.}

Drei Sporne trägt die bilderreiche Sprache der Anatomie. Der eine sitzt am Kopfe, als Griffelfortsatz des Schläfebeins, Calcar capitis bei den alten Meistern; der zweite ist das Fersenbein, Calcar pedis im Bauhin, und der dritte ist die im Hinterhorn der seitlichen Gehirnkammer vorfindliche, gekrümmte Erhabenheit, wenn sie einfach ist, d. h. nicht in Digitationen gespalten erscheint, worüber mehr im Artikel: Digitationes hippocampi.

\section{Calix oder Calyx?}

Es ist keine unnütze Wortklauberei, zu fragen, ob die Anatomie Calices oder Calyces zu schreiben hat. Calyx hat einen rein botanischen Begriff, - Calix einen aus den Gebrauchsgegenständen des gewöhnlichen Lebens geholten. Calyx ( $\alpha \dot{\alpha} \lambda \cup \xi$, von $x \alpha \lambda \dot{j} \pi \tau \omega$, verbergen), ist im Plinius die Blumenknospe, der Fruchtboden, und die weiche Schale der Früchte, im Gegensatz von Putamen, harte Schale, z. B. der Kastanien und Nüsse. Figürlich wurde es auch auf harte Schalen der Thiere, und auf die Kalkschale der Eier übertragen. In diesem Sinne kennt man Calyx in der Anatomie nicht. Calix dagegen, das griechische $x^{\prime} \lambda \lambda_{\xi} \xi$, ist der Pokal, Becher, und Kelch, als Trinkgefäss. Der Giftbecher des Sokrates, wird als Calix venenatus erwähnt. Die in das Nierenbecken einmündenden Nierenkelche, sind kurze und weite häutige Röhren, welche an einem Ende durch die Papillae renales geschlossen werden, am anderen Ende aber offen stehen, und mit einem Trinkglas oder Becher vergleichbar erscheinen. Deshalb nannte Winslow, welcher in der Botanik so gut zu Hause war, wie in der Anatomie, die Nierenkelche Calices, nicht 
Calyces '), und an uns liegt es, bei dieser Benennung zu verbleiben, wenn wir nicht etwa die Infundibula Halleri, oder die Tubuli pelvis renalis des Heister vorziehen wollen. Die alten Anatomen kannten das Nierenbecken meist als Lacuna pori uritidis, nach Berengarius, oder als Venter und Sinus amplus ureteris, nach Vesalius und Bartholinus. Die Nierenkelche waren ihnen insofern bekannt, als sie von fines lati et aperti ureterum reden, welche zur Aufnahme der Nicrenwarzen dienen: pro excipiendis renum carunculis.

Als Pelvis tritt das Nierenbecken zuerst im Bauhinus auf $^{2}$ ). Galen und Oribasius sprechen nur von einem Corpus

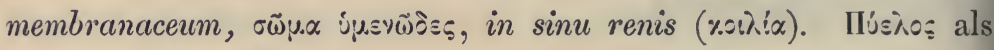
pelvis, war bei den griechischen Anatomen nur für den Hirntrichter gebräuchlich, welchen sie auch \%od́m und \%ंxvos nannten, von $\chi \dot{\varepsilon} \omega$, giessen. Die jetzt übliche Benennung des Hirntrichters, als Infundibulum, ist die übersetzte \%ox́r. Noch im Vesal finden wir Choana nur als Hirntrichter ${ }^{3}$ ). Bei den Restauratoren der Anatomie, welche meist geistlichen Standes waren, trifft man, statt Infundibulum, auf das ärgerliche Infusorium aus der Vulgata, wo Infusorium aber nicht als Trichter, sondern als Kanne zum Einschenken vorkommt (Zachar., IV, 2). Infusorium gehört nur dem Mönchslatein an, und muss aus dem guten Latein wegbleiben. Dic im Aufguss organischer Substanzen sich bildenden Infusoria, wären eines besseren Namens würdig, denn Infusorium ist und bleibt ein biblisches Wort, für ein Gefäss mit Henkel. Der hinteren Nasenöffnungen, welche wir Choanae nennen, gedenkt Galenus blos als Perforatio narium in os ${ }^{4}$ ), nicht als Choana. Hippocrates dagegen führt uns die Choana als Rachen vor ${ }^{5}$ ):

1) Expositio anat., T. III, §. 415 und 423.

$\left.{ }^{2}\right)$ Theatrum anat., Lib. I, Cap. 22.

3) Op. cit., Lib. VII, Cap. 11.

4) De usu partium, Lib. XI, Cap. 11.

5) De corde, I, 12 . 
infundibulum, per quod cibus et potus ventriculo infunditur. Dass auch die hinteren Nasenöffnungen in unserer Anatomie Choanae genannt werden durften, hat gar kein altgriechisches Zeugniss für sich, und ist ein blosses Belieben der Sprachignoranz und historischer Unwissenheit. Erst im vorigen Jahrhundert gelangte die Choana zum Plural, und zu ihrer neuen Verwerthung, als hintere Nasenöffnungen.

\section{Callosus,}

Der Balken des Gehirns führt dèn Namen Corpus sallosum, schwieliger Körper oder Hirnschwiele, weil er sich durch sein hartes Anfühlen, und seine Zähigkeit beim Versuch ihn zu zerreissen, von der weichen Markmasse der Hirnhemisphären, zwischen welchen er liegt, auffällig unterscheidet. Dieser Härte wegen, nannte Galen $\left.{ }^{1}\right)$ den Balken:

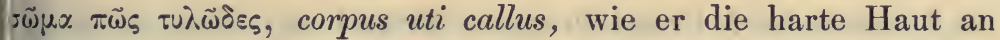

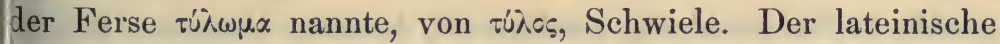
Ausdruck für tủios, ist Callum, wie er im Cicero und bei den Classikern häufig vorkommt. Nur Celsus spricht von Callus, als harter Grund eines Geschwürs, oder harte Wand einer Fistel, und dieses Celsische Masculinum dominirt in der Medicin als Calli pedum et digitorum, Hühneraugen, Callus ossium bei heilenden Beinbrüchen, und Callus der Geschwüre und Fisteln.

Das Corpus callosum ist die Vesal'sche Uebersetzung des

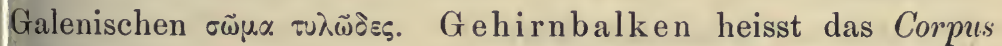
callosum, von dem nicht mehr gebräuchlichen Trabs cerebri. Trabs ist ein zugehauener Baumstamm, ein Balken. Die Anatomie verwendet nur die Verkleinerungsform Trabecula, für die Muskelbündel an der inneren Oberfläche der Herzkammern, trabeculae carneae cordis, und zuweilen für die stark nach innen

1) Administrationes anat., Lib. IX, Cap. 3. 
vorspringenden Muskelbündel der Harnblase. Im Catull steht Trabs für "männliches Glied". Die von Willis gebrauchte, und von Sömmerring aufgenommene Benennung des Balkens, als Commissura cerebri maxima ${ }^{1}$ ), sollte allen anderen vorgezogen werden.

\section{Calva und Calvaria.}

Die allen Christen, vom Calvarienberg her, bekannte Calvaria $^{2}$ ), ist nur in der medicinischen Sprache gangbar, als knöchernes Schädeldach. Calvaria ex interiori parte concava, extrinsecus gibba, utrinque laevis, heisst es schon im Celsus ${ }^{3}$ ). Das Wort für den ganzen Schädel zu gebrauchen, wie Cranium, fällt nur bei anatomischen Schriftstellern untergeordneten Ranges auf. Im Apulejus erscheint Calvarium als eine Art von Seefischen, welche ich für den Mugil cephalus halte. - In classischer Zeit war nur Calva bekannt. Sie ist aber immer eine rara avis bei Dichtern und Prosaikern, und drückt eigentlich nicht das knöcherne Schädeldach, sondern die haarlose Haut des Kopfes aus, von calvus, kahl:

und :

„Psilothro $\left.{ }^{4}\right)$ faciemque levas, et dropace ${ }^{5}$ ) calvam",

„Desine, si pudor est, miseram traducere calvam".

$$
\text { (Martial, Epigramm., Lib. III, 74.) }
$$

Als die römischen Frauen, im Kriege gegen die Gallier, sich ihre Haare abschnitten, um Bogensehnen daraus zu bereiten,

1) Hirn- und Nervenlehre, §. 41.

2) "Golgōthae locus est, capitis calvaria quondam."

(Te r tull., Carm. adv. Marc., II, 196.)

3) De medicina, Lib. VIII, Cap. 1.

4) Psilothrum (Ui $(\lambda \omega \theta$ po\%) war ein, das Ausfallen der Haare be förderndes Mittel, wie das Rusma der Türken.

5) Dropax (oे $\omega \pi \alpha \xi)$ war ein Pechpflaster zum Ausreissen de Haare bei Grindköpfen. 
rrhielten auch die Bildsäulen der Venus kahle Häupter. So st Venus calva des Lactantius und Vegetius zu verstehen. Wenn nicht die Haut des Schädels, sondern das knöcherne schädeldach selbst gemeint war, 'steht bei den römischen Autoren in der Regel: Os calvae. Nur im Livius stosse ich uff Calva als knöcherne Hirnschale: Galli, L. Posthumii alvam, auro celavere, idque sacrum vas iis erat, quo solemnibus ibarent $\left.{ }^{1}\right)$. In diesen Worten wird auf die Unsitte roher Völker lingewiesen, welche die mit allerlei Zierathen, selbst mit ein;elegtem Gold und Edelsteinen geschmückten Hirnschalen der ; etödteten Feinde, als Trinkgefässe bei festlichen Gelegenheiten rerwendeten.

Im Plinius kommt uns Calvaria, als knöchernes Schädellach, am öftesten unter. Der Sonderbarkeit wegen, erwähne ch zwei Stellen, welche erkennen lassen, dass die Calvarien wahrscheinlich die calcinirte Asche derselben), als Schönheitsand als Heilmittel angewendet wurden: terram e calvaria, psilotrum palpebrarum esse contendunt ${ }^{2}$ ), und: ex calvaria suspensi hominis, catapotia (Pillen) fecit Antaeus, contra canis rabiosi norsum ${ }^{3}$ ).

Im B runo ${ }^{4}$ ) findet sich auch Cadra, und das arabische Gamgama, für Calvaria, und im Plinius nur einmal: Coelum apitis, d. i. Schädelgewölbe, wie Coelum oris für Gaumenjewölbe: cerebrum, viscerum excelsissimum, proximum coelo capitis est ${ }^{5}$ ).

Im guten Deutsch soll Calvaria mit Hirnschale gegeben werden, nicht mit Hirnschädel, wie in den älteren deutschen anatomischen Handbüchern, da Schädel und Schedel, auch

1) Hist., Lib. XX1II, Cap. 24.

2) Hist. nat., Lib. XXVIII, Cap. 4, Sect. 11.

3) Op. id., Lib. XXXIII, Cap. 1, Sect. 2.

4) Mantissa nomenclaturae medicae, als Anhang zum Lex. med. des Barthol. Castelli, pag. 767.

5) Hist. nat., Lib. IX, Cap. 37. 
den Nebenbegriff von Fragmenten oder Trümmern enthält, wi z. B. in der Schweiz, die Ruinen eines Schlosses Mauerschede heissen, und überdiess Schädel, auch als ein verächtliche Ausdruck für den ganzen Kopf, in der Volkssprache sich ein genistet hat.

\section{Camera und Fornix.}

Die Anatomie unserer Tage besitzt nur mehr eine Camer oculi anterior und posterior. Vor Zeiten standen ihr auch Camera cordis und Camerae cerebri zu Gebote, welche, seit sie durcl Vesal zu Ventriculi cordis und cerebri wurden, ihren alten Name1 nur in den deutschen Herz- und Hirnkammern aufrecht er halten haben. Die Arabisten dichteten dem menschlichen Uteru: - sieben Camerae an, da sie den Uterus trächtiger Schweine, in mehrere, durch Einschnürungen von einander abgegrenzte Er weiterungen abgetheilt fanden, deren jede einen Embryo ent hält. Diese Erweiterungen nannten sie Camerae. M u ndinu übertrug die Camerae der Arabisten, auf die menschliche Gebär mutter, als Cellulae: Concavitas matricis (Höhle des Uterus) habe septem cellulas, tres in parte dextra, tres in parte sinistra, et unan in medio, in quibus sperma potest coagulari cum menstruo, et con tineri, et alligari orificiis venarum '). Alexander Benedett reducirte diese septem cameras et cellulas auf zwei: gemini matric sinus sunt, ab utraque laterum parte leviter discreti; in dextr masculinum, in sinistro femininum concipi voluint ${ }^{2}$ ). $\mathrm{Zu}$ de alten Camerae, sind bald nachher noch ein Paar neuere hinzt gekommen: 1. die Camerae cranii nach Albin ${ }^{3}$ ), als Vel tiefungen der Hirnschale, in welchen die Hemisphären de grossen und kleinen Gehirns eingelagert sind, und 2. di

1) Anathomia Mundini emendata, Edit. Möllerstadt, Cap. de an thomia matricis.

2) Anatomice, Lib. II, Cap. 24, de mulierum locis.

3) De ossibus, Lib. I, §. 49 und 51 . 
Camera pericardiaca des Bauhin '), Synonym für Herzbeutel, aeben der Arcula des Vidus Vidius, der Casula und Capsula les Andr. Laurentius (Herzkästlein und Herzhäuslein n der deutschen Uebersetzung des Bartholin). Alle diese Camerae haben sich nicht gehalten. Sie wurden, bis auf die Augenkammern, welche Haller rettete, sämmtlich verjessen.

Noch einer Camera sei hier gedacht - die einzige, welche len wahren Begriff der lateinischen Camera in sich schliesst. Es ist die Vesal'sche Camera cerebri ${ }^{2}$ ) = unserem Fornix iricuspidalis im Gehirn. Zur Erklärung Folgendes:

Camera, eigentlich camara (vom griechischen xaj.śpx), wurde von römischen Architekten gebraucht, um die gewölbte Decke eines Gemaches zu bezeichnen, wenn diese Decke aus Holz gezimmert wurde ${ }^{3}$ ). War die Decke aus Ziegeln gemauert, und mit einem Schlussstein versehen, hiess sie Fornix (Cicero, Seneca), oder Arcus. Auf und theilweise zwischen den Sehnervenhügeln, befindet sich ein unpaarer Markkörper, welcher, entsprechend der Convexität der Hügel, auf welchen er aufliegt, bogenförmig gekrümmt sein muss. Er wurde deshalb von Th. Willis als Fornix cerebri benannt, ein Ausdruck, welcher eigentlich nur eine Uebersetzung des

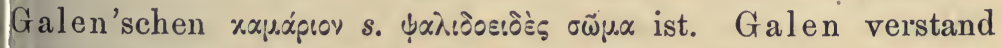
darunter den Fornix, als pars cerebri, quae supra cavitatem (mittlere Kammer) est ${ }^{4}$ ).

Von der gewölbten Decke eines Gemaches, wurde Camera auf das Gemach selbst übertragen, woraus die Kammer entstand und der Kamerad, in den romanischen Sprachen = „Stubengenosse“. Aber die erste und ursprüngliche Bedeutung

1) Theatrum anat., Lib. II, Cap. 16.

2) De corp. hum. fabrica, Lib. VII, Cap. 5.

$\left.{ }^{3}\right)$ Vitruvius, Architectura, Lib. VII, Cap. 3.

4) Galenus, De usu partium, Lib. VIII, Cap. 11, und Oribasius, Anatonica ex Galeno, pag. 11.

Hyrtl. Onomatologia anatomica. 
von Camera, als Gewölbe, liegt nur mehr in der nicht mehr cursirenden Camera des Vesal vor. Da es noch viele andere gewölbte Dinge gibt, wie Arcus (Bogen, Triumphbogen), Clypeus (Schild), Testudo (Rückenschild der Schildkröte), so werden uns die im Mittelalter abwechśelnden Benennungen für Fornix, als Arcus, Clypeus, und Testudo, verständlich. Das deutsche Gewölbe, das französische voûte, das englische vault, das niederländische welfsel, sind Uebersetzungen des Fornix, als Gewölbe der dritten Hirnkammer. Dass man dem Fornix einen Dreispitz anhängte, im Fornix tricuspidalis (gebildet nach der voûte à trois piliers des Lieutaud), widerspricht der anatomischen Autopsie, denn die zwei vorderen Columnae fornicis, und die zwei hinteren Crura fornicis, machen zusammen vier Spitzen des Fornix. Als gewölbte Decke oder Dach, hat Fornix auch im Fornix orbitae (Hildebrandt), im Fornix cranii, Schädeldach (Haller), im Fornix vaginae mihi, Scheidengewölbe, und als Bogen in den Fornices vasculosi renum $\left.{ }^{1}\right)=$ Arcus vasculosi renales ${ }^{2}$ ) Anwendung gefunden.

Warum heisst in der gerichtlichen Medicin die öffentliche Unzucht Fornicatio? Antwort: Weil wir im Horaz und Juvenal mit Fornices bekannt gemacht werden, als schmutzige Gewölbe, in welchen sich die gemeinsten Buhldirnen aufhielten:

"Contra alius nullam, nisi olenti in fornice stantem."

(Horatii Satyrae, Lib. I, Sat. 2, Versus 30.)

\section{Canalis und Foramen, - Hiatus und Trajectus.}

Ueberflüssig ist es nicht, darauf aufmerksam zu machen dass in der Osteologie die Begriffe von Canalis und Foramen. nicht scharf unterschieden werden. Häufig wird Forames

1) Schumlansky, De structura renum, pag. 27.

2) Nath. Highmor, Disquisitio anat., Lib. I, Cap. 4. 
yenannt, was eigentlich ein Canal ist. Das Umgekehrte kommt licht vor. Ich will aus dem reichen Material, welches die Anaomie in dieser Beziehung darbietet, nur Einiges ausheben.

Was in der Osteologie Canalis heisst, heisst mit Fug und Recht so, als ein langer Gang, mit einer Eingangs- und Aus;angsöffnung. Foramen heisst aber sehr Vieles, was eigentlich ,Canal" genannt werden sollte, z. B.: Foramina optica, suprarbitalia, parietalia, mastoidea, condyloidea, jugularia, spinosa, Foramen coecum ossis frontis, Foramen acusticum externum und nternum, Foramen incisivum, u. m. a. Diese Foramina sind nur lie Endmündungen kürzerer oder längerer Canäle, welche lickere Knochenstellen durchbohren. Bei mehreren derselben, ,etzt die anatomische Beschreibung hinzu: "sie sind eigentlich zurze Canäle". Wenn sie also Canäle. sind, warum nennt man ie nicht Canales, statt Foramina? Viel Unsinn liegt ferner in lem Ausdruck Foramen coecum. Ein Canal kann blind endigen, - ein Loch kann nicht blind sein, d.h. geschlossen, denn lann ist es kein Loch mehr. Sieh' Foramen coecum.

Die zwei Foramina eines kurzen Canals, könnten füglich ls Apertura ext. int., sup. inf., ant. post., unterschieden werden. Fat der Canal, ausser diesen beiden Oeffnungen, noch eine tritte, in der Länge seines Verlaufes, wie der Canalis Fallobiae, so darf diese nimmermehr Hiatus, sondern Apertura ateralis (spuria) heissen, wie sie Fallopia nannte ${ }^{1}$ ), denn Hiatus war bei den Classikern immer nur eine weitklaffende and sehr tiefe Schlucht in der Erde, oder in Bergen, figürich auch der weitgähnende Rachen der Raubthiere. Dagegen rann der Hiatus sacro-coccygeus, und der Hiatus aorticus des łwerchfells, figürlich diesen Namen führen, da die betreffenden Oeffnungen hinlänglich weit und tief sind.

Ein Canal muss eine Eigenwand haben. Hat er diese picht, so ist er kein Canal, sondern eine Passage, oder ein jchlitz. Niemand wird sagen, dass die Muskeln, welche von

1) Observat. anat., pag. 27. 
Nerven oder Gefässen durchbohrt werden, deshalb Canäle besitzen. Man spricht hier nur von Schlitzen, Fissurae. Der Leistencanal hat keine eigene Wand. Er ist nur ein Schlitz in der muskulösen Bauchwand, zum Durchgang des Samenstranges. Alle Gebilde, welche dieser Schlitz durchsetzt, verlängern sich in den Schlitz hinein, und kommen mit dem Samenstrang bis zum Hoden herab, welchen die Muskeln schlingenförmig umgreifen, als Cremaster: Die Aponeurose des äusseren schiefen Bauchmuskels, und die Fascia transversa aber, umhüllen, als abgeschlossene Säcke, den Hoden und den Samenstrang, so dass der Leistencanal gal keine äussere Oeffnung hat, wenn man sie nicht, durch Ablösen der Fascia Cooperi von der Aponeurose des Obliquus externus, künstlich erzeugt. Die Franzosen haben das Unschickliche in der Benennung des Leistencanals zuerst gerügt. Richet gab uns dafür das rechte Wort: Trajet. Wollten wir uns herbeilassen, den Trajectus (Diabasis) abdominis s. inguinalis, statt Canatis inguinalis zu inauguriren, wäre die Anatomie um ein classisches Wort reicher. Man erinnere sich an Trajectus Mosae, Maestricht, und Trajectus Rheni, Utrecht.

\section{Canthus und Encanthis.}

Die Augenwinkel, Anguli s. Sinus oculorum, hiessen bei den Griechen \%ov0oi, und werden auch im anatomischen Latein Canthi genannt. Der griechische xav0ós und der lateinische Canthus, bedeuten ursprünglich den metallenen Reif um ein Rad, durch welchen das Abreiben des Holzes verhindert wird. So berichtet der Scholiast zu Ilias, V, 725, und so finden wir es im Quinctilian, und Persius ${ }^{1}$ ). Hesychius definirt \%avós als Orbis oculorum. Die Lidöffnung der Thiere ist wirklich 
zreisrund, und von demselben Umfange, wie die gleichfalls zreisrunde Cornea. Deshalb sieht man das Weisse im Thiertuge nicht. Kavós wäre also eigentlich der Rand der Augenider, und uneigentlich erst die Commissur beider Ränder, sub

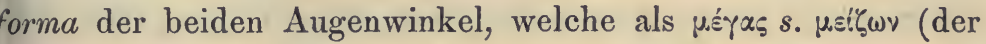

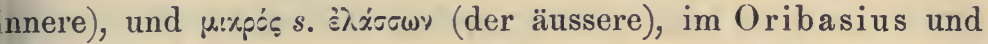
Rufus unterschieden werden. Langgeschlitzte Augenwinkel verrathen, nach Aristoteles, einen arglistigen Charakter: inguli si longi sunt, nequitiam significant ${ }^{1}$ ).

Der äussere Augenwinkel kommt unter dem Namen rxpurix im Julius Pollux vor"2), der innere als pavtrip und "rry'. 'Pavtrip heisst eigentlich der Befeuchter, und passt auf den inneren Augenwinkel, weil in ihm die Thränen zusammenlaufen, was auch die deutsche Benennung desselben, als

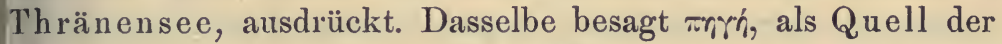
Thränen, welche, nach damaliger Meinung, von der Caruncula lacrymalis im inneren Augenwinkel bereitet werden. Noch im Casserius (Anfang des 17. Jahrhunderts), wird die Thränencarunkel als Glandula lacrymalis aufgeführt ${ }^{3}$ ).

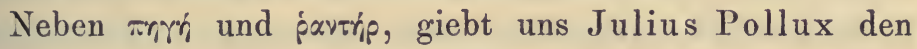

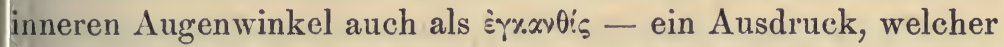
von den Neueren, nach C. Hofmann's ${ }^{4}$ ) Vorgehen, ganz willkürlich der Caruncula lacrymalis aufgebürdet wurde, während im Sinne Galen's, eine Wucherung der Thränencarunkel (Excrescentia carnis) damit gemeint ist, für welche sie heutzutage noch gebraucht wird (Encanthis fungosa).

1) Hist. anim., Lib. I, Cap. 9.

$\left.{ }^{2}\right)$ Ich finde ihn auch als Parotia bei den Latino-Barbari.

3) Vergleiche auch den Abschnitt Innominatus, über die Thränendrüse.

4) Commentaria in Galeni: De usu partium, num. 750 . 


\section{Capillitium und Verwandtes.}

Capillitium nehmen die Anatomen theils als Behaarung des Hauptes, theils als die behaarte Kopfhaut selbst. Capillus $=$ capitis pilus, soll nie für andere Haare am menschlichen Leibe gebraucht werden. Fehlerhaft ist es, von capilli der Schamgegend, der Achsel, der vorderen Brust- und Bauchwand zu reden, oder von scapulae capillatae. Dieser Fehler ereignet sich ungemein häufig. Welche ihn begangen haben, können nur eine Entschuldigung vorbringen. Sie besteht darin, dass selbst die Classiker andere Haare als die Kopfhaare, auch die Haare der Thiere, capilli nennen. Im Seneca finden wir capilli barbae, im Suetonius capilli malae (Wangenhaare), im Aurelianus capilli pubis. Diese Ausnahmen finden sich jedoch nur selten. Die Behaarung anderer Körperstellen, ausser dem Haupte, wird durch crines oder pili gebildet, nicht durch capilli. Crines will man zwar auch auf Kopfhaare beziehen, und zwar auf gescheitelte oder frisirte: crinis = coma, in plures ordines divisa, a xpirw, secerno (Forcell.), und im Festus: crines a discretione dicti, quam Graeci xpiscy appellant. Allein die Ableitung von crescere, ist für crinis ebenso wahr-

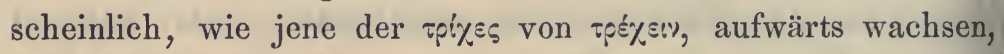
im Herodot. Es könnten dann die an was immer für einer Körperstelle herauswachsenden Haare, ebensogut crines als pili genannt werden. So spricht die Anatomie von einer pubes und einer cervix crinosa, und von einer areola mammae crinita, wie Ovid von den corpora pilosa der Bauern, coloni, und von ihren duris, aspera crura pilis (behaarte Schenkel).

Das Kopfhaar hatte noch andere Namen. Die gebräuchlichsten sind Coma und Caesaries. Sie sind den Dichtern geläufiger, als den Anatomen. Coma (\%óprin, von \%opíw, zieren) heisst das Haupthaar, insofern es Object einer besonderen Pflege ist, z. B.: coma in gradus ornata, im Suetonius, und comam torquere igne, die Haare brennen, im Ovid. Coma 
nvolvirt zugleich immer den Begriff der Fülle und Länge. Es steht daher auch für die Mähne des Pferdes, und für den Rossschweif auf dem Helm, sowie Comatus einen Menschen nit üppigem Haarwuchs bezeichnet, wie er an den Galliern and Germanen bewundert wurde. Das aquitanische (translpine) Gallien heisst, dieser Haarfülle seiner Bewohner wegen, m Pomponius Mela ${ }^{1}$ ): Gallia comata. - Caesaries, fast ;ynonym mit Coma, wird jedoch nur auf das männliche Haupt1aar angewendet, wahrscheinlich quia caeditur, weil es be;chnitten wird. Caesavies, als Bart, im Ovid, verläugnet den Tropus für Bartstreicheln nicht:

"Caesariem longae dextrâ deducere barbae."

(Metamorph., XV, 656.)

Ueber die besonderen Namen des Haarwuchses bestimmter Fegenden, wie Barba, Barbitium, Pappus, Julus ('ov̀оs, Backenpart), Propogonion (erster Bartwuchs), Civrus, Cincinnus, und Mystax, (Knebelbart), Antiae und Capronae (Schopf), handeln die Lexica erschöpfend. Ueber Vibrissae, Tragi, Hirci, Cilia und Supercilia, vergleiche die betreffenden Artikel dieses Buches.

Pappus habe ich nur ein einziges Mal im Rufus, als Spitzbart gelesen: pili in summo mento pappus $\left.{ }^{2}\right)$ ( $\left.\pi \dot{\alpha} \pi \pi \circ 5\right)$, sub mento autem hypena graecis vocibus dicuntur, latina nomina (desunt ${ }^{3}$ ). Pappus ist im alten Latein $=$ Greis. Von den grawen Haaren der Greise, fand höchst wahrscheinlich der Uebergang zu den grauen Wollhaaren und Samenflügeln in der botanischen Terminologie statt: pappus, lanugo ex floribus et fructibus decidua est, vel quae cum semine in auras effertur, wie z. B. bei den Arten von Senecio, Sonchus, u. m. a.

1) De situ orbis, Lib. III, Cap. 2.

2) Die mittelalterliche Bigotta, worüber Dietz nachzusehen, bezeichnet ebenfalls den Spitzbart.

3) De partibus corp. lum., pag. 27. 


\section{Capsulae.}

Die Kapselbänder der Gelenke wurden erst durch Winslow in die anatomische Terminologie eingeführt, als Ligaments capsulaires 1 ). Wir schulden ihm Dank für seine Kapseln, denn die früheren Benennungen derselben, waren viel zu lang, wie die Ligamenta membranacea, quae articulos cingunt, im Bartholinus²), und die Membranae, quae totum articulum cingunt, im Bauhinus ${ }^{3}$ ). Diese langathmigen Aus-

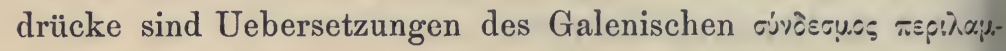

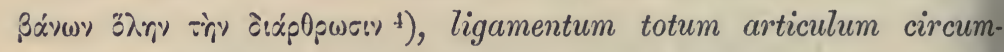
dans, was die Araber zu Ligamentum cingens und Cinctorium abkürzten (Avicenna). Vor Winslow war Capsula nur in einigen anderen anatomischen Anwendungen bekannt: 1. im Mundinus, als Capsula cordis, welche bei seinen Schülern und Anhängern, zur Casula wird (Laurentius), - 2. im Bartholinus, als Capsula atrabiliaria $=$ Ren succenturiatus, - 3. im Vesling, als Capsula seminalis = Samenblase, -4 . als Capsula renum adiposa $=$ Nierenfett, - und 5. im Glissoll, als die, vom Peritoneum irrigerweise abgeleitete Capsula vasorum ad portas hepatis 5 ), welche, als Capsula Glissonii, gleichwie die Winslow'sche Capsula lentis crystallinae, allgemein beibehalten wird.

Capsula ist das Diminutiv von Capsa, welche, als von capio entstanden, überhaupt ein Behältniss ausdrückt, und im Cicero speciell als Bücherkasten, sonst noch als Kleiderkasten vorkommt. Das rauhere Capsus, gebraucht

1) Exposition anat., T. I, §. 238, u. m. a.

2) Institutiones anat., Lib. IV, Cap. 3, de ligamentis.

3) Theatrum anat., Lib. IV, Cap. 4.

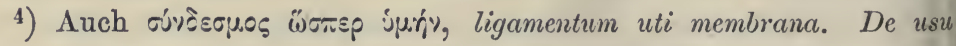
partium, Lib. I, Cap. 15.

$\left.{ }^{5}\right)$ Anatomia hepatis, Cap. 28. 
Vitruvius als Kutschenkasten, und Vellejus als Zwinger ür wilde Thiere. Totus de capsula, wie Seneca von einem Stutzer sagt, ist unser "wie aus dem Schächtelchen".

\section{Caput gallinaginis.}

Darüber Näheres im Artikel: Veru montanum.

\section{Cardiacus.}

Cardiacus war vor Zeiten etwas anderes, als die Anatomie laraus gemacht hat, welche die zum Herzen gehenden Nerven and Nervengeflechte, Cardiaci nennt.

Da das Herz, und der Mageneingang, Cardia (xapòi $\alpha$ ) aeisst, wird das Adjectiv cardiacus, in der medicinischen Sprache der Griechen, nur auf krankhafte Zustände dieser beiden Organe und auf ihre Heilmittel, bezogen. Remedia cardiaca und cordialia, heissen alle Herzstärkungen, und Passio sardiaca nennt Celsus eine acute Krankheit, in welcher, ob stomachi languorem, nimia imbecillitate et immodico sudore corpus digeritur (aufgelöst wird 1), zum Unterschied von Cardialgia, welche von Plinius als Rosio stomachi angeführt, und von den Neueren, mit dem Cardiogmus des Hippocrates verwechselt wird (unser Herzweh), welches mit heftigem Herz-

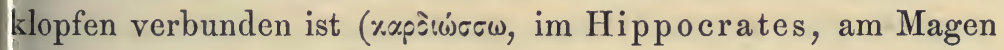
leiden).

Das Wort cardiacus schlich sich schon frühzeitig in die lateinische Sprache ein. Cicero nennt Herzkranke Cardiaci ${ }^{2}$ ), wie sie auch im Horaz und Juvenal gefunden werden:

"Cardiaco nunquam cyathum missurus amico"

(Sat. V, Vers 36)

1) De medicina, Lib. III, Cap. 19.

2) De divinatione, Lib. I, Cap. 38. 
d. h.: einem Herzkranken schicke keinen Wein. Pflanzen, welche auf das Herz wirken, erhielten das Prädicat Cardiaca, und behielten es für immer, wie z. B. Leonurus cardiaca, Linn. Morbus cardiacus hiess bei den Alten jede Krankheit, welche ad tabem perducit. Hier heisst aber cardiacus nicht herzleidend, sondern schwer (principalis im Paracelsus), und unheilbar. Die Medicin des Mittelalters war ja der Meinung, dass das Herz nie erkranke: cor, inter omnia viscera morbis non maceratur, und: cor nunquam male affectum visum est ${ }^{1}$ ).

Wir ersehen aus dem Angeführten, dass cardiacus nur für herzkrank und herzstärkend, in der Medicin im Gebrauch steht. Die Nervi cardiaci, die Plexus cardiaci, das Ganglion cardiacum, müssen es sich also gefallen lassen, dieses Grundes wegen, zu einfachen Nervi, Plexus, und Ganglia cordis herabgesetzt zu werden. Dann giebt es kein Missverständniss mehr.

\section{Caro und Caruncula.}

Mit Caro wurde in der alten Anatomie viel Missbrauch getrieben. Caro kann seinen griechischen Ursprung nicht verläugnen. Es ist gleich xpéą, - beide vom krawja des Sanskrit.

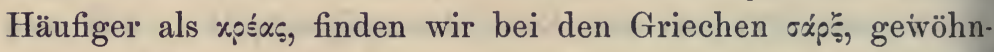
lich im Plural øx́prse, wie denn im Hippocrates alle Muskeln

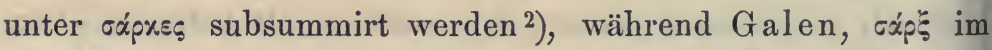
engeren und weiteren Sinne gebraucht: 1. als Caro s. Substantia muscularis, mit dem erklärenden Zusatz: quam in victimis edimus $^{3}$ ), und 2. als jedwede weiche organische Substanz: caro est concreta ex sanguine pars, humida et calida, flexionem mollitiemque corpori praebens ${ }^{4}$ ). Nach dieser vielumfassenden

1) Alex. Benedictus, Historia corp. hum., Lib. III, Cap. 10.

2) Aphorismi, IV, 16, und De fracturis, Cap. 2.

$\left.{ }^{3}\right)$ De probis et malis alimentorum succis, Cap. 4, in medio.

4) Definitiones medicae, LXXXIII. 
Pefinition, blieb Caro, bis zum Anfang des 18. Jahrhunderts, iner der gebrauchtesten anatomischen Termini, und zählte olgende Unterarten:

1. Caro simplex, wohin das Zahnfleisch, das Zäpfchen, er harte und weiche Gaumen, das Collum uteri, die Runzeläulen der Vagina, und die Glans penis gehörten.

2. Caro nervosa, zuweilen bei den Arabisten auch Caro aliens, von ihrer Eigenschaft, sich durch Blutcongestion zu rheben: Schwellkörper des Penis und der Clitoris, und die 3rustwarze.

3. Caro visceralis s. glandosa, mit Hoden, Brüsten, Thymus, 'lacenta, Pankreas, Leber, Lunge, Milz, Mandeln, Glandula ublingualis, submaxillaris und pinealis, nebst den sogenannten Imunctoria, welche ihren Namen daher erhielten, dass sie, icut spongiae, humores superfluos ad se adliciunt, ne in partes obiliores ruant, et, si intumescunt, viscerum pravam dispositionem ndicant $\left.{ }^{1}\right)$. Zu den Emunctoria zählte man die Parotis, und ie Lymphdrüsen der Achsel und der Leistengegend. Letztere :ommen auch, wie der Complex der Mesenterialdrüsen, als Yaro nodosa vor. Caro glandosa wäre demnach = Parenchyma, vorüber der betreffende Artikel nachzusehen.

4. Caro membranacea, weniger gebraucht als die übrigen Irten von Caro, waren alle dicken Schleimhäute, Pharynx, Pesophagus, Magen, Harnblase, selbst die Gebärmutter, da nan nur den häutigen Uterus der Thiere kannte, und die cheide.

5. Caro fibrosa, s. lacertosa, s. muscularis, welche alle Iuskeln umfasste.

Von der mittelalterlichen Caro, hat die Anatomie einige Reliquien aufzuweisen, wie die Caro quadrata Sylvii, auch Iassa carnea Sylvii, als Plantarursprung des langen Zehenleugers, - die Caro innominata, bis zu Wharton's Zeit der lleinige Name der Thränendrüse, deren Function man nicht

1) Bauhinus, Theatrum anat., Lib. I, Cap. 7. 
kannte, - die Papillae carneae des Herzens (Papillarmuskeln), - den Panniculus carnosus unter der Haut der Thiere, - den Monticulus carnosus urethrae, als Synonym des Caput gallinaginis, - die Trabeculae carneae, Fleischbälkchen des Herzens, - und das excarnare der Mundinisten, für "präpariren", dem das incarnatus, "fleischgeworden", im Credo der katholischen Messe, gegenüber'steht.

Die Carunculae, als Diminutiv von Caro (sapsiov und sxpжî̀เ৩v), können hier gleich mitgenommen werden. Carunculae

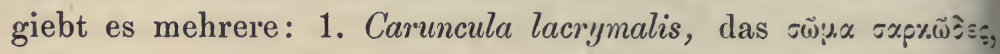
corpus carnosum, des Galen, quod prohibet, ne oculorum excrementa (Thränen) per angulum vacuarentur $\left.{ }^{1}\right),-2$ die C $a$ runcula cerebri mammillaris = Trigonum olfactorium, -3 . die Carunculae myrtiformes, -4 . die Carunculae renum = Papillae renales, - und 5. die nicht mehr in usu stehenden Carunculae valvularum semilunarium $=$ Noduli Arantii. Im Celsus finde ich auch den Nasenpolyp als Caruncula ${ }^{2}$ ). Fallopia substituirte der Caruncula, seine neuerfundene Carnicula ${ }^{3}$ ), welche unbeachtet blieb. Auch der deutsche Sprachgebrauch hat Dinge, welche kein Fleisch sind, als Fleisch benannt, wie das Zahnfleisch, Caro dentium, - die Fleischgeschwülste, Sarcomata, - die Fleischbrüche, Sarcocele, - das Mittelfleisch, als ein Complex der den Beckenausgang verschliessenden Muskeln und Weichtheile, - das wilde Fleisch, Excrescentiae s. Fungositates carnosae, - das wuchernde Fleisch, Caro luxurians, - den in's Fleisch gewachsenen Nagel, Paronychia, - die Fleischwärzchen, Papillae carneae, eiternder Flächen, - die Remedia incarnativa, welche die Granulirung der Wunden und Geschwüre befördern (quae carnem alunt, et ulcus implent [Celsus], die Sarcotica des Galen), - das Fleischige, für alles Weiche und Saftige, - "vom Fleisch fallen" für

1) De usu partium, Lib. X, Cap. 11.

2) De medicina, Lib. VI, Cap. 8.

3) Expositio de ossibus, Cap. 12. 
bmagern, - und das Fleisch, als das Sinnliche im Menschen "das Fleisch ist schwach").

Eine Unzahl alter und neuer, guter und schlechter Comosita von $\sigma^{\alpha} \rho \xi \xi$, steht den Aerzten, Anatomen und Botanikern, 1 allen Wörterbüchern zur Verfügung. Ein sehr ehrwürdiges arunter ist die Anasarca Galeni, als allgemeine Wasserucht, bei welcher sich das Wasser in dem Zellgewebe ( $\sigma \dot{\alpha} \rho \xi)$ nter der Haut ansammelt. Die Römer geben Anasarca nicht Is aqua inter cutem, wie Caelius Aurelianus ${ }^{1}$ ), sondern als qua intercus, wie Cicero, Plautus, u. A. Intercus ist somit ein Barbarismus. Hippocrates kennt diese Wassersucht

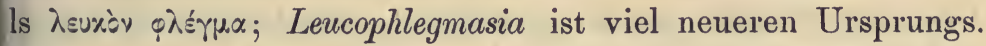

\section{Carotis,}

Für das Etymon von Carotis, hält man allgemein das Terbum xxpó(1), betäuben, in schweren und tiefen Schlaf verenken. Man beruft sich auf Aristoteles: apprehensis his enis ${ }^{2}$ ), corruunt homines, amissis sensibus, et palpebris clausis, nd auf Rufus: compressae carotides, hominem sopore et aphonia ravant. Durch das ganze Mittelalter war der Glaube herrchend, dass Compression und Verstopfung der Carotiden, jene Irt des krankhaften Schlafes erzeugt, welche unter der Form on Carus, Lethargus, und Apoplexia, sich kundgiebt. Galen, las medicinische Idol des Mittelalters, war nicht dieser Meinung:

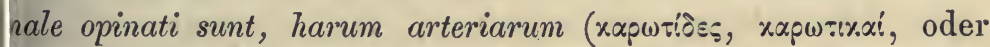

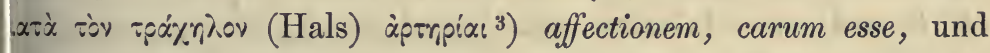
pezieht sich auf Hippocrates, welcher die Entstehung des

1) Morbi chronici, Lib. III, Cap. 8.

$\left.{ }^{2}\right)$ Vena wird häufig von den Uebersetzern der Griechen und der Araber, statt Arteria gebraucht.

3) Im Celsus auch Sphagitides, welche im Aristoteles vorkommen, von sẹxrí, Kehle. 
Carus, nicht von den Carotiden abhängig machte ${ }^{1}$ ). Obgleich Matthäus Curtius, durch Unterbindung beider Carotiden an lebenden Thieren, bewies: animalia in apoplexiam non incidere $^{2}$ ), blieben die Anatomen doch bei der allgemein verbreiteten Irrlehre, und nannten die Carotiden bald soporariae und soporiferae, wie Vesal, oder apoplecticae, wie Carolus Stephanus, oder lethargicae und Arteriae somni, wie die Uebersetzer der Araber. Den Namen Sphagitides, und dessen Entstellung zu Sphragitides (Carpus), und Phagoticae (G. Valla), theilten die Carotiden mit den inneren Jugularvenen, mit und neben welchen sie an der ๘ọar, (Hals, Kehle) gelegen sind. Die vermeintliche causale Beziehung zwischen den Carotiden und tiefem Schlaf, hat auch jener seitlichen Kopfgegend, an welcher der Schlag eines Zweiges der Carotis sehr deutlich gefühlt, und unter Umständen auch gesehen werden kann, zu ihrer Benennung als Schlaf und Schläfe verholfen.

Bei den Arabisten lesen wir von den Arteriae subethales und Subeteni, nachgebildet dem arabischen Subāt = sopor. Eine seltsame Verwechslung fand auch zwischen Phagotides und Parotides statt (im Alex. Benedictus), wenn der letztere Name nicht absichtlich gewählt wurde, um die gegen das $\mathrm{Ohr}$ aufsteigende Richtung der Carotis ext. auszudrücken. - Ueber die befremdenden, aber nach alten Anschauungen ganz gerechtfertigten Benennungen der Carotiden, als Arteriae juveniles und spermaticae, sieh' HL, §. XCVIII, Subeth und Subetales.

Richtiger als die Ableitung des Wortes Carotis von xápss, sopor, halte ich jene von xáp, Kopf. Wir haben unsere Kopfs chlagadern und Arteriae cephalicae dieser Ableitung zu danken. Da aber der xápos in der xx́px seinen Sitz hat, kommen wohl beide Ableitungen auf Eines hinaus.

1) De placitis Hippocratis et Platonis, Cap. VII.

2) Commentaria in Mundinum, Lugd., 1551, pag. 381. 


\section{Carpus und Metacarpus.}

Schon in der Ilias und Odyssee I), finden wir raprós als inen topographischen Begriff für jene Gegend des Armes, urch welche die Hand mit dem Vorderarm beweglich zuimmenhängt. So spricht auch Aristoteles ${ }^{2}$ ) vom xaprós. Im ralen finden wir xaptós nur im osteologischen Sinn, als In-

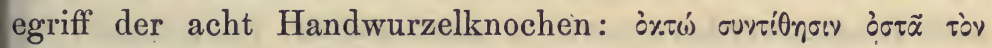

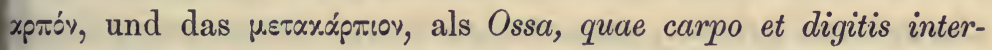
cta sunt ${ }^{3}$ ). Wir sollten also, dieser Autorität zu Liebe, nur on einem Metacarpium, nicht von einem Metacarpus reden. Vie man sich aber erlaubte, das Wort Metatarsus zu bilden, elches in keinem griechischen Autor aufgestöbert werden ann, so erlaubte man sich auch, das Galenische Metacarpion 1 Metacarpus umzuwandeln, ja sogar jeden einzelnen der fünf littelhandknochen einen Metacarpus zu'nennen. Es wird überies von einem Metacarpus und Metatarsus primus bis quintus esprochen, statt von einem Os metacarpi und metatarsi primum is quintum, wie es sein muss, da nur Ein Metacarpus und Ein Letatarsus am menschlichen Skelet sich vorfinden. Im Rufus

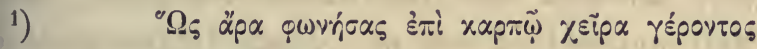

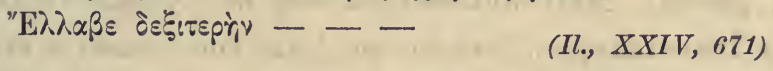

"So sprechend, fasst der Peleid am Gelenk die rechte Hand des Greises",

und in der Odyssee, XXIV, 398:

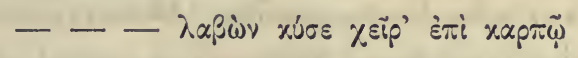

"Dolios küsste dem Odysseus die Hand am Gelenke".

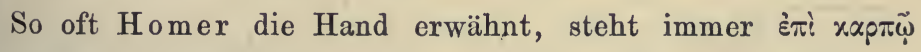
dabei.

2) Hist. anim., Lib. I, Cap. 15.

$\left.{ }^{3}\right)$ Oribasii Anatomica ex Galeno, pag. 160. 
Ephesius, werden Metacarpium und Tarsus als synonym behandelt ${ }^{1}$ ). (Sieh' den Artikel: Tarsus).

Die Etymologie von \%apสós festzustellen, hält schwer, da \% жprós ein vielsinniges Wort ist, mit der Grundidee von Frucht. Sollte, wie ich meine, Carpus sich auf rapyśw (eingehen, zusammenschrumpfen) zurückführen lassen, kann wohl die Handwurzel, als der schmalste Theil der ganzen oberen Gliedmasse, zu dem Namen raprós gelangt sein. Das Eingehen durch Dürrund Trockenwerden, wird ja auch auf die Feldfrüchte, und alle anderen Früchte, angewendet. Vesal ersetzt \%apmós immer durch Cubitale, - die Arabisten immer durch Rasceta ${ }^{2}$ ). Cubitale verdanken wir dem Gaza, einem Uebersetzer des Aristoteles. Wie ein Gelehrter und Sprachkenner in einen solchen Fehler gerathen konnte, begreife ich nicht; cubitalis heisst ellenlang (Plinius). - Dem Mönche Rasarius können wir es verzeihen, dass er in der Uebersetzung des Oribasius, Brachiale und Postbrachiale für Carpus und Metacarpus gebraucht. - Die deutsche Benennung Handwurzel datirt, wie jene der Fusswurzel, aus dem 17. Jahrhundert, und tritt uns in der deutschen Uebersetzung des Bartholinus zuerst entgegen.

Galen und Oribasius hielten es nicht der Mühe werth, den acht Knochen der Handwurzel besondere Namen zu geben. Man unterschied sie nur durch Ordnungszahlen. Die Benennungen, welche sie jetzt von einander unterscheiden, erhielten sie erst durch Michael Lyser ${ }^{3}$ ), dem Prosector bei Thomas Bartholin. Die neuere Zeit hat sich einiger Verwechslungen der Termini Lyseriani schuldig gemacht, wie denn z. B. das Lyser'sche Os trapezoides (Multangulum majus), und das Lyser'sche Trapezium (Multangulum minus), an den dritten

1) De partibus hominis, pag. 28 und 29.

2) Sieh' HL, §. LXXXVI.

$\left.{ }^{3}\right)$ Culter anatomicus, Hafniae, 1665, pag. 208, seqq. 
Knochen in der ersten Handwurzelschaar (Triquetrum Lyseri) verschleudert wurden.

Ueber die mittelalterliche Rasceta, als Aequivalent von Carpus, sieh' HL, §. LXXXVI.

\section{Cartilago.}

Ein echtes, urlateinisches Wort der Anatomie, wird durch Cartilago - bei den Arabisten Chartilago - gegeben. Nur im Plinius und im Celsus kommt es vor - sonst nirgends. Celsus drückt, wie wir, durch dasselbe den Knorpel aus. Er spricht von einer Cartilago auris, Cartilago narium, costarum, und gedenkt der Gelenksknorpel mit den Worten: haud ignorare non oportet, plurima ossa in cartilaginem desinere ${ }^{1}$ ). Plinius verwendet Cartilago noch etwas weiter. Er nennt auch die härtliche, aber saftige Substanz der Rüben, des Rettigs, der Maulbeeren, und das Mark gewisser Rohrarten Cartilago: nostratibus arundinibus subest fungosior natura, cartilagine bibula, quae superne tenui inarescit ligno ${ }^{2}$ ). .Cartilagineus und Cartilaginosus, beide gut, verdanken wir gleichfalls dem Plinius: animalia cartilaginea (certi pisces), pro spina cartilaginem habent ${ }^{3}$ ), und galbanum cartilaginosum, minimeque lignosum ${ }^{4}$ ).

\section{Cauda equina.}

Dem Andreas Laurentius wird der in der Anatomie beliebte Tropus der Cauda equina zugeschrieben. Er liess das Rückenmark sich an seinem unteren Ende in eine Menge

1) Lib. VIII, Cap. 1.

2) Hist. nat., Lib. XVI, Cap. 36, Sect. 26.

3) Op. cit., Lib. XIX; Cap. 5, Sect. 22.

4) Op. cit., Liz. XII, Cap. 25, Sect. 56 .

Hyrtl. Onomatologia anatomica. 
funiculi, caudam equinam referentes, auflösen ' $)$. Win gelehrter jüdischer Arzt, Benjamin Wolf Ginzburger, ein Schüler Haller's, wies jedoch nach, dass die Anatomie diesen Ausdruck aus der Hand des Talmud erhielt ${ }^{2}$ ). Ich habe diese Notiz aus Haller's Bibliotheca anatomica, T. I, pag. 126, entnommen: caudam equinam dixerunt Talmudici, quae finis est medullae spinalis.

\section{Cava.}

Da alle Venen hohl sind, muss es schon Manchem aufgefallen sein, dass nur die obere und untere Hohlvene, Venae cavae genannt werden. Die Sache erklärt sich ganz einfach. Galen, welcher die Leber für das einzige blutbereitende Organ (officina sanguinis, und princeps haematoseos organon) hielt, nannte die grosse Vene, welche von der Leber, durch

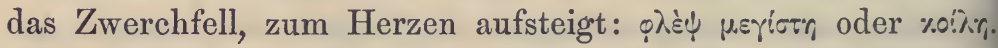

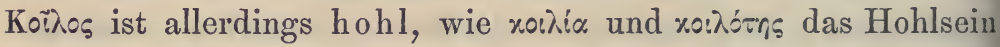
bezeichnen. Aber xoinos hat noch eine andere, sehr häufig in Anwendung kommende Bedeutung, und zwar jene von geräumig, bauchig, und schwellend. So finden wir im Homer xoìog immer als Beiwort der Schiffe der Archiver, wo es ihren Umfang, ihre Geräumigkeit auszudrücken hat, nicht ihr Hohlsein, welches keine poetische, sondern eine allgemeine und nothwendige Eigenschaft jedes Schiffes ist.

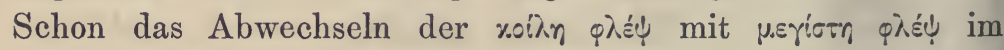
Galen, und schon im Aristoteles, beweist, dass hier \%oinin nicht als cava, sondern als crassa oder ventricosa angewendet wurde. Die Uebersetzer des Galen begingen den Fehler, xo:?\% nur mit cava auszudrücken, während die Restauratoren der Anatomie sich durchgehends der Worte magna, maxima, ampla, und crassa bedienen. Sie geben den wahren Sinn von \%oi $\lambda r_{r}$,

1) Hist. anat. corp. hum., Lib. X, Cap. 12.

2) Medicina ex Talmudicis illustrata, Gött., 1734, pag. 10. 
vie die Vesal'sche Vena caudicis. Nur sollte, da caudex = Stamm" ist, der grosse Reformator Caudex venarum statt Vena audicis gesagt haben. Bonus interea dormitat Homerus. Die Jebersetzer der Araber haben gleichfalls das arabische Wort ür Hohlvene: al-wārid, nicht mit Vena cava, sondern mit Vena entrem habens ausgedrückt, während die Latino-Barbari durch;ehends aller möglichen Verwechslung dadurch auswichen, dass ie das griechische $x^{0} \lambda \eta \eta$ beibehielten, aber in lateinischer Maske, Is chillis. Aus xoi $\eta \eta$ wurde chillis: 1. durch Substitution von $h$ für $k$ (welches in der italienischen Sprache fehlt), 2. durch leugriechische Aussprache des of als $i$, 3. durch Verdopplung les $l$, welche in jenem Zeitalter äusserst beliebt war, und in ehr vielen Worten vorkommt, und 4. durch den lateinischen Ausgang in is, wodurch chillis declinabel wurde. Wir haben Venam chillim im Mundinus und Berengarius vor uns.

Galen liess seine roìn ộśł schnurgerade bis zum Halse inaufsteigen, und sich, während dieses Weges, mit dem rechten Ierzen in Verbindung setzen, um durch dessen Vena arteriosa unsere Lungenschlagader) Blut in die Lunge zu senden, jedoch ur zu ihrer Ernährung. In der Höhe der Schlüsselbeine theilt

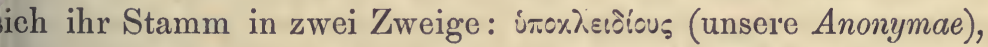
leren jeder wieder in eine $\mu \alpha \sigma / \alpha \lambda<\alpha$, unsere Axillaris, in eine

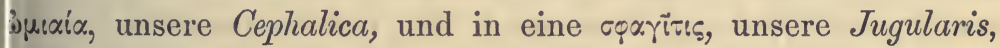
zerfällt.

Die naive Erklärung, welche der Uebersetzer der Anatomia reformata von Th. Bartholinus, über das Wort Hohlader bringt: ,sie holen das Geblüt von oben herab, und ron unten hinauf, um selbiges in das Herz einzugiessen"; kann die Existenz der Hohladern retten, die lateinischen Cavae könnten aber füglich durch Vena maxima superior et inferior ersetzt werden.

Mehr über die Cava, und ihre Halbschwester Chillis, in HL, §. VI, Alabari und Vena chillis. 


\section{Cavitas und ihre Verwandten.}

Es fällt mir schwer, ein so harmlos aussehendes Wort, wie Cavitas, des Barbarismus zu beschuldigen. Gravitas, Firmitas, Coecitas, und hundert andere gute Worte mit demselben Ausgang in itas, liessen vermuthen, dass auch Cavitas eine legitime Tochter der lateinischen Sprache ist. Aber sie ist es nicht.

Zur Bezeichnung von Höhlen, Gruben und Vertiefungen, bedient sich die Anatomie verschiedener Ausdrücke, von welchen die häufiger vorkommenden: Cavum, Cavitas, Cavositas, Caverna, Sinus, Recessus und Antrum sind. Cava werden nicht blos die drei Haupthöhlen des menschlichen Leibes genannt: Cavum cranii, thoracis, und abdominis; auch kleineren Höhlen fällt diese Benennung zu, wie Cavum narium, oris, dentis, laryngis, u. v. m. Von Cavitas und Cavositas, welche meistens an die Gelenksgruben vergeben-wurden (Cavitates articulares s. glenoideae), wird das erste ganz unrichtig für echt latein, das zweite für barbarisch gehalten. Das Umgekehrte ist das Richtige. Cavitas fehlt in den Classikern; Cavositas kommt wenigstens in den Kirchenvätern Lactantius und Tertullian zum Vorschein. Die Uebersetzer der Araber gebrauchen für Gelenkhöhle, mit Vorliebe das Wort Vacuitas, seltener Concavitas, woraus ihre Nachbeter - die Arabisten Cavitas machten, welche in der anatomischen Terminologie verblieb, und in allen Sprachen heimisch geworden ist (Cavité, Cavity, Cavita). Cavitas ist zugleich der einzige Barbarismus, welcher selbst von Vesal, dem gründlichen Kenner des classischen Lateins, beibehalten wurde. In Lib. I, Cap. 8, seiner grossen Anatomie, erscheint die Trommelhöhle als Cavitas, temporis ossi incisa, und in Lib. I, Cap. 12, wird die Stirnbeinhöhle genannt: Cavitas, inter duas ossis frontis squamas (squamae $=$ unseren tabulae der Schädelknochen). Cavea, Caverna, Sinus und Specus, sind bei den Latino-Barbari häufig anzutreffende 
Ausdrücke für allerlei Höhlen und Gruben kleinerer Art, vährend das bei den Poeten oft $\mathrm{zu}$ findende Antrum ${ }^{1}$ ), sich $\mathrm{n}$ die Anatomie nur als Antrum Highmori, und als Antrum yloricum Retzii verloren hat. Im Vesal überrascht uns Antrum uccinosum, als Schnecke ${ }^{2}$ ).

Von Recessus, als Grube, haben wir noch zwei Beispiele: len Recessus hemisphaericus und hemiellipticus, im Vorhof des Fehörlabyrinths. Im alten Rom dienten die Recessus et Anguli ls Aborte. Cornelius Celsus nannte die Mundhöhle: Reiessus oris.

\section{Cella und Cellula.}

Die Zelle, welche in neuester Zeit der anatomischen Structurlehre ihre wissenschaftliche Basis gegeben hat, ist ein altangestammtes Wort in der Anatomie. Einst führten die sehirnkammern diesen Namen. Die Arabisten sprechen von Arei Cellae im Gehirn: einer vorderen, mittleren, und hinteren, als Standorten des Verstandes, der Vernunft, und des Gedächtnisses, wie sie im Brunetto Latini, dem Lehrer des Dante, angefuhrt werden ${ }^{3}$ ). Seltener als die Cellae cerebri, ist die Cella

1) Vox poëtis, quam aliis usitatior (Forcell.). Daher Antra narium, Nasenhöhle, im Juvenal, und Antra palati im Sidonius Apollinaris.

2) Op. cit., Lib. I, Cap. 8.

3)

$\mathrm{Nel}$ capo son tre celle, Ed io dirò di quelle, Davanti è lo inteletto, $E$ la forza d'apprendere, Quello che puote intendere.

In mezzo è la ragione, E la discrezione,

Che scherne buono et malo, $E$ lo terno, et l' iguale. 
cordis, für Herzbeutel, welcher von den Arabisten häufiger Camera, Capsa, Casula, Capsula, oder Arca cordis genannt wird. Mundinus schrieb dem menschlichen Uterus sieben Cellae zu, da er an einem trächtigen Schwein, die Hörner des Uterus in mehrere, durch Einschnürungen getrennte Zellen abgeschnürt fand. Diese wenigen Anwendungen von Cella, verloren sich bald. Es erübrigt jedoch noch ein Hinweis auf die Cella, als Gehirnkammer, in der Cella media autorum, worunter der mittlere Raum der seitlichen Gehirnkammer verstanden wird, aus welchem die drei Hörner dieser Kammer hervorgehen. Dagegen behauptet sich die Verkleinerungsform, als Cellula, in reichlicher Menge in der anatomischen Terminologie, von den Cellulae des Siebbeins, bis zu den Cellulae der Schwellkörper, worüber nichts weiter zu sagen.

Die Cella der Römer, von celare, verbergen (unser Keller), war eine Kammer im Wohnhause, in welcher allerhand Gegenstände für den Hausbedarf aufbewahrt wurden. Wir kennen aus den Classikern die Cella vinaria, pomaria, lignaria, olearia, farinaria, u. m. a. Die Stübchen, welche arme Leute bewohnten, hiessen, wie die Schlafkammern der Dienerschaft und Sclaven, Cellae. Die Bedeutung der Cella, als Inneres eines Tempels, als Taubenschlag und Gänsestall, als Badezimmer und Bienenstock, bildet curiose Gegensätze. Wenn man im Mittelalter den Mönchen den Titel Cellarï gab, geschah dieses weniger der Cella ihrer Kirche, als ihrer Weinkeller wegen, weshalb denn die ernste Sprache von ihnen lieber als Cellularii und Cellulani redet, der Kleinheit ihrer Wohnzellen wegen. - Die zwei Adjective, welche die Anatomen aus Cellula bildeten: cellularis und cellulosus, sind im classischen Latein gänzlich unbekannt.

Dirietro sta con gloria,

La valente memoria,

Che ricorda e ritiene,

Quello, che in essa viene, 


\section{Cephalica.}

Die Vena cephalica theilt mit der basilica ein gleiches Schicksal. Sieh' HL, §. XLII, pag. 96-98. Sie ist, trotz

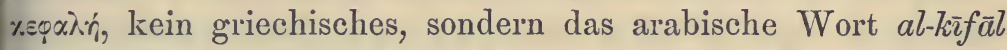
im Avicenna ${ }^{1}$ ). Der Uebersetzer des Canticum, Armegandus de Montepessulano, gab das kîfāl mit Cephalica, welches Wort sofort in der Anatomie heimisch blieb. Kein Grieche, kein Römer, liess je etwas von einer Vena cephalica hören.

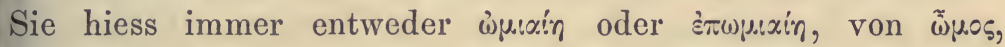

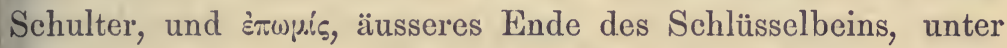
welchem sie aus der Tiefe auftaucht. Vesal behandelt sie deshalb als Vena humeraria. Den Namen Cephalica trägt sie mit vollem Recht, da es allgemein Sitte war, bei den arabischen und christlichen Aerzten, aus ihr bei Kopfleiden Blut zu lassen, quia abstrahit sanguinem a capite. Die Einbildung, dass die Venaesectio cephalicae dem Kopfleiden convenire, beruht eigentlich auf einem anatomischen Grund. Bei den Thieren, und ausnahmsweise beim Menschen, ergiesst sich die Cephatica in die Vena jugularis externa, oder, nach alter Ansicht, entsteht aus ihr. Die Eröffnung der Cephatica leitet also einen Theil des Blutes, welches, nach damaliger Meinung, in der Vena jugularis externa zum Kopfe aufsteigt, vom Kopfe ab, und muss bei allen Congestionen zum Kopf von Nutzen sein. Insbesondere wurde diese Aderlässe bei Augenentzündungen practicirt. Daher erklärt sich der alte Name Vena oculorum, im Savonarola und Bertapalia.

\section{Cerumen.}

Cerumen hat nie zur guten Latinität gehört. Es ist ein Barbarismus, welchen selbst die reichsten Lexicographen

1) Canticum, Pars IV, n. 4 und 5. 
ignoriren, und welcher nur im anatomischen Latein sich einwurzeln konnte. Das unappetitliche Ohrenschmalz, Cerumen (von Cera), welches weder Schmalz, noch Wachs ist, war den Römern nur als sordes aurium bekannt: minima bestiola auribus irrumpens, in sordibus aurium, tamquam in visco (Vogelleim) in-

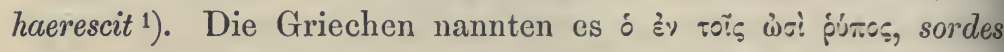

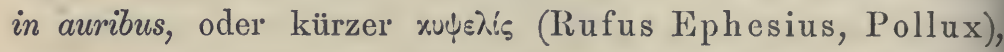

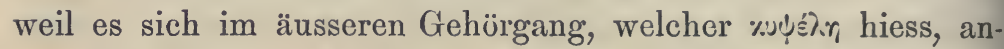
sammelt, und zwar als Excrement, durch welches das Gehirn von gallichten Unreinigkeiten gesäubert wird. Kuழ̣é̀in war eine generelle Bezeichnung für Gruben und Löcher. Aristoteles nannte deshalb die in Erdlöchern nistende Schwalbenart: xú ฺุ

Veranlassung zur Entstehung von Cerumen, gaben die Uebersetzer der Araber, welche das Ohrenschmalz mit Theer oder gelbem Wachs verglichen, und es deshalb Bitumen oder Cera nannten, woraus Bauhin ${ }^{2}$ ) und Isbrandus van Diemerbroek ${ }^{3}$ ) ihr Cerumina und Cerumen, d. i. contrahirt Cera aurium, Ohrenwachs, ersannen (la cire der Franzosen, ear-wax der Engländer). Der Uebersetzer des Rufus Ephesius setzt zu Cypselis die Bemerkung bei: quam et cerumina, et marmorata veteres Latini appellarunt. Marmorata, welches auch im Bauhin Aufnahme fand, macht uns keine Verlegenheit, da das Zeitwort marmorare, im besten Latein, das Tünchen einer Wohnstube mit einem marmorähnlichen Ueberzug bedeutet, und das Ohrenschmalz in ebenderselben Weise den äusseren Gehörgang übertüncht. Sordities und Spurcities aurium im Laurentius und Car. Stephanus, sind Uebersetzungen des griechischen p'jus. Die Amaritudo des Gerardus, entspricht dem arabischen marr des Avicenna, dessen Canon Gerardus übersetzte.

1) Cicero, De natura Deorum, Lib. II, Cap. 57.

2) Theatr. anat., Lib. III, Cap. 44.

3) Anatomia corp. hum., pag. 611 . 
Galen verwendete das Ohrenschmalz äusserlich als Heilittel gegen Panaritium und Skorpionsbiss ${ }^{1}$ ), innerlich gegen oliken, deren heftigste Anfälle dadurch beschwichtigt werden.

Ein ungewöhnliches Wort für Ohrenschmalz ist Pedora. Vir finden es im Keuchenius, in dessen Editio Sereni Samonici, Amstel., 1662, pag. 241. Da es im Balbus auch für en Schmutz gebraucht wird, welcher sich an unrein gehalnen Füssen anlegt, dürfte es ein verunstaltetes Paedor sein, n Cicero = Unflath, Unreinigkeit.

\section{Chiasma.}

Wenn die Griechen, beim Durchlesen eines Buches, aufllende oder unrichtig copirte Stellen, mit einem Randzeichen

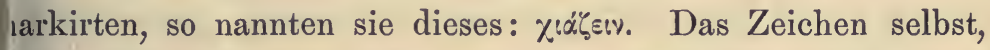
onnte nur ein schiefes Kreuz gewesen sein, wie auch wir es nzubringen pflegen, ähnlich dem Buchstaben X, und hiess: aop.a. Von einem anatomischen Chiasma, findet sich bei den riechischen Aerzten nichts vor. Man dringt es ganz unrichtig em Galen auf. Die betreffende Stelle über die Zusammenunft der Sehnerven, wurde eben nicht genau aufgefasst. Sie

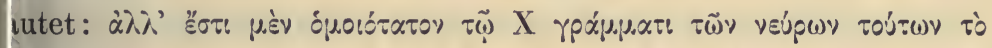
(ñip.x, sed horum nervorum figura literae $X$ simillima est ${ }^{2}$ ). Das Vort Chiasma erscheint unter diesen Worten gar nicht. ichiasma, welches Schreger ${ }^{3}$ ) dem Galen unterlegt, kommt a der griechischen Sprache nicht vor. Schiasma könnte nur on $\sigma_{i}^{\prime \zeta \zeta \omega}$, spalten, hergeleitet werden, und wäre dann = paltung, nicht aber = Vereinigung oder Durchkreuzung. ibensowenig kann Schema gleich Chiasma angesehen werden, rie aus obiger Stelle sich ergiebt.

1) De simplicium medicamentorum temperamentis, Lib. X, Num. 30.

$\left.{ }^{2}\right)$ De usu partium, Lib. X, Cap. 12.

3) Schreger, Synonymik, pag. 333. 
Galen fasste übrigens dasjenige, was wir Chiasma nennen, nicht als Kreuzung, sondern als eine Vereinigung der beiden Sehnerven auf ${ }^{1}$ ), welche stattfinden muss, um mit zwei Augen, einfach zu sehen, eine Meinung, welche bis in das 15. Jahrhundert anhielt: ut species (Bilder), binis oculis susceptae, una et simplex repraesententur ${ }^{2}$ ). Dass wir mit zwei Ohren einfach hören, ohne dass sich die Hörnerven miteinander verbinden, bedachte Galenus nicht.

Das Wort Chiasma, als Durchkreuzung der Sehnerven, taucht erst im Laurentius auf, und zwar als \%ajpós, mit der Erläuterung: quum nervi optici se ad crucis modum intersecent ${ }^{3}$. Vesal spricht vom Chiasma, als Coitus oder Congressus nervorum opticomum, und Berengarius als Incrutiatio, Durchkreuzung, welche er bei den Fischen deutlicher ausgesprochen findet, als beim Menschen. Alle übrigen Benennungen des Chiasma, beziehen sich entweder blos auf eine Verschmelzung der Sehnerven, oder auf eine wirkliche Durchkreuzung. So lesen wir im Bartholinus: Unio und Coalitus, im Vesling: Copula, Decussatio partialis im Vieussens, Confusio substantiae nervorum. opticorum im Haller, Decussatio im Sömmerring, Nexus im Blumenbach und Ackermann. Obwohl wir nur an eines theilweisen Durchkreuzung der beiden Sehnerven festhalten gebrauchen wir dennoch das Wort Chiasma fort und fort welches eine vollständige Decussation ausdrückt. Die Fäll von Mangel des Chiasma, wo jeder Sehnerv, ohne mit den der anderen Seite zusammenzukommen, zu dem Auge seine Seite ging, sind schon von Vesalius und Valverda beob achtet worden ${ }^{4}$ ).

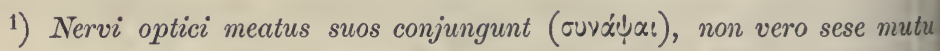
conscendunt (غे $\left.\pi \alpha \lambda_{\lambda} \lambda \dot{\alpha} \tau \tau \varepsilon \sigma \theta \alpha i\right)$, loco supra citato.

2) Alessandro Benedetti, Anatomice, Lib. IV, Cap. 14.

3) Hist. anat. corp. hum., Lib. XI, Cap. 8.

4) Mehr hierüber in Henle's Handbuch der Anatomie, III. Bd pag. 348 . 


\section{Choana, alt und neu.}

Was wir Choanae nennen, und was die Griechen \%od́m aannten, lässt sich nicht unter einen Hut bringen. Unsere

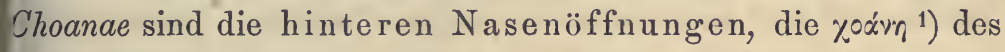
Galen ist der Gehirntrichter. Bleiben wir bei letzterem ;tehen. Xóxyog ist im Homer, eine Schmelzgrube, im Hesiod in Schmelztiegel, im Polyeuctes und in der Anthologia graeca, eine Form, in welche das geschmolzene Metall gegossen wird (forma fusoria). Die trichterförmige Gestalt der Schmelztiegel, bewirkte die Uebertragung von $y_{0}$ x́m auf einen gewöhnlichen Trichter, und auf den Hirntrichter, insofern, nach ältester Vorstellung, die Excrementa cerebri, sich in denselben ergiessen. Diese Excrementa waren zweierlei Art. Hören wir hierüber den Oribasius²), welcher bündiger schreibt als Galen: horum excrementorum alia sunt vaporosa et fumosa, 'alia vero aquosa et limosa (schlammig.). Die dampf- und rauchartigen streben, ihrer Natur zufolge, nach aufwärts, und entweichen durch die Nähte des Schädeldaches (ṕạ:i), - die wässerigen und schlammigen, ergiessen sich aus der mittleren Gehirnkammer, wo sie sich ansammeln, in den Trichter ( $0_{0} \alpha \mathrm{m}$ ) s. $\pi \dot{s} \leq \lambda \circ \varsigma$, verwandt mit pelvis), um theils durch die Siebplatte des Siebbeins in die Nasenhöhle abzuströmen, theils durch die Glandula pituitaria cerebri (unsere Hypophysis, sieh' dieses Wort) zum Gaumen (sis riry insep(í) zu gu gelangen. Die Wege, welche die dicken Hirnexcremente zum Gaumen leiten könnten, existiren zwar, wie wir wissen, nicht; aber sie wurden statuirt, und man hielt so fest an ihnen, dass selbst Vesal, der

1) Xox'v ist ein Hippocratisches Wort. Er nannte die Speise-

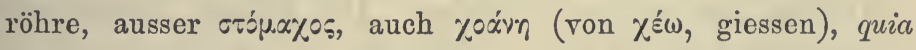
per eam, tamquam per infundibulum, cibus et potus in ventriculum infunditur. De corde, Lib. I, Cap. 12.

2) Op. cit., pag. 15. 
ehrliche, wahrheitsliebende Mann, sie abbildete. Dieses die kurzgefasste Geschichte der alten Choana.

Den Plural Choanae verdankt die Anatomie erst der neuesten Zeit. Im Haller begegnen wir den Choanae, als hintere Nasenöffnungen, obwohl diese keine trichterförmige Gestalt haben. Aber durch sie ergiesst sich der Nasenschleim in die Rachenhöhle, und sie können insofern immerhin als Choanae passiren, wenn man an den Stamm des Wortes denkt: $\chi^{\varepsilon} \omega$, giessen. Die sonstige Benennung der Choanae, als Aperturae narium posticae, ist zu langathmig, um den kurzen Choanae den Rang abzugewinnen.

Vergleiche Calyx, Pelvis und HL, §. LVII, Embotus.

\section{Choledochus und Cholecystis.}

Ductus choledochus heisst der durch die Vereinigung des Ductus cysticus und hepaticus gebildete, gemeinschaftliche Gallengang. Ueber choledochus habe ich vorerst zu sagen, dass es kein Adjectiv, sondern ein Substantiv ist, und deshalb, selbst wenn es bei einem Hauptwort weiblichen Geschlechtes steht,

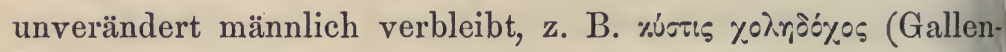
blase) im Oribasius und Galen, mit dem Genitiv $\left.\tau \tilde{r}_{\varsigma} \varsigma \chi_{\circ}\right\rangle_{r_{-}}$

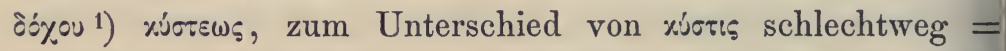
Harnblase, wie auch Cicero die Harnblase simpliciter als Vesica erscheinen lässt. Da choledochus aus \%oiฑ, Galle, und ¿ेÉ\%or.a!, aufnehmen, zusammengesetzt erscheint, passt es au

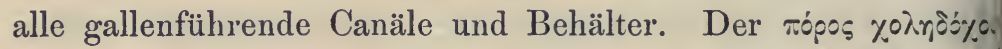
des Galen ist = unserem Ductus choledochus + Ductus cysticus

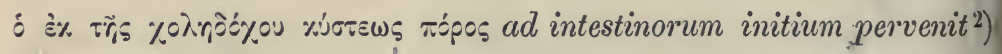
Von einem Ductus hepaticus und Ductus cysticus, ist bei der Griechen gar nichts zu finden. Die Namen Ductus s. Meatui

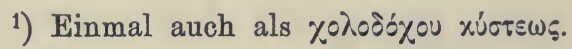

2) Oribasius, Anatomica ex Galeno, pag. 116. 
ppaticus und cysticus, so wie die Restriction des Ductus choleochus auf den gemeinschaftlichen Gallengang, datirt erst seit esal und Bauhin. - Im Rufus finden wir die Gallenblase

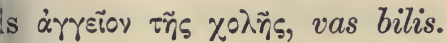

Gegen die neuerfundene Cholecystis, protestirt der Genius er griechischen Sprache. Die Gallenblase kann nur Vesica der Vesicula bilis nach Vesal, oder Cystis bilis nach Heister enannt werden. Cholecystis ist ein eben solches Unding neuer vention, wie Dacryocystis und Urocystis ${ }^{1}$ ). Da wäre der Folliılus felleus des Glisson, oder das Vasculum bilis der Araber, Is Behälter der Galle, noch vorzuziehen. Fragt doch einen riechischen Sprachlehrer, bevor ihr solche Missgeburten eures ngebildeten Griechischen in die Welt sendet.

\section{Chorda.}

Die anatomischen Anwendungen von Chorda, lassen sich lle auf die primitive Bedeutung der griechischen \%opòr zurückihren. Xopòn hiess anfänglich nur der Darm (ai yopòai, instina, bei den Dichtern), in welchem Sinne es auch im Latein es Petronius Arbiter gefunden wird ${ }^{2}$ ). Die. Medicin betzt noch ein Wort, in welches die Chorda, als Darm, schon or Alters eingegangen ist: Chordapsus, die Darmverschlinung = Ileus und Volvulus, nach der Erklärung des Galen: umor intestini tenuis, ad chordae similitudinem contorti $\left.{ }^{3}\right)$. Der ame Chordapsus, enthält nach Aretaeus: \%opò, Darm, und (w) brennen, kochen, um den heftigen Schmerz auszudrücken,

1) Im Vesal erscheint die Harnblase als Receptaculum urinae, als Vesica urinaria erst im Bauhin.

2) Satyricon, $L X V I, 7$.

3) De locis affectis, Lib. VI. Im Celsus, Lib. IV, Cap. 13, steht: Diocles Carystius, tenuioris intestini morbum \%ópò \џ̣, plenioris

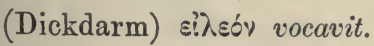




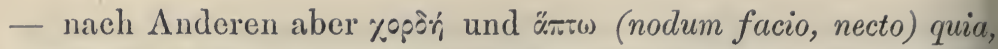
wie es im Gorraeus heisst, qui manum loco dolenti admovent, videntur sibi tangere chordam (Strang).

Nicht blos der Darm, auch die aus dem Darm bereitete Wurst, hiess yopòr ${ }^{1}$ ) und \%ópòsup.x ${ }^{2}$ ), bei den Römern: Chorda, wie in den Deipnosophistae des A th en a e us ${ }^{3}$ ), und im Petronius: habuimus caseum, et cochleas, et chordae frusta. - Von der Wurst ging es zu den, aus dem Darm bereiteten Saiten, Bogensehnen, Schnüren und Stricken über, mit welchen die Verbrecher auf das Kreuz gezogen, oder an dasselbe gebunden wurden: jam tibi chorda tenditur, in crucem recta (Plautus).

Als Saite ${ }^{4}$ ) wurde die Chorda in der Anatomie, nur durch die Chorda tympani und durch die Chordae vocales verwerthet. Die Chorda tympani stammt von Fallopia her, und zählt zu seinen schönsten Entdeckungen, obgleich es ihm nicht recht einleuchten wollte, dass er es mit einem Nerven zu thun habe ${ }^{5}$ ), was durch Eustachius sichergestellt wurde ${ }^{6}$ ). Die Chordae vocales Ferreinii ${ }^{7}$ ) (auch Chordae ligamentosae Winslovii), sind keine rundlichen Saiten, sondern breite membranöse Zungen, deren freier Rand die Stimmritze (glottis) begrenzt. Sie passiren deshalb nicht mehr, unter diesem alten und

1) Aristophanes, Acharnenses, Vers 1084.

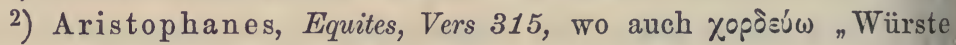
machen", vorkommt, Vers 214.

3) III, 14 und $I X, 1$.

4) Vocales impellere pollice chordas, die Saiten schlagen, im Tibullus, und reddidit icta suos, pollice chorda sonos, im Ovid.

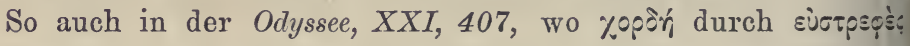

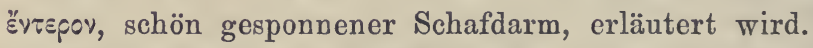

5) Chorda tenuissima, per medium tympanum percurrens, quam qui dam nervulum esse opinati sunt, ego quid sit ignoro (Observatione: anat., in Vesalii Opera omnia, T. II, pay. 699).

$\left.{ }^{6}\right)$ Caldani, de chordae tympani officio, in dessen Comment. anat Fasc. I, Num. 1.

7) Mém. de l’Acad. des sciences, 1741, pag. 409. 
igesehickten Namen, sondern als Ligamenta glottidis s. vocalia, thyreo-arytaenoidea ${ }^{1}$ ). Ueber die Ungereimtheit der letzteren onennung, sieh' Artikel ideus.

Chorda, als Bogensehne oder Strang, wird von den rabisten häufig statt Tendo angewendet. Wir kennen noch e Chorda magna Hippocratis = Achillessehne im Avicenna, elche auch, da die Sehne bei den Griechen veũpor hiess, als rvus latus erwähnt wird. Chorda, als Ligament bei den rabisten, hat nur in der Chorda transversalis cubiti, sein Annken hinterlassen.

Die Chorda spermatica im Schreger, passt nicht auf den eichen und laxen Samenstrang, ebensowenig, als die doppelte horda longitudinalis Lancisii der oberen Fläche des Hirnlkens, mit einer Saite verglichen werden kann, da sie nicht s freie Schnur, sondern nur als ein schwach aufgeworfener ium, uns zu Gesicht tritt. Crista und Stria würden sich 3sser schicken.

Die äusseren männlichen Genitalien, Chordae zu nennen, ein ganz willkürliches Belieben des Paracelsus ${ }^{2}$ ). Er hat ibei wahrscheinlich an die Spannung des Gliedes bei der rection gedacht. Die Neueren holten sich daher ihre Chorda nerea, als andauernde, entzündliche, und sehr schmerzhafte rection, mit oder ohne Krümmung des Penis.

\section{Chorion.}

Xóptov, nicht \%wécov, heisst im Galen, die äussere Haut

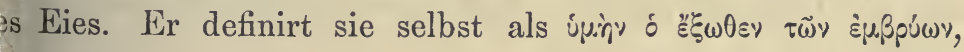

1) Alle diese Namen entstanden erst im vorigen Jahrhundert. Haller kannte die Bänder der Stimmritze, nur als Ligamenta laryngis, worunter aber auch alle anderen Bänder der Kehlkopfsknorpel verstanden werden können.

2) De origine et cura morbi Gallici, Lib. VII, Cap. 11, und Lib. VIII, Cap. 3. 


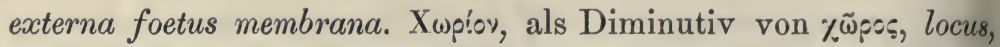
wäre ein „kleiner Ort", und als solcher unanwendbar auf eine Eihaut. Dagegen ist \%óplov eine "Haut" in genere, wie

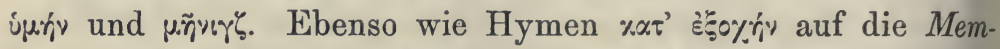
brana virginitatis, und Meninx auf die Membranae cerebri angewendet wurde, so auch \%ópıov auf die äussere Eihaut, deren grosser Umfang und Gefässreichthum bei den Wiederkäuern und Einhufern, nicht umhin konnte, die besondere Aufmerksamkeit der Laien und Anatomen, bei dem Gebären der Hausthiere, auf sich zu ziehen. Diejenigen, welche für \%wpiov Partei nehmen, stützen sich nicht auf $\chi \tilde{\omega} p o s$, locus, sondern, sehr gesucht, auf $\chi \omega \rho \xi \xi(\omega)$ secedo, weil die Häute der Frucht, erst nach der eigentlichen Geburt des Embryo, abgehen. Der Gefässreichthum des Chorion bei den genannten Thieren, war auch die Veranlassung, dass andere gefässreiche Häute odes Geflechte von Gefässen, Membranae choroideae und Plexu: choroidei genannt wurden, wie die Choroidea des Auges, di

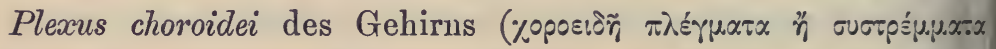
Galen). Selbst die Pia mater führt im Galen, ausnahmsweist diesen Namen ${ }^{1}$ ), welchen, nach dem Zeugniss des Rufus, schol Herophilus für die Gefässhaut des Gehirns gebrauchte. D: aber Paulus Aegineta (Epitome, Lib. VI, Cap. 75) die Ei

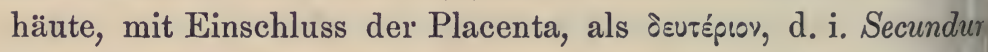
(quia partu quasi secundo eduntur), benannte, ergab es sicl dass auch das Chorion des Galen als Secundina übersetz wurde, und die Pia mater mit der Choroidea oculi, bei de Arabisten denselben Namen Secundina erhielten, welcher sic also nicht darauf bezieht, dass diese Häute, die zweiten a1 Gehirn und im Auge sind.

Vergleiche die Artikel Placenta, Secundina und Choroiden

1) De usu partium, Lib. VIII, Cap. 9. 


\section{Choroidea oder Chorioidea?}

Die Neueren, besonders die Augenärzte, schreiben Choioidea; die Alten aber alle: Choroidea. Wer hat Recht? Eine Haut heisst griechisch \%ópเov. Der Name wurde von Aristoeles 1) auf die äussere Unhü̈llungshaut des Embryo überragen (Chorion). Diese ist sehr gefässreich. Die zweite Haut les Augapfels, welche ihres Gefässreichthums wegen von Haller, Vasculosa oculi ${ }^{2}$, und von Georgius Valla und Jasserius: Sanguinolenta oculi ${ }^{3}$ ) genannt wurde, kann, in Hinsicht auf ihre Copia vasorum, mit dem Chorion verglichen verden, und es wäre demnach Chorioidea (die chorionähnliche faut), grammatikalisch vollständig correct. Allein unsere anaomischen Ahnen: Galen, Oribasius und Rufus, schrieben ie anders, als \%oposıò่ a aben, besser als wir, dass \%opós Tanz bedeutet. Mir kommt as sehr wahrscheinlich vor, dass nicht die drei genannten Coryphäen, sondern ihre Abschreiber, des Fehlers schuldig ind, welcher sich bei allen nachfolgenden Copisten wiederrolen musste, und endlich zu einer ständigen Form wurde. Schreiben wir also Choroidea mit ihnen, und ist diese Choroidea schlecht, tragen sie die Schuld, nicht wir. Zur Verantwortung zönnen sie nicht mehr gezogen werden. Medium tenuere beati, and schreibe, wie du willst.

Die Uebersetzer der Araber, behandeln die Choroidea als Secundina oculi. Dieses schreibt sich daher, dass man die Choroidea für eine Fortsetzung der Pia mater cerebri hielt, welche, ihres Gefässreichthums wegen, auch mit dem Chorion les Embryo verglichen wurde. Das Chorion des Embryo gehört aber zur Nachgeburt, Secundinae. Secundina oculi und Secundina

1) Historia anim., Lib. VI, Cap. 3.

2) Elementa physiol., T. V, pag. 363.

3) Jul. Casserius, Pentaestheseion, Lib. V, Cap. 25.

H y rtl. Unomatologia anatomica. 
cerebri, drücken also nicht aus, dass die Choroidea und die Pia mater, die zweiten Häute des Auges und des Gehirns sind, sondern dass sie der Secundina des Eies, an Gefässreichthum gleichstehen. Sieh' HL, §. XXX und LVI.

Die veralteten Namen Tunica acinalis und uvaeformis, sind

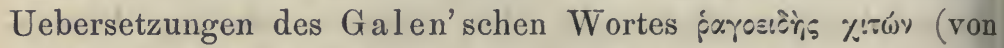
ṕx́, Weinbeere), mit deren Balg, die Choroidea und Iris zusammen verglichen wurden. Die Pupille stellte die Oeffnung dar, wo der Stengel der Beere ausgerissen wurde.

\section{Chymificatio und Chylificatio.}

Würde man bei dem alten Sinn des Wortes Clymus geblieben sein, so gäbe es keine Chymificatio. Abgesehen davon, dass die Verbindung eines Wortes mit ficatio (von facere, machen), nur dann erlaubt ist, wenn dieses Wort ein lateinisches ist, wie in Amplificatio, Magnificatio, Aedificatio, ete., ist Chymificatio, als Magenverdauung, gänzlich irrig, da Chymus nicht Magen brei, sondern überhaupt ein Saft, eine Flüssigkeit ${ }^{1}$ ) ist, und im Aristoteles auch Geschmack ${ }^{2}$ ). Das griechische Zeitwort für würzen und schmackhaft machen, lautet: \%ưį̧, und für Geschmack erregen: \%ứćc. Selbst das Blut wurde als \%upós behandelt, weil es ein Saft ist, woraus sich Ecchymosis erklärt, als Blutunterlaufung. Den späten Serenus Sammonicus müssen wir noch erwähnen, welcher zuers den Chymus mit dem Magen in Verbindung ibringt. Er schriel ein medicinisches Carmen heroicum, in welchem (XLVIII, 900

1) Quod liquidum est, Praxagoras Chymum appellat, heisst e: im Rufus Ephesius, Edit. Clinch, pag. 44. Auf derselber Seite wiederholen sich diese Worte, jedoch mit Chylus anstat Chymus. Oribasius ignorirt Chymus vollständig.

$\left.{ }^{2}\right)$ Historia anim., Lib. III, Cap. 2. Ihm folgte Galen, Oper. omnia, T. XI, pag. 449. 
Thymus als Magensaft vorkommt, welcher, wenn er schlecht eschaffen ist, ausgetrocknet werden muss:

\section{"Praeterea chymum stomachi desiccat iniquum".}

Die älteren Aerzte verstanden unter Chymus, theils den on seinen nicht ganz verdauten Bestandtheilen gereinigten hylus ${ }^{1}$ ), theils aber auch das Residuum der Darmverdauung - die Faeces ${ }^{2}$.

Von Chymus als Magenbrei, weiss nur die neuere Zeit 1 reden. Sie gab dem Chymus eine Bedeutung, welche ihm ach keinem einzigen alten Zeugniss zukommt. Im vollen Staat scheint Chymificatio zuerst im Jahre $1753^{3}$ ). Haller bedient ch desselben niemals. Bei den Aerzten hat es freundlichere ufnahme gefunden, als bei den Anatomen. Chymificatio muss ach Allem, für ein widersinniges Wort erklärt werden. Will an den Chymus, als. Magenbrei, gegen alle etymologische inrede, absolut durchsetzen, und ein Hauptwort bilden, welches le Magenverdauung ausdrückt, könnte dieses nur Chymōsis sein.

Von Chylus gilt dasselbe wie von Chymus. Xuiós ist Saft ad Feuchtigkeit (humor) im Allgemeinen. Ein aus Säften ereitetes, zertheilendes und erweichendes Pflaster, hat daher inen Namen: Diachylon. Im Galen wird der Chylus näher ezeichnet, als: humor incrassatus, tum in animantibus, tum in (antis ${ }^{4}$ ). Ebendort werden Schleim und Blut, als Unterarten es Chylus genannt. Im Rufus Ephesius ist Chylus mit hymus identisch, - beide als Saft. Im Oribasius steht thylus als das Product der Magenverdauung: io $x \varepsilon \%$ ז $\tilde{n}_{0}: \lambda\left(\alpha^{5}\right)$. Der milchige Saft, welcher, nach den Ansichten

1) Castelli, Lex. medicum, pag. 175, und Antonides van der Linden, Selecta medica, Ex. XIII, §. 282.

2) Ruland et Johnson, Lex. chemicum.

$\left.{ }^{3}\right)$ Cartheuser, de laesa chymificatione, Francof. ad Viadr. 4.

4) De simplicibus medicamentis, Lit. 1, Cap. 38.

5) Anatomica ex libris Galeni, pag. 100. 
der Alten, durch die Gekrösvenen aus dem Darme aufgesogen, und der Leber zur Blutbereitung zugeführt wird, heisst erst in neuerer Zeit Chylus. So schreibt Joh. Walaeus '): Chylum centies vidimus ex intestinis per venas lacteas ad principium mesenterii, inde ad hepar deferri. Die Lexica behandeln Chylus nie als ein lateinisches Wort, schweigen deshalb auch von Chylificatio, worin wir ihnen folgen wollen. Die Definitiones medicae von Gorraeus, das beste Werk über die Erklärung der griechischen Worte in der Medicin, erwähnen den Chylus, als abgedampften Pflanzensaft, besonders jenen, welcher durch Abkochung des Hordeum gewonnen wird (Ptisana), aber auch als Saft, welcher im Magen aus den Nahrungsmitteln extrahirt wird. Als die Chylusgefässe durch C. Aselli entdeckt wurden, nannte er sie Lactea und Venae lacteae, ihres milchigen Inhaltes wegen. Unsere Milchgefässe sind eine Uebersetzung davon.

Der Erste, welcher sich das Wort Chylificatio erdachte war G. Moebius ${ }^{2}$ ). Auch er verstand darunter die Magennicht die Darmverdauung. "Sie wurde sonst nur als Concoctu prima $^{3}$ ) von den Aerzten erwähnt. Als Darmverdauung kan die Chylification erst in diesem Jahrhundert in Schwung, un wird in der anatomischen und medicinischen Sprache, [trot: ihrer Barbarei, nicht leicht ausgemerzt werden können.

Chylosis wäre noch immer das Beste.

\section{Cilia,}

Cilium wurde von den Anatomen seinem altangestammte Sinn gänzlich entrückt. Die Bedeutung, welche es sich in $d \epsilon$

1) Epistola ad Th. Bartholinum, de motu sanguinis.

2) Dissertatio de chylificatione, Jence, 1644.

3) M. Hoffmann, de concoctione prima, Altdorf, 1662, wo w auch Chylosis vorfinden. 
odernen anatomischen Sprache angemasst hat, als Wimpera ar, kam ihm im alten guten Latein, niemals zu. Dort finden ir Cilium immer und immer als Augenlid 1). Um uns Glauben I verschaffen, berufen wir uns auf die achtbarsten Autoriten. Im Sextus Pompejus Festus ${ }^{2}$ ) heisst es ausdrücklich: 'ium est folliculus ${ }^{3}$ ), quo oculus tegitur, unde fit supercilium, id im Lactantius ${ }^{4}$ ): ut oculi munitiores essent ab injuriis, liorum tegminibus natura eos occuluit. Kurz und deutlich sagt idorus: Cilia sunt tegmina oculorum5). Wie Palpebra von

1) Die Anatomie besitzt nur noch Ein Wort, in welchem diese primitive Bedeutung von Cilium, als Augenlid, sich erhalten hat: Supercilium, was über den Augenlidern ist: die Augenbraue.

2) De verborum significatione, Lib. III.

3) Follis und Folliculus, seltener Folliculum, heisst jedes aus Leder oder Haut bereitete sackförmige Behältniss, wie Beutel, Geldbörse, Schlauch, Luftkissen, Ballon und Blasebalg; agitare follem, den Blasebalg treten. Als sackförmiges Behältniss und als Beutel, fand Folliculus schon in der ältesten Anatomie seine Unterkunft, wie im Caelius A urelianus, der Hodensack als Folliculum genitale, Magen und Gedärme, als ventris et intestinorum folliculi, und die Harnblase als folliculus schlechtweg gefunden werden. Im Juvenal erscheinen die Lungen als Folles (Blasebälge):

"Tunc immensa cavi spirant mendacia folles".

Die Benennung der einfachen schlauchförmigen Drüsen als Folliculi, ist ganz correct. Da aber jeder Sack oder Schlauch offen ist, und offen sein muss, um etwas aufnehmen zu können, ist der $a b$ origine geschlossene, niemals offen gewesene Folliculus clausus, welcher das was er enthält, nicht von aussen erhielt, sondern in sich erzeugte, ein nur in der Anatomie geduldeter Unsinn.

4) De opificio Dei, Cap. 10.

5) Origines, Lib. II, Cap. 1 . 
palpitare, so entstand auch Cilium aus cilleo, einem obsoleten Zeitwort $=$ bewegen, welches auch in oscillare "sich schaukeln" und in oscillum (nicht osculum), Schaukel und Hängematte, noch erkannt wird. Im Van der Linden und P. Bruno finden wir das Substantiv cillo, als Benennung des Zitterkrampfes des oberen Augenlides: cillo vocatur is, cui palpebra superior tremit perpetua agitatione. A celandis oculis, wie Berengarius meint, haben die Cilien sicher ihren Namen nicht erhalten 1), weil sie dann Celia heissen müssten.

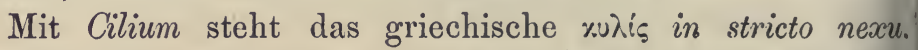

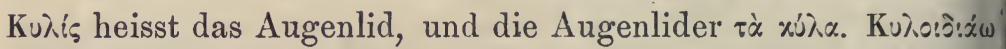
wird bei den besten Autoren angetroffen, für das Anschwellen der Lider nach Excessen. Mehr braucht man hoffentlich nicht, um sich überzeugt zu halten, dass Cilium, Augenlid ist, und nichts anderes. Wie fügte es sich nun, dass Cilium zur Wimper wurde. Daran ist ein locus dubius im Plinius Schuld. Er lautet: antiqui extremum ambitum genae superioris cilium vocavere ${ }^{2}$ ). Wir können ihn nur verstehen, wenn wir gena superior für oberes Augenlid nehmen. Der Rand (extremus ambitus) dieses Lides, zeigt sich mit steifen kurzen Haaren besetzt, wie es auch am unteren Lide der Fall ist. Auf diese Haare, welche vallum pilorum (Benedictus), oder pili oculorum (Bauhinus) hiessen, wurde erst in später Zeit, das Wort Cilium übertragen. Doch blieb es nicht bei dieser Ueber tragung allein. Der einmal begangene Fehler, gebar eine ganzt Generation von jungen kleinen Fehlern, da man das der Römern unbekannte Beiwort ciliaris schuf, und damit nich blos jenes Gebilde im Auge belegte, dessen 'gestrahltes Ansehen, an das Aneinandergereihtsein der Wimperhaare erinnert wie das Corpus ciliare, sondern auch jeden einzelnen Bestand theil dieses Körpers, als Processus oder Plica ciliaris benennes zu müssen glaubte. Sofort musste auch Alles, was nur irgendwi

1) Isagogae breves, in capite de palpebris.

2) Historia nat., Lib. XI, Cap. 37, Num. 157. 
um Corpus ciliare in Beziehung steht, wie das lange für 1ervös gehaltene Ligamentum ciliare s. Orbiculus ciliaris (der etzige Musculus ciliaris s. Tensor choroideae), die Impressiones iliares in der Zonula ciliaris, die Arterien, Venen und Nerven, :elbst das Ganglion, aus welchem die letzteren entspringen, las Beiwort ciliaris annehmen, wodurch unsere Sprache einen janz erklecklichen Zuwachs von Unrichtigkeiten und Unsinnigzeiten erhielt, an welchem wir uns wahrlich nicht erbauen zönnen. Den alten Namen des Ciliarkörpers, als Corona, in eine Rechte wieder einzusetzen, wie es theilweise geschah Corona ciliaris, Strahlenkranz), erscheint mir deshalb nicht äthlich, weil auch die Iris, und der ringförmige Uebergang der sclerotica in die Cornea, bei älteren Autoren als Corona figurirt.

Dass auch die feinsten Fortsätze gewisser Epithelialsellen, welche im lebenden Zustande flimmern, Cilien gea annt wurden, ging von Jenen aus, welche nicht wussten, dass Cilien nicht die Haare der Lider, sondern die Lider selbst sind. Die deutschen Benennungen Flimmerhare und Flimmerbewegung (Motus vibratorius), sind deshalb gut, weil n ihnen nichts von Cilien enthalten ist.

\section{Cisterna,}

Einen häutigen Sack, Cisterne zu nennen, hat sich noch kein Dichter erlaubt. Die Anatomen haben ein eigenes Recht, unnatürliche Vergleiche anzustellen. Sie machen davon den unbeschränktesten Gebrauch. So nannte L. Heister, ganz unnöthiger Weise, das etwas erweiterte Anfangsstück des Ductus thoracicus in der Gegend des dritten Lendenwirbels: Cisterna lumbalis, obwohl es bereits eine Menge von Namen führte, unter welchen das Receptaculum chyli des Bartholinus, am meisten angewendet wurde. Der Entdecker dieses Behältnisses, Jean Pecquet, nannte es ganz einfach Vesica und Saccus chyli, und Haller: Ampulla chylifera. 
Eine römische Cisterna war ein künstliches, in der Erde ausgegrabenes, und mit einem flachen Dache versehenes Reservoir, in welchem das aus den Dachtraufen des Wohnhauses (Stillicidia), gesammelte Regenwasser, für den Bedarf des Haushaltes aufbewahrt wurde. Die Cisterna hatte keinen Zulauf von Quellen oder Bächen her, und eignet sich deshalb nicht zur Benennung des Receptaculum chyli, welches durch den Truncus mesentericus und die beiden Trunci lumbales gespeist wird.

\section{Clavicula,}

Ueber die Etymologie von Clavicula, liesse sich ein kleines Buch schreiben. Zwar kein Buch, aber eine kurze Abhandlung hierüber, welche das Wichtigste über das Schlüsselbein der Griechen, Römer und Araber enthält, habe ich bereits veröffentlicht ${ }^{1}$ ). Ich kann mich deshalb hier kurz fassen, und zu dem bereits Gesagten einige Zusätze geben.

Unsere beste Autorität für sprachrichtige anatomische Knochennamen, Cornelius Celsus, kennt das Schlüsselbein nur als Jugulum: Jugulum, si transversum fractum est, nonnunquam per se recte coit, et sanari potest, sine vinctura ${ }^{2}$ ). Da Jugulum auch Kehle ist, setzte man Ossa juguli und Ossa jugularia, um deutlicher zu sein. - Clavicula findet sich zuerst im Canon Avicennae ${ }^{3}$ ), als Uebersetzung des arabischen Alchicab in den Noten des Andreas Alpagus (im arabischen Text: Tarquwah), und wechselt an anderen Stellen mit Furcula ab. Vesal und seine Schule adoptirten die Clavicula, und gebrauchen nebenbei auch Clavis ( $* \lambda \eta_{i}$ im Homer). Clavis hat, ausser Schlïssel, noch einige Nebenbedeutungen. Die wichtigste für uns ist der Clavis trochi, ein schwach S-förmig gekrümmter

1) HL, §. LX, pag. 121-126.

2) De medicina, Lib. VIII, Cap. 8.

3) Lib. I, Fen 1, Doctr. 5, Summa 1, Cap. 16. 
tab, mittelst welchem ein metallener, mit Schellen und Glöckhen behangener Reif, in Lauf gesetzt wurde. Diese Clavis, relche wir aus der Abbildung in Anthony Rich's Römischen 17terthiimern, pag. 161, kennen, sieht dem Schlüsselbein auf ein Iaar ähnlich. Wenn Spigelius versichert, dass noch zu seiner 'eit, in Padua S-förmige Schlüssel, claviculae, in alten Häusern n Gebrauch waren '), kann er nur von den S-förmig gebogenen 'hürklinken, nicht von Schlüsseln, gesprochen haben. Ein ;-förmiger Schlüssel ist eine baare Unmöglichkeit, weil er ich im geraden Schlüsselloch nicht d́rehen lässt, wohl aber :ann eine Thürklinke (Drücker), diese Form haben, wie wir ie jetzt noch häufig begegnen. Weil durch das Niederlrücken der Klinke, eine blos zugemachte Thür geöffnet wird, vie eine verschlossene durch den Schlüssel, wäre es wohl nöglich, dass die erst im Mittelalter aufgekommenen Klinken ${ }^{2}$ ), lenselben Namen wie die Schlüssel erhielten, welcher sofort uf die ähnlich geschweiften Schlüsselbeine, von dem Ueberetzer des Avicenna, Gerardus $\mathrm{Cr}$ emonensis, übertragen vurde. Die Sache erscheint um so glaubwürdiger, als ein im rïhen Mittelalter erfundenes Saiteninstrument, welches durch Niederdrüicken von Tasten gespielt wird, clavicordium oder lavicimbalum (italienisch clavicembalo, spanisch clavecimbano, ranzösisch clavecin) genannt wurde, und das altfranzösische lavier (unser Clavier) eine "Reihe von Drückern oder Tasten" bedeutet.

So viel steht fest, dass das Schlüsselbein, seinen Namen aicht von den Thürschlüsseln der Römer erbte. Wir kennen diese Schlüssel, von den grössten Schlüsseln der Stadthore, ois zu den kleinsten Schlüsseln der Schmuckkästchen römischer

1) De corp. hum. fabrica, Lib. II, Cap. 15.

2) Die Häuser in Pompeji haben keine Klinken, sondern drehbare Ringe oder Halbringe, Ansae ostii, welche auch als Klopfer dienten, wie die Knockers an den englischen Hausthüren. 
Damen, aus den in Pompeji aufgefundenen Exemplaren. Sie sehen alle wie unsere Schlüssel aus, haben einen Bart und einen Griff (Ring), und sind sämmtlich schnurgerade. Von Clavis, im Tibull und Livius als Riegel, hat das Schlüsselbein nichts als die Querlage. Es könnte jedoch immer Clavicula auf Clavis, als Riegel, bezogen werden, da das Schlüsselbein die Brust nach oben, wie ein Riegel, abschliesst. Die griechische $\% \lambda r_{i} \leqslant$ finden wir in der Odyssee, an mehreren Stellen, ebenfalls als Riegel, und in der Ilias als Schlüsselbein.

Die Celsischen Ossa juguli bedürfen keiner spitzfindigen etymologischen Erklärung, und sind schon deshalb den Claviculis vorzuziehen, wie auch die Kehlbeine und Drosselbeine im deutschen Bartholin, und im "Spiegel der Anatomy" keiner Auslegung bedürfen.

Dass in den alten Thesauris anatomiae historicis, Clavicula auch als $\mathrm{Knöchel} \mathrm{vorkommt,} \mathrm{erklärt} \mathrm{sich} \mathrm{aus} \mathrm{der} \mathrm{Anwendung,}$ welche Vitruvius von Clavicula macht. Er gebraucht dieses Wort für Zapfen '). Die Latino-Barbari, wie Gab. Zerbis, schreiben Cavicula.

Den Hintergedanken, welchen die Franzosen gehabt haben mochten, als sie das Schlüsselbein l'os pouilleux - den lausigen Knochen - nannten ${ }^{2}$ ), vermag ich nicht zu errathen.

\section{Clitoris.}

Clitoris, Kitzler, ist die griechische $x \lambda$ strop!s des.Rufus und Pollux: in medio pudendo muliebri, musculosa caruncula, nympha, myrton, ab aliquibus hypodermis, ab aliis clitoris nomi-

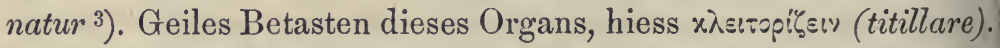

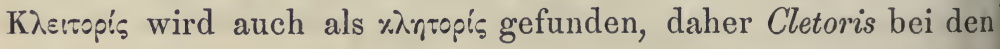

1) De architect. Lib. X, Cap. 11, n. 8.

2) Dictionnaire de médecine, 13. édit., Article: Clavicule.

3) Rufus, de partibus hominis, pag. 32 . 
Mundinisten. Der ältere lateinische Name Tentigo, von tendere, Arückt die Erectionsfähigkeit des Organs aus, so wie Colunella, (das \%i(w) des Hippokrates) seine Gestalt, welche wir m Zäpflein und Schamzünglein der Hebammen wiederzehren finden. Die Dulcedo amoris, der Oestrus Veneris, und las Irritamentum libidinis - den Arabisten geläufige Namen beziehen sich auf die geschlechtliche Bedeutung der Clitoris, wie Virga, Penis, Mentula, Cauda und Coles muliebris, die structurale Uebereinstimmung zwischen dem männlichen und weiblichen Glied ausdrücken. Speciell ist die, bei den Arabisten häufig genannte Cauda muliebris, eine Uebersetzung des arabischen Albathar im Avicenna.

Ueber Nympha, als Clitoris, vergleiche den Artikel Nymphae.

\section{Coccyx,}

Der Kuckuck (richtig Kukuk, weil von cuculus), war der Juno heilig, und hatte die Erlaubniss, auf ihrem Scepter zu sitzen. Er hat sich aber auch in der Anatônie eingenistet, als

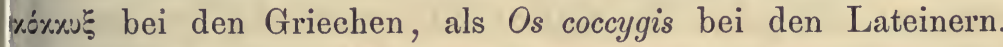
Kóx $\xi_{5}$ hat in allen Endungen, das $u$ lang, und doch sagt alle Welt: Os coccygis, während sie Os coccȳgis zu sagen hätte.

Das Os coccygis (Kuckucksbein im Blumenbach, Steissbein im Sömmerring), oder nach neuerer Auffassung: die Ossa coccygea, spielen in unserer Wissenschaft eine possierliche Figur. Herophilus wählte für das Ende der Wirbelsäule, den Namen $x^{\prime} \times \times v \xi$, weil die drei oder vier Knochenstücke dieses Endes, zusammen einem Kuckucksschnabel ähnlich sehen. Der Name convenirt somit nur allen Steissbeinen zusammen, nicht aber jedem einzelnen. Es sind deshalb keine Ossa coccygis, wohl aber ein $O s$ coccygis erlaubt. Die einzelnen Stücke des Os coccygis, müssen Vertebrae ossis coccygei, durchaus nicht Ossa coccygea, genannt werden. Vesal schreibt richtig: Os cuculi, a similitudine rostri cuculi avis. Riolan giebt eine andere, weit 
hergeholte, und komische Erklärung des Wortes: quia crepitus (Blähungen), qui per sedimentum (After) exeunt, ad id os allisi, cuculi vocis similitudinem effingunt! ${ }^{1}$ ) Hat je Meister Riolan den Kuckucksruf aus solchem Munde vernommen?

Galen trug Bedenken, dem Steissbein, welches so lange Zeit in knorpeligem Zustande verharrt, die Rechte eines selbstständigen Knochens einzuräumen, und hielt es mehr für eine Epiphyse des Kreuzbeins ${ }^{2}$ ). Von den Synonymen des Steissbeins, ist das Os caudae (jetzt noch bei den Franzosen: l'os de la queue), und das Os ani der Arabisten erwähnenswerth, weil das Osanum und Osanium der barbarischen Autoren des 14. und 15. Jahrhunderts, sich aus letzterem deduciren lassen. Die Sacra spina des Isidorus, für Steissbein, ist ein offenkundiger Tropus, nicht als pars pro toto, sondern als totum pro parte, da die Wirbelsäule sacra fistula und sacra spina (ispin eірpry') genannt wurde, wo ieprí = magna, nicht sancta. Vertex, als Synonym für Steissbein im Vesal aufgeführt, ist die xopup̣n des Julius Pollux, welche, obwohl eigentlich nur auf den Scheitel bezogen, doch auch für Gipfel und Spitze überhaupt angewendet wird, wie in Coryphaeus "an der Spitze stehend". In Mayer's Beschreibung des menschlichen Körper's, treffen wir: Acumen ossis sacri, ebenfalls auf ropup̣ fussend. Von den griechischen Synonymen, verdient nur das íp̧oríycy des Hippocrates genannt zu werden, weil es von Aristoteles ${ }^{3}$ ), auf den Fächer der Schwanzfedern bei den Vögeln übertragen wurde, und zum Uropygium entstellt, in der Zoologie für "Bürzel" eintritt, welchen auch Osiander dem menschlichen Weibe, durch sein Bürzelbein vindicirte ${ }^{4}$ ). Aus dem Steissbein, macht Weitbrecht, decoris causa,

1) J. Riolani Commentarius didacticus in librum Galeni de ossibus, Cap. 18.

2) Lib. de ossibus, Cap. 21.

3) Hist. anim. Lib. II, Cap. 12.

4) Lehrbuch der Hebammenkunst, §. 105. 
Eissbein! Dieser humoristischen Bemerkung, lässt sich eine streng wissenschaftliche substituiren. Die Schambeine heissen, weil sie in der Schamfuge zusammenschliessen, auch Schlossbeine, im Hochdeutschen: Schlussbeine. Im Holländischen und Altdeutschen findet sich Isbeen für Schloss- oder Schlussbein. Dieses Isbeen führt ganz leicht auf Eisbein, verstärkt Eissbein, für Steissbein, weil dieses die Wirbelsäule unten abschliesst. Ich glaube nicht, dass Weitbrecht so viel Linguist war, um auf diese Deduction hin, sein Wort angebracht zu haben. Der Humor dürfte somit wohl Recht behalten. Den Starrknochen des Kulmus'), kann ich mir aus der, relativ gegen die übrige Wirbelsäule, sehr geringen Beweglichkeit des Steissbeins erklären.

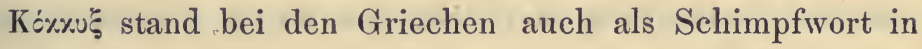
Verwendung. Da der Kuckuck seine Eier in fremde Nester legt, erhielten Menschen, welche dasselbe thun, wie Ehebrecher und geile Hähne überhaupt, dieses deutsame Prädicat. Plautus, welchem Aristophanes zum Vorbild diente, verwendet Cuculus in seiner Asinaria, in derselben Angelegenheit:

\section{„At etiam cubat cuculus; surge amator, $i$ domum!“}

\section{Cochlea.}

Wenn dem Aristoteles zugemuthet wird, dass er die Schnecke des Gehörorgans kannte (Pierer und Choulant ${ }^{2}$ ), erweist man ihm eine ganz unverdiente. Ehre. Aristoteles erwähnt, wo er vom Gehörorgan redet, nur das äussere Ohr und den äusseren Gehörgang. Alles Uebrige, was einwärts von diesen liegt, kannte er nicht im Geringsten. Trommelhaut, Trommelhöhle, Gehörknöchelchen, Labyrinth, waren ihm völlig unbekannt. Und dieser Mann soll die Schnecke

1) Anatomische Tabellen, Taf. 5.

2) Anat.-physiol. Realwörterbuch, T. II, pay. 179. 
entdeckt haben? Dass man es glauben konnte, war nur dadurch möglich, dass der Ausdruck: regio intima auris, cochleis

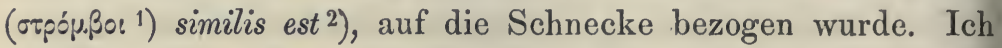
glaube nicht zu irren, wenn ich annehme, dass Aristoteles das blasenförmig aufgetriebene Os tympanicum s. Bulla ossea, welches ihm an den Schädeln von Fleischfressern und Wiederkäuern aufgefallen sein musste, mit der bauchigen Schale des Strombus verglich, mit welcher es wirklich so viel Aehnlichkeit hat, dass die regio intima auris eine cochleis similis genannt werden konnte. Aristoteles war ein eitler und redseliger Mann. Er hätte sicher von den Bestandtheilen des mittleren und inneren Ohres viel zu sagen gehabt, wenn sie ihm nur einigermassen bekannt gewesen wären. Alle Anatomen, lange vor der Entdeckung der Schnecke durch. Fallopia, haben unter Cochlea, und Concha interna s. Pelvis auris, nur die Trommelhöhle verstanden, weil sie vom Labyrinth, und von einer Schnecke des Labyrinths, ebensowenig wussten wie Aristotéles. Die 'T'rommelhöhle, welche sie ebenfalls nur höchst unvollständig kannten, indem sie nicht einmal von der Existenz der Gehörknöchelchen Notiz genommen haben, wurde, als Pars interna auris, der externa gegenübergestellt, und da die externa eine schneckenförmige Windung besitzt, den Helix, und eine schneckenförmige Vertiefung derselben, als Concha, so wurden auch der fast unbekannten Pars interna, die Namen Cochlea, Concha, Cavitas buccinata, Antrum buccinosum, etc., angedichtet ${ }^{3}$ ), unter welchen Ausdrücken sicher nicht die erst

1) Die Meerschnecke, welche Strombus heisst, und deren Repräsentant, Strombus gigas, aus den indischen Meeren in grosser Menge zu uns gebracht wird, hat ein weit weniger schneckenförmiges Gehäuse, als andere, z. B. Helix, welche zur Bezeichnung der Ohrschnecke viel besser getaugt hätte, als Strombus.

2) Hist. anim., Lib. I, Cap. 11.

3) Vielleicht auch durch die Worte des Aristoteles dazu rerleitet: regio intima, extremo osse auriculam imitans (loco cit.). 
n 16. Jahrhundert entdeckte Schnecke des Gehörs gemeint ein konnte, obwohl die Synonymiker nicht umhin können, die ür die Trommelhöhle angeführten Namen, auch bei der chnecke zu wiederholen, zum Beweise, dass sie mit der xeschichte der anatomischen Entdeckungen, auf welcher die ynonymik beruht, und aus welcher sie sich entwickelt hat, gar iicht vertraut waren. Im Eustachius erscheint das Cavum ympani als Concha auris interna, zum Unterschied der externa = Grube der Ohrmuschel + äusserer Gehörgang, und die jchnecke als Cochlea ${ }^{1}$ ). Bartholin erkannte es vor dritthalbundert Jahren, dass die Cochlea des Aristoteles, nicht die eutige Schnecke sein konnte, sondern die Trommelhöhle: avitas tympani, Aristoteli cochlea dicitur ${ }^{2}$ ). Zur Zeit des Iristoteles, war die anatomische Technik sicher noch nicht lahin gekommen, aus der Tiefe des härtesten aller Schädelknochen, ein Organ zu Tage zu fördern, von welchem Haller agt: haec in corpore humano machinula, mihi dudum artificioissima videtur omnium. Nachdem Fallopia die wahre und igentliche Schnecke entdeckt und als Cochlea beschrieben Iatte (a me vocata et descripta ${ }^{3}$ ), änderten Andere, ganz unïthiger Weise, den Namen derselben in: Cavitas cochleata and buccinata (Bartholin), Trochlea und Concha (Morgagni), Pelvis auris (Laurentius), und die Cavitas coeca (Vesling), velche Namen, wie schon gesagt, früher der Trommelhöhle igen waren.

Nur wenig anatomische Gegenstände passen so gut zu hrem Namen, wie die Cochlea. Cochleae hiessen die Schnecken und ihre Häuser, der spiralen Windung wegen ( $\delta \% \% \gamma_{i} \alpha_{\varsigma}$ im

1) Tabulae anatomicae, Edit. Colon., Tab. XX, Text dazu pag. 32.

$\left.{ }^{2}\right)$ Institutiones anat., Lib. IV, pag. 457.

3) Cavitas, duobus aut tribus gyris, in modum cochleae constat, neque exitum habet, unde cochlea, vel cochlearis cavitas, vel coeca dicenda est. (Observationes anct., in den Opera omnia Vesalii, T. II, pag. 699.) 
Aristoteles). Schrauben und Wendeltreppen wurden ebenfalls Cochleae genannt (Vitruvius). Die Windungen der Ohrschnecke, geben ihr das Recht auf gleiche Benennung. Die Cavitas coeca des Fallopia und Vesling1), für Schnecke, kann nur unter Berücksichtigung der blind abgerundeten Kuppel (Cupola) zugelassen werden. Bei dem französischen Ausdruck für Schnecke: limaçon, darf man nicht an den Limax der Zoologen denken. Dieser ist eine nackte Schnecke ohne Gehäuse (Limax ater, Linn.)

\section{Coecum.}

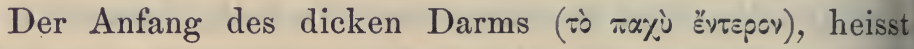
bei den Griechen चụ̣ióv. Hätten Galen und Oribasius je menschliche Leichen zergliedert, sie würden das Anfangsstück

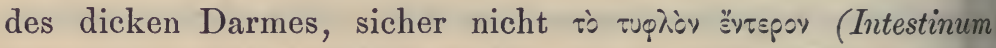
coecum, Blinddarm) genannt haben, denn dasselbe hat im Menschen ein so unscheinbares Ansehen, dass es keinen Anspruch darauf machen kann, für ein besonderes Darmstïck gezählt zu werden. Nur bei den pflanzenfressenden Säugethieren, erreicht das Coecum eine solche Grösse und Länge, dass es von Galen mit dem Magen verglichen, und dem-

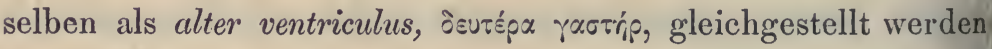
konnte ${ }^{2}$ ).

Schon Vesal hat es eingesehen, dass, wenn eine $\mathrm{Ab}$ theilung des menschlichen Darmes Coecum genannt werden soll, es nur der Wurmfortsatz sein könne: id quod Coecum appellandum esse duco, lumbrico similis appendix est ${ }^{3}$ ), und Salomon Albertus sagt es rund heraus: appendiculum.

1) Syntagma anatomicum, Edit. Blasii, pag. 237.

2) Oribasius, Anatomica ex Galeno, pag. 100.

3) De corp. hum. falrica, Lil. V, Cap. 5. 
imbrici contorti specie, quod Coecum vocant ${ }^{1}$ ). Galen wurde von er Grösse seines тuழ̣ióv bei den Thieren, welche er zu seinen natomischen Studien verwendete, so überrascht, dass er auch leich mit einer Theorie zur Hand war, und die bereits verauten Nahrungsmittel sich in ihm so lange aufhalten liess, is ihre Menge gross genug geworden, um auf einmal entleert u werden. Wäre dieser zweite Magen nicht vorhanden, würden, rie er sagt, die Excremente, foedo et nauseoso spectaculo, unnterbrochen aus dem After abgehen.

Der Blinddarm des Menschen ist für uns nichts anderes, Is das erste Haustrum des Colon. In demselben Sinne fasste Tesal den Blinddarm auf, als Initium coli, und Caspar Hof1ann, der gelehrte Commentator des Galen, als prima cellula oli $\left.{ }^{2}\right)$. Schon die Magistri scholae Salernitanae sprechen von am nur als Caput coli.

Die Araber fanden es unpassend, dass ein Darmstück, velches doch eine Oeffnung hat, blind sei. Sie nannten es eshalb: al-a'war, einäugig, welches die Uebersetzer mit em griechisch-lateinischen Zwitterwort Monoculum, deutlich enug ausdrückten. Das Monoculum hielt sich durch die ganze iestaurationszeit der Anatomie, in allen Schriften. Von Paraclsus wurde es zum Monocolon verdorben, - ein ganz sinnoses Wort. An die Fundula (Blindgasse) des Varro ${ }^{3}$ ), dachte Niemand. Musste aber schon der Blinddarm zum Einugigen umgestaltet werden, dann war nur Unoculum zu vählen. Unoculus wird im Macrobius, der einäugige König Intigonus genannt, ganz mit demselben Recht, wie dort uch Mrultoculus, als Beiname des Argus, vorkommt. Plautus Ind Aulus Gellius leisten uns für die gute Latinität dieses Wortes hinlängliche Gewähr. Caelius Aurclianus erwähnt

1) Historia plerarumque partium corp. hum., pag. 41.

2) Institutiones medicae, pag. 34.

3) De lingua latina, Lib. V, C'ap. 22, §. 111.

Hyrtl. Onomatologia anatomica. 
das Coecum als Typhloteron ${ }^{1}$ ), und zählt es unbegreiflicher Weise zum Dünndarm: Ulceratio fit in tenuissimis intestinis, ut pyloro, nestidi (wrorts, Jejunum Galeni), et typhlotero. Das barbarische Wort kann nur eine Syncope von uuphìr Ëvrspor sein.

Vergleiche über Antiquitäten des Blinddarms: HL, §. LXIV, Sect. III, Monoculum.

\section{Coeliaca.}

Von der xoikia (Unterleib) des Aristoteles, verblieb der Anatomie nur Ein Andenken, in der Arteria coeliaca, mit ihrem umgebenden ganglienreichen Nervenplexus (Plexus et Ganglion coeliacum). Der in seinen Erfindungen nicht immer unglückliche Dispensator nominum, Joh. Riolan, gab ihr diesen Namen ${ }^{2}$ ), weil sie die. Haupteingeweide des Unterleibes, Magen, Milz, Leber, Pancreas, und Zwölffingerdarm, versorgt. Im Vesal entbehrt die Schlagader noch einer besonderen Benennung. Er beschreibt sie blos als Truncus $^{3}$ ) primus magnae arteriae (aortae).

Das Adjectiv coeliacus ( $\times o t \lambda\left(\alpha \times \delta^{\circ}\right)$ ), spielte in der Medicin eine weit wichtigere Rolle, als in der Anatomie. Die alten Aerzte handeln von einer Passio coeliaca, welche wir jetzt Lienteria nennen (weisser Bauchfluss, als Abgang halb- oder nicht verdauter Speisen $\left.{ }^{4}\right)$. Derlei Kranke finden wir schon

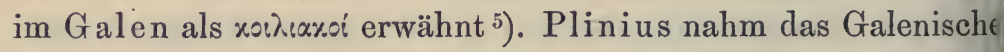
Wort in seine Sprache auf, und redet von coeliacis und dysen tericis, welchen er die Kuhleber als Heilmittel empfiehltt $\left.{ }^{6}\right)$

1) Morborum chron., Lib. IV, Cap. 6, de dysenteria.

2) Anthropographia, Lib. II, Cap. 18, de arteria coeliaca.

3) De corp. hum. fabrica, Lib. III, Cap. 13, ab initio.

4) Nach Varro, De re rustica, Lib. III, Cap. 16, leiden auch die Bienen an dieser Krankheit.

5) De remediis parabilibus, Cap. 13, ad coeliacos et dysentericos.

6) Hist. nat., Lib. XXVIII, Cap. 14, Sect. 58. 
Celsus widmet das zwölfte Capitel des vierten Buches seines Werkes: De medicina, dem Morbus coeliacus, aus dessen Beschreibung ich nicht klug werden kann: sub hoc morbo venter indurescit, dolorque ejus est, alvus nihil reddit, ac ne spiritum quidem transmittit (Blähungen?), extremae partes frigescunt, difficulter spiritus redditur.

Da alle Schlagadern, welche Unterleibsorgane versorgen, auf den Namen coeliacae Anspruch haben, kann es nicht gebilligt werden, wenn nur eine derselben so genannt wird. Der deutsche Name ist, wie so oft, auch hier vorzuziehen: kurze Bauchschlagader, da sie bald nach ihrem Ursprung in ihre drei Hauptzweige zerfällt. Leber gebrauchte diese Benennung zuerst. Auch obere Bauchpulsader wäre annehmbar (Mayer). Der Begriff Magenpulsader (Pierer) ist $\mathrm{zu}$ eng, und Eingeweidearterie (Sömmerring) wieder zu weit.

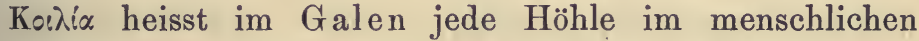
Leibe: Hirnhöhle, Herzhöhle, Kehlkopfhöhle, Nierenbecken, u. s. w. Aristoteles unterschied die Bauchhöhle, welche er жoi $\hat{i} \alpha$ nannte, von der Brusthöhle, welcher er denselben Namen

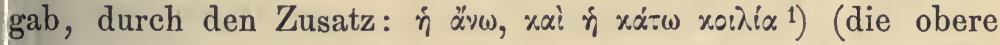
und die untere Höhle). Andere, wie Gorraeus, vermeinen,

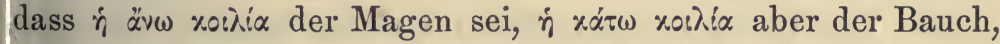
ungefähr wie wir den Magen Ventriculus, und den Bauch Venter zu nennen pflegen. Im Hippocrates stossen wir auf xoc $i \alpha$ auch als Geschwürshöhle. Alles recht, denn roı̀i $\alpha$ dependirt von xoî̀.os, hohl. Galen nannte die Vertiefung der Hohlhand, und des Plattfusses: toे xoì und Rufus die über dem oberen, und unter dem unteren Augenlid, bei tiefliegenden Augen sich ausprägenden Furchen:

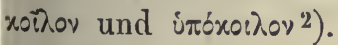

Sieh' den Artikel: Cava.

1) De partibus animalium, Lib. II, Cap. 3.

2) De partibus hominis, pag. 23. 


\section{Coleus.}

Die anatomischen Handbücher präsentiren uns mit Coleus, ein sehr sonderbares Synonym des Hoden. Sonderbar muss ich es nennen, weil man es für das griechische yolésos halten könnte, welches im Homer als Schwertscheide 1), im Aristoteles als Flügeldecke ${ }^{2}$ ) der Insecten auftritt, und in der neuen medicinischen Sprache, auch als Mutterscheide, verschiedene Zusammensetzungen eingeht. Wahrscheinlicher stammt es aber von culleus, Sack ${ }^{3}$ ), Hodensack, aus welchem metaphorisch, contentum pro continente, es auf Hode überging. Das italienische coglione (Hode), das provençalische collion, das französische coujon, und das spanische cojon, ergeben sich aus dieser $\mathrm{Ab}$. leitung. Im Nonius Marcellinus findet sich coleatus füs männlich. Von den Classikern kennen culeus nur Martial und der Auctor der Priapeia:

$$
\begin{gathered}
\text { "Stamus sub Jove, coleis apertis." } \\
\text { "Sulore pulso, }
\end{gathered}
$$

(Carmen XIII.)

Auch Cicero wird als Gewährsmann für culeus in den Lexici citirt. Das ist höchst possirlich. Cicero spricht (in seiner Epistolis ad Fam., XI, 22) allerdings von Colei, jedoch nich

1) Ilias, I, 194.

2) Hist. anim., Lib. IV, Cap. 7. Daher haben wir unsere Coleo ptera (Käfer), zum Unterschied der Gymnoptera, deren nackt Flügel unter keiner hornigen Decke sich verbergen.

3) Ein grosser Sack aus einer Schweinshaut oder Leder, zur Transport von Oel und Wein, wie er jetzt noch im südliche Italien gebraucht wird. Seine Grösse erklärt noch eine anderen Gebrauch, welchen die Römer vom Coleus machter Sie nähten die Elternmörder in ihm ein, um sie zu ersäufer insui in culleo (Plautus und Seneca). 
ls Hoden, sondern als zwei Familien, welche die Beinamen sanuvini und Cliternini führten, weil die eine derselben n dem Städtchen Lanuvium (das heutige Lavinia) an der Tia Appia zu Hause war, die andere in Cliternum, nach

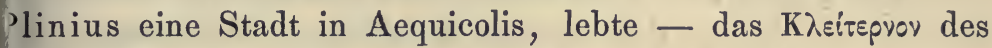
ptolemäus. Es kommt noch besser. In der Meinung, dass Yicero mit seinen Colei die Hoden vermeinte, erscheinen liternini und lanuvini im Anatomisch-physiologischen Realwörteruch, IV. Bd., pag. 84, als Synonyme von Testes!

Einen höchst wunderlichen Ausdruck für Hoden, als Mala racchica und braccica (wörtlich: die Aepfel in den Hosen, on braccae ${ }^{1}$ ), Beinkleider), enthalten die Priapeia:

"Quod movear non est, quia, si furaberis ipse "Grandia mala, tibi braccica mala dabo."

(Carmen $L X X I V$.

Jon den griechischen Benennungen des Hodens, als diôupos and boy.s, wird nur die erstere in der Anatomie verwendet. Sieh' den Artikel: Epididymis.) 'Opy เs, und seine überaus ahlreichen Composita, haben in der Medicin und Botanik hre Heimat gefunden, z. B. Cryptorchis (richtig Crypsorchis, fralen, von xpúụ:s, das Verbergen), und Orchideae, Pflanzen nit hodenförmigen Wurzelknollen. - Von der Homerischen

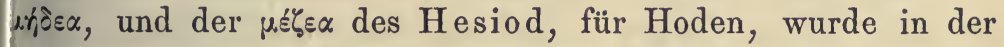
anatomischen Sprache nie Anwendung gemacht.

1) Braccae, auch bracae, weite Beinkleider im Ovid und Pomponius Mela. Die Gallier und Germanen, später auch die Römer, trugen solche Beinkleider; daher Gallia braccata = Gallia Narbonensis, die jetzige Provence. 


\section{Colon.}

Colon, x. bedeutet es: Glied des thierischen Leibes, - in zweiter: die Hauptabtheilung des dicken Gedärms, wie zuerst im Aristoteles. Aristophanes (Equites, 458), und Nicander (Alexipharmaca, 23), schreiben deshalb, um einer Verwechslung vor-

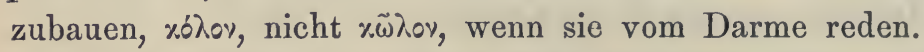

Der Abstammung des Wortes, lässt sich nicht leicht auf

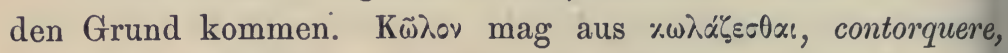

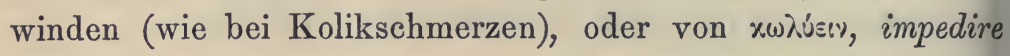
(quia in ipso excrementa impediuntur, ne statim decidant, $\mathrm{K} \ddot{\mathrm{u}} \mathrm{h}$ ), hervorgegangen sein. Gleichgültig hierüber, bemerken wir blos, dass die Aerzte, welche, wie mein klinischer Lehrer, colon

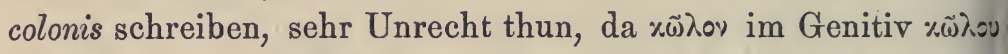
hat, das lateinische Colon somit Coli haben muss, was auch den Anatomen zu allen Zeiten einleuchtete, da sie Cellulae, Fasciae, Haustra, Plicae sigmoideae, und eine Valvula coli, nicht colonis, beschreiben. Plinius und Caelius Aurelianus setzen, statt Colon, Colum, woraus der nothwendige Genitiv Coli noch besser einleuchtet.

Die Latino-Barbari nöthigen uns ein Lächeln ab, wenn sie statt Colon, Collum schreiben, mit der Erklärung, quia plura habet colla, d. i. Einschnürungen. Die zwischen den Einschnürungen befindlichen Ausbuchtungen, sind die Cellulae des Zerbis, und die Camerae des Fallopia. Von ihnen führte einst das Colon den Namen Intestinum cellulatum und cameratum. Heute heissen diese Zellen Haustra, nach $\mathrm{Haller}$, welcher sie mit den Schöpfeimern (haustra) an einem Wasserrade (àv $\lambda_{i}(o v)$ verglich. Als supponirter Sitz der Kolikschmerzen, steht dem Colon der deutsche Name Grimmdarm gut an. 


\section{Columella cochleae,}

Sieh' den Artikel: Modiolus.

\section{Communicans faciei,}

Sieh' den Artikel: Pes anserinus.

\section{Complexus.}

Der Muskel des Nackens, welchen wir, zu unserem Ertaunen, Complexus genannt finden, zeigt sein Fleisch durch illerlei tendinöse Intersectiones unterbrochen, wie wir sie, in weit regelmässigerer Form, am Rectus abdominis, als Inscriptiones endineae kennen. Man unterschied vor Zeiten drei Abtheilungen in ihm, welche jetzt, als besondere Muskeln, unter den Namen: Complexus major, minor, und Biventer cervicis behandelt werden. Diese drei Muskeln, als Einer aufgefasst, gaben den Trigeminus der Compositus des Spigelius1), welchen Riolan, seines Durchflochtenseins wegen, als Complexus benannte, und in drei Muskeln auflöste, als Partes Complexi: unseren Biventer cervicis, Complexus major und minor.

Complexus ist kein Adjectiv, als welches es in der Anatomie dient, sondern ein Hauptwort, welches nie etwas anderes zu bedeuten hatte, als "Umarmung" (Complexus venereus, und currere ad alicujus complexum, Ci c e r o), oder "Zusammenfassung “. Das Adjectiv complexus in der Anatomie, wird für "durchflochten" genommen, was es nicht ist, und nicht sein kann. "Verflochten" (untereinandergewirrt) heisst im guten Latein perplexus, vor welchem man sich aber gescheut haben mag,

1) De corp. hum. fabrica, Lib. IV, Cap. 7. 
da das deutsche "perplex" einen anderen als anatomischen Sinn hat. - Durchflochten heisst pertextus.

Der Name Complexus hat sofort aus der Anatomie verbannt zu werden, denn er ist heller Unsinn. Was aber an seine Stelle zu setzen wäre, etwa pertextus, darüber möge der Areopag der Anatomen berathen, und sich den Dorsotrachelo-occipitalis des Dumas ${ }^{1}$ ) empfohlen sein lassen. Der Trachelo-occipitalis des Dumeril wäre ebenfalls zu berücksichtigen, und würde sich gut mit seinem bereits accreditirten Nachbar, dem Trachelo-mastoideus des Douglas und Cowper, vertragen.

\section{Conarium s, Glandula pinealis.}

Die Zirbel hat ihren Namen nie gewechselt. Sie erhielt ihn, als xwydxpov, von Galen, ihrer Gestalt wegen. Küvos heisst Kegel, und kegelförmiger Zapfen der Pinie und anderer Coniferen. Die Uebersetzer änderten das griechische Wort nicht, sondern versahen es blos mit einem lateinischen Auslaut, und machten einen Barbarismus aus ihm, als Conarium - die Zirbel der Deutschen. Galen sagt von seinem prov: corpus hoc, substantiâ glandula, ג̇òn, figurâ autem, cono per-

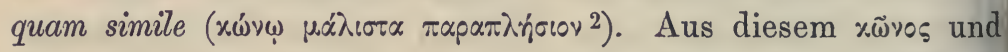
åßrł, ging die deutsche Zirbeldrüse hervor, als wörtliche Uebersetzung des Galenischen Ausdruckes, nicht als anatomisch richtige Bezeichnung des Wesens der Zirbel, welche keine Drüse ist. Die àốyş (glandulae) des Galen, waren bekanntlich keine Absonderungsorgane, sondern Ausfüllungs. und Verstopfungsmittel von leeren Räumen, wie es die Interstitia vasorum sind. Sie lagern deshalb vorzugsweise dort, wo

1) Nomenclature des muscles, pag. 134.

2) De usu partium, Lib. VIII, Cap. 14. 
n Loch abwechselnd $\mathrm{zu}$ verstopfen und aufzuthun ${ }^{1}$ ), oder ne Gefässverzweigung zu stützen kommt. So wurde denn ch die Zirbel theils für ein Verschlussmittel des Verindungsganges zwischen der dritten und vierten Gehirnammer angesehen, theils für eine nöthige Vorkehrung gealten, um die primären Verzweigungen der Vena magna aleni, welche sich in die Plexus choroidei cerebri auflöst, in arer Lage $\mathrm{zu}$ sichern: magnae venae divisionem opplet, in eum sum, in quem reliquas glandulas, venarum divisiones firmantes, rbitror factas fuisse ${ }^{2}$ ). Galen hatte sich also eine Vorstellung on der Verwendung der Zirbel gebildet, - wir haben keine.

An der Glandula pinealis müssen wir die Ausstellung nbringen, dass pinealis ein neues Wort ist, und richtiger inea geschrieben werden sollte, da wir eine nux pinea im 'linius, einen nucleus pineus (Fichtenkern und Fichtennuss) n Celsus, und eine pinus pinea (Pinie oder Pignole) im Tater Linné vorliegen haben. - Wie die Pinie in Italien eimisch ist, so die Zirbel (Pinus cembra, Linn., Zirm, errenbaum, von lat. cerrus) in Oberdeutschland. Die italienichen Anatomen übersetzten deshalb das \%.(w)x́pı mit Glandula inealis, die Deutschen (Hans von Gersdorf) mit Zirbelrüse.

Penis und Virga cerebri, für Zirbeldrüse, war schon zu Bartholin's Zeiten eine beliebte Obscönität: glandulam inealem, penem vocant, - ejusmodi nomina imponere, parvi idetur momenti ${ }^{3}$ ).

1) Wie der Pylorus, 'welchen Galen ebenfalls den Adenes anreiht, den Magenausgang bald öffnet, bald schliesst, ita etiam conarium, meatum, qui spiritum ex medio cerebri ventriculo in

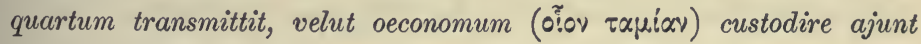
(loco cit.).

2) Galen, loco cit.

3) Institutiones anat., Liz. III, Cap. 6, pag. 278. 


\section{Conchae narium und andere Conchae.}

Den Alten war, vom Siebbein, nur jene durchlöcherte Platte genau bekannt, welche wir Lamina cribrosa nennen. Galen spricht von dieser Platte immer nur im Plural, als ob er ihre beiden, durch die Crista galli getrennten Hälften, für zwei separate Knochen gehalten hätte: loca ante meninges,

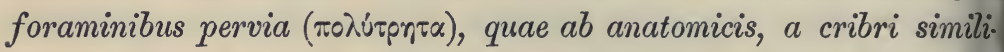

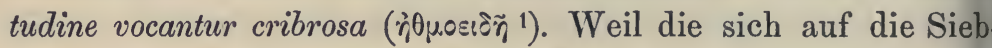
platte auflagernden Processus mamillares des Gehirns (spätere Riechnerven) paarig sind, liess Galen auch die Siebplatte aus zwei Hälften bestehen, - daher der Plural loca. An etlicher Stellen dehnt er aber die Bezeichnung ì̈0u.ícses, i. e. cribriforme auf jenen Complex von Knochenzellen aus, welcher unter de: Siebplatte lagert, und nach Winslow's Labyrinthus ethmoidalis heute noch als Labyrinth des Siebbeins erwähnt wird Hippocrates verglich diese Anhäufung von Knochenzelles

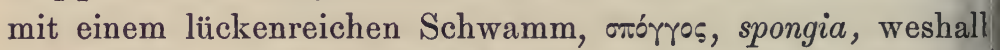

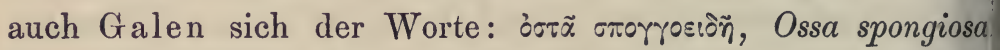
für sie bedient. Näheres über die Zellen dieses Knochen schwammes gab er nicht, und kennt überhaupt von ihnes

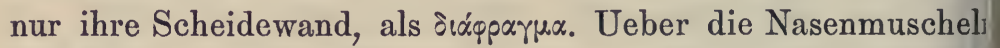
schweigt er. So verblieb es mit der Kenntniss des Sieb beins, durch die Restaurationsperiode der Anatomie, bis i den Anfang des 16. Jahrhunderts, wo Vesal und Fallopi die terra incognita der Nasenhöhle etwas näher untersuchter und Casserius Placentinus ${ }^{2}$ ) das erste Mal das Wor Conchae, Nasenmuscheln, hören liess, und zwar als Concha Veneris, nach der Formähnlichkeit mit dieser in Italien seb bekannten Seemuschel, aus der Gruppe der Tellina, in welche

1) De usu partium, Lib. VIII, Cap. 7.

2) Pentaestheseion, Lib. III, Cap. 6, de nasi fabrica. 
e Conchyliologen noch immer zwei Genera, als Venus und ytherea, benennen.

Da also die Nasenmuscheln als Conchae einmal gegeben aren, blieb den Anatomen nichts Anderes übrig, als ihre hantasie im Ersinnen anderer bildlicher Ausdrücke für diese nochen zu üben. Hierin waren sie auch sehr fruchtbar, und interliessen uns eine Menge von Synonymen, unter welchen ie Laminae fungosae und spongiosae, das Andenken an das ippocratische ođóryos erhalten, die Anfractus tortuosi und ubuli aber, sich gar nicht auf die Muscheln, sondern auf ie Meatus anfractuosi und tortuosi des Galen beziehen, mit elchen Namen er die verschlungene und verworrene Behaffenheit der Siebbeinzellen überhaupt ausdrücken wollte 1). lie Turbines und Cartilagines turbinatae, beziehen sich auf die ingerollte Form der Muscheln, und die Cucullae auf ihre ehnlichkeit mit einer Papierdüte (sieh' Cuculla), weshalb sie on Leber und meinem Lehrer Mich. Mayer, als "Stanitzeleine" übersetzt wurden. Buccina ${ }^{2}$ ) und Conchylia sind Tautogien für Concha (cornets und conques im Winslow, von seinem lebersetzer als Hörner gegeben). Am passendsten fiel der ergleich aus, welchen Haller zwischen den Nasenmuscheln

1) De usu partium, loco supra allato.

2) Buccina war ein schneckenförmig gewundenes Horn aus Messingblech, ähnlich unserem Waldhorn. Es wurde in den römischen Heeren gebraucht, um von dem Zelte des Feldherrn aus, das Signal zum Aufbruch oder zum Angriff zu geben (classicum), welches dann durch die Tuba den Fusstruppen, und durch den Lituus der Reiterei weiter verbreitet wurde.

$$
\text { "Buccina jam veteres cogebat ad arma Quirites." }
$$

Ursprünglich scheint eine bauchige grosse Meerschnecke, zu diesem Dienste verwendet worden zu sein, das Kinkhorn, Tritonium nodiferum, welches die Alten Buccina und Bucina nannten, 
und der Miessmuschel, Mytilus edulis, anstellte $\left.{ }^{1}\right)$. Die Aehnlichkeit der Nasenmuscheln, besonders der unteren, mit diesem Conchyl, ist wirklich frappant. Die Manicae Hippocratis, wie die Conchae narium in allen anatomischen Wörterbüchern genannt werden, waren immer nur wollene Filtrirtrichter in den Apotheken, statt deren auch Düten aus Fliesspapier gebraucht wurden. Das Drehen des Papieres zur Düte, mag wohl an die Krümmung gewisser Muschelschalen gemahnt haben, - Den ganz ungewöhnlichen Namen: Nasenhippen und Hippelchen, welchen der Uebersetzer der Chirurgischen Anatomie von Palfyn (I. Theil, Cap. 6) anwendete, verstehen die Wiener am besten zu interpretiren. Sie nennen einen dünngewalkten, dann zusammengerollten und gebackenen Teig, eine "Holippe" (gut deutsch hohle Hippe). In der Frankfurter Ausgabe des Casserius vom Jahre 1612, finden sich alle alten Synonyma der Nasen. muscheln zusammengetragen; ebenso die meisten in Pierer's Anat.-physiol. Realwörterbuch, V. Bd., Seite 586.

An die Conchae, als Nasenmuscheln, schliessen sich andere Conchae an.

1. Die Concha auris, xóræ’n des Rufus Ephesius. Sc. heisst die vom Anthelix umgebene Vertiefung des äusserer Ohres, welche sich in den äusseren Gehörgang fortsetzt Concha ist "Muschel". Die deutsche Anatomie erlaubte sich das ganze äussere Ohr, Ohrmuschel zu nennen. Die Ara bisten nennen die Concha auris: Alvearium.

2. Die Concha auris interna, im Morgagni (Epistol., XII Num. 10) = Cochlea, Schnecke des Ohres.

3. Die Concha oculi $=$ Augenhöhle, die Concha cranii $=$ Schädeldach, die Concha genu = Kniescheibe, die Conch cerebri $=$ Hirntrichter, und die Concha mulierum $=$ weibliche Scham, sind nur bei den Latino-Barbari heimisch. Stat Concha, liest man auch Conchus, wie im Griechischen xb́rys

1) Elem. physiol., T. V, §. 135 . 
att $\sigma^{\circ} \% / \%$. Die meisten dieser Anwendungen von Concha und onchus, rühren aus dem Onomasticon von Julius Pollux her Lib. II, Num. 38, 71 und 188), die Concha mulierum aber aus ristophanes. Keiner von beiden war Anatom, - der er'ste in Professor der Redekunst, der zweite ein Comödienschreiber. eine schamlose Muse, brachte die unfläthigsten Dinge in agischen Gewändern auf die Bühne, und wählte für die eibliche Scham, der beiden grossen Schamlefzen wegen, den usdruck Conchus - eine zweiklappige Muschel, Bivalve, mit elchem Vulva verwandt zu sein scheint.

\section{Condylus.}

Es ist noch Niemandem aufgefallen, und wurde deshalb uch von Niemandem gerügt, dass zwei Dinge von vershiedener Form und Verwendung, denselben Namen führen: ondylus. Ueberknorpelte Gelenksköpfe, und nicht übernorpelte, rauhe, an keinem Gelenk sich betheiligende, sonern zum Ursprung von Muskeln und Bändern dienende nochenerhabenheiten, heissen Condyli. Wir sprechen von Yondyli femoris et tibiae, von Condyli (Processus condyloidei) es Hinterhauptbeins, von einem Condylus maxillae inferioris, nd die französischen Anatomen von einem Condyle des Oberrmbeins, welcher mit dem Köpfchen der Armspindel articulirt unsere Eminentia capitata). Alle diese Dinge sind überknorpelte relenksbestandtheile. Wir belegen aber mit demselben Namen ondylus, die zu beiden Seiten des Ellbogengelenks angebrachten, icht überknorpelten Erhabenheiten des Oberarmbeins, welche Is Condylus externus et internus, s. extensorius et flexorius, in das Mllbogengelenk nicht einbezogen werden. Nicht der neueren Inatomie ist diese Verwechslung zur Last zu legen. Die triechen selbst gingen mit dem Beispiel voran, indem sie dem Norte xóvơ ich aber alle auf das Etymon xóvôos, rundlich, zurückführen 
lassen. Aristoteles versteht unter \%óvòùı!, die Gelenke zwischen den Fingerphalangen, weil im gebogenen Zustande, an ihrer Streckseite, harte, rundliche Hügel gefühlt und ge-

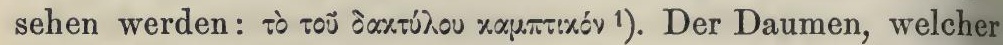
nach Aristoteles nur zwei Phalangen hat, hatte consequent nur einen xóvôùoc. Die übrigen Finger mussten also mit

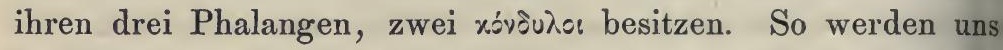

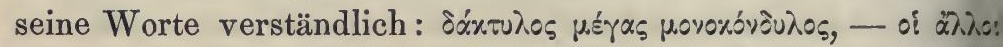

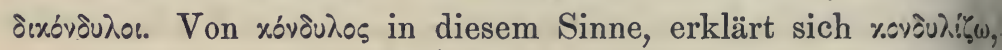
"mit geballter Faust schlagen".

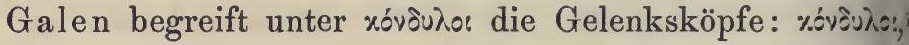

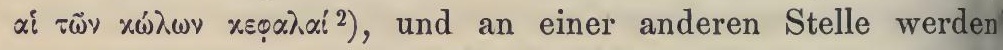

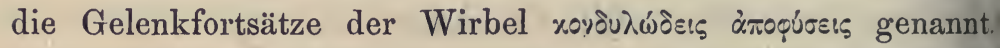
Im Oribasius erscheinen die beiden Tubercula des Oberarm. beins, und die beiden Knorren des Oberschenkelbeins, als

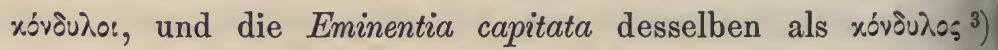

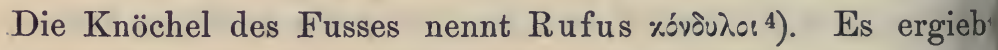
sich aus dieser kurzen Uebersicht, dass jede rundliche Er habenheit an den Endstücken der langen Knochen, sei sit überknorpelt oder nicht, Condylus genannt werden kann, wi denn auch der Name Condyloma, nicht blos auf ein syphilitische Gewächs an den Genitalien oder am After passt, sondern schor von Hippocrates auf jede rundliche Geschwulst, was imme für einer Natur, angewendet wurde. Celsus definirte das Con dyloma, als tuberculum, quod ex inflammatione quadam nascitur ${ }^{5}$ ) und Andere wollten nur die an den Fingern und Zehen v01 kommenden excrescentias callosas, carnibus duriores, et ossibu molliores, Condylome nennen (Gorraeus), weil die Finger gelenke xóvôùoเ heissen.

1) Hist. anim., Lib. I, Cap. 15.

2) De usu partium, Lib. XI, Cap. 18.

3) Anatomica ex libris Galeni, pag. 156, 158, und 250.

4) Onomasticon, Edit. Clinch, pag. 70.

5) De medicina, Lib. VI, Cap. 18. 
Auf die Autorität des Galenus hin, welcher die Gelenkrrtsätze der Wirbel Apophyses condyloideae nannte, sind wir erechtigt, jede rundliche Knochenerhebung "condyloid" zu

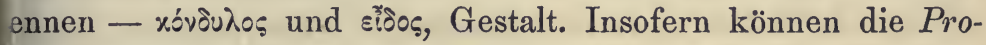
ssus condyloidei des Hinterhauptbeins und des Unterkiefer's tgelassen werden. Gebilde aber, welche in der Nähe der rocessus condyloidei liegen, wie die Foramina condyloidea, die oveae condyloideae, und die Canales condyloidei, müssen andere amen erhalten, da sie selbst keine rundlichen Erhabenheiten nd, sondern vor oder hinter solchen Erhabenheiten liegen. lie Präpositionen $a d$, ante, und post, eignen sich ganz gut, iese Gebilde umzutaufen, und künftighin Canales, Foveae, und oramina ad condylos, wenn sie seitlich dieser Fortsätze liegen, nte und post condylos aber, wenn sie vor oder hinter denllben vorkommen, zu beschreiben. - Gelenksgruben, welche jondyli aufnehmen, Cavitates condyloideae zu nennen, wie Valter gethan '), steht mit der Natur der Sache in Widerpruch, dieweil Gruben weder rundliche Hügel, noch Höcker nd. Cavitates pro condylis hätte gesagt werden sollen. Aus leichem Grunde ist auch die Benennung: Foramen supracondyideum und Processus supracondyloideus verwerflich. Erstere ihrt ein, den Condylus humeri internus durchbohrender Canal, elcher bei vielen Affen, Halbaffen, Insectivoren, Fleischessern, Nagern, Edentaten und Beutlern vorkommt, und die rteria ulnaris, mit oder ohne Nervus medianus, durch sich indurchtreten lässt. Sein Analogon im Menschen, ist der bnorme, nicht eben seltene Processus supracondyloideus, von elchem alle Handbücher voll sind. Sprachrichtig können sie ur Canalis und Processus supra condylum internum genannt erden, denn, wenn sie über einem condyloiden Fortsatz sich efinden, sind sie doch selbst nicht condyloid.

Jeden Formbestandtheil eines Knochens, welcher, im ngeren Alter, mit dem Hauptstück desselben durch Knorpel

1) Abhandlung von den trockenen Knochen, 2. Aufl., Seite 31. 
zusammenhängt, und erst im fortschreitenden Wachsthum des Knochens, mit ihm knöchern verschmilzt, nannte Vesal: Appendix ${ }^{1}$ ). Vor Vesal cursirten die barbarischen Ausdrücke: Applantatio, Additamentum, Adnascentia, Adnexus, selten Gibberus, worunter meistens nur Höcker, Protuberantiae, Tubercula, und Tuberositates, verstanden wurden.

\section{Confluens.}

Die Vereinigungsstelle des Sinus falciformis, des perpendicularis (rectus Lieutaudii), und der beiden Sinus transversi, entspricht der Protuberantia occipitalis interna. Sie ist es, welche eigentlich unter dem Torcular Herophili (sieh' dieses) verstanden werden muss, und wird erst in neuer Zeit als Sinus confluens ${ }^{2}$ ), und Confluens sinuum, in den Handbüchern erwähnt. Haller und Sömmerring ist dieses Wort noch nicht geläufig gewesen. Ein Sinus kann nicht zusammenlaufen (confuere), aber mehrere können es; deshalb ist Sinus confluens factisch unmöglich, - Confluens sinuum dagegen der Sache ganz entsprechend. Confluens und Confluentes, sind echte lateinische Worte. Sie stammen aus der besten Zeit, und dienten zu Benennung der Zusammenmündung zweier oder mehrere! Flüsse. Cum ad confluentem Rheni et Mosae (Rhein und Mosel pervenisset, heisst es im Julius Cäsar, und im Livius: $u b$ Anienem transiit, ad confluentes (wo der Anio in die Tiber ein mündet) castra posuit. In der Medicin hört man auch vo1 Variolae confuentes. Der Confuens, als Winkel, welchen zwe zusammenmündende Flüsse bilden, wurde von den römische: Feldherren gerne als Lagerplatz benützt, der Sicherheit zweie

1) De corp. hum. fabrica, Lib. I, Cap. 3.

$\left.{ }^{2}\right)$ Von confluo = convenio, von Flüssen gebräuchlich: Hippax. (Dnieper), infra Olbiam, cum Borysthene (Dniester) confluit, unc quinque amnium in unum confuens concursus (Plinius). 
Yeiten wegen. Aus den Lagern wurden Ortschaften und Städte, leren einige jetzt noch Namen führen, welche auf Confluens inweisen, wie z. B. Coblenz, am Einfluss der Mosel in den Shein. Nicht weniger als drei Ortschaften in Frankreich, und ine Stadt im Herzogthum Savoyen, heissen Conflans. In ler Anatomie steht Confluens sinuum, dem Torcular Herophili Is Synonym zur Seite.

\section{Conjugata.}

Nicht die Anatomen, sondern die Geburtshelfer der 1euesten Zeit, waren so unbesonnen, die untauglichste aller 3enennungen für den geraden Durchmesser der oberen Beckenipertur auszuwählen. Conjugata ist das als Adjectiv gebrauchte Particip von conjugare $=$ zusammenjochen, paaren, und ver1eiraten. Es steht mit conjuncta gleich, und drückt bei den Classikern eine verheiratete Person aus. Conjugatio steht im Arnobius für "Begattung". Metaphorisch wird es überhaupt ür alles Paarige verwendet, z. B. Folia conjugata in der Botanik; - auch die Nervenpaare hiessen bei den alten Anaromen Conjugationes, als wörtliche Uebersetzung der Syzygia m Galen. Der gerade Durchmesser des Beckeneingangs, conjugirt sich mit nichts, ist deshalb keine Conjugata, wohl aber eine Conjungens, da er das Promontorium mit der Schamuge verbindet. Man hätte für den guten geraden Durchnesser, Diameter recta, keine schlechte Neuerung einführen sollen. - Ueberflüssig erscheint es nicht, zu erinnern, dass Diameter weiblichen Geschlechtes ist. Diameter rectus, obliquus, und transversus, sind Barbarismen, in welche geburtshilfliche and anatomische Autoren, selbst Wörterbücher (Pierer) verfallen. 


\section{Conjunctiva.}

Das fürchterliche Latein des Berengarius, hat auch der Conjunctiva ihr Dasein geschenkt, und zwar, der Retina zu Liebe, als Conjunctina. In seinen Isagogae breves, in welchen weder die Seiten, noch die Capitel numerirt sind, steht, unter der Aufschrift de palpebris, folgendes: „Membrana, a pericranio orta, suam involvens cartilaginem, intraflectitur usque ad tunicam corneam, mediante Conjunctina, tegente musculos oculi." Um einen Druckfehler (statt Conjunctiva) kann es sich nicht handeln, da die ominöse Conjunctina, in demselben $\mathrm{Ab}$ schnitt sich wiederholt. Geben wir aber zu, dass ein Druckfehler vorliegt, so ist doch auch Conjunctiva nicht besser als Conjunctina, da es kein Hauptwort ist, und erst im kupfernen Zeitalter, ein Adjectiv conjunctivus im॰Tertullian auftaucht. Da aber der Sinn des lateinischen Wortes allgemein verstanden wird (conjungit palpebras cum oculo), und Conjunctiva die Mutter der deutschen Bindehaut geworden, wollen wir sie in Gnaden nicht weiter tadeln.

Von der Natur und Beschaffenheit der Conjunctiva, hatten die alten Anatomen sehr wenig Kenntniss. Die Conjunctiva palpebralis existirte für sie nicht, da sie, wie Galen, die Bindehaut für eine Fortsetzung der Beinhaut hielten. Sie verwechseln zugleich die Conjunctiva bulbi oft mit dem vorderen Abschnitt der weissen Sclerotica, mit welchem sie verwächst. Die alten Benennungen der Sclerotica, als: Album oculi, Candidum oculi, Albugo, Funda und Sphendone, werden deshalb auch an die Conjunctiva vergeben. Man liess die Conjunctiva bis dorthin gelangen, wo die Sclerotica in die Cornea übergeht, und gab dieser Stelle den Namen Corona oder Circulus, dessen auch die Iris theilhaftig wurde." Diese Verwechslung der Benennungen der Sclerotica, Iris, und Conjunctiva, muss dem Leser alter Schriften über 'das Auge, wohl bekannt sein, wenn er sie verstehen will. - Werden Gefässbüschel in der Conjunctiva bulbi sichtbar, änderte sich der Name in ragoides (rhagoides, 
traubig) und charoides, vielleicht choroides, geflechtartig (obwohl rhagoides und choroides schon der Choroidea gehörten), seltener in aemathoides (haematoides, blutig), im Benedictus selbst in das absurde rogoides, denn ṕóyos heisst ein Getreideschober. Der durch seine bizarre Nomenclatur berüchtigte Arabist, Gabriel Zerbis, nennt die Conjunctiva: Tunica circumocularis, oder Periobtalmium, andere Arabisten: Consolidans, quia consolidatur in rotunditate circuitus corneae.

Wollen wir also uns mit dem Namen Conjunctiva zufrieden geben. Nur die Entzündung der Conjunctiva als Conjunctivitis, lässt sich nicht ertragen, ebensowenig als Cerebritis, Pulmonitis, Ventriculitis. Den Ausgang in itis, als Bezeichnung der Entzündung, darf man nur griechischen Wörtern anhängen, wie in Arthritis, Pleuritis, Gastritis, Enteritis, u. v. a. Ein lateinisches Wort mit einem griechischen Schweif, erinnert an das Horazische :

„Humano capiti cervicem pictor equinam "Addidit. _ - - -"

\section{Coracoideus,}

Processus coracoideus heisst rabenähnlicher Fortsatz,

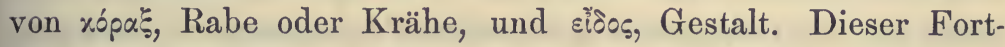
satz sieht weder einem Raben, noch dem Schnabel eines Raben gleich. Es giebt keine Raben, mit hackenförmig gekrümmten Schnäbeln. Die Worte, welche Galen für den sogenannten

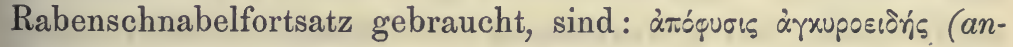
choralis und anchoraeformis im Adrianus Spigelius), oder oryposiòns (C-förmigig, unciformis, uncinatus). Nur den fast geradelinigen Fortsatz des Unterkiefers, welcher zur Befestigung des Schläfemuskels dient, nennt er trì fortsatz, wobei er jedoch nur an den Schnabel eines Raben gedacht haben konnte, dessen Gestalt mit diesem Fortsatz Aehnlichkeit hat. Die Erklärung, welche Oribasius von der 
Benennung des Hackenfortsatzes des Schulterblattes, als Processus coracoideus giebt, ist ganz absurd: processus ancyroeides, a nonnullis coracoideus vocatur, quia extrema ejus pars, ut corniculae rostrum, extrorsum vergit ${ }^{1}$ ). Sind denn die Schnäbel der Raben nach aussen gerichtet? - Schulterhacken und Hackenfortsatz, Processus uncinatus scapulae, mögen den wirklich lächerlichen Rabenschnabelfortsatz in Vergessenheit bringen!

\section{Cornu Ammonis.}

Jener Wulst im Unterhorn der Seitenkammer des Gehirns, welchen Arantius Pes hippocampi nannte, umgreift den Sehhügel nach aus- und abwärts, und beschreibt dabei ein Stück einer Spirale. Er rollt sich um den Thalamus opticus herum, und erhielt deshalb von Sömmerring den Namen: gerollter Wulst. Die Füsse der Seepferde haben keine Kniee, sondern stellen nur im Bogen gekrümmte Pfoten dar, wie an den antiken bildlichen Darstellungen derselben auffällt. Dieser Bogenkrümmung wegen, wurde der Seepferdfuss des Gehirns, von Winslow mit einem Widderhorn verglichen. Um aber dem menschlichen Seelenorgan, keine ordinären Hörner aufzusetzen, wurde aus dem Cornu arietis, ein Cornu Ammonis gemacht, was eigentlich auf dasselbe hinausläuft. Ein ägyptischer Gott ersten Ranges, war Amun Kneph. Er hatte seinen weltberühmten Tempel in der Oase der Lybischen Wüste, wo sein Standbild - eine männliche Figur mit einem Widderkopf als Vermittler der Fruchtbarkeit des Nilthales, verehrt wurde. Die Griechen liehen sich diesen Gott, als Z Ziss "A Aegyptiern aus, und die Römer, als Jupiter Ammon, von den Griechen. Auf die Hörner dieser mächtigen Gottheit, nicht auf gemeine Widderhörner, hatte es Winslow abgesehen, und

1) Anatomica ex Galeno, pag. 157. 
so kamen die Cornua Ammonis in die Anatomie, wo sie noch bei Jedem, der von ihnen zum ersten Mal liest oder hört, Verwunderung erregen.

Der Jupiter Ammon hat noch zwei andere Andenken in der Medicin hinterlassen. Das eine ist der Salmiak, contrahirt für Sal ammoniacus, weil dieses Salz im Sande der Ammons-Oase aufgesammelt wurde. Das andere ist das Gummi ammoniacum, welches als Harz aus einem Baume derselben Oase träufelt. Beide Namen kommen aus Celsus.

Sieh' den Artikel Digitationes hippocampi.

\section{Cornua limacum.}

Die Cornua stehen sehr häufig, sowohl für Hart- als Weichgebilde, in anatomischer Verwendung. Die Knochenlehre registrirt die Cornua sphenoidalia (Ossicula Bertini), die Cornua ossis hyoidei, die Cornua maxillae inferioris (Aeste des Unterkiefers), die Cornua ossis frontis (veraltet, jetzt Processus zygomatici), die Cornua sacralia und coccygea, u. m. a. Als Weichgebilde haben wir die Cornua der seitlichen Hirnkammern, das Cornu Ammonis, die Cornua s. Cornicula der Giessbeckenknorpel (Cartilagines Santorinianae), die Cornua glandulae thyreoideae, pericardii, uteri, u. m. a. Hieher gehören auch die Cornua limacum $=$ Thränenkanälchen. Nic. Stenson bediente sich zuerst dieses gut gewählten Tropus ${ }^{1}$ ), welcher immer in Gesellschaft der prosaischen Canaliculi lacrymales (Bartholin), und Ductus lacrymales (Haller) $\mathrm{zu}$ finden ist. Ein anderer Tropus, welchen Stenson ${ }^{2}$ ) für die Thränenröhrchen anwendete, hatte weniger Glück. Es sind die Colliciae, richtiger Colliquiae, ein im Vitruvius gebrauchter Ausdruck für Dach-

1) Observationes anat. de glandulis oculorum, pag. 88 .

2) De musculis et glandulis, p. m. pag. 38, 
rinne, von con und liquerre, zusammenfliessen. Das Wort ist zu wenig bekannt, um bei den Anatomen dieselbe Aufnahme gefunden zu haben, wie die ihnen näher stehenden Cornua.

\section{Coronoideus.}

Zwei Processus coronoidei haben sich in der Anatomie eingebürgert: der Processus coronoidens ulnae, und der Processus coronoideus maxillae inferioris. Ihre deutsche, nicht allgemein angenommene Benennung: Krähenfortsatz ${ }^{1}$ ), ging aus der Meinung hervor, dass corone, die xopúvn des Homer ${ }^{2}$ ), also 'Krähe und Rabe ist. Allerdings steht unter den vielen Bedeutungen, welche der xорйm zukommen, auch jene einer Krähe. Aber die Krähen tragen gar nichts an sich, was mit den fraglichen Fortsätzen Aehnlichkeit hätte. Der Schnabel der Krähe, an welchen man gedacht $z u$ haben scheint, ist lang, dick, gerade und spitzig, während diese Fortsätze kurz, platt, etwas gebogen und stumpf sind. Auch mit Krone geht es nicht (als Kronenfortsatz im Sömmerring), da Kronen kreisrund sind, der eine dieser Fortsätze aber stumpfpyramidal, der andere schwach hackenförmig gebogen erscheint. Wir müssen es also mit einer anderen Bedeutung von ropwivr versuchen. Kopávn und xopwvís ist in der Ilias und Odyssee, auch ein Hacken am Ende des Bogens, an welchem die Bogensehne mittelst eines Ringes eingehängt wird. Wenn man das obere Ende der Ulna, und den oberen Rand des Unterkieferastes ansieht, findet man sie mit einem tiefen Ausschnitt versehen (Incisura semilunaris, an der Ulna auch Cavitas sigmoidea oder lunata major). Dieser Ausschnitt wird, an beiden, nach vorn zu, von einem aufgebogenen Fortsatz begrenzt, welcher ihn

1) Nach Mayer, Beschreibung des menschlichen Körpers, II. Bd., pag. 246 , und 45.

2) Odyssee, Lib. XII, Vers 418. 
zugleich so vertieft, dass man eine beliebige Schlinge, oder einen Ring, an ihm aufhängen kann. So fassten Galen und Oribasius die ropúr, auf. Aus ihr wurde erst von Heister coronoideus und coronoides ${ }^{1}$ ) geformt, welche sich noch in allen Büchern als „krähenschnabelähnlich" herumtreiben.

Die Ausschnitte, welche am oberen Ende von Säulen und an Gesimisen, als Verzierung angebracht wurden, hiessen ebenfalls coronae und coronides (Hesychius). Kopwric ist vielleicht die Mutter unseres Karnieses. Ein Schnörkel am Ende eines Buches, hiess ebenfalls Coronis, woher die Redensart: rem ad coronidem perducere, eine Sache zu Ende bringen.

Vergleiche über Coronoideus, den Artikel Olecranon.

\section{Cotyle und Cotyledones.}

\section{Cotyle.}

Cotyle kommt, als Pfanne des Hüftgelenks, bei den lateinisch schreibenden Anatomen, gar nicht vor. Dagegen giebt es eine neugebildete Cotylitis bei den modernen Chirurgen, als Pfannenentzündung (erstes Stadium der Coxalgie), und ein Os cotyleale im Geoffroy St. Hilaire = Seitenwandbein, der Schalenform wegen, welche jedoch dem Stirn- und Hinterhauptsbein, in noch ausgesprochenerer Weise zukommt, als dem mehr flachen Seitenwandbein.

Bei den griechischen Aerzten, hiess eine tiefe Gelenksgrube: xotùr, und eine seichte: $\gamma \lambda \gamma_{i} \eta^{2}{ }^{2}$. Die Cotyle wurde durch Acetabulum ersetzt, die Glene aber perennirt noch in der Cavitas glenoidea.

Kot'่خ, war kein ausschliesslich anatomischer Terminus. Viele vertiefte, oder ausgehöhlte Gegenstände, wurden als

1) Compendium anatomicum, T. I, pag. 50 .

2) Oribasius, Anatomica ex Galeno, pag. 130, und Hippocrates, De ossium natura, Lib. I, Cap. 1. 


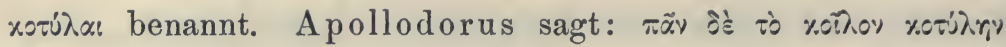
Ėxà่ouy, omne, quod cavum est, cotylen vocant. Einige Arten der

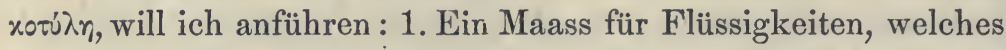

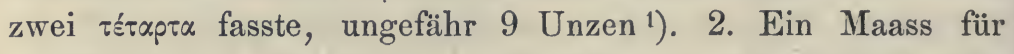
Trockenes, im Gewicht von $7 \frac{1}{2}$ Unzen = dem Hemixestos. 3. Ein kleines Trinkgefäss (Becher, Napf), in der Ilias und Odyssee öfter erwähnt. 4. Die hohle Hand und der hohle Fuss, im Julius Pollux. 5. Die Cimbeln, runde Erzplatten mit einer

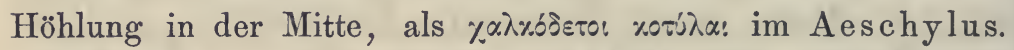
6. Das Kahnbein des Fusses, seiner napfförmigen Gelenkfläche wegen. - Das Beiwort cotylö̈dien (cotyloideus), wird von den Franzosen (seit Winslow), öfters für Dinge, welche zur Pfanne in Beziehung stehen, angewendet. Mancherlei kann sich auf die Pfanne beziehen, ohne cotyloid, d. h. pfannenförmig zu sein. Ich kenne ausser der Pfanne selbst, nichts an ihr, was pfannenförmig wäre. Das bourrelet cotylö̈dien des Winslow ${ }^{2}$ ), woraus sein Uebersetzer Cesticillus cotyloideus ${ }^{3}$ ) machte, unser Labrum cartilagineum acetabuli, ist ringförmig, aber nicht pfannenförmig.

II. Cotyledones.

Anatomen und Geburtshelfer verstehen unter Cotyledones, die $\mathrm{zu}$ einem Kuchen vereinigten Lappen der Placenta, von denen sich der eine oder andere, als Placenta succenturiata, völlig ablösen und selbstständig werden kann. Diese Anwendung von Cotyledo ist gänzlich verfehlt. Cotyledo kommt von 火otu่ $\eta$, muss also etwas napfförmig gehöhltes sein. Galen ${ }^{4}$ ) nannte die napfförmigen Erhöhungen an der inneren Oberfläche des Mutterschlauches trächtiger Wiederkäuer, in welchen

1) Gorraeus, Definitiones medicae, pag. 243, wo Näheres über dieses Maass zu finden.

2) Traité des os, num. 123.

3) Cesticillus ist ein neu gebildetes Wort. Es kommt von cestus (xєotbs), als „Gürtel“ im Varro, und als "liebeerregender Venusgürtel“ im Martial.

4) Comment. ad Hippocratis aphorismos, Lib. V, Aph. 18. 


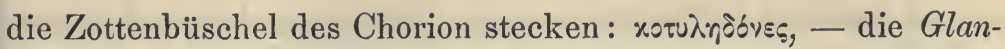
dulae uterinae der vergleichenden Anatomie. Er schrieb sie auch dem menschlichen Weibe zu, wo sie, nach Praxagoras, die offenen Mündungen der Uterinalvenen darstellen, aus welchen sich das Menstrualblut ergiesst: Cotyledones sunt oscula venarum, ad uterum pervenientium ${ }^{1}$ ), welche sich im schwangeren Zustande des Weibes, mit den Venen des Chorion durch Anastomose verbinden, um dem Embryo jenes Blut zuzuführen, welches sonst durch die Menstruation nutzlos vergeudet wird. Mundinus, und seine Schule, hielten dieses für eine ausgemachte Sache. Als der Cotyledo, als Gefässmündung, von der Anatomie aufgegeben werden musste, verblieb er doch in anderer Form in der Naturgeschichte, und zwar als Saugnapf an den Armen der Sepien (nach Aristoteles), als eine Pflanzengattung des Dioscorides ${ }^{2}$, und als die Samenlappen und Samenkuchen der neueren Botanik, deren einfaches oder paariges Vorhandensein, den Unterschied der Plantae mono- und dicotyledones bedingt.

\section{Coxa, Coxendix, und Anchae.}

Von den verschiedenen Anwendungen des urlateinischen Wortes Coxa (i $\%$ iov), bei Anatomen und Laien, hat sich nur Eine in der anatomischen Sprache der Jetztzeit erhalten - das Os coxae, Hüftbein. Celsus gebrauchte es schon in dem Sinne von Hüftgegend: dolor in inguinibus, et coxis, et feminibus est, aber auch als Oberschenkel: perfricare coxas et poplites. Plinius versteht unter coxa nicht den ganzen Oberschenkel

1) Galenus, De anatomia matricis, Cap. 10, versus finem.

2) Cum foliis, instar vasculi excavatis, umbilico humano similibus (Nabelkraut, Frauennabel), unde etiam Umbilicus Veneris audit. Näheres in St. Blancardi Lex. med., Edit. Kühnii, T. I, pag. 445, und T. II, pag. 1553. 
sammt Haut und Fleisch, sondern blos das Oberschenkelbein: fallente vestigio (durch falschen Tritt) cecidit, coxamque fregit. Die Classiker bedienen sich lieber des Wortes coxendix, wie Varro, Suetonius, und zwar theils für Hüfte, theils auch für Oberschenkel: coxendices vertuntur in acetabulis (Plin.).

Von Coxa, als Schenkelbein, bildeten die Italiener und Franzosen ihre coscia und cuisse, welche in der anatomischen Sprache das Oberschenkelbein ausdrücken, in der Küchensprache aber den "Schlegel". Die Portugiesen haben die lateinische coxa ganz intaminate aufgenommen: coxa, Schenkelbein. Die Wallachen entstellten es zu coapse. Die Spanier haben für Schenkel, des dicken Fleisches wegen, zwar nur muslo, nennen aber doch einen Hinkenden coxo, und das Schenkelstück des Harnisches quixote, ein durch Cervantes aller Welt bekannt gewordenes Wort. Den längsten Namen führt das Hüftbein im Vesal: os, sacri ossis lateribus commissum. Albin fehlte arg mit seinem Os coxarum, von welchem man glauben müsste, dass es beiden Hüften zugleich angehört $\left.{ }^{1}\right)$. Das "Dreppein" im Schylhans, drückt in Einfalt, aber wahr, den Zustand des Hüftbeins im Kinde aus, wo es aus drei durch Knorpel verbundenen Stücken: Darm-, Sitz- und Schambein zusammengesetzt erscheint. Bei den Arabisten macht den Neuling in der Lectüre der Alten, das Hüftbein als Os femoris, stutzig. Sie nennen gar nicht selten, diesen Knochen so, indem sie dem Gerardus folgen, welcher das Hüftbein „ob juncturam cum femore", Os femoris (Os quod femur portat) nannte.

Von Coxa als Schenkelkopf (luxcare coxam), als Hüftgelenkskapsel (ruptis ligamentis coxalibus), und als Hinterbacke (coxae macerrimae et tremulae), finden sich in den Schriften der Aerzte des Mittelalters Beispiele in Menge vor. Wir citiren sie nicht, da sich um die Sprache des Bruno, Rogerus, Villanovanus, Marignana und Consortes, Niemand mehr kümmert, und mit Recht.

1) De ossibus corp. hum., §. 183 . 
Das altdeutsche Eisbein, unterscheidet sich wenig von dem holländischen $I s$-been. Da dieses auch als Isch-been auftritt, glaube ich hierin ein Wahrzeichen der griechischen Abkunft

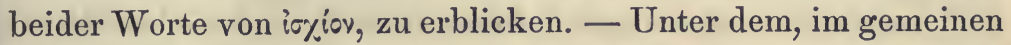
Leben bekannten Schlossbein, wird entweder das ganze Hüftbein, oder nur das Schambein verstanden, weil es mit dem der anderen Seite zusammenschliesst. Es heisst deshalb auch Schlussbein. Das Volk wendet Schloss- und Schlussbein in der Regel nur auf das weibliche Geschlecht an. Bei den Uebersetzern der Araber, tritt auch ein neues Wort für Os coxae auf, als Os anchae oder Os ancharum. Sie bedurften dasselbe, da sie das Oberschenkelbein, Os coxae nannten. Von Constantinus Afer, bis in die Zeit der Wiedergeburt der schönen Wissenschaften, treffen wir diesen Ausdruck in allen anatomischen und medicinischen Schriften an, theils als anchae schlechtweg = Hüft- und Gesässgegend, theils als os ancharum $=$ Hüftbein. Sporadisch kommt es noch im 16. Jahrhundert vor. Durch Vesal wurde es aus der Anatomie verabschiedet, und bleibend durch $O s$ coxae s. coxendicis ersetzt. Näheres über dasselbe, in HL, $\S . X$, Albartafa.

Lateinischen oder griechischen Stammes dürfte das Wort

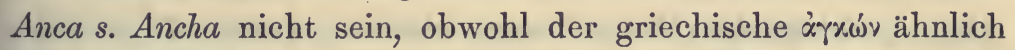
klingt. Aber die Bedeutung des àywóy als Ellbogen, lässt sich nicht auf "Hüfte" beziehen. Das lateinische ancus, im Festus ein Mann, qui aduncum brachium habet, ut exporrigi non possit, ist gleichfalls nicht $\mathrm{zu}$ verwenden. Dietz spricht sich für das altdeutsche ancha aus = Einbiegung. Eine solche Einbiegung zwischen Hinterhaupt und Hals, heisst vielleicht deshalb Nacken, welcher durch Versetzung zweier Buchstaben aus anca hervorging. Der Einbug am Kreuz und seine nächste Umgegend, könnte wohl ebendeshalb zu seiner Benennung ancha gekommen sein. Es ist nicht unmöglich, dass die Normannen, das deutsche Stammwort nach Unteritalien brachten, wo es von den Mönchen, welche die Araber in's Latein übersetzten, euphonischer als das harte coxa befunden, und sofort demselben 
vorgezogen wurde. Lange bevor ancha sich aus der lateinischen Sprache verlor, hat es sich andererseits in den romanischen Sprachen sesshaft gemacht, als französisch hanche, italienisch und spanisch anca, englisch haunches, und in den Compositis: éhanché und sciancato, lendenlahm.

\section{Cranium.}

Während unter Calvaria, nur das Schädeldach verstanden wird, ist Cranium der ganze knöcherne Schädel (to $\leftarrow \dot{j} \mu \pi \propto$ )

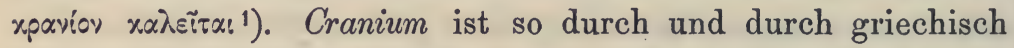
(xpoviov), dass es aus allen lateinischen Lexicis exilirt wurde. Aus Galen ${ }^{2}$ ) und Oribasius lernen wir, woher es stammt. To xpávos (im Genitiv xpáveos), im Eustathius tò xpávoy, im Lucian tò xpavior, ist ein Helm (galea). Da die Schädelknochen das Gehirn wie ein fester Helm umschliessen, erhielt ihre Gesammtheit den Namen Cranium, quia cerebrum, velut galea, $a b$ externis defendit injuriis. Kühn leitet mit Unrecht, xpaviov von xsípw, tondeo, ab. Mit Unrecht sage ich, da nicht die Schädelknochen, sondern die Schädelhaut geschoren wird. Als etymologische Wurzel von cranium, kann nur to xápr, Kopf, angesprochen werden. Von ihm stammt das Homerische xápๆvov, welches auch rápavov geschrieben wird (Eustathius), und per syncopen, xpaviov und cranium giebt.

Viel häufiger als xx́privov, finden wir den Plural xápriva,

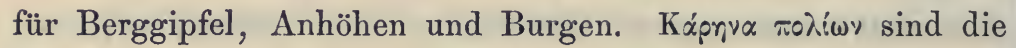

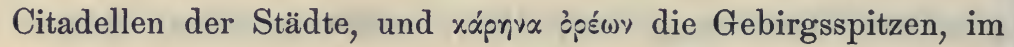
Homer, Anacreon und anderen Dichtern. Das alte róp wird den Aerzten auch durch das noch übliche Aristotelische xxp: $\beta$ api $\alpha=$ temulentia capitis, Eingenommenheit des Kopfes, in

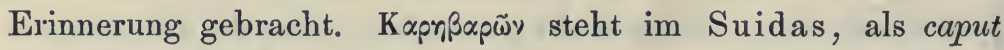

1) Julius Pollux, Onomasticon, Lib. II, Cap. 4, Num. 38.

2) Galenus, De usu partium, Lib. VIII, Cap. 9. 
vino gravatum. - Einer der horrendesten Barbarismen des Gabriel Zerbis, ist Carnerium für Cranium.

Zwei untergegangene Ausdrücke für Hirnschale, sind xóryos und xóry (Muschelschale), im Julius Pollux, und oxapioy (Kahn) im Aristophanes. Die Benennungen des Stirnbeins, als Os prorae, und des Hinterhauptbeins, als Os puppis, welche bei den Arabisten heimisch sind, können, als Schiffersprache, nur in Hinblick auf oxapiov und oxapis (Nachen), entstanden sein. In der That hat ein abgenommenes und umgekehrtes Schädeldach, grosse Aehnlichkeit mit einem kurzen und breiten Boote. Das gothische skip, das spanische esquife, und das französische esquif, sind entfernte Verwandte von Scaphis. Das altfranzösische esquiper, ein Schiff ausrüsten, ging in das neufranzösische équiper über. Equipage, als Schiffsmannschafft, und unsere Equipirung, ergeben sich daraus von selbst.

\section{Cremaster einst und jetzt,}

In den anatomischen Schriften des 14. und 15. Jahrhunderts, herrscht über die Begriffe von Cremaster, Didymus, und Tunica erythroides, eine grenzenlose Verwirrung. Bleiben wir vor der Hand bei Cremaster stehen. Würde man den Lehren Galen's, welche damals so hoch gehalten wurden, bezüglich des Cremaster, treu geblieben sein, wäre es zu keinem Missverständniss gekommen. Galen sagt deutlich und bestimmt: Corpora musculosa ( gastrii, in masculis ad testiculos descendunt ${ }^{1}$ ). An einem anderen Orte, nennt er diese Corpora muscularia: Cremasteres ${ }^{2}$ ).

1) De usu partium, Lib. XIV, Cap. 11.

2) De semine, Lib. II, pag. 635, des Vol. IV der Edit. Operum omnium Galeni, von C. G. Kühn. 
Oribasius') bezeichnet die Cremasteres näher: als duo graciles musculi, in utrumque testiculum pervenientes, quorum unus a pube, alter $a b$ ilium osse exoritur, womit das auf- und absteigende Stück der Cremasterschlinge gemeint sein muss. Fortfahrend: ipsorum munus est, testem attollere, unde Cremasteres vocantur. Der Uebersetzer Rasarius, fügt hinzu: hoc est suspensores. Mit Rufus Ephesius beginnt die Verwirrung. Ihm ist der Cremaster ein Nervus concavus (vEบ̃pov \%oì.०v, worunter er auch das Vas deferens verstanden haben kann ${ }^{2}$ ), qui cum arteria ad testem pervenit ${ }^{3}$ ). Während Vesal mit seiner Tunica carnea, quam testis musculum censemus ${ }^{4}$ ), und seinen Fibrae carneae rectae, quarum ope testis obscure sursum vellitur. ${ }^{5}$ ), dem Galen beitritt, handelt Mundinus vom Suspensorium, i. e. Cremaster, als gesammten Gefässcomplex des Samenstranges, durch welchen der Hode am Unterleib aufgehängt wird ${ }^{6}$ ), also = unserem Funiculus spermaticus. Diese Auffassung des Cremaster als Samenstrang, geht schon in einem unechten Buche des Galen voran ${ }^{7}$ ), in welchem es, Cap. 11, versus finem, heisst: Testiculi sunt conceptacula seminis, quod per cremasteres ad eos fertur, in quos (cremasteres) etiam alia vasa, testes nutrientia, descendunt. Berengarius verwechselt den. Cremaster mit unserer Tunica vaginalis communis des Samenstranges, welche er, wie alle Arabisten, für eine Fortsetzung des Bauchfells hielt, und Didimus s. Cremaster nannte ${ }^{8}$ ). Ganz unverständlich

1) Anatomica ex libris Galeni, pag. 237.

2) Auch bei den Arabisten erscheint das Vas deferens, als Vas nervosum.

3) De partibus hominis, Edit. Clinch, pag. 41.

4) Epitome, Cap. VI, de organis propagationis.

5) Ibid., Cap. II.

6) Anathomia Mundini, Edit. Möllerstadt (Melerstat), in cap. de anathomia didimi.

7) Galeno adscripta Introductio s. Medicus.

8) Isagogae breves, in cap. de vasis seminariis. 
klingt, was A. Benedictus über den Cremaster sagt: Intus (im Hodensack) tunicae sunt, quae testes velant, per singulos nervos dependentes, quos cremasteras Graeci appellant ${ }^{1}$ ). Um das Maass voll zu machen, sei noch bemerkt, dass S. Paulus den Nebenhoden (Parastata circosoides) als Cremaster behandelt ${ }^{2}$ ).

Seit Vesal hatten die Cremasteren keine absurden Auslegungen und Entstellungen mehr zu erleiden. Sie verblieben im Columbus, Fallopia, Laurentius u. A., die Musculi testis, und erhielten ihren angestammten Namen Cremasteres, erst durch Riolan im 17. Jahrhundert zurück. Der deutsche Name Hebemuskeln, richtiger Aufhängemuskeln der

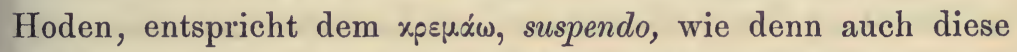
Muskeln im Bartholin ${ }^{3}$ ), als Musculi suspensores testiculorum erwähnt werden, mit der Bemerkung, dass es Menschen giebt, welche dieselben willkürlich in Thätigkeit versetzen können. Dass ausnahmsweise die Cremasteren, die Hoden ganz in die Bauchhöhle hinaufgezogen haben sollen, wird versichert. Der Name Musculus testicondus (Hodenverberger), welcher im Schreger auffällt, ging aus dieser Versicherung hervor. Die schon von Galen bemerkten, vom inneren schiefen Bauchmuskel abstammenden Fleischfasern im runden Gebärmutterband, wurden von Riolan ${ }^{4}$ ) als Cremaster mulieris benannt, und seither allgemein als Analogon des männlichen Cremaster anerkannt.

Das Wort xpsud́rzp. habe ich auch im Aristoteles gefunden, aber als Ankertau, so wie xpśp.xots und xpsuxop.ós, als chirurgische Schwebe, im Hippocrates ${ }^{5}$ ). Die spanischen Matrosen hörte ich ihre Hängematten cremastras nennen.

1) Anatomice, Lib. II, Cap. 20, de scorto (scroto).

$\left.{ }^{2}\right)$ Gorraeus, Definitiones medicae, pag. 246.

3) Institutiones anat., Lib. I, Cap. 22.

4) Anthropographia, Lib. V, Cap. 35.

5) De articulis, IV, 52 und 56. 


\section{Cribrosus und Cribrum.}

Das Siebbein ist eine Congeries cellularum, deren Complex wohl einem Schwamme, aber keinem Siebe gleicht. Nur ein kleines und schmales Plättchen an ihm - das oberste oder horizontale - ist wie ein Sieb durchlöchert. Mit Recht sagt C. Stephanus: in hoc osse, parum de cribro est, quum spongiam potius aequet.

Das Siebbein, als einen selbstständigen Schädelknochen, kannte Galenus nicht'1), da er sich mit der künstlichen Zerlegung des Schädels nicht befasste. Er wusste nur, dass in der Mitte des vorderen Reviers des Schädelgrundes, sich eine durchlöcherte Stelle befindet, entsprechend einer gleichen Durchlöcherung der harten Hirnhaut. Diese durchbrochene Stelle, liess die eingeathmete Luft in die Gehirnhöhlen hinauf, und die Excremente des Gehirns (purgamenta) in die Nasenhöhle herunter. Er sagt: ante meninges sunt ossa, admodum

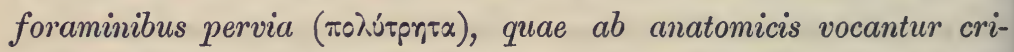

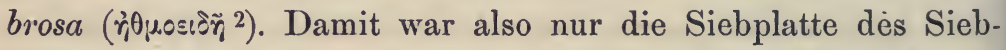
beins gemeint. Unter diesem Sieb giebt es viele Meatus tortuosi et anfractuosi, durch welche die Luft, bevor sie in das Gehirn gelangen kann, sich durchwinden muss, und dabei, wenn sie kalt ist, erwärmt wird: ne aër frigidus recta in cerebri ventriculos se insinuet, quod ipsum cerebrum immodice refrigeraret, omnemque vitam in periculum adduceret $\left.{ }^{3}\right)$. Er sagt weiter: es wäre besser gewesen, dieses Conglomerat von

1) Erst G. Fallopia wies seine Gleichberechtigung mit den übrigen Hirnschalknochen nach (Observationes anat., pag. 30, seqq.), und Vidus Vidius, sein Schüler, gab die erste, freilich sehr armselige Abbildung des emancipirten Siebbeins. Anatome corp. hum., Tab. V, Fig. 15 und 16.

$\left.{ }^{2}\right)$ De usu partium, Lib. VIII, Cap. 7.

3) Ibid., Cap. 6. 
Knochenzellen nicht Siebbein, sondern Schwammbein

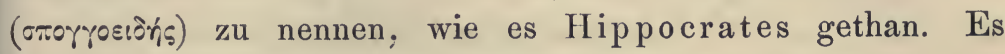
kann nicht verkannt werden, dass er dasjenige meint, was wir Labyrinthus ethmoidalis nennen. Aber das Siebbein, als einen selbstständigen, und aus seinen Verbindungen gelösten Knochen, hat er in seinem Leben nicht vor Augen gehabt. Sein Verehrer, Rufus Ephesius, war nicht weiser als er. Er erwähnt vom Siebbein nichts weiter als: ubi nasi initium

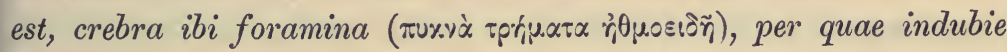
sternutamentum, mucusque propellitur ${ }^{1}$ ).

Die Restauratoren der Anatomie, welche den ganzen Schädelgrund Os basilare nannten, fassten die zarten Knochen im Inneren der Nasenhöhle, wie die Nasenmuscheln, die Pflugschar, das Gaumen- und die Thränenbeine, als Ossa, quae sunt infra basilare, zusammen. Sie kannten sich in denselben nicht recht aus, wie aus ihren Angaben über die Wege entnommen werden kann, auf welchen die Gehirnexcremente (Nasenschleim) in den Rachen und in die Mundhöhle gelangen. Nur der Siebplatte gedenken sie in Galen'scher Weise, und nennen sie ebenfalls Os ethmoides, auch ithmides und itmides ${ }^{2}$ ), und isthmoides, je nachdem sie bessere oder schlechtere Griechen waren. Die Latino-Barbari, welche den Galen übersetzten, gaben das

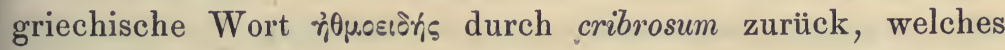
nie und nimmer der lateinischen Sprache angehörte, und leicht auf die Idee bringen könnte, dass, da der Reichthum an einer Sache durch ein Adjectiv in osus ausgedrückt wird (vitiosus, populosus, nemorosus, numerosus, verbosus, etc.), auch cribrosus "reich an S.ieben " bedeuten müsste. Die lateinische Sprache hat, ausser cribrarius und cribratus (beide "durchgesiebt"), kein Adjectiv von Cribrum. Cribriforme, obwohl auch neu,

1) De partibus corp. hum., pag. 34 .

2) Das Os itmides der Latino-Barbari (Zerbis), erklärt sich aus der neugriechischen Aussprache von $r_{i}^{2} \theta \mu \varepsilon_{1} \delta r_{i} s, n$ und $o r=i$, und einem weggeworfenen $h$.

Hyrtl. Onomatologia anatomica. 
wäre jedenfalls besser als cribrosum. Eustachius wich beiden aus, durch sein Os foraminulentum und Os cristatum.

Wenn es also kein Os cribrosum geben darf, so soll es auch im Grunde des Meatus auditorius internus, und im Vestibulum labyrinthi, keine Maculae cribrosae, sondern cribriformes geben. - Dem Cribrum benedictum der alten Aerzte, wollen wir unser stilles Beileid bezeigen. Sie hielten ohne Zweifel, ebenso wie wir, die Harnabsonderung für eine wichtige Ausscheidung schädlicher Stoffe aus dem organischen Haushalt, und benedeiten das Sieb, durch welches diese Ausscheidung vermittelt wird. Das Sieb liegt im Inneren der Niere, und zwar vertical. In dem Raume auswärts vom Sieb, wird das wässerige Blut durch die Vena renalis ergossen. In dem Raume einwärts vom Sieb, sammelt sich das Filtrat als Harn an, und wird durch den Harnleiter in die Blase abgeführt ${ }^{1}$ ). Die Löcher des Siebes, waren die Oeffnungen auf den Papillae renales. Das Cribrum benedictum that seine Schuldigkeit noch im 16. Jahrhundert, bis es durch die Entdeckungen des Lorenzo Bellini und Marcello Malpighi, über die Structur der Nieren, für immer aus der Küche des menschlichen Leibes beseitigt wurde.

Ebenso barbarisch wie cribrosum, ist Colatorium (von colare, durchseihen, filtriren). Die Siebplatte des Siebbeins kann wohl mit einem Sieb, aber ganz gewiss nicht mit einem Filtrirtrichter oder Durchschlag verglichen werden. Die alten Aerzte dachten mehr an die Colatura $\tilde{J} V I$, als an lateinische Grammatik, sonst hätten sie statt des unmöglichen Colatorium, richtig Colum gesagt, oder ganz kurzweg Cribrum, was keiner falschen Auslegung unterliegt.

1) St. Blancardi Lex. med., Artikel Cribrum. 


\section{Cricoideus.}

In Galen's Buch: De usu partium, kommt eine Cartilago cricoidea nicht vor. Galen benennt hier den Ringknorpel, nach seiner Ordnungszahl, als ȯsúrspos đóvòpos, zweiter Knorpel. Seine

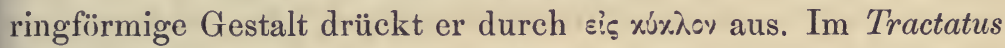
de vocis organo, P. I und III, dagegen, welcher zu den unechten Galenischen Schriften zu gehören scheint, findet sich der yóv¿̀pos xp:xos:ò̀ंs vor. Kpíxos ist jeglicher Ring - am Finger, am Pferdegeschirr, an der Wagendeichsel, u. s. w., - xplrosiòr, also "ringförmig“. Der Umstand, dass Galen in seinem, am meisten von Anatomen studirten Werk: De usu partium, den Ringknorpel nur durch eine Zahl ausdrückt, scheint es zu erklären, warum spätere Anatomen diesen Knorpel häufig Cartilago innomminata nennen, wie Fallopia, Bartholinus, u. m. A. - In der dem Galen zugeschriebenen Dissectio vocalium instrumentorum, 4, heisst es: haec cartilago, sine nomine a veteribus relicta fuit. Da \%oíros im Julius Pollux auch als xiprog auftritt, bedarf die Verwandtschaft von xpixos mit circus und circulus, keiner weiteren Bescheinigung.

Den längsten Namen führt der Ringknorpel im Vesal, welcher in seinem, Bestreben, alle griechischen anatomischen Ausdrücke zu latinisiren, die Cartilago cricoidea mit Secunda laryngis cartilago, quae perfectum circulum conficit, übersetzte. Crycoidea und Crecoidea im Fabricius ab Aquapendente 1) sind Barbarismen. Die Gestalt der Cartilago annularis s. cricoidea, sieht einem Siegelringe gleich, uti ovum ovo. Die Anatomen zogen aber den Vergleich mit jenen Beinringen vor, dessen sich die türkischen Bogenschützen beim Spannen des Bogens bedienen, um bei rasch aufeinanderfolgenden Schüssen, den nackten Finger gegen den Druck der zu spannenden Sehne

1) De larynge, Cap. 5. 
zu schützen. Haec cartilago anmulo osseo similis est, quem Turcae, sagittas ejaculaturi, pollici dextro imponunt, ut ejus annuli beneficio, nervum arcus (Bogensehne) fortius trahant ${ }^{1}$ ).

\section{Crista galli,}

Die Cristae gallorum sind gekerbt. Die Crista des Siebbeins ist nicht gekerbt, also ist sie keine Crista galli, sondern ganz einfach eine Crista ossis ethmoidei. Vesal, welcher bei der Auswahl seiner Benennungen, sonst immer einen richtigen Takt verräth, erfand diesen ungeschickten Tropus, welchen wegzubringen, erst Sömmerring, durch seine Crista ossis ethmoidei, Bedacht nahm.

Noch ungeschickter als Crista galli, ist der Processus acutus des Bartholin, und der Processus cristatus des Eustachius, denn der Fortsatz ist weder spitzig, noch mit einer Crista versehen. Alle übrigen, sehr zahlreichen Cristae in der Anatomie, sind, als scharfe Kämme und Kanten, ganz gut an ihrem Platz.

Ausserhalb der Anatomie, ist Crista der Kamm auf dem Helme, stricte der Federbusch auf dem Kamme, wie er von den Offizieren der römischen Legionen getragen wurde. Die Griechen trugen keine Federbüsche auf ihren Helmen, sondern Büsche aus Haaren der Pferdemähnen, wie auch ganze Rossschweife, welche zum Schutz des Nackens und Rückens, nach hinten herabwallten ( versteckt die Clitoris der weiblichen Scham unter der harmlos scheinenden Crista.

1) Bauhinus, Theatrum anat., Lib. III, Cap. 94. 


\section{Crotaphiticus.}

Kpórap̧os ist in der Ilias die $\mathrm{Schläfe}$ 1), von xporśc (schlagen, pulsiren), des Pulses der Arteria temporalis wegen. Kporapiital heissen im Galen die Musculi temporales ${ }^{2}$ ), und im

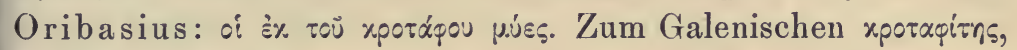
findet sich kein Adjectiv xporaфut\%ós, somit ist auch der Ausdruck Nervus crotaphitico-buccinatorius unrichtig. Palletta ${ }^{3}$ ) belegte mit diesem Namen einen kurzen Zweig des Ramus tertius paris quinti, welcher sich alsbald in einen Ramus temporalis und buccinatorius theilt. Es wäre crotapho- oder crotaphitobuccinatorius zu sagen gewesen. - Im Dryander ${ }^{4}$ ), wird der Schuppennaht des Schläfebeins als Crotaphia gedacht.

\section{Crureus und Cruralis.}

Crus ist "Unterschenkel“, und Musculus crureus s. cruralis somit jeder Muskel des Unterschenkels. Der Name wird jedoch nur auf den, zwischen den beiden Vasti liegenden Muskel angewendet, welcher sich mit diesen, und dem Rectus femoris, zu einer gemeinschaftlichen, an der Spina tibiae sich einpflanzenden Sehne verbindet. Der Name Crureus ist barbarisch, denn es giebt nur ein Adjectiv cruralis. Er ruihrt von Jac. Sylvius ${ }^{5}$ ) her. Noch barbarischer ist der Cruraeus von Jac. Douglas ${ }^{6}$ ). Die gute Benennung als Cruralis, erhielt er von Winslow ${ }^{7}$ ).

1) IV, 502, und $X X, 397$.

2) De musculorum dissectione, Cap. 6.

3) De nervis crotaphitico et buccinatorio, Mediol., 1784.

4) Anatomiae pars prior s. dissectio capitis, Fig. XII.

5) Isagoge, Lib. II, Cap. 7.

6) Myographia comparata, Cap. 41.

¡) Traité des muscles, §. 541 und 1093. 
Da er auf dem Schenkelbein aufliegt, wurde er von Cowper auch Femoreus genannt - Cuissieur von Dumas. Schreger's Bencnnung, als Musculus femoro-tibialis ${ }^{1}$ ), kann nicht gebilligt werden, da jeder vom Schenkelbcin zum Schienbein ziehende Muskel, ein Femoro-tibialis ist. Mein Vastus medius liesse sich statt Cruralis gebrauchen.

Sieh' den Artikel: Vastus.

\section{Cryptae.}

Die Anatomie hat die metaphorischen Ausdrücke Cryptae mucosae und sebaceae beliebt, welche richtiger Cryptae muciparae und sebiparae genannt werden sollten. Das Wort Crypta kam erst im 16. Jahrhundert, durch Carolus Stephanus, Professor der Anatomie und Botanik in Paris (nebenbei auch als tüchtiger Buchdrucker bekannt), in die anatomische Sprache, während es sonst nur im Kirchenlatein üblich war. So heisst es im Glossarium ad scriptores mediae et infimae latinitatis, T. II, pag. 1197 : cryptae appellantur sacella et oratoria subtervanea, in vetustioribus aedibus sacris. Wir finden sie jetzt noch unter den Hochaltären gothischer Kirchen. In einer Urkunde aus dem 9. Jahrhundert, welche Du Cange citirt, erscheint Crypta als Grupta, jetzt noch im südlichen Frankreich croupte, woraus sich die deutsche Gruft ergiebt.

Stephanus nannte nur die Grübchen, in welchen die ihm noch unbekannten Schleim- und Talgdrüsen ausmünden, Cryptae. Als, ein Jahrhundert später, diese Drüsen bekannt wurden, liess man ihnen den von $\mathrm{Stephanus} \mathrm{nur} \mathrm{für}$ ihre Ausmündung'söffnung gebrauchten Namen, welcher durch Haller's Autorität ${ }^{2}$ ), einen bleibenden Platz in der Anatomie

1) Nomenclatur der Muskeln, pay. 42.

2) Elementa physiol., T. V, Lib. 12, Sect. 1. Haller liess die capillaren Arterien in die Höhle der Cryptae einmünden, und 
erhielt, und zwar für jene kleinen Drüschen, welche einen einfachen, unverästelten Ausführungsgang besitzen, und welche dic Histologie unserer Tage als Glandulae acinosae und tubulosae simplices gruppirte. Nur die einfachen tubulösen Drüsen der Darmschleimhaut, werden heute noch öfters Cryptae Lieberkiihnii genannt, obgleich der Name nur auf die Mündungen dieser Drüsen passt. - Ausser zur Bezeichnung gewisser Drüsenformen, wurde Crypta auch für andere Gebilde gebraucht, wie z. B. Crypta Morgagni (Mayer), für Fossa navicularis urethrae, und Cryptae uteri (A. Vater), für die sackförmigen Erweiterungen der Venen des schwangeren Uterus. Die Meibom'schen Drüsen Cryptae zu nennen (Ruysch), lässt sich mit dem Begriff dieses Wortes nicht vereinbaren. Kpí $\pi \tau r_{6}$ (von «pí $\pi \tau(\omega)$, verbergen 1), war bei den Griechen ein Gewölbe zum Aufbewahren verschiedener Gegenstände. und der Ernte: in aedibus cryptae, apothecae, ceteraque, quae ad fructus conservandos magis, quam ad elegantiae decorem possunt esse (Vitruvius). Bei den Römern hiess Crypta ein langer, gewölbter Gang, welcher sich nur mit dem Kreuzgang eines alten Mönchsklosters vergleichen lässt, indem er drei Seiten eines grünbewachsenen, freien Platzes umgab. An seiner inneren Wand, waren kleine Fenster angebracht, welche auf einen Säulengang (Porticus) sich öffneten, und nur wenig Licht in den kühlen

sozusagen den Rohstoff liefern, aus welchem die Crypten ihre Absonderungsproducte bereiten. (Lib. cit., pag. 41, von den Talgdrüsen der Haare).

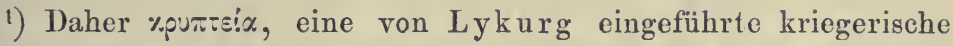
Vorübung der jungen Burschen in Lacädemon, wobei sich dieselben heimlich an die auf den Feldern arbeitenden Heloten (Sclaven) heranschlichen, um sie zu überfallen, auszuplündern, und gelegentlich auch todtzuschlagen, - eine würdige Ein-

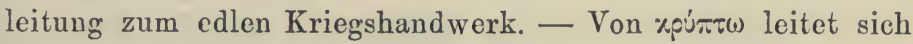

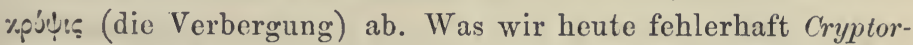
chis nennen, kommt im Galen immer nur als Crypsorchis vor. 
Raum der Krypta fallen liessen. Noch zeigt man in Pompeji die Krypta, welche die Priesterin Eumachia, zur Bequemlichkeit des promenirenden Publicums erbauen liess. Eine wohlerhaltene Inschrift belehrt uns, dass das Gebäude eine Krypta war, welche, wenn die Hitze der Jahreszeit, oder die Ungunst des Wetters, das Ergehen im Freien nicht gestatteten, den Lustwandelnden einen angenehmen Zufluchtsort darbot. Se neca und Suetonius sprechen von Krypten an den Häusern vornehmer Römer, und an den Theatern. Selbst an der Kaserne der Prätorianer, fehlte die Krypta nicht, wie auch in späterer Zeit, die Ställe für Wagen und Pferde bei den Arenen, sonst als Carceres erwähnt, Cryptae genannt wurden. Von unterirdischen Krypten, ist aus der Römerzeit nur die Crypta Suburrae (Juvenal), als Fortsetzung der Cloaca maxima, und die Crypta Neapolitana (Petronius), jetzt die Grotte von Posilippo, bekannt.

\section{Cubitus und Cubitaeus.}

Cubitus (xúßıtov, Hippocrates) erfreut sich dreifacher anatomischer Anwendungen. Die erste ist $=$ Ellbogen. Ihr zu Liebe haben wir eine Articulatio cubiti, und eine Arteria cubitalis. Die zweite = Ulna, Ellbogenröhre, ist schon im Celsus zu finden, wo er von den beiden Vorderarmknochen sagt: Radius superior breviorque, cubitus inferior longiorque est ${ }^{1}$ ). Die dritte stellt den Cubitus dem Olecranon und Ancon gleich. Die letztere findet sich in der Anatomie weniger, als in der Schriftsprache zu Hause, wo sie bei den besten Autoren angetroffen wird, als Stiitzpunkt beim Auflegen des Kopfes, oder beim Erheben des ganzen Leibes aus liegender Stellung, wie Virgil von der Dido:

„Ter sese attollens, cubitoque innixa levavit."

(Aeneis, IV, 690.)

1) De medicina, Lib. VIII, Cap. 1. 
Mit dem Ellbogen stossen, kommt als cubitis trudere, depulsare, pellere, oftmals vor. Auf dem linken Ellbogen sich stützend, lagen die Römer bei der Tafel, daher: in cubitum se reponere, sich zu Tisch begeben, im Horatius.

Von der zweiten Bedeutung des Cubitus = Ulna, wurde der Musculus cubitalis externus et internus des Winslow = Ulnaris ext. et int. entlehnt, welche Ausdrücke weitaus dem Cubitaeus ext. et int. (Riolan) vorzuziehen sind, da es kein

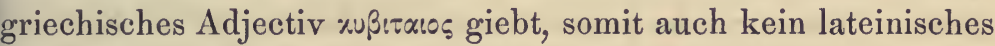
cubitaeus geben kann.

Cubitus, als Längenmaass, gleicht unserer Elle. (Sieh' den Artikel: Ulna.) Cubitus, als Elle, hat sich, mit wandelnder Form, in mehreren romanischen Sprachen installirt, wie im Spanischen codo (alt cobdo), im Portugiesischen covado, im Italienischen cubito, im Französischen coude, und im Wallachischen cod und cot.

Der deutsche Ausdruck für Cubitus: Ellbogen und Elbogen, entspricht ganz dem altdeutschen elboga, aus boga, Bug, und el, Arm, zusammengesetzt, also der "Armbug", wie es einen "Kniebug" giebt. Das altdeutsche el, Arm, findet sich im Rabanus Maurus als Elina.

\section{Cucularis oder Cucullaris?}

Die meisten Anatomen schreiben mit dem ersten Erfinder dieses originellen Ausdrucks, R. Columbus ${ }^{1}$ ): Musculus cucullaris. Einige folgen dem A. Spigelius, welcher Cucularis gebraucht: primus musculorum scapulae, cucularis dicitur ${ }^{2}$ ), obgleich der Zusatz: quod cum conjuge, cucullos monachorum non inepte exprimat, dafür Zeugniss giebt, dass Spigelius, welcher übrigens ein sehr guter Lateiner war, nicht an cuculus,

1) De re anatomica, Lib. V, Cap. 15 .

$\left.{ }^{2}\right)$ De corp. hum. fabrica, Lib. IV, Cap. 13. 
sondern an cucullus gedacht hat. Cuculus wäre "Kukuk", cucullus ist "Kapuze". Die deutsche Anatomie hat nie einen Kukuksmuskel, wohl aber einen Mönchskappen- oder Kapuzenmuskel geführt. - Man darf nicht von einem parigen Musculus cucullaris, oder von Musculi cucullares handeln, ebensowenig als von einem parigen Musculus trapezius, denn nur das Paar, nicht jede einzelne Hälfte des Paares, bildet eine Mönchskappe, mit weit auf den Rücken herabrëichendem Zipf. - Cucullus, im Klosterlatein Cuculla, war nicht blos den Mönchen bekannt. Schon die Römer trugen Cuculli als Kopfkappen, welche am Oberkleide (sagum, lacerna, oder poenula) befestigt waren. Leute, welche in Folge ihrer Beschäftigung im Freien, viel den Unbilden der Witterung ausgesetzt waren, trugen gewöhnlich solche Cuculli, wie jetzt noch die italieni- schen Barcarioli und Matrosen. Martial erwähnt derselben: „Non te cucullis asseret caput tectum."

(Epigram., XI, 93.)

Martial sagt uns zugleich, im zweiten Epigramm des dritten Buches, dass der eigentliche Sinn von Cucullus, jener einer Papierdüte ist, in welche Apotheker und Gewürzkrämer Pulver und Droguen einzuwickeln pflegten, wie es jetzt noch Brauch ist:

„Vel thuris piperisque sis cucullus.“

Die spitzige Form des Stanitzels, liess das Wort auf die spitz endigende Kapuze ïbertragen. Im Casserius Placentinus werden die Nasenmuscheln, ihrer eingerollten Form wegen, Cucullae genannt - die Stanitzelbeine der Wiener Anatomen. Zinn nannte den dïtenförmigen Scyphus Vieussenii, mit unterer Spitze und oberer Basis: Cucullus cochleae ${ }^{1}$ ).

Zur Entschuldigung des Spigelius kann noch angeführt werden, dass Cucullus auch als Cuculio vorkommt, wonach

1) Observationes anat., de cochlea auris, pag. 33. 
Cucularis nicht unbedingt zu verdammen wäre. Warum der deutsche Uebersetzer der Anatomie des Winslow, sich für Cucullaris zum Tischmuskel versteigen konnte, wird im Artikel Trapezius gesagt.

\section{Cunnus.}

Sieh' den Artikel: Vulva.

\section{Cupula,}

Cupula kommt in der Anatomie nur ein einziges Mal vor, als Cupula infundibuli cochleae, die gewölbte Decke der letzten halben Schneckenwindung, und des in ihr befindlichen Scyphus (Infundibulum). Seit Valsalva, gelangte dieser Ausdruck zu allgemeiner Geltung. Cupula ist das Diminutiv von Cupa. Cupa, verwandt mit dem deutschen Kufe und Küpe (Küfer und Küper, Fassbinder), war ein aus hölzernen Dauben (tabulae) construirtes, und mit eisernen Reifen (circuli) zusammengehaltenes Fass für Wein und Oel. Vinum de cupa, im Cicero, Wein vom Fass. Cupula wäre also „kleines Fass". Aber Cupula hat, nach dem Lex. lat. von Georges, auch die Nebenbedeutung von Gewölbe, in specie Grabgewölbe, und nur in diesem Sinne war Cupula für die Kuppel der Schnecke brauchbar. Kuppel aber, als Dach in Form einer Halbkugel, wie das italienische cupola, und das französische coupole, kommt von Kuppe, welcher Ausdruck, als rundlicher Gipfel, von Bergen (Schneekoppe), von den Fingerspitzen (Fingerkuppen), und von den grossköpfigen Radnägeln (Kuppnägeln) gebraucht wird. 


\section{Dartos, Erythroides, und Elytroides.}

Dartos, das nichtssagende Wort, hat seine Stellung in

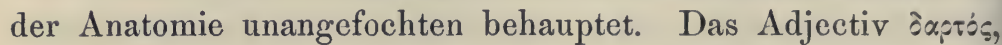

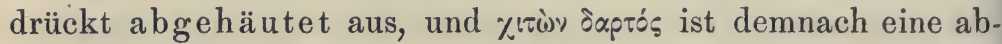

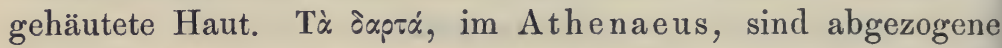
Fische. Japró, als ein anatomisches Object, wird uns zuerst von $\mathrm{Rufus}$ gebracht: circa testes tunicae sunt, erythroides una, dartos altera nominatur ${ }^{1}$ ). Der Uebersetzer fügt hinzu: latinis carent nominibus. Etwas mehr erfährt man aus dem untergeschobenen Buch des Galen: Introductio s. medicus. Dort heisst es, in Cap. XI: Testiculi duabus tunicis conteguntur, quarum tenuiorem erythroidem, valentiorem dar'tum appellant; - ab his est, quod scrotum ( $\dot{\eta}$ bै $\%$ ) dicitur. Dass mit Erythroides nur unser Cremaster, und mit Dartos nur die Fleischhaut des Hodens gemeint sein kann, ergiebt sich uns aus Gorraeus: prima et intima membrana, quae testem involvit, Epididymis est $\left(\right.$ Epididymis $=$ Albuginea testis $\left.{ }^{2}\right)$, post eam Erythroeides, tertia Dartos, carnosa et erythroide multo valentior, quarta et exstima scrotum est. Vesalius behandelt die Dartos als Membrana carnosa, und Spigelius als excoriabilis ${ }^{3}$ ), was dem Sinne des griechischen Wortes gleichkommt. Das Marsupium carneum im lateinischen Winslow, steht im Gegensatz zum Marsupium schlechtweg $=$ Hodensack.

Die Tunica erythroides, welche in obigen Citaten neben Dartos steht, lässt sich auf keine andere Haut des Samenstranges beziehen, als auf die Fleischbündel des Cremaster (ępuOpós, roth). Da nun aber auch die Dartos roth ist, wurde die Erythroides mit der Dartos nicht eben selten verwechselt, oder als synonym damit gehalten (wie im Pierer). Daraus

1) De appellatione partium, pag. 41 .

2) Sieh' den Artikel: Epididymis.

3) De corp. hum. fabrica, Lib. III, C'ap. 17. 
erklären sich auffällige und unverständliche Widersprüche in den anatomischen Schriften vor Vesal.

Die Tunica elytroides (unrichtig elythroides und ellythroides), wird mit erythroides, des ähnlichen Klanges wegen, verwechselt, obwohl, vi nominis, unter elytroides nur die Tunica vaginalis communis testis et funiculi spermatici (Neubauer) verstanden werden kann. "Eivtpov bedeutet schon im Hippocrates eineHülle oder Scheide. Er nennt die Häute des Rückenmarks:

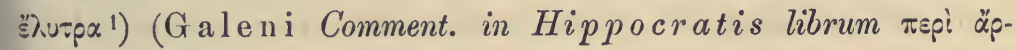
Opwr, 3). Tunica elytroides kann demnach nur die gemeinschaftliche Scheidenhaut des Hodens und Samenstranges sein, welche, ihrer Dünnheit wegen, die rankenförmig gewundenen Blutgefässe des Plexus pampiniformis durchscheinen lässt, und aus

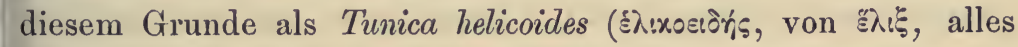
Gewundene) vorkommt ${ }^{2}$ ). - Während die Anatomen des 15. und 16. Jahrhunderts die Tunica elytroides häufig für erythroides anwenden, zeigte zuerst Rolfink den essentiellen Unterschied beider ${ }^{3}$ ). Wir sind durch die treffliche Schrift J. E. Neubauer's ${ }^{4}$ ), in den Besitz viel besserer Namen für die Scheidengebilde um den Hoden herum gekommen, und vernehmen darum nichts mehr von Tunica erythroides, elytroides, und helicoides.

\section{Decidua,}

Es wurde viel darüber gestritten, was die Membrana decidua $\mathrm{Hunteri}$ im schwangeren Uterus eigentlich sei. Einige

1) Im Aristoteles werden die Flügeldecken der Käfer, elytra genannt.

2) Riolani Anthropographia, Lib. II, Cap. 31.

3) Ordo et methodus generationi dicatarum partium, Jenae, 1664, Pars I, Cap. 16.

4) Diss. de tunicis vaginalibus testis et funiculi spermatici, Giessae, 1727. 
halten sie für eine Neubildung, Andere für die metamorphosirte Uterusschleimhaut. Diesen Streit haben die Anatomen auszufechten. Hier nur von der Benennung der Membran. W. Hunter, welcher diese Haut zuerst näher untersuchte und abbildete, gab ihr den Namen Decidua s. Caduca ${ }^{1}$ ), weil ihr deutliches Vorhandensein, nur auf die Dauer der Schwangerschaft beschränkt ist. Anatomen und Geburtshelfer, übersetzten diese Worte mit: hinfällige Haut. "Hinfällig" bedeutet so viel als "vergänglich"; deshalb entspricht das deutsche Wort der vergänglichen Existenz der Hunter'schen Membran. Nicht so deciduus. Deciduus findet nur dann Anwendung, wenn ein Ding, wie es ist, von dem Orte, wo es sich befindet, wegfällt (de und cadere). Das thut die Membrana decidua nie. Sie vergeht, aber sie fällt nicht ab. Plinius, in welchem deciduus oft erwähnt wird, bezeichnet damit die Geweihe der Hirsche, die Milchzähne, die Blätter der Bäume, den Blitz (ignes coeli decidui), und die Sternschnuppen, welche er für Sterne hielt, die vom Himmel in den Weltraum fallen (sydera decidua), und welche Seneca richtiger Stellae transvolantes nennt. Caducus hat zwar auch dieselbe Hauptbedeutung wie deciduus ${ }^{2}$ ), wird aber von Cicero im Sinne von vergänglich gebraucht: res humanae fragiles et caducae. Für eine Haut, welche dem Verfalle, dem Untergange geweiht ist, entspricht sonach Caduca weit besser als Decidua. Jeder Kenner der lateinischen Sprache wird es uns bestätigen.

Diese Membran war den Anatomen des 18. Jahrhunderts nicht gänzlich unbekannt. Die Membrana retiformis des Hoboken ${ }^{3}$ ), und die Membrana filamentosa des Röder er ${ }^{4}$ ), geben Zeugniss davon. Sie hat nur ein einziges Synonymon. Es

1) Anatomy of the human gravid uterus, Tab. 33 und 34 .

$\left.{ }^{2}\right)$ Aqua caduca, Wasserfall, bello caduci, gefallene Krieger, folia caduca, u. m. a.

3) Anatomia secundinae humanae, Ultrajecti, 1669, pag. 217 und 285.

4) De foetu perfecto, Argentorati, 1750, pag. 7. 
findet sich in Hildebrandt's Anatomie, als Pars uterina placentae. Ich halte diesen Ausdruck für ebenso unrichtig als Decidua, weil unter ihm nur jener Theil der Decidua verstanden werden kann, welcher der Anheftungsstelle des Mutterkuchens entspricht.

Was die Decidua reflexa und serotina sind, und ob es solche Membranen überhaupt giebt, gehört nicht vor unser Forum.

\section{Deferens vas,}

Dem Vas deferens kam ich zuerst im Carpus auf die Spur. Keiner seiner Vormänner wusste etwas vom Vas de. ferens. Sie nannten es entweder nach dem Vorbild der lateinischen Uebersetzung des Avicenna durch Gerardus: Evacuatorium oder Expulsorium seminis, oder nach Mundinus: Vas nervosum, womit sie dessen Härte ausdrücken wollten. Statt Vasa deferentia, kommen uns auch häufig die Canales, oder Pori, oder Meatus, oder Ductus deferentes in den Weg, selbst Itinera seminaria und Venae genitales - Alles als verschieden-

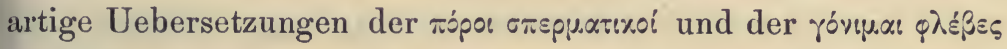
des Rufus. Bauhinus hatte an den Evacuatoria der Arabisten nicht genug, und verbesserte sie, nach seiner Art, zu Vibratores und Jactatores ${ }^{1}$ ). Er wollte wohl Ejaculatores sagen, nach dem Beispiel des Piccolhomini.

Carpus war im Latein ein wahrer Barbar. Ein gutes Wort hat er selten gebraucht. Sein Vas deferens muss uns, als Sprachrichter, schon deshalb verdächtig erscheinen. Bedenken wir noch, dass de, in allen seinen Zusammensetzungen, den Begriff herab oder herunter ausdrückt, so müssen wir unumwunden die Benennung: Vas deferens, für ein Gefäss, welches den Samen nicht herab-, sondern vom Hoden zum Unterleib hinaufführt, für eine verfehlte und verwerfliche

1) Theatrum anat., Lib. I, Cap. 28. 
erklären. Wir lesen in den Classikern von einem fulmen, in terras delatum, von einem semen, quod ex arbore in terram. defertur; Virgil lässt den Himmelsbogen (Iris) in terram deferri, und Cicero den Bodensatz einer Flüssigkeit deferri ad imum. Man möge also lieber bei den Pori spermatici des $\mathrm{Rufus,}$ als bei den Vasa deferentia bleiben. Die deutsche Sprache hat, wie immer, so auch hier ganz wohl daran gethan, die Vasa deferentia, als zurückführende Samengefässe zu geben, denn der Weg von den Hoden zu den Samenbläschen, ist ein rückläufiger.

\section{Dentes canini s, angulares, sapientiae, caysales,}

\section{Dentes canini s. angulares.}

Es muss auffallen, dass diesen Zähnen ihre absurden Namen am längsten verblieben. Sie passen nur auf die Fangzähne der reissenden Thiere. Die Zahnreihen des menschlichen Ober- und Unterkiefers, bilden parabolisch gekrümmte Bogen. Bei den Carnivoren dagegen, bildet die Reihe der Schneidezähne, mit jener der Mahlzähne einen stumpfen Winkel. An der Spitze dieses Winkels steht der gewaltige Fang-oder Reisszahn. Ihm entspricht durch seine Stellung, nicht durch seine Form, Länge, Grösse oder Stärke, im menschlichen Gebiss ein Zahn, welcher zwischen den Schneidezähnen und Mahlzähnen steht, und Eckzahn, dens angularis, heisst. Da der menschliche Zahnbogen keine Winkel (Ecken) bildet, passt auch der Name Eckzahn, nicht auf den fraglichen Zahn im Menschen, ebensowenig als dens caninus s. laniarius, Hundszahn, wie ihn Aristoteles zuerst nannte (xuvócous, im Galen

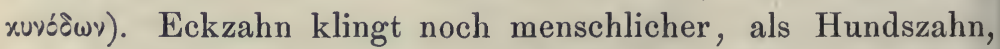
welcher nur in der Anatomie geduldet wird. Wird der Arzt einer Mùtter sagen: Ihr Kind bekommt die Hundszähne, und ein Zahnarzt zu einer Dame: Sie müssen sich Thren Hundszahn reissen lassen? Die beiden Zahnnamen haben sich aber 
in der Sprache der Anatomie und des gewöhnlichen Lebens so tief eingewurzelt, dass der bessere: dentes cuspidati im Vesal, Spitzzähne (der einspitzigen Krone wegen), kaum mehr gehört wird, obgleich die nächsten Nachbarn dieser Spitzzähne, ihrer zweispitzigen Kronen wegen, noch immer, nach Hunter ${ }^{1}$ ), bicuspidati, zweispitzige, heissen. Der Name Augenzahn, dens ocularis, convenirt nur dem oberen Spitzzahn, weil nach einer uralten, und täglich sich erneuernden Erfahrung, auf sein gewaltsames und ungeschicktes Ausbrechen (nicht methodisches Ausziehen), sich Entzündungen einstellen können, welche selbst den Inhalt der Augenhöhle in Mitleidenschaft ziehen, wie Celsus ${ }^{2}$ ) sagt: dens haerens (festsitzend) cum summo periculo evellitur, idque etiam majori periculo in superioribus dentibus fit, quia potest tempora oculosve concutere. Wie übrigens dieser römische Zahnbrecher gewirthschaftet haben muss, lässt sich daraus ersehen, dass er selbst gesteht: interdum maxilla loco movetur. Die Worte des Celsus wurden von den Chirurgen des Mittelalters so sehr respectirt, dass selbst unternehmende Männer, wie Lanfrancus war, sich scheuten, einen Stockzahn des Oberkiefer's zu nehmen ${ }^{3}$ ).

\section{Dentes sapientiae.}

Dieser im Ernst gemeinte, nicht humoristische Ausdruck, stammt von den Griechen her. Schon im Hippocrates heissen

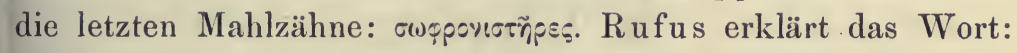

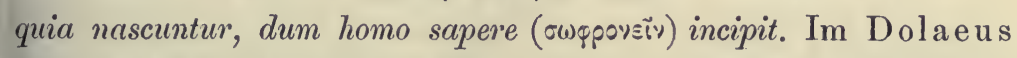
finden wir die Dentes rationis, und im Gorraeus, die Dentes sensus et intellectus. Erst Riolan machte sich über die Weisheitszähne, welche, gelinde gesagt, vor dem Forum der Wissenschaft, eine vox inepta sind, lustig, indem er alle anderen consequent Dentes stultitice nannte. - Mag der harmlose Weisheitszahn seine Beliebtheit im täglichen Leben behalten!

1) Nat. history of teeth, pag. 78 .

2) De medicina, Lib. VII, Cap. 12.

$\left.{ }^{3}\right)$ Ars completa totius chirurgiae, Tract. III, Div. 3, Cap. 8. Hyrtl. Onomatologia anatomica. 
Letzter Backenzahn, wie er im Sömmerring genannt wird, wäre für den Ernst der Anatomie zukömmlicher.

3. Dentes caysales, cayseles und caiseles.

Diese Benennung der Weisheitszähne, welche bei den Aerzten und Anatomen der Schola Monspessulana gefunden wird, konnte ich in keinem Lexicon auftreiben. Vermuthungen über den Ursprung eines so seltsam klingenden Wortes, habe ich an einem anderen Orte 1) vorgebracht. Arabisch, Hebräisch, und Griechisch, geben keinen Fingerzeig auf das Nationale dieses Fremdlings. Und doch ist Caysales, wie ich durch Professor Mussafia erst neulich erfuhr, ein ganz genuines und nur wenig entstelltes Wort der provençalischen Sprache, in welcher die Kinnlade cais, und darnach die Mahlzähne dents caissals heissen. Dietz ${ }^{2}$ ) leitet das Wort cais von dem lateinisehen cassus (capsus), "ein Behältniss" her, da die Kinnlade ein Behältniss für die Zähne bildet. Die Caysales haben also nichts Fremdartiges angenommen, als das $y$, welches die Mode der Zeit, so oft dem $i$ substituirte. Dass man nur die Weisheitszähne, nicht die Mahlzähne iiberhaupt, caysales nannte, befremdet wenig, da man auch die Benenuung der Mahlzähne als genuini im Cicero, auf die Weisheitszähne transferirte.

\section{Diaphragma,}

Ueber Diaphragma, wird in verschiedenen Artikeln dieses Buches, so viel gesprochen, dass ich mich hier kurz fassen kann. Der Stamm des Wortes Diaphragma, ist dıxp̧px́scscy, "durch eine Scheidewand trennen". Jede Scheidewand, mag sie quer, senkrecht, oder schief stehen, ist also ein Diaphragma. Plato verstand unter Diaphragma, nur das Zwerchfell, als Scheidewand zwischen Brust und Bauch. Die

1) HL, §. L்̇XX, Negueguil, und Nachträge dazu auf pag. 296.

2) Etymologisches Wörterbuch der Romanischen Sprachen, Artikel Casso. 
griechischen Anatomen dagegen, gebrauchten dieses Wort auch für das Mediastinum, für den Processus falciformis major, für die Trommelmembran, fuir die Nasen- und Herzscheidewand, für das Septum pellucidum, Hippocrates auch für den Gaumen. Dieser vielfachen Anwendungen des Wortes Diaphragma wegen, zogen viele Griechen es vor, das Zwerchfell Phrenes, Diazoma, Hypozoma, und Perizoma zu nennen, welche im Mittelalter durch Praecordia, Cinctus, Discrimen, und Dissipium wiedergegeben werden 1). Diaphragma ist blos: Septum in genere. Celsus that gut daran, das Adjectiv transversum, dem Septum anzuhängen ${ }^{2}$ ). Die Arabisten, welche auch einen breiten Muskel Panniculus (Fell) nannten, wie die Panniculi carnosi infimi ventris (Bauchmuskeln) bezeugen können, machten sich aus Diaphragma ihren Panniculus transversus, und dieser ist. die Mutter des deutschen Zwerchfells geworden, in welchem nicht das alte oberdeutsche Zwerch (quer), welches sich nur im Wienerischen „über zwerch" (kreuzweis) erhalten hat, sondern das Fell, das Auffallende ist, da sonst nur Häute überhaupt in der alten Anatomie Felle genannt wurden, wie Hirnfell, Brustfell, Bauchfell, Mittelfell, Trommelfell, etc.

\section{Diaphysis.}

Die anatomische Diaphyse ist ein, seiner ursprünglichen Bedeutung gänzlich entfremdetes Wort. Die Mittelstücke der Röhrenknochen heissen in der Anatomie Diaphyses. Galen kennt dieses Wort nicht. Im Hippocrates und Aristoteles

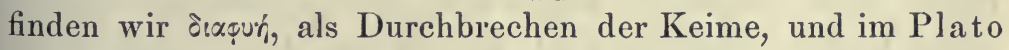
als Gelenksverbindung. Die Lexica führen es noch als Knoten

1) Sieh' über diese Worte, und andere Synonyma diaphragmatis, Pierer's Realuörterbuch, Artikel Diaphragma.

2) De medicina, Lib. V, Cap. 26. 
am Rohre, als Narbe an Früchten, und als Spalte zwischen je zwei Zähnen auf. Dí́ourı̨, das Durchwachsen im Theophrastus, kam erst im vorigen Jahrhundert in die Anatomie, wie es scheint durch Heister '), welcher unbegreiflicher WVeise sich auf Galen beruft. Galen kannte wohl Apoplyysis und Epiphysis, aber nicht Diaphysis. Die Ableitung des Wortes von $\delta$ ¿quj das Mittelstück der langen Knochen, als Zwischenglied zwischen den beiden Epiphysen, mit diesem Namen belegt wurde.

\section{Digitationes hippocampi.}

Das Seepferd der Dichter hat weder Zehen noch Klauen, sonder'n Hufe, wie andere Pferde, oder Schwimmfüsse. Die Anatomen wissen zwar, was sie unter Digitationes zu verstehen haben, aber ein Römer würde es nicht gewusst haben. Das Wort Digitatio, geht der lateinischen Sprache vollständig ab. Dass es sich bei den anatomischen Digitationen um Zehen, um Finger, oder um etwas Finger- oder Zehenähnliches handelt, versteht sich wohl von selbst. Digitatus, zehentragend, wendet Plinius an, um den Unterschied der Aves digitatae und palmipedes (Schwimmfüssler) auszudrücken. Digitatio könnte nach Art der Worte: conjunctio, separatio, compositio, compressio, etc., welche eine Handlung, keinen Zustand, bedeuten, nur den Act bezeichnen, durch welchen etwas in zehenartige Theile gespalten wird. Der Pes hippocampi ist jedoch entweder ein huftragender Fuss, oder ein Palmipes, ein Schwimmfuss, dessen Zehen nicht gespalten, sondern durch die Schwimmhaut zu einem Ruder verbunden sind. Ersetzt man Hippocampus durch Hippopotamus, wie Arantius that, so kann man eine Digitatio seines Fusses zugeben, da das Nilpferd, wie der Elephant, wirklich plumpe und kurze Zehen, ohne Nägel, an den Füssen

1) Compendium anat., Osteologia, §. 46 . 
hat: aliqua similitudine pedis animalis fissipedis, sed unguibus destituti ${ }^{1}$ ).

Die Anatomie der Jetztzeit verfügt über vier verschiedene Digitationes. Die erste gehört der Tuba Fallopiae an, deren Fimbrien hin und wieder Digitationes genannt werden (Ornamenta foliacea im Regnerus de Graf ${ }^{2}$ ), Pavillon im Winslow). Die zweite Art der Digitationes, bildet die Spaltung der Aponeurosis palmaris in vier zungenförmige Fortsätze, welche an die untere Fläche der Fingerscheiden treten (Loder). 3. Digitationes werden von den Anatomen des vorigen Jahrhunderts, auch die fleischigen Ursprungszacken jener Muskeln genannt, welche als Serrati bekannt sind. Man folgte hierin dem Beispiel Vesal's, welcher diese Ursprünge, an mehreren Stellen mit Fingern verglich: costis singulis, quasi digitos porrigendo ${ }^{3}$ ). Die vierte Art von Digitationes, sind jene des grossen und kleinen Seepferdfusses. Die drei bis vier Digitationen des grossen Seepferdfusses, sind kleine, ovale Erhabenheiten am unteren breiten Ende dieses Gehirntheiles. Sie könnten für Zehenstummeln imponiren. Die Digitationen des kleinen Seepferdfusses sind länger, aber schwächer ausgeprägt, und an Zahl, selbst an Vorkommen, sehr wandelbar. Ihnen verdankt dieser Hirntheil den Meckel'schen Namen: Eminentia digitata, welcher bezeichnender ist, als Calcar avis, bei den älteren französischen Anatomen ergot, der Sporn des Hahnes, da sich letzterer Name, nur auf den kleinen Seepferdfuss, wenn seine Digitationen zufällig fehlen, anwenden lässt. Das nämliche muss von der Unguis Haller ${ }^{\dagger}$ ) gesagt werden. Haller schreibt: Der kleine Seepferdfuss sei wie eine Vogelklaue krumm: in modum unguis incurvi avis rapacis ${ }^{5}$ ).

1) Haller, Elem. physiol., Lib. X, Sect. 1, §. 15.

2) De mulierum organis, Cap. XIV, pag. 258 der Opera omnia R. de Graaf.

3) De corp. hum. fabrica, Lib. II, Cap. 31.

4) Günther's Entwurf einer anatomischen Nervenlehre, 1789, pag. 29.

5) Elem. physiol. Lib. X, Sect. 1, §. 15. 
Hippocampus nannte Plinius einen kleinen, sehr bekannten Seefisch, jetzt Syngnathus hippocampus, - der einzige, welchen die Italiener nicht essen. Er hat einen Kopf, welcher wirklich jenem oines Pferdes ähnlich sieht. Er schwimmt nicht mit horizontal, sondern mit vertical gehaltenem Leib, welchen er durch das Padel seiner Rückenflosse (alle anderen fehlen)

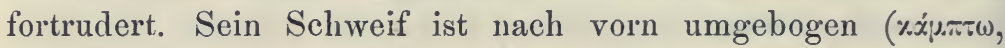
biegen), und dient als Greifschwanz, Cauda prehensilis, zum Umklammern der Seegewächse. Da er keine Füsse hat, kamn der Pes hippocampi nicht nach ihm benannt worden sein. Eine zweite Art von Hippocampus, sind jene fabelhaften Thiere, welche die Dichter der Muschelequipage des Neptuns und der Thetis vorspannen. Sie haben den Vorderleib eines Pferdes, aber statt des Hintertheiles, einen langen, aufgeringelten Drachen- oder Fischschweif. So nach einem sehr gut erhaltenen Pompejanischen Gemälde in den Römischen Alterthümern von Anthony Rich, pag. 311. Blos die pfotenähnlichen Vorderfüsse sind vorhanden, als wirkliche Pferdefüsse, mit Hufen, nicht mit Klauen oder Zehen. Solche Hippocampi sieht man in den Gärten Italiens häufig an Fontänen angebracht. Die Hippocampi an dem herrlichen Springbrunnen auf dem Domplatz in Salzburg, haben wahre Schwimmfüsse, d. h. durch Haut verbundene Zehen. So auch an dem monumentalen Brunnen von Bernini, auf der Piazza Navona in Rom. Diese Schwimmfüsse sind zugleich nicht im Winkel gebogen, denn sie haben keine Kniee, sondern prïisentiren sich als bogenförmig gekrümmte Pfoten, wodurch sie eben mit den bogenförmig gekrümmten Pedes hippocampi des Gehirns vergleichbar werden. Nur auf die italienischen Hippocampi mit Schwimmfüssen, kann die Benennung der Digitationes pedis hippocampi bezogen werden. Der erste, welcher dieses that, war ein Italiener: J. C. Arantius ').

1) Observationes anat., Venet., 1587, Cap. IV, pag. 45, Sieh' auch Caspar Hofmann, Comment. in Galeni librum de usu partium, Num. 559 und 643. 
Ein nicht minder auffälliger Name für den grossen Seepferdfuss, welchen Günther auftiseht, ist Ocrea, worunter man, wenn auch nicht ganz richtig, Stiefel versteht. Ein Stiefel im Gehirn! Man fühlt es, wie wahr Haller sprach: qui criticam anatomen scribit, multam inveniet mutandorum in cerebro nominum causam. Ocrea, x»nví, war ein Rüstungsbestandtheil aus Erz oder Zinn, welcher das Schienbein, bis über das Knie hinauf bedeckte ${ }^{1}$ ). Die Griechen und Etrusker trugen diese Schienen an beiden Füssen, die schwere römische Infanterie aber nur am rechten Knie, welches bei der Formirung eines Carré vorgesetzt wurde ${ }^{2}$ ). Die Abbildung in Rich's Alterthïmern (pag. 420), lässt auch nicht die entfernteste Aehnlichkeit mit dem gebogenen Pes hippocampi erkennen, welcher, eben seiner Biegung und Krümmung wegen, auch den Namen Cormu Ammonis s. arietis (Widderhorn) führt, obgleich dieser Name ursprünglich von Winslow nur den auf dem Seepferdfuss aufliegenden hinteren Schenkeln des Fornix, welche zugespitzt endigen, verliehen wurde, - die Frenula Tarini ${ }^{3}$ ). Einen Stiefel mit einem Horn zu vergleichen, fällt Niemanden ein. Wie kam es also zu solchem Vergleich? Durch eine von Günther verschuldete Verwechslung von Calceus (Schuh oder Halbstiefel) mit Ocrea. Die Aegyptier und Etrusker trugen Schuhe, mit einer langen, auf- und rückwärts gebogenen Spitze, wie man auf Monumenten sieht. Von den Etruskern kam dieser Schnabelschuh zu den Römern, welche ihn Calceus repandus, aufgebogener Schuh, nannten (Cicero), auch Calceus uncinatus (Cato). Im Mittelalter trugen die Adeligen, selbst wenn sie zu Pferde sassen, solche Schuhe, mit ungewöhnlich langen, aufgebogenen Schnäbeln. Die hackenförmige Biegung des Seepferdfusses konnte wohl die Anregung zu

1) Varro, de lingua latina, Lib. V, Cap. 116.

$\left.{ }^{2}\right)$ Vegetius, de re militari, Lib. I, Cap. 20.

3) Tarin, Adversaria anat., Paris, 1750, I, pay. 2. 
einem Vergleich mit dem Calceus repandus gegeben haben. Dadurch findet der Stiefel (Ocrea) Verzeihung, vorausgesetzt, dass er für den Schnabel eines Calceus repandus angezogen wurde.

\section{Diploëticus oder Diploicus? - Diploë,}

Wir finden allenthalben nur diploëticus. Es heisst immer: Venae diploëticae, Vasa diploëtica, Substantia diploëtica, - niemals diploica. Und doch ist nur diploicus sprachlich gut. Wenn aus griechischen Worten, welche in ein $\eta_{\text {e }}$ endigen, Beiwörter gebildet werden, so geschieht dieses durch Verwandlung des

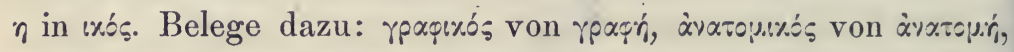

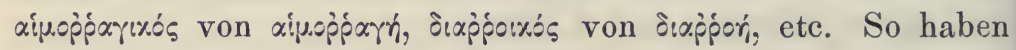
auch die lateinschreibenden Anatomen, viele ihrer Adjective nach dieser Regel gebildet, wie z. B. motus diastolicus und

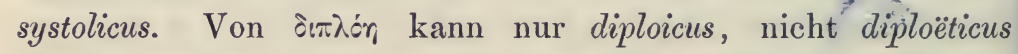
formirt werden. Die Adjective in $\dot{r}_{0} \times x_{0}$, , werden nur aus Hauptwörtern, welche in roıৎ endigen, gemacht, wie diaphoreticus, diureticus, phreneticus, patheticus, poëticus, exegeticus etc., von diaphorēsis, diurēsis, phrenēsis, pathēsis, poï̈sis, exegesis, u. s. w., welche alle die Penultima lang haben. Eine diploessis giebt es nicht, ergo auch kein Adjectiv diploëticus.

Noch ein Wort über Diploë. Bei ihrem ersten Auftreten in der Anatomie, war Diploë nicht das, was és jetzt ist. In der primitiven Aera unserer Wissenschaft, war Diploë, die "doppelte Tafel" der Hirnschalknochen. Als solche kommt sie schon im Hippocrates vor 1). Galenus folgte auch hierin seinem verehrten Meister und Vorbild ${ }^{2}$ ). $\Delta: \pi \lambda \iota^{\prime}$, als

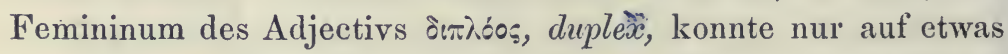
doppeltes angewendet werden. Heissen doch auch die Processus durae matris, welche Galen als Duplicaturen dieser Membran

1) In dem echten Buche de capitis vulneribus, Lib. II, Cap. 2 u. 3.

2) Methodus medendi, Lib. VI, Cap. 6. 


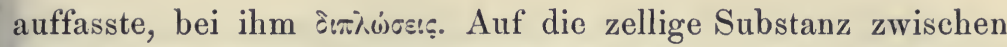
den beiden Tafeln der Schädelknochen, wurde Diploë erst

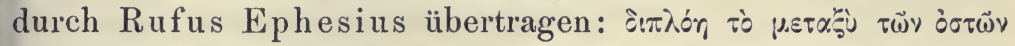
тој xpavios (diploë inter cranii ossa meditullium ${ }^{1}$ ). Und so verblieb es auch für immer.

In der alten Chirurgie begegnen wir der Diploë, als ein zusammengelegtes Tuch, zum Bedecken von Wunden und Geschwüren (Compresse), welches von $\mathrm{Paulus}$ A e gin eta $\pi \tau \dot{\gamma} \gamma \mu_{x}$, von Hesychius aber $\delta(\pi \lambda \omega \mu, x$ genannt wird. Diplö̈s, wie die Arabisten schreiben, ist keineswegs $=$ Diplö̈, da unter Diplö̈s immer nur ein Mantel, eine Toga verstanden

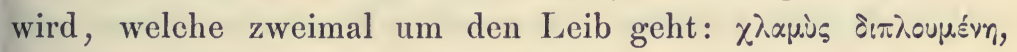
im Hesychius. Einige Anatomen, wie Rolfink, bedienten sich der Diploë und des Diploma als Ausdrücke für Doppelhäute, und die Chemiker für Doppelgefässe, Einsatzgefässe (vas clausum, quod in aliud vas, aqua fervente repletum immittitur, Kühn). Als solches erscheint Diploma schon im Galen (de locis aff., Lib. VII), wo er die Vorschrift zur Bereitung des Theriaks und der Unguente giebt. Sie müssen हेy $\delta เ \pi \lambda$. u.atı gekocht werden. Diploma hat jetzt nur die Bedeutung von „offener Brief" ${ }^{2}$, und jedem anderen gefalteten, zusammengelegten Papier, wie Pass, Urkunde, Anstellungs- und Ernennungsdecret, u. s. w. Diplomata civitatis heissen im Suetonius, die Urkunden über Verleihung des römischen Bürgerrechtes. Die Kunst, viel gefaltetes Papier anzuschreiben, heisst Diplomatik. Der Träger solcher Papiere (Courier), wie der Aufbewahrer derselben (Archivar), wird Diplomarius, unrichtig Diplomatarius genannt, beides neuere Bezeichnungen, schlechter als das alte Tabellarius, von tabula, Urkunde.

1) De partibus corp. hum., pay. 34 .

2) Literae principis vel magistratus, quibus alicui aliquid conceditur, dictae a forma $=$ tabula duplex. Forcell. 


\section{Disdiaclasten.}

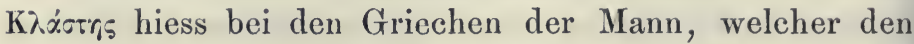
Weinstock beschneidet (Lex. Hesychii, = ג̇jasiouprós). $\Delta: \alpha$ -

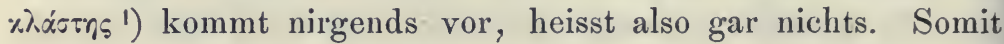
kann das moderne Disdiaclastes (Brü̈cke), nur zweimal gar nichts heissen. Mit der Erfindung solcher Worte, wird der Wissenschaft nicht gedient.

Es war nicht nöthig, für eine so bekannte Sache, wie es die Scheiben sind, aus welchen die Primitivfasern der animalen Muskeln bestehen, einen neuen Namen zu bilden. Es war zugleich unbesonnen, diesen Namen nach einer Eigenschaft jener Scheiben zu formiren, welche sie mit vielen anderen Körpern gemeinschaftlich besitzen - auf ihre doppelte Lichtbrechung. Der Name lautet Disdiaclasten. Sehen wir ihn etwas näher an, so stellt sich heraus, dass er mehr sagt,

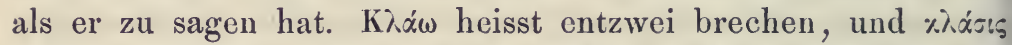

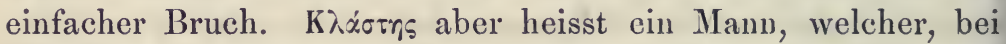
der Pflege des Weinstocks, Blätter und Ranken desselben ein-

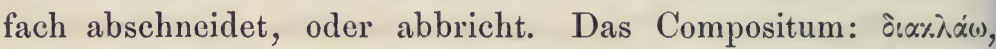
besagt: in Stücke zerbrechen, zersplittern, und das neu entstandene Disdiaclast, würde somit zu verstehen sein, als ein Doppelzersplitterer, unter welchem man sich eigentlich nichts Vernünftiges denken kann. Der Lichtstrahl wird von den Scheiben der Muskelfasern nicht einfach, sondern doppelt gebrochen, aber weder einmal noch zweimal zersplittert. Diclast für Doppelbrecher zu sagen, wäre zu entschuldigen gewesen, wenn schon überhaupt im Griechischen gemacht werden muss. Warum aber nicht bei den Scheiben bleiben, welche als Elementarscheiben der Muskelfasern, sich

1) Nur das Zeitwort $\delta เ \alpha \% \lambda \alpha^{\prime} \omega$, wird für durchbrechen, entkräften, und verweichlichen, im Aristophanes und Lueian angetroffen. 
ganz gut ausnehmen würden, oder auch als Sarcodisci anständig

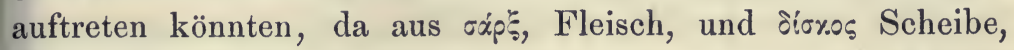
eine solche Verbindung hergestellt werden kann. Ridicula est simulatio graeci sermonis, quam adeo frequenter scriptores nostri aevi prae se ferunt; nisi enim id, quod optime latinis (vel germanis) verbis exprimi potest, graeco vocabulo insigniant, putant,

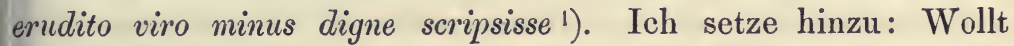
ihr schon griechische Worte machen, nun so lernt früher Griechisch.

\section{Diverticulum.}

Blind endigende Anhängsel des Darmkanals, Diverticula zu nennen, ist ein sprachlicher Missgriff leichteren Grades. Diverticulum war bei den Römern ein von der Hauptstrasse abzweigender Nebenweg $\left.{ }^{2}\right)$ : semita, quae a latere est viae militaris ${ }^{3}$ ). Dieser Nebenweg musste wohin führen. Die Diverticula des Darmes führen nirgends hin, weil sie blind endigen. Es kann für sie nur die Benennung Appendix angezeigt sein, welche sie auch im Haller führen ${ }^{4}$ ). Will man aber einen Tropus haben, nun so nenne man sie Deversoria oder Fundulae. Deversoria waren entweder die an der Heerstrasse gelegenen Herbergen (tabernae meritoricue des Valerius Maximus ${ }^{5}$ ), oder Häuser, welche sich reiche Privatleute an den Hauptstrassen bauen liessen, um bei länger dauernden Reisen, mit aller Bequemlichkeit darin zu übernachten ${ }^{6}$ ). Fundula wäre

1) C. G. K̈̈hn, Opuscula academica, Vol. II, pag. 261.

2) Terentius, Eunuchus, Act. 4, Sc. 2, Vers 7.

3) Der Arm eines Stromes, welcher sich wieder mit dem Hauptstrom verbindet, hiess im spätern Latein ebenfalls Diverticulum (Papinianus).

1) Elem. physiol., T. VII, Lib. XXII, Sect. 2, §. 20.

5) Meritoriae sicher nicht von meritum, sondern von merces, Lohn, weil für die Unterkunft in ihnen bezahlt wurde.

6) Cicero, ad famil. VII, 21. 
noch besser, da es ein Sackgässchen, ohne Ausgang bedeutet ${ }^{1}$ ). Dasselbe wurde bereits, als Fundulus, von Varro, auf den Blinddarm angewendet ${ }^{2}$ ).

Seit Ludwig seine Dissertation über die Darmdivertikel schrieb ${ }^{3}$ ), hat die Benennung Diverticula, dic früher übliche als Appendices verdrängt. Ist auch der Name Diverticulum nicht ganz stichhältig, so ist el doch verständlich. Die Diverticula Cotunnii, wie Mcckel die Aquaeductus Cotunnii richtig benannte ${ }^{4}$ ), verdienen allen Beifall, da sie wirklich Ein- und Ausgänge haben. Das Gegentheil muss von dem Diverticulum Vateri gesagt werden, welches kein Diverticulum ist, sondern eine Erhebung der Schleimhaut des Zwölffingerdarms, über der etwas erweiterten Verbindungsstelle des Ductus choledochus mit dem Wirsungianus ${ }^{5}$ ).

Die bei vielen Fleischfressern (Canis, Lutra, Phoca, u. m. a.) vorkommende, besonders beim Elephanten sehr entwickelte, ampullenförmige Erweiterung des gemeinschaftlichen Gallenganges, unmittelbar vor seiner Ausmündung in das Duodenum, in welche gewöhnlich auch der. Wirsungische Gang sich entleert, darf deshalb nicht Diverticulum, sondern muss Ampulla genannt werden. Von dem Diverticulum Heisteri $\left.{ }^{b}\right)$, worunter der obere Bulbus der inneren Drosselader verstanden wird, gilt dasselbe. Heister selbst stellt zu seinem Diverticulum, auch Saccus.

\section{Ductus, Aquaeductus, Meatus und Porus,}

In der Anatomie wimmelt es von Ductus, als Kanäle und Gänge. In der lateinischen Sprache wimmelt es auch von

1) Varro, de lingua latina, V, 32, §. 145.

2) Lib. cit., V, 22, §. 111,

3) Diss. de diverticulis intestinorum, Lips., 1779.

4) De labyrinthi auris contentis, Argent., 1777, §. 26.

5) A. Vater, de novo bilis diverticulo, Vitebergae, 1720.

6) Compendium anatomicum, T. I, pay. 159. 
Ductus, in einer Menge von Bedeutungen, aber nur ein einziges Mal als Kanal zur Leitung von Flüssigkeiten, im ductus aquae. Ductus kommt von duco, führen. Darum heisst die Anführung, das Commando der Soldaten: Ductus im Cicero ${ }^{1}$ ); das Führen der Feder: Ductus literarum im Quinctilian; die Führung schneidender Werkzeuge, wie des Messers, der Sense, des Schwertes; die Gesichtszüge: Ductus oris; der symmetrische Baustyl: Ductus aequalis im Lucretius; die Führung eines Grabens, einer Mauer: Ductus fossae und muri; die Führung, die Periode und der innere Zusammenhang einer Rede, die Art der Führung eines Processes, und die Aufführung eines Theaterstückes: Ductus schlechtweg, oder Ductus rei. Die staunenerregenden Aquaeductus der Römer, und unsere winzigen Ductus glandularum, passen schlecht zusammen. Obscure Anatomen, welche nicht als Vorbilder guter Latinität gelten können,

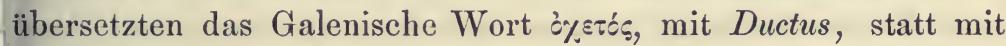
Canalis, und der einmal begangene Fehler, wucherte so fruchtbar fort, dass alle Drüsenausführungsgänge, selbst einige Blutgefïsse (Ductus Botalli, Ductus venosus Arantii), der Hauptstamm des lymphatischen Gefässsystems, der Thränennasengang, die Fallopischen Trompeten und die häutigen Bogengänge, zu Ductus gemacht wurden, während Canalis und Porus, nicht auf Wasser allein beschränkt sind, wie der Ductus, sondern Kanäle für was immer für eine Flüssigkeit abgeben können, welche weitsinnige Bedeutung, als offener oder geschlossener Kanal,

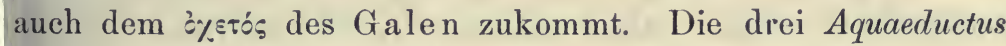
aber, welche in die Osteologie eingeschmuggelt wurden, wie der Aquaeductus Fallopiae, der Aquaeductus Cotunnii ad vestibulum und ad cochleam ${ }^{2}$ ), sind, wie Allen bekannt, keine Wasserleitungen, heissen aber in Ewigkeit so. Wir wollen die Ductus aus der Anatomie nicht ausmerzen, wohl aber die

1) Pompejus rem optime suo ductu gessit. Manil. 21.

2) De aquaeductibus auris humanae, Neap. 1761, und Viennae, 1774. 
Aquaeductus. Die Ductus kïnnen, jedoch nur als Tropen, in der prosaischesten aller Wissenschaften verbleiben.

Meatus, von meo, gehen, steht dem Canalis und Porus weit nach, indem meistens nur der Act des Gehens, des Fliessens, des Bewegens überhaupt, Meatus heisst: solis lunaeque meatus im Lucretius, meatus aquilae im Tacitus, der Flug des Adlers, meatus spiritus s. animae im Plinius, die Athembewegung. Aber auch das, worauf gegangen wird, der Weg, findet sich im Tacitus und Valerius Maximus, als Meatus vor, wie es in-unseren Häusern und Gärten, Gänge giebt. Als Flussbett wurde uns Meatus, schon durch die Classiker bekannt: Danubius in Pontum sex meatibus erumpit (Tacitus), und bifido meatu divisus Rhenus (Claudianus). Als cylindrischer, d. i. geschlossener Kanal, dient Meatus nie. Man soll deshalb lieber Porus acusticus externus et internus, statt Meatus auditorius externus und internus sagen, weil Porus, wie Canalis, immer ein röhrenartiges Hohlgebilde ist. So nannte schon Herophilus die Sehnerven, Pori optici, weil er sie für hohl hielt, um die Bilder der Gesichtsobjecte in die Gehirnkammern zu befördern 1), und im Galen finden wir den Gehörgang, den Samengang (Vas deferens), und die Gallengänge ganz richtig als rópo aufgeführt. Die drei Meatus narium, stehen mit der grammatikalischen Bedeutung von Meatus, nicht in Conflict, da sie keine geschlossenen Gänge sind, sondern offene Räume oder Wege, auf welchen die Luft durch die Nasenhöhle streicht. Beispiele für Meatus, als geschlossener, röhrenförmiger Kanal, sind nur in der alten Anatomie zu finden. 1. In dem Meatus urinarius (Ureter), als ungeschickte Uebersetzung des rópos oupricixós im Galen, welcher auch als Porus uritis, und durch Schreibfehler, als Porus viridis, in den Schriften der LatinoBarbari, sich herumtreibt. 2. Als Meatus seminalis, sowohl für das Vas deferens, als für die Tuba Fallopiae, welche für den Ausführungsgang des weiblichen Hodens (Testis muliebris, $i$. e.

1) Galenus, de symptomat. diff., Lib. I, Cap. 2. 
Ovarium) gehalten wurde, und den weiblichen Samen in die Höhle des Uterus führt, wo durch seine Vermischung mit dem männlichen, der Embryo entsteht.

\section{Ductus arteriosus Botalli.}

Der Ductus Botalli ist ein Anachronismus. Das die Pulmonal-Arterie mit der Aorta verbindende Gefäss, und seine unausbleibliche Obliteration, war schon zu Galen's Zeiten bekannt, wie folgende zwei Stellen aus Cap. 6, Lib. XV, de usu partium, bezeugen: quum haec vasa (Art. pulmonalis und Aorta) aliquantum inter se distarent, aliud tertium vas natura effecit, quod utrumque conjungeret, und gleich darauf: id vas, quod magnam arteriam (Aortam) cum vena, quae ad pulmonem fertur (unsere Art. pulmonalis), connectit, quum aliae omnes partes animalis augeantur (anwachsen), non modo non augetur, verum etiam tenuius semper effici conspicitur, adeo, ut tempore procedente, penitus tabescat et exsiccetur. Es war also historische Unerfahrenheit, oder Keckheit, sich im 16. Jahrhundert die Entdeckung dieses Ganges, und des gleichfalls von Galen ganz genau angegebenen Foramen ovale in der Scheidewand der Vorkammern des Herzens, zuzuschreiben. Die Franzosen belegten sofort beide Gebilde mit dem Namen ihres Landsmannes, als Conduit de Botal und Trou de Botal (Lieutaud). Botal selbst nannte den Gang Vena arteriarum nutrix, weil er venöses Blut in das Arteriensystem bringt ${ }^{1}$ ).

1) Opera omnia, Edit. Van Horne, L. B., 1660, pag. 66. Die Originalschrift Botal's: Commentarioli, Lyon, 1565, in welcher iiber den fang und das Loch gehandelt wird, ist sehr selten geworden. Da in den Operibus, auch über Lues venerea gehandelt wird, befindet sich in einem unteren Winkel des Titelkupfers, als Staffage, ein kleines Pärchen, in coitu flagranti! Die Figürchen sind so klein, dass sie ron den Argúsaugen der Bibliophilen, nicht bemerkt wurden. 
So viel über die Sache; nun auch über das Wort.

Der Mann, welcher sich für den Entdecker dieser beiden Gebilde hiclt, hiess nicht Botalli, sondern Leonard Botal. Er war in der piemontesischen Stadt Asti (Asta Pompeja) berühmt durch seinen lieblichen Vino d'Asti, und durch Alfieri's Geburtshaus - geboren, und gehörte, wic der Name ausdrückt, einer französischen Familie an. Die Franzosen haben ihn deshalb immer als ihren Landsmann reclamirt. Er studirte in Padua, wo sein anatomischer Lehrer Fallopia, den fraglichen Gang genau kannte, und in seinen Observationibus anatomicis beschrieb. Aber Botal war ein unternehmender Mann (wir sagen Schwindler), und wusste Nutzen davon zu ziehen. So schrieb er denn das oben erwähnte kleine Büchlein, welches in Frankreich so viel Aufsehen erregte, dass der Verfasser es sehr schnell zu einer angesehenen Stellung brachte, und Leibarzt König Heinrich III. und seiner Familie wurde. Die Italiener beurtheilten sein Verdienst weit strenger, und machten es eigentlich zu nichte. J. B. Carcanus, Professor in Pavia (De cordis vasorum in fetu unione, Ticini, 1574), und eine anonyme Schrift: De Botallianorum nupero invento, Patav., 1640, sicherten dem Galen die Ehre der Botallischen Entdeckungen.

Die französischen Namen, welche mit $l$ endigen, werden nicht mit Verdoppelung des $l$ latinisirt, sondern durch einfache Annexion von ius, wie Cabrolius (Cabrol), Fernelius (Fernel), Portalius (Portal). Somit hat man von Botal, Botalius, nicht Botallus zu machen.

\section{Duodenum.}

Wenn wir zurückschauen in das Alterthum der griechischen Medicin, erscheint uns der Zwölffingerdarm als Ecphysis (Ёxưvis Herophili), i.e. das aus dem Magen Hervorwachsende. Indem der Zwölffingerdarm kein Mesenterium besitzt, und keine Schlingen bildet, wie der übrige Dünndarm, sah man in ihm 
lieber einen Auswuchs, einen Appendix des Magens, als ein selbstständiges Stück des Darmkanals. Unser oft in Anspruch genommener Gewährsmann über die Dictiones Herophili, sagt hierüber: intestinum duodenum Herophilus éxф̣voเ (scil. ventriculi) appellat, et est principium intestini, priusquam in anfractus convolvatur '). Diese Ecphysis kommt aber schon im Hippocrates als Auswuchs anderer Art, als Knochenauswuchs vor. Herophilus charakterisirte sie also näher als dode-

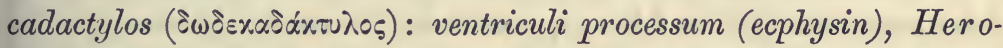
philus Dodecadactylon vocat, a duodecim digitorum longitudine, nomen ipsi imponens ${ }^{2}$ ). Der Uebersetzer des Canon Avicennae, Gerardus, brachte uns das barbarische Wort Duodenum ${ }^{3}$ ), welches von Mundinus aufgegriffen, von Vesal und von allen folgenden Anatomen beibehalten wurde. Barbarisch nenne ich das Wort, erstens, weil es von Gerardus zu uns kam, welcher nicht anders als barbarisch zu schreiben wusste, und zweitens, weil die Spätlateiner nur ein Duodennium, contrahirt für Duodecennium (Codex Theod.) erblicken lassen, und das Beiwort duodenus (je zwölf) im Julius Caesar, nur im Plural: duodeni, angewendet wurde. Celsus kennt das Duodenum gar nicht als ein besonderes Darmstïck: a pyloro jejunum intestinum incipit $\left.{ }^{4}\right)$. Statt der vox inepta: $\mathrm{Z}$ wölffingerdarm, liesse sich im Deutschen, sehr gut Gallendarm sagen.

Luschka äussert sich über die abgeschmackte Benennung des Zwölffingerdarms folgendermassen: „Im Widerspruche mit seiner von Herophilus eingeführten Benennung, besitzt das Duodenum weder eine der Länge noch der Breite von zwölf Fingern entsprechende Grösse, und sollte daher jener allen Sinnes entbehrende Terminus aufgegeben, und dieses Darmstück deshalb eher Intestinum pancreaticum genannt werden

1) De venarum et arteriarum dissectione, Cap. 1.

2) De locis affectis, Lib. VI, Cap. 3.

3) Canon, Lib. III, Fen 16, Tr. 1, Cap. 1.

4) De medicina, Lib. IV, Cap. 1 .

Hyrtl. Onomatologia anatomica. 
weil es der ganzen Länge seiner Concavität nach mit der Bauchspeicheldrüse, deren Gang überdies in dasselbe einmündet, in der innigsten räumlichen Beziehung steht" ${ }^{1}$ ).

\section{Dura und pia mater.}

Dura und pia mater stammen aus dem Anfang dieses Jahrtausends. Haly Abbas, welcher 994 starb, gebrauchte in seinen Almaleki (Liber regius) für Hirnhaut, den Ausdruck: umm al-dimāgh, welcher in der lateinischen Uebersetzung von Stephanus Antiochenus, mit mater cerebri richtig gegeben wurde. Die arabische Sprache drückt öfter das Erzeugende und Ernährende, mit umm, mater, aus, wie in mater fuviorum für Quelle, mater siderum für Nacht, mater arboris für Wurzel, mater caloris für Fieber, mater venarum für Hohlader, u. v. a. Haly führte diese poetische Sprachweise auch in die Anatomie ein, in den matres cerebri, welche fast in allen Sprachen bleibende Unterkunft fanden. Nur die deutsche Sprache hat ihre Aufnahme verweigert, und blieb bei der harten und weichen Hirnhaut, obwohl sie das Wort Mutter, als Erzeugendes und Einschliessendes, in vielen zusammengesetzten Ausdrücken ${ }^{2}$ ) verwendet, und auch den Uterus, Mutter, nennt, und Muttertrompeten, Mutterbänder, Mutterfraisen, Mutterkränzchen, und derlei mehr, alltäglich im Munde führt.

1) H. Luschka, Die Anatomie des Menschen etc., 2. Bd, I. Abth., Seite 205.

2) Mutterlauge, Essigmutter, Aalmutter, Schraubenmutter, Perlmutter, Muttererde (natürliche Gartenerde, im Gegensatz der künstlich zugerichteten), Muttergestein, Mütterchen (Metallring zur Aufnahme des Hackens einer Heftel), u. m. a. Wenn aber der Wein auf der Mutter lieg't, so ist hier Mutter = Hefe, Bodensatz, und kommt vom altdeutschen modder = dicker Schlamm. 
Avicenna nahm den Terminus des $\mathrm{Haly}$ nicht an, sondern bediente sich für die Hirnnhäute, des Wortes ghischājain, was Gerhardus Cremonensis mit Panniculus übersetzt. Er unterscheidet zwei Panniculi: den safĩq (spissus), und den raqīq (tenuis).

Die Griechen kannten nur zwei Hirnhäute: $\mu \tilde{r} v\left\llcorner\gamma \xi \xi x \lambda \eta \alpha^{\prime}\right.$

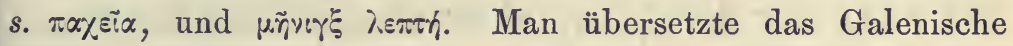

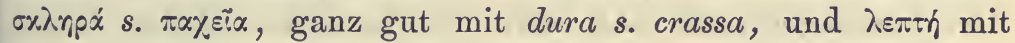
subtilis oder tenuis. Statt tenuis wurde aber von den Uebersetzern des Haly Abbas, welche Mönche waren, pius substituirt, da das arabische raqū $q$, nebst tenuis, auch misericors und pius bedeutet, welches letztere den frommen Männern besser zusagte, als tenuis. So kam die Pia mater zu ihrem frommen Namen, welcher ihr so lange anhängen wird, bis man sich gewöhnt haben wird, die drei Hirnhäute, histologisch: Meninx fibrosa, serosa, und vasculosa zu nennen. Letztere Benennung, für pia mater, kann sich selbst einer sehr alten Abstammung rühmen, denn im Oribasius finde ich, statt

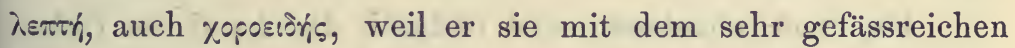
Chorion der schwangeren Gebärmutter vergleicht. Das Chorion, wird mit Amnion und Placenta, als Secundinae zusammengefasst (das griechische $\tau \grave{\alpha}$ dsútspa). Wir finden deshalb die Pia mater, im Mittelalter öfters als Secundina cerebri. Da sie die zweite damals bekannte Hirnhaut war, wäre sicher, wenn man diesen numerischen Rang hätte ausdrücken wollen ${ }^{1}$ ), Secunda cerebri, nicht Secundina gesagt worden.

Mehr Sprachliches über die Meninges, enthält HL, §. LVI, Dura und pia mater.

\section{Embryo.}

Embryo sollte Embryon geschrieben werden: tò Ėviòs $\tau \tilde{\eta} \varsigma$ rastpòs Bpúov (Eustathius), von Bpúw, wachsen, was im Leibe

1) Wie Achillinus und Laurentius meinen. 
wächst. Das griechische ěp.ßpuov ist generis neutrius, und hat

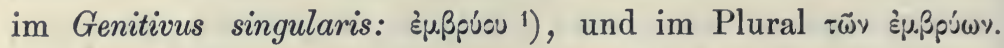
Es wäre also das gebräuchliche Embryo Embryonis, in Embryon Embryii zu corrigiren, wie es bereits mehrfach, besonders von Sprachkennern, wie C. G. Kühn, geschah. Ganz willkürlich, und ohne allen Grund, bezieht man Embryo auf die frühere, und Foetus auf die spätere Entwicklungsperiode der Frucht. Der Sprachgebrauch hält sich aber an keine stricte Regel, und behandelt Embryo und Foetus ganz promiscue. Im Galen finden wir auch xúnux ${ }^{2}$ ), als Bezeichnung einer ganz jungen Leibesfrucht, von xúw, empfangen. Embryo ist nur im medicinischen Latein, sonst nirgends, zu Hause. Die Franzosen, Italiener und Spanier, blieben bei Embryon (Embryon, Embrione und Embrion). Die Glossaria haben Embryum und Embrium.

\section{Emissaria,}

Um Seen abzuleiten, und dadurch das Land vor Ueberschwemmung zu schützen, oder um versumpfte Ländereien für den Ackerbau zu gewinnen, legten die Römer aus diesen Seen und Sümpfen Abzugskanäle - Emissaria - zu den nächsten Flüssen an ${ }^{3}$ ). Staunenerregende Arbeiten unternahmen sie zu diesem Zweck. Wir sehen sie jetzt noch wohlerhalten vor uns, in den Emissarien des Albaner und Fuciner Sees. Das letztere besteht aus einem, drei englische Meilen langen Tunnel, welcher mit Meissel und Hammer durch den Fels gehauen wurde, in einer Tiefe von tausend Fuss! Suetonius ${ }^{4}$ )

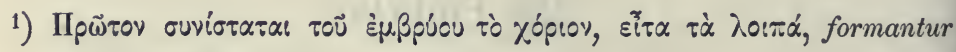
primo secundinae foetus, deinde reliqua.

2) De semine, Lib. I, Cap. 9.

3) Cicero, ad fam., XVI, 18, und Plinius, Hist. nat., Lib. XXXIII, Cap. 4, Seite 21.

4) Vita Claudiani, 20. 
sagt von ihm: per tria passuum millia, partim effosso monte, partim exciso, canalem aegre, et post undecim annos absolvit, quamvis continuis, triginta hominum millibus, sine intermissione operantibus. Fischteiche, kleine Seen in den Gärten, hatten gleichfalls ihre Emissaria (Plinius).

Die anatomischen Emissaria wurden nicht von Santorini entdeckt, sondern nur von ihm als Emissaria benannt 1). Galen kannte die Emissaria nicht. Was er àywyo! und bysto! (conductus und rivi) nennt, sind nicht die Emissaria, sondern die von den Sinus durae matris zur harten Hirnhaut abgehenden Venen. Berengarius, Nic. Massa, und Car. Stephanus gedenken ihrer ebenfalls, jedoch nicht als Abzugskanäle der Sinus, sondern als zuführende Gefässe derselben, weil zur Zeit dieser Männer, noch die Galenische Lehre in voller Geltung stand, dass die Venen das Blut $\mathrm{zu}$, nicht von den Organen führen.

Das Emissarium parietale wird im Riolan ${ }^{2}$ ), als Vena Jesue aufgeführt: Vena interdum reperitur in vertice, quae per duo foramina (unsere unconstanten Foramina parietalia) foras excidit, cujus meminit Rases in libro primo Continentis ${ }^{3}$ ), et appellat Venam Jesue. Ein arabischer Arzt, Namens Jesue, hat aber nie existirt ${ }^{4}$ ). Die Geschichte kennt aber zwei Mesue, den älteren und jüngeren. Der ältere (Abu Zakarijja Jahia Ben Mâsaweih), lebte vor Rases, konnte also wohl von ihm citirt werden. Er war durch ein halbes Jahrhundert Leibarzt der

1) Observationes anat., Venet., 1724.

2) Anthropographia, Lib. IV, Cap. 2.

3) Kitäb al-chawi, Liber continens s. Comprehensor, enthält das erste System der praktischen Medicin, und stand deshalb durch Jahrhunderte in hohem Ansehen.

4) Ein Arzt Namens Isa Ben Ali Cahhal, oft als Jesu Hali erwähnt, lebte zwar zu Anfang dieses Jahrtausends in Spanien, hat aber nur über die Krankheiten des Auges, und dessen Anatomie geschrieben, im Tadzkeret alcahhalia, welches in Haller's Bibliotheca anat., T. I, pag. 135, genannt wird, und in der alten Venetianer Collectio chirurgica abgedruckt wurde. 
Chalifen, von Harun al Raschid bis Motawakkel, und zugleich erster Arzt am grossen Hospital zu Bagdad. Die Araber verdanken ihm mehrere Uebersetzungen griechischer Aerzte. Er starb im Jahre 857 christlicher Zeit. Er schrieb ein berühmtes Werk: Nawādir al-tibb, dessen lateinische Uebersetzung: Selecta artis medicae, eines der ersten italienischen Druckwerke bildete, und 1489, zu Bologna aufgelegt wurde. Im Capitel de usu venaesectionis et cucurbitularum, werden zwei Löcher am Scheitel (alema und alihema - das al-qimmah des Avicenna) erwähnt, welche Mesue an Gräberschädeln gesehen hatte. Er dachte sich, dass Zweige der Kopfvenen (Jugularis, Guidez) durch sie zur harten Hirnhaut gehen. Da nun die Emissaria, als knochendurchsetzende Venen, bei den Griechen nicht vorkommen, welche nur die Sinus kannten, gebührt wohl den Arabern die Ehre, ein anatomisches Object zuerst beachtet zu haben, dessen erschöpfende Behandlung den Namen des Santorini, in album aeternitatis eingezeichnet hat. Die erste medicinische Anwendung des Wortes Emissarium, finde ich im Scribonius Largus, einem Arzte, welcher unter Tiberius, also zu Ende der aetas aurea latinitatis lebte, und ein Buch de compositionibus medicamentorum geschrieben hat. In diesem (Cap. 229) steht: emissarium vomicae facere, für Abscess eröffnen.

\section{Emulgentes,}

Nach den physiologischen Vorstellungen der Alten über die Harnsecretion, konnte es nur Venae emulgentes geben, aber keine Arteriae emulgentes. Diese letzteren kamen erst in viel späterer Zeit hinzu, blos der Gesellschaft wegen. Das in der Leber bereitete Blut, muss von seinem wässerigen Ueberfluss (superfuitas aguosa) gereinigt werden. Diese Reinigung besorgen die Nierenvenen, welche aus dem Stamme der Vena chillis (Hohlvene), das wässerige Blut ebenso an sich ziehen, wie die Vena splenica, das mit schwarzer Galle noch gemischte Blut, 
aus der Pfortader an sich nimmt. Die Nierenvenen überliefern das wässerige Blut den Nieren, wo das Wasser durch das Cribrum benedictum (sieh' cribrum) abgeseiht, und mit ein wenig cholera citrina (gelbe Galle) gefärbt, als Harn in die Blase geschafft wird. Die Nierenvenen melken also das Wasser aus der Hohlvene, zur Harnbereitung aus - inde nomen: venae emulgentes, welchen wir zuerst im Mundinus lesen '). Die Arteriae renales enthalten blos Lebensgeister, welche nicht gemolken werden. Sie konnten deshalb auch nicht Arteriae emulgentes genannt werden. - Als im Laufe der Zeit, die Ansichten über die Harnbereitung sich aufklärten, verblieb doch den Nierenvenen ihr alter Name, welchen man auch den Arterien beilegte (Bartholinus), weil zusammengehörige Arterien und Venen, gleichbenannt zu werden pflegen.

\section{Encauston dentis.}

Wenn die neueren Anatomen, mit Hunter, die Glasur der Zahnkronen Encauston s. Substantia encaustica nennen, so muss diese Benennung als unpassend gerügt werden. Das Adjectiv encaustus (Ëүrovoros), bezieht sich, wie aus Plinius ${ }^{2}$ ) zu ersehen, auf die Wachsmalerei der Alten, bei welcher der Pinsel in geschmolzenes, gefärbtes Wachs getaucht wurde. Was hätte der sehr harte Zahnschmelz mit diesen Wachsgemälden für eine Ideenverwandtschaft? Das Encauston, von Èyai tragen, und kam mit diesem neuen Begriff in die Anatomie, wo es, seiner Seltsamkeit wegen, beliebter wurde, als die altmodische Substantia vitrea, adamantina, und marmorea dentium. Encauston hiess aber auch die rothe Tinte, mit welcher die

1) Anathomia Mundini emendata, in cap. de anathomia duarum emulgentium.

2) Hist. nat., Lib. XXXV, Cap. 11, Sect. 41 . 
griechischen Kaiser ihre Namen unterschrieben. Die Italiener formten ihr inchiostro, Tinte, daraus, welches Wort bis zum französischen encre, durch Elisionen zusammenschrumpfte. Zahnschmelz und Zahnglasur stammen vom émail du dent des Charles Etienne (Carolus Stephanus) her, welcher die bisherige Substantia vitrea dentis, mit dem edleren émail vertauschte. Email aber steht durch das spanische esmalte, in nächster Verwandtschaft mit dem italienischen smalto, gebranntes Glas.

\section{Ependyma.}

Das modern gewordene Ependyma ventriculorum cerebri ist, milde behandelt, ein Pleonasmus. Man will damit die Auskleidung der Hirnhöhlen ausdrücken, für welche der Name

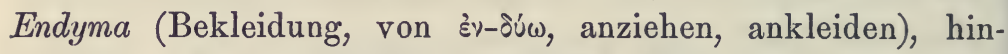
länglich sich geeignet hätte, da die Auskleidung der Hirnhöhlen nur aus einer einfachen, nicht aus einer mehrfachen Schichte besteht. Wurde über ein Kleid noch ein zweites angezogen, so hiess dieses bei den Griechen Ependyma

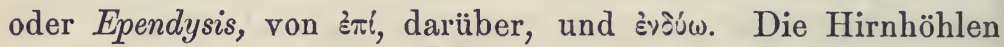
besitzen nur eine einfache Auskleidung, können also nur ein Endyma, kein Ependyma tragen.

\section{Ephippium und Sella turcica,}

Sieh' die Noten im Artikel: Stapes.

\section{Epicondylus und Epitrochlea,}

Zwei verunglückte Worte französischer Erfindung. Ich würde sie, ihrer Absurdität wegen, nicht berührt haben, wenn sie nicht auch in die deutsche Anatomie sich einzuschleichen 
gewusst hätten. Sie wurden von Chaussier erdacht, und haben unverdienter Weise bei Cuvier Aufnahme gefunden, wodurch sie eben den Deutschen acceptabel erschienen sein mögen.

Wir nennen das zur Verbindung mit dem Radius dienende Köpfchen am unteren Ende des Oberarmbeins: Capitulum oder Eminentia capitata. Die Franzosen blieben bei dem alten Namen desselben, als Condylus. Einwärts von ihm, liegt die allbekannte Trochlea für die Ulna, welche nie anders genannt wurde. Auswärts von der Eminentia capitata, und zugleich etwas über ihr, steht der Condylus externus humeri; - einwärts von der Trochlea, und höher über ihr, der Condylus internus. Chaussier hat für den Condylus externus seinen Epicondyle, und für Condylus internus seine Epitrochlée substituirt, in der Meinung, dass dieses Epi die seitliche und etwas höhere Stellung der beiden Fortsätze bezüglich des Condylus und der Trochlea ausdrückt. Schon die bekannten Worte der Anatomie: Epidermis, Epididymis, Epigastrium, Epiphysis, u. m. a., hätten ihn, ohne ein Lexicon zu consultiren, belehren können, dass $̇ \pi i$ nicht für neben oder an, sondern nur für auf in Verwendung steht. Epicondyle könnte nur ein Fortsatz heissen, welcher auf dem Condylus steht, und Epitrochlée nur ein solcher auf der Trochlea. Für Condylus und Trochlea sind Fortsätze auf ihnen reine Unmöglichkeiten, da sie die Beweglichkeit in den betreffenden, Gelenken gänzlich ausschliessen würden. Eine Eminentia capitata muss kugelrund sein, und eine Trochlea walzenrund. Ein Fortsatz auf dem einen oder anderen, wäre einem Sperrhacken gleich, welcher gar keine Bewegung zulassen würde, da er in einem Foramen coecum der anschliessenden Gelenkfläche des Radius und der Ulna stecken müsste, wie die Zahnwurzel in ihrer Alveole, und die dadurch gegebene doppelte Gomphosis, dem Ellbogengelenke selbst die leiseste Bewegung versagen würde. Hätte Chaussier die das Nebensein ausdrückenden Präpositionen $\dot{\alpha} \pi \dot{b}$ oder $\pi \alpha_{p} \dot{\alpha}$, statt $\dot{\varepsilon} \pi \dot{i}$, zu seinen neuen Wortbildungen verwendet, würden wir diese Strafpredigt zu halten, 
keine Veranlassung gehabt haben. Warum wollen also meine geehrten deutschen Collegen, nicht bei dem allgemein verständlichen Condylus externus und internus bleiben, und den Franzosen ihre Onomatopoëse zu ihrer eigenen Erbauung überlassen? Will man aber durchaus etwas Griechisches haben, parce qu'avec du grec on a toujours raison (Molière), so kann mit Exo- und Endocondylus vollkommen geholfen werden.

\section{Epididymis.}

So lange die Anatomie existirt, wurde unter Epididymis der Nebenhode verstanden. Der Gründer der anatomischen Wissenschaft, Galenus, war nicht der Erfinder des ganz

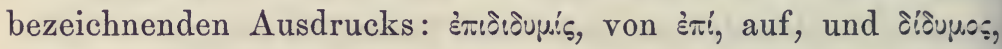
Hode 1). Das Adjectiv Siôvuos, drückt eigentlich zweifach und paarig aus. Es war eine Licentia anatomica, es zu einem Hauptwort zu erheben, und die Hoden damit zu belehnen (oi

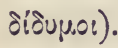

Galen blieb nicht immer dem Worte Epididymos treu.

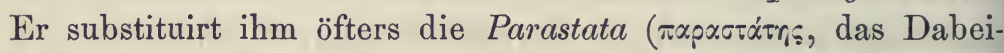
stehende, der Gefährte) des Hippocrates, welche, wegen der Windungen und Krümmungen des Samengefässes im Nebenhoden, den Beinamen cirsoides (xpob́s, eigentlich Varix ${ }^{2}$ ) erhielt, zum Unterschied von der Parastata adenoides, womit

1) Mehrere Stellen in Lib. IV, de usu partium, und in Lib. I, de semine, lassen es vermuthen, dass der Name von Herophilus herrührt.

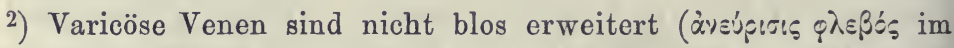
Paulus Aegineta), sondern auch geschlängelt. Da nun die Venen im Samenstrang, zum Plexus pampiniformis verschlungen und verkettet sind, hiess auch dieser Plexus bei einigen älteren Zergliederern: Parastata varicosa oder Corpus varicosum, wie z. B. im Bauhin. 
schon Herophilus die Samenbläschen, Andere aber die Pro-

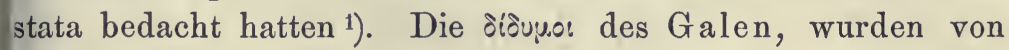
Caspar Hofmann als Gemelli und Gemini, und die Epididymis als Supergeminalis (glandula) übersetzt ${ }^{2}$ ), die Parastata

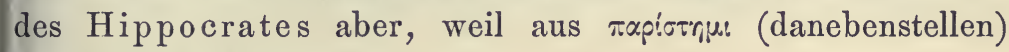
gebildet, als Assistens (Vesal).

So klar und sichergestellt also die Bedeutung von Epididymis ist, so gab es doch Anatomen, welche, ohne gerade zu den Latino-Barbari zu zählen, unter Epididymis nur die fibröse Umhüllungshaut des Hodens verstanden wissen wollten - die Albuginea testis.

Jacobus Sylvius, ein muthiger Streiter für die Placita Galeni, versündigte sich zuerst durch diesen Wortmissbrauch an seinem Idol und Meister, zu dessen Vertheidigung gegen Vesal's Angriffe, er mit mehr Muth, als Erfolg, eine sehr gelehrte Streitschrift schrieb. Im folgten Realdus Columbus, Gorraeus, und viele Lexicographen, selbst der sehr erfahrene W. Pape. Die fibröse Haut des Hodens, gehört zum Wesen dieses Organs. Sie liegt nicht auf dem schon fertigen Hoden als Nebensache auf. Nimmt man den Nebenhoden weg, so bleibt der Hode noch immer Hode. Nimmit man aber die Albuginea des Hodens weg, so zerfällt sein Bau. Epididymis, als Faserhaut des Hodens, ist also grundschlecht, da sie nicht ein accessorisches, sondern ein wesentliches Gebilde am Hoden repräsentirt. "Etwas umgeben" und „auf etwas aufliegen", ist auch bei den Griechen zweierlei.

1) Parastata adenoides und cirsoides werden nicht selten gegeneinander vertauscht, worüber J. Riolan sich weitläufig ausliess. Anthropographia, Lib. II, Cap. 31, pag. 271 der Pariser Ausgabe von 1626. Heutzutage sind beide Ausdrücke ganz vergessen und verloren.

2) Commentarï in Galeni libros de usu partium. Francof., 1625, I, n. 1016 . 


\section{Epistropheus.}

Sieh' die Artikel: Atlas und Vertebra.

\section{Epiploon.}

Das Epiploon (Netz) der Griechen, musste im Laufe der Zeit, dem lateinischen Omentum fast vollständig weichen. Nur in den Arteriis und Venis gastro-epiploicis, welche dem Magen und dem Netz zugleich angehören, in der Epiplocele, Netzbruch, in den Appendices epiploicae des Dickdarms, und im spanischen Epiplon, hat sich sein Andenken noch erhalten. Galen und Oribasius beschrieben das Epiploon als eine Peritonealfalte, welche vor dem Gedärm herabhängt, auf ihm gleichsam schwimmt: epiploon nominatum est, quia intestinis supernatat, - $\dot{\varepsilon} \pi \imath \pi \lambda \varepsilon \dot{\varepsilon} \varepsilon$, von $\dot{\varepsilon} \pi \iota \pi \lambda \hat{\varepsilon} \omega$, darüber hinschiffen, in der Odyssee. Hippocrates und Aristoteles, gebrauchen die Worte $\dot{\varepsilon} \pi i \pi \lambda(00$ und $\dot{\varepsilon} \pi i \pi \lambda$ oos nur in dem angegebenen anatomischen Sinne. Die alte lateinische Redensart: membrana superinnatans, erklärt sich daraus. Da die Fettablagerung im Epi-

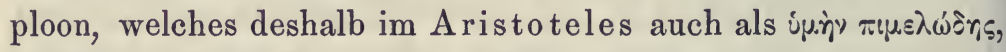
Fetthaut, vorkommt, den netzförmig anastomosirenden Blutgefässen folgt, und dieser Membran ein netzförmiges Ansehen verleiht, entstanden auch die Benennungen oartivn (im Hippo-

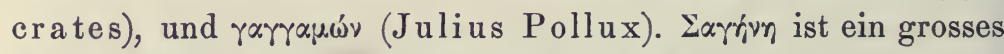
Netz, mit dem viele Fische auf einmal gefangen werden, ein

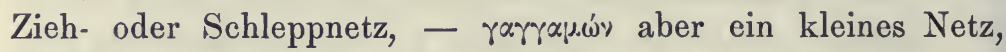
welches, nach Strabo, besonder's zum Austernfangen verwendet wurde. Die Griechen verglichen das Epiploon auch mit einem Sack, wie wir Deutsche vom Netzbeutel reden,

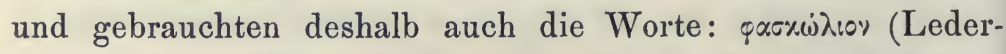

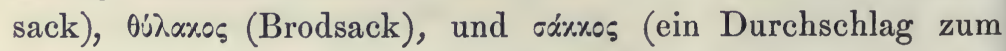
Klären des Weines). Diese Worte gehören jedoch zu den 
Seltenheiten. Sie beziehen sich weniger auf die netzförmige Form der Fettablagerung, als vielmehr auf den Habitus des Netzes, welches bei den Säugethieren einen förmlichen Sack oder Beutel bildet, entweder nur um die Gedärme, wie bei den Fleischfressern, oder auch um den Magen, wie bei den Wiederkäuern.

Ueber die Verwendung des Netzes, hatten die Alten die Ansicht, dass sein Fettreichthum zum Warmhalten der Eingeweide diene: calefaciendi causa (wie Oribasius sich ausdrückt), quod ex iis cognoscitur, qui vulnus in abdomine acceperunt, cum prolapsu omenti, quod si abscissum fuerit, aegri frigidiorem ventriculum sentiunt, minusque concoquunt, et pluribus operimentis extrinsecus egent ${ }^{1}$ ).

Die abnormen Adhäsionen des Epiploon an die Leber, an die Bauchwand, an den Uterus, waren dem Galen nicht unbekannt.

Sieh' den Artikel: Omentum.

\section{Epithelium und Endothelium.}

Alle Achtung vor Epithelium, wenn es noch dasjenige wäre, zu was es von Ruysch gemacht wurde. Ruysch ${ }^{2}$ ). erfand sich dieses Wort, um jene Epidermis damit zu benennen, welche die Papilla mammae, und die papillenreiche Zone der Lippen überzieht ${ }^{3}$ ). $\Theta \eta \hat{\lambda} \lambda \dot{n}$ ist "Papille " 4 ), und

1) Op. cit., pag. 93.

2) Thesaurus anatomicus III. N. 23.

3) Lelut, Sur l'épithelium, im Répertoire d'anatomie et de physiologie, T. III, pag. 159.

4) Eigentlich und allgemein die Mutterbrust, daher $\theta \eta \lambda \dot{\eta} v$ $\varepsilon \dot{\pi \varepsilon} \% \varepsilon เ \nu$, die Brust reichen. Nur Aristoteles fasste $\theta \eta \eta \lambda \dot{~ i m ~}$ engeren Sinne auf, als $\theta \eta \lambda \alpha i \mu^{\alpha} \alpha \tau \tau \tilde{\omega} \nu,{ }_{n}$ die Warzen der Brust". 
Epithelis, latinisirt Epithelium: was auf der Papille liegt. Epithelis wäre demnach ganz gut gebildet, wie Epigonis, Epididymis, Epiglottis, und Epidermis. Lange Zeit blieb das Epithelium des Ruysch ganz unbeachtet, bis es in neuester Zeit aus der Vergessenheit hervorgeholt, und anfänglich nur für den Zellenbeleg der freien Schleimhautflächen, dann aber auch für jenen der serösen Häute, aller Röhren und Kanäle, und der Gehirnhöhlen, allgemein eingeführt wurde, was von den Sprachkennern missbilligt werden kann, da nur auf der Zungenschleimhaut Warzen ( $\theta$ ni $\left.\alpha^{i}\right)$ vorkommen, auf allen anderen Membranen aber keine, somit auch kein Epithelium auf ihnen zugelassen werden kann. Man mochte das Unrichtige des Ausdruckes wohl gefühlt haben, und erkoren sich deshalb die deutschen Histologen, für das Epithel innerer Oberflächen, ein neues Wort: Endothelium, welches aber noch viel schlechter ist, als Epithelium in weiterer Bedeutung. Wir müssen es geradezu unsinnig nennen. Denn ist Thele eine Warze, so kann Endothel (von ëvoov, inwendig) nur innere Warze sein, oder was sich im Innern der Warze befindet. Im Innern der Warzen befindet sich aber kein Epithel, ergo ist auch Endothel ein Ungeheuer von Barbarismus. Das wäre voraus zu bedenken gewesen, bevor sich die allgemein anerkannte Sprachgelehrsamkeit der Deutschen und der deutschen Anatomen, eine solche Blösse gab.

Wozu alle diese neuen, griechisch aussehenden Worte, mit welchen sich die Histologie einen besonders gelehrten Anstrich zu geben vermeint? Quibus nova inveniendi facultas deest, iis novorum verborum libido pruritat (Agricola). Dem Endothel wäre übrigens leicht zu helfen, wenn man, wie es die Botaniker gethan haben, das richtige Endotheke ( $\theta \dot{\gamma} \times x_{n}$, als Scheide oder Ueberzug) vorzuziehen beliebte, oder das correcte Indumentum. Für Indumentum haben wir zwei Gewährsmänner: Aurelius Victor und Aulus Gellius. Bei letzterem giebt es ein Indumentum oris, als Gesichtsüberzug, Maske. 


\section{Extremitates.}

Extremitas, als Gliedmasse, ist eine Vox barbara. In später Zeit, und nur bei der Zunft der anatomischen Schullateiner, kam sie in Verwendung. So vielsinnig uns das Wort in den Classikern entgegentritt ${ }^{1}$ ), als Extremität im anatomischen Sinne, finden wir es bei ihnen nirgends. Sie kennen nur Artus und Membra.

Extremitates, als Gliedmassen, sind ein Vermächtniss der Latino-Barbari. Der erste, welcher die Gliedmassen so benannte, war Gerardus Cremonensis (12. Jahrhundert). In seiner Uebersetzung des Canon Avicennae, wird z. B. die Calefactio und Fricatio extremitatum, als Mittel gegen Ohnmacht (Casus subitus virtutis nerveae) empfohlen ${ }^{2}$ ), und etwas später ${ }^{3}$ ) heisst es: et scias, quod calefactio extremitatum perducit ad calefactionem stomachi, ex proximo. Ihm folgte das Heer, besser die Heerde der Arabisten. Fallopia und Spigelius bedienen sich, wenn auch nicht immer, der passenden Ausdrücke: Extrema und Partes extremae, für "Gliedmassen", während noch Alessandro Benedetti sich mit Superiora et Inferiora behilft. Mit dem rapiden Schlechterwerden des Lateins der anatomischen Schriften im 18. Jahrhundert, nisteten sich die Extremitates für immer in unserer Wissenschaft ein, nicht blos in der lateinischen, leider auch in der deutschen, und werden sie wahrscheinlich ebensowenig mehr verlassen, als sich die Engländer, Franzosen, Italiener, und Spanier, von ihrer Extremity, Extrémité, Estremità, und Extremitad, je trennen werden.

1) Extremitas bedeutet bald das äusserste Ende eines Dinges (extremitas regionis, lacus, Aethiopiae), bald seinen Umriss (extremitas circuli, picturae, auris), nur ein einziges Mal hervorragende Körpertheile ( $\mathrm{Ohr}$, Nase und Glied).

2) Lib. III, Fen 11, Tract. 2, Cap. 9.

3) Fen 12, Tract. 1, Cap. 27. 
Gute lateinische Autoren, wie es Vesal, Vesling, $\mathrm{Heister}$, und $\mathrm{Haller}$ waren, kennen nichts Anderes als Artus und Membra. Artus wurde nur für die Gliedmassen gebraucht, welche durch Gelenke (Articuli) in mehrere Abtheilungen zerfallen. $\mathrm{Zu}$ den Membra konnten aber auch andere hervorragende Theile des Leibes gezählt werden, z. B. das Membrum virile und der Rüssel des Elephanten, welchen Plinius unverholen eine Hand nennt.

Bei den Griechen überraschen uns die mit unserem Colon verwandten $\boldsymbol{x}_{\tilde{\omega} \lambda \alpha,}$, wie im Aeschylus, Sophocles, und den nach-Hippocratischen Aerzten. Das Colon (Darm) steht sicher mit den $\left.x_{\tilde{\omega}}\right\rangle \alpha$ in verwandtschaftlicher Beziehung, da es durch seine Einschnürungen ebenso gegliedert erscheint, wie die Gliedmassen durch ihre Gelenke. Hippocrates und Aristoteles legen den Händen, den Füssen, und dem Kopfe, das

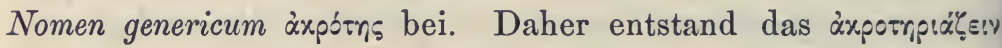
des Heliodorus ${ }^{1}$ ), was wir amputiren nennen.

In dem deutschen Wort Gliedmasse, ist Glied = Gelenk, welche Bedeutung es noch in Gliedschwamm und Gliedwasser aufweist, und Mass entspricht nicht der lateinischen Mensura, sondern dem altdeutschen mat, "verbinden", so dass Gliedmasse eigentlich als eine Verbindung mehrerer Gelenke verstanden werden muss. Das deutsche mat, gab das englische mate, ein Verbündeter, ein Gesell, besonders vom Schiffsvolk üblich (ships-mate). Ob nicht auch Matrose daher kommt?

\section{Fascia, Taenia, Vitta,}

Niemand bedarf einer Erklärung des Wortes Fascia. Da wir uns aber schon einmal in die Kritik der anatomischen Benennungen, selbst der bekanntesten, eingelassen haben, und

1) Stephani Blancardi Lexicon medicum, Edit. Kühn, T. I. 
allerlei an ihnen auszustellen fanden, können wir auch die Fasciae nicht ganz unbehelligt lassen. Nicht die Anatomie allein, auch die lateinische Grammatik, hat bei der Wahl der Termini technici unserer Wissenschaft, eine Stimme abzugeben. Die Anatomie sagt: Fascien sind in longum et latum ausgebreitete, oder scheidenförmige, ganze Körpertheile umschliessende fibröse Häute. Die lateinische Sprachkunde dagegen sagt: Fascia war nie etwas anderes als ein Band, ein langer und schmaler Streifen irgend eines Stoffes, und in Uebertragung auch eine schmale Binde um den Kopf, um die Arme, um die Schenkel, um die Brust, um den Unterleib, oder zur Befestigung der Schuhe. Diademe, als schmale Bänder, zum Zusammenfassen der Haare, heissen im Seneca und Suetonius: Fasciae. Ebenso die Wickelbänder der Säuglinge im Plautus (Fatschen der Wiener), die Wolkenstreifen im Juvenal, die Himmelszonen im Martial, und die Streifen cannelirter Säulen im Vitruvius. Als langes und breites, oder gar scheidenartiges Gebilde, lässt sich Fascia nirgends sehen. Die wortreiche Sprache der Griechen, hatte für jede Art der Fascien einen besonderen Namen: Sparganon für Wickelband des Säuglings, Diadema für Kopfband, Apodesmos für die Binde, durch welche das allzu üppige Wachsthum des Busens der Mädchen eingeschränkt wurde, Periscelis für Schenkelbinde, Podeion für Fussbinde, Telamon für Tragband, Parairēma für Würgeband zum Erhängen (Thucydides), Othonion für kleine Leinwandstreifen zum Verbinden der Wunden (Galen), Anadesmos für Haarband (Euripides), und Epidesmos für chirurgische Binde (Aristoteles). Was ferner die in Verbandarten sehr erfinderische Chirurgie des Mittelalters Fascia nannte, war immer nur ein langer und schmaler Bandstreif; nie ein breiter, oder gar ein röhrenartiger Leinwandfleck. Für diese beiden letzteren Verbandstücke, cursirten nur die Ausdrücke: Splenium und Manica. Die Sprachkunde verweist die Anatomie auf ihre eigenen richtigen Anwendungen des Wortes Fascia, als langer und schmaler 
Streifen, wie sie solche im Musculus fascialis (Sartorius '), in der Fascia longitudinalis anterior und posterior der Wirbelsäule, und in den drei Fasciae (Taeniae) des Colon besitzt. Selbst der Bandwurm war, durch sehr lange Zeit, nur als Vermis fascialis, und Fascia lata bekannt ${ }^{2}$ ). Wenn ein zollbreiter Muskel zum Fascialis gemacht wird, und drei lange Streifen am Dickdarm, welche nur 2-3 Linien Breite zeigen, ebenfalls Fasciae heissen, können doch die cylindrischen fibrösen Scheiden oder Hüllen der Arme und Beine, nicht auch Fasciae genannt werden. Da wäre die griechische Aponeurosis für diese Gegenstände noch brauchbarer, weil sie an keine bestimmte Form gebunden ist, während die Fascia der Sprachkenner, in ihrer Haupteigenschaft, lang, schmal, und bandartig sein muss.

Die Fascien des Colon werden auch Taeniae, oder Ligamenta, seltener Vittae genannt. Taenia ist eine Hallerische Benennung, als Taenia ligamentosa coli, von dem griechischen

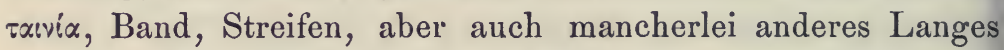
und Schmales, wie Wimpel am Mast, Landzunge und Sandbank im Strabo. Eigentlich ist Taenia nur das gefranzte

1) Den Namen Sartorius erdachte sich Spigelius: hunc musculum sartorium vocare soleo, quod sartores eo maxime utantur, dum inter consuendum, crus cruri imponunt. Er setzt hinzu: alii fascialem $v$. fasciam appellant, quod fasciam referat, cum longus admodum sit, et aequali fere latitudine. De hum. corp. fabrica, Lib. IV, Cap. 23. Sömmerring, welcher ein sehr guter, aber, wie seine Schriften zeigen, kein belesener Anatom war, mochte wohl von einem Musculus fascialis gehört und von ihm geglaubt haben, dass der Tensor fasciae latae damit gemeint sei, welchen er sofort immer als Musculus fascialis anführt. (Muskellehre, §. 261). Der Tensor fasciae latae hat es sonst nie erlebt, Musculus fascialis genannt zu werden. Er hiess, seit Spigelius, Musculus lati tendinis, und wurde von Albin Musculus tensor vaginae femoris genannt.

2) St. Blancardi, Lex. med., Edit. Kühn, T. I, pag. 623. 
Ende einer Vitta: longae taenia vittae 1). Die Anatomie hat eine Taenia hippocampi (Fimbria), und eine Taenia nervosa Halleri registrirt. Letztere Benennung, wie auch Intumescentia semilunaris Wrisbergii, führte das Ganglion Gasseri, bevor ihm R. B. Hirsch diesen Namen gab ${ }^{2}$ ). Den Namen Ligamenta, erhielten die Fascien des Colon durch Riolan. Da sie nichts $\mathrm{zu}$ binden haben, und das Colon bereits einige andere Ligamenta besitzt (Ligamentum hepato-colicum, lieno-colicum), wären die Ligamenta coli, trotz ihres häufigen Gebrauchtwerdens, aufzulassen.

Vittae im Valverda und Bonacciolus, sind eigentlich eine Profanation heiliger Gegenstände. Vittae hiessen die Kopfbinden der Priester und Priesterinen ${ }^{3}$ ), besonders der Vestalinen, wie auch die bunten Bänder, mit welchen die Blumenguirlanden auf dem Kopfe eines Opferthieres ${ }^{4}$ ), oder die Altäre und Säulen der Tempel ${ }^{5}$ ), umwunden wurden. Da abel auch die Kopfbinden der anständigen Frauen und Mädchen Vittae hiessen (Propertius), wären die Vittae coli den Ligamentis coli immerhin vorzuziehen, obwohl.sie heutzutage gar nicht mehr in der anatomischen Sprache gebraucht werden.

\section{Fel und felleus.}

Fel und Bilis unterschieden die Römer genau. Bilis war. die ergossene, $\mathrm{Fel}$ die in der Blase enthaltene Galle, oder die Gallenblase selbst. Ein Adjectiv biliarius, welches die Anatomen verwenden, hatten sie gar nicht. Was die Farbe oder

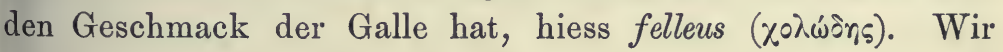

1) Aeneis, Lib. VII, Vers 352.

2) Pàris quinti disquisitio anatomica, Viennae, 1765, pag. 14.

3) Virgil, Aeneis, II, 221, und Juvenal, IV, 9.

4) Ovidius, ex ponto, III, 2, 75.

$\left.{ }^{5}\right)$ Tacitus, Hist., IV, 53, und Virgilii, Eclogae, VIII, 64. 
entnehmen aus Plinius einen sudor felleus, und aus Aure. lianus eine urina fellea. Vesica fellea müsste also gallichte, oder aus Galle bestehende, oder gallbittere Blase sein. Selbst die Latino-Barbari bedienten sich eines besseren Wortes. Sie sagten für Gallenblase kurzweg fel, wie schon Celsus sich ausdrückte: jecinori, ex inferiori parte, fel adhaeret. Im Cicero und Plinius, bedeutet ebenfalls $f e l$ die Gallenblase sammt ihrem Inhalt, während die aus der Gallenblase entleerte Galle, bilis genannt wird. Vesal hat mit seiner Vesicula bilis flavae, und Bauhin mit seinem Folliculus fellis gut gethan, während die Vesicula biliaria des Glisson, zu den Barbarismen zählt, indem ein Beiwort biliarius im echten Latein vermisst wird. Wie fel Galle und Gallenblase zusammen begreift, so wird auch im gewöhnlichen Leben, Galle für Gallenblase gebraucht, z. B. von Jägern, Fleischern, und Köchinnen.

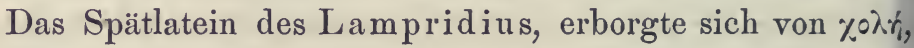

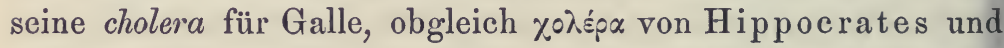
Galen bereits für eine bekannte Krankheitsform vergeben wurde. Die Bursa cholerae citrinae im Bauhin, wäre demnach kein stricter Barbarismus. Das Vasculum bilis der Arabisten, legitimirt sich dadurch, dass damals nicht blos die Blutgefässe, sondern alle häutigen Receptacula von Flüssigkeiten, Vasa genannt wurden, wie auch die Griechen ihre $\alpha \gamma \gamma \varepsilon i x$, für Gefässe und Behälter verschiedener Art, verwendeten. Dass die alten Aerzte und Anatomen, nicht bilis schlechtweg, sondern bilis flava, oder bilis citrina, sagen, geschieht nur, um die gelbe Lebergalle, von der imaginären bilis atra zu unterscheiden, welche aus der Pfortader, durch die Vena splenica zur Milz geleitet wird.

\section{Femur und Femen.}

Sieh' den Artikel: Interfemineum. 


\section{Fibella und Fibula.}

Bei den Einhufern findet sich blos die obere Hälfte des Wadenbeins vor, - bei den Zweihufern, den Chiropteren, und dem Nilpferd, blos die untere. Dieșe abortiven Zustände des Wadenbeins, waren die Veranlassung, dass man bei den genannten Thieren, den Namen Fibula in Fibella umstaltete. Man meinte, damit ein verkürztes, also ein verkleinertes Wadenbein auszudrücken. Ein ansehnlicher Fortsatz am oberen Ende des Wadenbeines, welcher bei den Beutelthieren niemals fehlt, wurde von R. Owen ebenfalls als Fibella bezeichnet. Fibella ist nun leider kein Diminutiv von Fibula, sondern von Fibra, und muss mit Fäserchen übersetzt werden, quia fibella parva fibra est, apud Casaubonum.

Im guten Latein, wird Fibella nie gefunden, ebensowenig als Fibrilla. Du Cange ${ }^{1}$ ) beruft sich auf Casaubonus, ad Capitolinum. Das Wort ist also ganz neulatein, und konnte die Anatomen nur durch seinen Ausgang bestechen; dasselbe als Verkleinerung von Fibula anzunehmen, da Aehnliches in $P a$ tella, Glabella, Puella, u. m. a., ihnen bereits vorlag. Interessant ist es, dass das Wadenbein, seinen lateinischen Namen Fibula, d. i. Heftel oder $\mathrm{Nadel}$, von der Gestalt des Knochens bei den obengenannten Hausthieren erhielt. Die abortiven Fibulae laufen nämlich alle spitzig aus, und ähneln sonach den Nadeln zum Nähen oder Heften, den Bolzen zum Vernieten, den Pfriemen, dem Dorn oder den spitzigen Zungen an den Schnallen, und an der Agraffe. Alle diese spitzigen Gegenstände hiessen

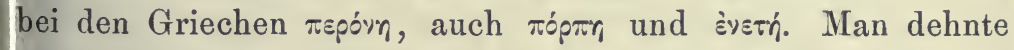
diese Benennung, auf das pfriemenförmige Wadenbein der Hausthiere aus, und Hippocrates übertrug sie auch auf das menschliche. Die angeführten spitzigen Dinge wurden von den Römern Fibulae genannt, das menschliche Wadenbein aber

1) Glossarium ad auctores mediae et infimae latinitatis, T. II, pag. 463. 
nicht. Dieses hiess Sura $\left.{ }^{1}\right)$. Erst Vesalius führte Fibula in die anatomische Sprache ein, als wörtliche Uebersetzung der

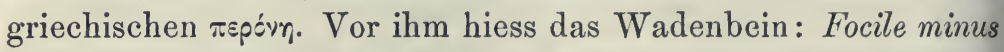
cruris, oder Canna s. Arundo minor cruris, über welche Worte ich an einem anderen Orte ausführlich gehandelt habe ${ }^{2}$ ).

Von Fibula, Nadel oder Heftel, schreibt sich Infibulatio her, eine chirurgische Verrichtung, bei welcher eine silberne Nadel (fibula), durch eine aufgehobene Falte der Vorhaut gestochen, und ihre beiden Enden gegen einander zugebogen und verlöthet wurden, um den Knaben vorzeitige Ausübung des Coitus, oder Selbstbefleckung, unmöglich zu machen ${ }^{3}$ ). Auch bei Sängern und Schauspielern, wurde sie vor Zeiten angewendet, um denselben ihre Stimme zu erhalten (ut coitum non faciant, ne vocem perdant, in Vet. Schol.).

Fibula, als Heftel und Agraffe, diente besonders dazu, lose Gewänder, wie die chlamys, das pallium, das sagum und paludamentum, auf der Schulter oder am Halse festzuhalten. Ein aufgeschürztes Kleid, wurde durch eine Fibula befestigt:

\section{„Aurea purpuream subnectit fibula vestem".}

Eine Reihe kleinerer solcher Fibulae, ersetzte auch eine Naht. So durften z. B. die priesterlichen Gewänder des Flamen Dialis, nicht durch Nähte oder Knöpfe, sondern mussten mit Fïbulae zusammengehalten werden.

Aus dem Galenischen Paracnemion, "das neben Wade oder Schienbein Liegende", lassen sich die Sura (= Fibula) des Celsus, und das deutsche Wadenbein leicht deduciren. Die Sprachforscher meinen, dass die deutsche Wade, bei den Oesterreichern der Wadel, von dem vuado des

1) Alterum cruris os, Sura recte nominatur, heisst es im Celsus, Lib. VIII, Cap. 1.

2) Das Arabische und Hebräische in der Anatomie, §. XXXV und LXXXVIII.

3) Celsus, de medicina, Lib. VII, Cap. 25, Sect. 3, infibulandi ratio. 
Rabanus Maurus kommt, und dieses vielleicht von vado, gehen. Da aber im Schwedischen Wade überhaupt einen fleischigen Theil des Leibes anzeigt, ist es wahrscheinlicher, dass, der hervorragend fleischigen Beschaffenheit dieses Körpertheiles wegen, zu seiner näheren Bezeichnung, die scandinavische Wade auch in das Deutsche übersiedelte. Das italienische mollame, und polpa della gamba, entspricht der Weichheit, und das französische gras des jambes, dem Umfang der Wade.

Etymologisch richtiger, als Wadenbein, nimmt sich das alte $\mathrm{Haft}$ - oder Klammerbein aus, denn Fibula stammt von figo, heften, wie das veraltete Figibula beweist. - Die Chirurgen des 13. Jahrhunderts verstehen unter Fibula, nicht blos das Wadenbein, sondern auch jede Naht der Schädelknochen. Sie schreiben auch Fikula und Figella - beide Worte von figo. Die im Mittelalter gangbaren Ausdrücke:-Tibia minima und Radius surae, haben ein frühzeitiges, nicht betrauertes Ende genommen.

\section{Fibra, fibrosus, und fibrina.}

Kein anatomisches Wort hat seine Bedeutung so auffallend geändert, wie Fibra. Bei den alten Anatomen, bis zu Vesal hinauf, ist Fibra = Lobus. Die Lunge und die Leber werden nicht in Lobi, sondern in Fibrae gespalten, und das Ohrläppchen heisst Fibra auris, nicht Lobulus auriculae. Diese Bedeutung von Fibra, als Lappen, holte man sich aus dem Celsus. Dort heisst es: pulmo in duas, jecur in quatuor fibrus dividitur '). Auch im Cicero erscheint Fibra als Lappen ${ }^{2}$ ), und bei den Dichtern werden die sämmtlichen Eingeweide, Fibrae genannt (fibrae bidentis im Seneca, fibrae terrae, als Inneres der Erde, im Plinius, und Promethea fibra im Ovid, die Leber des Japetiden, welche der Geier aushackte). Varro und Festus klären

1) Op. cit., Lib. IV, Cap. 1.

2) Dc divinatione, Lib. I, Cap. 10. 
uns hierüber auf, indem sie fibra von dem veralteten fiber. $=$ extremus ableiten, wonach fibra das Ende eines Dinges überhaupt, und somit auch die Lappen anzeigt, in welche ein Eingeweid zerfällt. So lange Fibra in der Anatomie als Lappen galt, hatte man für Faser keinen anderen Ausdruck als Villus (sieh' dieses Wort). Erst nach Vesal verschwand die Fibra = Lobus, aus der Anatomie, und wurde durch Lobus, Ala und Penula ersetzt. Die ivss des Galen, sind Fibrae in unserem Sinne, als Fasern der Muskeln, der Bänder und Sehnen, der Nerven, und der Membranen ').

Das anatomische Beiwort fibrosus, ist eine Neubildung; denn die Römer kannten nur fibratus. Fibrinus hatten sie zwar, aber nicht in dem Sinn, in welchem wir es seit Haller in der Fibrin (Faserstoff) nehmen, sondern als „vom Biber (fiber) kommend", wie vestes und pelles fibrinae, welche nach Plinius, im alten Rom ebenso geschätzt, und ebenso theuer bezahlt wurden, wie jetzt.

\section{Filamentum und Filum.}

Alle Welt versteht unter Filamenten, Fäden und Fasern. Die Anatomie insbesondere hat Nerven-, Muskel- und Zellgewebsfilamente, wie auch ein Chorion filamentosum, welches sie aber auch frondosum nennt, zum Unterschied von Chorion laeve. - Filamentum war, und ist jetzt noch, im echten Latein, weder als Faser noch als Faden bekannt. Es existirt blos in bescheidener Zurückgezogenheit, bei den mehr obscuren Schriftstellern; wie Fulgentius war, ein Flamentum. Dieses jedoch kommt von flare, blasen, und bedeutet Windsbraut, während Filamentum, filum zur Wurzel hat, und eine congeries filorum, einen Filz, oder irgend etwas aus Fäden Gewebtes oder Genetztes ebenso anzeigt, wie Capillamentum die

.) De usu partium, Lib. V, Cap. 6 . 
Gesammtmasse der Haupthaare. So nannten die Aerzte des Mittelalters den fadigen Bodensatz des Harns: Filamentum ${ }^{1}$ ), und den Filtrirtrichter aus Filz oder grobfaserigem Papier (Charta emporeutica), ebenso. Das alte und gute römische Filamen, wurde zu Flamen contrahirt - ein Name der Priester des Jupiter, Mars und Quirinus, welche die Umhüllung ihrer Häupter mit einem Faden (filum) befestigten. Flamen steht hier $=$ Filamen .

So bleibt uns denn nichts anderes übrig, als Filum statt Filamentum zu sagen. Fibra wäre nicht annehmbar, da es in der alten Anatomie immer nur als Lappen oder Flügel vorkommt: Fibrae pulmonis, und Fibra jecoris, wie in Celsus ${ }^{2}$ ): pulmo in duas fibras dividitur, ungulae bubulae modo.

Wir haben das filum, als filum terminale am Ende des Rückenmarks, und als filum linguae $=$ frenulum. Filamentum ist und bleibt barbarisch, wie das von den Latino-Barbari, für Vorhaut- und Lippenbändchen erfundene Filellum und Filetum.

\section{Fimbria.}

Aus dem anatomischen Register der Fimbrien, muss die Fimbria hippocampi weggestrichen werden. Sie ist keine Franze, sondern ein dünner Markstreifen am concaven Rande des grossen Seepferdfusses. Haase ${ }^{3}$ ) und Reil') verwechselten Franze mit Saum, da die Franzen am Rande (Saum) der Kleider angebracht werden. Die alten Benennungen der Fimbria hippocampi, als Taenia oder Limbus (Sylvius), hätten nicht verlassen werden sollen. Ebenso ist das Corpus fimbriatum Winslowii, für dasselbe Markgebilde, und der Margo fim-

1) J. Sylvius, Praxis medica, Lib. I, Cap. 55, §. 48.

2) De medicina, Lib. IV, Cap. 1.

3) Cerebri nervorumque anatome, §. 33.

4) Hild e brand t, Handbuch der Anatomie, 4. Aufl., III. Bd., pag. 409. 
briatus des breiten Gebärmutterbandes, verwerflich. Letzterer erscheint scharf und nicht zerfasert, und kam zu seinem Namen nur dadurch, dass er die Fimbrien der Tuba Fallopiae, mit dem Eierstock verbindet. Die Appendices epiploicae des dicken Darms, Fimbriae zu nennen (Pierer), muss aus demselben Grunde getadelt werden. Diese Appendices sind glatt und nicht gefranzt. Nur die Fimbriae tubae Fallopianae dürfen fortbestehen, als ausgefianzter Rand des Ostium abdominale tubae, welcher in diversen Schriften als Ornamentum foliaceum (de Graaf), Laciniae und Digitationes (Haller), Infundibulum und Vexillum (pavillon, Winslow), und Morsus diaboli (sieh' diese Artikel) vorkommt.

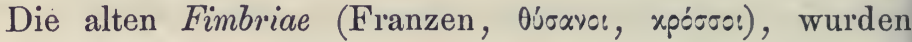
durch eine aufgenähte Ziereinfassung der Kleider gebildet, deren sich nur hohe Personen, Fürsten und Priester bedienten. Die Putzsucht der Frauen masste sich bald die Fimbrien, als Verzierung der Alltagskleidung an, statt der jetzigen Spitzen ${ }^{1}$ ). Julius Caesar, welcher álle Damen, und durch sie, ihre Männer für sich zu gewinnen wusste, trug an den Aermeln seiner Tunica, reiche Troddeln oder Franzen, und musste sich manchen Spott, dieser Galanterie wegen, gefallen lassen (Suetonius, Caes. 45). Franze sollte richtiger Franse geschrieben werden, wie im Schwedischen frans, und im Dänischen fryndse. Sie stammt ohne Zweifel von der mittellateinischen Frangia, welche sich auch im englischen fringe, im französischen frange, im italienischen frangia, und im sicilianischen Patois frinza zu erkennen giebt. Die lateinische Fimbria hat sich, das ist sicher, in frimbia und frambia umgeformt. Jetzt noch sagen die Daco-Romani (Wallachen): frimbie.

Vergleiche den Artikel: Lacinia.

1) Fimbria kommt aber auch als Büschel vor, wie im Cicero (Pis. 11): erant illi compti capilli, et madentes cincinnorum fimbrice (gesalbte Lockenbüschel). 


\section{Foetus oder Fetus?}

Etymologisch kann man beide Schreibarten, nach den Abstammungen, welche ihnen untergelegt werden, für richtig erklären. Sie finden sich beide in alten Inschriften und Texten. Hält man mit Jovianus Pontanus das Zeitwort foveo für die Wurzel, so ist foetus richtig, quia a matre fovetur. Ist aber die Wurzel das veraltete feo, erzeugen, so ergiebt sich auch fetus als correct. Der Grammatiker Varro, hält es mit fetus, und Festus sagt von dem Worte Fenus (Interessen des ausgeliehenen Geldes): fenus et feneratores a fetu dicta, quod crediti nummi alios pariant. Fetus, als Adjectiv, heisst fruchtbar und schwanger, wie die terra feta frugibus im Cicero, und die feta veneno colla serpentis im Silius Italicus darthun.

Jedenfalls wird häufiger foetus, als fetus in der Anatomie geschrieben, wie umgekehrt häufiger femina als foemina. Das ist ebenso Sache des Beliebens, wie es gleichgiltig ist, ob man fetura oder foetura (Zeugung), fecundus oder foecundus, fenu oder foenum (Heu) schreibt. Die Classiker verwenden fetus auch für Feld- und Gartenfrüchte: arborei fetus im Virgil, und Triticei fetus im Ovid.

\section{Folliculus.}

Sieh' den Artikel: Cilia.

\section{Fontanella.}

Der Name Fontanella gehört nicht der lateinischen, sondern der italienischen Sprache an. Er stammt von den grossen Chirurgen Italiens im 13. Jahrhundert her, welche, nach den 
Grundsätzen der Araber, deren treue Anhänger sie waren, an der Stelle, wo die Pfeilnaht auf die Stirnnaht stösst, das Glüheisen gegen Hirn- und Augenkrankheiten anwendeten, und die gebrannte Stelle, nach Abstossung des Schorfes, längere Zeit durch Anwendung reizender Mittel im Fluss erhielten. Sie glaubten, dadurch schädlichen Stoffen eine Abzugsquelle zu eröffnen, und nannten diese Stelle deshalb Fontanella, als Diminutiv von fonte, Quelle. Fontanellae sunt ulcera artificialia, per quae superfuitates materiae destillant, heisst es in der Interpretatio dictionum Guidonis Cauliaci von Joubertus. Das Brennen selbst, hiess Ustio arabica. Diese Brandfontanelle entspricht durch ihre Oertlichkeit, der weichen und deprimirbaren Stirnfontanelle der Neugebornen, welche sich erst am Ende des zweiten Lebensjahres schliesst, und so lange sie nicht verknöchert ist, ein von den Athmungsbewegungen abhängiges Heben und Senken bemerken lässt. Durch Namensübertragung wurde diese pulsirende Stelle, welche die Griechen Bpé\}rux, die Römer Vertex palpitans nannten, auch als Fontanella getauft, welcher aber gute Lateiner, wie Bauhin, ihren Fonticulus und Fons pulsatilis substituirten, aus dem Grunde, weil diese Stelle des kindlichen Kopfes häufig mit Borken besetzt erscheint, welche man für eine durch die Fontanelle ausgeschiedene und eingetrocknete Hirnfeuchtigkeit hielt, deren Quelle also (Fons) die Fontanelle ist. Vesal bediente sich noch des persisch-arabischen Ausdrucks Zeudech, welcher durch Corruption aus dem Zubendech des Mesue junior hervorging. Fallopia nannte die Stirnfontanelle Lacuna, und Laurentius Foveola, beide Worte die flache Einsenkung der Fontanelle ausdrückend. Volcherus Koyter bediente sich des Ausdruckes Folium, woraus das Blättlein unserer Hebammen entsprang. .

Wie schwer es zuweilen fällt, sich vorgefasster Meinungen zu entäussern, zeigt uns das anatomische Genie des Vesal, welcher, mitsammt seiner Schule, fest darauf beharrte, dass die Stelle der ehemaligen Fontanelle, durch das ganze Leben 
hindurch, die dünnste Gegend des Schädeldaches bildet: rarissima et tenuissima totius calvariae pars, et suturae nusquam laxius haerent ${ }^{1}$ ).

Ueber das im Mittelalter gangbare arabische Zeudech, und seine Etymologie, giebt Ausführliches HL, §. CIII, pag.242—247.

\section{Foramen coecum.}

Einem blinden Loch, d. h. einem solchen, welches kein Loch ist, könnte der gesunde Menschenverstand allerdings viel nachsagen. Es giebt zwar blinde Thüren und Fenster, blinde Wände und Schlösser, Blindsäcke und Blindgässchen; es könnte also auch blinde Löcher geben. Nur die Blindsäcke sagen zu viel für einen Sack, und gehören insofern zu den Pleonasmen, als alle Säcke an einem Ende blind abgeschlossen sein müssen. Ist ein Sack an beiden Enden offen, so wird er nicht mehr Sack, sondern Schlauch genannt.

Die Anatomie besitzt zwei blinde Löcher: 1. Das Foramen coecum der Zunge, und 2. das Foramen coecum vor dem Hahnenkamm an der Schädelbasis.

1. Das Foramen coecum der Zunge, wurde von Heinrich Meibom entdeckt und öffentlich demonstrirt. Es wurde deshalb als Foramen Meibomii, von Justus Schrader, einem Zuhörer des Meibom, beschrieben, in dessen Observationes et Historiae, etc., quibus accedunt quatuor Decades observationum anatomico-medicarum, Amstel., 1674. Letztere enthalten interessante anatomische Vorkommnisse, darunter auch, in Decas $I$, Obs. 3, das Foramen Meibomii. Den Namen Foramen coecum brachte ihm nicht Heister auf, wie es in den Geschichtswerken heisst, denn Heister sagt selbst: Foramen, quod coecum vulgo appellatur ${ }^{2}$ ). Morgagni, welcher das blinde Loch sehr

1) De corp. hum. fabrica, Lib. I, Cap. 6 .

2) Compendium anat., Edit. IV, T. II, pag. 107. 
genau untersuchte, und seine Beziehungen zu den Schleimdrüsen der Zunge nachwies ${ }^{1}$ ), nannte es Sinus ad radicem linguae, seine Anhänger aber: Foramen glandulosum Morgagni. Haller sagt von ihm: modo longins, modo brevius, nonnunquam obscurum ut vix appareat ${ }^{2}$ ).

2. Das Foramen coecum des Vesal ${ }^{3}$ ), welches entweder vom Stirnbein allein, oder zugleich vom Siebbein gebildet wird, ist kein blindes Loch, sondern, wie ich gezeigt habe, immer ein in die Nasenhöhle sich öffnender Gang, durch welchen ein sehr feines Emissarium geht. Ich wählte deshalb, statt blindes Loch zu sagen, den Ausdruck: Porus cranionasalis.

Der Terminus: Foramen coecum, kommt schon bei den

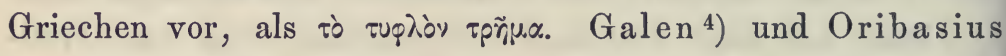
bezeichnen aber mit Foramen coecum etwas ganz Anderes, als wir. Sie verstehen darunter den inneren Gehörgang, in welchen sich ihr fünftes Nervenpaar (unser vereinigtes siebentes und achtes) hineinbegiebt. Der Grund dieser sonderbaren, schon vor Galen gebräuchlichen Benennung, wird von Galen damit angegeben, dass Jene, welche sich zuerst dieses Namens be-

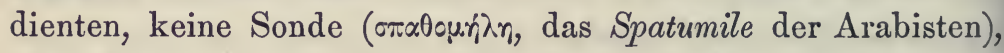
oder Borste, durch diesen Knochenkanal bis zur Ausgangsöffnung durchleiten konnten, und deshalb den Gang blind abgeschlossen sein liessen. Galen setzt ganz richtig hinzu, dass nicht die coecitas, sondern die flexuosa obliquitas des Canals, die Ursache sei, quare nihil elabatur (warum nichts durchgehe).

1) Adversaria anatomica, I, §. 8, abgebildet auf Tab. I, Fig. 1.

2) Elementa physiol., T. V, pag. 108.

3) De corp. hum. fabrica, Lib. I, Cap. 12.

4) De usu partium, Lib. IX, Cap. 10, und De dissectione nervorum, Cap. 6. 


\section{Foramen obturatorium.}

Das Foramen obturatorium, Verstopfungsloch, gehört zu den Sünden der neueren anatomischen Sprache. Sie wurde zuerst von Loder ${ }^{1}$ ) begangen. Erstens hat die lateinische Sprache kein Beiwort obturatorius, und hätte sie eines, so könnte dieses nur etwas zum Verstopfen Dienendes bezeichnen. Mit einem Loch lässt sich aber nichts verstopfen. Ich habe deshalb, statt Foramen obturatorium, immer Foramen obturatum gesagt, weil es durch eine fibröse Membran, welche richtig Ligamentum obturatorium heisst, verschlossen wird.

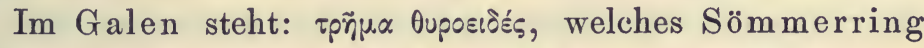
als Foramen thyreoideum aufnahm. Wie kann ein Loch mit einem Schilde, Өupsbs, verglichen werden? überdies noch mit einem viereckigen Schilde, wie es der 0upsós war! Das Widersinnige schwindet, wenn man beachtet, dass Galen nicht thyreoideus, sondern thyroideus schrieb ${ }^{2}$ ). Thyreoideus kommt ganz gewiss von Oupeós, Schild, aber thyroeides von Oúpo $=$ Thür und Oeffnung, Eingang, und Pforte ${ }^{3}$ ). Das Foramen thyroides ist demnach eine Oeffnung am Becken. Vesal und die Ausleger des Galen, sagen immer: ab ostii (nicht a scuti) similitudine ita vocatum. So verstanden es auch die Arabisten, welche das Sitz- und Schambein, als die beiden, das Foramen obturatum umgebenden Knochen, mit Os fenestratum bezeichneten. Dieser gefensterte Knochen, hat zu einer komischen Verwechslung in Pier'er's Anat.-physiol. Realwörterbuch (Artikel Schenkelknochen) Veranlassung gegeben. Unter den Synonymen des Schenkelbeins, wird das Os femoris fenestratum

1) Anatomisches Handbuch, I. Bd., §. 258.

$\left.{ }^{2}\right)$ Administrationes anat., Lib. III, Cap. 13, ad finem.

3) Als letztere auch im Plural: ai Oúpa!, wo ein fürstlicher Hof damit ausgedrückt wird (Xenophon), wie jetzt noch mit der ottomanischen Pforte. 
aufgeführt. Der Schenkelknochen hat aber kein Fenster, wohl jedoch das Os femoris der Arabisten, unter welchem sie das Hüftbein verstanden, weil dieses den Schenkelknochen in seiner Pfanne trägt. Der Schenkelknochen selbst, hiess bei ihnen Coxa.

Wir sind also darüber einig, dass wir das Foramen obturatorium, richtig Foramen obturatum zu nennen haben, dagegen die Muskeln, Gefässe, und Nerven, welche zu diesem Loch in Beziehung stehen, immerhin obturatorii genannt werden können. - Als das grösste Loch am menschlichen Skelet, wäre Foramen maximum nach Vesal, Foramen amplum nach Bartholin, und, seiner eiförmigen Gestalt wegen, Foramen ovale magnum, nach Blumenbach, besser zu verwenden, als das absurde Foramen obturatorium.

\section{Fornix tricuspidalis.}

Sieh' den Artikel: Camera.

\section{Fossa und Fovea.}

Die Anatomie verwendet seit jeher Fossa und Fovea als gleichbedeutend, und gebraucht beide indiscriminatim für Grube. Obgleich die römischen Schriftsteller nicht immer einen scharfen Unterschied zwischen diesen beiden Wörtern treffen, so ersieht man doch aus ihnen, dass sie Fovea für eine Grube überhaupt, Fossa aber für eine lange Grube, einen Graben, anwenden. Nie kommt Fovea, wohl aber Fossa, für Wallgraben, Wasserkanal, Abzugsrinne, Flussbett, selbst für Furche, vor. „Eine Grube machen ", heisst foveam fodere, - "einen Graben machen" aber: fossam ducere, weil er sich in die Länge zieht. Es sollte deshalb die Anatomie nur rundliche Gruben Foveae, längliche oder lange Gruben jedoch Fossae nennen. So macht sie es 
denn auch recht mit den Fossae hepatis, mit der Fossa Sylvii, Fossa innominata auris, Fossa lacrymalis, Fossa basilaris, Fossa supra- et infraspinata, Fossa ossis cuboidei, und von Fossa malleoli externi et interni zu reden, weil diese Gruben sich in die Länge dehnen. Unrecht aber ist es, eine Fossa glandulae pituitariae, Fossa trochanterica, Fossa poplitea, Fossa supratrochlearis, Fossa canina, Fossa axillaris, Fossa ovalis cordis, Fossa subscapularis, Fossae des Hinterhauptbeins und des Schädelgrundes, anzuführen, welche nach dem erwähnten Criterium, Foveae genannt werden müssen, weil sie nicht in die Länge gezogen, sondern rundlichen Umfangs sind. Uebrigens mag es mit diesen Dingen beim Alten bleiben, da sie nicht geradezu als unrichtig und fehlerhaft bezeichnet werden müssen.

\section{Frenulum.}

Kein Anatom hätte geahnt, dass sein vielgebrauchtes Frenulum, kein gutes lateinisches Wort sei. Bei den Classikern liegt nur Frenum vor, und dieses immer im Plural, als Frena und Freni, da das Pferd an zwei Zügeln geleitet wird. Ein Diminutiv von Frenum, ist bei ihnen, selbst in figürlicher Rede, eine res inaudita. Celsus erlaubte sich, auch das Singular, als Frenum, zur Bezeichnung des Vorhautbändchens zu verwenden ${ }^{1}$ ). Den Anatomen gefiel aber Frenulum besser, und so wurde dasselbe denn auch mehrfach benützt, wie im Frenulum labiorum am Munde und an der Schamspalte, im Frenulum praeputii, clitoridis, und epiglottidis, und im Frenulum der grauen Gehirnklappe. Wollte man sich an den classischen Plural Frena halten, so wäre nur das doppelte Bändchen der Clitoris, dieses Namens werth. Jedes andere Frenulum, müsste Habena oder Habenula, Halte (von habeo), genannt werden, deren ursprüngliche Bedeutung jene eines Riemens ist, womit etwas gehalten

1) De medicina, Lib. VII, Cap. 25, num. 2.

Hyrtl. Onomatologia anatomica. 
wird (griechisch rivio). Habenula steht auch im Celsus, für ein Stückchen Fleisch, welches aus einer $W$ unde ausgeschnitten wird 1). Im anatomischen Latein, wird Habenula gänzlich ignorirt. Ein einziges Mal habe ich eine Habenula Halleri, im Samenstrang, als Rest des embryonischen Processus vaginalis peritonei, notirt, und in meiner Anatomie angewendet.

\section{Furcula sterni.}

Beide Schlüsselbeine zusammen, werden in der Kindheit der Anatomie, häufig Furcula genannt. Ein Schlüsselbein allein, hiess immer Clavicula. Die Furcula, als die gepaarten Schlüsselbeine, wurde der Anatomie der Vögel entnommen, deren beide Schlüsselbeine an ihren unteren Enden miteinander verwachsen sind, und den aller Welt bekannten Gabelknochen, Furcula, bilden. Unglaublich, aber wahr ist es, dass es in jener Zeit Chirurgen gab, welche auch die beiden menschlichen Claviculae, zu einer einzigen Furcula verwachsen sein liessen: os furculae habet duo brachia, unum tendit ad humerum, et aliud ad alium ${ }^{2}$ ). Man kann diese Worte nicht anders deuten, als dass es ein einziges, aber zweiarmiges Schlüsselbein giebt. - Bei den Römern war Furcula entweder der Galgen (Furculae Caudinae), oder ein Strebepfeiler, um Mauerwerk zu stützen (Livius). Die lateinische furca, erzeugte die italienische forca, und diese gab den Mundinisten ihre Forcatura, d. i. die Gegend am Ende des Unterleibes, wo die Schenkel sich anheften, wie zwei Gabelarme. Die Spanier sagen dafür Horcajadura. Obwohl nun die Furcula, in dem besprochenen Sinne, als beide Schlüsselbeine zusammen, gänzlich aus der Anatomie verschwand, hat sie doch einen Schatten nach sich gelassen: die Furcula sterni, welche in allen Handbüchern zu Hause ist. Die Incisura semi-

1) De medicina, Lib. VII, Cap. 7, num. 8.

2) Guidon is Cauliaci Chirurgia magna, pag. 34. 
lunaris manubrii sterni wird damit gemeint. Man unterscheidet diese Furcula, als Furcula superior, von der inferior oder humilior, worunter ein gespaltener Processus xiphoideus verstanden wird.

\section{Galea.}

Am Kopfe liegt es, dass die Anatomie auch mit Hauben zu thun bekommt. Sie kennt eine sehnige Schädelhaube, Galea aponeurotica cranii, und eine Amnioshaube, Galea amnii, als einen auf dem Kopf des neugebornen Kindes zuweilen aufsitzenden Amniosrest. Die Chirurgie kennt noch eine Galea Galeni, als einen mützenförmigen Kopfverband '), die Pathologie eine Galea, als dolor capitis, qui totum caput, in modum galeae, comprehendit ${ }^{2}$ ), und die Botaniker nennen, seit Linné, die Oberlippe einer Corolla ringens, gleichfalls Galea (Helm). Die Zoologie hat zwar auch eine Galea s. Galeus, als eine Haifischart; aber diese Benennung gründet sich nicht auf galea, Helm, sondern auf $\gamma \alpha \lambda \varepsilon_{\eta} \eta(\gamma \alpha \lambda \tilde{\eta})$, Wiesel, weil der Fisch schwarz getupft ist, wie eine gewisse Wieselart, und deshalb von Aristoteles diesen Namen erhielt.

In den ersten Zeiten der Republik, trugen die römischen Soldaten theils Helme aus Leder oder Fellen, theils solche aus Metall. Nur die erstere Art hiess Galea, die zweite Cassis. Man verlor aber den ursprünglichen Unterschied bald aus den Augen, und Galea wurde zum allgemeinen Ausdruck für jede Art von $\mathrm{Helm}^{3}$ ). Domenico Santorini kam auf den Einfall, die Galea auch in die Anatomie einzuführen. Er nannte die Aponeurose, welche den Musculus frontalis mit dem occipitalis verbindet, weil sie, wie ein Helm, auf dem Schädeldach

1) Galenus, De fasciis, num. 29.

2) Valescus de Taranta, Philonium pharmac., Lib. I, Cap. 7.

3) Isidorus, Origines, Lib. XVIII, Cap. 14. 
aufsitzt: Galea tendinosa cranii ${ }^{1}$ ), welchen Ausdruck Winslow mit Coëffe aponeurotique übersetzte, woraus dann wieder durch Weitbrecht, die bleibende Galea aponeurotica cranii gebildet wurde ${ }^{2}$ ), welche F. Leber in Galericulus aponeuroticus umformte ${ }^{3}$ ), ohne Nachahmung zu finden.

Die Griechen hatten, nach Julius Pollux, ihre $\pi \S p !-$

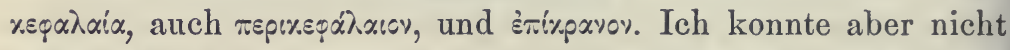
herausbringen, ob sie die Galea, oder das Periost des Schädeldaches damit meinten. Ebenśo unentschieden bleibt die Sache für das Almocatim der Arabisten. Erst als in der Restaurationsperiode der Anatomie, Pericranium für "Beinhaut des Schädels" in Aufnahme kam, wurde Epicranium nur auf unsere fragliche Aponeurose bezogen.

Ueber die Galea des Amnios habe ich, was Etymologie und Synonymie betrifft, in meiner Schrift: Das Arabische und Hebräische in der Anatomie, \&. I und XXIX, das Wichtigste angeführt.

Verwandt mit Galea ist Galerus, eine Mütze aus Thierfellen, wie sie die römischen Bauern trugen. Diese Mützen erhielten verschiedene Namen, nach den Thieren, deren Pelz

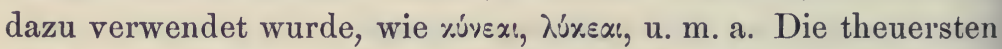

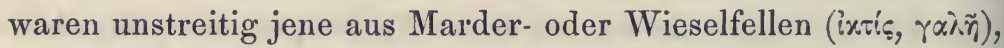
woher sich der Name der Mützen als galeae ergiebt. War sie aus dem Fell eines Opferthieres gemacht, durfte sie nur vom Pontifex und den Salii getragen werden (Apulejus und Juvenal). Galerus hiess auch die spät aufkommende Perrücke. Mit einer blonden Perrücke (nigram flavo crinem abscondente galero, Juvenal), prostituirte sich die Kaiserin Messalina (quae lassari viris, sed non satiari potuit) in den gemeinsten Hurenhäusern Rom's:

"Intrabat calidum veteri centone lupanar."

(Juvenal, Sat. VI.)

1) Observationes anat., Cap. I, §. 3.

2) Commentaria Acad. Petropol., T. VII.

3) Praelectiones anat., Vindob., 1778, pag. 137. 
Galeri sehen wir heute noch auf einigen Porträtstatuen und Büsten im Vatican. Sie sind merkwürdiger Weise abnehmbar, und aus einer anderen Steinart gemeisselt, als die Büste selbst. Die Alterthumsforscher glauben, dass es in der späteren Kaiserzeit, in Rom allgemeine Sitte unter den Frauen höherer Stände war, Perrücken zu tragen, und dass diese abnehmbaren Haartouren, auch an den Büsten der Frauen abnehmbar angebracht wurden. Aber es ist vernünftiger, anzunehmen, dass die Flatterhaftigkeit der Mode, welche mit den Haartrachten im alten Rom ebenso wechselte, wie überall, diese Unsitte entstehen liess. Eine Dame konnte sich, selbst im Bilde, nicht mit einer ausser Mode gekommenen Frisur sehen lassen. Der Künstler brachte also abnehmbare Galeri auf den Statuen an, welche mit jedem Modenwechsel geändert werden konnten, ohne die ganze, sehr kostspielige Statue, deshalb zu verwerfen, oder $\mathrm{zu}$ verletzen und $\mathrm{zu}$ verstümmeln.

Es geht durchaus nicht an, die Namen verschiedener Schiffsformen, wie Galeere (galère), Galeotte (galiot, altfranzösisch), Galeasse (galeazza), und Gallione (galion, spanisch) von galea abzuleiten, mag auch ein umgestürzter Helm von Leder, noch so gut auf dem Wasser schwimmen. Diesen Worten liegt das neulateinische galēa zu Grunde:

„Arrmo caput galěâ, pelagum percurro gale $\hat{a}$ ".

(Martinii Lex. philolog.)

Galēa ist aber ein arabischer Abkömmling, und zwar von chalājā, welches Wort nach Golius selbst wieder von chal̄ (femin. chalijjah), leer, hohl, kommt, so dass chalājā und chalijjū (spanisch galion), ein hohles, d. h. mit einem Verdeck versehenes, zugleich langes und schmales Schiff bedeutet, also Galeere. Durch Verdopplung des $l$, machten die Neulateiner aus Galea auch Gallea, Gallera, und Galleria. Der Leser weiss nun, warum ein gedeckter Gang Gallerie heisst. 


\section{Ganglion.}

Ganglien gab es in der Medicin, lange bevor die anatomischen Ganglien entdeckt wurden. Nach Galen ist ein

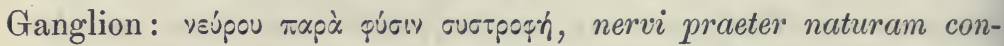
cretio (condensatio ${ }^{1}$ ), also etwas Pathologisches. So definirte auch Gorraeus die Ganglien, als: nervi nodosa et renitens contractio, doloris expers, nullo praeter naturam colore, in manibus et talis freqenter oriens, plerumque ex plaga, raro sponte proveniens. Diese Angaben passen auf das Ueberbein, welches die Pathologen jetzt noch Ganglion nennen. Dass diẹse Ganglien in den Nerven ihren Sitz haben, wurde schon längst als ein Galenischer, grober Irrthum erkannt und-verworfen. Unsere jetzigen (wahren) pathologischen Nervenknoten (Neuromata), kannte Galen ebensowenig, wie das moderne Wort selbst, welches übrigens geschickt gewählt ist.

Die ersten anatomischen Ganglien, welche man kennen lernte, waren die sympathischen. Galen hatte eine gewisse Vorstellung von ihnen ${ }^{2}$ ). Seine Worte sprechen dafür: natura substantiam nervorum, qui ad radices costarum ad ventrem feruntur (offenbar der Sympathicus gemeint), corpore crassiori ${ }^{3}$ ), ceterum autem simili circumdat; videbitur enim talis nervus esse conglobatus, und gleich darauf: nervus crassescit per substantiam,

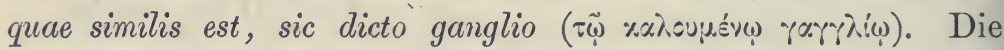
rundlichen Ueberbeine also, gaben ihren Namen dazu her, die Anschwellungen im Knotenstrang des Sympathicus, mit einem stehenden und unvergänglichen Ausdruck zu versehen, an welchem nur Vieussens eine Verbesserung anzubringen meinte, indem er sie, ganz ungriechisch, Gangliones nannte ${ }^{4}$ ).

1) Definitiones medicae, num. 353.

$\left.{ }^{2}\right)$ De usu partium, Lib. XVI, Cap. 5.

3) An einer anderen Stelle: adnata et circumfusa nervea substantia.

4) Neurographia, Lib. III, Cap. 5, pag. 160. 
Die Oleae (Oliven) des Vidus Vidius, die Corpora olivaria des Fallopia, die Nodi und Noduli Haller's, die Tumores gangliiformes des Winslow, die Plexus gangliiformes, und die Diverticula spirituum (Seitenwege der Nervengeister) des Willisius, sind überflüssige Variationen eines Ausdruckes, welcher sein uraltes Stammrecht niemals verlieren wird. Plexus gangliiformes (fehlerhaft Plexus ganglioformes), giebt es übrigens auch in der neueren Zeit, jedoch nicht als Ganglien, sondern als "Nervengeflechte, mit eingestreuten Ganglien ", wie sie im System des Sympathicus vorkommen. - Im Hesychius erscheint auch die Form $\gamma \alpha \gamma \gamma \gamma \alpha \dot{\lambda} \lambda$ :ov für $\gamma \alpha \gamma \gamma \gamma \lambda i o \%$.

Taryitor ist schliesslich kein Galenisches Wort. Hippocrates bediente sich desselben schon zur Bezeichnung derselben Geschwulst, deren Galen am obigen Ort Erwähnung machte.

Man könnte mit Krause, an einen hebräischen oder arabischen Ursprung des Wortes denken, denn das hebräische galgal, und das arabische dschall (gall), driicken etwas Zusammengeballtes aus. - Eine Ganglionitis (Piorry), ja sogar eine Centro-Gangliitis (Nissen), und eine Panto-Gangliitis (für Cholera) zu bilden, wie im etymologischen Lexicon von L. A. Kraus, dazu gehört mehr Courage, als griechische Sprachkenntniss. Sie machen einen wahrhaft peinlichen Eindruck. Hat denn die Medicin noch nicht der verwünschten Worte genug?

\section{Gaster und Gastrula.}

Im Galen hat Gaster ( $\gamma \alpha \tau \tau$ r $p$ ) doppelte Bedeutung: 1. als Unterleib $=x_{0}: \lambda i \alpha$, und 2. als Magen. Eine nur selten vorkommende Anwendung von Gaster, ist jene für Uterus (हेy

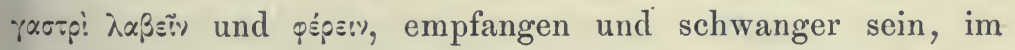
Aristoteles). Beide Bedeutungen haben der Medicin und Chirurgie sehr viele, der Anatomie aber nur etliche bekannte 
und selbstverständliche Anwendungen hinterlassen. So Gaster, als Unterleib, ein Epi-, Meso-, und Hypogastrium, obere, mittlere, und untere Bauchgegend, von welchen die mittlere neueren Ursprungs ist, und bei den Alten nicht vorkommt. Gaster, als Magen, hat sich nur in einigen Zusammensetzungen, und in dem Adjectiv gastricus erhalten, welches alle Organe führen, die mit dem Magen in Verbindung stehen. Wir haben ein Ligamentum phrenico-gastricum (richtiger phreno-gastricum) und gastro-lienale, ein Omentum hepato-gastricum und gastrocolicum, einen Plexus gastricus, die Arteriae gastro-duodenales und gastro-epiploicae, u. a. m. - Da auch der Bauch eines Muskels von Rufus Gaster genannt wird, wie wir am Gastrocnemius sehen, hat die Anatomie den zweibäuchigen Unterkiefermuskel, duce Riolano, Musculus digastricus genannt, welches Wort in keinem anatomischen oder profanen Autor Griechenlands aufzutreiben ist. Lateinische Schriftsteller, welche das Wort Gaster gebrauchen, vergessen ohne Ausnahme, dass ractíp generis feminini ist.

Wenn in der Evolutionslehre jenes früheste Stadium der Entwicklung des Keimes, in welchem die erste Anlage der Keimhöhle sichtbar wird, Gastrula genannt wird, so hat die sprachliche Kritik dagegen nichts einzuwenden. Gastrum kommt

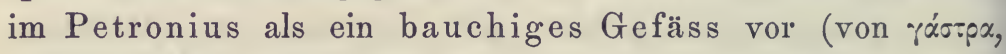
Schiffsbauch), und giebt eine Verkleinerungsform gastrula, welche vielleicht richtiger gastrulum zu lauten hätte.

\section{Gastrocnemius.}

Die Anatomie der Griechen kennt keinen Gastrocnemios, wohl aber eine $\dot{\eta}$ ractpoxyripia im Aristoteles, und ein to

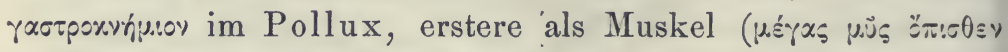

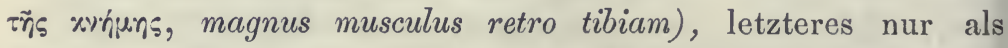
weicher und fleischiger Theil des Unterschenkels, Wade $\left(\dot{r}_{1}\right.$ rasinp tĩ̆s жvriurs, der Bauch der Wade). Spigelius spricht 
der erste von einem Gastrocnemius externus (unser Gastrocnemius), und einem Gastrocnemius internus = unserem Soleus. Riolan nannte dagegen die zwei Ursprungsköpfe des fraglichen Muskels: Gastrocnemius externus und internus, und der durch seine verliebten Abenteuer, wie auch durch seine anatomischen Verdienste bekannte Paduaner Professor, Domenico de Marchettis, fasste beide Ursprungsköpfe simpliciter als Gastrocnemius zusammen 1).

Der Name Gemelli rührt von Paré her (les jumeaux, die Zwillinge). Winslow adoptirte das Wort, welches jetzt noch in den französischen Anatomien Stand hält. Im Latein hat die Anatomie zwischen Gemelli und Gemellus wohl zu unterscheiden. Der Gastrocnemius kann, als ein aus zwei gleichen Ursprungsköpfen gebildeter Muskel, nur mit dem Plural Gemelli surae gegeben werden. Gemellus surae, wie Cowper den Gastrocnemius nannte, wäre nur Einer der beiden Köpfe, denn Gemelli sind im Catullus Zwillingsbrüder, Gemellus aber im Ovid einer der beiden Zwillingsbrüder. Dass man, statt Gastrocnemius, Gasterognymicus schreiben konnte, war nur dem Wiener Anatomen Michael Mayer möglich ${ }^{2}$ ). Allen Verlegenheiten und Missdeutungen, wäre durch Biceps surae, zweiköpfiger Wadenmuskel, vorgebaut.

\section{Gelasinus.}

Die eigentliche Bedeutung von Gelasinus ist: der Lacher. Democritus der Abderite, welcher alles menschliche Thun und Lassen belachte, wie es Heraclitus fortwährend beweinte, führte, nach Ä̈lian ${ }^{3}$ ), den Beinamen Gelasinus, von $\gamma \varepsilon \lambda \alpha^{\prime} \omega$, lachen. Aus römischen Inschriften ist uns auch ein Cajus Minucius Gelasinus, von gleicher humoristischer Gemüths-

1) Compendium anatomicum, 1652, Cap. 19.

$\left.{ }^{2}\right)$ Anatomie in Fragen und Antworten, Wien, 1821.

3) Variae Historiae, IV, 20. 
stimmung, bekannt. Zwei anatomische Objecte führen gleichfalls diesen Namen, weil sie beim Lachen zur deutlichen Ansicht gelangen: das Lachgrübchen der Wange, und die oberen Schneidezähne. Ueber die Lachgrübchen sieh' den Artikel Lacuna. Forcellini gedenkt derselben, quia miram ori conciliant venustatem, und in Tasso's Aminta, erscheinen sie als pozzette, che forma un dolce riso in bella guancia. Von den Griechen erwähnt die Gelasini, als Lachgrübchen, nur

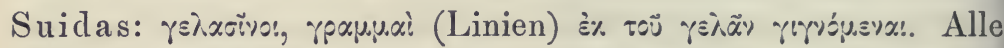

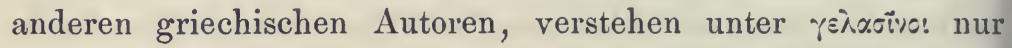
die Schneidezähne. Es genügt, wenn ich mich blos auf das Onomasticon des Julius Pollux ${ }^{1}$ ) berufe, welches über die Schneidezähne Folgendes sagt: Dentes quatuor medii, sectores

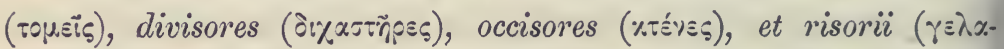
sivo:) vocantur, partim quia secant cibum et conscindunt, omneque quod iis incidit, dividunt, partim quod inter ridendum denudantur, et quod omne prehensum occidunt. In den Versen des Martial:

"Nec cibus ipse juvat, morsu fraudatus aceti, „Nec grata est facies, cui gelasinus abest,"

(Epigrammata, Lib. VII, Ep. 25)

kann mit gelasinus nicht das Lachgrübchen gemeint sein, sondern ein Schneidezahn, weil ein Gesicht ohne Lachgrübchen noch immer sehr schön sein kann, mit einer Lücke in der Mitte der Zahnreihe jedoch einen, wenn auch nicht geradezu unangenehmen, doch sicher auch keinen angenehmen Eindruck macht. Die Ausleger des Martial behaupten fest, dass der gelasinus nur einer der oberen Schneidezähne, und zwar der innere gewesen sein kann, weil er grösser ist als der äussere, und eine Lücke an seiner Stelle mehr auffallen muss, als anderswo. Da Martial seinen gelasinus nur im Singular aufführt, spricht dieser Singular, wie ich glaube, am deutlichsten

1) Lib. II, Cap. 4, num. 91. 
dafür, dass er an eine Zahnlücke, nicht an die beiden Wangengrübchen dachte.

Die Hinterbacken sind zwar weit von den Lippen und

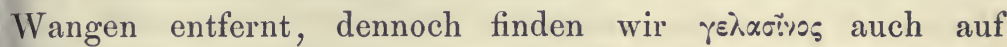
jene Vertiefung angewendet, welche an vollen Hinterbacken, dort sich bemerkbar macht, wo das Fleisch des Glutaieus maximus, in seine Sehne ïbergeht (Alciphron, Ep. I, 39, und Anthologia graeca, T. II, pag. 390).

\section{Gena, Geneion, und Mentum.}

Wir nehmen Gena nur als Wange. Unbestritten hat jedoch Gena eine doppelte Bedeutung, und zwar beide anatomisch. Dem ältesten römischen Dichter (vates antiquissimus) Ennius, welcher im Jahre 510 ab urbe condita, d. i. 240 Jahre vor Christo geboren wurde, sind Genae, die Augenlider: pandite genas, macht die Augen auf ${ }^{1}$ ). Ein anderer alter Dichter, Pacuvius, versteht unter Gena nur die Wange, wo der erste Bart keimt:

„Nunc primo opacat flore lanugo genas $\left.{ }^{2}\right) . "$

Ebenso Virgil:

„Tum mihi prina genas vestibat flore juventus.“

Im Isidorus lese ich eine Phrase des Ennius: imprimere genam genae, nicht für "sich abküssen", sondern für "A ugenschliessen". Im Plinius werden die Genae theils als Augenlider, theils als Wangen erwähnt: pili quadrupedibus in superiore tantum gena, volucribus in inferiore, und: infra oculos malae, quas prisci genas vocabant ${ }^{3}$ ). Das Alter der Gena, als Wange,

1) Festus, De verborum significatione, Lib. VII, sub initio.

2) Festus, ibid.

3) Hist. nat., Lib. XI, Cap. 37, Num. 58. 
bezeugen auch die Worte der zwölf Tafeln: neve feminae genas radunto, d. i. "die Weiber sollen sich ihre Wangen nicht zerkratzen", was bei Leichenbegängnissen, als Zeichen der Trauer, zu geschehen pflegte ${ }^{1}$ ).

In späterer Zeit, und unter den Anatomen, wird Gena nie mehr als Augenlid, sondern nur als Wange erwähnt, wo der Bart zuerst keimt ${ }^{2}$ ). Das Wort scheint auch dem Homerischen

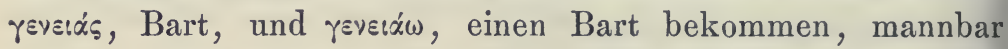
werden, nicht fern zu stehen. Von Gena, als Wange, erhielten die Stockzähne ihren Namen Genuini im Cicero, weil sie die Wange berühren (quia a genis dependent, Festus). Gena, als Augenhöhle, braucht Ovid: expilare genis oculos, die Augen ausreissen.

Das lautverwandte Үร́vsเo des Hippocrates ${ }^{3}$ ), dient fortan in der Anatomie als Kinn, als Kinnbart4) im Homer, und als Kinnbacken im Aristoteles. Im Galen und Oribasius, behält es ausschliesslich die Bedeutung Kinn, und diese ist auch in unserer Anatomie, die allein gekannte. Wir haben zwei Muskeln, welche am Kinn entspringen. Der eine geht zum Zungenbein, der andere zur Zunge. Sie wurden deshalb von Riolan: Geniohyoideus und Genioglossus genannt. Alle Welt nennt sie gegenwärtig so, denn die Namen sind graphisch ${ }^{5}$ ), weil sie Ursprung und Ende der Muskeln ausdrücken. Nur möge man beherzigen, dass, wenn das ei im griechischen geneion, im Latein zu $i$ verschmilzt, dieses $i$ lang ist, und diese Muskeln somit genīohyoideus und geñ̄oglossus zu sprechen sind, was proh dolor! nie geschieht. Rufus Ephesius

1) Plinius, loco citato.

2) Nur bei den Arabisten stossen wir auf Gena superior und inferior, für Ober- und Unterkiefer.

3) De natura hominis, n. 31 .

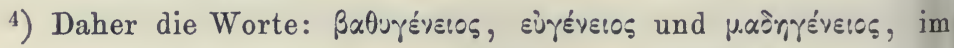
Pollux, als barbatus, pulchre barbatus und barba carens.

5) Vergleiche den Artikel: Ideus, als Ausgang von Muskelnamen. 


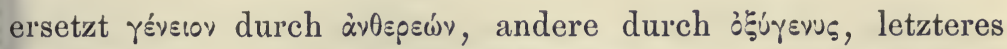
nur für Thiere, deren Unterkiefer aus zwei, am Kinn unter einem spitzigen Winkel zusammenstossenden Hälften besteht.

Das lateinische Mentum entspricht dem révıı৩. Celsus definirt mentum, als malae (maxillae) inferioris media pars, unde barba nascitur. Plinius nennt deshalb das Kinn: barbamentum. Durch Elision der ersten zwei Silben, entstand mentum.

\section{Genu und geniculatum corpus.}

Genu, das griechische yóvu, ist und war nie etwas anderes als Knie. Seine Verkleinerungsform Geniculum dagegen, bedeutet im Plinius auch die Knoten an den Halmen. Nicht von genu, Knie, sondern von geniculum, Knoten, tragen die zwei Corpora geniculata des Gehirns ihre, von Santorini zuerst gebrauchten Namen ${ }^{1}$ ). Diese halbelliptischen Körper, liegen an der unteren Gegend des Sehnervenhügels, zwischen diesem Hügel und dem Hirnschenkel. Santorini verglich sie mit den Corpora quadrigemina, und nannte sie Corpora geniculata, knotige Körper. Richtiger hätte er beide zusammen Corpus geniculatum nennen sollen, da auch Corpus quadrigeminum besser ist, als Corpora quadrigemina. Das Corpus geniculatum hat zwei Knoten (genicula), wie das Corpus quadrigeminum vier. Der einzige Sömmerring hatte die Sache richtig aufgefasst. Er spricht nur von Einem Corpus geniculatum mit zwei Höckern ${ }^{2}$ ), wie von einem Vierhügel, mit vier Höckern. Da eine rundliche Erhabenheit doch nieht $\mathrm{Kn}$ ie genannt werden kann, worunter man figürlich sich nur eine Ecke oder einen Bug denken kann, wäre es richtiger, mit Mayer: gegliederter Körper, als mit den übrigen Anatomen: knieförmiger Körper zu sagen.

1) Observationes anatomicae, pag. 63.

2) Hirn- und Nervenlehre, §. 48. 


\section{Gingiva,}

Um der unprosodischen Aussprache Ginǧva, welche ich so oft bei den Rigorosen aus dem Munde der Candidaten und ihrer Professoren vernehmen musste, für immer ein Ende zu machen, citire ich den Vers Juvenal's:

\section{"Frangatur misero gingīvâa panis inermi."}

(Satyra X, 200.)

Die richtig betonte Gingiva, hat in allen Tochtersprachen der lateinischen, ihre Nachkommenschaft hinterlassen: im Italienischen Gengiva, im Französischen gencive, im Spanischen las encias, im Wallachischen Gingie, und im Provençalischen Angiva. Das griechische ỡ $\rangle_{0 \%}$, ist in der Anatomie gänzlich verschollen. Ein Andenken an dasselbe bewahrt nur die Chirurgie, in ihrer Epulis und Parulis. Die der Zunge zugekehrte Fläche

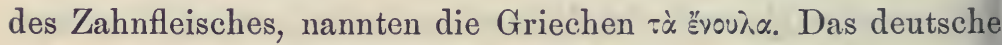
Zahnfleisch stützt sich auf die Caro dentium der Arabisten,

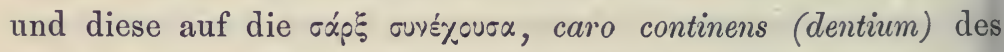
Galen.

Für die altdeutschen Benennungen des Zahnfleisches, als Beuler und Bildern, im Wienerischen noch als Billen zu treffen, liegt im Rabanus Maurus das Stammwort vor. Dasselbe lautet: Bilorna.

Mehr über Gingiva, und sein arabisches Aequivalent Gumaur und Gumur, in HL, §. LXIX, pag. 149, seqq.

\section{Ginglymus,}

Galen übernahm das Wort Ginglymus aus dem Hippocrates, welcher die Rolle des Oberarmbeins r.ryhuposioris nannte, da er sie mit einer Thürangel verglich, welche ríryivpos heisst. Galen aber erhob Ginglymus zu einer Gelenksart, 
welche wir Winkelgelenk nennen: ginglymus fit, dum ossa sese vicissim ingredientia conjuncta sunt ${ }^{1}$ ). Er hatte dabei das Ellbogengelenk vor Augen, wo wirklich zwei Knochen sese vicissim ingrediuntur, indem die Incisura semilunaris major ulnae die Trochlea des Oberarmes umgreift, und eine Grube des Oberarmbeins (Fossa supratrochlearis) das Olecranon der Ulna in sich aufnimmt. Das Umgriffenwerden der absteigenden Gelenkfortsätze der Wirbel (Lendenwirbel), durch die aufsteigenden des nächst unteren Wirbels, reiht Galen ebenfalls den Ginglymi an.

Hauptbedingung für einen Ginglymus ist das Vorhandensein einer Rolle (Sieh' den Artikel: Trochlea). Wir fügen deshalb dem Muster eines Ginglymus, wie es in der Articulatio brachio-ulnaris gegeben ist, noch die Finger- und Zehengelenke, das Knie- und Sprunggelenk bei, - letztere schon modificirt, da das Schienbein und das Sprungbein auch eine Drehung um eine verticale Axe, nicht blos um die Horizontalaxe der Trochlea, gestatten. Eine grobe Entstellung hatte der Ginglymus durch C. Hofmann ${ }^{2}$ ) erlitten, als Ginglysmus.

Das mittelalterliche Cardo und Articulatio cardiniformis, entspricht dem Ginglymus vollkommen, wie das deutsche Gewerb- und Wechselgelenk, oder Gewinde schlechtweg (Walter), und die charnière des Winslow.

\section{Glabella.}

Das Adjectiv glabellus, ist die Verkleinerungsform von glaber, unbehaart, kahl. Das zum Substantiv erhobene Femininum, bezeichnet als Glabella eigentlich den zwischen den behaarten Augenbrauen, über der Nasenwurzel, unbehaart

1) De ossibus ad tirones, in Prooemio.

2) Institutiones medicae, Lib. I. 
bleibenden Raum - Stirnglatze, nach Sömmerring ${ }^{1}$ ), wird aber gewöhnlich schon in der Osteologie, als die dreieckige, zwischen den beiden Arcus superciliares liegende Stelle aufgeführt. Das Wort glabellus kommt nur im Apulejus vor (Metam. V), als glabellum feminae, unbehaarte weibliche Scham, und Cupidinis corpus glabellum (Flor. num. 3).

Bei den Griechen, hiess diese Stelle prøóppuor (in der Mitte zwischen den Brauen, óppúss), und die Menschen mit verwachsenen Brauen, bei welchen also die glabella fehlte: euvóppuss. Man erblickte im Synophrysmus ein Attribut besonders schöner Gesichtsbildung, was noch im Orient der Fall ist, weshalb sich dort die Frauen, einen einfachen schwarzen Streif, quer über die Stirne zu malen pflegen, als Stellvertreter verwachsener Augenbrauen.

\section{Glandula.}

Die ersten Drüsen, von welchen die Anatomie Kenntniss nahm, waren die Mesenterialdrüsen. Dass sie schon Herophilus kannte, wird uns durch Galen verbürgt $\left.{ }^{2}\right)$. Wir kennen die Gekrösdrüsen, als kleine, rundliche, gefässreiche Organe, welche entweder vereinzelt, oder wie in der Gekröswurzel, in Haufen zusammengedrängt liegen. Ihre glatte Oberfläche scheint die Ursache ihrer Benennung, als $\alpha \delta$ śvє६, gewesen zu sein, wenn dieses Wort wirklich, wie $\mathrm{Kraus}^{3}$ ) angiebt, aus $\alpha$ priv. und

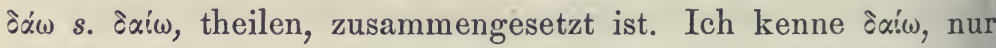

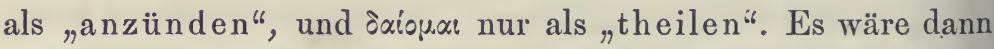

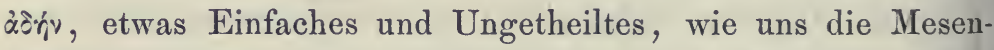

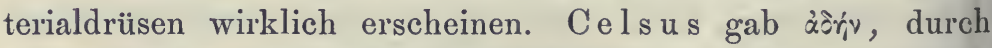
Glandula, i. e. parva glans, kleine Eichel, - ein Wort, welches,

1) Knochenlehre, $\$ .90$.

2) De usu partium, Lib. IV, Cap. 19.

3) Kritisch-etymologisches, medicinisches Lexicon, 3. Aufl., pag. 23. 
ausser Martial ${ }^{1}$ ), keinem Classiker bekannt ist. Vesal kennt nur Glandes. Im $\mathrm{R}$ ufus heisst es : glandulosae carnes, quas Graeci adenas vocant ${ }^{2}$ ). Die Kleinheit und rundliche Form dieser Drüsen, wird durch Glandula besser ausgedrückt, als durch

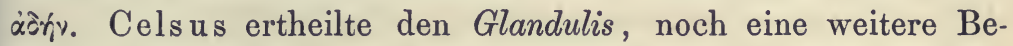
deutung. Er nannte auch die Drüsenanschwellungen Glandulae ${ }^{3}$ ), wie wir im Deutschen ebenfalls Drüsen, für Drüsengeschwulst gebrauchen. Dass auch alle zusammengesetzten Drüsen, nach und nach $\mathrm{zu}$ den Glandulae (Eichelchen) gestellt wurden, geschah dadurch, dass man sie als Anhäufungen einfacher Glandulae auffasste. Sie wurden deshalb unter der Rubrik Glandulae conglomeratae subsummirt, während die einfachen Mesenterialdrüsen, und alle anderen Lymphdrüsen, als Glandulae conglobatae verblieben. Die Römer hatten auch in ihrem Glandium, ein eigenes Wort für die beiden grössten Glandulae conglomeratae, für die Thymus und für das Pancreas, geschaffen. Diese beiden Drüsen waren, wie die Milchdrüsen eines hochträchtigen Schweines, von den Feinschmeckern sehr gesuchte Leckerbissen (suaves in cibo, Gal.), und haben sich dadurch die Ehre einer besonderen Benennung wohl verdient. Die Preise dieser Delicatessen waren so enorm, dass der Staat durch Verordnungen dagegen einschreiten musste: extant censoriae leges, glandia in coenis, gliresque (Siebenschläfer), apponi vetantes (Plinius).

Was die Ansichten des Alterthums über die Leistung der Drüsen anbelangt, so konnten diese, in Anbetracht des Umstandes, dass man die Ausführungsgänge mehrerer Drüsen

1) Ter poscit apri glandulas, quater lumbum, et utramque coxam leporis, et duos armos, von der Tafel eines Schlemmers, Epigrammata, Lib. VII, 20.

2) Op. cit., pag. 38 .

3) Si aetas procedit, glandulae, et strumae, et alia tubercula oriuntur, und an einem anderen Orte: ulcus madet, neque alitur, et in cervicibus glandulae oriuntur. De medicina, Lib. VIII, Cap. 4.

Hyrtl. Onomatologia anatomica. 
damals noch nicht kannte, nur sehr ungenügende sein. Man war aber damals ganz damit zufrieden. Diesen Ansichten zufolge, wurde das Heer der Drüsen, in drei Classen getheilt. 1. Absondernde Drüsen, wie die Hoden, die Milchdrüsen, die Unterkiefer-Speicheldrüse, die Thränencarunkel, welche als das alleinige Erzeugungsorgan der Thränen galt, der Hirnanhang, als schleimbereitende Drüse, welche ihr Secret durch die Siebbeinlöcher in die Nasenhöhle abführt, und die Meibom'schen Drüsen, welche Galen kannte, und für talgbereitende Drüsen erklärte: unctuosa corpora ( $\lambda \iota \pi \alpha \rho \grave{\alpha} \sigma \omega \dot{\mu} \alpha \tau \alpha)$, emolliendarum sua pinguedine palpebrarum gratia, natura comparavit ${ }^{1}$ ). 2. Die zweite Classe umfasste jene Drüsen, welche, wie die Thymus, die Glandulae mesaraicae, und das Pancreas, nur zum Schutz und zur Lagesicherung der grossen Blutgefässe dienen, auf welchen sie aufliegen : velut stabilimenta quaedam, ne motibus violentis, rami a truncis divellerentur (Gorraeus). 3. Die dritte Gruppe endlich waren die sogenannten Emunctoria, d. i. die Lymphdrüsen in der Achsel, in den Leisten, am Halse, und die Parotis im Gesicht. Ihre Bestimmung lag darin, spongiarum instar, die humiditates superfluas und nocivas aus den ihnen nächstgelegenen Organen aufzunehmen, und sie unschädlich zu machen, Gott weiss wie. Schon das Wort Emunctorium (von mungere, schneutzen ${ }^{2}$ ), ist ein miserables. Es kommt in der Vulgata ${ }^{3}$ ) als Lichtputze vor. Gemeine Leute sagen: das Licht schneutzen.

Das deutsche Wort Druise, convenirt eigentlich nur den Glandulis conglomeratis. Denn Drüse, im Niedersächsischen Dröse, ist das altdeutsche Dros, das schwedische Druse und Drosse = ein Haufe. Daher auch in der Mineralogie Druse,

1) De usu partium, Lib. X, Cap. 7.

2) Emungi digitis vel cubitis, sich mit den Fingern, oder am Aermel schneutzen (Suetonius und Macrobius), und emunctae naris homo im Horaz, ein pfiffiger Kerl.

3) Exodus, 25, 38, B. A. 
ein Stück Gestein, welches seiner hügeligen Oberfläche wegen, dem Auge als eine Anhäufung mehrerer gleichartiger Theile erscheint. Die pathologische Anatomie nennt die Pseudoplasmen mit solcher Oberfläche: drusig. Im deutschen Norden hört man Bries für Drüse. Die Thymusdrüse heisst bei den Fleischhauern Wiens: das Briesel, welches Wort aber auch aus Brösel entstanden sein kann, des kleinkörnigen Ansehens dieser Drüse wegen.

\section{Glenoidalis,}

Eine flache Gelenksgrube nannte Galen rin'm, zum Unterschied von einer tiefen: y.ơu่ $\left.\eta_{1}{ }^{1}\right)$. Er entlehnte diesen Ausdruck aus Hippocrates, welcher jede Gelenksgrube über-

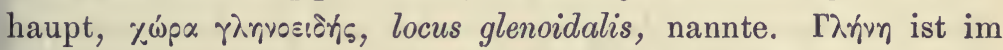
Homer der Augenstern ${ }^{2}$ ), dessen spiegelnder Glanz, die Veranlassung gegeben haben mag, dass auch Gelenksflächen, ihres im frischen Zustande glänzenden Ansehens wegen, $\gamma \lambda \tilde{n} v \alpha \iota$ ge-

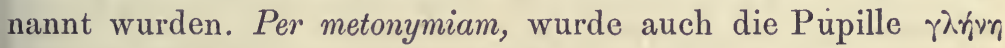
genannt (Sophocles). Die Anatomie unserer Zeit, hat vorzugsweise zwei Gelenksflächen mit dem Beisatz glenoidalis ausgezeichnet: die Cavitas s. Fossa glenoidalis des Schulterblattes, und des Schläfebeins.

Da die primitive Bedeutung von Yirín, Augapfel und Augenstern ist, übersetzten die Araber dieses Wort nicht mit Gelenksgrube, sondern mit Auge (ain). Daher erklärt es sich,

1) De ossibus ad tirones, in prooemio.

2) Ilias, XIV, 494:

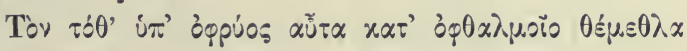

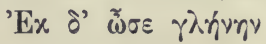

„Unter der Brauen ihm stach er die untersle Wurzel des Auges,

„Dass ihm der Stern ausfloss - - - . 
warum etliche Gelenksflächen, in den Schriften der Arabisten, sonderbarer Weise, als oculi auftreten, wie z. B. oculus scapulae und oculus genu.

\section{Glomer und Glomerulus.}

Glomer und Glomerulus sind der classischen Sprache fremd. Sie kennt nur glomus, mit dem Genitiv glomi und glomeris, wie glomus lini im Plinius, und glomus lanae im Horaz. Glomus ist ein Knäuel. Das Convolut der Dünndarmschlingen, heisst bei den Arabisten: Glomus intestinorum. Das Diminutiv Glomerulus, gebrauchte für die Nierenknäuel, zuerst Schumlansky, de structura renum, pag. 1015. Früher nannte man sie Glandulae albicantes (Malpighi), Corpuscula glandulas mentientia (Ruysch), Globuli minutissimi renum (Morgagni), und Corpuscula ovata (Monro, oval-shaped bodies). Im lateinischen Winslow, erscheinen auch die Talgdrüsen der Haut, als glomi cutanei.

\section{Glottis.}

Aus Glottis ist etwas ganz Anderes geworden, als sie ursprünglich war.

Der Kehlkopf wurde von den Griechen mit dem zungenförmigen Mundstuick ( $\gamma\rangle \omega \tau \tau ! \zeta)$ einer Pfeife verglichen, und erhielt daher der innere Raum desselben, in welchem die

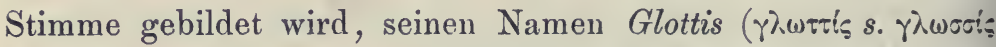
als Diminutiv von $\gamma \lambda(\omega) \sigma \sigma \alpha$, attisch $\gamma \lambda(\omega) \tau \tau \alpha)$, so wie der Knorpel, welcher über dem inneren Raum des Kehlkopfes schwebt, Epiglottis hiess. Die lateinischen Uebersetzer des Galen und Oribasius, bedienten sich sofort des Ausdiuckes Lingula,

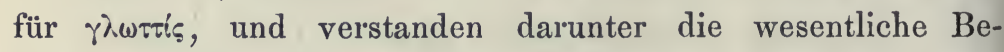
dingung der Tonbildung, weil das Mundstück aller sogenannten Zungenpfeifen (Clarinett, Hoboe, und Fagott), die wesentliche 
Bedingung der 'Tonerzeugung bildet. Bei der Anwendung des Wortes Glottis, wurde also nicht auf die Zunge, sondern auf das tönende Mundstück der Schalmei reflectirt, dessen vibrirende Blättchen allerdings auch zugleich die Form von Zungen haben, und heute noch in der Acustik Zungen genannt werden. Es ist nothwendig, die Worte des Galen vorzuführen: in spatio laryngis interni, corpus positum est,

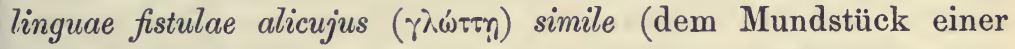
Pfeife ähnlich ${ }^{1}$ ). Dieses Corpus erstreckt sich vom Eingang des Kehlkopfes, bis zum Anfang der Luftröhre: ab orificio, quod a finibus cartilaginis arytaenoideae et thyreoideae efficitur, ad connexionem laryngis cum trachea ${ }^{2}$ ). Nicht was wir jetzt Stimmritze nennen, sondern der ganze innere Raum des Kehlkopfes, hiess ihm somit Glottis.

Da man erst ziemlich spät, durch Fabricius ab Aquapendente, einsehen lernte, dass zwei Bänder im Innern des Kehlkopfes, und die zwischen diesen Bändern befindliche Spalte oder Ritze, die eigentlichen Instrumenta vocis sind, wurde der Name Glottis, auf diese Spalte übertragen, und die betreffenden Bänder: Ligamenta glottidis (Haller), Chordae vocales (Ferrein), s. ligamentosae (Winslow), genannt. Mit der letzteren Benennung steht es sehr übel, da es sich nicht um Saiten, sondern um membranöse Zungen handelt. Der Unterschied zwischen diesen beiden Dingen bezüglich ihrer Schwingungen, wurde vor Chladni, noch zu Ferrein's und Winslow's Zeiten, nicht scharf genug aufgefasst. Nicht mit Glottis zufrieden, weil sie griechisch ist, schuf sich Vesal seine Rima laryngis. Diese ging aber bald in die Rima glottidis über, welche durch $\mathrm{Haller}$ einen bleibenden Platz in der Anatomie erhielt.

Nach der Abbildung, welche Anthony Rich ${ }^{3}$ ), von einer alten Flöte, Tibia, giebt ${ }^{3}$ ), sah das Mundstück derselben,

1) Oribasii Anatomica ex Galeno, pag. 61.

2) Ibidem.

3) Römische Alterthümer, pag. 355. 
ganz wie jenes unserer Hoboe aus, war aber breiter als dieses. Es bestand aus zwei zungenförmigen, etwas concaven Holzplättchen, welche ihre Concavität einander zukehrten, und somit eine enge Spalte zwischen sich frei liessen, deren lanzettförmige Gestalt, jener einer Stimmritze gleicht ${ }^{1}$ ). Wenn Tibia mit Flöte übersetzt wird, darf man nicht an unsere Flöte denken, welche kein Mundstück, sondern nur ein einfaches Mundloch besitzt, mittelst welchem, durch Anblasen von der Seite her, die Luft im Inneren des Instrumentes, in stehende Schwingungen versetzt wird. Andere Arten der Tibia, wie z. B. die älteste Form derselben, der Monaulos des Martial 2), hatten das Mundstück unserer Clarinette, mit einem einfachen Plättchen (Zunge ${ }^{3}$ ). Diese Flöten führten den anatomischen Namen Tibiae, weil die Schienbeine der grossen Haussäugethiere, wie die Röhrenknochen der Vögel, den Stoff der ersten und einfachsten Blasinstrumente bildeten, wie jetzt noch bei den Wilden Neuhollands, die Schienbeine des Känguruh's, und gelegentlich auch eines getödteten Feindes, ausschliesslich zu diesem musikalischen Gebrauch dienen. Warum Flöten blasen nicht tibia canere, sonder tibiis canere heisst, ergiebt sich daraus, dass gewöhnlich Ein Musiker, zwei Tibiae zugleich blies, welche mit der rechten und linken Hand gehalten wurden, daher tibiae dextrae et sinistrae, von welchen die dextrae ein tieferes Tonregister hatten, als die sinistrae (gravi bombo, Apulejus), und von Herodot deshalb, männliche Flöten genannt werden. Die Lexica irren, welche das Umgekehrte angeben.

Was über wahre und falsche Stimmritze, und deren Bänder, in den Anatomien gesagt wird, bietet keinen Stoff zur Fortsetzung dieser kurzen Kritik über Glottis.

1) Römische Alterthümer, pag. 355.

2) Der Monaulos, wie er einstens leibte und lebte, steht noch bei den neapolitanischen Dudelsackpfeifern (Pifferari) im Gebrauch.

3) Abbildung in Anthony Rich, Op. cit., pay. 625 . 


\section{Glutaei.}

Glutaei (nicht Glutei) heissen die Gesässmuskeln. Г̀outós im Homer, ist Hinterbacke ${ }^{1}$ ). Hippocrates braucht aber үioutós für rundliche Knochenfortsätze und Gelenksköpfe. So nennt er den grossen Trochanter und den Kopf des Schenkel-

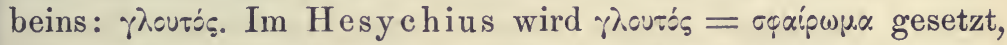
als rundliche Erhabenheit, und im Suidas bedeutet rioutóv:

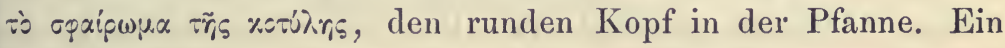
volles und derbes Gesïss, konnte, seiner Rundung wegen, wohl Anspruch auf yioutós machen, wie denn auch die rundlichen Sehhügel, im Galen als ż̀ rìoútı aufgeführt werden. Wenn nun Yìcutós die ältere Benennung für Trochanter major ist, zugleich aber auch auf Gelenkskopf passt, wird es uns verständlich, wieso bei den Patres dẹ Anatomie, zuweilen dem Schenkelbein, drei Trochanteres zugeschrieben werden konnten, deren einer der Schenkelkopf ist. Noch im 17. Jahrhundert, finden wir den Schenkelkopf als Trochanter erwähnt. Nicht widersinnig, aber sonderbar, muss uns diese Benennung vorkommen. Der Schenkelkopf dreht sich ja, und kann somit immerhin einen Namen tragen, welcher von tpo\%s stammt. Trochanter für Schenkelkopf ist jedenfalls besser, als das Vertebrum des Zerbis. Vergleiche den Artikel: Trochanter.

\section{Gomphosis.}

Galen definirt seine Gomphosis, als eine Art von Synarthrosis (Knochenverbindung), ubi os ossi clavi ad instar infigitur ${ }^{2}$ ).

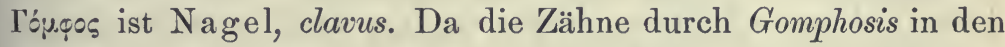
Kiefern haften, wie der Nagel in der Wand, heissen auch die

1) Ilias, V, 66-68, und XIII, 651 und 652 .

$\left.{ }^{2}\right)$ De ossibus ad tirones, in prooemio. 
Molarzähne im Rufus Ephesius róụ̣:o!, und das Wackeln der Zähne: gomphiasis (Gorraeus). Galen dehnte aber seine Gomphosis, auch auf die Verbindung einzelner Hand- und Fusswurzelknochen aus, deren Beweglichkeit eine sehr geringe ist, was wir besser mit Amphiarthrosis ausdrückeu, welches so viel sagen will, als: beschränktes Gelenk. Das Wort ist zwar neuerer Mache, aber gut zu brauchen, neben Synarthrosis (Symphyse), Diarthrosis (freies Gelenk), und Enarthrosis (Pfannengelenk). Gomphosis übersetzten die lateinischen Autoren, mit Clavatio, Claveatio und Inclavatio. Beide Worte sind dem guten Latein fremd. Besser wäre Conclavatio, da es ein Adjectiv conclavatus giebt.

\section{Habenula,}

Sieh' den Artikel: Frenulum.

\section{Hallux,}

Wie mag der barbarische Hallux entstanden sein? Die grosse Zehe führt im Glossarium Isidori, den Namen Allex. Wir kennen dieses Wort aus Plautus ${ }^{1}$ ), als allex viri, scherzweise für kleines Männlein, Duodezmännchen, Tom Puce. Allex wird auch Hallex geschrieben, und diese Schreibart muss für die richtigere angesehen werden, da Festus das Wort Hallus, von dem scharf aspirirten $\alpha \lambda \lambda \varepsilon \sigma \theta \alpha$, saltare, ableitet, indem die grosse Zehe sich gerne, besonders beim Tragen enger Fussbekleidung, auf die nächste zweite schief hinauflegt. Der Grammatiker Festus hat dagegen, in seiner Significatio verborum: Allus und Hallus. Hallus definirt das Glossarium Labb.

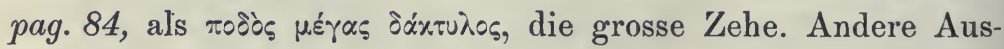
drücke für grosse Zehe, sind nicht bekannt. Die Latino-Barbari

1) Poenulus, Act. V, Sc. 5, Vers 31. 
nachten ihren Hallux, welcher jetzt noch in der anatomischen Sprache allein herrscht, dadurch, dass sie das $x$ des Isidoischen Allex, dem $s$ im Hallus des Festus substituirten. Der barbarische Hallux, hat einen anatomischen Genitiv : hallucis wie im Flexor, Extensor, Abductor hallucis). Dieser ist eo ipso wuch barbarisch, da nur hallicis (von dem richtigen hallex) gesagt werden darf.

\section{Helicotrema,}

Jedes Loch, jede Oeffnung, welche an der Schnecke des

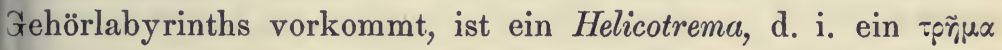

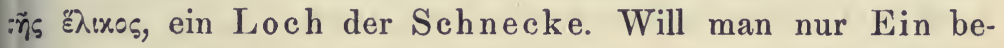
stimmtes Loch in der Schnecke, mit diesem Namen auszeichnen, ;o muss diesem Helicotrema, der Name des Anatomen beijegeben werden, welcher das Wort zuerst für dieses besondere Loch neu construirte. Dieser Anatom war Breschet, welcher lie Oeffnung in der Schneckenkuppel, durch welche die Scala ympani mit der Scala vestibuli im freien Verkehr steht, hélicorème nannte. Also nicht Helicotrema schlechtweg, sondern Helicotrema Brescheti, wodurch die Anatomie zugleich ihren Dank dem Manne ausdrückt, welcher sie mit einem neuen Worte, wenn auch nicht mit einer neuen Sache, bereicherte. Der Sinn des Helicotrema Brescheti, liegt eigentlich schon im Scyphus Vieussenii. Sieh' dieses Wort.

\section{Hepar und Jecur.}

Da sich aus dem griechischen Wort Hepar, viel leichter in Adjectiv bilden lässt, als aus dem lateinischen Wort Jecur,

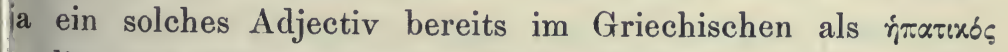
vorliegt, wird Hepar (bei den Latino-Barbari Epar, wegen des priechischen $\left.{ }_{\eta}^{\sim} \pi \alpha_{p}\right)$, in der Anatomie ausschliesslich für Leber gebraucht. 
Das Adjectiv hepaticus kommt jedem anatomischen Gebilde zu, welches mit der Leber in Beziehung steht, während jecorosus im Caelius Aurelianus, und jecinerosus, auch jecoriticus ${ }^{1}$ ), bei den Spätlateinern, nur für leberklank angewendet werden.

Ein bei den Restauratoren der Anatomie öfters auffallender Name für Leber, ist Ficatum. Man erräth allsogleich, dass aus diesem Ficatum, das spanische higado, das italienische fegato, und das französische foie abstammen. Ficatum ist kein barbarisches, sondern ein echt lateinisches Wort. Die Leber der Gans war, wie jetzt, so auch bei den Römern, eine leckere Speise. Die Gourmands liebten besonders die Leber einer mit trockenen Feigen gefütterten weissen Gans:

\section{"Pinguibus et ficis pastum jecur anseris albi".}

(Horatii Sat. $I I, 8,80$.)

Eine solche Leber, heisst im Apicius, welcher sie zu bereiten lehrte, Ficatum, von ficus, wie das griechische ouxwiò $\gamma_{1}^{\pi} \pi x_{0}$

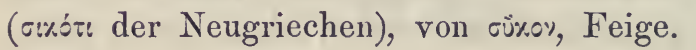

\section{Hilus renis,}

Wer zuerst die anatomische Sprache mit diesem gramma tikalischen Fehler verzierte, kann uns gleichgiltig sein. Wen Pierer und Choulant's Realwörterbuch ${ }^{2}$ ), diese Ehre dem Eustachius vindicirt, so muss ich ihn dagegen in Schuti nehmen, denn in der von Lancisi 1714 besorgten Herausgabr seiner Tafeln, ist nirgends von Hilus renis die Rede, und die in Pierer citirte Pagina 33, enthält nichts als die Erklärung de

1) Jecur, auch Jocur im Plinius, hat einen dreifachen Genitir jecoris, jecinoris und jocinoris, aus welchem obige Beiwörter ge bildet wurden.

2) T. VI, pag. 844 . 
auf Tab. XXI abgebildeten Knochen. Erst in nach-Hallerischer Zeit drängt sich uns der Hilus renis auf, welcher von Vesal nur als Sinus, von Fallopia als Porta renis (sieh' den Artikel: Vena portae), von Winslow als Concavité, und von Leber als Excisura erwähnt wird. Barbarisch, sagte ich, ist das Wort Hilus, weil es den Römern nul als Hilum bekannt war. Sie verstanden, nach Festus, unter Hilum: id quod grano fabae adhaeret, also die Macula nigricans am concaven Rande der Bohnen, bei neueren Botanikern die Keimgrube $=U m$ bilicus. Diese kleine Macula, veranlasste die Römer, von einer ganz unbedeutenden Sache zu sagen, dass sie ne hilum werth sei, woraus durch Contraction nihilum, und aus diesem durch Abkürzung, nilil sich hervorbildete.

Den Einschnitt am concaven Rande der bohnenförmigen Niere, Hilum zu nennen, ist ein ganz guter und haltbarer Vergleich; aber Hilus darf er nimmermehr heissen. Galen nannte die einander zugekehrten concaven Ränder der Nieren: vì oqú. Wir finden deshalb auch Sima renis pars, zur Bezeichnung des Niereneinschnittes angewendet, wie z. B. von Bartholin.

Dass auch einige andere Einschnitte Hili, und noch ärger Hyli genannt wurden, sehen wir im Hilus lienis, im Hilus cartilaginis thyreoideae (obere Incisur des Schildknorpels), und im Hilus cerebri, womit jener Einschnitt an der unteren Fläche einer Hirnhemisphäre gemeint wurde, in welche sich der Pedunculus cerebri einpflanzt. Der einzige Loder schreibt das richtige Hilum ${ }^{1}$ ), statt Hilus.

\section{Hircus, Hirquus.}

Unter Berufung auf den späteren Abschnitt: Tragus, lässt sich über Hircus nur wenig sagen. Hircus, als Bock, sollte füglich den Tragus ersetzen. Denn es ist ein echt lateinisches

1) Anatomische Tafeln, Tab. 71, Fig. 7. 
Wort, und keine vox ambigua, wie der latinisirte griechische Tragus, welcher nur in seiner Muttersprache, Bock bedeutet. Einen Antihircus dürfte er aber nicht mit sich bringen, da dieser ebenso barbarisch wäre, wie Antibrachium.

Hirci heissen in der Anatomie die Achselhare. Bei den Römern dagegen war hircus, ein alter ausgewachsener Ziegenbock. Die Achselhaare nannten sie pili alarum, und den Sclaven, welcher sie auszurupfen hatte: alipilus. Die bekannte, nicht wohlriechende Atmosphäre des Bockes, liess auch den penetranten Geruch des Achselschweisses, als hircus benannt werden, wie im Horaz:

und :

"Pastillos Rufinus olet, Gorgonius hircum," "Gravis hirsutis cubat hircus in alis."

Ein schmutziger, unreinlicher Kerl, erscheint im Plautus, als

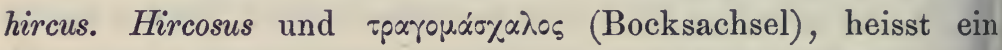
Mensch, welcher einen starkriechenden Achselschweiss absondert (Aristophanes).

Die Haare der Achselhöhle bilden, besonders bei schwarzhaarigen Menschen, ziemlich lange krause Büschel, welche an dem Odor caprinus participiren, und deshalb auch Hirci genannt wurden, jedoch nur von den Anatomen. In den Schriften der Montpellienser, treten Grandebalae an die Stelle der Hirci. Des Wortes Provenienz ist unklar, vielleicht, des Büschels wegen, hyperbolisch grand balai. Hadrianus Junius führt es in seinem Nomenclator omnium rerum, pag. 15, als bekannt auf. Grandebalae sind noch im Bauhin ') zu finden.

Hircus wird auch Hirquus geschrieben, und in dieser Form, gewöhnlich als Augenwinkel gebraucht. Forcellin erklärt diesen Gebrauch: quia hirci, ardore libidinis, obliqu. aspiciunt, oculis in angulos retortis. So versteht sich auch der Vers in den Eclogae Virgilii:

1) Pili subalares grandebalae dicuntur (Theatrum anat.), Lib. II Cap. 2. 
„Novimus et qui te transversa tuentibus hirquis, "Praeciderint

Allenfalls sind die steifen Haare der Cilien (pili hircini), dem hirquus, als Augenwinkel, nicht ganz fremd. Das höchst auffallende Verdrehen der Augen gegen die Winkel zu, ist bei abgestochenen Ziegenböcken eine wohlbekannte Sache. Der Wiener Humor drückt die liebende oder frömmelnde Augenverdrehung, derb mit den Worten aus: "wie ein abgestochener Geisbock".

\section{Histo- oder Histiologie.}

Beide Schreibarten haben ihre Anhänger. Welche ist die richtigere? 'Ioriov kommt sehr oft, aber immer nur als Segel im Homer vor ${ }^{1)}$. Als Gewebe kennen es nur die späteren

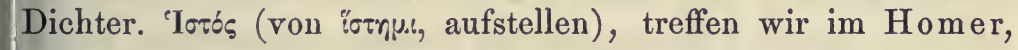
als Schiffsmast (Odyssee, $X V, 289$ ), und als Webebaum (Odyssee, X, 221). Als Gewebe tritt es in der Ilias und Odyssee auf ${ }^{2}$ ). Da nun die Segel aus Leinwand, also aus Gewebtem bestehen, lässt sich zwischen Histion und Histos kein besonderer Unterschied machen, und ist somit Histologie so gut wie Histiologie.

\section{Humerus.}

Humerus war den Römern, die theils fleischige, theils knöcherne, gerundete Erhabenheit, welche auf der oberen und äusseren Seite der Brust, beweglich aufsitzt — unsere Schulter,

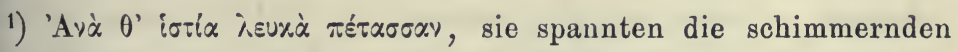
Segel.

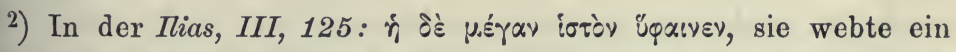

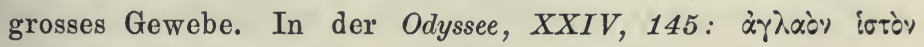

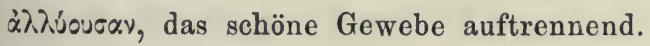


im weiten Sinne des Wortes. Drei Knochen, welche in diese Wölbung einbezogen werden, Schulterblatt, Schlüsselbein und Oberarmbein, wurden deshalb Ossa humeri genannt, und jeder einzelne: Os humeri. So sind denn in der Anatomie, drei ganz verschiedene Knochen zu dem Namen Humerus gekommen. Wir haben ein Oberarmbein, als Os humeri (schon seit Celsus), ebenso ein Schlüsselbein, als Humerus im Vesal, und ein Schulterblatt, als Os latum humeri (wieder im Celsus), und als Latitudo humeri im Laurentius. Von diesen drei Knochen, blieb das Oberarmbein im unangefochtenen Besitz der Bezeichnung als Humerus, welche dem ebenso oft vorkommenden Os brachii vorzuziehen ist, da brachium, wie das griechische Bpoxi $i \omega v$, sich auf den ganzen Arm, oder nur auf den Vorderarm bezieht. Die anatomische Sprache richtete sich auch darnach, da sie von Vasis und Nervis circumflexis humeri, nicht brachii, handelt, und einen Musculus humero-ulnaris (Brachialis internus), und zwei Humero-radiales (Supinatores) aufführt. Leider bleibt sie hierin sich nicht consequent, und tändelt in verschiedenen Compositis, noch mit Brachium statt Humerus.

\section{Hyaloidea,}

Der Glaskörper, Corpus vitreum, heisst im Galen:

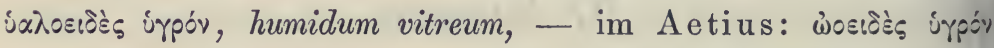
(eiförmige Feuchtigkeit, vielleicht wollte er albuminöse Feuchtigkeit sagen). Eine Haut, welche den Glaskörper umgiebt, und zu seinem Wesen gehört, vermissen wir bei den Griechen. Wenn dennoch behauptet wird, dass Rufus Ephesius die Membrana propria des Glaskörpers kannte, und als Hyaloidea benannte, - eine Angabe, welche seit Fabricius ab Aquapendente, in den Geschichtswerken und anatomischen Wörter büchern wiederholt wird, - so beruht dieses auf einer irrigen Auffassung der Worte des Rufus, welche doch so deutlich sind, dass man nicht begreift, wie sie missverstanden werden 
Medicin und Anatomie, mit schlechten, neuen, schwer oder gar nicht verständlichen griechischen Worten zu vertauschen. Einen hervorragenden Beleg für diese Manie, giebt uns die Hydroperione von Velpeau. Er hielt dieses Wort für tauglicher, als den weltbekannten Ausdruck Liquor amnii. Die Zusammensetzung von Hydroperione, ist höchst originell. Was kann sich der Franzmann anderes gedacht haben, als "jิ $\omega_{p}$

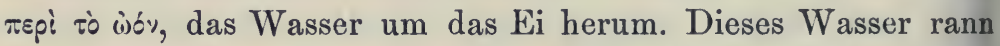
zur Hydroperione zusammen. Umgiebt der Liquor amnii das Ei? Nein. Er umgiebt den Embryo, welcher in den ersten Schwangerschaftsmonaten in ihm schwimmt. Ist one jemals als ein Ausgang statt ఉóv in usu gewesen? Nein. War es nöthig, dass für den altbekannten Liquor amnii, ein neues Wort, gegen alle Sprachregeln zusammengedichtet werde? Niemand wird es bejahen. Die Sucht, durch neue Worte, sich einen gelehrten Anstrich zu geben, bedenkt alles dieses nicht. Aber die Mitwelt scheint es doch bedacht zu haben. Denn die Hydroperione ist inglorie verschollen. Selbst das neueste Dictionnaire de médecine, von Littré und Robin, hat sie nicht aufgenommen. Möge es anderen, ähnlichen Missgeburten, auch so ergehen. "Auferat atra dies, et funere mergat acerbo."

\section{Hymen.}

Weder die Griechen noch die Römer, hatten ein Wort für Jungfernhäutchen. Das griechische Wort iuriny, bedeutet, wie

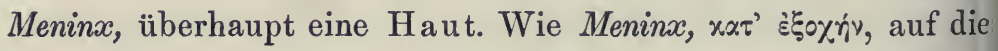
Hirnhäute bezogen wurde, so auch Hymen, in später Zeit, auf das Häutchen am Eingang jungfräulicher Genitalien. Pleura, Peritoneum, Pericardium, Zwerchfell, Hirnhäute, Herzklappen, u. v. a. erscheinen im Aristoteles und Galen, als ipúvıє. Bei den Römern war Hymen der Hochzeitsgott und das Hochzeits. lied, nie etwas anderes. Lange brauchte es, bis der Hymen als ein reguläres anatomisches Attribut der Jungferschaft 
allgemein anerkannt wurde. Viele Anatomen der alten Schulen, wollten von ihm nichts wissen. Dasselbe an lebenden Jungfrauen zu untersuchen, dazu hatten sie ebensowenig Gelegenheit, wie ein Anatom der Jetztzeit, und die weiblichen Leichen, welche sie von den Galgen erhielten, waren gewiss keine reinen Jungfrauen. Sonst achtbare Anatomen jener Zeit bezweifeln, oder läugnen unbedingt, die Existenz eines jungfräulichen Hymen, wie Varolius, Laurentius, und Pinaeus (Pineau 1). Erst Vesal und Spigelius setzten den Hymen, als Claustrum virginitatis in seine bleibenden Rechte ein, während Mundinus von einer Membrana vaginae praetensa, Achillinus von einem velamen subtile, quo tegitur os matricis, und Zerbis von einer Membrana ante collum matricis (Scheide) reden. Als Repagulum pudicitiae, Keuschheitsriegel, wird der Hymen im Macrobius erwähnt. Die Zona castitatis des Carolus Stephanus, beruht auf einer Verwechslung mit dem Keuschheitsgürtel, welchen vor Zeiten keusche Frauen und Jungfrauen um den Leib trugen, um sich von öffentlichen Dirnen zu unterscheiden. Haller's Auffassung des Hymen als Valvula vaginae, beginnt, als Scheidenklappe, den Hymen aus der deutschen anatomischen Sprache zu verdrängen, denn das bisher gebräuchliche Jungfernhäutchen, ist doch etwas zu trivial. Classische Dichter besingen das Jungfernhäutchen als Flos virginitatis, woher sich der jetzt noch in der gerichtlichen Medicin gebräuchliche Ausdruck Defloration, für Entjungferung schreibt ${ }^{2}$ ).

1) Dazu bemerkt Spigelius: Ridendi imprimis illi, qui nunquam, vel raro inveniri, et nisi praeter naturam existimant. De hum. corp. fabrica, Lib. VIII, Cap. 19.

2) Die sinnigen und schönen Verse des Catullus, mögen hier ein Plätzchen finden:

Ut flos in septis secretus nascitur hortis,

Ignotus pecori, nullo contusus aratro,

Quem mulcent aurae, firmat Sol, educat imber,

Multi illum pueri, multae optavere puellae.

Hyrtl. Onomatologia anatomica. 
Im Riolan ${ }^{1}$ ) lese ich folgende merkwürdige Stelle: quam membranam (Hymenem) in Beatissima Virgine ab obstetricibus inventam fuisse, cum de ejus virginitate dubitaretur, Suidas prodidit. Das ist eine fette Ente! Ich habe den Suidas, über diesen neuen Beweis der immaculata conceptio, mit Sorgfalt nachgesehen, und, im Artikel Hymen, nichts angetroffen, was auf diese Stelle im Riolan, nur im entferntesten bezogen werden könnte. Suidas, ein Grammatiker und Lexicograph des 11. Jahrhunderts, kennt Hymen nur als Hirnhaut!

An hochpoetischen Synonymen ist der Hymen überreich. Man kann deren ein halbes Hundert im Pierer und Choulant finden (Artikel Hymen). Selbst die Hebammen haben mit ihrem Jungfernschlösslein und Jungfernröslein zur Vermehrung derselben beigetragen. Hymen ist ein männlicher Gott. Man hat darum der Hymen, nicht das Hymen zu sagen, wie es allerwärts geschieht.

Die griechischen Ausdrücke Eugion und Eugium im Pierer, sind der Membrana virginitatis gänzlich fremd. Da sie

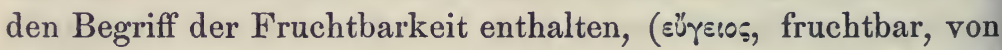
عư gut und $\gamma \tilde{\eta}$ Erde, im Theophrastus, u. A.), gehören sie zum Uterus, nicht zum Hymen.

\section{Hypoglossus,}

Hypoglossus ist ganz darnach angethan, für einen Barbarismus erklärt werden zu müssen. Wenn durch ein Beiwort ausgedrückt werden soll, dass ein Nerve unter der Zunge liegt

Idem, cum tenui carptus defloruit ungue,

Nulli illum pueri, nullae optavere puellae.

Sic virgo dum intacta manet, tum chara suis, sed

Quum castum amisit, polluto corpore florem,

Nec pueris jucunda manet, nec chara puellis.

1) Anthropographia, pag. 304 und 305. 


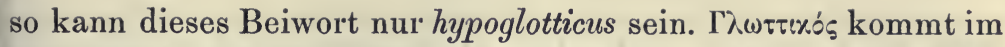
Aristoteles als "zur Zunge gehörend"vor, und i $\pi \circ \gamma \lambda$ íøoros

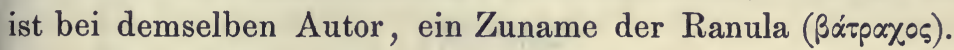

Das Gesagte gilt auch für die Riolan'schen Muskelnamen: Styloglossus, Genioglossus und Hyoglossus. Sie sollen, statt in $u s$, in icus endigen.

\section{Hypophysis.}

Hypophysis, als Gehirnanhang, gehört gänzlich der Neuzeit an. Den Gehirnanhang erwähnt Galen entweder schlecht-

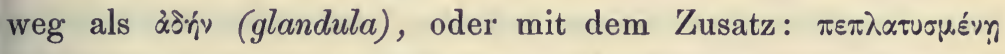

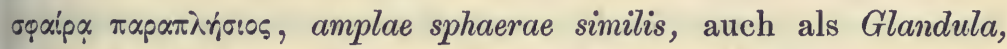
quae infundibulum cerebri (Hirntrichter) excipit ${ }^{1}$ ). In den weiteren Auseinandersetzungen jenes. Capitels, erscheint daher ג̇ơnv, als ein Glied der langen Reihe von Auswurfsorganen, welche die Purgamenta s. Excrementa cerebri, als Nasenschleim, ab- und auszuführen haben. Daher übersetzt Vesal den àঠriv Galeni, mit glans, in quam pituita destillat, oder mit Glandula pituitaria. Obwohl die Betheiligung des Gehirnanhanges an der Excretion des Nasenschleimes, durch V. C. Schneider, im 17. Jahrhundert, mit aller Gründlichkeit und für ewige Zeiten widerlegt wurde, verblieb doch der Name Glandula pituitaria cerebri bis auf Sömmerring ${ }^{2}$, welcher die Benennung Hypophysis in unsere Terminologie einführte. Sie erscheint von nun an ausschliesslich, oder als Appendix cerebri übersetzt, in den anatomischen Schriften. Hypophysis, (ìjó, nach unten zu, und 甲̛́ (w, wachsen), wird nur von den späteren griechischen Aerzten, als krankhafter Auswuchs, Excrescentia, selten für Cataracta, gebraucht. - Die französischen Anatomen halten sich lieber an glande pituitaire, als an Hypophyse.

1) De usu partium, Lib. IX, Cap. 3.

2) Hirn- und Nervenlehre, §. 62. 


\section{Ideus, eides, und odes, als Endsilben anatomischer Beiwörter.}

Was hier gesagt wird, gilt von einer langen Reihe vielgebrauchter Adjective. Diese sind: adenoideus, allantoideus, ancyroideus, arachnoideus, arytaenoideus, axoideus (alter Name für Epistropheus), bathmoideus (sinusartig, von dem Hippocratischen Worte $\beta \alpha \theta \mu i$, Gelenksgrube), belonoideus (nadelförmig), ceratoideus, chalcoideus (Beiname der drei Keilbeine des Fusses), choroideus, cirsoideus, clinoideus, colloideus (leimähnlich), condyloideus, conoideus, coracoideus, coronoideus, cotyloideus (napfförmig), cricoideus, cuboideus, deltoideus, dermatoideus, elythroideus (scheidenförmig), erythroideus, ethmoideus, glenoideus, graphioideus (styliformis), hyaloideus, hyoideus, lambdoideus, lemniscoideus (schlingenförmig), lepidoideus, lithoideus, mastoideus, meniscoideus, myoideus, odontoideus, ostoideus, pimeloideus (fettartig), psalidoideus (gewölbt), pterygoideus, pyrenoideus (kernförmig), rhagoideus, rhomboideus, scaphoideus, scolecoideus (vermiformis), sesamoideus, sigmoideus, sphaeroideus, sphenoideus, styloideru, trapezoideus, und xiphoideus.

Alle diese Worte sind latinisirte Griechen '). Als lateinische Epitheta, kamen sie erst im Anfange des 17. Jahrhunderts in der Anatomie in Aufnahme, meistens durch J. Riolan. Viele dieser Sorte stehen jetzt noch in Gebrauch. Es fragt sich erstens, ob sie gut sind, und zweitens, wie sie ausgesprochen werden müssen. Die betreffenden griechischen Adjective, enden mit єıò'দs. Es steht den Lateinern zu, den Diphthong $\varepsilon$ in $i$

1) Die entsprechenden griechischen Worte in $\varepsilon ı \delta$ r 9 , habe ich aus griechischen Autoren zusammengetragen. Sie sind also alle echt, bis auf meniscoideus, welches der neueren Zeit angehört, und ein Pleonasmus ist, da schon das Stammwort meniscos, im Aristoteles, in der Bedeutung von "halbmondförmig“ gebraucht wird. Ebenso colloideus (das Colloid von Laennec). 
zu contrahiren, und die Endsilbe $\eta s$ in eus zu verwandeln, so

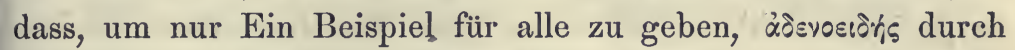
adenoideus ausgedrückt werden kann. In diesem adenoideus ist das $i$ lang, weil es für sı steht, und das e kurz, wie in allen Adjectiven in eus (aurěus, argentěus, ferrěus, plumběus, etc.). Man darf also nicht anders als adenoìdĕus sagen, wie denn auch in den, dem Griechischen nachgebildeten deutschen Worten: adenoid, alcaloid, sarcoid, myxoid, u. s. w., der lange Accent auf das $i$ fallen gelassen wird. Es ist aber leider zur allgemeinen Unsitte der Anatomen geworden, die Betonung gerade umzukehren. Sie sagen: adenor̃dēus, deltǒ̀dēus, hyoùdēus, etc. Auf gleiche Weise werden auch alle obgenannten Worte in der Aussprache misshandelt. Dass es nicht mehr geschehe, müssen alle Sprachkundigen wünschen. Aber der Missbrauch hat sich so tief eingenistet, dass er, trotz aller grammatikalischen Rügen, sich nicht ausmerzen lassen wird.

Ein langes $e$ in eus, kann nur dann mit Widerstreben zugelassen werden, wenn dieses eus, per licentiam, statt aeus (dem griechischen a.os) steht. Man kann peronēus, glutēus, peritonēum, etc. sagen und schreiben, jedoch mit der Reservation, dass man eigentlich peronaeus, glutaeus, peritonaeum, etc. zu sagen und zu schreiben hätte. Deltoidēus, Hyoidēus, Condyloidēus, Cricoidēus, und Thyreoidēus, muss gänzlich untersagt werden, weil es ein Deltoidaeus, Hyoidaeus, Condyloidaeus, etc. nie gegeben hat.

Für die eingangs aufgereihten Adjective, wäre es gleich besser, wenn wir von dem Rechte Gebrauch machten, griechische Worte unverändert in die lateinische Sprache aufzunehmen. Man sehe sich das interessante Büchlein an, welches Alex. Saalfeld ${ }^{1}$ ) über diese Nostrificirung griechischer Worte herausgegeben hat, und man wird sich überrascht finden durch die grosse Menge von Beiwörtern, welche der Sprachgebrauch mit

1) Index graecorum vocabulorum, in linguam latinam translatorum, Berol., 1874. 
der romana civitas belehnt hat, obgleich die anatomischen nur in geringer Zahl angeführt werden. Es kann dem Lateiner nicht verwehrt werden, in allen drei Geschlechtern adenoides, deltoides, hyoides, etc. zu sagen, aber immer nur mit langem $i$. J. B. Morgagni war der Erste, welcher von dieser Erlaubniss ziemlich häufig Gebrauch machte, und die anatomischen Adjective in ides, statt oideus, in Verkehr setzte.

Lautet ein griechisches Adjectiv in osıòns aus, so darf das osı in $\omega$ contrahirt werden, wodurch adenōdes, neurōdes, sarcōdes, haematōdes, deltōdes, hyōdes entsteht, natürlich mit langem $o=\omega$. Der Fungus haematōdes und sarcōdes sind schon lange in der Medicin heimisch; der Musculus deltōdes, das Os hyōdes, der Processus pterygōdes, u. s. f., könnten es auch werden. Bis jetzt kommen sie nur sporadisch vor.

Sollen die früher aufgezählten Worte, auch in die deutsche anatomische Sprache eingereiht werden, so müssen sie mit oid endigen: condyloid, scaphoid, sphäroid, u.s. w., niemals aber darf man condyloidisch, scaphoidisch, sphäroidisch sagen, wie es im Anat.-physiol. Realwörterbuch immer geschieht, da der Ausgang eines Beiwortes in is ch, schon eine Beschaffenheit oder Aehnlichkeit ausdrückt, oidis ch also ein Pleonasmus wäre.

Einer der grössten Philologen Deutschlands, Fr. Ritschl, hat sich, in Folge einer an ihn gerichteten Anfrage von Prof. Kilian, mit dieser anatomischen Bagatelle abgegeben ${ }^{1}$ ). Möge es auch uns nicht verübelt werden, so lange bei derselben verweilt zu haben. Es war wirklich nothwendig.

1) Kilian, Ueber die richtige Aussprache der in ideus ausgehenden anatomischen Adjective, in Göschen's Deutscher Klinik. 


\section{Ideus, als Ausgang von Muskel-, Bänder-, und Gelenksnamen.}

Einmal musste es doch gesagt werden, dass alle Muskelnamen in ideus, mit Ausnahme von dreien (Rhomboideus, Trapezoideus, und Deltoideus), baarer nonsens sind. Riolan erfand die aus zwei griechischen Worten zusammengesetzten Muskelnamen, welche Ursprung und Endè des betreffenden Muskels ausdrücken. Sie wurden allgemein angenommen, da sie sehr bequem sind. Wenn sie nur auch sprachlich richtig wären! Ueber jeden derselben muss der Amtseifer eines Grammatikers, welcher die Sache genau nimmt, in Aufregung gerathen. Was heisst z. B. Sterno-cleido-mastoideus, und Stylo-hyoideus auf deutsch? Sie heissen: der Brustbein-Schlüsselbeinwarzenförmige Muskel, und der Griffel-Ypsilonförmige Muskel. Ein Heer von Muskeln führt solche, noch nie getadelte, weil sehr wohlklingende Namen. Wenn der Knochen, oder der Knorpel, an welchem sich ein Muskel ansetzt, einen Namen hat, welcher seine Aehnlichkeit mit einem bekannten Dinge ausdrückt, wie alle Knochen- und Knorpelnamen auf єเঠेंs, so darf doch der Muskel, welcher sich an diesen Knochen oder Knorpel anheftet, nicht auf ideus auslauten, da er selbst, als Muskel, diesem bekannten Dinge nicht ähnlich ist ${ }^{1}$ ). Wie wurden denn vor Riolan diese Muskeln genannt? Sie wurden von Vesal und Fallopia durch Zahlen unterschieden, und von Arantius nach ihrer Wirkung benannt. Depressores und Levatores ossis hyoidei $\mathrm{zu}$ sagen, wäre z. B. ganz zweckentsprechend, anstatt Sterno-, Omo-, Stylo-, Thyreo-, Mylo-, und Genio-hyoideus. Ebenso

I) Rhomboideus, Trapezoideus, und Deltoideus, sind als Muskelnamen richtig, da diese Muskeln wirklich die Gestalt eines Rhombus, eines Trapezes, und eines Delta haben, somit in ideus (eı rís) auslauten können. 
264 184. Ideus, als Ausgang von Muskel-, Bänder-, und Gelenksnamen.

könnten die Muskeln des Schild- und Giessbeckenknorpels, sehr gut nach ihrer Function benannt werden. Warum sollte man, statt des sesquipedalen Sterno-cleido-mastoideus, nicht Nutator capitis sagen, wie die Deutschen bereits dafür ihren Kopfnicker gefunden haben? Da man nur mit dem Kopfe nickt, versteht sich bei Nutator der Zusatz capitis von selbst, und kann wegbleiben. Sustentator capitis wäre der beste Name, da der Kopfnicker das Haupt in jenen Stellungen erhält, welche ihm durch andere Muskeln gegeben wurden.

Die neueren Schriftsteller über Nomenclatur der Muskeln, Dumas, Chaussier, Dumeril, u. A., arbeiteten alle mit den Riolan'schen Fehlern. Wirkungsnamen sind und bleiben unter allen Umständen die besten. Länger als die Riolanschen, werden sie auch nicht ausfallen. Betheiligen sich mehrere Muskeln an derselben Wirkung, wie es beim Zungenbein der Fall ist, so könnte ihrem gemeinschaftlichen Wirkungsnamen, ein externus und internus, ein anterior, posterior, und lateralis, zur Unterscheidung beigesellt werden, wenn man nicht das $O s$ hyoideum bei seinem wahren Namen ' $\Upsilon$, $H y$, nennen will, wo es dann einen Sterno-, Thyreo-, Omo-, Stylo-, Genio-, und Mylo-hyalis gäbe, gegen welche keine Sprachkritik etwas einwenden kann.

Die Muskeln der Zunge, welche ihre in glossus endigenden Namen, gleichfalls dem Riolan verdanken, müssten alle, da es keine griechischen Composita mit glossos giebt, in glossites endigen, wozu bereits im Crotaphites des Galen (Schläfemuskel, von xpóraৎos, Schläfe) ein Vorbild gegeben ist. Den Nervus hypoglossus hat bereits Heister in Nervus motorius linguae, und Sömmerring in seinen Zungenfleischnerven umgewandelt. Für Musculus hyoglossus, müsste Deprimens linguam, - für Genioglossus: Protrusor oder Exsertor linguae, - für Styloglossus: Abductor und Levator linguae gesagt werden. Will man aber keine physiologischen Namen, nun - dann sind Hyo-, Genio-, und Styloglossites oder -glotticus, dem Hyo-, Genio-, und Styloglossus vorzuziehen, weil ein griechisches Adjectiv 


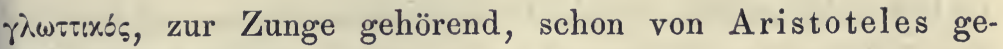
braucht wurde ${ }^{1}$ ).

Was hier von den Muskelnamen in ideus gesagt wurde, gilt auch für alle Bänder- und Gelenksnamen dieser Art. So müsste die Articulatio talo-scaphoidea in talo-navicularis, die Articulatio calcaneo-cuboidea in cubo-calcanea, die Ligamenta thyreo-arytaenoidea in thyreo-arytaenica umgeformt werden, was auch geschehen wird, wenn die Anatomie aufhören soll, über die miserabelste aller 'T'erminologien erröthen zu müssen.

\section{5. lleum.}

Vor Allem muss ich bemerken, dass Ileum kein Galenisches Wort ist. Galenisch ist nur Ileus, eì sós, als Krankheit = Darmverschlingung, Volvulus, von $\varepsilon i \lambda \varepsilon ́ \omega$, zusammendrängen,

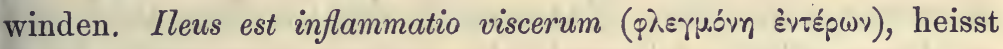
es in den Definitiones medicae Galeni, Num. 273. Was wir Intestinum ileum nennen, wird, zusammen mit dem jejunum,

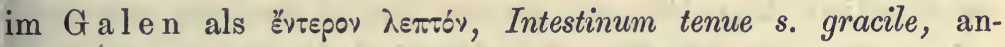
geführt. Ileum, als ein Stück des Dünndarms, präsentirt sich uns zuerst in dem griechischen Text der Anonymi introductio anatomica ${ }^{2}$, einem spät nach Gal en geschriebenen Compendium anatomicum.

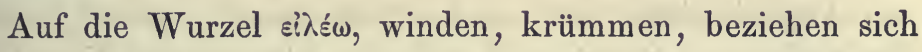
auch die obsoleten anatomischen Ausdrücke für Dünndarm: Intestinum convolutum, involutum, circumvolutum, gyratum, contortum, und glomeratum, in den Schriften der Arabisten, und in dem deutschen Krummdarm. Da das Ileum alle anderen Darmabtheilungen an Länge übertrifft, nannte es Avicenna: Intestinum longum. Die französischen Chirurgen Dionis und

1) De partibus anim., Lib. IV, Cap. 6.

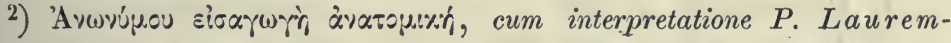
bergii, Lugd., 1618. 
Palfyn, behandeln es als le long boyau. Boyau (alt boel) ist der Botellus des Martial 1), = einem mit Schweinfleisch gefüllten Dünndarm (Bratwurst).

\section{6. llium, lleum, llei, oder Ilii?}

Das Darmstück des Hüftbeins, vulgo Darmbein, hat so viele Namen, dass die Frage sich aufdrängt, welcher der richtige ist. Os ilium, Os ileum, Os ilei, und Os ilii, sind lauter neuere Benennungen dieses Knochenstücks. Die Griechen

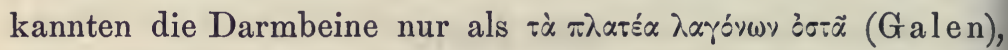

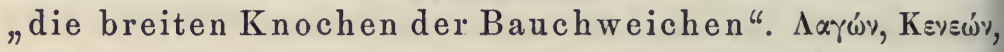
- und $\Lambda \alpha \pi \alpha$ pr , hiess jene Gegend des Unterleibes, welche zwischen den Rippen, der Scham, und dem Hüftbeine liegt - unsere Bauchweiche. Der Galenische Name ging in die lateinische Anatomie nicht über. Vesal stellte das Os ilium auf ${ }^{2}$ ), und an dieses sollten sich auch alle anderen Anatomen gehalten haben. Denn ilia, mit dem Genitiv ilium und iliorum (letzteres im Caelius Aurelianus), ist der Plural von dem ganz verschwundenen ile, ilis, Weiche. Ilia sind die Bauchweichen, somit giebt Os ilium genau dasselbe, was der Galenische Ausdruck sagen will. - Os ileum, welches im Heister vorkommt, und nach ihm oft genug wieder auftaucht, ist ein Barbarismus, da ein Adjectiv ileus, der lateinischen Sprache gänzlich abgeht, ileum aber als Genitivus pluralis der ilia, wie im Vesal, ilium zu lauten hätte. - Os ilei, sehr häufig gebraucht, kann seinen Ursprung nicht verläugnen. Das Os ilei hat auf seiner inneren Fläche, die Schlingen des Intestinum ileum aufliegen, und wurde als Träger derselben Os ilei genannt, wogegen nichts einzuwenden. - Os ilii, bei welchem man zuerst an $\mathrm{Homer}$ 's heiliges "I $\lambda$ ıov denken möchte, ist ein grammatikalischer Fehler

1) Epigrammata, $V, 78$.

2) Op. cit., Lib. I, Cap. 29. 
des Uebersetzers der Winslow'schen Anatomie, und konnte nur in dem Wahne, dass ilium der Singular von dem oberwähnten Plural ilia sei, sich ergeben haben.

Alles zusammengehalten, stellt sich heraus, dass Os ilium, und Os ilei, ohne Anstand als gleichberechtigt angesehen werden können. - Os ilium gelangte weit weniger in Verkehr, als Os ilei. Der deutsche Name Darmbein, stützt sich auf Os ilei, nicht auf Os ilium.

\section{Incus,}

Das zweite, mit dem Hammer articulirende Gehörknöchelchen, hat nie einen anderen Namen geführt, als Amboss, Incus. Amboss lässt das altdeutsche bossen ${ }^{1}$ ), schlagen, durchblicken, wie incus das cudere. Incus hat im Genitiv incudis, nicht incudinis, wie Morgagni, und andere Italiener schreiben, weil in ihrer Muttersprache der Amboss incudine heisst. Hammer und Amboss wurden, wie Haller sagt: ob summam viciniam, zugleich entdeckt; von wem, ist unbekannt. (Sieh' den Artikel Malleus.) Vesal gab ihm den Namen Incus, seiner Aehnlichkeit mit einem kleineren Amboss wegen: cujus amplior pars plana est, altera instar coni rotundata. Da er aber selbst mit diesem Vergleich nicht zufrieden war, setzte er hinzu: nihil obstat, hoc ossiculum denti molari, duabus tantum radicibus praedito, conferre ${ }^{2}$ ). Aber auch dieser Vergleich hinkt, da es Mahlzähne mit so stark divergenten Wurzeln, wie es die zwei Fortsätze des Ambosses sind, nicht giebt. Bleiben wir also schon bei Incus, wenngleich wir wissen, dass der Kopf des Hammers nicht auf diesen Amboss schlägt.

1) Die bosse der Franzosen, eine durch einen Schlag entstandene Beule, und unser noch gebräuchliches bossiren, erhabene Arbeit aus Wachs oder Gyps verfertigen, lassen sich auf bossen zurückführen.

2) De corp. hum. fabrica, Lib. I, Cap. 8. 
Das Ossiculum lenticulare s. orbiculare Sylvii, führt seinen Namen nicht von dem alten Pariser Anatomen Jacobus Sylvius, sondern von dem deutschen Franciscus Sylvius de le Boë, Professor in Leyden in der zweiten Hälfte des 17. Jahrhunderts. Sylvius hat selbst nichts über diese seine Entdeckung geschrieben, aber seine Schüler und Freunde, besonders Bartholin und van der Linden, posaunten die Entdeckung in die ganze Welt aus. Dass dieses Knöchelchen, welches nie selbstständig auftritt, sondern, wie schon Winslow mit seiner epiphyse de l'enclume ausdrückt, immer eine Epiphyse des langen Fortsatzes des Ambosses ist, lange vor Sylvius, von Columbus bemerkt und angegeben wurde, ist nicht wahr, denn was dieser Mann von dem "Capitulum rotundum, quod ad incudis processum accedit" sagt, bezieht sich auf den Kopf des Steigbügels, nicht auf das Sylvische Beinchen. Nur J. C. Arantius scheint, wenn ich seine Worte richtig verstehe, das wahre Ossiculum Sylvii, als einen Anwuchs des langen Fortsatzes des Ambosses, wirklich gekannt zu haben ${ }^{1}$ ).

\section{Infundibulum,}

Sieh' den Artikel: Pelvis.

\section{Innominatus s. Anonymus.}

Eine der abgeschmacktesten Redensarten der Anatomie, besteht in den Partes innominatae. Sollte die Anatomie, welche sich so gerne mit der Bildung neuer Worte befasste, wirklich nicht wissen, wie sie ein Organ zu nennen habe? oder ist sie zu voll von Verehrung gegen die Alten, welche vergessen haben, die Dinge, die sie beschrieben, auch zu benennen? Jeder unbefangene Mensch muss es höchst auffallend finden,

1) Observationes anat., Cap. 17. 
eine bekannte Sache unbenannt zu nennen. So etwas war nur in der anatomischen Sprache möglich - der reichsten an Sonderbarkeit und Widersinnigkeiten. Die Anonyma haben sich zwar in der neueren Anatomie etwas verringert, aber es existiren immer noch einige, welche sind:

1. Arteria innominata s. anonyma. Galen beschreibt die primäre Theilung der Aorta, wie er sie bei Wiederkäuern sah 1). Er lässt die Aorta in einen auf- und absteigenden Ast zerfallen. Die Verzweigung des aufsteigenden Astes schildert er ausführlich, ohne ihm einen Namen zu geben. Das Wort

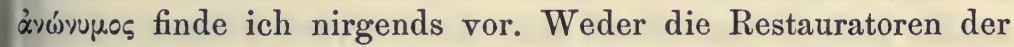
Anatomie, noch die Männer der Vesal'schen Zeit, reden von einer Arteria innominata. Sie kennen nur den Truncus ascendens aortae. Erst die Commentatoren des Buches: De usu partium, Caspar Hofmann und van der Linden, im 17. Jahrhundert, hielten es für angezeigt, der von Galen nicht benannten Arterie, den Namen Anonyma oder Innominata beizulegen, welcher Name bis heute aushielt. Er wurde aber nicht an die aufsteigende Aorta der Wiederkäuer, sondern an den ersten Ast des menschlichen Aortenbogens ${ }^{2}$ ) vergeben. Truncus brachio-cephalicus habe ich, die Arteria innominata nach französischem Vorbild genannt, und bei dieser Benennung möge man bleiben.

2. Os anonymum s. innominatum. So heisst das Hüftbein (Os coxae), aber nicht nach Galen, sondern nach seinen Erklärern. Galen sagt nur: Ossa, quae nullum nomen sibi totis

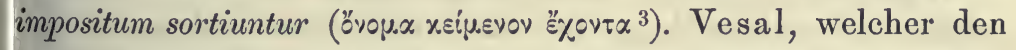
Galen sorgfältig studirt hatte, um ihn so gründlich widerlegen zu können, bemerkt dazu: Galenus affirmat, integro huic ossi, nullum nomen inditum fuisse, unde ג̇̀óvvoo\%, ac si dicas innominatum, quidam id appellarunt ${ }^{4}$ ). Da wir im Deutschen ein

1) De usu partium, Lib. XVI, Cap. 10.

2) Der Aortenbogen hiess Girgilus s. Girgillus, viel später Arcus.

3) De ossibus ad tirones, Cap. 20.

$\left.{ }^{4}\right)$ De corp. hum. fabrica, Lib. I, Cap. 29. 
Hüftbein, und im Latein ein Os coxae (nach bester Autorität des Celsus) besitzen, können wir das Os anonymum s. innominatum fallen lassen. Es figurirt ohnedies nur als Synonymon.

3. Die drei Keilbeine des Fusses, heissen im Fallopia:

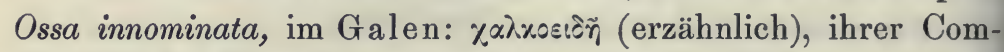
pactheit und Härte wegen. Da die Keile zum Holzspalten aus Erz gemacht wurden, übersetzte man $\chi_{\alpha} \lambda_{\text {r.osiò } \gamma_{\varsigma}}$ mit cuneiformis.

4. Die Processus anonymi des Hinterhauptbeins, sind ebenfalls keine Galenischen Erinnerungen, sondern überflüssige Erfindungen der neueren Zeit, für welche füglich andere Worte, welche Hügel bezeichnen, substituirt werden können. Diese Fortsätze verbinden sich nicht mit anderen, von welchen ein Name für sie hätte hergenommen werden können. Walte ${ }^{1}$ ) gebrauchte deshalb das Adjectiv anonymus, für die an der oberen Fläche der Partes condyloideae des Hinterhauptbeins vorfindlichen flachen Hügel. Sie haben eigentlich nur die Furche der Pars basilaris zu vertiefen, in welcher das verlängerte Mark liegt (Fossa pro medulla oblongata), um keine Verschiebung des Markes bei den Drehbewegungen des Kopfes zuzulassen.

$\mathrm{Zu}$ den nicht mehr gebräuchlichen Anwendungen von Anonymus s. Innominatus, gehören folgende:

1. Cartilago anonyma. So hiess der Ringknorpel des Kehlkopfes ${ }^{2}$ ), bevor er durch Galen zu seinem jetzigen Namen: Cartilago cricoidea kam. Im Theophilus Protospatharius ${ }^{3}$ ) führt der Ringknorpel diese Benennung (nomine carens cartilago, in der lateinischen Uebersetzung), welche von Th. Bartholinus noch nicht vergessen war ${ }^{4}$ ).

1) Abhandlung von den trockenen Knochen, 2. Aufl., pag. 62.

2) Es heisst im Galen: quia haud facile alicui rei, quae in mundo nomen sortita est, assimilari potest, sine nomine a veteribus relicta fuit. De vocis instrumentis, Cap. 4.

3) De corp. hum. fabrica, Lib. III, Cap. 15, pag. 178.

4) Institutiones anat., Lib. II, Cap. 9, pag. 233, der Leydener Ausgabe von 1641 . 
Die Araber übersetzten anonymus mit lā isma lahu, woraus durch Corruption das Ghalsamah der Arabisten entstand 1).

2. Glandula innominata $=$ Thränendrüse. Der innere

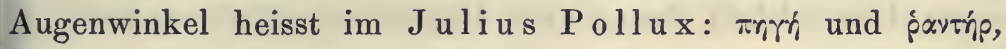
die Quelle und der Benetzende. Man war nämlich der Meinung, dass die Thränen nicht blos im inneren Augenwinkel zusammenfliessen, sondern in -ihm auch erzeugt wẻrden, und hielt die Caruncula lacrymalis für das Organ der Thränenbereitung. Unsere Thränendrüse am äusseren Augenwinkel, welche die Griechen so gut kannten, wie wir, musste für sie ein ganz räthselhaftes Organ sein, dem Galen keinen Namen zu geben wagte. Th. Wharton hiess sie deshalb zuerst Glandula innominata Galeni ${ }^{2}$ ). Andere (Bartholin) zogen Caruncula innominata vor, weil ihnen Caro und Caruncula so viel als Drüse war ${ }^{3}$ ). Erst durch Nicolaus Stenson wurde die wahre Natur dieser Caruncula innominata, und ihre Benennung als Glandula lacrymalis festgestellt. I s e $\mathrm{n} \mathrm{fla} \mathrm{m} \mathrm{m}$ machte sie, in einem Anfall dichterischer Laune, zur Glandula tristitiae $\left.{ }^{4}\right)$.

3. Lobus anonymus hepatis heisst bei älteren Anatomen, bis Haller, der Lobus quadratus, wahrscheinlich, weil der hinter ihm liegende Leberlappen, vor ihnen Lobus Spigelii genannt wurde, wie es jetzt noch üblich ist.

4. Der Sulcus innominatus auriculae, kommt auch als Fossa s. Cavitas innominata in allen Anatomien vor. Man versteht darunter die kleine Vertiefung zwischen den oberen Schenkeln des Anthelix. Sie ist so unbedeutend, dass man es nicht der Mühe werth hielt, ihr einen passenden Namen zu geben.

1) Sieh' HL, §. LXII.

2) Adenographia, Lond., 1656, pag. 182.

3) Sieh' den Artikel: Caro und Caruncula.

4) Oratio de denominatione partium corp. hum. a pathematibus, Erlang., 1795. 
5. Lineae innominatae nannten die Geburtshelfer die an der inneren und äusseren Fläche des Os ilei befindlichen halbmondförmigen Linien, besonders die innere (Plenk), welche einen Bestandtheil des oberen Randes des kleinen Beckens bildet.

6. Nervus innominatus, ein von Em. König ${ }^{1}$ ) dem fünften Nervenpaar, welches ohnedies an einem wahren Ueberfluss von Benennungen leidet, aufgebürdeter, ungeschickter Name.

7. Im Pierer und Choulant ${ }^{2}$ ) wird ein Truncus innominatus Loweri, als jenes Stück des Aortenbogens erwähnt, aus welchem die Carotiden und Subclavien entspringen.

\section{Inguinalis.}

Das nur von Plinius gebrauchte Beiwort inguinalis, welches oft, aber ganz verfehlt, auch inquinalis geschrieben wird, hat in der Anatomie, durch den Canalis und Annulus inguinalis, durch die Regio inguinalis, den Nervus ileo-inguinalis, und durch die Glandulae inguinales, bleibende Aufnahme gefunden. Plinius ${ }^{3}$ ) belegte damit eine Pflanze, quae in vepribus (Dornbüsche) nascitur, et inguinis dolores prohibet (unser Schamkraut, Buphthalmum spinosum, Linn.?). Das Stammwort inguen, Plural inguina, bezeichnet die Gegend, wo die vordere Fläche des Unterleibes, in jene des Oberschenkels übergeht (ubi coxendices imo ventri junguntur). Diese weich anzufühlende Gegend, welche bei gebogenem Hüftgelenk, einen einspringenden Winkel bildet, besitzt eine sehr feine und zum Schwitzen inclinirende Haut. Daher im Deutschen: die Dünnen, und die Weichen

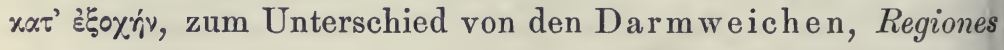

1) Regnum animale, Basil., 1682, pag. 149.

2) T. IV, pag. 846 .

3) Hist. nat., Lib. XXVI, Cap. 9, Sect. 59. 
iliacae, und von den Rippenweichen, Hypochondria. Des Schwitzens wegen, leitet man inguen von inquinare, besudeln, ab (inquinamentum, der Schmutz, im Vitruvius), - Einige auch von unguere, beschmieren. Celsus und Plinius, bringen uns inguen und inguina in Fülle für unsere Leistengegend, welche ihren Namen von dem bei mageren Personen, und bei gestrecktem Hüftgelenk, durch die Haut hindurch, wie eine scharfe Leiste sicht- und fühlbaren Ligamentum Poupartii entlehnte. Ich finde die Leistengegend zuerst im Leber ${ }^{1}$ ) erwähnt, während die anderen deutschen Anatomen, vor Leber, nur von den Weichen reden. Auch Geschwülste, nicht blos in der Leistengegend, sondern auch an anderen Orten, werden von Lucilius und Frontinus inguina genannt, wie denn auch das dem inguen parallele Bouß $\omega$, theils Leisteng egend, im Homer ${ }^{2}$ ), theils entzündliche, oder erysipelatöse und scirrhöse Geschwulst in dieser Gegend, im Hippocrates ${ }^{3}$, oder an anderen Leibesstellen ausdrückt. Galen nennt alle Tumores glandularum am Halse, am Nacken, und neben den Ohren, sowie die Abscesse dieser Geschwülste: Bubones ${ }^{4}$ ). Aus dem letzteren Grunde ist der Buboncus von Schmalz (Leistenabscess), eine verwerfliche Tautologie, weil bubo und oncus, jedes für sich, schon einen Abscess ausdrückt.

Euphemistisch gebrauchen die Dichter, wie Horaz, Ovid, Martial, und Juvenal, inguen auch für die männlichen und weiblichen, äusseren Geschlechtstheile, z. B. medicatum inguen, für die Castoreumsäcke des Bibers. Diese hielt man für die Hoden des Thieres, welche es sich selbst ausbeissen soll - woher castrare $=$ castorare. So ist Juvenal zu verstehen:

1) Vorlesungen über Zergliederungskunst, pag. 377.

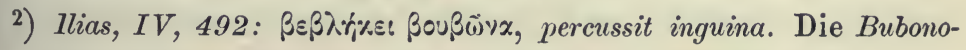
cele $=$ Leistenbruch, ist allen Aerzten bekannt.

3) Aphorismi, IV, 55.

4) Methodus medendi, Lib. XIII, Cap. 5.

Hyrtl. Onomatologia anatomica. 


$$
\text { "- - - imitatus castora, qui se }
$$

"Eunuchum ipse facit, cupiens evadere damno "Testiculorum, adeo medicatum intelligit inguen."

(Sat., XII, 34.)

Statius und Suetonius, geben inguina für den ganzen Unterleib. (inguina suffodere, den Bauch durchbohren).

\section{Inscriptiones tendineae.}

Den Musculus pyramidalis abdominis kannte Galen nicht. Er zählte somit nur acht Bauchmuskeln, vier auf jeder Seite. Die Recti abdominis beschreibt er quoad originem et finem ganz

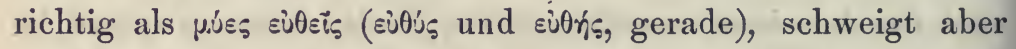
von den Inscriptiones tendinieae, weil diese bei den Thieren, welche er secirte, viel weniger ausgeprägt sind, als im Menschen.

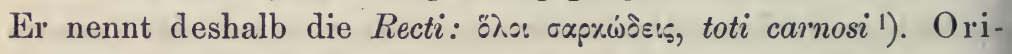
basius, welcher mit der menschlichen Anatomie besser bekannt war, als Galen, deutet die Inscriptionen als rastpop̀papial, d. i. suturae ventris an ${ }^{2}$ ). Von den Restauratoren der Anatomie, erwähnt nur Carpus die Inscriptiones tendineae, als Intermedia nervea s. ligamentalia, quae longos musculos in latum dividunt, und deren er blos zwei angiebt: eine über, eine unter dem Nabel ${ }^{3}$ ). Vesal vermachte uns den Namen Inscriptiones: Recti musculi, transversim ipsis inductas inscriptiones exprimunt ${ }^{4}$ ), und dieses Vermächtniss wird in der Anatomie bis heute treu bewahrt. Die Intersectiones des Lieutaud sind passender, als die figürlichen Inscriptiones. Die Enervationes

1) De musculorum dissectione, in Opera omnia, T. XVIII, B, pag. 939.

2) Anatomica ex Galeno, pag. 234. Galen kennt das Wort Gastroraphia nur als chirurgische Baúchnaht. (Administrationes anat., Lib. V, Cap. 6.)

3) Isagogae breves, Cap. de musculis longis ventris inferioris.

4) De corp. hum. fabrica, Lib. II, Cap. 31. 
tendineae des Achillinus, hätten ganz wegbleiben können, und die Divisiones des Bartholin, sind leicht entbehrlich. Besser, aber auch nicht nothwendig, wären: Myogrammata, und die Myocommata von Rich. Owen, welcher die letztere Benennung, nur auf die Segmente der langen Rückenmuskeln der Fische anwendete. Casserius fasste die Inscriptiones auf eine ganz eigene Weise auf, indem er nicht von einem, sondern von vier Recti abdominis auf jeder Seite spricht, welche an den betreffenden Inscriptiones entspringen und endigen.

\section{Interfemineum.}

Interfemineum ist doppelsinnig, einerseits als Mittelfleisch, andererseits als weibliche Scham ${ }^{1}$ ), denn beide befinden sich zwischen den Schenkeln, inter femina. Femen ist die antiquirte Form von Femur. Femur hat deshalb im Genitiv ebenso oft Feminis, wie Femoris. Im Celsus holen wir uns den Legitimationsschein für Femen, als anatomischer Ausdruck: ima spina in coxarum osse definit, - inde femina (femora) oriuntur $\left.{ }^{2}\right)$. Plinius er'wähnt des Aufreibens der Schenkel beim Reiten, als femina atteri. Livius spricht von Verstümmelten: succisis feminibus. Varro lobt die Hähne, cum feminibus pilosis, cruribusque brevibus ${ }^{3}$ ). Suetonius gedenkt der Feminalia (Beinkleider), welche weichliche Menschen, wie Kaiser Augustus, zu tragen pflegten, nach gallischer Sitte: hyeme quaternis tunicis et feminalibus muniebatur. Erst als die Toga nicht mehr in der Mode war, wurden die Feminalia ein allgemein getragenes Kleidungsstück, was sie bei den in kalten Ländern stehenden römischen Truppen, von jeher waren. Femen als Foemen zu

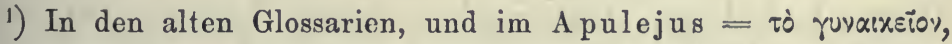
membrum muliebre, oder muliebria des Tacitus.

2) De medicina, Lib. VIII, Cap. 1.

3) De re rustica, Lib. IIL, Cap. 9 
schreiben, war nur per analogiam üblich, da man auch Femina (Weib) als Foemina schrieb.

Mit all' dem Gesagten über Femen = Femur, wird bewiesen, dass es keineswegs als gerechtfertigt erscheint, nur das weibliche Mittelfleisch ein Interfemineum oder Interfoemineum zu nennen, wie es in der Anatomie Brauch geworden. Hier handelt es sich ja nicht um femina, Weib, sondern um foemen $=$ femen $=$ femur, Schenkel. Auch wäre aus Interfemineum, d. i. "zwischen den Weibern", gar kein anatomischer Sinn herauszufinden. Nur das Feminal des Apulejus (Genitiv Feminalis) hält vor dieser Kritik Stand, da es für "weiblicher Geschlechtstheil" gebraucht wird, also von femina, Weib, entstanden sein muss.

Ein anatomischer Etymolog wollte, als er eben nicht recht bei Sinnen war', Interfemineum für einen Schreibfehler von Interforaminium angesehen wissen, worunter er das weibliche Mittelfleisch verstand, weil es zwischen zwei Löchern, dem After und der Schamöffnung, liegt. Nicht dem Regnerus de Graaf, wie Pierer anführt, sondern dem Pierer selbst, fällt dieser Unsinn zur Last.

\section{Internodia.}

Sieh' den Artikel: Phalanges.

\section{Interosseus.}

Nie ändert ein Wort, wenn es mit anderen zu einem neuen Wort verbunden wird, seine ursprüngliche Bedeutung. Osseus, knöchern, muss auch in seinen Zusammensetzungen knöchern bleiben. Interosseus hat deshalb gar keinen Sinn für einen Grammatiker. Den Anatomen dagegen, dient dieses Wort zur Bezeichnung von Muskeln, Gefässen, Nerven, Bändern, 
und Spalträumen, welche zwischen zwei Knochen liegen. Riolan vermachte uns dasselbe für die $\mathrm{Zw}$ ischenknochenmuskeln der Palma und Planta ${ }^{1}$ ). Er glaubte gut daran gethan zu haben, denn die bisherigen Benennungen dieser Muskeln, waren ellenlange Umschreibungen, wie z. B.: parvi musculi, qui collocantur inter ossa metacarpi (seu pedii $=$ metatarsi) im Fallopia.

Abgesehen von dem grammatikalischen Bedenken, wäre Interosseus auf viele andere Muskeln beziehbar, welche am Vorderar'm und am Unterschenkel, zwischen den beiden Knochen dieser Gliedabtheilungen liegen, wie auch auf die Interspinales, Intertransversarii, Intercostales, ja eigentlich auf alle Muskeln, da jeder derselben zwischen zwei Knochen ausgespannt ist. Doch so weit wollen wir nicht gehen, und für die Interossei manus et pedis, blos die Benennungen: Intermetacarpei und Intermetatarsei vorschlagen, gegen welche hoffentlich nichts eingewendet werden wird. Die Intermetacarpei waren schon einmal da, aber als schlechte Intermetacarpiaei ${ }^{2}$ ), und die Intermetatarsei wurden schon von Cabrol aufgestellt, aber von den späteren Anatomen nicht beachtet ${ }^{3}$ ).

\section{Intestinum.}

Obwohl unter Intestinum von den Classikern Alles verstanden wird, quod intus est, findet doch dieses Adjectiv, zum Substantiv Intestinum erhoben, seine Anwendung nur für den Darmkanal (ह้vгspx), als Intestinum tenue et crassum bei Celsus, und als Intestinum medium = Mesenterium im Cicero. Sieh' die Abtheilungen des Darmkanals in den Artikeln: Duodenum,

1) Anthropographia, Lib. V, Cap. 29, und Cap. 44.

$\left.{ }^{2}\right)$ Schreger, Nomenclatur der Muskeln, pag. 19.

3) Barthol. Cabrol, Alphabeton anat., h. e. Elenchus, corp. hum. partes delineans, Montpell., 1604. Ein sehr selten gewordenes Buch. 
Jejunum, Ileum, Coecum, Colon, und Rectum. - Eingeweide überhaupt hiessen Viscera $\left(\sigma \pi \lambda x_{\gamma}^{\prime} \gamma / \gamma^{\nu}\right)$, nicht Intestina.

Das deutsche Eingeweide hat eine weitere Bedeutung, als das lateinische intestinum, denn es umfasst die sämmtlichen Organe in der Bauch- und Brusthöhle. Aus dem niedersächsischen Küttel, für Eingeweide, haben die Wiener ihre Kutteln erhalten. Von dem mittellateinischen calduna, entlehnten die niederdeutschen Mundarten ihre Kaldaunen, böhmisch kaltaun, - noch in der Lausitz, aus slavischer Zeit, als Kalden erhalten.

Das veraltete deutsche Wort Weide, war für alle inneren Organe des thierischen Leibes gebraucht (Adelung). Eingeweide, ausweiden, stammen von ihm.

Wie die Latino-Barbari nicht blos lateinische Namen misshandelten, sondern auch neue sich erfanden, so hinterliessen sie uns das unmögliche intranea für intestina: jecur, inter omnia intranea, maximum (Guido).

\section{Iris.}

Sieh' den Artikel: Uvea.

\section{Ischiaticus oder Ischiadicus?}

Dieses vielgebrauchte Adjectiv kann, nach dem griechi-

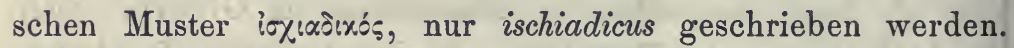
Dass es zuweilen auch als ischiaticus vorkommt ( $\mathrm{Leber}$, Günther, Mayer, u. m. a.), schreibt sich von Winslow her, welcher den Hüftnerv nerf sciatique nannte 1), was auch im Französischen, Italienischen; Spanischen und Englischen

1) Traité des nerfs, §. 318 . 
Sitte wurde (sciatico, ciatico, sciatic). Offenbar beruhen diese

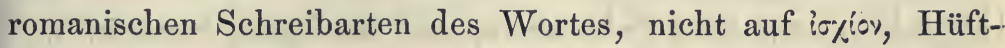
knochen, sondern auf der scia $=$ Hüftgelenk der Latino-Barbari.

\section{Ischium der Alten und Neueren.}

Im Rufus Ephesius treffen wir Ischium als Hüftgelenk, und als Band, welches den Schenkel mit dem Hüftbein ver-

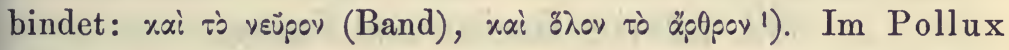
sind Ischia $=$ Hinterbacken (utrimque carnosae post lumbos

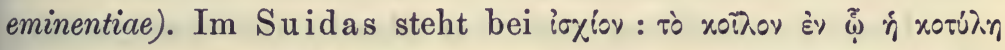

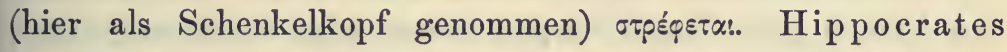
nennt das ganze Hüftbein: iø/iøy, Homer nul das Hüftgelenk:

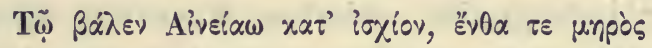

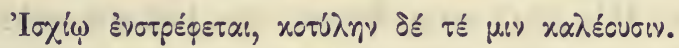

„Hiemit traf er Aeneas das Hüftgelenk, wo des

Schenkels

„Bein in der Hüfte sich dreht, das auch die

Pfanne genannt wird."

$$
\text { (Ilias, } \nabla, 305 .{ }^{2} \text { ) }
$$

Lauter Willkürlichkeiten! Was wir jetzt als Ischium s. Os ischii benennen, ist nur ein Theil des Hüftbeins, welcher unter der Pfanne liegt, und auf dessen Knorren, Tuberositas ossis ischii, die Leibeslast beim Sitzen ruht. Die Etymologie von ischium

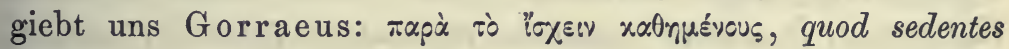
sustineat.

Der Begriff des Ischium, als Sitzbein allein, nicht als Hüftbein, ist schon im Galen enthalten, welcher das Hüftbein

1) Op. cit., pag. $` 33$.

2) An einer anderen Stelle der Mlias (XI, 399), wie in der Odyssee (XVII, 234), steht iø fiov nicht für Hüftgelenk, sondern für Hüftbein. 
in drei Theile eintheilt: $\tau \widetilde{\omega} \vartheta \lambda \alpha \gamma \delta$ v

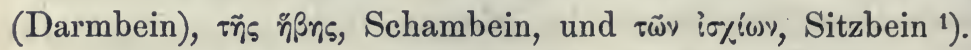

Das Os ischii des Galen, nahm Vesalius nicht an, und setzte dafür sein Os coxendicis, worunter die Classiker das ganze Hüftbein verstehen. Aber Vesal's Autorität imponirt den Anatomen heute noch, denn sie setzen dem Os ischii immer das $O s$ coxendicis zur Seite.

\section{Isthmus faucium und Fauces.}

Dass die Oeffnung zwischen Mund- und Rachenhöhle, den Namen eines festen Körpers führt, wird schon aufgefallen

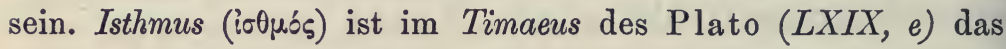
schmale Verbindungsglied zwischen Kopf und Brust - der Hals. Im Hippocrates heisst die Halsgegend: Isthmion. A ristoteles bezeichnet als io $\theta$ p.ó, einen schmalen Streif Landes, durch welchen eine Insel mit dem Festland verbunden wird - Landzunge, Erdzunge, wie der Isthmus von Corinth, der Isthmus der Chersonesus Taurica (Landenge von Perekop), und der Isthmus der Chersonesus Thracia am Hellespont. Wir haben noch den Isthmus von Suez, und den Isthmus von Panama zu erwähnen. Im Dionysos Periergetes heisst ein langer und schmaler Bergrücken: i $\sigma 0 \mu \omega_{\zeta}$, , lauter feste Körper, keine Löcher. Die Anatomie selbst verwendet Isthmus, sehr oft zur Bezeichnung einer schmalen Stelle, oder eines schmalen Körpers, z. B. Isthmus glandulae thyreoideae, Isthmus Vieussenii, Isthmus urethrae, der schmale Abschnitt der Harnröhre zwischen der dicken Prostata, und dem dicken Bulbus urethrae ${ }^{2}$ ). Die

1) De ossibus ad tirones, Cap. 20.

2) So fasste Haller den von ihm zuerst gebrachten Isthmus urethrae auf. Nicht dass die Harnröhre hier enger wäre, als anderswo in ihrem Verlauf, sondern dass sie wegen Mangel äusserer Auflagen an dieser Stelle, gegen die dicke Pars 
schmale Nasenscheidewand finde ich im Lexicon St. Blancardi, als Isthmus narium verzeichnet. Propertius ist der einzige römische Dichter, welcher Isthmus nicht als Landenge, sondern als Meerenge aufführt (Dardanellen): Propontiacâ, qua fluit Isthmos aquâ $\left.{ }^{\prime}\right)$. Der Begriff der Enge, nicht jener des festen Zustandes, hat den Galen veranlasst, den Namen Isthmus, figürlich auf die enge Verbindungsöffnung zwischen Mund- und Rachenhöhle zu übertragen: isthmus illa pars est, quae os et gulam (Schlund) interjacet, mit dem Zusatz: per metaphoram ab isthmis proprie sic dictis ita nominata ${ }^{2}$ ). Im Oribasius dagegen wird der Galenische Isthmus, anders definirt: als locus communis gulae et laryngis, d. i. der Ort, aus welchem Luftund Speiseröhre ausgehen, mit dem Zusatz: isthmum vocant, quia angustus oblongusque est ${ }^{3}$ ). Dass damit unser Pharynx gemeint ist, liegt auf der Hand, trotz des widersprechenden angustus. Bleiben wir bei der Galenischen Lehre vom Isthmus, als Oeffnung zwischen Mund und Rachen (unser Racheneingang), so ergiebt es sich leicht, warum Galen die Mandeln: Paristhmia nannte; - sie liegen zu beiden Seiten des Isthmus.

Wenden wir uns vom Isthmus faucium $\mathrm{zu}$ den anatomischen Fauces selbst, so muss vorerst festgestellt werden, dass Fauces $=$ Isthmus faucium ist, + dem, was man durch diese Oeffnung sehen kann (obere Rachengegend). Warum eine einfache Oeffnung, zu einer Benennung in plurali gekommen ist, und man nicht Faux sagt, ergiebt sich aus den Fauces eines römischen Wohnhauses. Das Atrium, die eigentliche Wohnstube der alten Römer, mit Altar, Bett, Webstuhl und Herd (vom Rauch des letzteren schwarz gefärbt, inde atrium), wurde

prostatica und Pars bulbosa dünner erscheint. Elem. physiol., T. VII, Lib. XXIV, Sect. 1, §. 33.

1) Elegiarum Lib. III, eleg. 21.

$\left.{ }^{2}\right)$ Galeni Comment. in Hippocratis Aphorismos, in Opp. omn. Edit. Kühn, T. XVII, B. pag. 632.

3) Oribasii Anatomica ex Galeno, pag. 209. 
in späterer Zeit der Vorsaal eines Empfangzimmers, welches das Familienarchiv enthielt (tabulae), und deshalb Tablinum hiess. Rechts und links vom Tablinum, führten zwei dunkle Gänge, welche nur von den Sclaven benützt wurden, aus dem Atrium in den inneren Säulengang des Gebäudes: Peristylium. Es waren immer zwei solche Gänge, der Symmetrie wegen. Einer allein wurde gar nie angebracht. Die Gänge hiessen Fauces. Es war nie Gelegenheit von Einer Faux zu reden. Celsus $\left.{ }^{1}\right)$ transferirte die pluralen Fauces, auf die einfache Rachenöffnung des Menschen, wo sie bis zur Stunde noch existiren. Plinius nennt den ganzen Rachen Fauces: summum gulae (der obere Theil der Speiseröhre) Fauces vocatur ${ }^{2}$ ).

Nimmt man das erwähnte Atrium im archäologischen Begriff, als eigentliches Wohnzimmer, so soll man nicht die Vorkammern des Herzens, sondern die Kammern Atria nennen, und das Atrium vaginae in Vestibulum umwandeln, wie es die Franzosen schon gethan haben (le vestibule du vagin). Da nun aber das Atrium in den Häusern der Reichen, ein Vorsaal des Tablinum war, kann man auch das Atrium cordis und vaginae nicht für ganz verwerflich halten.

\section{Jejunum.}

Nur dürftige Nachricht schöpfen wir aus den Alten über

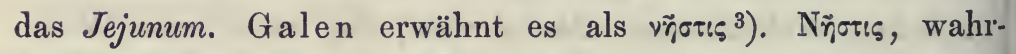

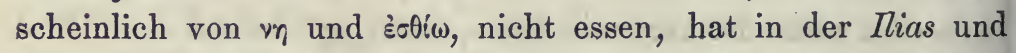
Odyssee, die Bedeutung von nüchtern, und wurde sofort mit

1) De medicina, Lib. IV, Cap. 4.

2) Hist. nat. Lib. XI, Cap. 35. Einer sehr schicklichen Benennung für den Isthmus faucium bediente sich Nic. Stenson. Er nannte ihn Fretum oris (Observ. anat. II), in Anbetracht der Getränke, welche durch diese Meerenge strömen.

3) De usu partium, Lib. V, Cap. 3. 
jejunus übersetzt. Galen erklärt selbst den Begriff seiner ทก๊̃๘ı mit: jejunum intestinum, quia ubique est vacuum. Er fand nie verdaute oder halbverdaute Nahrungsreste in ihm. In demselben Capitel, zählt er, wie später Celsus, auch das Duodenum zum Jejunum, und sagt von der vĩ̄orıs: primum omnium intestinorum, alimentum in ventriculo concoctum accipit. - Das Jejunum hielt, trotz seiner höchst sonderbaren Anwendung, Stand bis auf die Jetztzeit, obwohl kein Anatom sagen kann, dass es sich von seiner Fortsetzung, dem Ileum, so sehr unterscheide, um einen besonderen Namen zu verdienen. Seit Vesal, kehrt die alte Sage in allen Büchern wieder: quod reliquis intestinis inanius et magis vacuum reperiatur ${ }^{1}$ ). Schon dieser Comparativ zeigt an, dass es dem Vesal nicht recht ernst war mit seinem Unterschied zwischen Jejunum und Ileum. Aus dem deutschen Leerdarm, machte Heuermann sogar seinen Hungerdarm ${ }^{2}$ ).

Nur wenig Anatomen, wie Wiedemann ${ }^{3}$ ), gaben das alberne Jejunum ganz auf, und behandeln es nur als oberen Schlingencomplex des Ileum. Wenn schon ein überflüssiger Unterschied zwischen Leer- und Krummdarm gemacht werden soll, so möge man vĩ̄ols, wie es die Deutschen mit ihrem Leerdarm, und Winslow mit seinem intestin vide gethan haben, nicht als jejunum, sondern als vacuum übersetzen.

\section{Jugum, Jugulum, Jugularis.}

\section{Jugum.}

Die Anatomie hat nur zwei Anwendungen von Jugum. 1. Die Juga alviolaria, die den Zahnzellen entsprechenden Erhabenheiten an der äusseren Platte der Processus alveolares der

1) Op. cit., Lib.V, Cap. 5.

.2) Physiologie, III. Bd., §. 1080.

3) Handbuch der Anatomie, §. 115. 
Kiefer, und 2. Die Juga cerebralia $=$ Gyri, Gehirnwindungen . Beide Anwendungen beziehen sich nicht auf Jugum, als Joch der Zugthiere, sondern auf Jugum, als ein zwischen zwei Bergspitzen sich hinziehender Gebirgskamm, welcher in Tyrol und in der Schweiz Joch genannt wird. Das anatomische Adjectiv jugale, tritt zuerst im Celsus auf, als $O s$ jugale, für Jochbein, weil es mit dem Schläfebein zum Jochbogen zusammengejocht wird. Jac. Sylvius drückte diese Verbindung noch drastischer aus, durch sein Os conjugale. Sonst war bei den Römern jugalis, nur das was im Joch geht, z. B. equi jugales, und was zur Ehe gehört, wie der lectus jugalis,

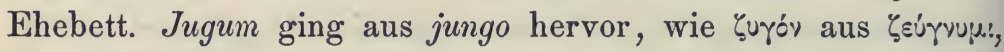
verbinden.

\section{Jugulum.}

Jugulum kommt nur in der Anatomie des Celsus, im Os juguli (Schlüsselbein) vor. Bei den Römern war jugulum, die Grube über dem Schlüsselbein: jugula concava im Cicero, mit den Redensarten jugulum dare oder praebere, sich erstechen lassen. Diese Grube hat, der grossen Gefässe, wegen, welche in ihr lagern, eine hohe chirurgische Wichtigkeit, und ihre Verletzungen sind, wenn sie tief gehen, in der Regel schnell tödtlich. Deshalb heisst jugulare "erstechen", und in genereller Anwendung „um's Leben bringen“. Jugulum wird auch im weiteren Sinne genommen, als die ganze vordere Halsgegend - Kehle, wo durch Compression der Luftröhre (Erdrosseln), dem Leben ebenso schnell ein Ende gemacht wird, wie durch einen Stich in das eigentliche Jugulum. Jugulare drückt somit ebenso erwürgen, wie erstechen aus. Die Anatomie bildete sich das nicht römische Adjectiv:

3. Jugularis.

Die Venen und die Lymphgefässgeflechte, welche mit dem Jugulum im Verkehr stehen, führen diesen Namen, wie auch gewisse Löcher, Ausschnitte und Knochenfortsätze, mit welchen die Vena jugularis interna, während ihres Verlaufes bis in die Schädelhöhle hinauf, in Beziehung tritt, wie die 
Foramina jugularia, und die Processus jugulares des Hinterhauptbeins. Die Incisura jugularis sterni, bildet die untere Grenze des Jugulum im zweiten Sinne als Kehle. Da es noch eine zweite Gegend am Halse giebt, deren Verletzung zu den schwersten zählt, - das in der chirurgischen Anatomie bekannte Trigonum colli superius, - wird auch dieses als Fossa jugularis superior, von der inferior, welche über dem Schlüsselbein liegt, unterschieden.

Was die Lateiner Jugulum nennen, nannten die Griecher oparry, und verstanden darunter auch den Act des Tödtens durch Halsdurchschneidung. Die grosse Blutader am Halse, deren Durchschneidung schnell tödtet, erhielt daher den Namen ẹpaíns Q $\lambda \varepsilon_{\dot{y}}$ von Galen (Guidez der Arabisten). Der erste lateinische Uebersetzer des Galen, Nicolaus Rubertus, ein Benedictinermönch auf dem Monte Cassino, gab dieses eparinns mit dem selbstgebildeten Worte jugularis, welches nun durch neun Jahrhunderte, in der anatomischen Sprache sich eingebürgert hat. Das deutsche Wort Drossel, alt Druzzel, bezeichnet, wie das englische throat und throttle, eigentlich in ältester Anwendung, den Kehlkopf und die Luftröhre, und, als totum pro parte, den ganzen Hals - die Gurgel.

\section{Labium und Labrum.}

Labium und Labrum, beide von lambo (quia lambuntur) haben, wie Lippe und Lefze, doppelte Anwendung: 1. als Lippe, 2. als glatter oder umgebogener Rand eines runden Gefässes, wie die Labia inflexa cucurbitarum, umgebogene Ränder der Schröpfgläser, im Caelius Aurelianus, und labrum im Ausonius, runder Wallgraben um einen festen Ort. Die Anatomie hat sich angewöhnt, Labium zu brauchen, wenn von zwei Lefzen zugleich die Rede ist: Labia oris, Labia majora et minora vulvae, Labia cristae ossis ilei, Labia lineae asperae femoris, u. m. a. Sie sagt in diesem Falle nie Labra. Labrum 
dagegen braucht sie nur im Singular, wenn von der Ober- oder Unterlippe allein gesprochen wird, oder von dem kreisförmigen Rand einer Grube oder Vertiefung, z. B. Labrum (nicht Labium) cartilagineum fossae glenoidalis scapulae und acetabuli, nach Weitbrecht.

Das griechische $\chi \varepsilon i \lambda . \circ$, hat denselben doppelten Sinn, wie Labium und Labrum, und überdies noch jenen von Rüssel, Schnauze, Schnabel, und in der Ilias von Flussufer.

\section{Labyrinthus,}

Nicht Winslow, wie Pierer meint, sondern der grosse Fallopia, hat die anatomische Terminologie, mit dem Labyvinthus bereichert - ein zu gewaltiges Wort, ägyptischen, nicht griechischen Ursprungs, mit welchem er die Höhlen und Gänge der innersten Sphäre des Gehörorgans belegte: quum haec cavitas tot habeat meatus et cuniculos (Bogengänge 1), merito labyrinthus dicetur, in quem prospicit fenestra ovalis, clausa a stapede etc. ${ }^{2}$ ). Winslow übertrug das Labyrinth auch auf die Zellen des Siebbeins, eigentlich nur auf die zwei Conchae ethmoidales, als Labyrinthe des narines ${ }^{3}$ ). Dieser Zellencomplex verdient den Namen eines Labyrinths, als multiformis, et dictu difficilis cavitas, wie Haller sich ausdrückt ${ }^{4}$ ).

1) Cuniculus ist Kaninchen. Aber auch die von diesem Thiere gegrabenen Gänge, hiessen Cuniculi, wie das cuniculos agere, Minengräben anlegen, im J. Caesar. Der Cuniculus des Fallopia, steht somit $=$ Canalis semicircularis. Im Bartholinus heissen die Canales semicirculares: Semicirculi ossei excavati, und Funiculi. Letzterer Ausdruck kann aber nur auf die Canales semicirculares membranacei bezogen werden.

2) Observ. anat., in Opp. omn. Vesalii, Edit. Lugd., T. II, pag. 699.

3) Exposition anatomique, T. I, num. 247.

4) Elem. physiol., T. V, pag. 129. 
Das Labyrinth des Gehörorgans, erscheint im Bartholinus auch als Fodina, mit welchem Worte er anzeigen wollte, dass die Gänge desselben im Felsenbein ausgegraben sind (fodere, graben ${ }^{1}$ ). Im Vesal wird nur das Vestibulum, als Fodina und Forum metallicum erwähnt. Er dachte dabei offenbar an eine Erzmine, a qua multae plateae, aut viae, aut cuniculi (Bogengänge) excurrunt, qui in amplam cameram rursus revertuntur ${ }^{2}$ ). Die Hallerische Intima pars organi auditus, hat, weil sie zu lang ist, das alte Labyrinth nicht verdrängen können. Es ist in der anatomischen Sprache aller Nationen adoptirt worden. - Das Winslow'sche Siebbeinlaby rinth, wurde überall ebenso beifällig aufgenommen, obwohl die alten Bezeichnungen desselben als Pars cavernosa und spongiosa ossis ethmoidei, zu Ehren des Hippocrates, welcher das Siebbein oтóryos (Schwamm) nannte, hätten beibehalten werden können. Aber bei einem Schwamm, lässt sich nicht viel Poetisches denken, während bei einem Labyrinth, das ganze Alterthum von Aegypten, Creta, Lemnos und Italien, und die Gestalten des Daedalus, des Minotaurus, des Theseus, und seiner Geliebten Ariadne, welche er auf der Insel Naxos sitzen liess, vor das geistige Auge treten, - eine unschuldige Zerstreuung in der ermiidenden Beschreibung des Geruch- und Gehörorgans.

\section{Lacertus.}

Sieh' die Artikel: Caro und Musculus.

\section{Lacinia,}

Die römișche Lacinia, welche die Anatomie in den Laciniae der Muttertrompeten, und im Ligamentum laciniatum des inneren

1) Institutiones anat., pag. 457.

2) Examen observationum Gabr. Fallopiae, im zweiten Bande der Opp. omnic Vesalii, pag. 771. 
Knöchels am Fusse, zu benutzen wusste, macht giltigen Anspruch auf griechische Abstammung. $\Lambda$ axis ist ein Fetzen, ein Lappen, ein Lumpen, und $\lambda \alpha x i \zeta(\omega)$ zerfetzen und zerreissen - das lateinische lacerare. Der Effect des Zerreissens besteht in Fetzen, welche einzeln auch Zipfel heissen, daher die Tubenzipfel in der deutschen Uebersetzung des Lieutaud.

Lacinia, in ältester Bedeutung, war eine natürliche Flocke der Schafwolle, welche noch nicht in eine Franse zusammengedreht wurde. Die freien und lose herabhängenden Büschel am Rande eines gewebten Wollstoffes, waren ebenfalls als Laciniae bekannt, gleichwie die sack- oder tropfenförmigen Hautauswüchse unter der Kinnlade der Ziegen 1), welche die alten Künstler, auch am Halse ihrer Faunen und Satyren anzubringen liebten, um deren wollüstigen Instinkt anzudeuten. In der Folge wurden die Quasten, an den Ecken verschiedener Kleidungsstücke, wie der Chlamys (Plautus), des Pallium (Petronius), der Toga (Suetonius), Laciniae genannt. Sie waren mit einem Einschluss von Blei beschwert, um sie anmuthig und stabil herabhängen zu lassen, damit sie der Wind nicht aufwirbeln könne. Da sie an den Zipfen des Kleidungsstückes hingen, wurden die Zipfe selbst Laciniae genannt, wodurch auch der Anatomie das Recht erwuchs, alles Zipfelige: laciniatum zu nennen.

Mehrere römische Redensarten erklären sich aus Lacinia, als Zipf. Da der Zipf des Mantels oder der Toga zuweilen sehr lang war, und bis auf die Erde reichte, wurde er, um das Gehen nicht zu stören, aufgehoben; in den Arm genommen, oder über die Schulter geworfen (Anabolium), so dass Jemand einen Andern an der Lacinia fassen, und anhalten konnte, wie wir ihn beim Knopfloch nehmen; aliquem laciniā tenere, im Plautus. Oder man bediente sich dieses Zipfels, um sich den Schweiss vom Gesicht zu wischen (sume laciniam, et absterge tibi sudorem, im Plautus), oder die Schmarotzer banden allerlei

1) Plinius, Hist. nat., Lib. VIII, Cap. 76. 
Tafelzeug, besonders aber Esswaren in die lacinia ein (allium in laciniis ferunt colligatum, Plinius), wie es die Beduinen jetzt noch mit dem Zipf ihres Chaik zu thun pflegen, in welchen sie, wenn sie lange Excursionen vorhaben, ihre tägliche Ration von Kutkus einbinden.

\section{Lacuna.}

Von den einst so populären Lacunae, hört man in der Anatomie der Jetztzeit fast gar nichts mehr. Höchstens dass das Wangengrübchen (Gelasinus ${ }^{1}$ ), und das Grübchen in der Mitte der Oberlippe ${ }^{2}$ ), nach Lactantius Firmianus, noch als Lacuna genae, und Lacuna labii superioris angeführt wird. An Gelegenheit den Ausdruck Lacuna zu gebrauchen, fehlt es in der Anatomie nicht. Denn Lacuna ist Vertiefung, speciell eine mit Wasser gefüllte, da sie aus Lacus entstand. Festus

1) Der Gelasinus des Suidas (von $\gamma \varepsilon \lambda \dot{\alpha} \omega$, lachen) ist das Lachgrübchen. Der Gelasinus des Martial dagegen, ist der Schneidezahn, weil er beim Lachen entblösst wird. Ganz widersinnig heisst das Wangengrübchen auch Rima gelasina im Pierer. Es erscheint, statt des Grübchens, zuweilen wohl eine Falte, aber keine Spalte (Rima). Den vor Alters gangbaren Namen des Lachgrübchens, als Umbilicus Veneris, erklärt Berengarius: quia assimilatur concavitati repertae in foliis illius herbae, quae vocatur Umbilicus Veneris et Cotyledon. Im Ovid (Amor. Lib. III, Vers 283) wird das Grübchen als Lacuna erwähnt, bei Gelegenheit wo der Dichter sich eine lächelnde Schönheit malt:

"Sint modici rictus, sint parvae utrimque lacunae."

2) Gewöhnlich als Philtrum (nach dem pì tpov im Rufus Ephesius), seltener, wie im Bauhin, als Amatorium und Amabile, da Philtrum von erscheint das Philtrum als Sulculus. Spherion im Carpus ist ein verhunztes und überdiess noch widersinniges Sphaerion, und Hypsia ein Barbarismus optimae notae.

Hyrtl. Onomatologia anatomica. 
sagt ausdrïcklich : la cuna aquae collectio est, et a lacu derivatur. So verstehen sich die Lacunae salsae der Dichter, für Meere. Abstrahirt man von dem Wasser, so kann Lacuna, wie das griechische $\lambda \alpha \dot{\alpha} \times$ \%o, von welchem es abstammt, für jegliche Vertiefung einstehen, wie sie denn auch, als Synonym von Crypta, Sinus, Folliculus, Pelvis und Recessus, angetroffen wurde. Wir begegneten der Lacuna, als Hirntrichter, als Nierenbecken, und als eingesunkene Fontanelle bei den Arabisten, als Schleimdrüse der Nasenhöhle, der Scheide, der Harnröhre, und als taschenartige Vertiefung der Mastdarmschleimhaut (Sinus Morgagni). Länger als andere, hielten sich die Lacunae im Atrium vaginae, als Lacunae Graafianae ${ }^{1}$ ). Auch das aus Lacuna gebildete Beiwort lacunosus, welches im Apulejus vorkommt: vallis lacunosa, ein an Vertiefungen und Wasserlachen reiches Thal, hat in der Anatomie Anwendung gefunden. Die Sinus lacunosi mammae im Pierer, entsprechen den Erweiterungen und Ausbuchtungen der Ductus galactophori im Bereich des Warzenhofes der Brust.

Eine Nebenbedeutung von Lacuna, liegt in Lücke und Höhle. Insofern kann die von Hesselbach gebrauchte Benennung der beiden, unter dem Poupart'schen Bande gelegenen, durch die Fascia ileo-pectinea von einander getrennten Löcher oder Oeffnungen, deren innere zum Durchtritt der Schenkelgefässe dient, während die äussere den Musculus ileo-psoas, und den Nervus cruralis enthält, als Lacuna vasorum und Lacuna musculorum, nicht angefochten werden. Unrichtig ist es, mit vielen Neueren, die Höhle im Zahnkörper Lacuna zu nennen. Lacuna dentium war bei den Classikern nur die Lücke, welche durch das Ausfallen oder Ausreissen eines Zahnes, in der Zahnreihe gegeben wird - die Zahnbresche.

1) De mulierum organis, Cap. 6. 


\section{Lacunar und Pavimentum.}

Die getäfelte, nicht gewölbte Decke eines Gemaches, hiess bei den Römern Lacunar, - der Boden aber Pavimentum, von dem veralteten pavio, "schlagen oder stampfen", weil das Pavimentum durchgehends aus einer festgestampften Mosaik von Steinchen, Kalk, Gyps und Erde, bestand, was wir Estrich 1) nennen. Diese Worte wurden von Haller, und seinem Schüler Zinn, für Decke und Boden der Augenhöhle (Zinn ${ }^{2}$ ), und der Hirnkammern (Haller ${ }^{3}$ ), gebraucht, während bisher diese Wände als Fornix und Basis, und speciell in der Augenhöhle als Planum frontale und maxillare orbitae, in den Lehrbüchern unterschieden wurden. Es wird Niemanden beirren, wenn er den harten Gaumen, mit den widersprechenden Worten, Lacunar und Pavimentum erwähnt findet. Der harte Gaumen ist, von der Mundhöhle aus gesehen, ein Lacunar, von der Nasenhöhle aus, ein Pavimentum.

Lacunar steht mit der vorangehenden Lacuna, im innigsten Verbande. Denn ein getäfelter Plafond, hatte bei den Römern viereckige, in den Häusern der Wohlhabenden, reich mit Fresken auf Goldgrund, oder mit Sculpturen verzierte ${ }^{4}$ ),

1) Dieses Wort wartet schon lange auf seine Erklärung. Wahrscheinlich ging es aus dem mittellateinischen astracum (der gepflasterte Zimmerboden) hervor, denn es wird auch Aestrich geschrieben. Astracum mit strada, und durch dieses mit stratum, ein mit Steinen bestreuter oder gepflasterter Weg (von sternere), in Zusammenhang zu bringen, drängt sich von selbst auf. Estrade dagegen, = dem spanischen estrado, stützt sich auf stratum, als Polster, und drückt somit einen erhöhten Sitz aus.

2) Descriptio oculi humani, Gott., 1755, pag. 153.

$\left.{ }^{3}\right)$ Elem. physiol., T. IV, Lib. X, §. 18.

4) Non ebur, neque aurum, méa renidet in domo lacunar, Horaz, Od. II. 18. 
vertiefte Felder (lacuncie). Die erhabenen Ränder dieser viereckigen, oft ziemlich grossen Felder, waren durch die Sparren und Balken gebildet, welche das Dach des Hauses, oder, bei mehrstöckigen Häusern, den Boden eines oberen Gemaches trugen ${ }^{1}$ ).

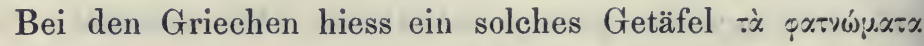

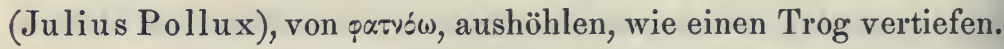
Da auch ein langer, hölzerner, in Fächer abgetheilter Trog, in welchem den Pferden und Rindern das Futter vorgestreut

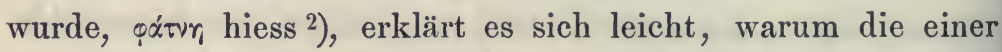
Krippe vergleichbaren Zahnfächer der Kiefer, im Galen eben-

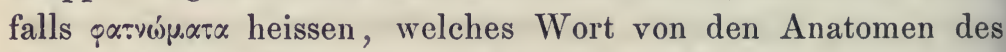
Mittelalters zu Phatnia und Fatnia abgekürzt wurde, und in dieser verdorbenen Form, ebenso oft vorkommt, als die guten Bothria (griechisch $\beta$ ofpiov, ein Diminutiv von $\beta$ ótpoe, Grube).

Das mit Lacuna sehr nahe verwandte Laquear, drückt ebenfalls den getäfelten Plafond eines Gemaches aus, und deutet auf laquei hin, weil die Einfassung der Felder des Getäfels, gezogenen Seilen ähnlich sah. Nur die lateinschreibenden Geburtshelfer, reden von einem Laquear vaginae = unserem Scheidengewölbe, Fornix vaginae.

\section{Laminae und Lamina spiralis.}

Breite und flache, dünnere oder dickere Platten von $\mathrm{Holz}$, Metall, oder Stein, hiessen Laminae, - kleinere und dïnnere: Lamellae und Lamellulae. Wir finden doliorum laminae, als Fassdauben, im Plinius, ein tegmen ferveis laminis consertum, als Panzer im Tacitus, und eine lamina columnae percussae, Bruchstück einer Säule im Ovid. - Der Anatomie kam

1) Vitruvius, VII, 2, 2, und Cicero. Tuscul. VII, 21; auch Horaz, Od. II, 18, 2.

2) Ilias, V, 271. 
das Wort sehr gelegen, für Blätter und Lamellen aller Art. Bekannt ist die Lamina spiralis cochleae, die Lamina cribrosa und papyracea des Siebbeins, die Lamina oder Tabula vitrea der Schädelknochen, die Lamina fusca zwischen Choroidea und Sclerotica, die Laminae durae matris, mediastini, omenti, ossium, u. m. a. Längst aufgelassen wurden die Lamina prima cutis = epidermis, im Vesal und Bauhin, und die Laminae aurium, Ohren, im Arnobius und Caelius Aurelianus: laminas aurium pertundere, die Ohren stechen. Die von Eustachius entdeckte Lamina spiralis der Schnecke, welche den Schneckenkanal in zwei Treppen theilt, scalae (rampes der Franzosen), und deshalb auch als Septum canalis cochleae vorkommt, zerfällt in eine knöcherne und häutige Zona. Die letztere, welche, wie die häutigen Bogengänge, von Valsalva entdeckt wurde, führte lange seinen Namen, als Zona Valsalvae ${ }^{1}$ ). Das hackenförmig gekrümmte, spitze Ende der Lamina spiralis ossea, erwähnte zuerst Zinn als Hamulus ${ }^{2}$ ).

Vergleiche den Artikel: Scalae.

\section{Larynx.}

Ueber den allbekannten Larynx habe ich nur eine kurze Bemerkung zu machen. Bei den griechischen Anatomen ist Larynx männlichen Geschlechts. Wir sagen deshalb im Deutschen der Larynx, nicht die Larynx. Ich tadelte die lateinschreibenden Anatomen, welche durch die Bank, Larynx als

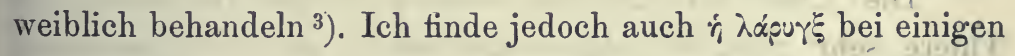
Grammatikern, und nehme meinen Tadel zurück. Auffallend ist es, dass Aerzte und Laien, in alter griechischer Zeit,

1) De aure humana, Bonon. 1704, pag. 76.

2) Observationes botanicae et anatomicae, Gött. 1753, pag. 33 und 34.

3) HL, §. $L X X I$. 
Pharynx häufig mit Larynx und Trachea verwechseln. Galen selbst macht sich dieser Verwechslung schuldig: caput asperae arteriae (Luftröhre), quam etiam pharyngem appellamus ${ }^{1}$ ).

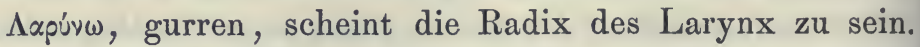
- Der deutsche Kehlkopf ist das übersetzte Caput gutturis s. Caput fistulae der Arabisten.

\section{Lema und Gramia.}

Der weisse, seifenartige Stoff, welcher sich bei jüngeren Individuen, während des Schlafes zwischen den Augenlidern, besonders aber am inneren Augenwinkel ansammelt, und an der Luft zu gelblichen Bröckchen erhärtet, heisst Lema = $\lambda$ rinu $_{\text {(nicht }} \lambda \tilde{n}_{1}, \alpha$, Wille). Das Wort wurde von den Anatomen dem Plinius entlehnt, welcher von lippitudines et lemae oculorum spricht ${ }^{2}$ ). Oefter wird der Lema, Gramia substituirt, welches nach Nonius = pituita oculorum ist. Festus dagegen spricht von Gramiae, als vitia oculorum, quae alii glamas vocant. Auch dem Plinius sind die Gramiae eine Augenkrankheit, wahrscheinlich die Lippitudo, denn $\gamma \lambda \alpha_{\alpha} \mu \omega \nu$ ist im Aristophanes ein Triefäugiger. Das griechische $\gamma \lambda \alpha \mu_{\mu n}$ ändert, wenn es in die lateinische Sprache übergeht, die Liquida $\lambda$ in $r$, was auch in anderen Worten sehr oft geschieht. Im Pollux sind die Verba $\gamma \lambda \alpha \mu \tilde{\alpha}, y$ und $\lambda \eta \mu \tilde{\alpha} \nu$, gramiosis oculis esse, identisch, als lippire ${ }^{3}$ ). Der Plural Lemae und Gramiae wird von den Anatomen dem Singular vorgezogen.

Die Lema der Hirsche, welche in der Brunstzeit der Thiere sehr reichlich abgesondert wird, und in Tropfenform erhärtet, wurde, ihres penetranten Geruches wegen, als nervenstärkendes Heilmittel verwendet: Lema oder Lacryma cervina.

1) De placitis Hippocratis et Platonis, Lib. II.

2) Historia naturalis, Lib. XXIII, Cap. 1, Sect. 24.

3) Onomasticon, Lib. IV, Cap. 25, Sect. 185. 
Die deutsche Benennung der Lema, als Augenbutter, verdanken wir Reil. Sie könnte, mit dem Ohrenschmalz, uns Ekel vor allem Gebackenen einflössen. Eine Emulsion von Fett und Schleim, ist doch keine Butter. Niemand hat daran gedacht, Besseres zu wählen.

\section{Lemniscus und Laqueus.}

Der Lemniscus ist in der Chirurgie weit besser bekannt, als in der Anatomie, wo er nur ein einziges Mal sich blicken lässt. Seiner Nationalität nach, gehört er der griechischen Sprache an, als $\lambda$ np.vif\%og, worunter ein Band oder Streifen, auch eine Vogelschlinge, verstanden wird. Celsus erwähnt den Lemniscus, als einen der Länge nach gefalteten, in Essig getauchten Leinwandstreifen (implicitum in longitudinem linamentum), welchen er nach der Operation der Atresia vaginae membranacea einlegte, um das Zusammenwachsen der Wundränder zu verhüten 1), und Paulus A egineta (Lib.VI, Cap.24), wie auch Vegetius (Lib. II, Cap. 14 und 18), handeln über die übrigen chirurgischen Anwendungen des Lemniscus, als Verbandzeug, Wieke, Setaceum, und Charpie. Die ausgefranzten Ränder, oder das faserige Wesen des Lemniscus, veranlassten Reil, eine Faserstrahlung des Gehirnstammes (verlängertes Mark), ${ }^{5}$ welche ober der Olive in die Brücke eintritt, und durch die Basis des Vierhügels, in den Thalamus opticus gelangt, woselbst sie in eine Menge strahlig divergirender Fasern auseinanderweicht, Lemniscus zu nennen 2).

Ausser der Gehirnanatomie, befasst sich keine andere anatomische Disciplin, mit dem solitären Lemniscus. Bänder von Goldblech, an Kränzen, welche als besondere Auszeichnung an hohe Gäste, an einziehende Sieger, an gekrönte

1) De medicina, Lib. VII, Cap. 28.

2) Archiv für Physiologie, IX. Bd., 1809, Tab. XI. 
Dichter, verliehen wurden, hiessen bei den Römern gleichfalls Lemnisci: Coronae datae, lemniscis aureis interpositis (Livius). Die Gehirnanatomen setzen für Lemniscus, öfter Laqueus, obwohl Laqueus immer den Begriff einer Schling e ') involvirt, welcher dem Lemniscus nicht zukommt. Lemniscus ist Band, und wird auch von den Franzosen, als le ruban, in der Gehirnanatomie verwendet (le ruban de Reil, Gratiolet).

\section{Lien und Splen,}

Das altlateinische Wort für Milz, ist Lien. Splen ist ein griechisches Fremdwort ( $\sigma \pi \lambda \dot{\gamma} v)$, welches von den römischen Aerzten Celsus, Caelius Aurelianus, und Vegetius, nie gebraucht wurde. Von Lien habe ich nichts zu sagen, als dass der Genitiv desselben, nicht, wie man allgemein zu hören bekommt, liĕnis, sondern liēnis zu lauten hat. Die Gewähr für diese Prosodie, kann man sich im Plautus holen. - Von den anatomischen Adjectiven lienalis und splenicus, ist das erstere neulatein; - die Römer kannten nur lienicus, und dieses als

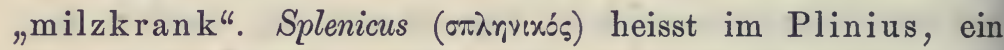
"Milzsüchtiger".

Die weiche Consistenz gab der Milz ihren deutschen Namen. Milt ist weich, schwammig, milde. Daher das englische milt, das italienische milza, das spanische melsa, das altfranzösische mou (molle), während la rate von dem niederländischen rate, locker, weich, abgeleitet wurde. In Norddeutschland heisst auch die Milch (der Hoden) der Fische Milte und Milz.

\section{Ligamentum.}

Wie Band von binden, so stammt Ligamentum von ligare. Häufiger als Ligamentum, erscheint in den Classikern, Ligamen

1) Z. B. laqueo collum inserere (Cice ro), laqueum injicere (Livius), in laqueos cadere (Ovid), u. v, a. 
für Band. Ligamentum finde ich meist nur als chirurgischen Verb and: vulneribus ligamenta, quibusque sistitur sanguis, parare ${ }^{1}$ ), und aurium ligamenta, sola excusare potest valetudo ${ }^{2}$ ). Im Griechischen

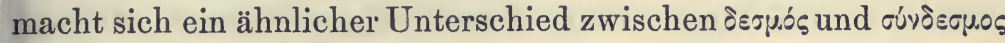
bemerkbar. Ersteres ist Band überhaupt, letzteres aber das anatomische Band, nach dem Galenischen Text: syndesmos est corpus nervosum (fibrös), ex osse ortum habens, insertum vero in os, aut in musculum ${ }^{3}$ ). Erst die neuere Zeit brachte es auf, auch häutige Verbindungen zweier Organe Ligamenta zu nennen, welche früher nur als Vincula, Plicaturae, oder schlechtweg als Membranae, vorkamen. Das überall anzutreffende Adjectiv ligamentosus, ist eine anatomische Neubildung, und insofern uncorrect, als das Wort mit bänderreich, nicht aber mit bandartig übersetzt werden muss, welches letztere die Anatomen eigentlich meinten. Insofern kann gegen den Apparatus ligamentosus der Nackengelenke und des Sinus tarsi, nichts eingewendet werden, da damit ein Complex von Bändern ausgedrückt wird.

Die Ligamenta alle wollen wir in Ruhe lassen, selbst wenn sie nicht den histologischen Bau von fibrösen Bänderı haben, wie z. B. die Ligamenta intervertebratia, und die als Bänder beschriebenen Faltungen von Schleimhäuten oder serösen Häuten. Wir haben uns nur mit zweien derselben eingehender abzugeben.

1. Ligamenta mucosa. Solche werden in der Höhle des Kniegelenks, und im Handwurzelgelenk erwähnt. Die letzteren sind Fältchen der Synovialmembran, und erhielten ihren unverdienten Namen: Ligamentula mucosa, von M e ckel. Das Ligamentum mucosum patellae, welches in allen Handbüchern herumvagirt, ist ein wirkliches, fibröses Ligament, mit Synovialüberzug, und besitzt eine Stärke, welche man diesem

1) Tacitus, Annules, $X V, 54$.

2) Quinctilian, 11, 3, med.

3) De motu musculorum, Lib. I, Cap. 1. 
schmalen Bändchen gar nicht zumuthen würde. Der ungeschickte Name: mucosum, rührt wohl daher, dass man dieses Ligament für eine blosse Dependenz der Synovialmembran hielt, deren Secret, in der langen Reihe seiner Namen (Gluten, Unguen, Smegma, Phlegma, Axungia, Aqua glarealis, Unguentum) auch als Mucus und Mucilago articulorum verzeichnet wurde.

2. Ligamentum Poupartii. Warum das von Vesal1) gekannte, und von Fallopia ${ }^{2}$ ) sehr gut beschriebene Band zwischen Spina ilei und Schamfuge, Ligamentum Poupartii heisst, verstehe ich nicht. Fr. Poupart hatte nur die Keckheit, oder die historische Unwissenheit, dieses altbekannte Ligament, als etwas Neues zu beschreiben ${ }^{3}$ ), und erntete dafür den Dank seiner Landsleute. Der alte Heister spricht der Erste vom Ligamentum Poupartii ${ }^{4}$ ), gesteht aber in einer Note des zweiten Bandes (pag. 53), dass Vesal dasselbe schon ganz gut kannte (plane satis indicavit). Winslow ${ }^{5}$ ) spricht nur von einem Ligamentum Fallopii, fasste es aber, wie Vesal und Morgagni, nicht als ein Ligamentum sui juris, sondern nur als den unteren Rand der Aponeurose des äusseren schiefen Bauchmuskels auf. Am meisten empfiehlt sich der Arcus cruralis Meckelii, als Benennung dieses Bandstreifens, denn man soll, genau genommen, Dinge nicht Bänder nennen, welche zwischen unbeweglichen Knochen ausgespannt sind, und diese nicht zu verbinden brauchen, da sie ohnediess nicht von einander

1) In Lib. II, Cap. 31, der grossen Anatomie, heisst es von der Aponeurose des äusseren schiefen Bauchmuskels: superiori coxendicis (i. e. ossis ilei) et pubis regioni, ubi hanc excarnem reperit, implantatur. Das ist zwar keine Beschreibung, aber doch ein testimonium scriptum, dass Vesal die Sache nicht unbeachtet gelassen hat.

2) Observationes anat, pay. 85 .

3) Mém. de l'Academie des sciences, 1705, Obs. 5, pag. 51.

4) Compendium anat., T. I, pag. 75.

5) Expos. anat., Traité des muscles, n. 115. 
lassen können. Das Ligamentum transversum scapulae, und das Ligamentum obturatorium, sind einer besseren Benennung gewärtig.

\section{Ligula und Lingula.}

Es müssen nothwendig zweierlei Ligulae unterschieden werden. Die eine ist ein Diminutiv von Lingua, und wird deshalb auch Lingula geschrieben, welches Wort Martial, für die schlechtere Schreibart erklärt:

"Quamvis me ligulam dicant equitesque patresque,

„Dicor ab indoctis, lingula grammaticis."

(Epigram., Lib. XIV, 120.)

Den Anatomen steht es frei, alle zungenförmigen Gebilde von kleinen Dimensionen, Ligula oder Lingula, Zünglein, zu nennen, wie wir factisch eine Ligula oder Lingula des Carotischen Kanals, des Inframaxillarkanals, und des Oberwurms im kleinen Gehirn besitzen. Auch die Epiglottis wurde, ihrer zungenähnlichen Gestalt wegen, von Celsus Lingula ${ }^{1}$ ) genannt, und seinem Beispiele folgten mehrere Anatomen, von Bauhinus bis Hildebrandt. Der Name Lingua fistulae für Epiglottis, kommt bei den Uebersetzern der Araber sehr häufig vor.

Es giebt aber noch eine zweite Art von Ligula, welche nicht mit Lingua verwandt ist, sondern auf ligare, binden, hinweist. Das Schlüsselbein z. B., hat doch sicher keine zungenförmige Gestalt, und heisst Ligula im Bauhin und seinen Zeitgenossen, weil es das Brustbein mit der Schulter verbindet. Die Ligula im Gehirn (synonym mit Taenia s. Fimbria hippocampi) kann doch, als ein sehr dünner und langer Markstreif, ebensowenig mit einer Zunge verglichen werden, verbindet aber den Fornix mit den Klauen des Seepferdfusses, und heisst deshalb im Deutschen: das Bändchen. Ich will noch einen handgreiflichen Beleg für den Ursprung der Ligula von ligare,

1) De medicina, Lib. IV, Cap. 1. 
von den römischen Schustern herholen. Sie nannten die beiden durchbohrten Ohren oder Klappen an einem Schuh, durch welche die Schuhriemen, corrigiae, gezogen wurden, um sie über dem Rücken des Fusses zusammen zu binden: Ligulae (Juvenal und Martial).

Dieses Wenige genügt, um die Berechtigung zweier Ligulae in der Anatomie sicher zu stellen.

\section{Linea alba abdominis.}

Ueber Ursprung und Bedeutung der durch Ambrosius Paraeus der Anatomie verliehenen Linea alba = Linea candida Spigelii (nicht Linea semicircularis Spigelii, wie sie Schreger irrig interpretirt), so wie über ihre Synonyma, sieh' HL, §. II, Achib.

\section{Lympha und lymphatica vasa.}

Ein allbekanntes, aber in seiner anatomischen Verwendung missverstandenes Wort, schwebt über diesen Zeilen. Dem Habitus nach, wird Lympha für griechisch gehalten. Kein griechischer Autor, Prosaiker oder Poet, gebrauchte es je. Es ist uralt lateinisch, und, da es im Glossarium des Isidorus, auch als limfa auftritt, ganz sicher mit dem bekannten Adjectiv limpidus verwandt. Klares und reines Quellwasser, wird von den Dichtern durch lympha ausgedrückt.

„Nuda superfusis tingamus corpora lymphis,"

und :

(Ovidii Metamorph., I, 459.)

„Dic, corpus properet, fluviali spargere lympha, "Et pecudes secum, et monstrata piacula ducat."

(Virgilii Aen. IV, 635.)

In der Prosa wurde es nie gebraucht, mit alleiniger Ausnahme des Varro ${ }^{1}$ ): invocans. Deos agricolarum, Lympham er

1) De re rustica, Lib. I, Cap. 1. 
Bonum Eventum, quoniam, sine aqua, omnis arida et misera agricultura est. Im spätern Serenus Sammonicus, welcher nicht zu den Vorbildern guter Latinität gezählt wird, gerathen wir auf die erste medicinische Anwendung von Lympha als Lympha intercus (Oedem, Hautwassersucht 1 ).

Heutzutage verwendet man Lympha, um den Inhalt der Saugadern, das Blutserum, auch den flüssigen Eiter, z. B. die Lymphe der Blattern, damit zu bezeichnen, was alles essentia vom sprudelnden Quellwasser so verschieden ist, quantum distant aera lupinis.

Viel ärger ist die Anatomie mit lymphaticus umgegangen. Kein Mensch findet an den Vasa lymphatica etwas auszusetzen, quae in omnium ore versantur. Und dennoch sind Vasa lymphatica nur wahnsinnige und tobsüchtige Gefässe. Lymphaticus ist $=$ furens und mente captus. Plinius heilt mit Helleborus die melancholici und lymphatici, - Apulejus lässt Jemanden, velut lymphaticum, aus dem Fenster springen, und Seneca nennt lymphaticos, qui sine mente sunt. Genug an den drei Beispielen. Wer mehr wünscht, wende sich an Gesner und Forcellini. Warum aber lymphaticus = rasend und wahnsinnig, darüber giebt uns die von Wenigen bestrittene Verwandtschaft von lympha mit nympha Aufschluss. Es handelt sich ja nur um einen anderen Anfangsbuchstaben, und die Substitution von $l$ für $n$, ist in der Geschichte der Wortbildung keine seltene (Döderlein, II, 14). Im Festus heisst es: lymphae dictae sunt a nymphis. Von den Nymphen aber ging dieselbe Sage, wie vom Pan. Der plötzliche Anblick beider, oder vielmehr die Einbildung, sie gesehen oder ihren Ruf gehört zu haben, machte die Leute wie rasend ${ }^{2}$ ). Kriegsheere wurden durch diese contagiöse Hallucination, förmlich debandirt, und

1) $X X V I I, 501$.

2) Qui effigiem nymphae viderint, furendi non fecisse finem (F e s t us), und Deus Pan (der Gott der Wälder, Heerden und Hirten) acuta et terribili voce, vanos immittit terrores. 


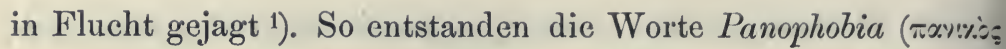
ósoc, unser panischer Schreck), und Nympholeptos. Nympholeptos autem Latini lymphaticos appellant, lautet das gewichtige Zeugniss im Festus. Varro setzt für nympholeptos: lympholeptos (uti dixerunt nostri). Demnach sind die Vasa lymphatica des Th. Bartholinus²), welcher der Erfinder dieses Namens war, nicht mehr anzuhören, und müssen wir den nebenbei noch cursirenden Vasis serosis oder absorbentibus, den Vorzug geben, da ein Kenner der lateinischen Sprache, bei ihnen nicht an Tobsucht und Hundswuth zu denken gezwungen ist.

In den Comödien des Plautus, kommen auch nummi lymphatici vor, tolle Geldstücke, welche immer aus dem Beutel springen wollen $\left.{ }^{3}\right)$ : sunt mihi intus, nescio quot nummi aurei lymphatici.

Sieh' auch den Artikel: Nympha.

\section{Lyra und Psalterium.}

Lyra und Psalterium werden immer zusammen genannt. Die Autoren verstehen aber Verschiedenes unter diesen Worten. Die Meisten wenden sie auf die dreieckige Stelle an, welche durch die Divergenz der hinteren Schenkel des Fornix gegeben wird, und deren dritte oder hintere Seite, der Balkenwulst bildet. Sie tritt vor Augen, wenn das Corpus callosum quer durchschnitten, und seine hintere Hälfte nach rückwärts umgelegt wird. Andere, wie Hildebrandt, nennen nur den Spaltungswinkel der Crura posteriora fornicis, Leie r oder Psalter, oder die zwischen diesen Crura liegende Partie des Plexus choroideus medius, oder, wie Sömmerring ${ }^{4}$ ), die über

1) Livius, Lib. X, Cap. 28.

2) Vasa lymphatica in homine nuper inventa, Hafn., 1654.

3) Poenulus, Act. 1, Sc. 1, Vers 135.

4) Hirn- und Nervenlehre, pag. 34. 
diesem Plexus liegende quergestreifte Marklamelle, im Sinne von dem Leipziger Professor, Justus Gottfried Gunz ${ }^{1}$ ), nicht Günz, wie er gewöhnlich von Jenen genannt wird, welche sein Büchlein nicht in der Hand gehabt haben. Bergmann verlegte das Psalterium an eine ganż neue Stelle, und zwar in den Aquaeductus Sylvii, dessen längsgestreifte Wand, als Psalterium s. Organon pnéumaticum benannt wird ${ }^{2}$ ). Man hat also ohne Zweifel, bei der Wahl dieser beiden Worte, ein Dreieck im Auge gehabt. Ein solches bildet allerdings der Rahmen einer Harfe, zu welcher die Gefässe des Plexus choroideus, oder die Querstreifen an der erwähnten Marklamelle, die Saiten abgeben. Harfe darf mit Psalterium, aber ja nicht mit Lyra übersetzt werden. Das griechische $\psi \alpha \lambda$ triprov war dreieckig, und führt deshalb im Aristoteles den Beinamen rpi-

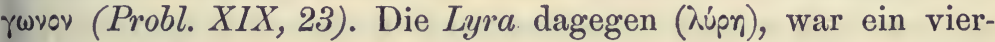
eckiger Rahmen, mit geraden, oder S-förmigen Seitenwänden.

Da die Lyra und das Psalterium Saiteninstrumente waren, welche mit den Fingern gespielt wurden, mochten wohl beide Worte von den Anatomen für identisch genommen worden sein, ja man setzte der Lyra, erbaulicher Weise noch Davidis hinzu, da der königliche Psalmist der Juden, auf den Kästen der alten Kirchenorgeln, häufig in effigie thront, mit der dreieckigen Harfe in den Händen.

Der Fornix tricuspidalis heisst im Galen und Oribasius,

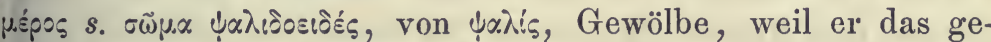
wölbte Dach der dritten Gehirnkammer bildet. Es kann wohl

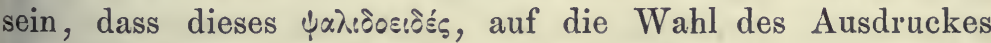
Psalterium für die Spaltungsstelle des Fornix, mehr Einfluss hatte, als der Psalter, worunter auch ein Gebetbuch, und der Blättermagen der Wiederkäuer, verstanden wird.

1) Programma de cerebro I et II, Lips. 1750, pag. 7 und 8.

$\left.{ }^{2}\right)$ Untersuchungen über die innere Organisation des Gehirns, pag. 4. 


\section{Magma,}

Unter Magma reticulé verstand Velpeau jene gelatinöse Substanz, welche sich in den ersten Entwicklungsphasen des menschlichen Eies, zwischen Amnios und Chorion befindet, und zwar an der Stelle, wo später die Placenta sich entwickelt. Das Wort Magma in die Anatomie einzuführen, war kein glücklicher Gedanke, da es, schon seit uralten Zeiten, in der Medicin an zwei ganz andere Dinge verliehen ist. M $\alpha \dot{\gamma}\}$ $\alpha$ nannte Galen den Rückstand, welcher nach dem Auspressen der saftreichen Früchte des Myrobalanon zurückbleibt '). Andere verstanden darunter dicke Salben: unguenta spissa, pauco liquore subacta, ne diffluant (Gorraeus), wie das Hedychroon des Andromachus, über dessen Beschaffenheit Galen sich umständlich

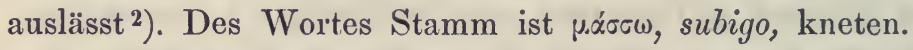

Die gelatinöse Flüssigkeit zwischen Amnios und Chorion, an der Stelle, wo sich die Placenta bildet, wurde von Velpeau für einen Ueberrest der Allantois gehalten. Von Fasern ist sie nicht durchzogen, deshalb auch nicht reticulé. Man meint, dass sie, wenn sie an Menge zunimmt, und sich weiter zwischen Chorion und Amnios ausbreitet, als falsches Wasser, vor dem Abgang des eigentlichen Fruchtwassers (Liquor ammii), bei der Geburt entleert wird. Dugès schlug vor, dem falschen Wasser den Namen Hydrallante (hydropisie de l'Allantoüde) zu geben. Warum nicht lieber Allantohydor, welches den Begriff: Wasser der Allantois, weit besser und richtiger in sich schliesst, als Hydrallante.

1) De compositione medicamentorum, Lib. VII, Cap. 7.

2) De antidotis, Lib. I, Cap. 10. 


\section{Mala.}

Wir haben einen Canalis und einen Nervus zygomaticus malae, Joch-Wangenkanal und -Nerv, und ein Os malare, Jochbein. Nur von Mala habe ich ein Wort zu sagen. Das hart tönende $x^{1}$ ) mit dem anhängenden Vocal, elidirten die Römer gerne, wenn es nicht am Anfang oder am Ende eines Wortes stand. Sie sagten ala für axilla, Achsel, und sagten auch mala für maxilla. Andere halten dafür, dass mala keine $\mathrm{Ab}$. breviation von maxilla ist, sondern aus mando, kauen, hervorging, wie scala von scando. Im Celsus fällt mir auf, dass er maxilla den Unterkiefer, das Jochbein aber, sammt dem Oberkiefer, mala nennt: maxilla est mobile os, malae autem, cum toto osse, quod superiores dentes excipit, immobiles sunt. Gleich darauf erscheint aber der Oberkiefer als Os superius malarum ${ }^{2}$ ).

Maxilla ist das griechische rrótos. Hip pocrates spricht

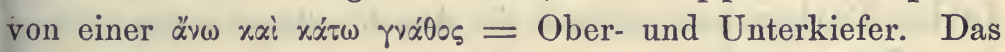
ganze Oberkiefergerüste, welches wir als einen Complex mehrerer Knochen kennen, wurde nur als Ein Knochen aufgefasst. Als man die einzelnen constituirenden Bestandtheile desselben zu isoliren lernte, und jeden derselben mit einem besonderen Namen versah, blieb der Hauptname: maxilla superior, dem grössten unter ihnen, während der nächst kleinere, als $O s$ zygomaticum, oder maxillare secundum, benannt wurde. Statt maxillare secundum, wurde bald, per abbreviationem, malare gesagt, wozu es vielleicht noch eine Veranlassung gab. Die hart anzufühlende rundliche Erhabenheit im Antlitz, welche gleich unter dem Auge sich befindet, nannten die Griechen, ihrer Rundung wegen, $\mu \tilde{\eta} \lambda_{0} \%$. M $\tilde{\eta}_{\lambda}$ ov wurde zum malum, Apfel, der Lateiner, und der Knochen,

1) Litera vasta, wie sie Cicero nennt: ita vestra axilla, ala facta est, fuga literae vastioris.

2) De medicina, Lib. VIII, Cap. 1.

Hyrtl. Onomatologia anatomica. 
welcher diese Erhabenheit zunächst bildet, konnte sehr wohl auch deshalb Os malare, der Apfelknochen, genannt worden sein, nach welcher Benennung das französische pommette geformt wurde. Die Erklärung des Isidorus ${ }^{1}$ ), stimmt hiemit zusammen: genae, etiam malae vocantur, quod infra oculos promineant in rotunditatem, während der Nachsatz: sive quod sint super maxillas, mala für eine contrahirte maxilla ansehen lässt.

Dass unsere Mala, Wange, nicht von malum, Apfel, sondern von maxilla herstammt, beweist uns überzeugend das weibliche Suffix $a$. Wäre malum der Stamm, würde die Wange auch so genannt worden sein, da gar kein Grund vorliegt, das um in $a \mathrm{zu}$ verwandeln, um so weniger, als es sich um einen Gegenstand generis neutrius, um ein $O s$ handelt.

Die griechischen Synonyma für die Ossa malaria, sind i $\pi \dot{\omega} \pi \ll$ und i $\pi \circ \varphi \theta \dot{\lambda} \lambda \mu \iota \alpha$. Sie kommen im Rufus Ephesius vor. Der Uebersetzer gebraucht Subocularia, unter welchem Namen die Jochbeine im Mittelalter sehr oft erwähnt werden. Im Julius Pollux heissen auch die Anschwellungen des unteren Augenlides, durch Blut- oder Wassererguss: Hypopia ${ }^{2}$ ).

\section{Malleus,}

Die Gehôrrknöchelchen wurden erst im 15. Jahrhundert bekannt. Man schreibt die Entdeckung des Hammers und Ambosses dem Achillinus zu (1480), nach dem Zeugniss des Nicolaus Massa ${ }^{3}$ ). Nach Fallopia, gebührt dem Berengarius Carpensis die Ehre dieses Fundes ${ }^{4}$ ). Keiner

1) Origines, Lib. XI, Cap. 1.

2) Onomasticon, Lib. II, Cap. 4, S. 52.

3) Epistolae medicinales, T. I, pag. 55, b, und Liber introductorius anatomiae, Venet., 1536, pag. 93.

4) Observationes anat., in Vosalii Opera omnia, T. II, pag. 698. 
der beiden Männer kann der wahre Entdecker dieser Knöchelchen gewesen sein, denn Achillinus erwähnt derselben in keiner seiner anatomischen Schriften ${ }^{1}$ ), welche ich sorgfältig durchgesehen habe. Er erwähnt blos die Trommelhaut, als Miringa, und die Trommelhöhle, als Cavitas auris ${ }^{2}$ ). Berengarius spricht über diese zwei Gehörknöchelchen, als von zwei bereits bekannten Dingen, wie der Aúsdruck: secundum aliquos beweist. Er äussert sich zugleich, nach seiner Art, über die Leistung des Hammers und Ambosses, deren Namen er nicht einmal kannte: huic panniculo (Trommelfell) adjacent duo ossicula, quae in suo motu se invicem percutiunt, a quibus causantur omnes species soni ${ }^{3}$ ), und in seinen Commentarien über M undinus: ista ossicula, secundum aliquos, causant sonum. Diese Aliqui müssen also die beiden Knöchelchen, (schon vor Berengarius) gekannt haben.

Den Namen Malleus, erhielt der Hammer zuerst von N. Massa, wie gesagt wird: a capite crassiori. Vesalius spricht entweder von einem Os malleolo comparatum s. assimilatum, oder von Malleolus schlechtweg, und Eustachius von einem Os malleum referens. Auf den ersten Blick muss es auffallen, dass der Malleus einem Hammer, wie wir ihn kennen, gar nicht gleichsieht. Wie entstand also der Name? Wir kennen die Hämmer, deren sich die Römer bedienten, sehr

1) De corp. hum. anatomia, Venet., 1521, und Annotationes in Mundinum, Bonon., 1520.

2) Achillinus genoss als Philosoph einen weit grösseren Ruf (Magnus Achillinus), denn als Anatom. Er war in der Lösung schwieriger Probleme so flink und geschickt, dass ein Sprichwort sagt: Aut diabolus, aut Magnus Achillinus. (Mich. Medici, Compendio storico della scuola anat. di Bologna, 1857, pag. 47: ebbe ingenio cosi pronto ed acuto, che, occorrendo diradare questioni intralciate ed oscure, era invalso il proverbio, volerci aut diabolum, aut Magnum Achillinum.)

3) Isagogae breves, in cap. de auribus. 
genau, theils aus Abbildungen auf Monumenten, theils aus conservirten Exemplaren in den archäologischen Sammlungen. Eine dieser Hammerformen wurde nur von den Fleischhauern und Opferpriestern gebraucht, um einen Ochsen, durch einen wuchtigen Schlag auf den Kopf, zu betäuben, worauf ihm erst der Hals durchschnitten wurde, um das Blut herauszulassen 1). Dieser Hammer von hartem Holz, war sehr schwer, und wurde mit beiden Händen geschwungen. Er bestand aus einem ganz runden Kopf, welcher an einem Stiel steckte, war also eigentlich nur ein riesiger Schlägel. Mit diesem Schlägel stimmt Kopf und Stiel des Malleus im menschlichen Ohre ganz gut zusammen. - Vesal vergleicht den. Hammer mit dem Oberschenkelbein! Universum ossiculum femori opportune assimilabitur ${ }^{2}$ ). So ungereimt dieser Vergleich auf den ersten Blick zu sein scheint, so entbehrt er doch guter Anhaltspunkte nicht. Das Caput femoris ist das Caput mallei, das Collum femoris das Collum mallei, die Trochanteren wiederholen sich in den zwei Fortsätzen des Hammerhalses, der Hals des Hammers bildet mit dem Griff denselben stumpfen Winkel, wie das Collum femoris mit dem Mittelstück, und das Manubrium des Hammer's, wäre ein eingeschrumpftes Mittelstiick des Femur, an welchem man sich aber die zwei Condyli am unteren Ende wegdenken muss. - Der Griff des Hammers kam erst durch Verheyen zu seinem Namien als Manubrium ${ }^{3}$ ) (le manche $d u$ marteau im Winslow). Früher hiess er Processus longus (Vesal), Processus tenuis (Columbus), Pedunculus (Casserius), Cauda (Riolan), Petiolus (Vesling), und Pedunculus s. Pediculus (Bauhin).

1) Ovid, Metamorph., II, 625. Abbildungen davon in Anthony Rich, Römische Alterthümer, pag. 377.

2) De corp. hum. fabrica, Lib. I, Cap. 8.

3) Compendium anat., Lovan., 1693, Lib. I, Tr. 4, Cap. 17. 


\section{Malleolus.}

Der anatomische Malleolus (Knöchel), bézieht sich auf die rundköpfige Form des römischen Malleus (sieh' 220 Malleus). Rundliche und hart anzufühlende Erhabenheiten, wie die Knöchel am Fusse, wurden, nicht von den Römern, sondern erst im Spätlatein, Malleoli genannt 1). Kein römischer Schriftsteller führt Malleolus als Knöchel. Im Celsus heissen sie Tali. Im classischen Latein ist Malleolus in zweifachem Sinne bekannt. Erstens als kleiner Hammer, wie im Celsus: scalprum malleolo ferire, den chirurgischen Meissel mit dem Hammer schlagen. Zweitens als ein Kriegsgeräth eigener Art, ein Brandgeschoss, welches von seiner Aehnlichkeit mit einem rundköpfigen Hammer diesen Namen erhielt: malleolos et faces (Fackeln) ad inflammandam urbem comparavit Catilina (Cicero). Durch Ammianus Marcellinus wurde uns die Beschreibung dieser Malleoli hinterlassen ${ }^{2}$ ). Sie bestanden aus einem hölzernen Schaft, an dessen vorderem Ende ein mit brennbaren Stoffen gefülltes, rundliches Drahtgeflecht befestigt war, aus dessen Mitte eine scharfe Eisenspitze hervorragte. Das Ganze sah förmlich einem Malleus gleich. Bevor dieses Geschoss wie ein Pfeil mit grosser Kraft abgeschossen wurde, wurde der Brennstoff im runden Gitterballen angezündet. Wie es in Schiffswände, Verhaue, oder Kriegsmaschinen des Feindes einschlug, bohrte sich die Eisenspitze fest, und das durch Wasser unlöschbare Feuer verzehrte Alles, was es erreichte.

Das deutsche Wort Knöchel, hat eine weitere Verbreitung in der Anatomie, als der lateinische Malleolus. Wir haben 1. Knöchel an Händen und Fingern, als die stark vorspringenden, kugelrunden Streckseiten der betreffenden

1) Zuerst von Vesal, Opera omnia, T. I, pag. 117 und 118, und von seinem Schüler Colu mbus, De re anatomica, Lib. I, Cap. 30 .

2) Historia rerum gestarum, Lib. XXIII, Cap. 4, 14. 
Gelenke, bei geschlossener Faust, 2. ein Knöchelbein = Sprungbein, und 3. Knöchel des Schenkelknochens (Sömmerring) $=$ Condyli femoris.

Nur die Italiener haben für Knöchel einen Ausdruck, welcher an $\mathrm{Hammer}$ (Malleus) gemahnt: martellino. Die französischen chevilles sind, so wie die altitalienischen caviglie, und die spanischen clavije, aus der clavicula entstanden, im Sinne des Vitruvius, als Zapfen. Die englischen ancles, sind die altdeutschen Aenkel = Fussibug, und Knochen am Fussbug, verwandt mit àyæẃv.

Ueber Sprachantiquitäten von Malleolus, verdient HL, §. XLII, Cahabin, Malleoli, nachgesehen zu werden.

\section{Mandibula und Maxilla,}

Sind Mandibula und Maxilla identisch, oder von verschiedener Bedeutung? Fragen wir unsere beste Autorität in Sachen lateinischer Worte der Anatomie, so erhalten wir folgende Auskunft: maxilla est mobile os, eaque una est ${ }^{1}$ ). Maxilla wäre also Unterkiefer. Der Oberkiefer dagegen heisst im Celsus: Os malarum, wahrscheinlich weil er von den Malae, Wangen, bedeckt wird: dentium pars in maxilla (Unterkiefer), pars vero in superiori ossi malarum (Oberkiefer) haeret. Mandibula (von mando, kauen) kommt im Celsus nicht vor. Dagegen bedeutet es im Macrobius sowohl Ober-als Unterkiefer: post septem menses dentes incipiunt mandibulis emergere ${ }^{2}$ ).

$\mathrm{Ob}$ Mandibula oder Mandibulum zu schreiben, inter judices lis est. Ich glaube, Mandibulum sei das Richtige, da alle ähnlich auslautenden Worte generis neutrius sind, wie patibulum, Galgen, frangibulum, Nussknacker, vestibulum, infundibulum, und vertibulum, Wirbel, im Lactantius. Dass aber Maxilla

\footnotetext{
1) Celsus, De medicina, Lib. VIII, Cap. 1.

$\left.{ }^{2}\right)$ Somnium Scipionis, Lib. I, Cap. 6.
} 
auch für den Oberkiefer gebraucht wurde, finden wir im Plinius: Crocodilus maxillas superiores tantum movet, und bald darauf: camelus, in superiore maxilla dentes primores non habet. Demzufolge steht es den Anatomen frei, den Ober- und Unterkiefer ganz getrost Maxilla oder Mandibula zu nennen, niemals aber den Unterkiefer Os malare. Es ist übrigens, schon seit lange, in der lateinischen Anatomie, wenn es sich um guten Styl handelt, gebräuchlich, bei Anwendung von Maxilla, hinzuzugeben superior oder inferior, während Mandibula, ohne Adjectiv, immer nur dem Unterkiefer gilt, quia sola mandibula mandendo movetur.

Wie Mandibula von mando, und mâchoire von mâcher (kauen), so kommt Kiefer vom altdeutschen kiefen (kauen), welches sich noch im Wienerischen als kiefeln bemerkbar macht. In den deutschen Anatomien des vorigen Jahrhunderts, lesen wir Kiefel statt Kiefer. - Kinnlade bezieht sich nur auf den Unterkiefer. L a de drückt eigentlich einen Kasten aus, worin irgend etwas aufbewahrt wird, wie aus Bettlade, Bundeslade für die Gesetztafeln der Hebräer, Handwerkslade zum Aufbewahren der Zunfturkunden, Armenlade für Sammelgelder der Armen, u. s. w., zu. ersehen. Das mittellateinische Ladus, und die Ladula des Mönchslatein, drücken ein kleines Behältniss, ein Fach zum Aus- und Einschieben aus, österreichisch ein "Ladel". Auf dieser Ladula beruht die Kinnlade, mit ihren vielen kleinen Behältern für die Zahnwurzeln. Heissen doch die, durch das Ausfallen der Zähne, bei alten Pferden entstehenden Lücken: die Laden.

Das spanische quixada (Kiefer) kann, wie das provençalische cais, nur aus dem lateinischen casso und quasso, zermalmen, entstanden sein. 


\section{Manubrium sterni.}

Manubrium sterni ist kein sprachlicher Fehler, aber eine unrichtige Begriffsauslegung. Einer allgemeinen Gepflogenheit zufolge, wird das Brustbein in den Griff, in den Körper oder die Klinge, und in den Schwertfortsatz eingetheilt. Man braucht nur ein Brustbein anzusehen, um diese Eintheilung unrichtig zu finden. Im Ganzen lässt sich wohl das Brustbein mit einem kurzen römischen Schlachtschwert vergleichen, welches nicht zum Hieb, sondern zum Stoss diente. Wird das oberste, kurze Stück des Brustbeins, Griff genannt, so hat man ein Schwert, dessen Griff breiter und dicker als seine Klinge ist. Ein Schwert von solcher Gestalt, wäre kaum zu brauchen. Fasst man aber, wie es Vesal ${ }^{1}$ ) zuerst gethan, das oberste, und das darauf folgende mittlere, lange Stück des Brustbeins, zusammen als Griff auf, so bildet das oberste Stück nur den Knauf zu diesem Griff, und das mittlere Stück ist es, welches von der Hand gefasst wird. Freilich existirt dann von diesem Schwert nur eine sehr kurze Klinge - als Processus xiphoideus. Da aber alle guten alten Anatomen, die Anschauungsweise des Vesal zur ihrigen machten, und erst durch Heister die unrichtige Auffassung in Mode kam, möge man zur alten Ausdrucksweise zurückkehren, und das jetzige Manubrium lieber $\mathrm{Knopf}$ oder $\mathrm{Knauf}$, und die jetzige Klinge Griff nennen, welcher auch durch die an seinen Seitenrändern befindlichen Grübchen zur Aufnahme der Rippenknorpel, an das quergeriefte Ansehen eines gewöhnlichen Schwertgriffes erinnert. Findet man die Klinge dieses Schwertes zu kurz für einen solchen Griff, nun, so mag man aus dem Schwert einen Dolch machen, wie Bartholinus gethan, und das jetzige Manubrium, als Pomum s. Caput s. Nodus pugionis ansehen, die jetzige Klinge aber als Capulum (von capio), der

1) De corp. hum. fabrica, Lib, I, Cap. 19. 
eigentlich von der Hand gefasste Griff. Allerdings ist auch für einen Dolch, der Processus xiphoideus eine sehr kurze Klinge ${ }^{1}$ ).

Die Anatomie hat noch zwei Manubria. Das eine ist das Manubrium manus ${ }^{2}$ ), worunter sie den Radius versteht, nach dem bei älteren französischen Anatomen beliebten le porte-main und le manche de la main, der Griff der Hand, indem sich der Radius mit den zwei grössten Knochen der ersten Handwurzelreihe unmittelbar verbindet, also die Hand eigentlich trägt, oder ihren Stiel bildet, während die Ulna den dritten, kleinen Handwurzelknochen, nur per interventum cartilaginis interarticularis berührt, also die Hand nicht trägt. Die Griechen nannten den ganzen Vorderarm $\pi \tilde{r}_{i} u s$, und die Ulna ebenso. Die Ulna wurde für den wichtigeren der beiden Vorderarmknochen angesehen, da sie eine innigere Verbindung mit dem Oberarmbein eingeht, als der Radius. Letzterer, xspxis genannt, galt deshalb nur für einen Nebenknochen der Ulna, und heisst deshalb im Hippocrates to $\pi \alpha \alpha_{\pi}$ ri i $_{10 \%}$. Hieraus versteht es sich, warum die Arabisten den Radius Os adcubitale, und Albin denselben Additamentum ulnae nennen konnten.

Das zweite Manubrium ist der Griff des Hammers: Manubrium mallei, für welchen Bauhin den zweideutigen Namen Pediculus gebrauchte. Wahrscheinlich wollte er Pedunculus sagen. Pediculus ist allerdings Stiel, aber auch Laus, das griechische posip, woher Phthiriasis, Läusesucht. Celsus versteht unter Phthiriasis, blos die Läuse an den behaarten Rändern der Augenlider ${ }^{3}$ ).

1) Ausführliches hierüber sieh' in meiner Schrift: Das Arabische und Hebräische in der Anatomie, §. XLV, Cassum.

2) Blumenbach, Geschichte und Beschreibung der Knochen, §. 337, Note c.

3) De medicina, Lib.VI, Cap. 6, num. 15: Genus quoque vitii est,

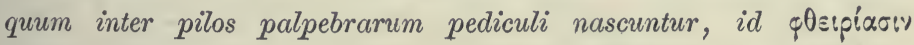
Graeci nominant. 


\section{Masseter.}

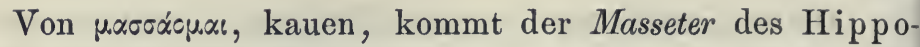

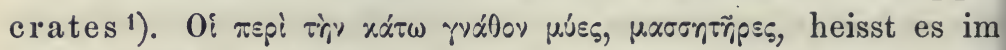
Rufus Ephesius. Masseter blieb unverändert. Nur im zweiten Commentar des Galen über das Hippocratische Buch: IIspi äpopwy, verliert der Masseter ein $s$, und heisst Maseter, und im Jac. Douglas wird er, durch Reuchlinische Aussprache des $\eta$ als $i$, zum Massiter. Der Musculus pterygoideus internus, welcher gleiche Wirkung mit dem Masseter hat, wird deshalb auch Masseter internus genannt, welche Benennung jedoch den Griechen gänzlich fremd ist. Man citirt zwar dafür dén Galen (De administrationibus anat., Lib. V, Cap. 2); ich habe aber bei aufmerksamer Durchsicht dieses Capitels, welches nur von den Schultermuskeln handelt, nichts von einem Masseter internus vorgefunden. Der Name Pterygoideus. internus wurde zuerst von Riol an jenem Muskel ertheilt, welchen seine Vorfahren nur als Musculus maxillae, in ore latitans, kannten.

Der griechische Masseter musste sich allerlei Latinisirung gefallen lassen, wie Mansorius im Columbus (von mandere, kauen), Manducatorius und Manducator (von manducare $=$ mandere), von Sömmerring gebraucht, Masticatorius im Ambroise Paré (vom französischen mastiquer = masticare, kauen, von $\mu \dot{\alpha} \sigma \tau \alpha \xi$, Mund), und Molitor im Carolus Stephanus, welcher in der deutschen Uebersetzung des Bartholinus von Wallner (Niirnberg, 1677), uns als Mühler, neben dem Essmäuslein, erfreut. Man schrieb nämlich damals die laterale Verschiebung des Unterkiefers, durch welche die Speisen zwischen den Mahlzähnen (molares) zerrieben werden, nicht dem Pterygoideus externus, sondern dem Masseter zu. Der Musculus zygomato-maxillaris des Chaussier, hat den Masseter nicht verdrängen können.

1) De articulis, II, t. 6. 


\section{Mastoideus und Mamillaris.}

Galen erwähnt am Schläfebein drei Processus (Ėxqúceı!c): den styloideus, zygomaticus (

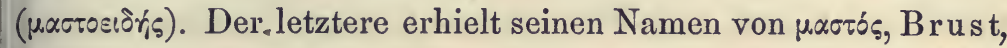

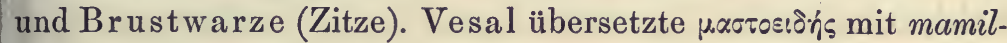
laris, von mamilla, welches den Classikern nicht fremd ist, und im Juvenal für Brustwarze, und im Vellejus für Brust angetroffen wird. Processus und Apophysis mastoidea behielten aber im Gebrauch immer die Oberhand über mamillaris und mammiformis (Bartholin). - Den deutschen Anatomen fällt eine Fahrlässigkeit zur Last. Sie sagen alle: Warzenfortsatz. Der Fortsatz wurde aber nicht mit einer Warze (0'jusov s. àxpoyopòíw), für welche er viel zu gross ist, sondern mit einer Brustwarze ( $\mu . \alpha \sigma o ́ s)$ verglichen. Man möge sich also schon bequemen, Brustwarzenfortsatz zu sagen und zu schreiben. Ist man pressirt, nehme man Zitzenfortsatz, was ebensoviel sagt, und in den älteren deutschen Anatomien, als ein stehender Terminus gefunden wird. Der ehrliche Wiener Elias Wallner, welcher 1677 den Bartholinus übersetzte, ergötzt uns mit Duttelfortsatz. Im gemein Wienerischen heissen die Brüste "Dutteln" - wie Tüte und Zitze aus Hellas stammend, von ti 0 in, Brustwarze, mit zahlreichem Anhang: englisch teat, italienisch tetta und zitta, spanisch teta, französisch teton, in den slavischen Mundarten cecy, und im Venetianischen zezzolo, woher zuzeln, und der Stellvertreter der Brustwarze - der Zuzel, im österreichischen Dialect.

Wenn wir nun dem Processus mastoideus, seinen altehrwürdigen Namen gerne hingehen lassen, müssen wir uns doch gegen die viel später entstandene Incisura mastoidea und die Cellulae mastoideae (Winslow), gegen die Sutura mastoidea, gegen Sömmerring's Foramina mastoidea, gegen den Angulus mastoideus des Seitenwandbeins, wie gegen den Sterno-cleidomastoideus feierlichst verwahren, denn alle diese Dinge, welche 
in Beziehung zu einem brustwarzenähnlichen Knochenfortsatz stehen, sind doch selbst nicht brustwarzenähnlich, können also nie mastoid genannt werden. Sieh' die zwei Artikel über Ideus.

Einen sehr bezeichnenden Ausdruck für'den Processus mastoideus, bildete sich Sömmerring in seinem Zapfen des Schläfebein s ${ }^{1}$ ).

\section{Matrix.}

Nur im figürlichen Sinne wird Matrix für Gebärmutter gebraucht. Das fremdartige Wort macht keinen guten Ein-

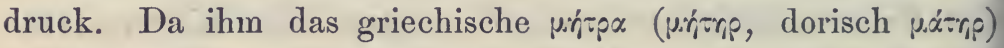
zu Grunde liegt, welches durch eine Unzahl von Composita, in der medicinischen Welt eine Rolle spielt (Metritis, Metrorhagia, Metrodynia, etc.), so ist es selbst die Mutter geworden von dem französischen matrice und dem spanischen matriz, und wurde auch in den deutschen Sprachschatz, mit oder ohne Verbindung, als Mutter, Bärmutter (Tragmutter, von dem altdeutschen büren, tragen), und Gebärmutter, eingeführt. Das Capitel im Mundinus, welches von der Gebärmutter handelt, führt die Aufschrift: De anathomia matricis, und im Berengarius: De matrice non praegnante. Ebenso im Benedetti, welcher sich aber auch des Ausdruckes loci muliebres bedient, wie stellenweise Plinius, worunter aber, nebst der äusseren Scham, auch das ganze weibliche Geschlechtssystem zu verstehen ist. Matrix wird als femina brutorum, quae foetus gratia alitur (der Zucht wegen), definirt. Tauri ad matrices heissen im Columella die Zuchtstiere, und Gallina matrix eine Bruthenne. Plinius und Vegetius sind die einzigen römischen Autoren, welche matrix als Gebärmutter aufweisen. Bei Anderen trifft man matrix nur als ein Ding erwähnt, welches ein anderes einschliesst, bewahrt,

1) Knochenlehre, §. 128. 
erzeugt, oder den Grund seines Daseins enthält (Eva matrix generis humani, im Tertullian). Eine Anzahl deutscher Worte entspricht derselben Vorstellung, wie: Perlmutter, Schraubenmutter, Aal- und Essigmutter, Mutterlauge, Muttergestein, und Mütterchen, als ein Öhr von Draht an den Kleidungsstücken, in dessen Höhlung ein Häckchen eingreift. Hieher gehört auch die Matrize, als kupferne Form der Schriftgiesser, zum Guss der Buchstaben, und Matrikel, als Buch, in welches die Namen einer bestimmten Classe von Menschen eingetragen werden (Immatrikuliren der Studenten).

Die nicht mehr gebräuchliche Hystera des Julius Pollux,

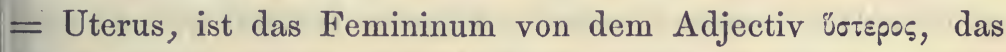
letzte, hinterherkommende. Hystera passt auf Uterus, da dieser das letzte (unterste) Organ in der Bauchhöhle ist. Von ihr rührt die allgemein bekannte Hysterie her, und eine Menge von Zusammensetzungen (Hysterotomia, Hysteroptosis, Hysteromochlion, etc.). Die Stera des Schylhans, kann nur eine verstümmelte Hystera sein.

Von der Delphys und Gone des Hippocrates '), erübrigt nur die erstere mehr, aber nicht in der Anatomie, sondern in der Zoologie, zur Bezeichnung einer Familie von Säugethieren, welche einen doppelten Uterus besitzen: Didelphys. Adelphos, Bruder, besagt: aus demselben Uterus. - Das im Pierer auffallende Eugium, konnte ich, als anatomischen Terminus für Gebärmutter, in keinem griechischen Autor finden. Es ist

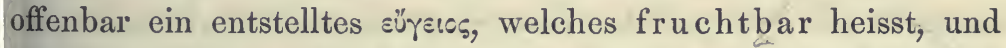

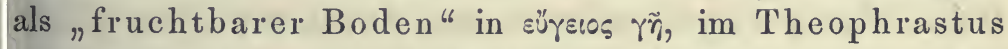
vorkommt. Da ältere Anatomen, z. B. Rolfink, vom Uterus auch als Arvum naturae (Saatfeld) reden, kann Eugium als eine gelehrt aussehende Uebersetzung jenes Ausdruckes angesehen werden.

Die einzige Autorität, auf welche wir uns zu stützen haben, wenn es sich um eine richtige lateinische Bezeichnung

1) Lib. de sterilitate, XII, 8 . 
eines Organs handelt, ist Celsus. Er hat weder Matrix, noch Uterus, sondern nur Vulva ${ }^{1}$ ), worüber in dem Abschnitte Vulva, das Nähere enthalten ist.

\section{Meconium.}

Meconium heisst der schwarzgrüne, pechartige Darminhalt des Neugebornen, welcher bei der ersten Darmentleerung abgeführt wird. In der Sprache der Hebammen als Kindspech bekannt, führt er in den Schriften der Geburtshelfer, noch zwei andere erwähnenswerthe Namen: Heidenkoth ${ }^{2}$ ), und schwarze Renne ${ }^{3}$ ). Der Heidenkoth, noch deutlicher Heidendreck, schreibt, wie die Heidenhaut, seinen Namen daher, dass er vor der Taufe abgeht; die schwarze Renne aber ist ein norddeutscher Volksausdruck, welcher der Renne entstammt, worunter die gepflasterte oder, nackte Gosse verstanden wird, in welcher Wasser und Unrath aller Art durch die Strassen zieht (Rennstein).

Meconium, unxxívtov, ist im Hippocrates: Mohnsaft. Wir unterscheiden zwei Arten von Mohnsaft. Die eine quillt aus den Köpfen der Mohnpflanze, wo sie verletzt werden, von selbst hervor. Das ist das eigentliche Opium. Die andere Art wird durch Auspressen und Sieden der ganzen Pflanze gewonnen, als ein schmutzfarbiger Saft, welcher durch $\mathrm{Ab}$ dampfen zur Syrupsdicke, eine schwarzbraune Farbe annimmt. Dieser Farbe wegen, nannte schon Aristoteles das Kinds-

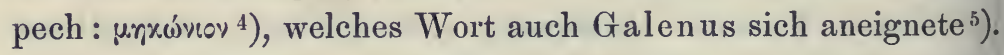

1) De medicina, Lib. IV, Cap. 1.

2) Osiander, Lehrbuch der Hebammentunst, §. 311.

3) Deutsche Uebersetzung ron Fr. Mauriceau's Traité des maladies des femmes grosses, etc., Basel, 1680, Buch III, Cap. 17.

4) Hist. anim., Lib. VII, Cap. 10.

5) An animal sit id, quod in utero est. Cap. 5. 
Und so heisst das Kindspech jetzt noch in der wissenschaftlichen Sprache, ohne je durch ein Synonymon in seiner allgemeinen Anwendung beeinträchtigt oder ersetzt worden zu sein. Die schwarze Farbe des eingedickten Mohnsaftes lehrt uns auch verstehen, warum Aristoteles die Tintenblase der Sepien, ebenfalls $\mu$ ri $\varkappa \omega \nu$ nannte ${ }^{1}$ ).

Mrixusy ist schon in der Ilias die Mohnpflanze, wird aber auch für den Mohnkopf und den Mohnsaft von griechischen Schriftstellern verwendet. Man leitet den Namen von dem hebräischen פור (mug), schlaff machen (betäuben) her, während

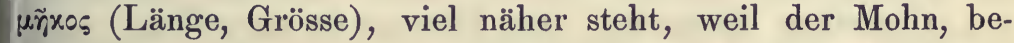
sonders der Papaver orientalis, sehr hoch wächst. Kühn denkt an $\mu$ ì xเveiั, nicht bewegen, quia sensibus, papaveris sopore vinctis, membra nihil agere possunt ${ }^{2}$ ).

Der erste lateinische Uebersetzer des Aristoteles, Gaza, gab ganz treffend prrixiviov durch Papaverculum, eigentlich kleiner Mohnkopf, denn Meconion ist die Verkleinerungsform von mecon (papaver). - Die schwarze Farbe des Meconium steckt dahinter, dass auch das schwarze Pigment der Choroidea, gezierter oder blos alberner Weise, Meconium genannt wurde, wie von $\operatorname{Janin}^{3}$ ), und seinem deutschen Uebersetzer.

\section{Mediana.}

Galen erwähnt zwar eine Hautvene im Ellbogenbug, durch welche eine Verbindung zwischen Cephalica und Basilica unterhalten wird, giebt ihr aber keinen besonderen Namen ${ }^{4}$ ).

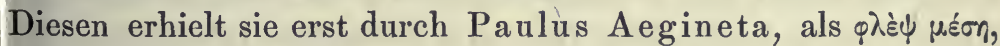

1) Op. cit., Lib. IV, Cap. 4 und 5, und noch öfter.

$\left.{ }^{2}\right)$ St. Blancardi Lex. med., T. II, pag. 925.

3) Mémoires sur l'œil et ses maladies, Lyon, 1772 ; deutsch Berlin, 1776, pag. 11.

4) Administrationes anat., Lib. III, Cap. 5. 
welche im Celsus mit Vena ad medium, und im Mundinus mit Vena media ausgedrückt wird. Den Namen Vena mediana, erhielt sie erst durch den Uebersetzer des Canticum Avicennae. Dort heisst diese Vene Al-madjan, und ohne Artikel Madjan. Dieses Madjan ist nicht $=$ media, sondern ein Eigenname, und zwar der Name eines arabischen Commentators des Canticum: Madjan Ibn Abderrahman. Nach ihm wurde unsere Vene $A l$-madjan̄ genannt, woraus Armegandus seine Mediana fabrizirte. Medianus ist zwar ein gutes lateinisches Wort, wie im Digitus medianus, und in den Columnae medianae der römischen Baukunst. Als Benennung einer Vene aber, welche im Latein des Celsus und Caelius Aurelianus immer nur als media oder ad medium vorkommt, ist Mediana arabischen Stammes = Al-madjan, Ader des Madjan. Sieh' HL, §. LXXVI, und die Nachträge dazu auf pag. 295.

\section{Mediastinum.}

Das Mediastinum der Anatomen, und der Mediastinus der Dichter, haben nichts miteinander gemein, als dass beide aus medius hervorgingen. Sinn und Bedeutung derselben ist ganz verschieden. Das anatomische Mediastinum, sind zwei senkrecht stehende Pleuraplatten (Mittelfelle), welche die Brusthöhle in eine rechte und linke Hälfte theilen, und das Herz zwischen sich enthalten. Galen, welcher die Pleura ipuny ims-

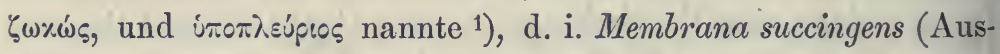
kleidungshaut), und subcostalis ${ }^{2}$ ), wählte für das Mediastinum

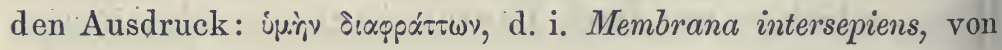

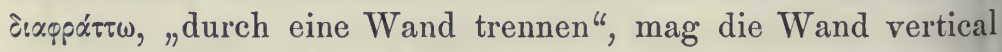

1) De usu partium, Lib. VI, Cap. 3.

2) Pleura war bei den Griechen zuerst die Seite, daher ihre Pleuritis, Seitenstich, dann aber auch Rippe, weil sie an der Seite der Brust liegt. 
oder horizontal stehen. Das Médiastinum ist ein verticaler, das Diaphragma ein horizontaler Hymen diaphratton. - Mediastinum blieb nicht blos auf die Pleura beschränkt. Auch andere Scheidewände massten sich diesen Namen an, wie das Septum pellucidum, als Scheidewand der Vorderhörner beider Gehirnkammern 1), der Processus falciformis der harten Hirnhaut (Mediastinum cerebri), als Scheidewand der beiden Hemisphären des grossen Gehirns, die Trommelhaut (Mediastinum auris im Bartholin), als Scheidewand zwischen dem äusseren Gehörgang und der Trommelhöhle, und das Mesenterium, als Medianum, abgekürzt für Mediastinum, im Vesal. Da schon Galenus seinen Hymen diaphratton, auch im Plural auftreten lässt, musste er gewusst haben, dass das Mediastinum aus zwei Pleuraplatten besteht, welche wir Laminae mediastini zu nennen pflegen. Der zwischen ihnen befindliche Raum ist das Cavum mediastini.

Wir können Mediastinum nur als Amalgam dreier Worte: per medium tensum, auffassen, und müssen demgemäss das anatomische Mediastinum, für einen Barbarismus erklären, um so mehr, als das Wort erst durch die Latino-Barbari in Aufnahme kam. Alle übrigen älteren Benennungen des Mediastinum, welche nicht mehr gebraucht werden, wie Discretorium, Diribitorium, Distributorium, und Discrimen, sind gut latein, und wörtliche Uebersetzungen der vox Galenica $\delta\llcorner\alpha-$ фра́ $\tau \tau \omega$. Sie wurden in den Werken von Caelius Aurelianus, Celsus, Lauremberg, und Vesling ${ }^{2}$ ) aufgesammelt, und sind auch auf das Diaphragma anwendbar.

Der Mediastinus der Dichter tritt in doppelter Form auf. Erstens als ein Sclave, welcher die niedrigsten Verichtungen im Hause oder in der Landwirthschaft zu vollziehen hatte: in mediis aedibus stans, ad obsequia paratus (Priscianus), und: potest ager ducentorum jugerum subigi duobus jugis boum, totidem

1) Bartholinus, Institutiones anat., Lib. III, Cap. 6.

2) Syntagma anatomicum, Edit. Blasii, Cap. 9, pag. 139.

Hyrtl. Onomatologia anatermica. 
bubulcis (Rinderknechte), et sex mediastinis (Columella). Desgleichen hiess ein in der Mitte der öffentlichen Bäder aufgestellter Sclave, zur Bedienung von Jedermann: Mediastinus ${ }^{1}$ ). - Eine zweite Bedeutung von Mediastinus, wie mir vorkommt eine gesuchte, beruht auf der angenommenen Zusammensetzung

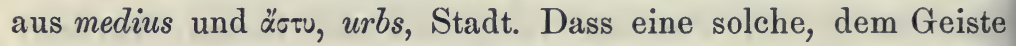
der römischen Sprache widerstrebende Zusammensetzung möglich war, lässt sich daraus vermuthen, dass im Terentius,

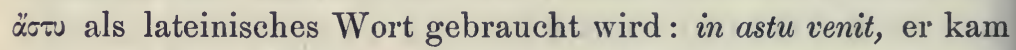
in die Stadt. Mediastinus wäre dann: qui in media urbe vivit, ein Städter. Mit dieser Auslegung, glaubt man, wird der Horazische Vers verständlich:

„Tu mediastinus, tacita prece rura petebas."

(Epistola XIV, ad Villicum suum.)

Es giebt aber noch eine andere. Mediastini hiessen auch jene Allerweltsdiener, welche, wie unsere Commissionäre, auf öffentlichen Plätzen sich aufstellten, um zu allerlei Verrichtungen gedungen zu werden. Der Villicus des Horaz, war ein solcher Diener. So der Ausleger des Horatius, Joh. Bond. Die

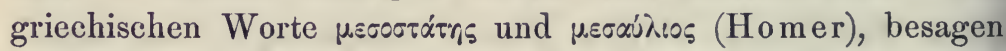
ebenfalls einen Sclaven: qui in media aula vel domo stat. Unwahrscheinlich ist es, dass Mediastinus auf einen Sclaven bezogen wurde, welcher eine mittlere Stellung im Range, zwischen den oberen und unteren Dienern eines Hauses einnahm. Wir hätten dafür nur einen einzigen Anhaltspunkt: Mesonauta, ein Matrose mittlerer Classe, zwischen dem Steuermann und den Ruderknechten.

Der kurz vorher citirte Horazische Vers, soll von den Anatomen auswendig gelernt werden, da er ihnen klar macht, dass man nicht Mediastīnum, sondern Mediastīnum zu sagen hat.

1) Martinii Lex. philologicum, T. II, lit. M. 


\section{Medulla oblongata,}

Wer zum ersten Male ein blossgelegtes Hirn und Rückenmark sieht, hält das Rückenmark für eine Verlängerung, für einen Schweif des Gehirns. In der Kindheit der Anatomie, hiess auch das Rückenmark Cerebrum longum, und selbst in guter Zeit, wurde es noch Cauda cerebri genannt. Bartholin ${ }^{1}$ ) theilte das centrale Nervensystem in zwei Theile ein: Pars globosa, eigentliches Hirn, und Pars oblongata, quam nos caudam vocabimus, Rückenmark. An letzterem unterschied er wieder eine Pars intra calvariam, das ist unser verlängertes Mark, und eine Pars in spinam delapsa, unser Rückenmark. Die Pars intra calvariam, enthält den Calamus scriptorius, worunter er die ganze vierte Hirnkammer verstand, welche er auch als Ventriculus nobilis auszeichnete, weil in der Umgebung desselben, alle Hirnnerven ihre Entstehung nehmen, um den in der vierten Kammer bereiteten Spiritus animalis in sich aufnehmen zu können. Die Onomatologia medica completa ${ }^{2}$ ), nennt deshalb das verlängerte Mark: Aestheterium s. Sensorium commune, welche Benennung von den Neueren auf das ganze Gehirn ausgedehnt wurde. - Bartholin's Pars oblongata intra calvariam, gelangte durch Heister ${ }^{3}$ ) zu der kurzen Benennung: Medulla oblongata, welche Haller ${ }^{4}$ ) adoptirte. Sie wurde allgemein, und existirt heute noch. Es wäre an ihr nichts weiter auszusetzen, als dass über das Adjectiv oblongata, alle Sprachkenner den Stab brechen müssen. Es heisst die Manen Vesal's beleidigen, wenn Schreger dieses Wort dem grossen Manne in den Mund legt. Vesal erwähnt blos, dass die Medulla dorsalis von Einigen Cerebrum longum genannt

1) Institutiones anat., Lib. III, Cap. 3.

2) Medicinisches Lexicon, Frankfurt und Leipzig, 1756.

3) Compendium anat., Editio quarta, T. I, pag. 137.

4) Elem. physiol., T. IV, Lib. X, Sect. 3, §. 2. 
wurde (aliis longum cerebrum appellare libuit ${ }^{1}$ ). Macrobius sagt, dass schon zu seiner Zeit (5. Jahrhundert), die Aerzte das Rückenmark Cerebrum longum nannten ${ }^{2}$ ).

Während alle Wörterbücher oblongus als länglich registriren, beobachten sie über oblongatus ein feierliches Stillschweigen. Und solches möge auch die Anatomie bewahren, trotz Heister und Haller, denen nur das Schullatein geläufig war. Medulla prolongata möge also recht bald die Medulla oblongata verdrängen. "Verlängern" heisst nicht oblongare oder elongare, sondern prolongare oder producere. Bei dieser Gelegenheit könnte auch die barbarische Medulla dorsalis, in die anständige und richtige Medulla dorsualis umgebildet werden. Dorsalis darf ebensowenig als oblongata, in geläuteter Sprache fortbestehen.

Der Bulbe rachidien (richtig Bulbe rhachidien), welcher von Flourens für Moëlle allongée in Aufnahme kam, führt schon im Meckel den Namen Bulbus rhachiticus.

\section{Meninx und Myrinx.}

Meninx, $\mu \tilde{r} v i \gamma \xi$, wurde zur Bezeichnung verschiedener Häute, bei den Griechen gebraucht. Selbst die Haut, welche sich auf dem Wein in den Fässern bildet, heisst im Hesy-

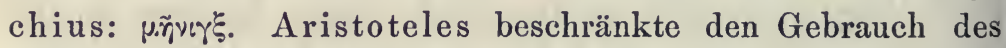
Wortes auf die Hirnhäute ${ }^{3}$ ). Und dabei blieb es bis in die Gegenwart. Ueber die zwei Arten von Hirnhäuten, sieh' den Artikel: Dura und pia mater.

Das 'Trommelfell finden wir in älteren Schriften sehr oft als Myrinx und Myringa erwähnt, zuerst im Hieronymus

1) Op. cit., Lib. IV, Cap. 11.

2) Saturnalia, Lib. VII, Cap. 9.

3) Hist. anim., Lib. I, Cap. 16. 
Capivaccius 1). Ich halte diese Myrinx für eine alterirte Meninx, als Haut überhaupt, welche füglich an die Stelle des allzuviel sagenden Derma auditus im Hippocrates (¿́śpux mpos tìy $\dot{\alpha} x o r i y)$ gesetzt werden konnte. Von Bartholin bis in die neueste Zeit (Leber), finden wir die Myrinx, entweder als Hauptname für Trommelfell, oder als Synonym desselben, neben Septum membranaceum, Diaphragma, Operimentum, Tegumentum auris, Mediastinum auris, und Tympanum schlechtweg. Haller hat für Tympanum, da die Trommelhaut doch keine ganze Trommel ist, seine bleibende Membrana tympani eingeführt ${ }^{2}$ ).

\section{Menisci.}

Gerade jener Zwischengelenksknorpel, welcher kein $M e-$ niscus ist, führt den Namen Cartilago meniscoidea. Der Interarticularknorpel des Kinnbackengelenks, hat keine halbmondförmige Gestalt, und soll somit auch nicht meniscoidea genannt werden, wie es von Loder zuerst geschah ${ }^{3}$ ), und fortwährend

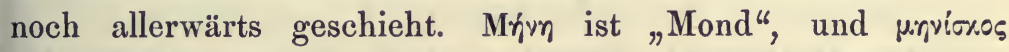
"kleiner Mond", lumula. Nur wenige Zwischenknorpel sind halbmondförmig. Die Namen: Cartilagines lunatae, semilunares, falciformes, sigmoideae (C-förmig), passen nicht auf sie. Die nicht halbmondförmigen Zwischenknorpel des Kinnbackengelenks, des Carpo-Ulnargelenks, und des Schlüsselbeingelenks, können nur den Namen Cartilagines interarticulares führen; womit die Lage dieser Knorpel im betreffenden Gelenk ausgedrückt wird. Die ganz eigenartige Form vieler Zwischenknorpel, welche mit einem einzigen Wort nicht bezeichnet werden kann, erfordert eine Umschreibung. Kein

1) Practica medicinae, Francof., 1594, pag. 333.

2) Elem. physiol., T. V, Lib. XV, Sect. 1, §. 11: rectius membrana tympani, quam tympanum dicendum est.

3) Anatomisches Handbuch, 2. Aufl., I. Bd., S. 277. 
lateinischer Lexicograph hat das Wort Meniscus aufgenommen, und die Griechen haben es nur für die halbmondförmige Schlachtordnung (Polybius), und für ein gebogenes Schirmdach über einer Bildsäule (Aristophanes) gebraucht. Ein

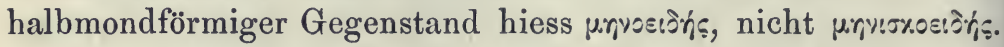
- Die Vesal'sche Zeit hatte für die Zwischenknorpel den gut gewählten Ausdruck: Cartilagines interpositae, während Vesal selbst diese Knorpel, welche er als Cartilagines aliae, den die Gelenksenden der Knochen überziehenden Knorpeln entgegenstellt, nur durch eine umständliche Beschreibung kennzeichnet, ohne ihnen einen besonderen Namen zu geben ${ }^{1}$ ). Die Deutschen wählten das Beste mit ihren Schaltknorpeln. Diese liessen sich als Cartilagines intercalares übersetzen, welche viel besser wären, als die Cartilagines interarticulares, da diese nicht inter articulos (zwischen den Gelenken), sondern intra articulum (im Gelenk) liegen.

\section{Mesenterium und Mesaraion.}

Das Msox́patov der Griechen, hat seine anatomische Berechtigung gänzlich an Mesenterium abgetreten. Nur das

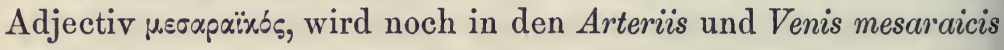
angetroffen.

Merápa:toy und Msøevtéploy sind, der Sache nach, identisch:

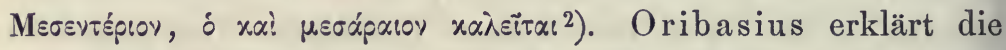
sprachliche Verschiedenheit beider Ausdrücke: mesenterium a situ, meseraeum (mesaraion) a peculiari substantia nominatur ${ }^{3}$ ). Wie ist das zu verstehen? Nicht der Darmkanal allein, wie es heutzutage beliebt wurde, sondern der ganze Inhalt der Bauchhöhle, hiess im Homer: tò हैvтspov (von ṡvtós, drinnen),

1) De corp. hum. fabrica, Lib. I, Cap. 10, ad finem.

2) Galenus, De administrationibus anat., Lib. VI, Cap. 5.

3) Anatomica ex Galeno, pag. 109. 
wie auch das lateinische Intestinum, von intus, und das altdeutsche Inster, dasselbe ausdrückt. Das Mesenterium steht, wie eine senkrechte Scheidewand, in der Mitte der Bauchhöhle; ist also das medium intestinum des Unterleibes, das $\mu . \varepsilon \varepsilon \vee y-$ tếp!ov des Aristoteles 1). Ebenso lässt sich auch das Mediastinum in der Brusthöhle, als contrahirt für medium intestinum erklärén. Für Medium intestinum, als Mesenterium, bietet uns Cicer o seine treffliche Zeugenschaft dar: succus, quo alimur, permanat ad jecur, per quasdam, a medio intestino, ad portam jecoris ductas $^{2}$ ) vias, womit die Venae mesaraicae gemeint sind. -

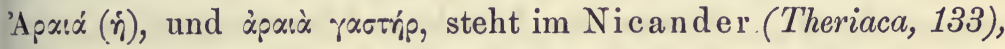

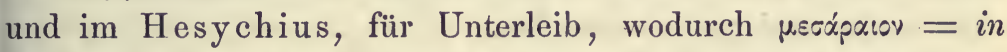

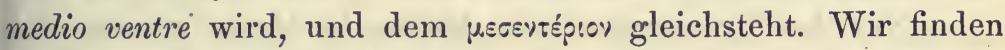
dasselbe wirklich als Medium im Benedetti, und als Mitten im Altdeutschen. Damit wird aber der Ausdruck des Oribasius: a peculiari substantia, nicht erklärt. Um dieses thun zu können, müssen wir auf eine andere Bedeutung von àpatós zurückblicken. Sie liegt in dünn und zart $^{3}$ ). Das Mesaraion bezieht sich also sicher auf das Mesenterium, als dünne, zarte und durchscheinende Bauchfellsfalte.

Hält man sich an pécos, als das in der Mitte Befindliche, so kann man nur von einem Mesenterium des dünnen Darmes reden. Die Mesenterien des Colon, des Rectum, liegen nicht in der Mitte, sind also keine Mesenteria. Insofern das Mesenterium nur dem dünnen Darm zukommt, muss das Mesaraion selbst für bezeichnender als Mesenterium gehalten werden. -

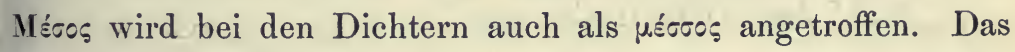
Messenterium der Latino-Barbari, wäre demnach kein Barba-

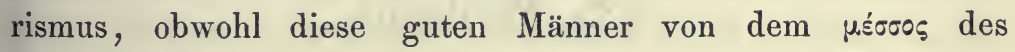

1) De partibus animal., Lib. II, Cap. 3.

2) De natura Deorum, Lib. II, Cap. 55, §. 137.

3) In der Ilias und Odyssee, finden wir àpxiós öfter, als Epitheton zarter und dünner Gegenstände, wie der Stimmé, der Hände, und der Füsse. 
Sophocles ganz gewiss nichts wussten. - Gegen das Mesoraeum, welches Kraus in Schutz nimmt, müssen wir uns feierlich verwahren, denn es lässt sich dafür kein etymologischer Anhaltspunkt geben, ebensowenig als für meseraicus, welches in einem medicinischen Repertorium, dem richtigen, aber übereilter Weise für einen Druckfehler erklärten mesaraicus, substituirt wurde!

Das doppelte Mesenterium uteri (Ligamenta lata), das Mesenteriolum processus vermicularis, die Mesenteriola tendinum (an die Sehnen tretende Falten der Synovialhaut in den Vaginis tendinum fibrosis), können als harmlose Licentiae poëticae, den Anatomen nachgesehen werden.

Nur das Mesenterium des dünnen Gedärms musste sich in Falten legen, welche den zahlreichen Krümmungen und Windungen dieses Darmes entsprechen. Dadurch erhält es Aehnlichkeit mit der gefalteten Halskrause, welche die Adeligen, Honoratioren, und Prediger zu tragen pflegten, und kros oder krös hiess. Krös wird mit dem cumulativen Ge, und dem euphonischen $e$ am Ende, zum Gekröse, schwedisch krås, dänisch kros, böhmisch okruzy. Die faltenlosen Mesenterien des Colon transversum, der Curvatura sigmoidea, und des oberen Stückes des Rectum, sind keine Gekröse, werden aber dennoch so genannt.

\section{Metacarpus.}

Sieh' den Artikel: Carpus.

\section{Metatarsus.}

Sieh' den Artikel: Tarsus.

\section{Mitralis,}

Es giebt nur Eine Valvula mitralis. Die Valvulae mitrales der Autoren, sind ein grammatikalischer Fehler. 
Mitralis ist ein neulateinisches Wort. Das alte Latein kennt nur mitratus, eine Mütze aufhabend, wie die Arabes mitrati des Plinius. Mitralis soll die Aehnlichkeit mit einer Mitra ausdrücken. Die zwei Klappenzipfe am Ostium venosum der linken Herzkammer, wurden zusammen, nicht einzeln, von Vesal mit einer Bischofsmütze oder Infel, Mitra, verglichen: dissectionum proceres, duas tantum membranulas (Klappen) orificio (venoso) praefici asserunt, quas mitrae episcopali non admodum inepte contuleris, si eas anteriori posteriorique mitrae cacumini assimilaveris ${ }^{1}$ ). So wie es nur Eine Valvula tricuspidalis im rechten Herzen giebt (sieh' dieses Wort), welche drei Spitzen oder Zipfel hat, so giebt es im linken Herzen nur Eine Valvula mitralis, welche zwei Spitzen oder Zipfel hat. Von Valvulae mitrales zú reden, ist ebenso unrichtig, als der allgemein eingeführte Ausdruck: Valvulae tricuspidales. Zwei Valvulae mitrales würden zwei Bischofsmützen, also vier Zipfe geben, während doch nur zwei vorhanden sind. Wir dürfen also nicht von zwei, sondern nur von Einer Valvula mitralis reden. - Die Valvula mitralis führte zur Zeit Galen's noch keinen besonderen Namen. Er erwähnt sie nur mit der generellen Bezeich-

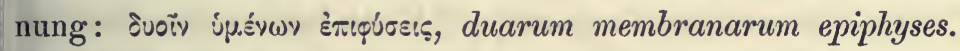

Die Mitra des Bischofs kam in das Herz, wie der Teufel in den Weihbrunnkessel. Sie gehört zum Mönchslatein, und hält sich allen Lexicis fern. Das Glossarium mediae et infimae latinitatis, von Dufresne Du Cange enthält, im T. IV, pag. 841-845, Alles was über Mitra, als priesterliche Kopfbedeckung, gesagt werden konnte. Mitrae gab es in der Welt, bevor es Bischöfe gab, und ich werde zeigen, dass die römische Mitra, nicht die entfernteste Aehnlichkeit mit der zweizipfeligen Klappe des Herzens, und mit der Mitra der Bischöfe hat. In geduldiger Ergebung vernehme der Leser, dass Mitra ein griechisches Wort ist ( $\mu_{i \tau p} \alpha$ ), und in seiner ursprünglichen Bedeutung, eine lange Schärpe ausdrückt, an deren Enden

1) De corp. hum. fabrica, Lib. VI, Cap. 13. 
Bänder (redimicula) angenäht waren, welche, nach der verschiedenen Verwendung der Schärpe, dazu dienten, dieselbe an etwas festzubinden. So Athenaeus, V, 28. Die Griechen gebrauchen Mitra auch als Gürtel, welchen die Jungfrauen trugen, woher גuptтpos im Callimachus, ein sehr junges, nicht mannbares Mädchen heisst, welches den Gürtel noch nicht nöthig hat. Der Gürtel, welchen die Krieger um die Hüften trugen, um sich gegen den Druck und das Aufreiben durch den weitherabreichenden Brustharnisch sicher zu stellen, heisst im Homer ebenfalls pítrpa'). Als Kopfbedeckung bestand die Mitra der Perser, Araber, und Kleinasiaten, aus einer langen und breiten Binde, welche den ganzen Kopf, von der Stirn bis zum Genick, die Backen, und das Kinn bedeckte, unter welchem sie weggeführt wurde ${ }^{2}$ ). Die Mitra der griechischen Frauen, war eine buntscheckige Schärpe (versicolor, Plinius), welche um den Kopf gewickelt, und unter dem Kinn festgebunden wurde. In Rom beschränkte sich ihr Gebrauch gewöhnlich auf die liederlichen Dirnen, welche durch die bunten Mitrae, die Aufmerksamkeit der Männer auf sich zu locken wussten, wie zahlreiche Stellen im Ovid, Juvenal und Properz ersichtlich machen. Als ein starkes Tau, welches mitten um den Rumpf eines Schiffes gebunden wurde, um seine Flanken widerstandsfähiger gegen Stürme zu machen, erwähnt Isidorus ${ }^{3}$ ) die Mitra, und Tertullian sagt:

\section{"- - - spiras mandare morantes, "Oblaqueare mitram, clavorum stringere nisus."}

(Carmen de Jona et Ninive, 42.)

Als conische, mit der Spitze nach vorne umgebogene, und unter dem Kinn mit einem Bande befestigte Mütze, war die Mitra in der alten Welt eine fast allgemein gebrauchte Kopf bekleidung.

1) Ilias, IV, Vers 137.

2) Claudianus, Laudes Stiliconis, I, 156.

3) Origines, $X I X, 4$. 
Die phrygische Mütze der französischen Revolution, welche ich noch in unserer Zeit, hie und da von den Mädchen in Nimes und Arles getragen sah, wo sie diesen hübschen griechischen Gesichtern sehr gut steht, ist eine Mitra.

Mit allen diesen Arten von Mitrae, hat die zweizipfelige Klappe des Herzens keine Formähnlichkeit, wohl aber mit der bekannten Bischofsmütze in unseren Tagen, welche der alten Kopfbedeckung der Hohenpriester der Hebräer nachgebildet ist, und nach oben in eine vordere und hintere Spitze ausläuft.

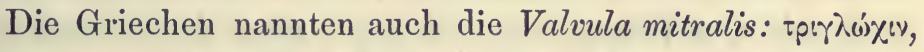
obgleich, wie schon Vesal bemerkt, sehr unrichtig, da die Spitzen der beiden Klappen, nicht scharf sind, wie Pfeilspitzen, sondern abgerundet. Die deutsche Benennung: mützen förmig e Klappen (Meckel), muss weggeworfen werden, da es sich nicht um eine Mütze überhaupt, sondern gerade um eine Bischofsmütze handelt. Sömmerring hat durch seine zweizipfelige Klappe das Rechte getroffen. Ihm ging Haller mit der Valvula bicuspidalis voraus.

Einen trotz seiner Unechtheit, doch gefälligen und annehmbaren Ausdruck für die zwei Klappenzipfe der linken Kammer, habe ich im A. Benedictus ausgekundschaftet. Er lautet: Bivalvium 1), wie für die drei Klappenzipfe der rechten Kammer: Trivalvium. Als neue Worte, können sich Bivalvium und Trivalvium, auf das classische Bivium und Trivium berufen.

\section{Modiolus und Columella cochleae.}

Modiolus ist das Diminutiv von Modius, ein römisches Getreidemaass $=16$ Sextarii, unser Scheffel, und drückt also ein kleines Maass aus. Es hält nicht schwer, unter den verschiedenartigen Nebenbedeutungen, welche dem Worte Modiolus zufallen, jene herauszufinden, welche es herbeiführte, dass die Spindel der Schnecke, Modiolus genannt wurde. Es

1) Anatomice, Lib. III, Cap. 14 und 16. 
bieten sich deren sogar zwei dar; beide mit Rücksicht auf die hohle Cylinderform des Modiolus. Die erste ist' der Modiolus des Celsus ${ }^{1}$ ), das cylindrische, hohle und gezahnte Eisen des Trepans, welches die Griechen \%oty'xny nannten. Die zweite ist die Nabe am Rade, ein hohler Holzcylinder, in welchem die Axe steckt, und in dessen äusseren Umfang, die Speichen des Rades eingesetzt sind. Beide Gegenstände lassen einen Vergleich mit der Axe der Schnecke zu, an deren äusserer Oberfläche die Lamina spiralis haftet. Diese Axe ist zwar nicht hohl, wie der Trepan und die Nabe, aber sie ist doch porös, wie spanisches Rohr, indem sie in sich eine Menge sehr feiner, und, genau in ihrer Mitte, einen weiteren Kanal enthält, durch welche Kanäle die Filamente des Gehörnerven, zur Lamina spiralis gelangen, auf welcher sie endigen. - Eustachius war der Erste, welcher die knöcherne Axe der Schnecke, Modiolus nannte ${ }^{2}$ ). Es war nicht nöthig, die übrigen, sehr verständlichen Namen dieser Axe: als Columella, Pyramis, Conus und Nucleus (Heister), durch einen neuen zu verdrängen, welcher erst erklärt werden muss. Von den alten Namen rettete man noch die Columella, insofern man nur den dicken Basaltheil der Schneckenspindel Modiolus, den dünneren aber Columella nennt. Die deutschen Benennungen des Modiolus, als Säulchen, Walze, Pyramide, Axe, und Kern, werden immer seltener, während die Blumenbach'sche Spindel aushält, obwohl sie unter diesen Benennungen die unpassendste genannt zu werden verdient, da sie nicht an beiden Enden, zugespitzt ist.

\section{Morsus diaboli und Morsus Adami.}

Mehrere Pflanzen führen bei den alten Botanikern, den Namen Morsus. Wir lesen 1. von einem Morsus ranae, Frosch-

1) De medicina, Lib. VIII, Cap. 3.

2) De organo auditus, edit. 1561, pag. 160. 
biss und Krötenbiss, eine Species der Gattung Nymphaea, quae sic appellatur, quod ranae ejus morsu gaudeant (Lex. med. Steph. Blancardi), 2. von einem Morsus gallinae, Hühnerbiss, Alsine media Linn., einem guten Futter für Hühner und Hausvögel, und 3. von einem Morsus diaboli, Teufelsabbiss, devils-bit, = Scabiosa succisa Linn., welche einst als ein unfehlbares Heilmittel bei allen äusseren Schäden gepriesen wurde, und, wunderbarer Weise, selbst verlorene Glieder wieder nachwachsen machte (L. A. Kraus, Med. Lex.). Sie hat einen einfachen Wurzelstamm, welcher sich plötzlich in kleinere Würzelchen zerfasert, was die Botaniker Radix succisa und praemorsa nennen, weil sie wie abgenagt aussieht. Auf diesem Ansehen der Wurzel, basirt der Ausdruck Morsus diaboli. Die abergläubischen Kräutersammler gaben der Wurzel diesen Namen, weil sie glaubten, der Teufel nage sie an, um sie zu verderben, damit sie den Menschen nicht mehr als vielgebrauchtes Heilmittel dienen könne: cacodaemon, tantae efficaciae radicem, hominibus invidens, statim ubi succreverat, eam undique circumrodit (Kühn). Von Bauhin bis Haller, waren alle Professoren der Anatomie, in Deutschland, Holland,' und Frankreich, zugleich Professoren der Botanik, und lasen über erstere im Winter, über letztere im Sommer. Sie mussten also mit den Volksnamen der Pflanzen bekannt geworden sein, und konnten somit auch Veranlassung finden, botanische Namen in die Anatomie zu verpflanzen, und umgekehrt. Die Fimbriae s. Laciniae der Tuba Fallopiae (morceau frangé des Ch. Etienne), wurden, ihrer Aehnlichkeit mit den Wurzeln des Morsus diaboli wegen, ebenso genannt, und der populäre Ausdruck machte sich bald so beliebt, dass ihn selbst Haller annahm. Kein anatomisches Handbuch hat, bis auf den heutigen Tag, den gottlosen Namen verschwiegen.

Ein zweiter Morsus, lässt sich nicht so leicht erklären. Es ist der von Vesal, unter den Synonymen des Zungenbeins, aufgezählte Morsus Adami. In keinem vor-Vesal'schen Autor, habe ich diese Benennung des Zungenbeins aufstöbern können. 
Sie scheint dem Vesal privatim anzugehören. Kein späterer Schriftsteller wendet sie an. Einen Gedanken aus ihr herauszuklügeln, vermag ich nicht.

\section{Motorius und Sensitivus.}

Die besten Zeugenschaften legitimiren Motorius, zwar nicht als "Bewegung erregend", wie in unseren Nervis motoriis, aber doch als "voll Bewegung und Handlung", d. i. "lebhaft". Comoedia motoria (quae affectibus abundat, et tumultuose agitur), hiess das den Römern sehr gefallende Intriguenstück. Dass ein Adjectiv auf orius, auch eine Verwendung ausdrücken kann, sehen wir an Nervus visorius, gustatorius, olfactorius und auditorius. Ergo transeat motorius, obgleich "Bewegungsnerv" besser mit Nervus motor übersetzt würde. Motor ist $=$ motum ciens, motum excitans (For cell.), wic, unter anderen, im Martial (XI, 39):

„Cunarum fueras motor, Charideme, mearum."

Nicht so sensitivus.

Sensitivus, sensibilis, und „Sensibilität", gehören in denselben Kram. Sie sind sprachliche Neoplasmen, deren Verständlichkeit uns mit ihrer sonstigen schlechten Beschaffenheit ausgesöhnt hat. "Empfindung erregend" heisst im guten Latein sensificus (quia sensum facit ${ }^{1}$ ), auch sensiferus (quia sensum adfert ${ }^{2}$ ). Sensitivus war anfänglich dem Schullatein der Philosophen eigen : anima sensitiva, appetitus sensitivus. Durch Reil kam es in die Physiologie, als Atmosphaera sensitiva nervomum ${ }^{3}$,,

1) Macrobius, Saturnalia, Lib. VII, Cap. 9: nervi, spiramentum sensificum, ad sua loca deducunt.

2) Lucretius, De natura rerum, Lib. II, Vers 240 und 272.

3) C. Berend, De atmosphaera nervorum sensitiva, Gedani (Danzig), 1816. 
jenes ätherische Unding, welches die Nerven umgiebt, und ebenso empfindlich sein soll, wie sie selbst. Durch den Bellschen Lehrsatz erhielten die Nervi sensitivi und motorii, ihre eigentliche anatomische Weihe, und werden unter solchem Schutz und Beistand, so lange bei uns verbleiben, als wir für Empfindungs- und Bewegungsnerven lateinische Ausdrücke brauchen. - Galen unterschied schon motorische und sensitive

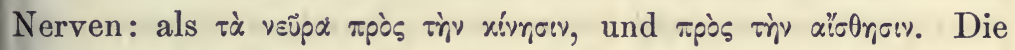

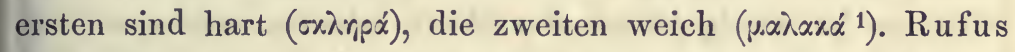
Ephesius nennt nur die Empfindungsnerven veüpa, und zwar

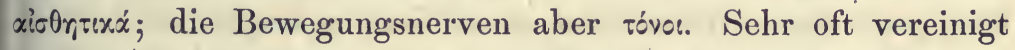
er beides, Bewegung und Empfindung, als eine allgemeine Eigenschaft der Nerven, was auch im Galen und Oribasius vorkommt.

\section{Musculus und Lacertus.}

Von dem vielsinnigen Worte Lacertus, vegetirt in der Anatomie noch der Lacertus fibrosus der Bicepssehne, ein aus der Endsehne des Biceps brachii, in die Vagina antibrachii übergehendes Verstärkungsbündel. Lacertus in diesem Sinne, hält eine etymologische Probe nicht aus.

Die Lexica definiren Lacertus, als pars brachii musculosa, quae est ab humero ad cubitum. Dichter gebrauchen Lacertus für den ganzen Arm, z. B. cupidis lacertis fovere aliquem, im Propertius, und laevo dependet palma lacerto, im Virgil (das Schild hängt am linken Arme). In den Redensarten : lacertos circum colla implicare, und lacertis colla innectere (umarmen), erscheint Lacertus gleichfalls als ganzer Arm. Die fleischige Beschaffenheit des Oberarms, scheint die Ursache gewesen zu sein, dass Lacertus auch für Muskel überhaupt gebraucht wurde, woran besonders die Anatomen des Mittelalters Gefallen

1) De administrationibus anatomicis, Lib. VII, Cap. 8. 
fanden. Gorraeus sagt ganz entschieden: p.is lacertus est, wic

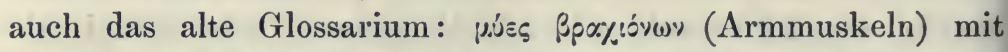
lacerti ausdrückt. Exercitatio lacertos exprimit, die Uebung entwickelt die Muskeln, lesen wir im Varro. Bis lange nach Bartholin, finden wir in den anatomischen Schriften Lacertus, als Vicarius musculi. Man schuf sich deshalb auch in der Medicin das Beiwort lacertosus, für musculös, wofür auch torosus gilt (collum torosum und cervix torosa, fleischiger Nacken, im Ovid ${ }^{1}$ ). Es wurde jedoch das Wort Lacertus, nicht auf alle Muskeln angewendet, sondern nur auf die langen und pfriemenförmigen, deren Gestalt mit einer Lacerta verglichen werden kann. Eine Fischart, welche einen zwar spindelförmigen, aber zugleich in der Mitte dicken und fleischigen Leib hat, wurde ebenfalls Lacertus genannt ${ }^{2}$ ), und verzeihlicher Weise Pisciculus für Lacertus, wie dieses für Musculus, gesetzt. Namentlich verblieb der Name Pisciculus, dem Biceps brachii länger als den anderen Muskeln ähnlicher Form (Semimembranosus, Semitendinosus, Gracilis), und im Italienischen cursirt jetzt noch il pescetto für Biceps. Das uralte $\left.\mu_{\text {ü }}^{3}{ }^{3}\right)$ - musculus - überlebte aber den Lacertus, und wurde auch der deutschen Sprache einverleibt, als Maus, Mäuslein und Muskul, bis es

1) Torus hiess alles Bauschige und Wulstige, daher auch die Matratze eines Bettes oder Sopha's, weil sie durch das Absteppen eine bauschige Oberfläche erhält. Sopha, ist wie Matratze, ein arabisches Wort. Soffah nannten die Araber eine Ruhebank vor dem Hause, und Al-mattrah, ein Polster, woher zunächst das spanische Almadraque, ein Kissen, stammt, und auch das portugiesische madraço, ein Faullenzer.

2) Dahin gehörten vorzugsweise Colias, Saurus, und Scomber, nach Aldrovandus, de piscibus, Lib. II, Cap. 53.

3) Ganz sicher von pisg, als Maus, quia musculum refert excoriatum, wie Spigelius sagt, nicht von úsetv, zusammenziehen, weil von diesem Zeitwort nur das Hauptwort $\mu \omega^{\prime} \omega \nu$, nicht

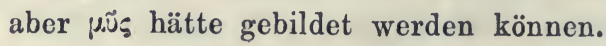


endlich durch J.A. Schaarschmidt ${ }^{1}$ ), zum modernen Muskel wurde, von welchem es kein Abkommen mehr haben wird.

Wenn jetzt noch hie und da von Lacerti gesprochen wird, so versteht man darunter entweder, nach Hildebrandt, Muskelbündel überhaupt (Fasciculi), oder nach Heister, speciell jene an der inneren Oberfläche der Herzkammern, welche gewöhnlich Trabeculae carneae, Fleischbälkchen, geheissen werden.

Nach dieser Auseinandersetzung, kann Lacertus nur etwas Fleischiges sein, nicht aber ein Verstärkungsbündel einer Gelenkskapsel oder einer fibrösen Membran, wie der Lacertus medius Weitbrechti in der Membrana obturatoria atlanto-occipitalis, und der Lacertus fibrosus der Sehne des Biceps. Hier muss unbedingt für Lacertus, Fasciculus eintreten, als Diminutiv von Fascis, ein Bündel.

\section{Musculorum denominationes insolitae.}

Keine Wissenschaft hat ein so buntes Repertorium seltsamer Benennungen, wie die Anatomie. Sie verschmäht es nicht, ihrem ernsten Handwerk, zuweilen einen heiteren Anstrich zu geben. Sie lässt sich von ihrem Humor und Witz, von ihrer Bosheit und Unanständigkeit, allerhand Namen einflüstern, welche durch ihre Sonderbarkeit auffallen, und von welchen einige, weil sie zu lachen geben, nicht ungern angebracht werden. Allerdings hat die Würde der Wissenschaft, sie nicht mit liebenden Armen aufgenommen, und für jeden derselben, einen ernsten Stellvertreter aufgestellt. Allein sie lässt sich dieselben dennoch als Nebensache gefallen, und vergisst selten auf sie, wenn sie Musterung abhält über Synonyme. Deshalb wollen auch wir diesen Curiositäten, insofern sie Muskelnamen betreffen, ein Plätzchen gönnen. Wem die Sache waschhaft vorkommt, der überschlage diese Paar Seiten.

1) Myologische Tabellen, Berlin, 1747.

Hyrtl. Onomatologia anatomica. 


\section{Musculi alopeces.}

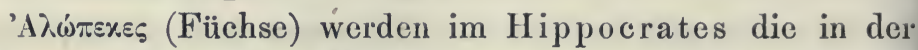
Lendengegend lagernden Rückenmuskeln genannt. Dieser Ausdruck lehrt uns das Hippocratische Wort grypalopex (lenden-

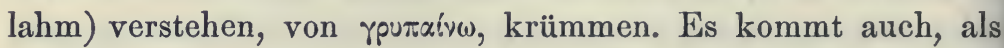
Spottname, im Aristophanes vor. - Galen nennt die Lendenmuskeln (Psoae) $\left.2 \lambda \omega ́ \pi \varepsilon \varsigma_{\varsigma}{ }^{1}\right)$. Das kritisch-etymologische Lexicon von Kraus erklärt sich diese sonderbare Benennung daraus, "dass die Füchse besonders lange Lendenmuskeln haben". Alle Marderarten haben aber längere Lendenmuskeln als die Füchse. Dass diese Muskeln „einem lange gezogenen Fuchsbalg“" gleichen, wie es ebendort heisst, ist mir, und hoffentlich auch Anderen, ganz unverständlich. Julius Pollux ${ }^{2}$ ) und A thenaeus, führen die Lendenmuskeln ebenfalls als $\dot{\lambda} \boldsymbol{\omega} \pi \varepsilon x \varepsilon \varsigma$ auf. Von diesen kamen sie in den Text des Vesal ${ }^{3}$ ) und Fallopia ${ }^{4}$ ), fanden aber dort ihr Ende, und sind heute gänzlich verschollen.

2. Musculus amatorius und Musculus indignabundus s. iracundiae.

So nennt Isenflamm den Rectus oculi externus ${ }^{5}$ ), denn der verstohlene Seitenblick gilt einem geliebten Wesen. In Peuschel's Physiognomischen Abhandlungen, pag. 192, wird er als Liebesmuskel erwähnt. - Andreas Laurentius belegt nicht den Rectus oculi externus, sondern die beiden schiefen Augenmuskeln zusammen mit dem Namen Amatorii ${ }^{6}$ ), weil sie, als Rotatores bulbi, nach Spigelius als Circumagentes s. Volventes bulbi ${ }^{7}$ ), den Verliebten behülflich sind, ihre Augen zu

1) De musculorum dissectione, C'ap. 25.

2) Onomasticon, Lib. II, Cap. 4, Num. 185.

3) De corp. hum. fabrica, Lib. II, Cap. 38.

4) Observationes anatomicae, T. I, pag. 390 .

5) Oratio de denominatione partium corp. hum. ex animi pathematibus, Erlanyae, 1795.

6) Casserii Pentaestheseion, Lib. V, Cap. 18.

7) Opifices circumductionis im Vesal. 
verdrehen. - Durch Abwenden der Augen wird aber auch Unwille und zornige Verachtung ausgedrückt. Der Rectus ex $x$ ternus wurde deshalb von Riolan Musculus indignabundus, und von Molinetti Musculus iracundiae genannt ${ }^{1}$ ).

3. Aniscalptor und Anitersor.

Ueber diese unfläthige Benennung des Latissimus dorsi, sieh' den Artikel: Aniscalptor.

\section{Musculus attentionis.}

Das Aufrichten der Ohren (Ohrenspitzen) ist bei vielen Säugethieren ein Zeichen der Aufmerksamkeit. Ferd. Leber nannte deshalb den Heber des äusseren Ohrs (Attollens auriculam, Spigelius), wohl nur scherzweise, den Musculus attentionis ${ }^{2}$ ). Dieser Chirurg, Anatom und Folterarzt, unter Kaiserin Maria Theresia, hatte viel Wiener Humor, von welchem wir in diesem Capitel Einiges zu hören bekommen.

\section{Musculus bibitorius und Musculus laetitiae.}

Es ist eine Gewohnheit jedes Trinkenden, beim Leeren des Glases, die Augen auf dasselbe zu richten, welche Bewegung durch beide Recti interni vollzogen wird. Casserius bemerkt deshalb von diesen Muskeln, dass sie „a barbaris, Musculi bibitorii" genannt werden. Wer diese Barbaren sind, sagt er nicht. Man kann nur vermuthen, dass er die Deutschen darunter meinte, welche, so oft sie mit den Römerzügen nach Italien kamen, wie einst die Gallier, durch ihre Leistungen im Essen und Trinken, unter den nüchternen Italienern solches Aufsehen erregten, dass jetzt noch, aus jener Zeit, ein bezügliches Sprichwort in Italien cursirt. Eine Gesellschaft von Italienern, welche nach ihrer Art weidlich tafelte, sagt von sich : abbiamo mangiato e bevuto come due Tedeschi! Auch etwas

1) Diss. anat. path., Cap. 4.

2) Praelect. anat., Vindob. 1778. Mit Randnoten von M. C. Guld en er. 
für den Nationalruhm. Da das Trinken heiter stimmt, nennt Isenflamm den Musculus bibitorius, auch Musculus laetitiae ${ }^{1}$ ).

\section{Buccinator.}

G. Cowper gab dem Muskel, welcher die fleischige Grundlage der Backe, bucca, bildet, den Namen Buccinator ${ }^{2}$ ), welcher in den deutschen Anatomien des vorigen Jahrhunderts, als Trompetermäuslein, und Posaunenbläser zu finden ist. Bucina (buccina) war bei den Römern ein dem Waldhorn ähnliches Instrument, mit welchem bei den Heeren die Hauptsignale gegeben wurden. Das Wort kommt von Bucca, Backe, welche der Bläser dieses Instrumentes, auf Bildern wenigstens, voll nimmt. Buccinator kürzte Riolan zu Bucco ab, was er wohl nicht geflissentlich gethan hat, da Bucco in der römischen Comödie, die stehende Figur des Tölpels war, welcher die aufgeblasenen Backen hinhält, um, zur Erheiterung des Publikums, eine schallende Ohrfeige (salpicta) auf dieselbe zu erhalten (Arnobius). In allen Anatomien der Welt, hat sich der Buccinator festgesetzt, obgleich er den Namen nicht verdient, da ein guter Horn- oder Trompetenbläser, selbst der Bombartonist in einer Militärbande, die Backen niemals aufbläht, was nur die 'Tritonen an Springbrunnen, und die Posaunen-Engel auf Kirchengemälden thun, sondern im Gegentheile hohl macht, damit von der ausgestossenen Luft, nichts zum Schwellen der Backe vergeudet, sondern alles in das Blasinstrument eingetrieben werde. Der Name Alveolo-labialis würde unbedingt den Vorzug verdienen. Denn der Mola-molaris von Schreger macht glauben, dass der Muskel von Kiefer zu Kiefer geht.

\section{Musculus calanticae.}

Musculus calanticae ist eine veraltete Benennung des Platysma myoides. Im 16. Jahrhundert kommt sie öfters vor, -

1) Oratio supra citata.

2) Myotomia reformata, Cap. 10. 
nach Salomon Albertus nicht mehr. Calantica war eine Mütze, mit welcher die Isispriester ihre kahlgeschorenen Köpfe bedeckten. Von dieser Mütze hingen zwei lange Flügel oder Lappen über den Hals, bis auf die Brust herab, an welche der Erfinder der Musculus calanticae gedacht haben muss. Die Calantica wurde von den römischen Frauen angenommen, welche es bequem fanden, die Lappen der Mütze vor das Gesicht zu halten, wenn sie auf der Strasse unerkannt bleiben wollten. Das Platysma hält ganz gut den Vergleich mit diesen Flügeln aus; der Name Musculus calanticae konnte sich aber dennoch gegen das altangestammte Platysma nicht behaupten, und ging unter.

\section{Musculus caninus.}

Die Grube an der Gesichtsfläche des Oberkiefers, heisst Fossa canina, des nahen Hundszahnes wegen. Wir könnten eine Fossa dentis canini zulassen, aber eine hündische Grube nicht, ebensowenig als einen hündischen Muskel, Musculus caninus. So hiess, nach Santorini ${ }^{1}$ ), der Aufheber des Mundwinkels, welcher aus der Fossa dentis canini entspringt, bevor er von Albin, den nicht mehr geänderten Namen: Levator anguli oris erhielt.

\section{Musculus cannelatus.}

Die breite und flache Sehne des Obturator internus, besitzt dort, wo sie die Incisura ischiadica minor passirt, drei bis vier longitudinale Einschnitte, in welche ebensoviel. erhabene Leistchen des Knorpelbeleges jener Incisur eingreifen. Diese Einrichtung hat die seitliche Verschiebung der Sehne zu beschränken. Das gefurchte Ansehen, welches die Sehne durch diese Einschnitte erhält, verglich Lieutaud, mit der Cannelirung einer Dorischen Säule, und nannte den Muskel sofort Le cannelé, wogegen zu erinnern, dass nicht der Muskel,

1) Observationes anat., Cap. 1, §. 24 und 36 . 
sondern seine Sehne cannelirt ist, weshalb die verfehlte $\mathrm{Bc}$ nennung auch nicht Stand hielt.

\section{Musculus catenae und Musculus hippicus.}

Der Tibialis anticus des Riolan, erhielt von Adrianus Spigelius den Namen Musculus catenae ${ }^{1}$ ). Die Motivirung dieses sonderbaren Namens, bringt der Nachsatz: a me ita vocatus, quod dissecto per transversum ejus tendine," aut amputato, catenam aegri, cujus beneficio ambulantes pedem flectant eleventque, portare coguntur. Dieser Grund lässt sich hören.

Ueber die Benennung des Tibialis anticus als hippicus (Meckel ${ }^{2}$ ), vermag ich keine Aufklärung zu geben. Ich habe diesen Ausdruck bei keinem andern Anatomen gefunden. Es wird nicht $\mathrm{zu}$ viel gewagt, wenn ich denke, dass der Erfinder des Musculus hippicus, eigentlich Reitermuskel sagen wollte, da der Tibialis anticus den Fuss adducirt, und seinen inneren Rand etwas hebt, wie der Reiter, nach der steifen, altspanischen Schule, den Fuss im Bügel stehen hat. Es kommen in der anatomischen Sprache ärgere Dinge vor, als dass das Ross (i $\pi \pi \circ$ ), mit dem Reiter verwechselt wurde.

\section{Musculus consiliarius.}

Der Rathsherrenmuskel, Musculus consiliarius, vertritt den langen Sterno-cleido-mastoideus, als Kopfnicker. Er ist ein Kind der anatomischen Laune des alten Jenenser Professors Guernerus Rolfink. Ferdinand Leber in Wien, welcher immer mit den Magistratsräthen, der Aufhebung der Folter wegen, in Hader lag, machte sich in seinen lateinischen Vorlesungen für Mediciner, durch Wiederholung dieses Muskelnamens, auch auf Kosten dieser Rathsherren lustig. In seinen deutschen Vorlesungen für die „Bader“, verstärkte er die

1) De corp. hum. fabrica, Lib. IV, Cap. 24.

2) Handbuch der Anatomie, II. Bd., §. 1257. 
Jaherren, durch das Epitheton „arschquetschend", in Hinsicht auf die lange Dauer ihrer Sitzungen ${ }^{1}$ ).

\section{Corrugator superciliomum.}

Der Corrugator superciliorum wurde zuerst von Volcherus Koyter beschrieben ${ }^{2}$ ), und heisst deshalb hie und da auch Musculus Coiteri. Den Namen Corrugator supercilii erhielt er von Guil. Cowperus ${ }^{3}$ ), und trägt ihn seither, uti lucus, a non lucendo. Denn er runzelt nicht die Augenbrauen, sondern nähert sie einander, wodurch die Haut der'Glabella, sich in senkrechte Falten zu legen gezwungen wird. Er muss also Corrugator glabellae genannt werden.

\section{Custos virginitatis.}

Die älteren Anatomen betrachteten die drei Adductores femoris als Einen Muskel, und nannten diesen nach Bartholin: Triceps femoris (der Triceps cruralis v. Sabatier). Da er die Schenkel gegen einander presst, wie beim Schluss des Reiters, macht er auch die weibliche Schamspalte unzugänglich, und wurde von Hildebrandt deshalb Custos virginitatis genannt ${ }^{4}$ ).

\section{Cingulum Halleri.}

Albin und Haller fassten zuerst die Gesammtwirkung der breiten Bauchmuskeln in's Auge, welche in einer Zusammenschnürung des Unterleibes besteht. Die breiten Bauchmuskeln beider Seiten zusammen, wurden deshalb Cingulum vastissimum abdominis genannt: quod viscera abdominis continet, eorum elapsui resistit, retrorsumque en reprimat ${ }^{5}$ ).

1) Notae scriptìe ad praelect. anat. Leberi, per C. M. Guldener.

2) Observationes anat. et chir. perutiles. Norimb., 1573, pag. 109.

3) Myotomia reformata, Cap. 6 .

4) Lehrbuch der Anatomie, II. Bd., \$. 1264.

5) Elementa physiol., T. II, Lib. 8, Sect. 1, §. 30. 
15. Musculus deltois.

Der Riolan'sche Deltoides konnte sich diese Verkürzung gefallen lassen, weil sie die Griechen bei anderen Worten in oides, oft anwendeten, und wir in der Anatomie ein solennes Beispiel dafür in Allantois, statt Allantoides, besitzen, wozu noch die seltenen Stylois und Hyois, anstatt Styloides und Hyoides, zu rechnen sind. Sieh' den Artikel: Allantois.

\section{Musculus dormitator.}

Ein Leber'sches Synonym für den Sphincter der Augenlider, von dormitare, eben einschlafen, was den Zuhörernn seiner derbwitzigen Vorträge, nicht häufig passirt haben wird.

\section{Musculus ephebaeus.}

Fallopia hat den Pyramidalis abdominis, als selbstständigen Bauchmuskel zuerst erwähnt, mit der Bezeichunng: musculus quidam totus carnosus, weil er eine eigentliche Sehne, wie andere Muskeln, nicht besitzt. Seine Sehne ist die Linea alba: Sylvius nannte ihn Musculus Fallopiae, und da er in ihm eine Verstärkung des Rectus sah: Succenturiatus recti. Da der Pyramidalis auf dem unteren Ende des Rectus aufliegt, erklärt sich der Name im Arantius: Operculum carneum. Riolan gab ihm seinen bleibenden Namen: Pyramidalis. Er hatte eine ganz aparte Ansicht über seine Verwendung: hi musculi cornua ossis pubis molliter contegunt, ne in coitu, ex mutua partium istarum collisione et attritu, tendines rectorum laedantur ${ }^{1}$ ). Man hielt damals die Sehnen der Recti für höchst empfindlich, und fürchtete ihre Verletzungen, der consensuellen Folgen wegen (Nic. Massa). Riolan, welcher eine Vorliebe für griechische Muskelnamen hatte, und die meisten der jetzt noch üblichen erfand, hatte auch für den Pyramidalis, einen solchen in Ephebaeus bereit. "Hßr, ist Mannbarkeit, aber auch behaarte Scham, und Schambein. An der Schamfuge

1) Anthropographia, Lib. V, Cap. 33. 
entspringend, konnte der Pyramidalis allerdings auf Ephebaeus Anspruch machen, wenn nur das Wort ṡøripaıs, im Griechischen nicht einen ganz anderen Sinn hätte. Es heisst jugendlich, wie ย̈ฒrßßos Jüngling, weil ihm die Haare auf der Scham wachsen.

\section{Musculus fascialis.}

Ueber den Musculus fascialis, als Synonym des Sartorius, und über die unrichtige Uebertragung dieses Ausdruckes auf den Tensor fasciae latae, sieh' den Artikel: Fascia.

\section{Musculi fidicinales.}

Guilielmus Cowperus nannte die vier kleinen und wurmförmigen, in der Hohlhand von den Sehnen des tiefliegenden Fingerbeugers abtretenden, und in die Rückenaponeurose der Finger sich einpflanzenden Muskeln: Musculi fidicinales ${ }^{1}$ ). Der Name könnte nur den sämmtlichen Beugemuskeln der Finger conveniren, nicht aber diesen Filigranmuskeln, von welchen man weiss, dass sie nur das erste Fingerglied beugen, die zwei letzten aber strecken. Ihr alter Name: Musculi vermiculares (Cabrol), und ihr jetziger, von Albin herstammender: Musculi lumbricales, reicht vollkommen aus, diese Muskeln passend zu benennen. Nur mögen sie im Deutschen lieber Spulwurmmuskeln, als Spulmuskeln genannt werden, da eine Spule (caulis pennae), und ein Spulwurm, doch nicht ganz identische Dinge sind.

\section{Musculus humilis s. Musculus pauperum.}

Die Demuth und Unterwürfigkeit schlägt die Augen nieder. Deshalb nannte Casserius den Rectus oculi inferior (Depressor oculi im Spigelius), Musculus humilis ${ }^{2}$ ) - der Demuthsmuskel des Kulmus und Mayer. Leber spricht von ihm, als Musculus pauperum, weil kein armer Teufel "hoffärtig dreinschaut".

1) Myotomia reformata, Cap. 28.

2) Pentaestheseion, Lib. V, Cap. 18. 
21. Musculus immersus und cartophorus.

Der Musculus subscapularis, wurde, seiner zwischen Thorax und Schulterblatt eingesenkten, ganz versteckten Lage wegen, von Riolan ${ }^{1}$ ) auch Musculus immersus genannt - das eingesenkte Mäuslein im Kulmus. Riolan übersetzte nur den von Ambrosius Paraeus diesem Muskel gegebenen Namen: l'enfoncé und le plongé. Winslow brachte ihm den Namen le porte-feuille auf ${ }^{2}$ ), weil er es sein soll, durch dessen Wirkung etwas unter dem Arm getragen und gehalten wird. Das Latein des Uebersetzers lautet: cartophorus! und die deutschen Uebersetzungen haben sogar "Briefträger" und „Futteralträger".

22. Musculus incisorius oder incisivus.

Weder Incisorius, noch Incisivus, ist ein römisches Wort. Nur Incisor ist ein solches. Aber zugegeben, dass sie solche wären, könnten sie nur "einschneidend" bedeuten. Ein solcher Name passt schlecht auf den Aufheber der Oberlippe. Santorini könnte uns selbst keinen Grund angeben, warum er für einen Muskel, welcher in gar keiner Beziehung zu den Schneidezähnen steht, auch bei dem Act des Zerschneidens mit den Zähnen, gar nicht betheiligt ist, einen so widersinnigen Namen ausdachte. Albin fühlte das Unrichtige an der Sache, und verhalf dem Muskel zu seinem Recht, als Levator labii superioris.

23. Musculus lividus.

Sieh' hierüber den Artikel: Pectineus.

24. Musculus marsupialis s. bursalis.

Die Sehne des Obturator internus wird, gleich nach ihrem Hervortritt aus dem Becken, von dem Fleisch der beiden Gemelli so umhüllt, dass diese Muskeln einen förmlichen Beutel

1) Anthropographia, Lib. V, Cap. 24.

2) Exposition anat., T. II, §. 863 . 
um dieselbe bilden. Deshalb hiessen sie auch Marsupium carneum (Beutelmuskel im Meckel), und der Obturator internus, dessen Sehne im Beutel liegt: Musculus marsupialis s. bursalis ${ }^{1}$ ).

\section{Musculus mensalis.}

Da das Wort $\tau \rho \alpha \dot{\pi} \pi \zeta \alpha$, eine Syncope von $\tau \varepsilon \tau \rho \alpha \dot{\pi} \varepsilon \zeta \alpha$ ist $=$ Tisch mit vier Füssen, so wurde der Musculus trapezius, auch mensalis, Tischmuskel genannt (Schaarschmidt, Myologische Tabellen, Tab. 15). Sieh' den Artikel: Trapezius.

\section{Nephrometrae und Neurometrae.}

Obsolete, nur im Vesal und Fallopia noch enthaltene Benennungen der beiden Psoasmuskeln. Die im Rufus Ephesius vorliegenden Ausdrücke sind veupoprńropes und veupopiritpa. Sollte das Lenden-Nervengeflecht, dessen Zweige den Psoas durchsetzen, oder die Lage der Niere auf dem Psoas, die Ursache sein, dass der Muskel mit einem so auffälligen, verdientermassen nicht mehr gebräuchlichen Namen belegt wurde? Spigelius macht von Neurometra einen anderen, sehr verständlichen Gebrauch. Er nennt die fibröse Kapsel der Niere so: quod in ea, velut in matrice, renes continentur $\left.{ }^{2}\right)$.

\section{Musculus nauticus.}

Eine Spigelische Benennung des Tibialis posticus: hic a me nauticus vocari solet, quod eo nautae potissimum utuntur, dum malum scandunt ${ }^{3}$ ). Der Muskel adducirt den Fuss, so dass der Matrose, mit beiden Füssen den zu erklimmenden Mast fassen, und sich an demselben weiter und weiter hinaufheben kann. Beim Schwimmen, wird dieser Muskel nicht mehr als andere Fussmuskeln, in Anspruch genommen. Es war deshalb

1) Cowper, Myotomia reformata, Cap. 32 .

2) Op. cit., Lib. VIII, Cap. 13.

3) Op. cit., Iib. IV, Cap. 24. 
ein Fehler, nauticus mit Schwimmmuskel zu übersetzen (Meckel). Schiffer- oder Matrosenmuskel, hätte gesagt werden sollen.

\section{Opisthothenar.}

Ein Sömmerring'scher Name für den gemeinschaftlichen Ursprungsbauch des Sacrolumbalis und Longissimus dorsi ${ }^{1}$ ). Das Wort ist neu. Im Hippocrates begegne ich einen Opisthenar, als Rücken der Hand, zum Gegensatz von Thenar, hohle Hand. "O merring hat, in Hinblick auf Thenar, als fleischiger Ballen der Hand, den genannten Muskelbauch, als Opisthothenar, d. i. hinterer Fleischbauch, bezeichnen zu sollen geglaubt. Da die Medicin bereits eine Opisthocyphosis und einen Opisthotonus besitzt, kann sie auch einen Opisthothenar annehmen, nur darf dieser nicht Opistothenar geschrieben werden, wie es oft geschieht. Chaussier hat auch eine Arteria opistogastrica aufgetischt, welche jedoch der alten Coeliaca keine Concurrenz gemacht hat.

29. Musculus osculatorius.

Ein Leber'scher Scherzname für Sphincter oris.

30. Musculus patheticus.

- Sieh' über diese Benennung des Obliquus oculi superior', den Artikel: Patheticus.

\section{Musculus patientiae.}

Er ist ein Kind der Laune des sich in witzigen Muskelnamen öfter gefallenden Adrianus Spigelius²), welcher jedoch auch den practischen Levator scapulae daneben setzte. Der deutsche Uebersetzer machte sein geduldiges Mäuslein

1) Muskellehre, §. 193.

2) Op. cit., Liz. IV, Cap. 13. 
daraus, und Browne gar seinen Levator patientiae - den Geduldaufheber!

32. Musculus prodigus s. Musculus mendicantium, u. Reserator.

Leber bediente sich bald des einen, bald des anderen dieser Namen, für den Supinator longus, welcher, weil er die Hohlhand nach oben kehrt, wie beim Almosenempfangen, oder weil er die Handbewegung des Geldausgebens, und des Schlüsselumdrehens vollzieht, alle drei Benennungen behalten mag.

33. Musculus religiosus und superbus.

Andacht erhebt die Augen zum Himmel. Deshalb nennt Leber den oberen geraden Muskel des Auges: Musculus religiosus, auch Admirator. Casserius dagegen bemerkt im Pentaestheseion, Lib. V, Sect. 1, Cap. 18: hic musculus a physiognomicis superbus dicitur. Spigelius gebraucht elatus - das hoffärtige Mäuslein des Kulmus.

34. Risorius Santorini.

Ueber diesen lächerlichen Muskel, sieh': Risorius.

35. Sartorius.

Die irrige Vorstellung, dass dieser lange und dünne Muskel, die schwere Last des einen Fusses über den anderen lege, wie die Schneider bei der Arbeit zu thun pflegen, verleitete Spigelius, demselben den allgemein und ausschliesslich gebrauchten Namen Sartorius, Schneidermuskel, beizulegen. Sieh' Note zum Artikel: Fascia. Riolan gab dagegen den Schustern die Ehre, mit seinem Sutorius ${ }^{1}$ ).

36. Scandularius.

Die Dächer alter Schlösser und Kirchen sind häufig mit Hohlziegeln (imbrices), statt mit flachen Ziegeln (tegulae)

1) Op. cit., Lib. V, Cap. 42. 
gedeckt. Die Hohlziegeln liegen in doppelter Schichte. In der unteren Schichte kehren sie ihre Concavität aufwärts, in der oberen Schichte nach abwärts, so dass sie ineinander greifen. Solche Dächer dauerten viel länger, als Flachziegeldächer, sind aber viel schwerer als diese, und erfordern einen sehr starken Dachstuhl, weshalb sie jetzt, wo das Holz theuer ist, nicht mehr construirt werden. Ein solches Hohlziegeldach musste Winslow vor Augen gehabt haben, als er den Musculus transversus plantae, Dachdecker, le couvreur, nannte ${ }^{1}$ ). Der Muskel macht den Plattfuss in seiner Längsrichtung hohl, durch Zusammendrängen seines äusseren und inneren Randes. Mit den so gehöhlten Füssen, soll sich der Ziegeldecker auf den convexen Hohlziegeln gleichsam anklammern. Die lateinische Uebersetzung des Winslow, gebraucht Scandularius für couvreur, wohl nicht ganz richtig, da Scandula nicht Hohlziegel, sondern Schindel ist, an deren planer Fläche sich ein gehöhlter Fuss nicht anklammern kann. Bleiben wir also beim Transversus pedis des Riolan, denn so stark ist der couvreur nicht, dass er die Hohlkelle des Fusses, je zum Greifen und Halten bringen könnte.

\section{Nares, Naris, Nasus.}

Nares, der Plural von Naris, heissen bei den Classikern die Nasenlöcher: fasciculum. (Blumenstrauss) ad nares admovere, Cicero. Der Singular naris, bezieht sich nur auf Ein Nasenloch :

$$
\text { „In cava nullus, stet tibi nare pilus." }
$$

(O vi d.)

Metaphorisch stehen nares für die äussere Nase: nares corrugare im Quinctilian, die Nase rümpfen, nares digitis emungere im Macrobius, sich in die Hand schneutzen, und homo obesae

1) Exposition anat., T. II, §. 555. 
naris im Horaz, dicknasig. Die Anatomie erweiterte den Begriff der nares, von den Nasenlöchern, zur $\mathrm{Nasenhöhle,}$ wie in Septum narium, Conchae narium, Membrana mucosa narium, u. m. a.

Nasus war immer nur die äussere Nase, das auffallendste und hervorragendste Gebilde im menschlichen Antlitz, daher: Promontorium faciei im J. M. Hofmann ${ }^{1}$ ), und Queen of the face, im Shakespeare. Die Alae nasi erscheinen, nach alter Mode, im Fallopia noch als fibrae narium, wo fibra = Lappen, wie im Celsus: fibrae pulmonum, Lungenlappen. Pinnae narium heissen die Nasenflügel im Bauhin. Pinna, eigentlich penna, ist Feder, aber metonymisch auch der ganze Flügel (pinnae praepetes aquilae, schnelle Flügel, im Cic ero), selbst die Flosse der Fische, wie im Plinius. Die Pterygia des Rufus ( $\pi \rho \varepsilon ́ p v \xi)$, sind ebenfalls Nasenflügel. Hypenae (Schreger) haben die Nasenflügel niemals geheissen. Schreger konnte sich in jedem griechischen Lexicon überzeugen, dass i $\pi r_{\text {rv }}$ nur Oberlippe, wohl auch Schnurrbart, bedeutet. Ich würde das Hippocratische

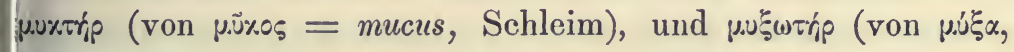
Rotz), nicht anführen, wenn nicht zwei Ableitungen davon in den neueren medicinischen Werken aufgetaucht wären, wie: Mycterophonia von Ploucquet, näselnde Stimme, und Mycteroxerosis (乡npós, trocken), Stockschnupfen, im Kraus.

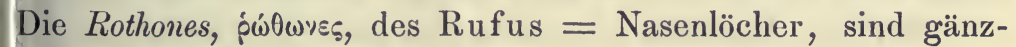
lich verschollen.

'Pís als Nase, und pives, als Nasenlöcher', weist die Ilias und Odyssee auf. Im Galen wird der Plural pivss, für Nase, Nasenlöcher, und Nasenhöhle gebraucht, - im Rufus $\dot{\eta}$ pís nur für die äussere Nase. Das Wort hat sich in dem selten vorkommenden Ausdruck: Ganglion rhinicum (für Ganglion spheno-palatinum), und in einer Schaar von Compositen erhalten, viele gute alte, und sehr viele schlechte neue. Man denke an die Rhinoptia von Bégin (als Schielen) im Dict. de méd.,

1) Sieh' den Artikel: Promontorium. 
an die Rhinantralgia, (Nasenhöhlenschmerz) im Kraus, und an Geoffroy St.-Hilaire's Rhinencephalus (Cyclopsbildung mit Rüssel), welcher nicht anders als mit "Hirn in der Nase", überrsetzt werden kann. Anticyram eant omnes!

\section{Nervus, Nervosus, und Neurula,}

Ueber den alten Hippocratischen Sinn von Nervus (ฯยบ̃poy), nicht blos als Nerv, sondern als alles Weisse und Faserige, wie Sehne, Flechse und Band, handeln die Artikel: Aponeurosis, Chorda, und Tendo. Im Sinne des Aristoteles, als Nerv, wäre es überflüssig, mehr als das Wort zu nennen. Interessant ist es, dass Galen selbst, im Beginn des Buches de motu musculorum, das Wort vєüpov, von vยúєเv, (nicken, nuere) herleitet, quia nervi membra nutare, et articulos flectere faciunt!

Nervosus wurde in der Anatomie des Mittelalters alles genannt, was wir jetzt als fibröses Gewebe und als Bindegewebe zusammenfassen. Selbst die Gewissheit, dass die Fasern dieser Gewebe, keine Nerven sind, konnte dieses Wort nicht aus der Anatomie vertreiben. Ja selbst in unserer Zeit, spukt noch hie und da das Centrum nervosum diaphragmatis, und ganz ungescheut auch die Tunica nervea der Eingeweide (Zellhaut).

Wie die Entwicklungsgeschichte sich ein Gastrula schuf, so auch eine Neurula (Rauber). Das Wort hört sich gut an, kann aber vor der grammatikalischen, und wie mir scheint, auch vor der sachlichen Kritik nicht bestehen. Rauber versteht unter Neurula ein Folgestadium der Gastrula, in welchem die definitive Anlage des Embryoleibes vollzogen wird. In ihm geschehen die Vorbereitungen zu dem später erfolgenden Auftreten des Nervensystems. Es ist also im Stadium der Neurula noch kein Nervensystem angelegt, wesshalb der Name Neurula, welcher doch offenbar von veũpoy abgeleitet wurde, mir nicht passend erscheint, abgesehen davon, dass man es nicht gerne sieht, wenn einem griechischen Worte, zwei lateinische 
zweier Wort-Monstrositäten: Neurilema und Neurhymen, von welchen die letztere, als absolut lebensunfähig, gleich nach der Geburt mit Tod abging, das erstere aber bis zum heutigen Tag am Leben blieb.

Das Gorgonenhaupt eines doppelten Barbarismus starrt uns aus Neurilema entgegen. Erstens verwandelt veũpov, wenn es mit einem zweiten Worte verbunden wird, sein $o$ niemals in $i$. Eine sehr grosse Anzahl solcher Composita, älteren und neueren Datums, bestätigen dieses in allen Wörterbüchern. Auch die Anatomie sagt nicht Neurilogia, Neurigraphia und Neuritomia, sondern Neurologia, Neurographia und Neurotomia. Neurilema könnte sich demnach, anständiger Weise, nur als Neurolema präsentiren. Zweitens ist $\lambda \eta_{\mu \alpha} \alpha$ durchaus nicht Scheide, sondern Wille, Gemüthsbewegung und Muth, und als solches nicht zu anatomischen Wortbildungen geeignet. Wollte man das Wort retten, durch Substitution von $\lambda \tilde{r} \mu \mu x$ für $\lambda \tilde{\eta} \mu \alpha$, in der Meinung, dass $\lambda \tilde{\eta} \mu \mu \alpha$, als von $\lambda \alpha \mu \beta \alpha \dot{\alpha} \nu \omega$, nehmen, abstammend, für ein Aufnahmsgebilde, für eine Scheide, passen dürfte, so protestirt der gute Geist der griechischen Sprache energisch dagegen, da $\lambda \tilde{n}_{\mu} \mu \alpha$, immer nur das Genommene, niemals das Aufnehmende bedeutet. Wir finden deshalb $\lambda \tilde{n} \mu \mu \alpha$ als Gewinn, Einnahme, und auch als Annahme, d. i. Vordersatz, aus welchem ein Nachsatz sich ergiebt. Man denke an das bekannte Dilemma. Geht es mit

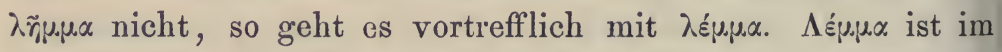
Theophilus Rinde, im Hippocrates Schale ( Gurkenschale), im Dioscorides Ueberzug (velamentum), und

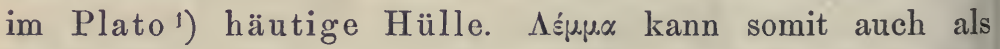
Scheide, in anatomische Dienste aufgenommen werden. Das Reil'sche Neurilema, muss somit, wenn es länger fortbestehen soll, Neurolemma geschrieben und gesprochen werden, sonst möge man lieber gleich bei der ordinären Nervenscheide (Vagina) verbleiben, was man auch ganz gewiss thun

1) Timaeus, LXXVI, a. 
würde, wenn sich Neurilema nicht so allgemein und ausschliessend, in die anatomische Sprache eingenistet hätte.

Neurolima lese ich in der Onomatologia anthropotomica von Fr. Cosmus Laurentius ${ }^{1}$ ), und Neurilyma im Kritisch-etymologischen Wörterbuch von Kraus. Für das zweite dieser beiden Worte, lässt sich ein etymologischer Gedanke finden, wenn man dasselbe, als aus neuron und dem Homerischen $\varepsilon^{\prime} \lambda \nu \mu \alpha$, Umhüllung, zusammengesetzt ansieht.

\section{Neuriorhabdia.}

Die Neuriorhabdia verschwanden ebenso schnell, als sie kamen. Sie thaten gut daran, denn ausser ihrem Erfinder ${ }^{2}$ ), hat Niemand für sie Partei genommen. Die Neuriorhabdia

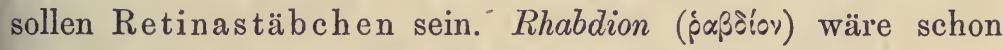
recht, als Stäbchen oder Rüthchen, von ṕáßjos, Ruthe und Stab. Neurion dagegen (to veupiov), war niemals Nerv, wie veüpov, sondern immer nur Darm- oder Metallsaite, und Sehne eines kleinen Bogens. Alle griechischen Lexica äussern sich übereinstimmend, über diese ausschliessliche Bedeutung. Warum also nicht Neurorhabdia (besser Neurorrhabdia) sagen, wie man Neurorrhaphia (veupop̀pạia) nicht für Nervennaht, sondern für "Schuhflicken" sagt.

Die lateinischen Ausdrücke für die Retinastäbchen : Bacilli und Coni, verdienen auch eine kleine Rüge. Denn Bacillus (Stäbchen) ist ein spätlateinisches Wort des Isidorus im 6. Jahrhundert ${ }^{3}$ ), während Bacillum, als Verkleinerungswort von Baculum, sich auf die Autorität des Cicero stützt: lituus (Krummstab der Auguren und Lictoren) incurvum, et leniter a summo inflexum bacillum est, und unser bester medicinischer

1) Romae, 1831, Prolusio, pag. 7.

2) Bidder, in Müller's Archiv, 1839, pag. 371, seqq.

3) Origin. Lib. $X X, \S .13$. 
Gewährsmann, Celsus, führt uns bacula, nicht baculi und bacilli, vor, wo er von der Einrichtung der Verrenkungen des Hüftgelenks spricht: habenas (Streckriemen) ad valida bacula (Stäbe) deligare ${ }^{1}$ ). Dass die Coni der Retina, keine Coni sind, weiss Jeder, der sie je unter dem Mikroskop gesehen hat. Sie sind Bacilla, aber mit einem grossen, eingelagerten Kern. Die deutsche Benennung: Zapfen, entspricht besser als Coni, lässt sich aber im Latein nicht anbringen, da die Römer nur Fasszapfen, Obturamenta, und Thürzapfen, Cardines masculi, kannten, für eine zapfenförmige Gestalt aber keinen charakterisirenden Ausdruck hatten.

\section{Nucha.}

Dieses von der Anatomie und Medicin adoptirte Fremdwort stammt aus dem Arabischen. Der Mönch Constantinus A fer, führte es in die anatomische Sprache ein, und sagt von ihm: vox arabica est. Alle lateinischen Lexica ignoriren es gänzlich. Das arabische Wort im Rases und Avicenna, lautet $n u c h \bar{a}^{c}$. Es drückt aber nicht den $\mathrm{Nacken}$, sondern das Rückenmark aus. Der Nacken, eigentlich die Nackengrube, heisst bei den arabischen Aerzten nuqrah. Die Aehnlichkeit von nucha und nuqrah, erklärt es uns, wie auch das Genick nucha genannt werden konnte, und jetzt noch genannt wird, im Ligamentum nuchae, in den Emplastris nuchalibus, und in der Luxatio nuchae ${ }^{2}$ ). Durch volle vier Jahrhunderte, von Constantinus bis Vesalius, wurde Nucha immer nur als Rückenmark gebraucht. Drei Beispiele dazu: medulla spinae, nucha dicitur (M. Hundt), - nucha, medulla spinae est (Mundinus), und nucha sicut cerebrum, velatur dura et pia matre (Berengarius). In Kaiser Friedrich II. Jagdbuch ${ }^{3}$ ) lese

1) De medicina, Lib. VIII, Cap. 21.

2) B. D. Mauchart, de luxatione nuchae (Kopf-Nackengelenk), Altdorf, 1747.

3) De arte venandi cum avibus, Lib. I, Cap. 36 . 
ich: Nucha dicitur medulla spinalis, a cerebro usque ad extremum caudae. Die Nucha als Rückenmark, hat schon lange ausgelebt; die arabische nuqrah (Nacken) dagegen, wurde von allen romanischen Sprachen und vom Neulatein aufgenommen, und lebt in ihnen fort als nuque, nucha und nuca. Das Mal de nuque beim Pferde, ist eine seröse oder eiterige Ansammlung in der Bursa atlantoidea. Sie wird durch das starke Ligamentum nuchae. in zwei Buchten getheilt. Beim Rinde heisst diese Krankheit écrouellet. Paracelsus ${ }^{1}$ ) spricht nur von der Medulla oblongata als Nucha, und sucht in ihr den Sitz der hinfallenden Sucht.

Das Rückenmark kam durch Alexander Benedictus, welcher die arabische nucha (wie alle anderen arabischen Worte) aus der Anatomie auszumerzen beflissen war, zu seinem ständigen Namen: Medulla spinalis. Macrobius (5. Jahrhundert) nannte es: Cerebrum longum, von welchem wir noch in vor-Vesal'scher Zeit häufig zu hören bekommen. Celsus hat Medulla in spina, und Vesal: Medulla dorsalis.

Die Micha des Cornelius Agrippa kann nur eine misshandelte Nucha sein. Der deutsche Nacken, welcher sich im englischen neck, im schwedischen nacke, und im ungarischen nyak wiederspiegelt, gehört nicht zu nucha, sondern zu dem Geschlecht der Worte nicken und neigen.

Ueber die arabische Nucha und Nuqrah, wie auch über die lateinischen und griechischen Synonyma von Rückenmark, finden sich geschichtliche Nachweise in HL, §. LXXXI und LXXXII.

\section{Nucleus und Cytoblast,}

Nucleus und Nucleolus, Kern- und Kernkörperchen, können sich unangefochten überall blicken lassen. Die grammatikalische Vogelscheuche Nucleololus, für Kernchen in den

1) Paragraph., Lib. III, Cap. 1, §. 1. 
Kernkörperchen, hätte aus der neueren Histologie ausbleiben sollen, welche ohnediess schon überreich an unmöglichen Worten ist. Der ehrliche Nucleus, als Zellenkern, bekam, durch den pruritus onomatopoëticus der. Histologen, einen viel gelehrter aussehenden Rivalen, im Cytoblast. Wir wollen bei xíros, als Zelle, ein Auge zudrücken, obgleich dieses Wort, welches von $x^{j} \omega$, schwanger sein, herstammt, Alles ausdrückt, was etwas in sich aufnimmt, wie Schädelhöhle im Plato, Brusthöhle im Aristoteles, und Bauchhöhle im Athenaeus. Aber

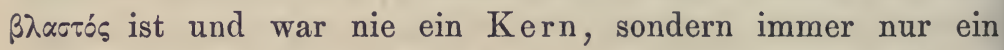
Keim, oder ein junger Trieb, oder ein sprossendes Blatt einer Pflanze. Cytoblast kann deshalb unmöglich für Zellenkern gebraucht werden, wohl aber für eine aus der Mutterzelle hervorsprossende Tochterzelle. Man scheint dieses schon geahnt zu haben, denn man nahm, für Zellenkern, seine Zuflucht zu xápvov. Wir lesen Karyokinesis, als Ausdruck für die Vorgänge in dem sich zur Theilung anschickenden Zellenkern 1). Kápuov war den Griechen nicht der Kern der Nuss, sondern die Nuss zusammt dem Kern, insbesondere Wallnuss, Haselnuss, auch Kastanie, und Stein der Steinfrüchte. Daher stammt Caryophyllon, Nussblatt oder Blattnuss (Gewürznelke), und Caryocatactes, Nussknacker (Corvus caryocatactes). Insofern der Stein der Steinfrüchte in currenter Sprache auch Kern genannt wird, und zwischen Kern und xápuov eine gewisse Lautähnlichkeit sich heraushören lässt, wäre es ungerecht zu sagen, dass die Karyokinesis («ápuov, Nuss, und xivnorৎ, Bewegung), lieber bei den Chinesen hätte bleiben sollen. Fremdworte dieser Art, verläugnen die gute Absicht ihres Erfinders nicht, sind aber wahrlich überflüssig. Der Kern heisst übrigens

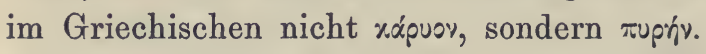

1) Archiv für microsc. Anatomie, XVI. Bd. 


\section{Nymphae und Myrtiformis,}

Die einsame Nympha der alten griechischen Anatomen, hat Gesellschaft erhalten. Es giebt jetzt ihrer zwei. Die anatomische Nympha war bei unseren griechischen Meistern immer das, was wir Clitoris nennen, also ein unpaares Gebilde. Durchblicken wir die besten Zeugnisse hiefür. Galen sagt: inter has alas (Schamlefzen) caruncula exorta, vijup vocatur, quam, si multum prominet, Aegyptii excidere consueverunt ${ }^{1}$ ). Im Rufus Ephesius und im Pollux, wirdnympha, als excrescentia

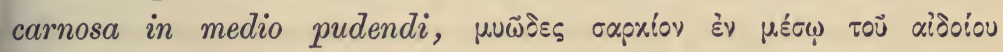
erläutert, und im Stephanus, als Epiphysis cutanea intra pudendum muliebre, ad urinarium meatum sita. Oribasius vergleicht die einsame Nympha, mit dem Zäpfchen (uvula): ut pharyngi gurgulio propugnaculum est, ita utero nympha ${ }^{2}$ ).

Wenn neuerer Zeit zwei Nymphae an die Stelle der Einen traten, und die beiden kleinen Schamlippen darunter verstanden werden, so ist nur die Unbekanntschaft der Autoren mit den griechischen Texten, an dieser Substitution Schuld. Gegen die angeführten Zeugnisse kann keinerlei Bedenken obwalten, um so weniger, als die kleinen Schamlefzen, von jenen Griechen, welche die Clitoris vijuqn nennen, immer nur als $\pi \tau \varepsilon \rho \gamma \omega \dot{\omega} \mu \alpha \tau \alpha$ besprochen werden. Der șchlagendste Beweis dafür, dass víu.̣n

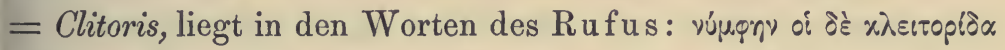
bvop.'̌́,ovet, aliqui nympham clitoridem vocant.

Im Pollux treffen wir auch mit Myrton, als Stellvertreter für Clitoris, zusammen. In der That wird die Clitoris zuweilen so klein angetroffen, dass sie der Beere des Myrtenbaumes, welche pujproy heisst, nicht unähnlich sieht. Aus diesem Myrton

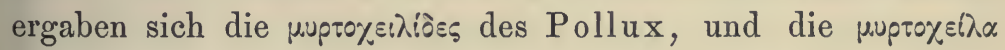

1) Liber Galeno adscriptus: Introductio s. Medicus, Cap. 10, pone finem.

2) Anatomica ex libris Galeni, Edit. Dundass, Lugd., pag. 129. 
des Rufus, ein den kleinen Schamlippen gegebener Name, gegen welchen nichts eingewendet werden kann, da die Labia minora, nach oben mit dem púprov zusammenhängen, und als Lippen derselben betrachtet werden können. Haller nannte, aus demselben Grunde, die kleinen Schamlefzen: Crura clitoridis. Mit der Vorhaut des männlichen Gliedes, werden sie als Praeputia, von Berengarius verglichen $\left.{ }^{1}\right)$. Das Myrton des Pollux, ist schon sehr lange verblüht und verdorrt, bis auf einen unbedeutenden Rest, welcher in den Carunculae myrtiformes fortlebt: reliquiae hymenis attriti, quae ob similitudinem cum baccis myrti, ita vocantur, wie Laurentius sagt.

Ueber Myrton verwirrt uns keine Nebenbedeutung. Aber Nympha hat deren viele, wie z. B. die verlobte Braut, - die Wassernixe, - das Grübchen im Kinn, - die Spitze der Pflugschar, - die eben aus dem Ei gekrochene flügellose und wurmähnliche Bienenlarve, - die sich eben öffnende Rosenknospe, - und, nach Hesychius, auch die geflügelte männliche Ameise.

Den Plural: Nymphae, sandte der sonst belesene Kenner der griechischen Sprache, Adrianus Spigelius, in die anatomische Welt, mit den Worten: nymphae dictae, vel quia primae sponsum admittunt, vel quia nympharum officio funguntur, ut enim illae vivis, et scaturientibus praesunt aquis, sic hae urinae rivulo praefectae videntur ${ }^{2}$ ). Um den ersten Theil dieses Satzes zu verstehen, erinnere ich, dass vúp.̣ schon im $\mathrm{Homer}$ als Braut zu treffen ist.

Das Lesen alter Anatomen, wird in puncto puncti, dadurch erschwert, dass die Worte Alae, Labia, Pterygomata, und Cremna, bald für die grossen, bald für die kleinen Schamlefzen herhalten müssen.

1) Isagogae breves, Cap. de matrice non praegnante.

2) De hum. corp. fabrica, Lib. I, Cap. 4. 


\section{Oesophagus.}

Das Wort Oesophagus kann sich eines sehr ehrwürdigen Alters rühmen. Es wurde von Aristoteles für Speiseröhre

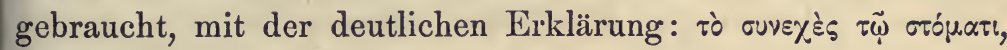
continuatio oris ${ }^{1}$ ). Alle griechischen Anatomen und Aerzte verschmähten dieses Wort, und zogen ihm Stomachus vor - die Gula der Lateiner.

Man denkt bei oircopáros an oï $\omega$, tragen, und parsĩy, essen,

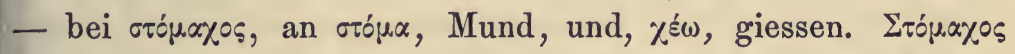
kommt schon im Hippocrates vor, aber nicht als Speiseröhre, sondern als Blasenhals, und Muttermund. Celsus nahm den Stomachus als Speiseröhre in seine Sprache auf: duo itinera colli (zwei Gänge), unum stomachum (Speiseröhre), alterum asperam arteriam (Luftröhre) vocant. Von Celsus übernahm Vesal den Stomachus. Seine Nachfolger jedoch zogen durchgehends Oesophagus vor. Bei diesem blieb es auch, bis in unsere Zeit, wo Stomachus nur von den Aerzten, nicht von den Anatomen, für M a g e $\mathrm{n}$ angewendet wird, wie die Remedia stomachica, magenstärkende Mittel, und viele Composita bezeugen. Die Griechen nannten den Magen nie anders, als raothp. Ueber Gula, und das arabische Meri, sieh' HL, §. LXXVII.

\section{Olecranon,}

Das Olecranon, Ellbogenhöcker, sollte von rechtswegen

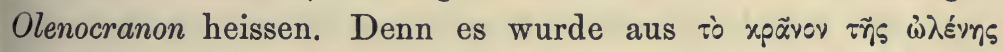
(caput cubiti) construirt. Ich finde jedoch Olenocranon nur ein einziges Mal im Aristophanes²), während alle griechischen Aerzte und Anatomen, fast ohne Ausnahme ف̇ᄎéxpavov, leibhaftig

1) De partibus animalium, Lib.II, Cap. 3.

2) Pax, Vers 443. 
gebrauchen. Nur im Pollux, und einmal auch im Galen,

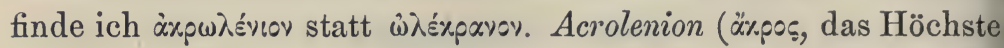
und $\omega \lambda \varepsilon^{\prime} \eta \eta$, Ellbogen), ist ebenso Summum cubiti, wie Acromion = summus humerus. Der an der Streckseite des Ellbogengelenks vorspringende Höcker, auf welchen wir den gebogenen Arm stützen, bildet die erhabenste und härteste Stelle des ganzen Ellbogens ( $\left(\lambda \lambda^{\prime} v \eta\right.$, cubitus), und wurde deshalb von den Lateinern als Caput oder Vertex cubiti bezeichnet (Celsus). Am trockenen Knochen erscheint dieser Vertex cubiti als ein starker, hackenförmig gekrümmter Fortsatz, welcher die Rolle des Oberarmbeins umgreift. Dieser Krümmung wegen, wurde er von Galen und Rufus àruóv genannt, welches in allen seinen Anwendungen, nur einen Einbug, auch den Armbug, ausdrückt ${ }^{1}$ ).

Die anatomischen Handbücher führen, statt Olecranon, häufig Tuberositas ulnae und Processus anconaeus an (letzteres barbarisch, - sieh' Artikel: Anconaeus). Die Gibbositas und der Gibber ulnae der alten Anatomen (gibberum im Zerbis!), lässt sich im deutschen Ellbogenhöcker noch erkennen, während unser Hackenfortsatz der Ulna, dem griechischen

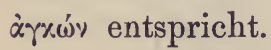

Realdus nannte die zwei Ecken, welche die Incisura semilunaris major ulnae begrenzen, Coronae, nach dem Beispiele Galen's, welcher spitze Fortsätze der Knochen, überhaupt als rop $\omega^{\prime} \alpha_{\ell}{ }^{2}$ ) bezeichnet. Demzufolge unterscheiden die Patres anatomiae an der Incisura semilunaris ulnae, eine Corona inferior und superior. Die Corona superior ist das Olecranon; - die Corona inferior besteht noch als Processus coronoideus ulnae ${ }^{3}$ ).

Die morphologische Uebereinstimmung des Olecranon mit der Patella, liess für ersteres den Tropus Patella fixa, und für

1) Nur im Aristoteles zeigt sich ày Oberarms (Hist. anim., Lib. I, Cap. 15).

2) Oribasius, Anatomica ex Galeno, pag. 130.

3) Vergleiche den Artikel: Coronoideus. 
letztere jenen des Olecranon mobile erfinden. Das Additamentum necatum, ein von Vesal für Olecranon angeführtes Synonym '), verstehe ich absolut nicht.

\section{Omentum.}

Das Omentum, Netz, bereitet den Etymologen mehr Schwierigkeiten, als den Anatomen. Die Anatomen wissen, was sie unter dem grossen und kleinen Netz zu verstehen haben. Die Etymologen dagegen sind nicht darüber einig, woher das Wort abgeleitet werden könnte. Zwei Meinungen machen sich geltend. Die Einen sagen: Omentum ist gleich Operimentum per syncopen, und Operimentum $=\mathrm{Decke}$, U eberzug und Deckel, von operio, zudecken. Das Omentum deckt die Gedärme, bei Thieren auch den Magen zu, ist also ein Operimentum, und wird durch Contraction zum Omentum. Diese Ansicht hat etwas für sich. Es werden nämlich verschiedene Häute, welche Organe umhüllen und bedecken, Omenta genannt, wie die Omenta cerebri (Meninges), die Omenta ossium (Periostea) im Macrobius, Valverda, und Achillinus, und die Omenta oculorum (Deckel der Augen), nur einmal im Plinius, für Augenlider, beim Pferde. Omentum, quasi Operimentum, lässt sich Bartholinus, vernehmen ${ }^{2}$ ). Dieser Meinung wird jeder Anatom beitreten. Die Verwendung des Omentum als Operimentum, trat auch bei den Thieropfern ein. Es war nämlich Sitte, bei den Opfern, die kleinen zerschnittenen Eingeweide (exta prosecta), mit dem fettreichen Omentum zu überdecken, damit sie rascher durch das Feuer verzehrt wurden. Die Wurstmacher in Paris, bedienen sich heute noch der zierlich geaderten Kalbs- und Schafsnetze, um die in ihren Schaufenstern ausgestellten Delicatessen damit zu umhüllen,

1) Opera omnia. Ed. Lugd., T. I, pag. 142.

$\left.{ }^{2}\right)$ Institutiones anat., Lib. I, Cap. 8. 
wo dann die hinter diesem Schleier halbverborgenen appetitlichen Sachen, dem lüsternen Auge um so begehrenswerther erseheinen. Die zweite Ableitung, von Omen (Augurium), bietet weniger Sicherheit dar. Zwar wurde aus fulmen fulmentum, und aus momen momentum gemacht, aber dass aus omen omentum entstand, quia haruspices omina ex omentis capiebant ${ }^{1}$ ), will mir nicht recht einleuchten. Es bleibt also bei Operimentum.

$\mathrm{Zu}$ den nicht mehr üblichen Benennungen des Netzes gehören:

1. Die Mappa ventris des Vesal, welche wie eine Schürze vor den Gedärmen, vom Magen herabhängt. Mappa, nach Quinctilian ein punisches Wort, bedeutet ein Vortuch (Serviette), welche die Gäste eines Gelages, zum Essen mitbrachten, und mit Speiseresten gefüllt, wieder nach Hause nahmen (Horatius und Petronius).

2. Pluma, gleichfalls im Vesal: Bruxellensi idiomate hoc nomen meretur omentum, quia tenue est, ne ventriculum gravet.

3. Zirbus, das arabische al-tsarb, worüber in HL, $\S . C I V$, umständlich gesprochen wird. Lebte noch zu meiner Schülerzeit, in der Hernia zirbalis, Netzbruch.

4. Marsupium adiposum, Saccus und Sacculus, im Bartholinus, der sackförmigen Bildung des Netzes wegen - im Deutschen Netzbeutel. Das französische coëffe und coiffe, das englische cowl (eigentlich Kaputze, a monks kowl), das spanische el redaño de las tripas, deuten ebenfalls auf die Sackform des Netzes hin.

5. Tela, im Französischen toile, eigentlich Gewebe, aber auch Netz, weil jedes Gewebe im Grunde ein Netz von so dicht gedrängten Fasern ist, dass die Lücken des Genetzes ganz verschwinden.

6. Craticula, ein Rost, aus einem rechtwinkelig vernetzten Drahtgeflecht, wurde nur von Spätlateinern für Netz gebraucht.

1) G. J. Voss, Etymologicon linguae latinae, pag. 354 . 
7. Güdel und Magensack sind Uebersetzungen, welche Hans von Gersdorf dem arabischen Zirbus angedeihen liess.

8. Das Reticulum der Arabisten, wurde dem Reticello (Reticella) der Italiener nachgebildet. Der Name bezieht sich entweder auf die netzförmige Fettablagerung, oder auf die sackförmige Gestalt des Netzes.

Ueber die griechischen Synonyme von Omentum, handelt der Artikel Epiploon dieses Buches.

\section{Orbita.}

Nicht von Albertus Magnus, wie das Anatomische Realwörterbuch von Pierer und Choulant angiebt, sondern von Gerardus Cremonensis, dem ersten Uebersetzer des Canon Avicennae, wurde das Wort Orbita, der anatomischen Spraché aufgebürdet. Gerard u s ${ }^{1}$ ) sagt: „secundum par nervorum, a foramine, quod est in orbita, quae totum comprehendit oculum, egreditur“, und an einer anderen Stelle ${ }^{2}$ ): „sutura mandibulae, quum pervenit ad orbitam, in tres separatur ramos, quorum unus progreditur super orbitam, donec supercilio continuetur, alter similiter continuatur, praeter quod orbitam non ingreditur, et tertius similiter continuatur, postquam orbitam ingreditur". Orbita ist demnach unsere A ugenhöhle, und somit barbarisch, da es, mit dieser Bedeutung, weder in der Blüthe- noch in der Verfallszeit der lateinischen Sprache, je gebraucht wurde. A u sonius ${ }^{3}$ ) belehrt uns über den wahren Sinn von Orbita, mit den Worten: „Orbita duas res significat, rotam ipsam, et vestigium ejus in molli solo", also Rad, und Geleise. Im Plinius kommt noch Orbita als Kreisfurche vor, welche ein Band in der Rinde des Weinstockes zurücklässt, und im Julius

1) Canon, Lib. I, Fen 1, Doctr. 5, Summa 3, Cap. 2.

2) Ibidem, Summa 1, Cap. 4.

3) In Varronem, II, 1, 59. 
Solinus ${ }^{1}$ ) gerathen wir auf Orbita lunae, als Kreisbahn dieses Gestirnes. In der lateinischen Uebersetzung des Oribasius von $\mathrm{R}$ as a rius, kommt die Trochlea des Oberarmbeins, als Orbita brachii vor, während im griechischen Text $\dot{\eta} \tau p \circ \%$

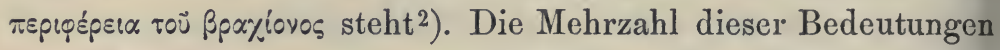
von Orbita fusst auf etwas Kreisrundem, wie denn auch Orbita ohne Widerrede von Orbis, Kreis, deducirt werden muss. Wenn aber die Augenhöhle weder ein Kreis, noch eine Furche ist, darf sie auch nicht Orbita genannt werden. Eine hohle, vierseitige, liegende Pyramide, hätte einen anderen Namen erhalten sollen. Sie erhielt ihn auch, wie gleich gezeigt wird, aber verlor ihn mit der Zeit wieder. Nur das absurde Orbita, hat Stand gehalten.

Im Rufus Ephesius erscheinen die Augenhöhlen als $\pi \cup \wedge \hat{\imath}\left(\delta \varepsilon \varsigma^{3}\right.$ ), welche die Uebersetzer als pelviculae und arculae

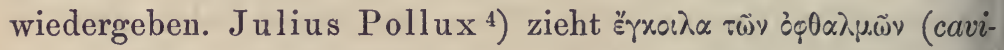
tates oculorum) und xóryol (conchae und conchulae) vor, obwohl letzteres schon lange an Hirnschale und Ohrtrichter vergeben war. Celsus ${ }^{5}$ ) begnügt sich mit dem zweideutigen: Foramina oculorum, welchem die Arabisten Antra, Capsae, Cavitates, Cavernae, und Foveae oculorum substituirten. Wir werden

1) Polyhistor, Aetna, 230.

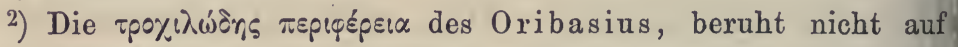
Trochilus, sondern auf Trochilia. Tpo\%! $\lambda i \alpha$ ist Rolle, Winde

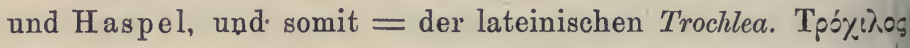
dagegen kennen wir nur als Zaunkönig oder Strandläufey. Aristoteles hat zuerst dieses Wort gebraucht, welches später auch von Plinius angenommen wurde. Es ergiebt sich daraus, dass es widersinnig ist, das Ellbogengelenk als Charniergelenk, einen Trochilus zu nennen, wie es bei den Anatomen minorum gentium öfters geschieht.

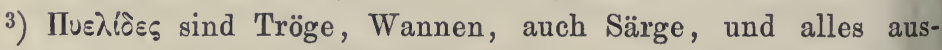
gehöhlte Geräth aus Holz.

4) Onomasticon, Lib. II, Cap. 4, de interioribus oculorum.

5) De medicina, Lib. VIII, Cap. 1. 
bei ihnen auch durch Orbitates oculorum überrascht. So weit reichte das Latein dieser Mönche nicht, dass sie gewusst hätten, Orbitas bedeute im classischen Latein, entweder Kin derlosigkeit oder Elternlosigkeit (orbus filiis vel parentibus), wofür Cicero und Plautus Bürgschaft geben.

Orbita, als Radspur oder Geleise, vegetirt noch im Hochdeutschen als Augenleise, und im Niedersächsischen als Augenlese, für Augenhöhle.

\section{0s tincae.}

Auf den komischen Einfall, den Muttermund, Os tincae, Schleienmaul, zu nennen, verfiel zuerst Berengarius Carpensis. Er verglich den Muttermund, seines glatten und härtlichen Anfühlens wegen, nicht blos mit den dicken und glatten Lippen der Schleie (Cyprinus tinca Linn.), sondern auch mit jenen des Harders (Mugil), und säugender Hündchen Alle drei Vergleiche lassen sich anhören, denn die Aehnlichkeit des Os uteri mit diesen Dingen, braucht nicht erst gesucht zu werden. Im Capitel de matrice non praegnante der Isagogae, heisst es: os matricis formam habet mugili, sive.tencae piscis, sive catuli noviter nati. Die Tenca des Berengar, ist unsere Schleie, Tinca chrysitis Cuv. Die Sonderbarkeit, und, wie nicht zu läugnen, die Richtigkeit des Vergleiches besonders bei Frauenzimmern, welche nie geboren haben, machte das Os tincae bei allen Anatomen, wie auch bei den Hebammen populär, so dass Schleienmaul (zu meiner Schülerzeit Tin cak nochen genannt), als Synonym des äusseren Muttermundes, wohl nie mehr aufgegeben werden wird. Auch die Franzosen haben ihr museau de tenche. - Mehrere, besonders ältere Anatomen, verstehen unter Os tincae, die ganze Pars vaginalis uteri, wie Columbus, während die meisten, nur den zweilippigen äusseren Muttermund, also genannt sein lassen. Mit letzteren halten auch wir es. Durch die bei den Italienern so oft beliebte Anbringung des Schmarotzer- $h$, wurde ihnen 
das Os tincae zum Os tinchae. - Von den ältesten Benennungen des äusseren Muttermundes: corona und rosa, erübrigt noch in unserer Zeit die Krönung, als jener Moment des Gebärens, in welchem der Kindskopf', mit seiner grössten Peripherie, im Muttermunde steht - das couronnement der Franzosen. Die Rosa aber gab dem Monatsfluss seinen Volksnamen: Rose und Blume. - Bei unseren Hebammen heisst der Muttermund das Mutterschloss, weil er in der Schwangerschaft fest geschlossen ist, und erst bei herannahender Geburt sich aufthut. Hundsschnautze und Schweinsrüssel sprechen für den ästhetischen Sinn dieser Damen. Sie drücken eine besonders lange, und eine schief abgestutzte Pars vaginalis uteri aus.

\section{Ovarium.}

Ovarium ist kein altrömisches Wort, sondern ein Terminus anatomicus recens. Der Erste, welcher sich seiner bediente, war der Däne Nicolaus Steno (Stenson ${ }^{1}$ ). Die Bläschen im Eierstock waren schon lange vor Steno, den Anatomen unter dem Namen Vesicae, Vesiculae, oder Sinus, bekannt. Vesalius, Fallopia, Volcherus Coiter, Rodericus de Castro, und Laurentius, sprechen von diesen Vesiculae und Vesicae. Ihnen zu Liebe wurde auch der Eierstock Vesicarium ${ }^{2}$ ) genannt. Als Ova fasste sie Steno zuerst auf. Er gab sofort den bisher

1) Specimen myologiae, Florent., 1667, pag. 117.

$\left.{ }^{2}\right)$ Schreger, Synonymik, pag. 267. Geronimo Sbaragli, Professor in Bologna, (nicht Sparagli, wie er im Schreger genannt wird) gebrauchte diesen Ausdruck in seiner Schrift: de vivipara generatione scepsis. Viennae, 1696, pag. 304. Diese Scepsis ist in einem sehr rauhen und unangenehmen Styl geschrieben, dem man das unnatürliche Vesicarium, zu Gute halten muss. Ebenso selten, und nur dem Fabricius bekannt, ist Vitellarium (De formatione ovi, pag. 8). 
nur als Testes muliebres ${ }^{1}$ ) (altdeutsch Geburths-Geylen) benannten Eierstöcken, den bleibenden Namen Ovaria, welchen Regnerus de Graaf und alle folgenden Anatomen: „propter vesicularum similitudinem cum ovis avium ${ }^{2}$ )", angenommen haben. Es ist deshalb chronologisch unrichtig, die Eierstocksbläschen, Ovula Graafii zu nennen. Sie sollten besser Ovula Stenoniana heissen, denn Steno ist älter als Graaf. - Mit den Ovulis war auch die alte Lehre zu Falle gebracht, dass die Eierstöcke, als Testes muliebres, Samen erzeugen wie die Hoden, und dass durch die Vermischung des männlichen und weiblichen Samens in der Gebärmutter, die menschliche Frucht zu Stande käme.

Ovarium, als Substantiv, war den Römern nicht bekannt. Als Adjectiv ovarius (oophylax), bezeichnet es jenen Sclaven, welchem die Pflege der Haushühner, und die Auf bewahrung: der Eier anvertraut war (Forcellini). In Rom wurde seh. viel auf frische Eier gehalten. Man verspeiste sie nach dem Bade, und als Einleitung zur Mahlzeit, - daher die Redensart: $a b$ ovo. Geschickte Ovarii waren von den Gutschmeckern sehr geschätzt; - man errichtete ihnen selbst Monumente. - Die Griechen hatten zwar ఓ́xp:ov, aber nicht als Eierstock, sondern als "kleines Ei". Gegen das medicinisch beliebte Oophoron (Oophoritis, Eierstocksentzündung), lässt sich nichts einwenden. Es ist sehr alt. Schon Aristoteles gab der Fischwelt den Beinamen wopópos $\left.^{3}\right)$.

\section{Palatum durum und molle.}

Bis Vesal unterschied man einen harten und weichen Gaumen nicht. Das Hippocratische Diaphragma oris, passt

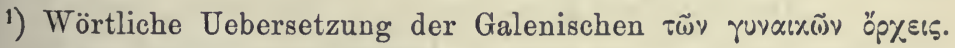
De usu partium, Lib. XIV, Cap. 12, und an vielen anderen Stellen.

2) De mulierum organis, Cap. XII, pag. 228.

3) Historia animalium, Lib. IX, Cap. 37.

Hyrtl. Onomatologia anatomica. 
gleich gut auf den harten, wie auf den weichen Gaumen. Man sprach nur im Allgemeinen vom Palatum ') s. Altum oris, als

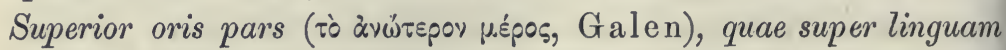
est, instar tholi (Kuppel) leviter concava. Diese Concavität des Gewölbes der Mundhöhle, wurde oftmals durch Coelum oris ausgedrückt, da auch das Himmelsgewölbe sich im Bogen über die Erde spannt. Im Cicero ${ }^{2}$ ) tritt das Himmelsgewölbe sogar als Palatum coeli auf. Auch Galen gefiel sich in diesem Vergleich. Er nennt den Gaumen: oupavós und oupaví\%.ร ${ }^{3}$ ),

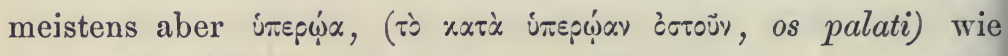
Homer ${ }^{4}$ ), welches Wort auch die meisten griechischen Aerzte

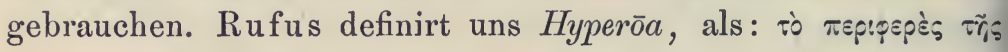

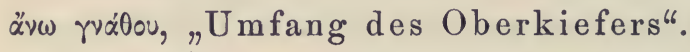

Vesal unterscheidet der Erste, den harten Gaumen vom weichen. Der weiche Gaumen wird als carnea fungosaque portio ad extremum ossis palati erwähnt ${ }^{5}$ ). Die für den weichen Gaumen sonst noch gebräuchlichen Benennungen, als Palatum molle und pendulum (Fallopia), Velum palati

1) Palatum, nach Berengar: quia aperto ore palam evadit, war bei den Römern das Organ des Geschmackes: voluptatem palato percipere, Cicero, wie wir im Deutschen von einem leckeren Gaumen reden. Der deutsche Gaumen, kann mit dem griechischen $\gamma \varepsilon u j \mu, \alpha$, Geschmack, oder mit dem obsoleten lateinischen gumia im Lucilius, Leckermaul, in genetischer Verbindung stehen. Letzteres kommt wahrscheinlicher heraus, da der Gaumen im Altdeutschen des Rabanus Maurus giumen und giuma heisst.

2) De natura Deorum, II, 18, 45.

3) Definitiones medicae, $N$. LXXXVIII.

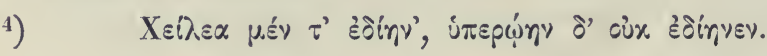
„Dass er die Lippen ihm netz', und nicht den

Gaumen ihm netze."

$$
\text { (Ilias, XXII, 495.) }
$$

5) Examen observationum Fallop., in Opp. omn. T. I, pag. 825. 
(Winslow), und die ganz gut gewählte Valvula faucium (Schaarschmidt), erklären sich von selbst.

Als Scheidewand zwischen Mund- und Rachenhöhle, wurde der weiche Gaumen auch Diaphragma und Claustrun oris genannt, welchen Ausdruck wir zuerst im Hippocrates begegnen 1).

\section{Palma und Vola manus.}

Wenn wir genau sein wollen, dürfen wir Palma und Vola manus, nicht für identisch halten, obwohl sie in der Anatomie dafür gelten. Palma manus ist die Flachhand; - Vola manus die Hohlhand. Die deutsche Benennung Mittelhand, passt auf beide Begriffe, weil sie die Mitte zwischen Handwurzel und Fingern einnehmen. Palma wiederholt die griechische $\pi \alpha \lambda \alpha$ un. So hiess der breite Theil oder die Schaufel eines Ruders. Diese ist nicht hohl, sondern flach, somit passt auch Palma nur auf die Flachhand. Die Griechen waren hierin genauer als wir. Sie nannten die Flachhand Metacarpion, die Hohlhand aber Cotyle ${ }^{2}$ ) oder Thenar $\left.{ }^{3}\right)$, letzteres mit Berücksichtigung des Daumen- und Kleinfingerballens, welche die Vertiefung der Hohlhand begrenzen. Wir verstehen heute unter Metacarpus, die fünf Knochen der Mittelhand, die Griechen jedoch unter ihrem Metacarpion, die ganze Mittelhand, mit Fleisch und Haut ${ }^{4}$ ). Die lateinischen Uebersetzungen

1) Epidem., Liz. II, S. 2.

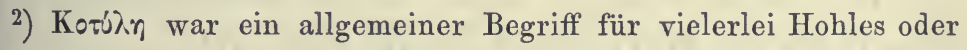

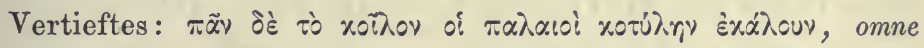
concavum veteres cotylen vocarunt (Athenaeus, XI, 479). Becher, Schale, Mass für Flüssigkeiten, Napf, Gelenksgrube, Concavität der Hand und des Fusses, alles war xotúخ in.

3) Sieh' dieses Wort.

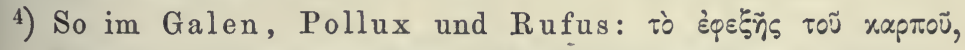

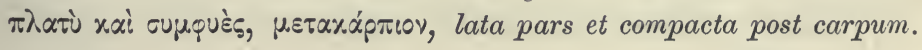




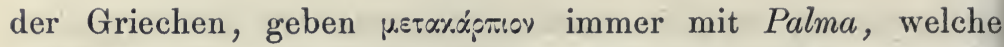
auch im Celsus nie durch Vola ersetzt wird. Palmaris kann somit auch Alles genannt werden, was in der Mittelhand vorkommt, mag es die obere oder untere Seite derselben einnehmen. Der Sprachgebrauch aber versteht unter palmaris, nur was an der concaven Seite der Mittelhand liegt, und nennt das an der convexen Seite Befindliche: dorsalis.

Nur in der Poesie wird die ganze Hand, sammt Fingern, palma genannt per synecdochen: amplexus tremulis altaria palmis, im Ovid, und duplices tendens ad sidera palmas, im Virgil. Der Palmbaum, dessen Blätter einer Hand mit ausgestreckten Fingern ähnlich sehen, erhielt daher seinen Namen. Die Elasticität, Stärke, und Zähigkeit seines Holzes, machte die Zweige der Palme, zu Trophäen des Siegers, und zum Kampfpreis der Athleten und Wagenlenker.

Das spanische palmear, beklatschen, das neulateinische palmare, und das mönchische palmizare, beohrfeigen, beruhen auf Palma, als Flachhand, wie im: plana faciem contundere palma (Juvenal).

Um die Ableitung von Vola, streiten sich zwei Parteien. Die Einen berufen sich auf Bo $r_{r}$, Wurf, weil wenn Schweres geworfen werden soll, es mit der Hohlhand gefasst wird. Dieser Anschauung steht aber entgegen, dass Vola nicht blos Hohlhand, sondern auch Hohlfuss bedeutet, wie die Definition des Festus deutlich zu verstehen giebt: vestigium medii pedis concavum, sed et palma manus, vola dicitur, und im Plinius finden wir ebenso deutlich: vola medietas palmae et pedis. Die Anderen bringen Vola mit volare, fliegen, in Verbindung. Eine Stelle in Matth. Martinius ${ }^{1}$ ), scheint dieser Ableitung günstig: vola in avibus est pars alarum, quarum motu pennae agitantur. Diese pars alarum kann nur der Bug des Vogelflügels sein, oder die Schulter mit ihrer Achselgrube. Jedenfalls wird eine Vertiefung gemeint, und eine solche ist die flache Grube,

1) Lexicon philologicum, T. III, Vola. 
welche in der Mitte selbst einer gestreckten Hand gesehen wird, und nie verstreicht: der Handteller, Poculum Diogenis, mit welchem der Philosoph im Fass, sein Trinkwasser schöpfte, wie der Hund mit der Zunge. Vola ist auch das

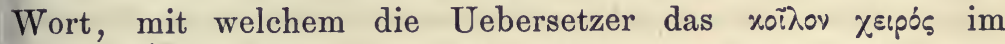

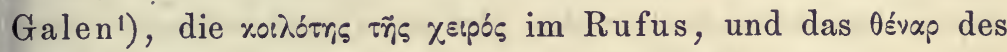
Hippocrates wiedergeben. Vola drückt also nur die Grube in der Flachhand, und latiori sensu, die Beugeseite der Hand aus, während Palma auf Beuge- oder Streckseite keine Rücksicht nimmt. Die Arcus volares, die Rami volares der Arterien, Venen und Nerven der Hand, dürfen nie palmares genannt werden, so wie alle kleinen Muskeln in der Hohlhand, volares, nicht palmares heissen sollen. Der Palmaris brevis des Riolan (Caro quadrata manus Spigelii), würde seine Lage in der Hohlhand, nur durch Volaris ausgedrückt sehen.

Ueber Haller's Palmae plicatae im Canalis cervicis uteri, sieh' den Artikel: Arbor vitae.

\section{Palpebra.}

Ueber Palpebra, welches Wort entweder, wie die Etymologen angeben, von palpare, sanft streicheln, oder, wie ich meine, von palpitare, zucken und zwinkern descendirt, sieh' den Artikel: Gena. Die Ausdrücke cor palpitat im Cicero, praecordia palpitant im Seneca, ignis palpitat im Statius, und lingua palpitat im Ovid, sprechen für die Abstammung von palpitare.

\section{Pampiniformis plexus.}

Unter Plexus pampiniformis wird allgemein das Geflecht verstanden, welches die Zweige der Vena spermatica interna,

1) Isagoge, Cap. 10, Exteriorum partium appellationes. 
im Samenstrang bilden. Die Griechen nannten dieses Geflecht xipcosiòns. Rufus Ephesius spricht von den inneren Arteriae

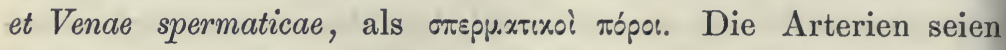

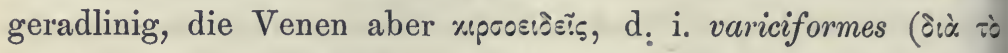

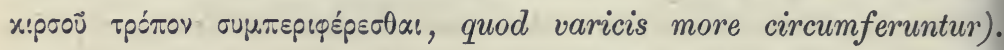
Kipoós heisst im Galen die Erweiterung der Venen (unser

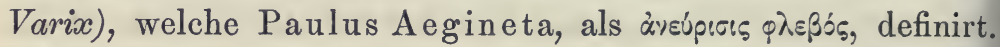
Varicöse Venen werden aber nicht blos weiter. Sie verlängern sich auch, und müssen sich, im gegebenen Raume, rankenförmig schlängeln. Diese Schlängelung, nicht die Erweiterung, liegt dem lateinischen pampiniformis zu Grunde, welches Bauhin ${ }^{1}$ ) auf den genannten Plexus anwendete, statt des bisher üblichen variciformis. Pampinus ist zwar eigentlich der frische Trieb des Weinstockes, aber auch die Weinranke, deren bekannte Drehung, mit den gewundenen Venenstämmchen des Plexus pampiniformis verglichen werden kann. Nur hätte Bauhin, statt des neugeschaffenen pampiniformis, dem Plinius sein altes und echtes pampinatus, für "rankenförmig" entlehnen sollen. Da auch der Epheu (Hedera), nicht blos um den Stab des Bachus, und die Häupter von Weintrinkern und Dichtern gewunden wurde, sondern sich auch spontan an altem Gemäuer emporrankt, da ferner die geringelten Gäbelchen des Weinstockes, im Varro und Plinius Capreoli heissen, gab uns Laurentius, statt pampiniformis, das mehr poetische hederaceus und capreolaris. Die drei Worte drücken die Windungen und Krümmungen der venösen Elemente dieses Plexus ganz richtig aus, aber der Gebrauch fand an pampiniformis mehr Gefallen, und machte es zum allgemein angenommenen Attribut dieses Geflechtes.

Die oft ansehnliche Dicke des Plexus pampiniformis (cirsoides), brachte es nach sich, dass man den Plexus für einen accessorischen Nebenkörper der Samenwege ansah, und ihn sofort, nach Herophilus, $\pi \alpha_{p} \alpha_{\sigma} \sigma \alpha \dot{t} t \eta \xi \%$ \%

1) Theatrum anat., Lib. I, Cap. 5. 
welcher viel besser auf den, an den eigentlichen Hoden angeschmiegten Nebenhoden passt, dessen Samengefäss in zahllosen Schlängelungen und Windungen verlauft. Hippocrates

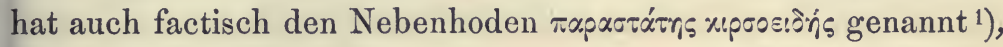
was von Laurentius mit Assistens varicosus übersetzt wurde.

Die Auslegung des im Vesal zu findenden Wortes lumbris $^{2}$ ), für Plexus pampiniformis, will ich versuchen. Die Uebersetzer der Araber, welche diesen uns unbekannten Ausdruck zuerst auftischten, verglichen den Plexus pampiniformis, mit den seitlichen Adergeflechten des Gehirnes, welche, ihrer: langgestreckten Form, und ihrer rothen Farbe wegen, mit Würmern verglichen wurden, und auch als Vermes cerebri, in den Uebersetzungen erscheinen ${ }^{3}$ ) (arabisch $d \bar{u} d$ ). Der grie chische Name für Wurm ist Scolex, der lateinische für Regenwurm: Lumbricus. Wie leicht konnte eine abgekürzte Schreibart von Lumbricus, für Lumbris genommen worden sein.

\section{Pancreas.}

Pancreas, welches Bauhinus wörtlich mit totum carnosum übersetzt, ist ein Galenischer Terminus anatomicus. Wer das griechische \%és, nur im Sinne des Homer, als essbares Fleisch kennt, versteht nicht, was mit Pancreas eigentlich gemeint sein kann, da es wörtlich „ganz aus Fleisch bestehend" übersetzt werden muss. Tò xpéas, ist das thierische Fleisch. Kpéas usixóv und ßostxóv, caro suilla et bovina, so wie

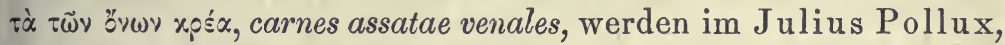
dispensirt ${ }^{4}$ ). Es wird jedoch nicht blos Fleisch, sondern auch

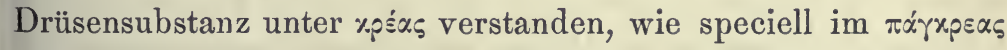

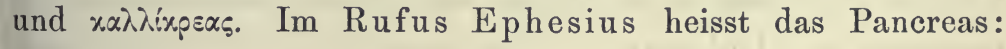

1) De venis, Lib. XXI, Cap. 6 .

2) Opera omnia, Edit. Lugd., T. I, pag. 450.

3) Sieh' den Artikel: Vermis.

1) Onomasticon, Lib. VI, Cap. 9. S. 55. 


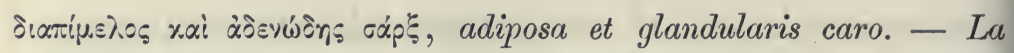
créatine des Chevreul, eine stickstoffige Grundsubstanz des Muskelfleisches, ist, nebst dem Pancreas, das Einzige, was die Anatomie, vom alten xpéšs, in ihrer Sprache noch bewahrt.

Die auf Pancreas bezüglichen Stellen des Galen und Oribasius, lassen sich auf zwei Dinge beziehen. Erstens auf die Magenspeicheldrüse, zweitens aber auf das Conglomerat von Lymphdrüsen, welches bei sehr vielen Thieren, insbesonders schön ausgebildet bei den Fleischfressern, in der Wurzel des Mesenterium angetroffen wird. Indem diese Anhäufung von Lymphdrüsen, bis an den Kopf des Pancreas reicht, und mit ihm verwächst, haben die Alten beide Gebilde nicht streng auseinander gehalten. Ihre Angaben passen theils auf das eine, theils auf das andere dieser Organe. Dieses gilt besonders von Galen. Man kann ihm mit Recht vorwerfen, dass er, da menschliche Leichen, in welchen das eigentliche Pancreas als eine stattliche Drüse auftritt, erwiesener Massen von ihm nicht secirt wurden, das wenig entwickelte Pancreas der Fleischfresser, welche er secirte, gegen ihr grosses und schönes Lymphdrüsenconglomerat in der Radix mesenterii, übersah, und deshalb statt Pancreas auch Callicreas (x $\alpha \lambda \lambda i x_{p} \in \alpha \varsigma$ ) gebrauchte 1), welches schmeichelhafte Prädicat, das menschliche Pancreas wahrlich nicht verdient. Er wiederholt ferner öfter und nachdrücklich, wie das Pancreas den zahlreichen Ramificationen der Blutgefässe nicht blos zur Grundlage dient, sondern dieselben auch ringförmig umschliesst (substravit simul, ac in orbem circumdedit ${ }^{2}$ ), was nur auf das Conglomerat der Mesenterialdrüsen der Thiere passt. So erklärt es sich, warum die Commentatoren des Galen, dem Pancreas seine Lage nicht hinter dem Magen, sondern in medio mesenterio anweisen, wie Dolaeus. - Der Entdecker der Chylusgefässe, G. Aselli, welcher seine neuen Gefässe, im Hunde in das

1) De venarum et arteriarum anatomia, Cap. 1, non procul ab initio.

2) De usu partium, Lib. V, Cap. 2. 
Drüsenaggregat des Gekröses zusammenlaufen sah, spricht deshalb von diesem Aggregat als Pancreas (Pancreas Aselli der vergleichenden Anatomie), und erwähnt das eigentliche Pancreas nur als Organon innominatum.

Während Mundinus, und die Restauratoren der Anatomie, es uns zweifelhaft lassen, ob sie das retroventriculare Pancreas des Menschen, vom mesenterialen Pancreas der Thiere zu unterscheiden verstanden, trennt Vesalius das menschliche Pancreas scharf und bestimmt vom thierischen ${ }^{1}$ ). Da er aber den Ausführungsgang des Pancreas nicht kannte, wusste er über die Bestimmung dieser Drüse nichts zu sagen, als die Worte Galen's zu wiederholen, dass die Drüse nur dazu diene, die Stämme der Blutgefässe zusammenzuhalten, und ihrer Verästelung als Stütze zu dienen $\left.{ }^{2}\right)$ : praecipuis vasorum et nervorum ramis attenditur, ut illorum divaricatio reddatur securior. Im Oribasius heisst es ebenso: hic locus (Pfortader, Blutgefässe, Nerven und Gallengang) magno praesidio indigebat, quo vasa distribuenda munirentur, quapropter glandulosum quoddam corpus substravit, ac in orbem omnibus circumdedit, divisionesque replevit, ut nihil sine munitione sit $\left.{ }^{3}\right)$. Darüber, dass das Pancreas zugleich dem Magen als Unterlage und Polster (substerniculi ac pulvinaris instar) $\mathrm{zu}$ dienen habe, machte sich Fallopia lustig, indem er darauf hinwies, dass die Thiere, quae prona incedunt, et quorum pancreas supra, non sub ventriculo jacet, dann eines Pancreas nicht bedurft hätten ${ }^{4}$ ). Das Umlagertsein der oben genannten Gefässe durch das Pancreas, drückt auch das Wort Affusio aus ${ }^{5}$ ). Pandenon des

1) De corp. hum. fabrica, Lib. V, Cap. 4, versus finem.

2) Eine Verwendung, welche die alte Anatomie, auch der Thymus andichtete.

3) Anatomica ex Galeno, pag. 111.

4) Observationes anat. in Vesalii Opp. omn., T. II, pag. 744.

5) Columbus, De re anatomica, Lib. XI, Cap. 6. Er gab diesen Namen auch der Placenta, deren Substanz quasi circumfunditur vasis umbilicalibus eorumque ramis. 
Arch. Piccolhomini, ist ein verschnittenes Panadenon, wie auch das Corpus pantadenodes des Van Diemerbroeck, in Schreger's Synonymik. Lactes bezieht sich nicht blos auf das Pancreas, sondern auch auf die Thymus, und manches Andere, wie ich in $\S$. LVIII, meiner Abhandlung: Das Arabische und Hebräische in der Anatomie, eingehend dargelegt habe. Der deutsche Name: Bauchspeicheldrüse, ist hier, wie so oft auch für andere Organe, der beste. Das englische sweet-bread, ist keine Benennung des Pancreas, wie Schreger sagt, sondern der Thymus, welche schon bei den Römern ein Leckerbissen für Feinschmecker war.

Sieh' den Artikel: Caro.

\section{Panniculus, Pellicula, Membrana, Tunica.}

Die Uebersetzer der Griechen, haben die Worte Membrana und Tunica, in die Anatomie eingeführt, als Uebertragungen von spiny und $\chi เ \tau \dot{v} v$. Die Uebersetzer der Araber, bedienen sich für ghischājain (Häute), ausschliesslich des Ausdruckes Panniculi. Nur ausnahmsweise finden sich die Pelliculae, aus welchen die Deutschen ihre Felle (Brust-, Bauch-, Mittelfelle, und das Zwerchfell) gebildet haben. Panniculus war durch Jahrhunderte das Wort für jede Art von Haut. Die Arabisten nannten die Hirnhäute, die doppelten Häute der Arterien, und die einfachen der Venen, die Herzklappen, die häutigen Schichten des Darmcanals, das Zwerchfell, die serösen Häute in der Brust und im Unterleib, den Herzbeutel, das Jungfernhäutchen, die kleinen Schamlefzen, die Bindegewebsstrata, u. v. a., panniculi. Nur sehr dünne Panniculi wurden auch Pelliculae genannt, wie z. B. die Halbmondklappen des Herzens, im Berengarius. Das Wort kommt von pannus, T'uch oder Lappen. Im Celsus werden Leinwandlappen zu Verbänden, panniculi genannt. Als die Panniculi der Arabisten, den Membranae und Tunicae weichen mussten, hat sich ein 
Rest derselben, im Panniculus adiposus, fetthältiges Bindegewebslager unter der Haut, und im Panniculus carnosus der Thiere erhalten.

Tunica, für Haut, ist ein Tropus. Denn im eigentlichen Sinne, bedeutet das Wort jenes Unterkleid, welches die Römer unmittelbar auf dem Leibe trugen, und über welches die Männer ihre toga, die Frauen ihre palla anzogen, wenn sie aus dem Hause gingen. Erst durch Uebertragung gelangte die Tunica zur Bezeichnung einer Bedeckung, oder einer Haut, wie sie uns im Plinius und Celsus unterkommt. Membrana dagegen war immer nur eine thierische Haut, entweder als anatomisches Object, oder durch Kunst präparirt, um darauf $\mathrm{zu}$ schreiben = Pergament, wie im Cicero: Homeri carmen, in membrana scriptum.

\section{Papilla,}

Es ist noch nicht lange her, dass die Papillae begonnen haben, eine Rolle in der Anatomie zu spielen. Die Römer kannten Papilla nur als Brustwarze. Papilla, sagt Isidorus: quia eam infantes, dum lac sugunt, quasi papant (papare, im Plautus und Persius, essen, unser "pappen“). Nur Dichter durften sich erlauben, die ganze Brust papilla zu nennen, wie im Martial:

„Fascia crescentes dominae compesce papillas, „Ut sit, quod capiat nostra, tegatque manus."

Die Römer hielten nämlich grosse Brüste (equina quales ubera, Horaz), nicht für schön, und suchten das Wachsthum derselben durch Bandagen derart einzuschränken, dass sie mit der Hohlhand bedeckt werden konnten.

Der Erste, welcher die Papilla mammae, auf einen anderen anatomischen Gegenstand übertrug, war Carpus. Er nannte die Nierenwärzchen, welche man vor ihm nur als Carunculae kannte, a similitudine formae: carnes, papillis 
muliebribus similes $\left.{ }^{1}\right)$. Dieser Ausdruck wurde durch Diemerbroeck zu Carunculae papillares abgekürzt, und durch Haller in die jetzt noch gebräuchlichen Papillae renales umgeändert. Hierauf kam Highmor mit seinen Carunculis papillaribus, Bartholin mit seinem Processus papillaris = mastoideus, und Cowper mit seinen Musculi papillares in den Herzkammern. Diesen folgten Lieutaud und Winslow, mit ihren Processus papillares und Papillae medullares für die Corpora mamillarias. candicantia des Gehirns. Durch Malpighi, welcher die Tastund Geschmackswärzchen zuerst Papillae ${ }^{2}$ ) nannte, wurde dieses Wort auch in die feinere Anatomie eingeführt, bei welcher es auch fortan bleiben wird. Nur erscheint der Name der grossen Brustwarze, für so kleine Gegenstände nicht ganz passend. Aber Papillulae giebt es nicht, und wir müssen mit den Papillis uns zufrieden geben. Die Darmzotten wurden von Helvetius ${ }^{3}$ ), nicht gut passend, papilles genannt. Für sie taugt nur Ein Name: Villi, welchen sie durch.Lieberkühn erhielten ${ }^{4}$ ), und der berufen war, die bisher angewendeten Flocculi und Flocci, Tubuli und Cylindri, für immer aus dem Feld zu schlagen.

Das griechische Wort für Papilla mammae ist $\theta \eta \lambda \lambda$, von

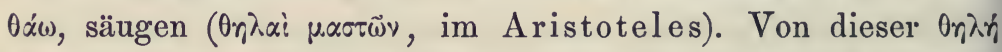
bewahrt die anatomische Sprache nur Ein Andenken, in dem neugebildeten Epithelium. Sieh' dieses Wort.

\section{Parenchyma, Prosenchyma, und Enchyma.}

Nach unabweislicher prosodischer Regel, muss Parenchy̆ma, nicht Parenchȳma gesagt werden, denn im Griechischen

1) Commentaria in Mundinum, pag. 179.

2) De tactus organo, in Opp. omn., Edit. Lugd., pag. 204, und Epistola de lingua, ibid., pag. 167.

3) Mémoires de l'Académie des sciences de Paris, 1721, Tab. XV, Fig. 1, 3 und 4.

4) De fabrica et actione villorum intestinalium, Lugd., 1745. 


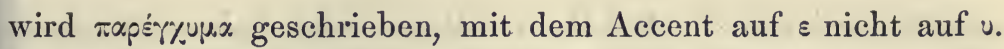
Dieses uralte Wort hat, ausser seinem ehrwürdigen Alter, nichts für sich. Dasselbe behauptet dennoch heute seinen Platz in der Anatomie, in demselben Sinne, welcher ihm von seinem Erfinder: Erasistratus, fast 300 Jahre vor Christo, beigelegt wurde. Die Schriften des Erasistratus gingen zwar verloren. Aber im Galen sind Bruchstücke aus denselben enthalten, welche uns belehren, dass die eigentliche Substanz der drüsigen Organe, der Leber, der Milz, der Nieren und Lungen, von

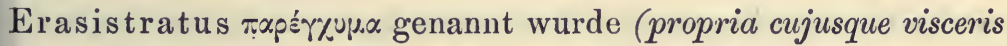
substantia). Parenchyma, von $\pi \alpha \alpha_{p} \gamma^{\prime} \kappa^{\varepsilon} \omega$, "neben hineingiess en", entstand aus der Vorstellung, dass der feinere Bestandtheil des durch die Venen den Organen zugeführten Blutes, sich aus den Gefässen in die Zwischenräume derselben ergiesse, dort erhärte, und zur Bildung und zum Wachsthum der organischen Substanzen verwendet werde. Aus den zahlreichen Stellen im Galenus, welche diese Ansicht des Herophilus kundgeben und bekräftigen, will ich nur die deutlichste anführen: $\pi \alpha \rho \varepsilon$ $\gamma$ -

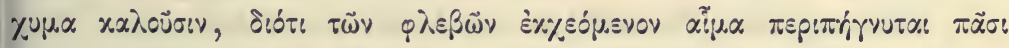
toìs àysiols, parenchyma vocant, propterea quod ex venis effusus sanguis, circa vasa omnia concrescat ${ }^{1}$ ). Ebenso klar spricht Oribasius ${ }^{2}$ ).

Die Uebersetzer der Griechen hatten ihre liebe Noth mit dem unfügsamen Parenchyma. Der beste Translator Galeni, C. G. Kühn, giebt für Parenchyma: Affusio, welches schon von Realdus Columbus, bezüglich der Substanz des Pancreas und der Placenta gebraucht wurde. Vesal, und seine Schule, verwerfen zwar Parenchyma nicht, ersetzen aber dasselbe mit Vorliebe durch Caro, worunter damals nicht blos das Muskelfleisch, sondern die Substanz der Organe überhaupt verstanden wurde. Spigelius führte vermittelnd seine Caro

1) De simplicium medicamentorum temperamentis, in prooemio.

2) Anatomica ex libris Galeni, Lugd., 1735, pag. 76, 114 und 118. 
parenchymatica ein 1), und Bartholinus seine Substantia parenchymatosa s. visceralis ${ }^{2}$ ). Erst durch $\mathrm{P}$ faff und Blumenbach ${ }^{3}$ ) gelangte Parenchyma zu seiner nicht mehr verlassenen, und allgemein acceptirten Geltung. Obgleich die Fortschritte der Anatomie, über die Substanz der drüsigen Organe ganz andere Aufschlüsse gebracht haben, als dass dieselbe ergossenes und geronnenes Blut sei, siedelte sich doch das Parenchym, als formelle Redensart, unverändert in der anatomischen Sprache aller Nationen (nur im Spanischen als parenquima) an, und wird nimmermehr aus ihr herauszubringen sein. Die deutsche Sprache hätte ein Wort, welches ganz geeignet wäre, an die Stelle des sinnlosen Parenchyma zu treten, dasselbe lautet: Substanzwesen.

Im Aristoteles kommt uns ein ähnliches Wort unter, mit gleicher Bedeutung: Procheuma, von $\pi p 0 \% \hat{\varepsilon} \omega$, ergiessen: $\tau \dot{x}$

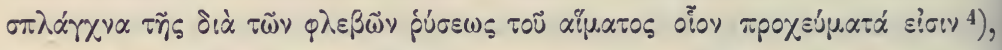
zu deutsch: Die Eingeweide sind gleichsam Ergüsse des durch die Adern fliessenden Blutes.

Das aus der Botanik in die Anatomie transferirte Prosenchyma (Prosenchymzellen, als Zellen mit körniger Auflagerung), unterliegt keinem Anstand, da das Zeitwort $\pi p o \sigma \varepsilon \gamma \xi^{\varepsilon} \omega$, mit der Bedeutung noch hinzugiessen, von Aristoteles gebraucht wird. Enchyma dagegen (im Galen हैץ\%uน, als Hineingegossenes), passt absolut nicht für die so beliebten und allgemein gebrauchten Enchymzellen, da das, was in diesen Zellen enthalten ist, niemals ausserhalb der Zellen war, und somit nicht in dieselben eingegossen werden konnte ( $\gamma_{\gamma} \gamma \tilde{\varepsilon} \omega$, eingiessen, einschenken).

1) Op. cit. Lib. IV, Cap. 2.

2) Op. cit., in prooemio.

3) Institutiones physiol., Edit. 4, §. 20.

4) De partibus animalium, Lib. II, Cap. 1. 


\section{Parotis und Ductus Stenonianus.}

Was wir Ohrspeicheldrüsen nennen, hiess bei den

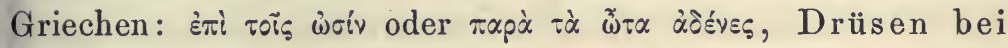
den Ohren. So im Galen 1). Parotides dagegen hiessen bei den Griechen nur die entzündlichen Geschwülste und Abscesse an den Ohren, welche die neuere Medicin Parotitides nennt. In den Definitiones medicae Galeni, num. CCCLXXII, heisst es: Parotides abscessus secundum aures sunt; succedunt ut plurimum febribus, atque ab iis liberant. Da solche metastatische und kritische Abscesse, immer an beiden Ohren zugleich auftreten, wurde solche sympathische Brüderschaft, auch durch Castores ausgedrückt (Galenus, loco cit.). Diese epidemisch grassirende Entzündung, nennen die Deutschen: Bauernwetzel, die Engländer: mumps. Im Plinius werden die Parotides, als Geschwülste am Ohre, öfters erwähnt, z. B.: folia althaeae strumas et parotides tollunt ${ }^{2}$ ). Paulus A egineta nannte nicht blos die entzündlichen, sondern alle Arten von Geschwülsten neben den Ohren: Parotides (Gorraeus).

Von der Ohrspeicheldrüse, als Absonderungsorgan des Speichels, hatten die Alten keine Ahnung. Sie kannten wohl die Drüse, aber nicht ihren Ausführungsgang. Die Drüse selbst rangirten sie, mit den Achsel- und Leistendrüsen, in die Gruppe ihrer Emunctoria, und war ihnen die Ohrdrüse speciell ein Emunctorium cerebri, welches die humiditates superfuas aus dem Gehirn, spongiae ad instar aufzusaugen hatte.

$\mathrm{Als}$ die Bedeutung der Drüse, als Absonderungsorgan des Speichels, festgestellt war, wurde sie auch mit einem besonderen Namen beehrt. Riolan wählte das Wort Parotis. Hätte er gewusst, dass Parotis in der Galenischen Medicin, als Krank-

1) Comment. in Hippocratis Lib. I epidemiorum, und an vielen anderen Stellen.

2) Hist. nat., Lib. XX, Cap. 21, Sect. 84 . 
heitsname eingebürgert war, würde er vielleicht einen besseren gewählt haben. Da die Drüse von nun an Parotis hiess, musste ihre Entzündung, nach dem Vorbild von Pleuritis, Enteritis und Gastritis, auch Parotitis genannt werden. Gut, dass Galen das Wort nicht mehr hört. Er würde es ebenso schlecht finden, wie wir etwa eine entzündete Entzündung der Ohrspeicheldrüse finden würden. Uebrigens passt Parotis (von

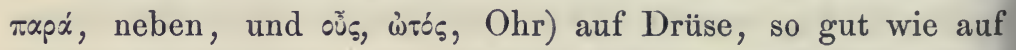
ihren entzündlichen Tumor. Das Wort mag also hingehen. Der bezügliche Satz im Riolan lautet: sub aurium radice, corpora quaedam glandulosa reperiuntur, quae a loco parotides glandulae vocari possunt ${ }^{1}$ ). Dass diese Parotis eine Speicheldrüse sei, wusste auch Riolan nicht. Man erfuhr dieses erst 40 Jahre später durch Nicolaus Stenonius, dessen eigentlicher Name Nic. Stenson, d. i. der Sohn des Sten, filius Stenonis war, wesshalb ihn seine Coaevi entweder Steno, oder Stenonisius, oder Stenonis (scil. filius) nannten, wie die Hebräer ihre Nathansohn, Abrahamsohn, Joelsohn, etc. lieben. Der von Stenonius gefundene Ausführungsgang der Parotis ${ }^{2}$ ), erhob diese zur Würde einer absondernden Drüse, und das Emunctorium ging so zu Grunde, dass nichts mehr in der Folge von ihm verlautete, um so mehr, als auch für die Achsel- und Leistendrüsen, ihre wahre Natur als Lymphdrüsen festgestellt wurde. Der Ductus Stenonianus ist doch ein zu dicker Gang, um auf seine Entdeckung viele Jahrhunderte warten zu müssen. Hippocrates kannte ihn, hielt ihn aber für einen Nerven, und Bauhin und Bartholin sprechen von ihm, als von einem Band der Drüse neben dem Ohre. - Die Holländer machten dem Stenson die Ehre der Entdeckung streitig, und vindicirten sie ihrem Landsmann Gerhard Blaës (Blasius),

1) Anthropographia, Lib. IV, Cap. 10, de glandulis oris.

2) Entdeckt 1660, und zuerst beschrieben in Steno's Inauguraldissertation de glandulis oris, et inde prodeuntibus vasis, Lugd., 1661. 
worüber in der kleinen Schrift des N. Hoboken: Ductus salivalis Blasianus, in lucem protractus, Ultraj. 1662, gehandelt wird. Der Engländer Walter Needham versicherte, den Gang des Stenson, schon im Jahre 1658 entdeckt und dem Stens on gezeigt zu haben. Warum schwieg der.Mann so lange, und erwähnt seine angebliche Entdeckung erst in der, anno 1667 $\mathrm{zu}$ London erschienenen Schrift: de formato foetu, in praefatione, und in Cap. 3? Jedermann kann es sehen, dass schon im Jahre 1609, im Pentaestheseion des Casserius 1), die Einmündung des Ductus Stenonianus in die Mundhöhle abgebildet ist.

\section{Patella und Rotula,}

Von den beiden lateinischen Benennungen der Kniescheibe: Patella und Rotula, ist nur die erstere gut latein, die letztere barbarisch. Celsus führt uns die Patella vor, als os parvum, molle, cartilaginosum, quod patellam vocant ${ }^{2}$ ). Patella war eigentlich den Römern eine flache Schale, in welcher, wie in unseren „Reindln", die Speisen gekocht und zugleich aufgetragen wurden. Die Wurzel ist patêre, offen stehen, der flachen Vertiefung wegen. Die menschliche Kniescheibe kann nur schwer mit einer solchen Schale verglichen werden, weil ihre hintere Fläche nicht die gehörige Tiefe zeigt. Aber das Wort ist einmal da, und so ist mit Celsus darüber nicht weiter zu rechten. Die französischen und englischen Volksausdrücke für Kniescheibe: palette du genou und knee-pan, haben auch die flache Vertiefung dieses platten Knochens in's Auge gefasst (palette $=$ catillus s. excipula, Aderlassschale), während die deutsche Kniescheibe, aus dem Discus genu der Arabisten hervorging. Die das Aufblühen der Saaten (patescere) in Schutz nehmende Gottheit, hiess ebenfalls Patella oder Patellana

1) Org. Aud. Tab. IV, Fig. 1, num. 10.

2) De medicina, Lib. VIII, Cap. 1.

Hyrtl. Onomatologia anatomica. 
(Arnobius). Dieses himmlische Wesen wurde aber auch angerufen, wenn das Schloss einer Thüre, oder eines Kastens, nicht aufgehen wollte.

Rotula, als Kniescheibe, zählt zu den Barbarismen. Rotula, als Rädchen, rpo\%iร\%os, kommt im Plautus und Plinius vor. Von diesem Rädchen holten die alten Anatomen ihre Rotula gewiss nicht. Da Rotula, als Kniescheibe, erst im Mittelalter sich blicken lässt, und zwar bei den italienischen und spanischen Anatomen, so muss angenommen werden, dass sie, das Scutum genu (hebräisch maghen), im lateinischen Canon, mit dem italienischen Wort für Schild: rotella, und mit dem spanischen rodela wiedergaben, welche beide sie zu Rotula latinisirten. Im Französischen kennt man die Patella gar nicht mehr, sondern nur la rotule. - Von den veralteten Ausdrücken Pomum genu, und Oculus genu, haben wir von letzterem einen Nachklang im italienischen ginocchio, Knie, im spanischen hinojo, und im wallachischen genunche. Auch im spanischen cenogil, Strumpfband, lässt sich der Oculus genu noch erkennen.

Die griechischen Ausdrücke für Kniescheibe: $\mu \dot{j}\rangle \eta$ im Galen, und èmryouvis im Homer, waren in Vesal'scher Zeit noch als mola und epigonis im Umlauf. Jetzt sind sie verschollen.

Ueber Sprachantiquitäten von Patella, handelt HL, §. LXXXVII, Rasga.

\section{Patheticus,}

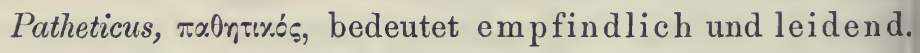
Aristoteles gebraucht es für den leidenschaftlichen Ausdruck, - unser pathetisch. Der Obliquus oculi superior und inferior, bewirken die Drehung des Augapfels, um seine gerade Axe, das Rollen des Auges, welches bei leidenschaftlicher Aufregung zu Tage tritt. Thomas Willis konnte somit immerhin dem vierten Hirnnervenpaar, welches zuerst durch Fallopia zum Rang eines selbstständigen Paares erhoben wurde, 
den Namen Patheticus oculorum beilegen ${ }^{1}$ ). Er hatte aber mit diesem Namen nicht so viel Glück, wie mit seinen übrigen neurologischen Entdeckungen, denn man bedient sich fast allgemein des Ausdrucks: Nervus trochlearis, weil der obere schiefe Augenmuskel, dem Musculus trochlearis angehört.

Hundert Jahre vor Willis, hatte schon Gabriel Fallopia die Autonomie des Nervus trochlearis s. patheticus anerkannt, und ein eigenes Par nervorum cerebri aus ihm gemacht, welches er aber nicht als Par quartum zählte, sondern, seines weit hinter den übrigen Hirnnerven fallenden Ursprungs wegen, als Par octavum, den bisher bestandenen sieben Hirnnerven anreihte ${ }^{2}$ ). Sieh' den Artikel: Trochlea.

\section{- 266. Pectineus.}

Die Schamgegend und das Schambein hiessen bei den römischen Dichtern, Prosaikern, und Aerzten: Pecten und Os pectinis. Celsus spricht es deutlich aus: a coxis oritur os, quod pectinem vocant, rectius in viris, recurvatum magis in exteriora in feminis ${ }^{3}$ ). Das griechische $x \tau \varepsilon i \xi$, hat nach $\mathrm{J}$ ulius Pollux, dieselbe doppelte Bedeutung. Warum der Kamm als Nomenclator herbeigezogen wurde, erklärt Forcellini: quod in regione pubis sit lanugo, qualis, dum pectinatur lana vel linum, pectini adhaerere solet ${ }^{4}$ ). Kann nicht besser interpretirt werden, denn die Fäden, welche beim Kämmen von Wolle und Flachs, auf dem Striegel zurückbleiben, haben wirklich das krause Ansehen der Schamhaare. Da der Kamm im Französischen peigne heisst, welches im Altfranzösischen peignil lautet, erklärt sich die sonst unverständliche Benennung der behaarten

1) Cerebri et nervorum anatome, Lond., 1664, Cap. 21.

$\left.{ }^{2}\right)$ Observ. anat., im T. $I I$ der Opp. omnia Vesalii, pag. 738.

3) Op. cit., Lib. VHI., Cap. 1.

4) Totius latinitatis lexicon, T. III, pag. 320. 
Schamgegend, als pénil, welches dem penis gänzlich fremd bleibt. Als das Os pubis, durch Vesal, über das Os pectinis die Oberhand erhielt, rettete man doch ein Andenken des alten Namens, im Pecten ossis pubis, Schambeinkamm. Von diesem erhielt der Musculus pectineus durch Riolan seinen Namen ${ }^{1}$, welcher pectinĕus nicht pectinēus gesprochen werden muss (sieh' aeus und eus), um ihm seinen neulateinischen Ursprung nachsehen zu können, denn die Adjective pectineus, pectinalis und pectinaeus (Douglas), apud antiquos exulant, welche nur pectinarius kennen.

Der Pectineus besitzt, nur so lange die Leiche frisch ist, die hellrothe Muskelfarbe. Beginnt die Fäulniss, so wird er durch das aufgelöste, und schnell sich zersetzende Blut in der Vena cruralis, welche unmittelbar vor ihm liegt, missfärbig, und erhielt deshalb den Namen Musculus lividus ${ }^{2}$ ) - das blaue, auch das blasse Mäuslein, in den deutschen Anatomien des vorigen Jahrhunderts. Ich möchte ihn Pubofemoralis nennen, welches richtiger wäre, als der Pubo-trochantericus von Schreger ${ }^{3}$ ), da er sich nicht am kleinen Trochanter, sondern unter denselben, am Schafte des Schenkelbeins selbst, festsetzt.

\section{Pedunculus.}

Pedunculus erfreut sich des Rufes, einer der populärsten Barbarismen der Anatomie zu sein. Stiel war bei den Römern Pediculus, nicht Pedunculus. Nur die Zweideutigkeit des Pediculus - denn auch die La us heisst so - bewirkte seine Ersetzung durch das neue Pedunculus ${ }^{4}$ ). Celsus gebraucht

1) Anthropographia, Lib. V, Cap. 41.

2) Adr. Spigelius, Op. cit., Lib. IV, Cap. 22.

3) Nomenclatur der Muskeln, pag. 21.

4) Nonius Marcellus, de varia significatione verborum, Lib. II, Num. 699. 
petiolus, welches jetzt noch in der Botanik, als Blattstiel dient, und Plinius pedusculus, zwar nicht als Stiel, sondern als kleiner Fuss.

In der Gehirnanatomie cursiren die Pedunculi cerebri und cerebelli, Stiele oder Schenkel des grossen und kleinen Gehirns, und die Pedunculi conarii, Zirbelstiele. An die Stelle des Pedunculus mallei (Stiel des Hammers), trat das von Casserius gebrauchte Manubrium mallei, Griff des Hammers. Der Pedunculus cerebri kommt im Haller und Sömmerring als Caudex cerebri, d. i. Hirnstamm vor.

\section{Pelvis.}

Pelvis, Becken, (französisch bassin, italienisch bacino, englisch bason, spanisch bacinete), ist das griechische $\pi \varepsilon \lambda_{1 \zeta}(\pi \varepsilon \lambda \lambda i \xi)$. Es bedeutet im Allgemeinen ein weites und tiefes Gefäss, sowohl Becher als Schüssel und Schale. Die griechischen Anatomen gebrauchten $\pi \hat{\varepsilon} \lambda_{l \varsigma}$ nicht, sondern das Homerische $\pi \dot{\varepsilon} \lambda_{\text {. }}$, ein Ausdruck für verschiedene ausgehöhlte Dinge, wie Wanne und Trog. Galen belegte mit ihm den Hirntrichter: cavitas,

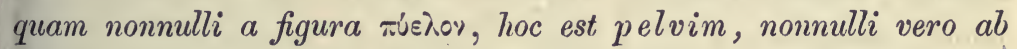
usu \%od'vr, hoc est infundibulum vocant ${ }^{1}$ ), und im Rufus

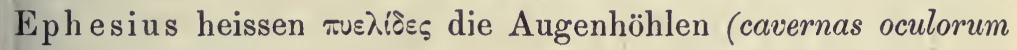
Graeci pyelides vocant, nos [der Uebersetzer] arculas s. pelviculas ${ }^{2}$.

Bei den Römern war Pelvis ein weites und tiefes Gefäss, mit umgelegtem Rand (pelvis patula, im Juvenal). Nach Verschiedenheit seiner speciellen Verwendung, erhielt es verschiedene Namen, z. B. malluvium (maniluvium) zum Hände waschen, pelluvium (pediluvium) zum Füsse waschen, etc. M undinus und seine Schule, gebrauchen das Wort nicht für das, was wir jetzt Becken nennen, sondern für drei andere

1) Oribasius, Op. cit., pag. 21.

2) Op. cit., pag. 67. 
anatomische Objecte, 1. als Pelvis cerebri, für den Hirntrichter, 2. als Pelvis auris, für die Trommelhöhle, und 3. als Pelvis renis, für den trichterförmig beginnenden Harnleiter. Die letztere hat sich bis auf unsere Zeit erhalten. Realdus Columbus, Prosector und Schüler des Vesal; spricht zuerst von einer Pelvis, im jetzigen osteologischen Sinne: Ossa haec (Hüftbein und Kreuzbein) elegantissime conformant pelvis imaginem, quae uter'o, vesicae, ac intestinis, tutius continendis, a natura parata est. Vesalius sagt: ob lavacri (Waschbecken) similitudinem, pelvis dicenda. Ergötzlich lässt sich Rolfinck vernehmen: cavitas, in qua ceu in lavacro natavimus, dum uteri materni ergastulo fuimus inclusi. - Als einen Hauptabschnitt des Skeletes, haben weder die Griechen noch die römischen Aerzte, das Becken betrachtet. Sie zählten seine Knochen theils zu den Wirbeln, wie das Kreuz- und Steissbein, theils zur unteren Extremität, wie die Hüftknochen. Galen erwähnt zwar den Knochenring, welchen das Kreuzbein mit dem Hüftknochen bildet, giebt ihm aber, als Hauptbestandtheil des Stammes keinen Namen: horum ossium interna superficies, unum efficit magnum osseum fornicem ( $\mu \varepsilon \gamma \alpha \dot{\lambda} \lambda \eta \eta^{\prime} \biguplus \alpha \lambda(\delta \alpha)$, qui operit simul et munit omnes partes, quae ipsius capacitatem occupant ${ }^{1}$ ). Galen's Eupuxwpía bezieht sich nur auf die Beckenhöhle, und drückt im Allgemeinen einen weit e $\mathrm{n} \mathrm{R}$ a u $\mathrm{m}$ aus, (sujoús, latus, und

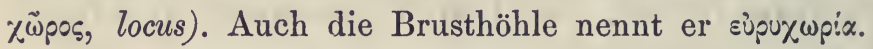

Die neuere Anatomie hat den alten Anwendungen von Pelvis, noch zwei hinzugefügt: 1. Pelvis foraminis ovalis tympani (Pierer), jene Vertiefung zwischen Eminentia pyramidalis und ovalem Fenster, welche Meckel Sinus tympani nannte ${ }^{2}$ ), und 2. die Arteria pelvica posterior und pelvi-cruralis, zwei unbeachtet gebliebene Meckel'sche Ausdrücke, für Arteria hypogastrica und cruralis. Das Os pelvio-cephalicum in der Cephalogenesis von Spix, womit das Hinterhauptbein gemeint ist, da

1) De usu partium, Lib. XIV, Cap. 13, versus finem.

2) Handbuch der menschlichen Anatomie, Bd. IV., pag. 121. 
es die hintere tiefe Ausbuchtung der Hirnschale bildet, wurde nie ernstlich berücksichtigt.

$\mathrm{Ob}$ unser deutsches Becken, von dem lateinischen bacca des Isidorus, als vas aquarium, oder, nach Dietz, aus dem celtischen bac, Höhlung, hervorging, kann uns gleichgiltig lassen. Das mittellateinische Bachinus und Bacinus, ergiebt sich ganz sicher aus bacca. Nicht unwichtig erscheint es mir in dieser Hinsicht, dass man vor Zeiten nicht Becken, sondern Bäcken schrieb.

In der neueren Anatomie hat das uralte Infundibulum, noch eine moderne Verwendung gefunden. Man hat, ganz unnöthiger Weise, die ausgebuchteten Endsäckchen der Bronchien, Infundibula ${ }^{1}$ ) genannt, obwohl sie einer Maulbeere ähnlicher sind, als einem Trichter.

\section{Penis.}

Ich könnte jetzt nur wiederholen, was ich über Penis, und seine zahlreichen, ergötzlichen Synonyma, an einem anderen Ort erschöpfend gesagt habe, und verweise deshalb den Leser auf HL, pag. 265, seqq., wo alles zusammengetragen wurde, was über die betreffenden Worte gesagt werden kann. Hier nur ein Nachtrag, über einige seltene, oder gänzlich ignorirte Synonyme von Penis.

Als die schönen Künste und Wissenschaften, nach tausendjährigem Todesschlummer, auf Italiens classischem Boden wieder erwachten, brach auch für die lateinische Sprache eine bessere Zeit heran, als sie bisher in den Schulen zu durchleben hatte. Das Studium der Classiker wurde von den Italienern mit Eifer betrieben, und wirkte auf die Sprache aller Wissenschaften in der wohlthätigsten Weise zurück. Selbst die Anatomen wollten und konnten nicht zurückbleiben. Sie gefielen sich

1) Rossignol, Sur la structure du poumon, Bruxelles, 1846. 
darin, von ihrer classischen Sprachbildung dadurch Zeugenschaft zu geben, dass sie ungewöhnliche und seltene Ausdrücke, welche ihnen die Lectüre der römischen Dichter darbot, in ihre Sprache aufnahmen, und als Termini technici verwertheten. So kamen die Worte in unsere Wissenschaft, welche ich jetzt aufzählen will. Ich habe sie im A. Benedetti, im G. Valla, Realdus, Fallopia, Piccolhomini, wie auch im Bauhinus, C. Stephanus, und J. Riolan aufgelesen. Sie sind heutzutage wieder gänzlich aufgegeben, da das Latein der Anatomen, wenigstens der Dissertationes inaugurales, und ähnlicher Gelegenheitsschriften, leider nur zu oft zum mittelalterlichen Barbarismus hinneigt, und, wenn es so fort geht, ihn bald übertroffen haben wird. Selbst der Stern der grössten Namen in der Anatomie, schickte sich zum Erbleichen an, wenn sie sich in den Kopf setzten, auch einmal ein lateinisches Opus zu verfassen (Wrisberg, Meckel der letzte, J. Müller, u. A.).

1. Als vielgenannt erscheinen Coles und Veretrum. Coles kommt von Caulis, wesshalb es auch als Colis geschrieben wird. Caulis ist aber Stängel einer Pflanze, und Stiel irgend eines Dinges. Im Homer als xaviós enthalten, bedeutet es Lanzenschaft, und wurde metaphorisch von Aristoteles dem männlichen Gliede verliehen. Veretrum, von vereor, schämen, entspricht dem Homerischen aiòws, und wurde von uns als Schamglied adoptirt.

2. Fascinus und Verpa. Der Horazische Fascinus, ist eine Personification des männlichen Gliedes, welches eigentlich Fascinum hiess $=$ dem griechischen $\beta \dot{\alpha} \sigma x$ xyov. Dieses leitet seine Abstammung von $\beta \alpha \sigma \alpha \alpha i v \omega$ her $=$ verschreien und verhexen. Im Plinius finden wir, dass Amulette, welche männliche Glieder darstellten, als Mittel gegen den bösen Blick und anderen Teufelsspuk in Credit standen, besonders für Kinder in der Wiege, aber auch für Hausthiere, insbesondere Kühe und Schafe. Fascinus est genus incantationis (Verzauberung), quo non solum infantes et homines, sed et equi, pulli, agni, aliaque domestica animalia, marcescunt et emoriuntur, heisst es in Bruno's 
Lexicon. In allen romanischen Sprachen, und im Englischen, hat Fascinatio ein Heimatsrecht erworben, um den Act, oder den Zustand der Bezauberung auszudrücken.

3. Ueber Verpa und Verpus, sieh' die betreffenden Artikel dieses Buches.

4. Nervus und Vas. Nervus, für männliches Glied, hat Horaz (Epod.VIII, 17), Tibullus (ad Priap., in Phall.Carm.63), und Juvenal (Sat. $I X$ und $X$ ). In einer Comödie des Aristophanes (Aves), wird die Erection durch das Zeitwort vEveúpura: ausgedrückt. - Unter dem scheinbar harmlosen Vas bemäntelt Plautus im Poenulus das Zeugungsglied. Das gekrönte Scheusal Heliogabalus erhielt von diesem Vas den Beinamen Vasatus, welcher ihm sehr viel Freude machte.

5. Gurgulio und Mentula. Gurgulio, eigentlich Zäpfchen im Halse, eignet sich nicht schlecht zum Substitut für Penis, wie im Persius ${ }^{1}$ ), und die Mentula des Catullus²), erklärt Spigelius: quia rigida haec pars, viro mentem eripit.

6. Veru und Veruculum, als Bratspiess und Wurfspiess, wird in der Anatomie geduldet, da die gleichwerthigen Hasta und Jaculum, bei den lasciven Comödienschreibern und Dichtern den Penis vertreten.

7. Phallus ( $\left(\alpha \lambda \lambda \delta_{\zeta}\right)$ drückt bei Herodot und Lucian, nur ein künstlich nachgebildetes Glied aus. Phallus kommt von $\varphi \dot{\alpha} \lambda$ irs, Pfahl. Als Versinnlichung der Zeugungskraft der Natur, wurde ein riesiger Pfahl aus Feigenholz, welcher die Gestalt eines männlichen Gliedes hatte, bei den Bachusfesten, in feierlichem Aufzug, von Priestern durch die Strassen getragen (Aristophanes, Acharn.). Aehnliches wurde uns von der Verehrung des Lingam in Indien, von Dr. Stangenwald berichtet. Für den wirklichen Penis, als Theil des menschlichen Körpers, wurde Phallus von den griechischen Aerzten nie gebraucht.

1) Sat. IV, Vers 38.

2) Mentula tam grandis, tantus tibi Pipile nasus,

Ut possis, quoties arrigis, olfacere. 
Diese Unart erlaubten sich nur ihre deutschen Collegen, welche ohne Noth, eine Unzahl Composita mit diesem Worte bildeten, um krankhaften Zuständen des Gliedes, zu gelehrttönenden Namen zu verhelfen, wie Phallocampsis. für Chorda venerea, und Phallorhoea für Tripper. Ich kann es nicht unterlassen, bezüglich des Wortes Phallorhoea, eine Bemerkung zu machen, welche alle in rhoea ausgehenden medicinischen Krankheitsnamen betrifft. Die griechischen Aerzte hatten nur ein einziges, einen krankhaften Ausfluss ausdrückendes Wort, welches mit

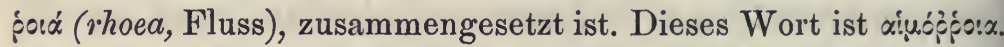
Alle anderen Worte in rhoea, welche in der Medicin so zahlreich angetroffen werden, sind Neubildungen. Ist das Vorwort eines solchen Compositums, eine Flüssigkeit, so kann die Neubildung zugelassen werden, wie Blennorrhoea, Spermatorrhoea, Galactorrhoea, Dacryorrhoea, etc., denn sie entspricht dem griechischen Vorbild Haemorrhoea. Ist aber das Vorwort keine Flüssigkeit, sondern ein Organ, dann sind alle diese neuen Worte Barbarismen, und zwar der lächerlichsten Art. Fragt einen Griechen, was Phallorrhoea, Balanorrhoea, Metrorrhoea, Proctorrhoea, Otorrhoea, u. s. w., heissen, so wird er sagen, dass sie einen Ausfluss von männlichen Gliedern und Eicheln, von Gebärmüttern, Mastdärmen, und Ohren ausdrücken, nicht aber Ausflüsse aus diesen Organen. Und doch führen alle Aerzte, alle Kliniker, alle medicinischen Schriften, diese Worte fortwährend vor, weil sie die absolute Lächerlichkeit derselben nicht einsehen. Phallorrhoea ist also ein Fluss, bei welchem männliche Glieder ergossen werden, wie Haemorrhoea, ein Fluss, bei welchem Blut ergossen wird. - Das kläglichste aber unter allen mit rhoea neugebildeten Worten, ist die Seborrhoea. Erstens kann ein spisses Fett (sebum), wie der Hauttalg, nicht fliessen, und zweitens kann das connubium infelix eines lateinischen und griechischen Wortes, nur einem erbärmlichen Zwitter das Dasein geben.

8. Tutunus ist $=$ Priapus. Nur versteht man unter Priapus, blos das erigirte männliche Glied sammt Zugehör (Scrotum), 
welches in verkleinerter Form aus Erz, von den römischen Frauen, die sich Kinder wünschten, als Amulet getragen wurde, und jetzt noch von den Weibern in Calabrien in dieser Absicht sporadisch getragen wird. Tutunus war aber nicht blos das Glied, sondern eine ganze Gottheit in persona, mit erigirtem Glied. Das Aussehen dieser Gottheit muss ein höchst groteskes gewesen sein, denn der erigirte Penis derselben war länger, als sein göttlicher Besitzer, vom Wirbel bis zur Sohle. Immania pudenda, horrensque fascinus, sagt Arnobius ${ }^{1}$ ), und etwas später wird dieser Gott, noch bestimmter, genitalibus propriis inferior genannt (kürzer als sein Glied ${ }^{2}$ ). Noch absonderlicher muss der Act der Verehrung gewesen sein, welchen fromme Damen diesem Götzen angedeihen liessen. Man übersetze sich die Worte des Arnobius, welcher als Vorkämpfer des Christenthums, sich kein Blatt vor den Mund nahm, um die scheusslichen Scandale dieses Götzendienstes, der Welt recht anschaulich vor Augen zu führen: Tutuni horrenti fascino, vestras inequitare matronas, et auspicabile ducitis, et optatis. Die Commentatoren lassen, aus Anstandsgefühl, diese Stelle unberührt. In den Comödien des Aristophanes, welche an Schlüpfrigkeit, wie an crasser Gemeinheit, Unglaubliches leisten, lässt sich eine ergiebige Nachlese von Tropen veranstalten, welche aber meistens nur auf die Glans penis bezogen weiden können. Ich erwähne qryós (im $P a x)=$ Eiche, quia glandes producit (ein Wortspiel); - ferner oưx.\%, Feige (ebenfalls im Pax), und

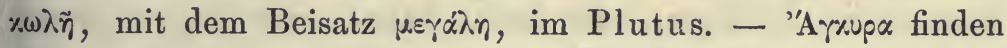
wir im Epicharmus, wegen des Festhaltens in der Vagina nach dem Coitus bei Hunden, und xóvtı̀os im Eupolis, welches eine Verkleinerung von xovtós, Stange, zu sein scheint. In Pierer's und Choulant's Anatomisch-physiologischem Realwörterbuch ${ }^{3}$ ), sind etliche neunzig lateinische und griechische

1) Adversus gentes, Lib. IV, Cap. 7.

2) Op. cit., Lib. VI, Cap. 25.

3) Bd.VI, Artikel: Penis. 
Synonyme für Penis zusammengestellt, welchen ich noch einige hinzufügte.

Das französische Pénil bedeutet nicht das männliche Glied, sondern den behaarten weiblichen Schamberg, welchen die Griechen Hebe und Gynaecomystax (Weiberschnurrbart) nannten.

\section{Pennatus und Semipennatus.}

Als man, nach Haller, anfing, in der Anatomie zu generalisiren, und Systeme aufzustellen, in welchen die Knochen, Muskeln, und Drüsen, nach ihrer äusseren Form eingereiht werden konnten, erstand auch die Gruppe der Musculi pennati und semipennati. Ich konnte nicht herausbringen, welcher Anatom der Erfinder dieser sonderbaren Muskelnamen war, und habe, bei der Geringfügigkeit der Sache, keine besondere Mühe darauf verwendet. So viel steht fest, dass vor Haller, man von Muskeln dieses Namens nichts wusste. Gegen Ende des vorigen Jahrhunderts, scheint Ch. Andr. Mayer, der erste gewesen zu sein, welcher diese Muskelgruppen erwähnt '). Musculi semipennati sind jene, deren Fleischbündel sich in schiefer Richtung an eine, den Rand des Muskelkörpers bildende Sehne ansetzen, während zu den Musculi pennati jene gehören, welche ihre Sehne in der Axe haben, so dass diese Sehne von beiden Seiten her schiefe Fleischbündel empfängt. Da das Bild solcher Muskeln an die ganze oder halbe Fahne einer Feder (penna) erinnèrt, erscheint auf den ersten Blick pennatus und semipennatus ganz passend gewählt worden zu sein. Leider hat aber pennatus bei den Classikern einen anderen Sinn, als sich die Anatomen dachten. Pennatus ist beflügelt, beschwingt, und befiedert. Der Pegasus erscheint im Plinius, als equus pennatus, die Bienen als apes pennatae, die beflügelten Amoretten im Claudian, als pennata cohors, und die beflügelten Zephyre

1) Beschreilung des menschlichen Körpers, Bd. III, pag. 55. 
im Lucretius, als zephyri pennati. Da nun unsere fraglichen Muskeln keine Flügel haben, ist pennatus und semipennatus auf sie nicht anwendbar. Allein unsere censorielle Strenge kann gemildert werden, indem wir den Vergleich eines Musculus pennatus mit einem Pfeil gestatten, an dessen Schaftende, schief gegen die Axe gerichtete Federchen eingesetzt sind, wie denn Plinius die schöne Metapher für Pfeil gebraucht: fermm pennatum, mit dem noch schöneren Zusatz: quam sceleratissimam humani ingenii fraudem arbitror, siquidem, ut ocyus mors perveniret ad hominem, alitem illam fecimus, pennasque ferro dedimus ${ }^{1}$ ). Auch die Wurfspiesse werden im Seneca, ihrer Befiederung wegen, pennata spicula genannt ${ }^{2}$ ).

Wenn also pennatus, als eine Metapher, im Catalog der Muskelnamen geduldet werden darf, erfreut sich semipennatus dieser Schonung nicht, denn der Muskel, auf welchen dieser Name angewendet wird, hat nicht zwei halbe Flügel, sondern einen ganzen. Bipennes und unipennes wären den pennatis und semipennatis, meiner Meinung nach, vorzuziehen.

\section{Perilympha.}

Das. Wort Perilympha ist so jung, dass es noch in kein Lexicon der medicinischen Sprache aufgenommen werden konnte. Die französische Anatomie hat es erfunden, und die Deutschen haben es fast allgemein adoptirt. Man drückt damit die seröse Feuchtigkeit aus, welche die 'beiden Vorhofssäckchen des Gehörlabyrinthes theilweise bespült, zum Unterschiede von Endolympha, welche im Inneren der Säckchen enthalten ist.

Ueber die Berechtigung des Wortes, lassen sich zwei Bedenken erheben. Erstens ist es ein Nomen hybridum, in welchem das griechische $\pi \varepsilon p^{i}$, mit del uralten lateinischen

') Hist. nat., Lib. XXXIV, Cap. 14, Sect. 39.

2) Thyestes, 861 . 
Lympha verbunden wird. Sieh' dieses Wort. Perilympha ist somit ein sprachlicher Missgriff, wie Periorbita. Es war auch nicht nöthig, solche neue Worte zu schmieden, da die alten: Humor labyrinthi und Periosteum orbitae, ganz correct und leicht verständlich sind. - Ein zweites Bedenken ist noch gewichtiger. Wenn die Hülle eines anatomischen Organs, eine besondere Bezeichnung erhalten soll, so wird diese dadurch gebildet, dass man dem Namen des betreffenden Organs, die Präposition $\pi \varepsilon \rho^{\prime}$ vorsetzt. So entstanden: Pericardium, Periosteum, Pericranium, Perimysium, Perichondrium, etc., - in der Botanik auch Pericarpium und Perianthium ${ }^{1}$ ). Diese Worte drücken Häute aus, welche das Herz, den Knochen, die Hirnschale, den Muskel etc., umgeben und einhüllen. Schafft man also eine Perilympha, so sagt dieses Wort eigentlich: was um die Lymphe herum ist, nicht aber eine umgebende Lymphe, wie der Gevater der Pevilympha sich gedacht haben wird. Bleiben wir also schon bei der Aquula Cotunnii, welche von jedem Anatomen verstanden wird, und deshalb nicht verdrängt werden soll.

\section{Perineum,}

Sieh' die Artikel: aeus, eus, und Interfemineum.

\section{Periosteum oder Periostium?}

Für beide Ausdrucksweisen finden sich Gewährsmänner.

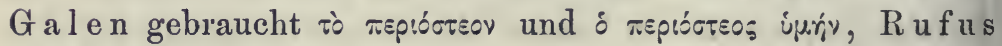

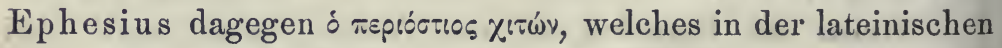
Uebersetzung von Rasarius, immer als Periostium, niemals

1) Es sei zugleich auf den Herpes periscelis, und auf die Binden in der alten Chirurgie: Pericnemis und Peritrachelium, hingewiesen. 


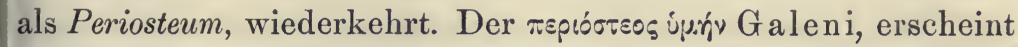

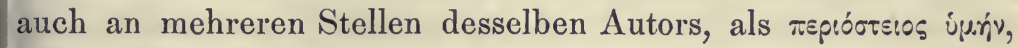
wie z. B. im Lib. I, Cap. 10, de semine. Periostium und Periosteum wären somit gleich gut. Periosteum wird aber ungleich häufiger gebraucht, als Periostium, welches letztere in neuerer Zeit so selten geworden, dass man es für einen Barbarismus halten könnte.

Anders verhält es sich mit den lateinischen Uebersetzungen des Wortes. Man thut dem Vesal Unrecht, wenn man ihm das barbarische Circumossale zuschreibt, wie es in Schreger's Synonymik, und im Anatomisch-physiologischen Realwörterbuch geschieht. Vesal umschreibt, als trefflicher Linguist (utriusque lingruae gnarus), die Beinhaut als Membrana ossa succingens oder circumcingens ${ }^{1}$ ), wohl auch anderswo als Membrana ossibus circumducta oder ossa amplectens. Auf Circumossalis, welches er zur wörtlichen Uebersetzung von $\pi \varepsilon p$ เócrsov, inter parenthesin hinzufügt (ac si circumossalem membranam diceres), legt er selbst keinen Werth. Er musste, bei seiner grossen Belesenheit, wohl gewusst haben, dass seine Vorfahren, die Latino-Barbari, schon eine Membrana circumossualis besassen (Berengarius), welche ihnen Niemand nachsagte. Das in A. Monro's Anatomy of the bones auffallende Synonymon für Beinhaut: Omentum osseum, ist kein neueres Spracherzeugniss. Es wurde aus dem Macrobius entlehnt: omentum, quod est impositum ossi ${ }^{2}$, und dient nur als Beleg, dass Omentum aus Operimentum (von operire, bedecken) durch Contrahirung hervorging, und Omentum ossium soviel als Involucrum ossium heisst. Die zerschnittenen Eingeweide der Opferthiere, wurden von den Priestern mit dem fettreichen Netz derselben bedeckt, um schneller verbrannt zu werden. Dadurch kam das Omentum zu seinem Namen, welcher ganz anstandslos auf andere bedeckende Membranen übertragen werden konnte.

1) De hum. corp. fabrica, Lib. I, Cap. 1.

2) Saturnalia, Lib. VII, Cap. 9. 
Die Composita, mit vorausgehendem ذ̇ระšsy, werden mit

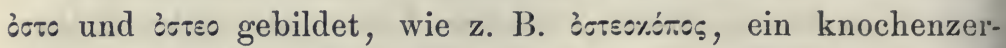
malmender Schmerz im Hippocrates, und bovsioyix, das Sammeln der Knochen, nach dem Verbrennen der Leiche, im Diodorus Siculus.

\section{Peritoneum oder Peritonaeum?}

Bei den griechischen Aerzten finden wir drei Ausdrücke

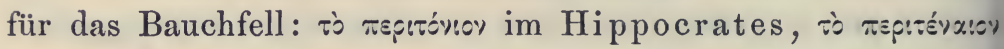

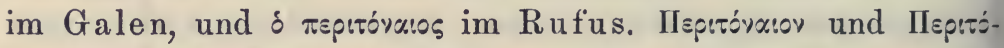
va:og sind nur Adjectiva. Das erstere steht im Aristoteles

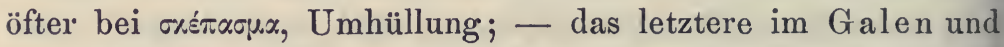
Oribasius, bei juptiv und $\chi^{\prime} \leftarrow \omega \dot{v}$, Haut. Hauptwort und Adjective beruhen auf $\pi \varepsilon p$ man sagen könnte: eine die Baucheingeweide umspannende, oder über sie gespannte Haut. Werden diese Worte im Latein verwendet, so entsteht Peritonium (nie gebraucht, obwohl ganz richtig), und Peritonaeum, aber nicht Peritoneum, welches letztere gerade fast ausschliesslich in usu steht. Wenn ein griechisches Wort in a.os, a! $\alpha$, oder a.o\%, latinisirt wird, kann es nur in aeus, aea, und aeum auslauten. Von einer Endigung in eus, ea, und eum, kenne ich kein einziges Beispiel. Der Lateiner sagt z. B.: cyrenaeus, cephalaea, und hypogaeum, niemals: cyreneus, cephalea, und hypogeum, schon deshalb nicht, weil das $e$ in diesen Worten positione ante vocalem kurz ist, während das ae, als griechisches $\alpha$, immer lang gehalten wird. Auffallender Weise sprechen die Anatomen, welche Peritoneum schrieben, es nicht als Peritonĕum, sondern als Peritonēum aus. Indem sie diesen prosodischen Fehler begehen, gestehen sie zu, dass sie eigentlich Peritonaeum zu schreiben und zu sprechen haben. Cornelius Celsus belehrt uns nicht darüber, ob es erlaubt ist, Peritoneum

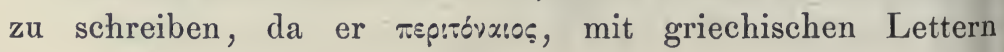


schreibt 1). Caelius Aurelianus kennt nur Peritonaeum: quod omnia viscera continet atque contegit $\left.{ }^{2}\right)$. Mit ihm sollen es auch die Anatomen halten. Vesal, der gelehrteste Antagonist des Galen und seiner Lehre, welcher auch die griechische Sprache in der Anatomie nicht dulden wollte, hat doch das Galenische Peritonaeum nicht verstossen.

Die deutsche Sprache, welcher man die Anerkennung zollen muss, dass sie sich viel bessere anatomische Ausdrücke zu schaffen wusste, als es die griechischen und lateinischen sind, hat auch für Peritonaeum das rechte Wort gefunden: Bauchfell. - Die zahlreichen lateinischen Synonyme für Peritonaeum, drücken alle den Grundgedanken einer vereinigenden, umspannenden, und überziehenden Haut aus, wie Membrana praetensa und Operimentum praetensum im Spigelius, Cinctum und Cinctus im Wolfgang Seber, dem Uebersetzer des Julius Pollux, Velamentum abdominale im lateinischen Galen, Membrana succingens im Rasarius, und die arabischen Worte Chamel und Ziphac der Latino-Barbari. Ueber letztere enthält das Nähere §. XCV meiner Schrift: Das Arabische und Hebräische in der Anatomie.

Ueber andere, meist technische Verwendungen von Pentonaia und Pentonaion, giebt Julius Pollux Auskunft. (Sieh' Index zum Onomasticon.)

\section{Perone.}

Näheres über Perone, im Artikel: Fibula.

\section{Pes anserinus.}

Diesen albernen Tropus hat Winslow auf dem Gewissen. Er sagte von dem strahligen Zerfahren des Communicans faciei

1) De medicina, Lib. IV, Cap. 10.

2) Morbi acuti, Lib. III, Cap. 17.

Hyrtl. Onomatologia anatomica. 
in und vor der Ohrspeicheldrüse, il ressemble à une patte d'oie ${ }^{1}$ ). Der Vergleich gefiel, und fand bleibende Bestallung in der Anatomie. Ja man fügte noch einen Pes anserinus minor hinzu, in welchen sich der Nervus infraorbitalis im Gesichte auflöst. Meckel kam der Vergleich doch zu närrisch vor, und er erkor sich für den Gänsefuss, den schicklicheren Ausdruck Plexus parotideus. Da man aber von der Gans nicht so leicht lassen wollte, machte Rosenmüller seinen ganz ungeheuerlichen Plexus anserinus ${ }^{2}$ ) daraus, das Gänsegeflecht. Warum bleibt man nicht bei Haller's Plexus, wenn es schon durchaus für nothwendig erachtet wird, dem strahligen Zerfahren, welches an so vielen Nerven sich zeigt, gerade beim Communicans faciei einen besonderen Namen zu geben.

Der Nervus communicans faciei s. facialis, erhielt diesen Namen von Wrisberg ${ }^{3}$ ). Man sieht nicht recht ein, was das communicans eigentlich $\mathrm{zu}$ bedeuten habe. Wrisberg wollte damit die weitreichende Verbreitung dieses Nerven im Gesichte ausdrücken, quia omnibus faciei partibus ramos communicat. Facialis sagt gar nichts, da jeder Nerv im Gesicht, ein facialis ist. Sympathicus parvus von Winslow, und Consensorius parvus von Andersch, sollen dasselbe ausdrücken wie communicans, quia cum nervo trigemino, vago, sympathico, et cum nervis cervicalibus superioribus, pluribus anastomosibus connubium init. Motorius faciei wäre am entsprechendsten, und Septimus am kürzesten.

Da der Septimus, mit dem Octavus (Acusticus) zusammen, in den Meatus auditorius internus eingeht, wurden beide Nerven lange Zeit als Ein Paar aufgefasst, und zwar als Par quintum der Alten, Par septimum der Neueren. Das harte Anfühlen des Septimus, gegen das weiche des Octavus, veranlasste schon Fallopia, die beiden Nerven als portio dura und portio mollis

1) Expos. anat., Traité des nerfs, Num. 91.

2) Handbuch der Anatomie, 1808, pag. 400.

3). Note 99 zu Haller's Grundriss der Physiologie. 
paris quinti zu benennen ${ }^{1}$ ), welche, als mittlerer Weile das fünfte Paar des Fallopia, durch den Zuwachs des Olfactorius und Trochlearis, zum siebenten Paar avancirte, sich in Portio dura et mollis paris septimi veränderte. Diese Benennung verblieb ihnen so lange, bis Sömmerring diese beiden Nerven als selbstständige Hirnnervenpaare von einander trennte ${ }^{2}$ ).

\section{Pes hippocampi s, hippopotami major et minor.}

Aus der Fabelwelt der Thiere, hat sich die Anatomie die Pedes hippocampi und aus der monstrorum ferax Africa, die Pedes hippopotami geholt. Ueber beide sieh' den Artikel: Digitationes hippocampi.

\section{Phalanges,}

Für die Glieder der Finger und Zehen, giebt es nur eine einzige lateinische Benennung - Internodia; - alle übrigen sind griechisch. Die Gelenke der Finger hiessen, wie alle anderen Gelenke an den Gliedmassen, Nodi ${ }^{3}$ ), weil sie aufgetriebener erscheinen, und sich härter anfühlen, als die ihnen zunächst befindlichen Gegenden. An einen Vergleich mit den Knoten an Rohrgewächsen, scheint nicht gedacht worden zu sein, da die Knoten des Rohres nicht beweglich sind. Heissen nun die Gelenke der Finger Nodi, so müssen die kurzen Knochen der Finger, welche die Nodi bilden, Internodia genannt werden. Die Internodia waren es denn auch, welche die

1) Ego, quintum par, ex parte dura et molli constare dicam. Observ. anat., Venet., 1561, pag. 148.

2) Hirn- und Nervenlehre, pag. 228.

3) Articulorum nodi im Plinius, und crura sine nodis, steife Füsse, im Jul. Caesar. 
Sulemet ${ }^{1}$ ) der Arabisten aus dem Verkehr brachten. - Im A ristoteles heissen die Fingergelenke xóvôùঃ, weil sie, bei geschlossener Faust, rundliche Hervorragungen bilden ${ }^{2}$ ) (Condylomata). Im Rufus wird nur das mittlere Fingergelenk \%óvôù.os

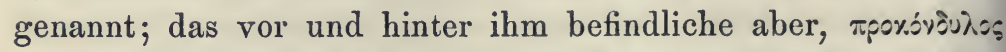

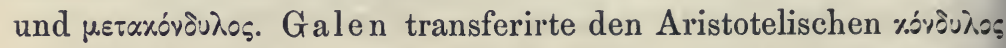
$=$ Gelenk, auf die Fingerglieder selbst, und die Anatomen des Mittelalters folgten ihm hierin mit ihren condyli $=$ Fingerglieder. Dass sie dieselben auch Scuticulae nannten, beruht sicher nicht auf parvum scutum, wie Stephanus meint, da sie mit kleinen Schildern gar nichts gemein haben, wohl aber auf Scutula, worunter Cato eine kleine Walze versteht, welche zum Fortrollen geringerer Lasten verwendet wurde. Die walzenförmige Gestalt der Internodia, könnte nur für die ersten Zehenglieder, Veranlassung zu dieser Benennung gegeben haben, denn die Internodia der Finger sind nicht cylindrisch, sondern platt. Scuticulae könnte auch für eine

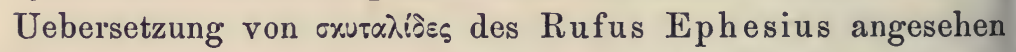
werden, worunter dieser Autor sowohl kurze runde Stäbchen, als die Fingerglieder versteht. Celsus spricht von den Fingergliedern nur als Ossa terna digitorum.

Der Aristotelische Name der Fingerglieder: Phalanges, hat sich am längsten erhalten, und alle übrigen vergessen gemacht ${ }^{3}$ ). Er convenirt ihnen ganz gut, da die Glieder eines Fingers, in einer Reihe aufeinander folgen, wie die sechsfachen Reihen der Soldaten in der griechischen Phalanx. Laurentius erklärt die anatomische Phalanx: phalanx vocatur horum ossium series, quia velut in acie stare videntur. Phalanx war also ursprünglich nicht das Fingerglied, sondern die Reihe der Fingerglieder. Vesal übersetzt deshalb Phalanx mit Acies und Agmen. Nur per tropum war es möglich, die

1) HL, §. XCIX.

2) Hist. anim., Lib. II, Cap. 11.

3) Hist. anim., Lib. I, Cap. 15, und Lib. III, Cap. 34 . 
ganze Process wurde als ein Act des Durchseihens und Filtrirens gedacht. Wir können es an uns selbst beobachten, dass, bei vernachlässigter Reinigung der Nase, dünner Nasenschleim aus den Nasenlöchern sich in das Grübchen der Oberlippe herabsenkt, so dass auch dieses Grübchen, gleichsam als das letzte Glied des ganzen Filtrirapparates, Filtrum genannt worden sein kann. Die Sache erschien mir um so plausibler, da Filtrum im Du Cange, auch als Philtrum vorkommt. - Dem eben Gesagten steht aber entgegen, dass Philtrum als Grübchen der Oberlippe, schon von den Griechen verbürgt wird. Sein Ursprung aus dem neulateinischen Filtrum, so consequent er sich verfolgen liesse, kann also nicht zugegeben werden. Im $\mathrm{Rufus}{ }^{1}$ )

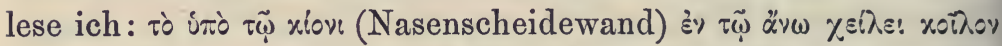

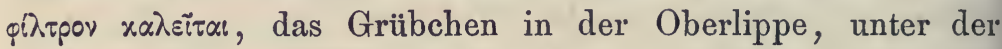
Nasenscheidewand, wird $\varphi\left(\lambda \tau p o \nu\right.$ genannt, und im Pollux $\left.{ }^{2}\right)$ :

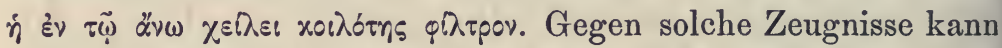
sich kein anderes etymologisches Raisonnement halten, wenn gleich wir durchaus nicht einsehen, wie so das griechische

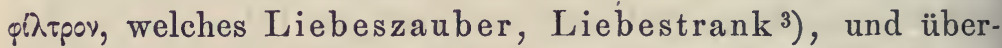
haupt Alles, was Liebe erweckt (von $\varphi(\lambda \varepsilon \dot{s} \omega$, amare), bedeutet, mit der Grube in der Oberlippe zusammengebracht werden konnte. Besagte Grube gehört weder zu den sieben Schönheiten, noch wurde sie je von verliebten Dichtern besungen, und fehlt den hässlichsten Megären, wie auch den beschnurrbarteten Männern nicht. Höchstens könnte das Philtrum, als ein Attribut des Mundes, welcher von je her mit den Liebesaffairen selbst bis zu dem von Arnobius ${ }^{4}$ ) erwähnten stuprum oris

1) De partibus hominis, pag. 26. Ebenso pag. 48 .

2) Onomasticon, Lib. II, Cap. 91.

3) $\quad{ }^{3}$ Nec data profuerint pallentia philtra puellis, "Philtra nocent animis, vimque furoris habent."

(Ovidii Ars amandi, II, 105.)

4) Die Kraftworte lauten : "In lupanaribus promptae (feminae) venalia prosternunt corpora, nihil pati renuentes ad oris stuprum paratae." Adversus Gentes, Lib, II, Cap. 42. 
(quod animus memminisse horret) - zu thun hatte, auf einige Berechtigung Anspruch erheben. Das wäre aber im höchsten Grade gesucht, und wir können dem Philtrum nicht anders helfen, als dass wir es für eine der vielen, unerklärlichen Launen des Sprachgebrauches halten. - Der Wurzel $\varphi$ i $\lambda \varepsilon$ getreu, übersetzten unsere naiven Vorfahren, Philtrum mit Amatorium und Amabile. - Ecce, maxima de nihilo, nascitur historia!

\section{Pharynx.}

Die Verwechslung von Larynx mit Pharynx abgerechnet (sieh'Artikel: Larynx), war Pharynx ${ }^{1}$ ) nie etwas anderes, als der hinter dem Isthmus faucium befindliche, trichterförmige Sack, welcher sich in die Speiseröhre fortsetzt. Nur im Aristoteles finden wir фqápư̧ als Hals (oder Gurgel, Kehle), und im Heliodorus als Wamme des Stieres. Galen definirt den Pharynx, wie wir es nicht besser thun könnten, als: latum spatium (Ejpuywpia), quod, dum aperitur os, et deprimitur lingua, apparet, ubi gemina ora sunt: videlicet stomachi (Speiseröhre) et laryngis. Noch kürzer drückt sich Plinius aus: summum gulae pharynx vocatur. In S tephani Diction. med. wird Larynx als Synonym von Pharynx erwähnt.

\section{Phrenicus,}

Phrenicus ist ein, nur in der Anatomie heimisches, aus qpévss gebildetes, neues Adjectiv 2). Phrenes und Diaphragma

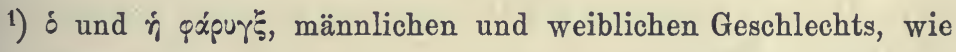
Larynx.

$\left.{ }^{2}\right)$ Es giebt nur ein griechisches Adjectiv ppevtrixós. Im Hippocrates wird es auf einen an Phrenitis Leidenden angewendet. Phrenitis = delirium ex inflammatione cerebri, - im Celsus: insania febricitantium, Lib. II, Cap. 3. 
sind synonym, somit phrenicus = diaphragmaticus. Die థ̣pśves wurden schon von Hippocrates und Aristoteles für Zwerchfell gebraucht, und kehren mit derselben Bedeutung im Galenus, Oribasius, und Rufus, sehr oft wieder. Es

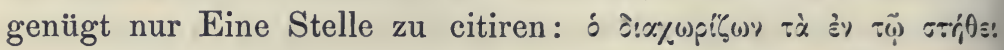

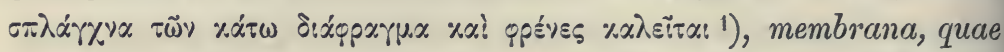
pectoris viscera ab inferioribus disjungit, Diaphragma vel Phrenes

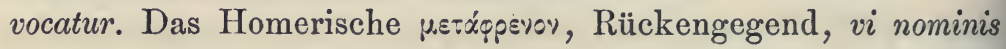
das hinter dem Zwerchfell Liegende, hat sich auch in die Anatomie einzudrängen versucht (Laurentius, Spigelius), brachte es aber nicht zu einer bleibenden Stellung.

Schwieriger fällt es zu sagen, warum ein einfaches Ding; eine Benennung in plurali erhielt. Ich will es versuchen. Фpri, gleicht unserem Denk-, Empfindungs- und Willensvermögen, als Seele und Gemüth. Leidenschaftliche Erregung und Affecte verschiedener Art, welche die Seele in Aufruhr bringen, oder sie bedrücken, wie Kummer und Trauer, haben einen auffallenden Einfluss auf die Athmungsthätigkeit des Zwerchfells. Solcher Affecte giebt es viele, und ebenso viele Rück-

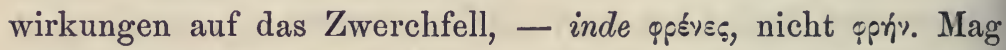
diese Erklärung dem Leser auch gewagt erscheinen, besser ist sie als keine. Vielleicht giebt es auch keine für eine blosse Laune des Sprachgebrauchs. Wäre, wie die alten Glossarien sagen, der Grund der Benennung als Phrenes, darin zu suchen, quod diaphragmate inflammatione affecto, mens quoque laedatur, et continuum prope delirium excitetur (Gorraeus), so müsste das

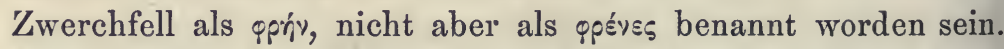
Man beliebte ganz willkürlich, Phrenes mit Praecordia zu übersetzen. Praecordia - wieder ein Plural - kann nur die vor-

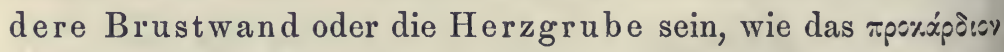
des Julius Pollux.

Da kein griechisches Beiwort opsv'xós aufzutreiben ist, so wäre es räthlich, das lateinische phrenicus, allenthalben in

1) Rufus Ephesius, De partibus hominis, pag. 38 . 
diaphragmaticus umzuändern, - auf die Paar Buchstaben mehr kommt es ja nicht an. Das Ligamentum phrenico-hepaticum und phrenico-gastricum aber müssen unbedingt in phreno-hepaticum, und phreno-gastricum umgeschrieben werden, da sie vom Zwerchfell, nicht vom phrenicus ausgehen. Das ist keine naseweise Worttändelei, sondern eine grammatikalische Nothwendigkeit.

Uebrigens hat der Nervus phrenicus, bevor Bauhin ihn mit diesem Namen hervorhob, Nervus septi transversi oder diaphragmatis geheissen. Die übrigen älteren Benennungen dieser Nerven, worunter zwei sehr komische ${ }^{1}$ ), finden sich in den Synonymien von Schreger, Pierer und Choulant.

\section{Placenta}

Das Wort Placenta kommt, vor Realdus Columbus in der Anatomie nicht vor. Nicht Fallopia, wie es im Pierer heisst, sondern Columbus, gab dem Mutterkuchen diesen Namen. Die Res anatomica des Columbus erschien 1559, die Observationes anatomicae des Fallopia drei Jahre, und die Opera omnia 23 Jahre später. Columbus gedenkt dieses Organs als Affusio, worin ich eine verunglückte Uebersetzung von Parenchyma sehe, und setzt erklärend hinzu: in modum orbicularis placentae (ein parenchymatöser Körper von Kuchengestalt ${ }^{2}$ ). Mundinus und seine Anhänger hatten für den Mutterkuchen, welchen sie nur als pars secundinae kannten, keinen besonderen Namen. Erst Alexander Benedictus erfand sich einen solchen, in seiner fleischigen Hervorragung: Exstantia carnosa involucri (Chorii $\left.{ }^{3}\right)$. Auch Aristoteles, Galen

1) Nervus parvus harmonicus, und Nervus quadragesimus sextus, aus Andersch, Tractatus de corporis hum. nervis aliquibus, §. 48 und 77 .

$\left.{ }^{2}\right)$ De re anatomica, Lib. XII, de formatione foetus.

$\left.{ }^{3}\right)$ Anatomice, Lib. II, Cap. 24, de mulierum locis (ad finem). 
und die griechischen Aerzte, kannten den Mutterkuchen nur als ox́pł, d. i. Caro (sieh' diesen Artikel), und zwar eine Caro, welche die Verbindung der Gebärmuttervenen mit den Venen des Chorion zu sichern hatte (caro concreta circa vasorum orificia ${ }^{1}$ ).

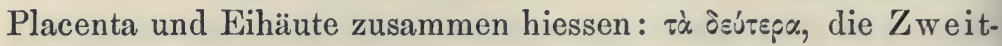
gebornen, woraus die Lateiner ihre Secundinae bildeten (sieh' diesen Artikel).

Placenta ist eine Frucht des griechischen Sprachstammes. Sie kommt von $\pi \lambda \alpha^{\prime} \xi$, Kruste, platter Körper oder Kuchen

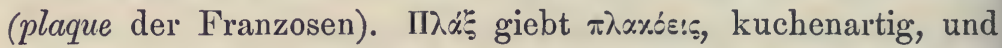

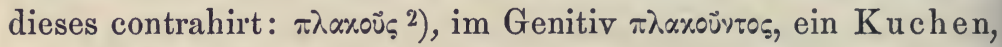
aus welchem die altrömische Placunta, und darnach die minder rauhe Placenta hervorgingen. Placenta tritt ïberall nur als Kuchen auf. Dieser Kuchen wurde aus feinstem Weizenmehl, Honig, Milch, und Käse bereitet ${ }^{3}$ ), und, in vier Theile zerschnitten, den Gästen bei der Tafel ausgetheilt, oder, bei festlichen Veranlassungen, den Bekannten in's Haus geschickt: misi hyblaeis madidas thymis placentas (Martial). In den Gloss. Philox. finden wir Placentarius, als Zuckerbäcker. Placentae aus Rosenblättern (rosaceae), waren einst officinell, als Umschläge auf den $\mathrm{Kopf}^{4}$ ), und die Placentulae ad tussim, werden jetzt noch in den Apotheken gehalten (Pruminzen- [Mentha pip.] und Katarrhzelteln der Wiener).

Arantius verglich den Mutterkuchen, seines Gewichtes und seines Gefässreichthums wegen, mit der Leber ${ }^{5}$ ); und nannte ihn sofort Hepar uterinum. Der runde Fibrinkuchen, welcher in der Aderlassschale schwimmt, heisst seit undenklichen Zeiten: Hepar, s. Crassamentum, s. Placenta sanguinis

1) Galenus, De usu partium, Lib. XV, Cap. 4.

2) Sehr oft in den Comödien des Aristophanes zu finden.

3) Cato, De re rustica, Cap. 76 .

4) Morley, Coll. chym. Leid., Cap. 363.

5) De humano foetu opusculum, Romae, 1564, Cap. 6. 
(Blutkuchen). Fast alle Benennungen dẹs Mutterkuchens in fremden Sprachen, spanisch und italienisch ausgenommen, beziehen sich zugleich auf die Eihäute.

\section{Planta und Plantaris.}

Wie es kam, dass Pflanzen und Fusssohlen denselben Namen, Plantae, führen, wurde noch nicht aufgeklärt. An planus zu denken, weil Fusssohlen und Blätter der Pflanzen plan sind, wäre doch etwas zu weit ausgeholt, obwohl es bei Planta pedis, als Fusssohle, nahe liegt, an planities zu denken.

Celsus versteht unter Planta, das ganze Fussgerüst sammt Weichtheilen, nicht blos die untere Fläche des Fusses 1). Ebenso Plinius, wo er von den Füssen (plantae) der Inder sagt, dass sie bei Männern eine Elle lang sind, bei Weibern aber so kurz, dass sie struthopodes, Straussfüssler, genannt zu werden verdienen ${ }^{2}$ ). Exsurgere in plantas, im Seneca, lässt uns gleichfalls die planta nur als ganzes Fussgestell annehmen. Im Virgil u. A. dagegen wird mit Planta, nur die untere Fläche des Fusses ausgedrückt:

\section{„Ah! tibi ne teneras glacies secet aspera plantas."}

Mit den Dichtern halten es auch die Anatomen, und die planta pedis, als Fusssohle, wird kein Ende nehmen. Dieses wünschen wir nur recht bald dem unerträglichen Musculus plantaris, unter welchem man seit Paraeus und Riolan, jenen kleinen, aber sehr langsehnigen Muskel versteht, welcher, mit dem Gastrocnemius und Soleus, die Achillessehne bildet, also nicht in den Plattfuss hinab kommt. Ich habe für ihn den Namen Gracillimus surae vorgeschlagen, nach dem. Jambier grêle des

1) De medicina, Lib. VIII, Cap. 23.

2) Hist. nat., Lib. VII, Cap. 2, Sect. 2. 
Winslow ${ }^{1}$. Henle betrachtet den Plantaris als dritten und kleinsten Kopf des Triceps surce. Auch Extensor pedis minor könnte er, nach Douglas, genannt werden, insofern er an der Bildung der Achillessehne participirt. Der petit fémoro-calcanien ist einer der besten Muskelnamen, welche Chaussier

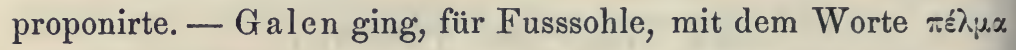
voran ${ }^{2}$ ), welches ebenso Fusssohle, als Schuhsohle bedeutet.

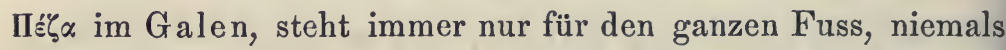
für Fusssohle, wie Schreger glaubt, ebenso wie $\pi$ sò̆or nie für Plattfuss, sondern ausschliesslich für den Complex der fünf Mittelfussknochen, welchen wir Metatarsus nennen. Das Hippocratische $\sigma \tau \tilde{n} \theta 0 \xi \pi 0 \delta \delta$, wurde noch weniger für Plattfuss angesprochen, sondern immer nur für den convexen Fussrücken, weil $\sigma \tau \tilde{n} 005$, ein allgemeiner Ausdruck für alles Hervorstehende ist, und in specie die gewölbte Brust von Homer damit bezeichnet wird.

Indem die Fusssohle auf weichem Boden ihren Abdruck hinterlässt, als Fussspur, fand Vesal an dem metaphorischen Vestigium des Cicero, für Plattfuss, so viel Gefallen, dass er es öfter gebraucht, und seine Schüler ebenfalls. $A$ vestigio ad verticem, von der Sohle zum Scheitel, lesen wir im Plinius, und im Lactantius: non est quisquam tam ineptus, qui credat, esse homines (Gegenfüssler), quorum vestigia sunt superiora quam capita.

\section{Platysma myoides,}

Dieser Name des breiten, subcutanen Halsmuskels, wurde zuerst durch Fallopia ${ }^{3}$ ) aus dem Oribasius entlehnt, wo es von ihm heisst: haec musculosa pars, clarioris doctrinae causa,

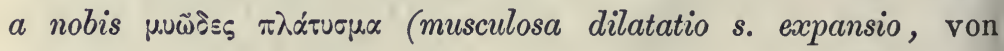

1) Traité des muscles, §. 589.

2) Oribasius, Op. cit., pag. 253.

3) Observationes anat., Cap. de auricularum musculis. 
$\pi \lambda \alpha \tau^{\prime} s$, breit) vocabitur $\left.{ }^{1}\right)$. Santorini machte aus den zwei Galenischen Worten ein einziges: Platysmamyodes ${ }^{2}$ )!

Vesal periphrasirte den Muskel als primus, qui buccas et labia movet, und Casserius, welcher ihm einen Antheil an der Bewegung des Ohres zuschrieb, nannte ihn Musculus auriculae et utrique labro communis. Diese Benennungen wurden aber aufgelassen. Es blieb, neben dem Platysma, nur der Quadratus s. Tetragonus genae, nach Cowper, und der Subcutaneus s. Latissimus colli von Jac. Douglas. Der Kürze wegen, wird unser Muskel schlechtweg auch blos Platysma genannt.

Galen nannte auch ein auf einem Leinwandfleck aufgestrichenes Pflaster: Platysma ${ }^{3}$ ), und Aëtius spricht von

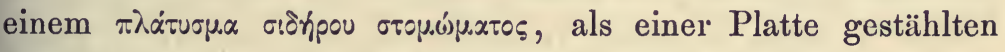
Eisens ${ }^{4}$ ), dessen er sich als Verbandgeräth bediente.

Als ein altersschwacher Ausdruck, möge das Platysma myoides bald der Vergessenheit anheimfallen. Denn alle breiten Muskeln des Rückens und des Bauches, sind ja eigentlich Platysmata, und das Platysma colli ist so gut ein wahrer und echter Muskel, wie der Glutaeus oder Gastrocnemius, während das Adjectiv myoides, ihm blos die Aehnlichkeit mit einem Muskel zugesteht. Ich würde mit Douglas für Subcutaneus colli stimmen, wenn das Wort grammatikalisch richtig wäre. Die Classiker kennen nur Subtercutaneus. Latissimus colli, und Platysma colli, wären deshalb vorzuziehen.

1) Oribasius, Anat. ex Galeno, pag. 173. Das betreffende Capitel im Oribasius führt den Titel: De musculis sub colli cute latentibus, ac buccas moventibus. Das Platysma war also damals schon, als ein Muskel der Backen und der Lippen anerkannt.

2) Observationes anat., Cap. 1. §. 33.

3) De compositione medicamentorum, Lib. IV, Cap. 14.

$\left.{ }^{4}\right)$ Gorraeus, Defin. med., pag. 378. 


\section{Pleura,}

Pleura, als Rippenfell, ist eine Metonymie. Pleura ist ein griechisches Wort, welches nie für Rippenfell gebraucht

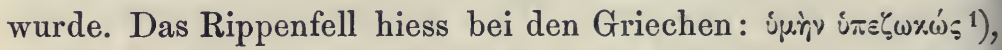
d. i. Membrana succingens (costas), nach Vesal's richtiger Uebersetzung. II $\lambda \varepsilon u p \alpha ́$, und die poetische Nebenform $\pi \lambda \lambda_{\varepsilon u p \delta ́ v,}$ drücken die Seite eines Gegenstandes ${ }^{2}$ ), auch des menschlichen Körpers aus, wie im Aristoteles. Daher kommt Pleuritis, von Paracels us zu Pleuresis verdorben, als entzündlicher Seitenstich. Da die Rippen an den Seiten des Thorax liegen, wurden sie

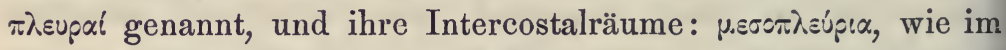
Galen und Oribasius. Die Membran, welche die Rippen an ihrer inneren Fläche überzieht, erhielt erst spät, und zwar von den lateinschreibenden Restauratoren der Anatomie, den Namen Pleura. Pleura est panniculus, substantia durus et nervosus, in quantitate magna cooperiens omnes costas ${ }^{3}$ ). Vesal behielt die Pleura des Mundinus bei: Membrana costas succingens, vulgo pleura dicta, und sicherte, durch seine Autorität, ihren Bestand für immer. Die Haut mag den Namen Pleura führen,

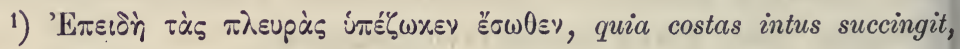
Oribasius, Op. cit., pag. 70.

2) Z. B. iøó $\pi \lambda \varepsilon u \rho o v=$ gleichseitiges Dreieck im Julius Pollux,

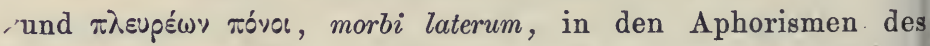
Hippocrates. Wir werden auch bei lateinischen Dichtern, durch Costa statt Latus überrascht, wie: equi conscendere costas, vom Aufsitzen des Reiters im Lucretius, und tardi costas aselli vilibus onerare pomis, den Esel beladen, im Virgilius. Das französische côte und côté, Seite, das spanische cuesta, und das italienische accostare, von der Seite her nähern, beruhen auf demselben Begriff von costa, als Seite.

3) Anathomia Mundini emendata, Cap. de anathomia panniculorum pectoris. 
da sie an der Seite des Thorax haftet, und die Rippen überzieht, weshalb sie auch im Bartholin als Membrana costalis gefunden wird. Aber Membrana pleuritica oder pleuretica, wie im Alex. Benedictus, darf sie niemals heissen, da man ein gesundes Organ, nicht nach einem seiner krankhaften Zustände benennen kann.

Auffallender Weise betrachteten unsere Vorfahren die Pleura nicht als eine selbstständige Membran, sondern liessen sie entstehen: ex tunicis, quae nervos intercostales, ex spina dorsi egredientes tegunt, a quibus continuitas illi (pleurae) est cum meningibus cerebri ${ }^{1}$ ).

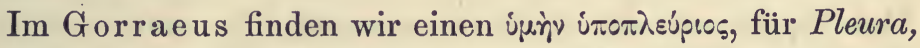
und erkennen diesen Ausdruck in der Membrana subcostalis des Sylvius und Riolan wieder.

\section{Plica,}

Plicae giebt es nur in der Anatomie. Das Wort Plica gehört dem Mönchslatein zu Anfang des 13. Jahrhunderts an. Früher war es unbekannt, oder wenigstens nicht gebräuchlich. Zur selben Zeit wurde auch der in Polen endemische Weichselzopf (gozdzieć, Judenzopf, Maarenflechte), zuerst Plica polonica genannt. Die Mönche schrieben plices und plicae. Du Cange citirt aus Urkunden: quatuor plices in longitudine. Plica war auch ein in Falten gelegter Bestandtheil der Mönchstracht, welcher den Hals umgab, a plicatura. Durch die Mönche kam Plica in ihre lateinischen Uebersetzungen der griechischen und arabischen Aerzte, und ist bis nun in der Anatomie so heimisch geworden, dass es von Niemand für barbarisch gehalten wird.

Aus plicare, falten, giebt es nur zwei Descendenzen im Plinius: plicatilis, zusammenlegbar, und plicatura, der Act

1) Th. Bartholinus, Institutiones anatomicae, Lib. II, Cap. 4. 
des Faltens, auch Falte. Plicatura hat gleiche Entstehung wie scriptura, von scribo, junctura von jungo, mixtura von misceo, fractura von frango, und viele ähnliche. Da die plica kürzer, und somit bequemer ist, als die plicatura, fand sie überall Aufnahme. Alle Faltenbildungen heissen Plicae. Ja es wurden selbst Dinge, welche keine Falten sind, wie die Processus ciliares, und die Cristae der weiblichen Scheide, Falten genannt, während die griechischen Worte für Falte, $\pi \tau$ 's und $\pi \tau \dot{\jmath} \gamma \mu . x$ (von $\pi \dot{v} \sigma \sigma \omega=$ plico), nie von den griechischen Anatomen gebraucht wurden. Ptygma kommt nur im Aretaeus als gefaltete, zusammengelegte Leinwand, als Compresse zum Verband vor. Das Hippocratische $\pi \lambda \lambda^{\prime} \alpha_{\alpha} s$ (Leistengegend), 'stammt nicht von

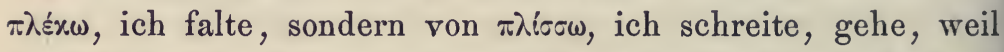
beim Gehen, die Leistengegend sich einbiegt, als Leisten $\mathrm{nbug}$. Plicatus, als Particip von plicare, aus der palma plicata uteri bekannt, verstösst gegen keine Regel. Die italienischen und französischen Worte: $p l i^{1}$ ) und piega, sind Stiefkinder von plica; - das englische fold aber, welches vom niedersächsischen feald und folden entstand, und das spanische falda oder halda, gehören zur deutschen Falte.

\section{Pomum Adami, und Pomum s. Malum granatum.}

\section{Pomum Adami.}

Die Araber, insbesondere Haly Abbas, belegten verschiedene rundliche Erhabenheiten, am und im menschlichen Körper, mit dem Namen Pomum; z. B. den Kniescheibenvorsprung, den grossen Trochanter, den Schenkelkopf, u. m. a. Die Griechen verfuhren ebenso mit ihrem $\mu$.

1) Ja nicht plie, denn plie ist der Name eines bekannten, breiten und flachen Seefisches, welcher von Ausonius zuerst Platessa genannt wurde - Platteis der Deutschen, platija der Spanier, Pleuronectes platessa $\mathrm{L}$ in $\mathrm{n}$. 
nur für rundliche Erhabenheiten, welche sich weich anfühlen, wie die Brüste, die Hoden, die Schilddrüse, und die Mandeln. Der den spanischen Arabern bekannteste Apfel, war der in Granada. wild wachsende Granatapfel. Sie setzten deshalb dem Pomum, gerne das granatum bei. Den Vorsprung, welchen der Kehlkopf nur am männlichen Halse bildet, nannten sie Pomum viri, und da vir im Arabischen adam heisst, machten die hebräischen wie die lateinischen Uebersetzer, aus dem Pomum viri, ein Pomum Adami, welchen die frommsinnige Beschränktheit jener Zeit, mit der Erbsünde in Zusammenhang brachte, da dem Adam, auf Gottes Ruf: wo bist Du! ein Theil der Frucht vom verbotenen Baum, vor Schreck im Halse stecken blieb, und die Geschwulst am. Halse erzeugte, welche alle Männer, weil alle in Adam gesündigt haben, als amende honorable tragen müssen: ad posteros propagatum istius maleficii signum ${ }^{1}$ ). Eben dieses scharfsinnigen Commentars wegen, wird das Pomum Adami, in Ewigkeit aus der Anatomie, welche auch heiter sein kann, nicht wegzubringen sein, unbeirrt durch den vernünftigen Nodus gutturis, und die Prominentia laryngea (Lieutaud, Winslow, Haller).

2. Pomum s. Malum granatum, auch punicum.

Durch's ganze Mittelalter dauerte diese Benennung des Schwertknorpels. Woher sie stammt, sagten die Anatomen damals schon, - aber Jeder anders. Der Eine verglich den Schwertknorpel mit einem Blüthenblatte des Granatapfelbaumes (Berengarius), der Andere nur mit der Spitze eines solchen Blattes (Vesal), ein Dritter mit der Rinde des Granatapfels selbst (Curtius). Alle diese Erklärungen taugen nichts, denn Pomum granatum ist weder Blüthenblatt, noch Rinde des Granatapfels, sondern der Apfel selbst, und mit diesem hat der Schwertknorpel keine Aehnlichkeit. Wie kam er also zu diesem Namen? Ganz einfach. Der Schwertknorpel ist nicht selten etwas aufgebogen. Seine Spitze hebt die Haut des Epigastrium

1) Ger. Blasii Editio Syntagmatis Veslingii, pag. 166.

Hyrtl. Onomatologia anatomica. 
zu einem Hügel auf. Solche Hügel mussten die Araber an den halbnackten und zaundürren Leibern der Beduinen oft genug zu sehen bekommen haben. Sie nannten einen solchen Hügel, wie so viele andere, Pomum, welchem sie noch granatum oder punicum anhängten.

Mehr über den Schwertknorpel, und seine zahlreichen Benennungen, enthält HL, $\S . X V$, Alchangiar.

\section{Praecordia.}

Sieh' den Artikel: Scrobiculus cordis.

\section{Praeparantes Venae et Arteriae.}

Die Griechen nannten alle Gefässe, welche sich an der

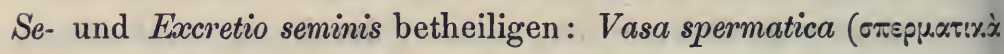

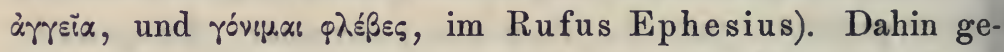
hörten die Arterien, Venen, und die Samengefässe. Die lateinischen Uebersetzungen der Griechen nannten diese Gefässe Vasa seminaria. Die Samenbereitung galt zu allen Zeiten als die wichtigste Absonderung. Deshalb zeichneten die Restauratoren der Anatomie die Arterien und Venen des Hodens,

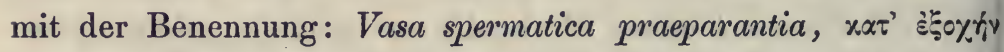
aus, während sie die Samengefässe, von den kleinsten, bis zum Hauptausführungsgang des Hodens, Vasa deferentia nannten, quae semen a didimis ad cavernas conservantes (Samenbläschen), et ad canalem virgae (Harnröhre) deportant (Berengarius).

Während man in jener finsteren Zeit, den Arterien im Allgemeinen nur wenig Einfluss auf die Absonderungen einräumte, wird dieser Einfluss den Arteriis spermaticis in demselben Grade zugesprochen, wie den Venen. Berengarius sagt: $a b$ istis vasis (Arterien und Venen) materia spermatis ad testes transit, in quorum substantia acquirit albedinem, et virtutem 
generativam ${ }^{1)}$. Die Samenmaterie ist also schon im Blute vorgebildet, und erhält im Hoden ihre Befruchtungsfähigkeit, oder, nach damaliger Vorstellung, ihre Umwandelbarkeit in die Frucht. Der linke Hode giebt den Stoff für weibliche, der rechte für männliche Embryonen. Das war keine blosse Meinungssache. Man hatte einen anatomischen Grund dafür. Die Venae praeparantes des linken Hodens kommen aus der linken Nierenvene. Die Nierenvenen ziehen den wässerigen Bestandtheil des Blutes der Hohlvene an sich (emulgent), und hiessen deshalb Venae emulgentes. Sie führen dieses sehr wässerige Blut zu den Nieren, um das Wasser dort, als Harn, abscheiden zu lassen. Die aus der linken Vena emulgens entspringende Vena praeparans des linken Hodens, führt somit ebenfalls wässeriges Blut, während die aus dem Stamme der Hohlvene entspringende rechte Vena praeparans, kein so stark gewässertes Blut, dem rechten Hoden zuführt. Aus dem stark gewässerten Blut lässt sich aber blos der Stoff für weibliche Embryonen ableiten, - der Stoff für männliche Embryonen muss somit aus dem rechten Hoden importirt werden : sperma dextri lateris mares generat, quia sua materia est magis mundificata ab aquositate, sinistri vero feminas, quia frigidum est et aquosum, et ab emulgentibus, sanguine aquoso repletis, venit ${ }^{2}$ ).

Die Venae praeparantes sind in der Nähe des Hodens sicut varices contortae, revolutae, et molles, ne testes proximos, sua duritie laedant. So wusste man auch den Plexus pampiniformis (die Parastata cirsoides des Herophilus), auf welchen diese Worte hindeuten, freilich nur auf alberne Weise zu erklären. Solche Albernheit galt damals für Scharfsinn.

1) Isagogae breves. Cap. de vasis seminariis.

2) Berengarius, Op. cit., in eodem Capitulo. 


\section{Praeputium.}

Praeputium hat seine Probe bestanden. Es sieht zwar ganz wie eine vox barbara aus; darf aber nicht dafür gehalten werden. Denn Seneca und Juvenal, wie auch die Kirchenväter, und die Vulgata ${ }^{1}$ ), leisten uns hinlängliche Bürgschaft für die gute Latinität des Wortes. Es scheint entweder dem griechischen Proposthion nachgebildet zu sein, welches $=$ ax.

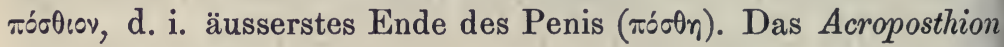
des Aristoteles, drückt aber mehr aus, als Praeputium. Praeputium nennen wir nur die Haut um die Eichel, während A ristoteles unter Acroposthion, Eichel und Vorhaut zusammen-

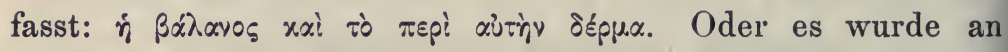
praeputare, wegschneiden, als radix verbi gedacht ${ }^{2}$ ). Allein in praeputare ist, wie in amputare, das $u$ kurz, während es in praeputium lang ist. Das Metrum eines Vocals im Stammwort, bleibt in allen Derivatis dasselbe.

\section{"Impatiensque morae pavet, et praepūtia ducit $\left.{ }^{3}\right)$, ,}

heisst es in der sechsten Satyre des Juvenal, und in der zehnten: mox et praepuitia ponunt. Dass es mit dem praeputare, für amputare, nichts ist, können wir auch daraus entnehmen, dass die Römer schon das Wort praeputium gebrauchten, bevor sie noch von der Circumcisio Judaeorum Kenntniss hatten, deren erst im Horaz Erwähnung geschieht (Judaeus apella, d. i. sine pelle). Selbst auf puteo, ich stinke, ist die Erklärungswuth der Etymologen verfallen: id quod putet (Perottus). Dass das Präputium, und das von ihm erzeugte Smegma, nicht wohl riecht, mag wohl die'Hauptveranlassung seiner Abtragung

1) Genesis, III, 11, III, 14, und III, 23.

2) G. J. Voss, Etymologicon, pag. 406.

$\left.{ }^{3}\right)$ Praeputia ducere, steht hier für Onaniren. 
gewesen sein '), so wie auch in der Vulgata, Unreinigkeiten, nicht blos physischer, sondern auch moralischer Natur, figürlich praeputia genannt werden: circumcidimini Domino, et auferte praeputia cordium vestrorum ${ }^{2}$ ), welches sich im Lactantius wiederholt, als: circumcidite praeputium cordis vestri ${ }^{3}$ ). Ein Anatom aus finsterer Zeit, Didacus Lopez, nahm das Praeputium cordis nicht figürlich, sondern als Herzbeutel, wie wir auch Scrotum und Bursa, auf diese Hülle des Herzens angewendet finden.

Wir können noch aus einem anderen, zwar seltenen, aber guten Wort, auf die Ableitung des Praeputium von $\pi \delta \circ \theta \eta$ (männliches Glied), und seinem Diminutiv $\pi \dot{c} \sigma \theta 10 v$ schliessen. Es ist

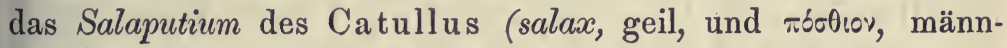
liches Glied), als Schimpfwort für einen geilen Kerl. - Die

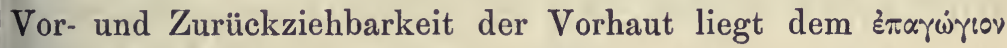
des Dioscorides zu Grunde.

Das Praeputium giebt uns Gelegenheit, den Doppelsinn eines häufig gebrauchten Wortes zu erwähnen: Recutitus. Recutitus, aus cutis resecta ableitbar, ist ein Mann ohne Vorhaut. So im Martial und Persius. Liess sich aber ein Jude, bei seinem Uebertritt zu den Heiden, seine Vorhaut wieder per artem chirurgicam restauriren, so hiess er im alten und im neuen Testament (Paulus), ebenfalls Recutitus. Celsus beschreibt uns das Verfahren, durch welches eine glans nudata, decoris causa wieder mit einer neuen Vorhaut versehen wurde ${ }^{4}$ ).

1) Omnis res superflua, simulque gravis (statt graveolens, stinkend), praeputium vocatur, ideo abjicienda et removenda (Martinii Lex. $P$. ex A benmelech).

2) Jeremias, $I V, 4$.

3) Opera, $I V, 17,8$.

4) Op. cit., Lib. VII, Cap. 25: ad tegendam glandem. 


\section{Processus Folii oder Processus Ravii.}

Der lange Fortsatz des Hammers führt den Namen: Processus Folii s. Ravii. Weder Folius noch Ravius sind in der Anatomie bekannte Männer. Ihre Namen werden, bei Gelegenheit des Processus longus mallei, zum ersten, und zum letzten Mal gehört. - Caecilius Folius, 1615 in Udine geboren, war Arzt und Professor anatomiae (?) in Venedig. Er schrieb eine Nova internae auris delineatio, welche $1645 \mathrm{zu}$ Venedig erschien, und viele Figuren mit sehr wenig Text enthält. In derselben erscheint der lange Fortsatz (jedoch ohne spatelförmigem Ende) zuerst abgebildet. Der Wittenberger Professor, Sal. Alberti ${ }^{1}$ ), so wie der wackere Fabricius

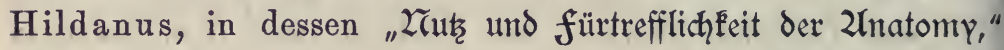
Bern, 1624, pag. 190, erwähnten schon den Fortsatz, wenn auch nur flüchtig. Die erste Abbildung gab aber Folius, und nennt ihn kurzweg Processus spinosus.

Jacobus Rau (more saeculi latinisirt als Ravius), war ein ehrlicher Schwabe, studirte in Leyden, beschäftigte sich mit Anatomie, viel mehr aber mit Chirurgie, welche er mit einer neuen Methode des Steinschnitts bereicherte. In Amsterdam übte er die Praxis aus. Seine avaritia und morum asperitudo, wird von seinem Biographen, Laur. Heister, streng getadelt. Mit Ruysch, dessen Nebenbuhler er war, konnte er sich nicht vertragen, und nahm deshalb den Ruf auf die, durch Bidloo's Tod vacante anatomische Lehrkanzel in Leyden an. Dort richtete er sich ein anatomisches Museum ein, welches er der Universität vermachte, und dessen meist osteologischen Inhalt, sein Schüler, B. S. Albinus, in der kleinen Schrift: Index suppellectilis anatomicae, Leidae, 1721, veröffentlichte. In dieser Sammlung waren viele Kinderköpfe, mit separat aufgestellten Gehörknochen. Der Malleus sehr junger Kinder, hat einen

1) Historia plerarumque partium corp. hum., 1581, pag. 84 . 
langen, spatelförmigen, und in die Glaserspalte sich hineinlegenden Fortsatz, welcher später mit dem Os tympanicum verwächst, so dass, wenn man den Hammer mit Gewalt ausheben will, dieser Fortsatz abbricht. Rau hat über diesen langen und spatelförmigen Fortsatz nie selbst etwas geschrieben. Aber sein Schüler, Mich. Bern. Valentin, erwähnt denselben, nach Präparaten des Ravius, in seinem Amphitheatrum zootomicum, Francof., 1719, und legte ihm den Namen seines Lehrers bei. Der Processus Ravii wurde durch den hochverdienten Ohranatomen, Professor Fridericus Cassebohm in Halle, in sein berühmtes Werk de aure humana aufgenommen, und behauptet, da auch Boerhave ${ }^{1}$ ) denselben annahm, fortan seine Stellung neben dem Processus Folii. Es wäre also Processus Folii = langer Fortsatz des Hammers bei Erwachsenen, Processus Ravii aber, = langer Hammerfortsatz mit spatelförmigen Ende bei Kindern. Jedem das Seine!

\section{Promontorium.}

Das Gebiet der Anatomie wurde reichlich mit Naturschönheiten ausgestattet. Wir finden in ihm Berge und Thäler (Mons Veneris, Vallecula Reilii), Seen und Bäche (Lacus und Rivus lacrymarum), Quellen mit Nymphen (Fons pulsatilis und Nymphae), Felder und Blumen (Campus Halleri für Sehfeld, Flos virginitatis für Hymen, - Rosenader und Mutterrose für $O s$ uteri), und drei Vorgebirge, Promontoria, wie sie Trinacria hatte. Das erste ist das Promontorium am Beckeneingang, entsprechend der Verbindung des Kreuzbeins mit dem letzten Lendenwirbel

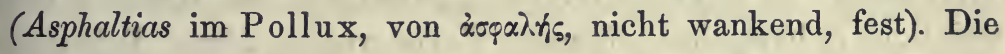
Geburtshelfer nahmen von ihm viel früher Notiz als die Anatomen, da durch ein allzustarkes Hereinragen desselben in den Beckeneingang, die Geburt erschwert, selbst unmöglich

1) Praelectiones in institut. proprias, T. IV, pag. 358. 
gemacht werden kann. Baudelocque erschien zuerst mit seiner Saillie 1 ), welche Osiander zum Promontorium vergrösserte ${ }^{2}$ ). Das zweite Vorgebirge befindet sich an der inneren Wand der Trommelhöhle, indem die erste Windung der Schnecke, die betreffende Wand der Trommelhöhle hervorbaucht. Diese Erhabenheit musste sich lange mit dem bescheidenen Namen einer Tuberositas tympani begnügen, welche ihr Lieutaud beilegte, bis sie durch Walter ${ }^{3}$ ) zum imposanten Promontorium tympani erhoben wurde. - Das dritte Promontorium ragt aus dem Gesicht heraus, als Promontorium faciei - Nase, worüber J. M. $\mathrm{H}$ offmann eine gelehrte Dissertation geschrieben hat ${ }^{4}$ ).

\section{Pronaus,}

In den anatomischen Handbüchern, welche sich in Synonymik einlassen, findet sich Pronaus, für Scheiden-Vorhof, Vestibulum vaginae. Severinus Pinaeus (Pineau) construirte sich dieses Wort, welches weder griechisch, noch lateinisch ist. In seinem Opusculum de notis virginitatis, Paris, 1597, Lib. I, Cap. 9, gebraucht er es für den Scheideneingang: „sinus pudoris naviculae formam habet, unde pronaus nobis dicitur". Wie mag ihm der Gedanke zu dieser Composition gekommen sein? Hätte er Pronaos statt Pronaus gesagt, so könnte kein Zweifel darüber sein, dass er "Eingang zum Tempel" damit meinte, denn tò $\pi \rho b$ vaov bedeutet „Vorhof eines Tempels". Da er aber Pronaus schrieb, hatte er offenbar an vaüs, Schiff, gedacht, wie auch das Citat besagt. In trivialer Redensart, hiess bei den Römern, die weibliche Scham, ihrer oblongen F orm wegen, Navis. Beispiele

1) L'art des accouchements, T. I, pag. 122.

2) Grundriss der Entbindungskunst, T. I, pag. 26.

3) Abhandlung von den trockenen Knochen, 2. Aufl., pag. 84.

4) De faciei promontorio, odoratus organo, Altdorf, 1682. 
genug davon im Plautus ${ }^{1}$ ). Plena navis bemäntelt im Macrobius ${ }^{2}$ ) die Scham während der Begattung. Diese Navis, עaüs, giebt mit pro, das gänzlich unbekannte Pronaus, als Vorhof

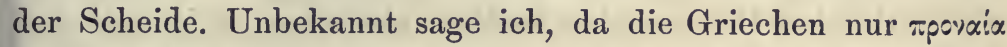
kennen, als Beiname der Athene, unter welchem sie in Delphi verehrt wurde, weil dort ihr Tempel vor jenem des Apollo stand. Die weibliche Scham wird zwar nirgends Scapha oder Scaphis genannt, aber Scaphium heisst im Juvenal das Nachtgeschirr, dessen sich die Frauen bedienten, und dessen kahnförmige Oeffnung, der Gestalt der Schamspalte entspricht. Scaphis ist aber auch ein kleines Schiff. Alles dieses, oder gar nichts davon, mag dem Pinaeus vorgeschwebt haben, bevor er mit dem Pronaus an das Licht der Welt trat. - Wir haben, statt Pronaus, das sachgemässe Vestibulum vaginaie.

\section{Prostata und Parastata.}

Nach dem Zeugniss des Galen, gab Herophilus den

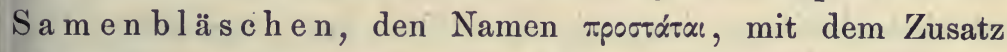

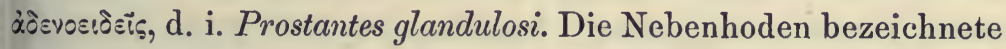

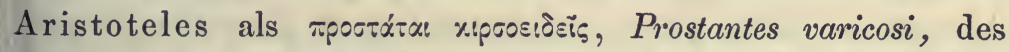
vielfach gewundenen Samengefässes wegen ${ }^{3}$ ). Galen nannte

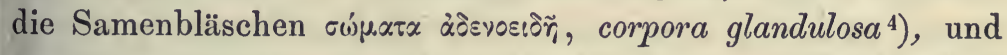

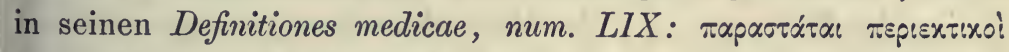

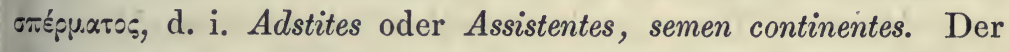

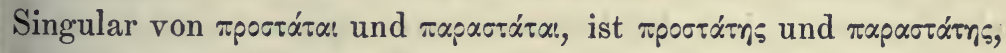
beide generis masculini. Da aber irriger Weise geglaubt wurde,

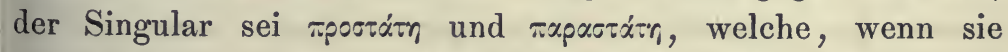

1) Im Rudens, Act. III, Sc. 2, Vers 24, - im Miles, Act. III, Sc. 3, Vers 47, - in den Menaechmi, Act. II, Sc. 3, Vers 55.

2) Saturnalia, Lib. II, Cap 5.

3) De usu partium, Lib. XIV, Cap. 40.

4) Tbidem, Cap. 9. 
existirten, generis feminini sein müssten, entstand das weibliche Hauptwort Prostata und Parastata, während sprachrichtig nur ein männliches Prostates und Parastates existiren kann. Prostatai waren also dem Herophilus die Samenbläschen. - Jenes Organ, welches wir Prostata nennen, scheint Galen gar nicht gekannt zu haben, denn er spricht nirgends von ihm. Da die Samenbläschen sich innig an den oberen Rand der Prostata anschmiegen, und mit ihm durch Bindegewebe fest verbunden sind, glaube ich annehmen zu sollen, dass Galen unter seinen Parastatai, Samenbläschen und Prostata zusammengefasst hat, und beide von einander nicht $\mathrm{zu}$ unterscheiden wusste. Hätte Galen menschliche Leichen secirt, er würde, bei der Genauigkeit seiner Untersuchungen, den ${ }^{2}$ Unterschied von Prostata und Vesiculae seminales bald herausgefunden haben. Aber bei Thieren fällt es uns jetzt noch öfter schwer, zu sagen, wo die Prostata aufhört und die Samenblasen anfangen. Die Wiederkäuer, welche Galen in grösserer Menge als die kostspieligeren Affen zergliederte, haben nur drüsige Samenbläschen, aber gar keine Prostata, und die Fleischfresser entbehren der Samenbläschen gänzlich, besitzen aber, wie die Affen, eine ringförmige Prostata. Veranlassung genug, dass in jener entlegenen Zeit, ein Anatom, zu einem klaren und festen Begriff über diese Organe nicht leicht gelangen konnte. Hierin ist der Grund zu suchen, warum auch der Restaurator anatomiae, Mundinus, es vorzog, weder der Prostata, noch der Samenbläschen, mit einem Worte zu gedenken $\left.{ }^{1}\right)$. Berengarius erwähnt blos die Samenbläschen als Cavernae, nicht die Prostata: vasa deferentia, inter rectum et vesicam, dilatantur in plures cavernas, et dein collum vesicae (unsere pars prostatica urethrae) perforant et evomunt sperma inter virgam ${ }^{2}$ ). Dem Vesal und Fallopia war es vorbehalten,

1) Anathomia Mundini emendata, in Cap. de anathomia vasorum spermaticorum.

2) Isagogae breves, Cap. de vasis seminariis. Das CapiteI de virga enthält ebenfalls keine Erwähnung der Prostata. 
die Verwirrung zu heben, indem sie Prostata und Vesiculae seminales, als zwei besondere, von einander unabhängige Organe feststellten. Vesal nannte die Prostata: Corpus glandosum oder Assistens glandosus, in wörtlicher Uebersetzung der Galenischen

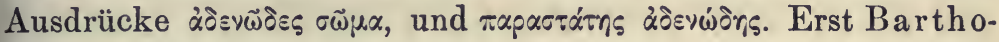
linus gab der Prostata ihren gegenwärtigen Namen, hielt sie aber noch immer für ein paariges Organ: glandulae duae, ad radicem penis, supra sphincterem sitae ${ }^{1}$ ), wozu die nicht selten durch eine mediale Furche getrennten Seitenlappen der Drüse, Anlass gegeben haben müssen.

Die Samenbläschen, welche bisher, wie der Nebenhode, Parastatae varicosae s. cirsoideae hiessen, erhielten ihren jetzigen Namen, als Vesiculae seminales, durch Rondelet, welcher dieselben vom Delphin zuerst genauer beschrieb?2). Fallopia gab uns ihre Anatomie beim Menschen, und behielt die Benennung des Rondelet bei: geminae quasi vesiculae, circa cervicem vesicae, non unam habent cavitatem, ut aliae vesicae, sed multiplicem et anfractuosam, videnturque varicum complicationem formare $^{3}$ ). Da man früher auch die Krümmungen und Windungen des Vas deferens im Nebenhoden, mit Varices (x.poós, varix) verglich, erklärt es sich, warum zwei so verschiedene Organe, unter demselben Namen stehen.

Aus allem Vorhergegangenen lässt sich folgern, dass Prostata, richtiger Prostates, kein Galenisches Wort ist, sondern ein Paar Jahrhunderte vor Galen in der anatomischen Sprache auftauchte (Herophilus, 300 Jahre vor Christus). Der gelehrte Grieche, C. G. Kühn, welcher die beste Ausgabe des Galen und der alten griechischen Aerzte veranstaltete, konnte mit Recht sagen: neque in Galeno, neque in alio medico graeco, occurrit

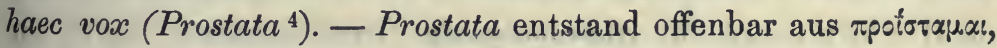

1) Institutiones anat., Lib. I, Cap. 23.

2) Haller, Elem. physiol., T. VII, pag. 108.

$\left.{ }^{3}\right)$ Observationes anat., in Vesalii Opera omnia, T. II, pay. 748 .

4) Im Lex. med. Blancardi, T, II, pag. 1200. 
ante collocari, vorstehen, wie die deutsche Benennung: Vorsteherdrüse sehr gut ausdrückt. Prostates heisst übrigens im

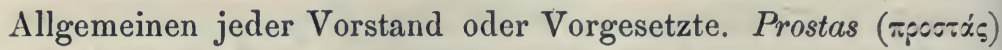
führt uns Vitruvius als ein Vorzimmer an, Athenaeus als Hure, quae prostat, woher prostibulum und prostitutio ihre Entstehung herleiten. Dass man die Prostata nicht zu den Harnwerkzeugen, sondern zu den Geschlechtsorganen stellte, beweist uns auch der obsolete Name: Testes minores im Varolius. - Die Prostata wird in alle Ewigkeit fortbestehen, - die Parastatae fristen nur, als Synonyme von Samenbläschen und Nebenhoden, ein kümmerliches und unbeachtetes Dasein.

Ueber Parastatae enthalten noch Einiges die Artikel: Epididymis und Cremaster.

\section{Protuberantia.}

Ein nur in der Anatomie bekanntes, und oft gebrauchtes, romanisches Wort. Die lateinische Sprache besitzt nur das Zeitwort protuberare, welches nicht der besten Zeit, sondern dem späten Polyhistor Solinus angehört, wo es im Sinne von excrescere in tuberis formam auftritt. Dagegen ist Protuberantia in allen romanischen Sprachen heimisch, als Protuberanza (italienisch), Protubérance (französisch), und Protuberancia (spanisch). Die Restauratoren der Anatomie, welche sämmtlich Italiener waren, latinisirten das italienische Idiom, wie sie es mit anderen Worten zu thun pflegten, indem sie den lateinischen Ausgang atio, in antia umstellten, wie in Colligantia im Mundinus, für Colligatio (Colligatio causarum im Cicero), Appropinquantia im Berengarius, für Appropinquatio (Appropinquatio mortis im Cicero), Extuberantia im Lanfrancus, für Extuberatio (Geschwulst im Plinius), Concordantia im Achillinus, für Concordatio (Üebereinstimmung), Festinantia im Guido, für Festinatio, Eilfertigkeit (omni festinatione properare in patriam, Cicero), und viele ähnliche. Wenn man also richtiger Protuberatio zu 
sagen hätte, so kann doch Protuberantia nicht geradezu für barbarisch erklärt werden, da es viele andere, gut lateinische Worte mit gleicher Endigung imitirt, wie Distantia, Abstand, im Vitruv, Radundantia, Ebbe und Fluth, im Plinius, Fragrantia, starker Wohlgeruch (fragrantia unguentorum im Val. Max.), Temperantia, Mässigung (temperantia voluptatibus imperat, Sen.), und Exuberantia, Ueberfluss (besonders als Wortreichthum im Cicero).

Die Osteologie und die Gehirnlehre bemächtigten sich mit Vorliebe der Protuberantia, für diverse Arten von Hervorragungen und Erhabenheiten. Wir besitzen in der Knochenlehre eine Protuberantia occipitalis externa und interna, eine Protuberantia mentalis, frontalis, pyramidalis (in der Trommelhöhle), cubitalis (für das Olecranon), und in der Nervenlehre eine Protuberantia basilaris (Varolsbrücke), eine Protuberantia nervi olfactorii (Bulbus), eine Protuberantia mammillaris (Corpora mammillaria), und quadrigemina (Vierhügel). Diese Ausdrücke kamen aber erst durch Spigelius in Gang. Seinen Vormännern dienten Gibber und Gibbus, Prominentia, Projectura, Eminentia, Additamentum (im Vesal), Explantatio (im Ingrassias), Enascentia, Excessus (im Gorraeus), Excrescentia, selbst Excrementum (Excrementa costarum im Sidonius Apollinar is ${ }^{1}$ ).

Die griechischen, dem Galen entnommenen Ausdrücke für Protuberanz, sind Ecphysis, und Apophysis. Das im Pierer und Choulant stolzirende Synonymon für Protuberantia, als Hyperocryphia, ist eine unausstehliche Verunglimpfung des

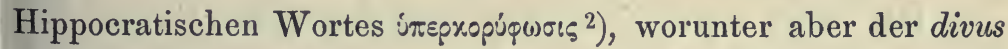

1) Epistol. Lib. I, ep. 1. Das Latein des Sidonius (5. Jahrhundert nach Christus) gehört schon zum ausgearteten: multa mullo modo imitanda, verba audacter novata, aut insolenter deducta, a latina gravitate abhorrentia, sagt Forcellini. Einen Beleg für dieses harte Urtheil liefert das Excrementum costae für Rippenkopf.

2) Lib. de dissectione, I, 7, und $I I, 3$. 
medicinae pater, nicht Knochenerhabenheiten, sondern die Lappen der Lunge und der Leber verstanden hat. Erhabenheiten und Hervorragungen an Knochen führen bei ihm den Namen $\pi \rho \circ \beta \diamond \lambda \eta$, , ein genereller Ausdruck für alles Hervortretende und Vorspringende, ja sogar für den Elephantenrüssel im Aretaeus, und für den zum Stoss vorgehaltenen Speer und den Hieb des Schwertes, im Xenophon und Plutarch.

\section{Psoas.}

Psoas ist der Genitiv von $\dot{\eta} \psi \dot{\sigma} \alpha$, Lendengegend und Lendenfleisch. Kann der Genitiv eines Wortes, vernünftiger Weise, als Nominativ verwendet, und dem Genitiv ein Artikel im Nominativ vorgesetzt werden, wie im "der Psoas"? Nein. Also darf es keinen Psoas geben. Nur wenn man vor psoas, den Nominativ Musculus setzt, hat die Sache Sinn, als „Muskel der Lende". Niemand hätte sich unterstehen sollen, den Musculus im Geiste wegzulassen, und in der Schrift psoas allein zu setzen. Galen hat die $\psi \dot{b} \alpha$, von Hip pocrates übernommen, welcher sie aber jonisch als yú $\alpha$ schrieb. G ale n nennt den Lendenmuskel: $\left.\dot{\eta} \psi^{\prime} \alpha \alpha^{1}\right)$, die beiden Lendenmuskeln aber: $\alpha \dot{t}$

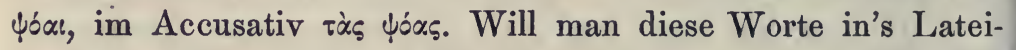
nische verpflanzen, um den Carnes lumborum des Rasarius auszuweichen, so muss Ein Lendenmuskel: Psoa, beide aber: Psoae genannt werden.

Der durch seine vielen und schweren Fehler in der Erfindung griechischer Worte für anatomische Objecte, bekannte Riolan, führte auch den Genitiv Psoas für die Lendenmuskeln ein 2). Nie wurde ein Unsinn so treu bewahrt, und so lange von aller Welt nachgeschrieben, wie dieser Psoas magnus und

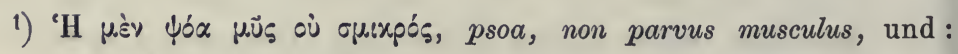

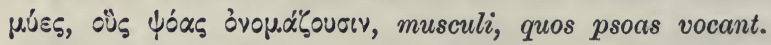

2) Anthropographia, Lib. V, Cap. 41. 
parvus. Man hätte die Musculi lumbales des Spigelius nie aufgeben sollen, besonders wenn man durch den Zusatz interni, sie vor einer Verwechslung mit den äusseren Lendenmuskeln (Sacrolumbalis und Longissimus dorsi) verwahrt hätte. Winslow hat die Psoasmuskeln schon als lombaires internes behandelt ${ }^{1}$ ). Riolan sprach noch überdiess den Frauen den Musculus psoas parvus ab : in feminis non reperitur. Den kleinen Lendenmuskel, einen halben Psoas zu nennen (le mi-psoas), konnte nur einem Franzmann in den Sinn kommen (Habicot).

Hippocrates überlieferte uns noch einen anderen Ausdruck für die Lendenmuskeln: $\ddot{\lambda} \lambda \mid \ddot{\omega} \pi \varepsilon \kappa \varepsilon \varsigma$ (Füchse, oder vielmehr

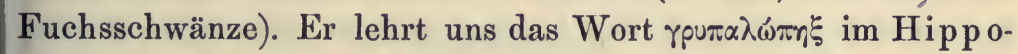
crates verstehen: lendenlahm, mit krummen Lenden (von

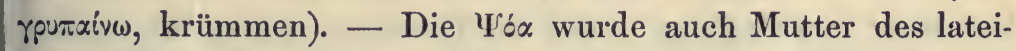
nischen Wortes psoadicus. Ich finde im Caelius Aurelianus, de morbis chronicis, Lib. V, das erste Capitel überschrieben: de ischiadicis et psoadicis. Das Capitel handelt von unserer Lumbago. Vergleiche auch HL, §. LXXV, Matnaim, Musculus psoas.

\section{Pulmo oder Pulmones?}

Diese müssige Frage wird schon im Anatomisch-physiologischen Realwörterbuch von Pierer und Choulant ventilirt. Lunge und Lungen, Pulmo und Pulmones, sind beide gut, da für beide die besten Zeugenschaften vorliegen. Cicero ${ }^{2}$ ) sagt Pulmones: in pulmonibus inest adsimilis spongïs mollitudo. Ebenso kommt der Plural im Plautus vor: renes dolent, pulmones distrahuntur. Plinius gebraucht den Singular ${ }^{3}$ ): sub corde pulmo est, und Ovidius, Juvenalis, Persius und Aulus Gellius,

1) Traité des muscles, §. 364 .

2) De natura Deorum, Lib. II, Cap. 55.

3) Hist. nat., Lib. XI, Cap. 37, Sect. 42. 
sagen ebenfalls Pulmo. Cicero selbst bleibt nicht bei seinem Pulmones; - er hat auch Pulmo incisus ${ }^{1}$ ).

Insofern man die Lunge, ihrer Theilung in eine linke und rechte Hälfte wegen, als ein doppeltes Organ ansehen kann, sind Pulmones gerechtfertigt. Insofern aber diese beiden Hälften, ganz gleichen Bau haben, an einem einfachen Stiele (Trachea) hängen, und ihre Arterie, als ein einfacher Stamm aus dem Herzen kommt, lässt sich statt Pulmones, auch Pulmo sagen. Wenn Haller Pulmo verwirft, und nur Pulmones haben will, weil auch Renes existiren, so ist zu erwidern, dass die Renes in ihren zu- und ausführenden Gefässen, vollkommen getrennte Organe sind, die Lungen jedoch nicht. Die Nieren sind schon $a b$ origine doppelt, die Lunge wird es erst im Verlauf ihrer Entwicklung. Auch die Griechen, Aerzte wie Laien,

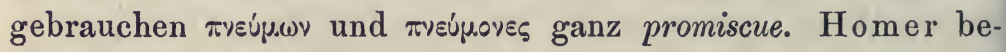

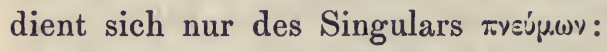

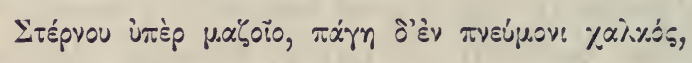

"Ueber der Warz' in der Brust, und es drang in die

Lunge das Schwert ihm."

(Ilias, IV, 5282).

Pulmonalis dagegen gehört, wie lumbalis, zu den neuen und unrichtigen anatomischen Wortbildungen. Die Alten hatten kein anderes, aus pulmo gebildetes Beiwort, als pulmonarius und pulmoneus. Ersteres = lungenkrank, - letzteres = zur Lunge gehörig. Von lumbus, Lende, bildeten sie lumbare, Lendenschurz oder Gürtel, als Neutrum von lumbaris (schlecht lumbalis, weil ein vorhergehendes $l$, die Endsylbe lis nicht verträgt). - Das jonische $\pi \lambda$.éúwy hat durch Umstellung des $\lambda$, den lateinischen Pulmo gegeben. Die moderne Pathologie, insbesondere die französische von Piorry und Andral, verwendete das grie-

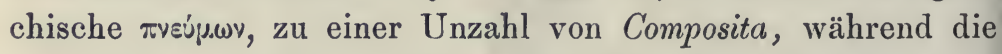

1) De divinatione, Lib. I, Cap. 35.

2) Gleichlautend in $\Pi$., Lib. $X X, 486$. 
Wir ersehen aus diesen Arten von Pulpa, dass Weichheit die Haupteigenschaft derselben ist. Fleischig (musculös), braucht die anatomische Pulpa nicht $\mathrm{zu}$ sein, wie es die römische sein musste: caro musculosa, sine osse et pinguedine, nach der Definition des Isidorus '). Aber auch allerlei andere, weiche, organische Gebilde, wurden von den Römern Pulpae genannt, wie die schwellenden Brüste und Hinterbacken der Mädchen im Cicero, und das Weiche am Obste im Scribonius Largus. So ist auch das Weiche an den Fingerspitzen, die weiche Drüsensubstanz, zum Unterschied von dem härtlichen Parenchym, und die Schleimhaut des Gaumens, nur figürlich zur Pulpa geworden, während die Pulpa lienis und die Pulpa nervi acustici, richtiger Pulpamentum hätten genannt werden sollen, da die Pulpa als ein fleischiges Ding, immer faserig sein musste, und erst durch Zerhacken zum Brei: Pulpamentum oder Pulmentum (griechisch b̧⿻上丨) wurde. Die

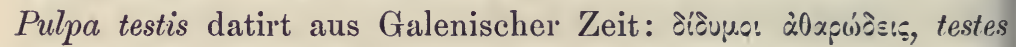
ex materia pulti simili constant (ג̇ox́pr, Mehlbrei).

Als Arzneimittel verschreiben wir Pulpa tamarindorum, cassiae, dactylorum, und colocynthidis, welche theils durch Auskochen, theils durch Zerstampfen der betreffenden saftigen Früchte bereitet wird.

\section{Pupillae.}

Kleine Mädchen heissen Pupae. Martial, IV, 20 :

„Dicit se vetulam, cum sit Caerellia pupa."

Die kleinen angekleideten Figuren, mit denen die Mädchen bis in die Jahre der Mannbarkeit spielten, wo sie dieselben sodann der Venus weihten: ut Dea ipsis faustum matrimonium cederet, hiessen ebenfalls pupae - unsere Pupen. - Das kleine Figürchen, welches sich von uns selbst, im Auge eines

1) Origines, Lib. 1I, Cap. 1. 
zweiten abspiegelt, liess auch das Sehloch der Iris, in welchem dieses Bildchen erscheint, Pupilla nennen (Cicero, De natura Deorum, II, 57, und Plinius: media oculorum tunica fenestravit pupillam ${ }^{1}$ ). Sonst wurden nur verwaiste Mädchen und Knaben pupillae und pupilli genannt, und ihr Vermögen: pecuniae pupillares. Die Anatomie hat sich aus Pupilla, ihre Membrana pupillaris gebildet. Für Pupilla findet sich bei alten Anatomen auch pupula und pupilio (Casserius). Letzteres ist barbarisch, ersteres gut, wie Lucretius verbürgt, De rerum natura, Lib. $V, 309$ :

„Ut, lacerato oculo circum, si pupula mansit "Incolumis, stat cernendi vitreata potestas."

Das griechische xópr und rivín, hat dieselbe mehrfache Bedeutung wie pupilla, als Mädchen, Spielzeug, und Sehloch. Aus ersterer allein bildeten sich die neueren Augenärzte, einige vielverwendete Composita.

Die altmodischen Benennungen der Pupille als Visio (Arabisten - die öụ! ses Rufus), Fenestra und Foramen oculi (Bauhin), und Lumen (Vegetius), fussen auf der optischen Unentbehrlichkeit der Pupille, für welche die deutsche Sprache das treffendste Wort besitzt: Sehloch, Sehe (Oken). In älteren Schriften wird Pupilla statt Iris gebraucht, - ein Missbrauch, welcher lange anhielt, und es uns erklärt, wie Lieutaud die Pupille la prunelle nennen konnte, was sich doch nur auf die blaue Farbe der Iris beziehen kann. Ein löblicher Ausdruck für Pupille, ist das Nigrum des Fel. Plater.

\section{Pylorus,}

Galen nannte den Magenausgang nicht Pylorus, sondern

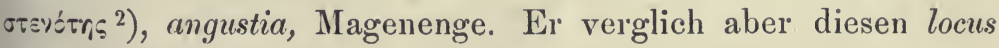

1) Op. cit., Lib. II, Cap. 37, Sect. 55.

2) De usu partium, Lib. IV, Cap. 7. 


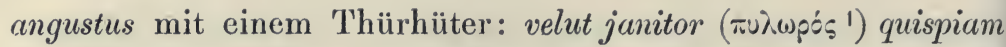
justus, nulli ante, quam in chylum redactum sit et concoctum, tran-

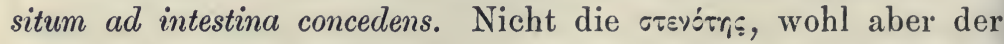
$\pi \cup \lambda \omega \rho o ́ s$, wurde ein stabiler anatomischer Terminus, dessen lateinische Uebersetzung, als Ostiarius, Hostiarus, und Janitor, ehedem viel öfter gebraucht wurde als jetzt. - Mundinus spricht von Pylorus, als Portanarium, hinter welchem das italienische portinajo, Portier, steckt. Phylax traf ich nur ein einziges Mal im Valverda. Er hat es dem Julius Pollux ausgeführt. Pileron und Pilorium sind zwei, von Zerbis, dessen Name ehrenhalber nie genannt werden kann, dem Pylorus angethane Misshandlungen. - Von Magenausgang, unterer Magenmund, und Pförtner, sprechen die Deutschen. Die Membrana orbicularis des Riolan, und der Circulus Halleri, sind nur Synonyme für die Valvula pylori des Vesal, deren Kreismuskelfasern den Magenausgang während der Verdauung vollkommen abschliessen, weshalb Sömmerring die Pylorusklappe geradezu als Sphincter ventriculi behandelt ${ }^{2}$ ). Galen spricht von einer drüsigen Beschaffenheit des Pylorus: in multis

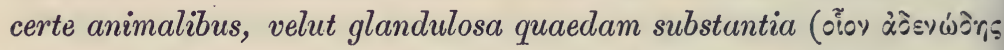

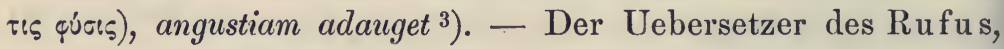
umschreibt den Pylorus, mit primus intestini exortus. Van Helmont schrieb seiner Zeit eine gelehrte Abhandlung über die Thätigkeit des Pförtners. Sie führt den Titel: Pylorus Rector ${ }^{4}$ ). Galen liess einen Gang aus der Gallenblase zum Pylorus gehen ${ }^{5}$ ).

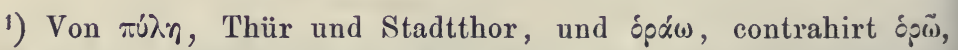
sehen, blicken, ergo der Wächter, welcher auf das Thor zu sehen hat.

2) Eingeweidelehre, §. 141.

3) Loco cit.

4) Im Ortus medicinae, Amstel. 1648.

5) Administrationes anat., Lib. VI (Gorraeus). 


\section{.. .. 301. Pyriformis oder piriformis?}

Spigelius nannte den am Kreuzbein entspringenden, und durch die Incisura ischiadica major, zum grossen Trochanter zichenden Drehmuskel des Oberschenkels, zuerst Pyriformis ${ }^{1}$ ). Riolan gab ihm den nicht zu rechtfertigenden Namen Iliacus externus; - Vesal und Columbus numerirten ihn blos als quartus femoris musculus, und Winslow beschrieb ihn als pyramidalis - a similitudine formae. Die deutschen Anatomien des 17. Jahrhunderts, geben pyriformis, als birnförmig. Die Birne hiess bei den Römern nicht pyrum, sondern pirum. Deshalb wäre piriformis das Richtige. Da aber das griechische Ypsilon, nicht selten in latinisirten Worten, in $i$ umgewandelt wird, wie, um nur Ein bekanntes Beispiel anzuführen in fio, werden, entstehen (von ழ̣ú( ), so mag man auch pyriformis gestatten, obwohl dieses Beiwort sich auf gar keine römische Autorität berufen kann. Da ferner das auflodernde Feuer $\pi \tilde{\rho} \rho$ heisst, und die Birne, wie die Flamme, ex lato, in oblongum et acutum fastigiatur (Forcell.), kann pyriformis auch etymologice nicht geradezu verworfen werden, steht aber hinter dem richtigeren piriformis zurück, welches auch immer als birnförmig, nicht als flammenförmig übersetzt wird.

\section{Quadrigeminus.}

Es darf nur Corpus quadrigeminum, nicht Corpora quadrigemina gesagt werden. Der schlichte Verstand meint, dass, wenn geminus doppelt ist, bigeminus vierfach bedeutet, und quadrigeminus achtfach. Wenn dem so wäre, müsste allerdings das Corpus quadrigeminum, richtiger bigeminum genannt werden. Wer sich aber in den Wörterbüchern ein wenig umsieht, findet,

1) De corp. hum. fabrica, Lib. IV, Cap. 22. 
dass diese Conceptio a priori, durch den Sprachgebrauch widerlegt wird. Bigeminus, als doppelt, wird er zwar nicht finden, aber quadrigeminus sicher, als vierfach. Wenn also der Markkörper über dem Aquaeductus Sylvii, vier Erhabenheiten zeigt, so kann er, mit Fug und Recht, Corpus quadrigeminum genannt werden, und dieses wäre richtiger, als der Pluralis usitatissimus: Corpora quadrigemina, weil man sich darunter eine ganze Gesellschaft von Vierhügeln denken kann. So gut der deutsche Vierhügel des Sömmerring ist, so schlecht sind seine Corpora quadrigemina, wenn sie auch von allen Anatomen der Welt nachgesagt werden. Es darf bei quadrigeminus, durchaus kein Plural sein, und deshalb sind auch die Eminentiae quadrigeminae des Haller, die Tubercula quadrigemina des Lieutaud, und die Monticuli quadrigemini des Rolando, verwerflich. Ein einziger Anatom hat, meines Wissens, den Singular gebraucht, als Eminentia quadrigemina $\left.{ }^{1}\right)$. Im $\mathrm{Henle}^{2}$ ) wird Eminentia quadrigemina = bigemina gehalten, was sprachlich unrichtig ist, obwohl der Singular zusagt.

Das vordere Paar des Vierhügels Nates s. Clunes $^{3}$ ), Hinterbacken, zu nennen, und das hintere Paar, Testes, Hoden, ist eine Unanständigkeit, welche wir wahlich im Vesal nicht gesucht hätten ${ }^{4}$ ). Heute werden diese Worte nur oblectamenti causa, und, vor Allem, der Kürze wegen, gebraucht, denn mit Nates und Testes ist man schneller fertig, als mit "vorderes und hinteres Vierhügelpar".

1) M a y e r's Beschreibung des menschlichen Körpers, Band VI, pag. 161.

2) Nervenlehre, pay. 123, Note 1 .

$\left.{ }^{3}\right)$ Clunes und Nates werden von Dichtern und Prosaikern, für Hinterbacken gebraucht. Sie sind gauz gleichbedeutend, wie

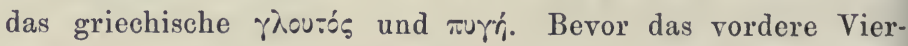
hügelpaar den Namen Nates erhielt, war dieser an die Sehhügel vergeben, als Uebersetzung der Galenischen yjoj̃

4) Op. cit., Lib. VII, Cap. 9. 
Als Pons Sylvii, führt der Vierhügel seinen Namen nicht von dem alten, streitsüchtigen Gegner des Vesal, Jacobus Sylvius, sondern von dem Deutschen Franciscus de la Boë Sylvius, einem Edelmann, welcher als Professor der Medicin in Leyden, sehr berühmt wurde, und in seinen Dissertationes medicae selectae, Amstelodami, 1663, P. I, Num. IV, Thes. 21, den Vierhügel und den Aquaeductus unter ihm, genauer als seine Vorgänger beschrieb, weshalb beide seinen Namen erhielten.

\section{Radius.}

Der Radius ist ein anatomisches Vermächtniss des Celsus. Er sagt von den beiden Knochen des Vorderarmes: radius, quam Graeci xspxiò $\alpha$ vocant, superior breviorque, cubitus vero (unsere Ulna), inferior longiorque, et radio plenior (stärker ${ }^{1}$ ). Die Galen'sche xspxíg ${ }^{2}$ ), wurde dem Homer entlehnt, welcher darunter das Webschiff versteht ${ }^{3}$ ). Auch der Stab, mit welchem das Gewcbe auf dem alten, aufrechtstehenden Webstuhl festgeschlagen wurde, heisst in der Odyssee xepxíg. Später ging der Name auf einige andere stabförmige Werkzeuge und Geräthe über, und durch Galen auf den Radius, durch Pollux auf das Schienbein. Der Celsische Radius bezeichnet eigentlich nichts anderes, als etwas stabförmiges, wie es z. B. die Speiche eines Rades ist. Diese Aehnlichkeit drückt der deutsche Speichenknochen ganz bestimmt aus, während der Name Spindel, und der nicht mehr gangbare Spille, welcher in der deutschen Uebersetzung von Monro's Osteology, pag. 391,

1) De medicina, Lib. VIII, Cap. 1.

2) Oribasius, Op. cit., pag. 158.

3) Ilias, Lib. XXII, Vers 448 :

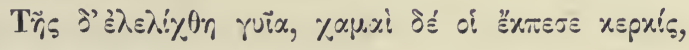
„Und ihr erbebten die Glieder, es sank zur Erde das

Webschiff." 
auffällt, der oblongen Spindel oder Spille am Rocken, entlehnt wurde. Die Spille gerieth in Vergessenheit, aber die Armspindel erhält sich noch immer.

Da die Armspindel neben der Ulna ( $\pi \tilde{r} \%$ s) liegt, heisst

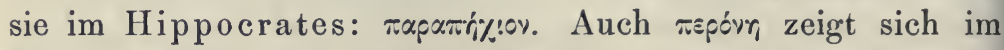
Hippocrates, da sie dem schwächeren der beiden Knochen des Unterschenkels, der Fïbula, rspévr, entspricht. - Die bei den Arabisten vorkommenden Ausdrücke: Canna und Arundo minor, sind Uebersetzungen des arabischen qanāh, Rohr und Röhre, - ein schicklicher Ausdruck für einen Röhrenknochen. Nur soll man Röhre, hier nicht mit Ellbogenpfeife übersetzen, wie es der ehrliche Wallner gethan, in seinem deutschen Bartholinus. - Ueber Focile minus der Latino-Barbari, sieh' HL, $\S . X X X V$, Assetum.

Das Os adcubitale (neben der Ulna), und das Additamentum ulnae im Vesal, drüicken es unverkennbar aus, dass die Ulna als Hauptknochen des Vorderarms galt: Ossium asseti (arabisch al-sāid, Vorderarm), princeps, quia fortius (Guido).

\section{Ramificatio,}

Die Gefässlehre kann ohne "R amification" nicht existiren. Sie ist eine ihrer übelsten Angewöhnungen. Das Geäste, die Verzweigung eines Baumes, heisst Ramale, im Ovid, Seneca, und Tacitus. Ramificatio ist, wie Rectificatio, Amplificatio, Nostrificatio, neuesten Ursprungs. Die lateinschreibenden Anatomen gebrauchen häufig das ebenso barbarische Diramatio, für Gefäss- und Nervenverzweigungen. Weil im Cicero, Sacrificatio, als Opfern, und Testificatio, als Zeugenbeweis, und im Macrobius, Magnificatio, als Erhebung vorkommt, hielt man sich bereehtigt, auch eine Ramificatio zu schaffen, welche, streng genommen, nur etwas $\mathrm{zum} \mathrm{Ast}$ machen, nicht aber ein Zweigwerk ausdrücken könnte. Leider haben sich die Ramificationen in der deutschen 
an der Benennung Vence raninae geworden sein soll. So sagt Bauhinus: venae notabiles sub lingua, a colore magis, quam a figura (!) ranarum, raninae dictae ${ }^{1}$ ), und Bartholinus: venae insignes sub lingua, raninae dictae sunt, ob colorem ${ }^{2}$ ). Von der Ranula des Vegetius, und dem $\beta$ x́ $p \% \%$ des Paulus Aegineta, hatten diese Männer, allem Anschein nach, nichts gehört.

Die Venae raninae haben sich aber nicht blos in der Anatomie acclimatisirt, - sie erzeugten auch eine minime laeta progenies, in den Arteriae raninae. So heissen nämlich die Arteriae profundae linguae, seit Winslow. Da sie im Fleische der Zunge stecken, nicht aber unter ihr liegen, wie die Venae raninae, mit welchen sie weder an Stärke noch an Verlaufsweise übereinstimmen, kann der Name raninae ihnen nicht beigelegt werden. Nur der schwache Ramus sublingualis der Zungenarterie, wurde von Haller, mit einiger Reserve, Arteria ranina genannt: ramum sublingualem arteriae lingualis, possis raninum dicere, a venae sociae nomine ${ }^{3}$ ).

\section{Raphe.}

Orthographisch kann die Naht nur Rhaphe, nicht Raphe, heissen, denn die Griechen schrieben paprí, nicht paşry, wie sie

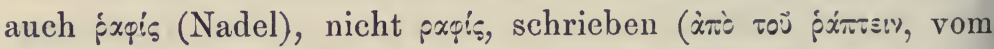

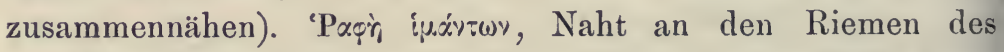
Pferdegeschirres, kommt schon im $\mathrm{Homer}^{4}$ ), vor. In die lateinische Anatomie hat Rhaphe, als Naht der Schädelknochen, niemals Eingang gefunden. Dagegen wurde sie an zwei Dinge vergeben, welche nieht nahtähnlich aussehen, 1. an die Rhaphe scroti, eine mediale, wenig erhabene Crista der Mittelfleisch-

1) Theatrum anatom., Lib. III, C'up. 79.

2) Institutiones anat., Lib. III, Cap. 13.

3) Elem. plıysiol., T. V, Lib. XII, Sect. 1, §. 8.

4) Odyss. XXII, 126. 
und Hodensackhaut ${ }^{1}$ ), und 2. an die Längsfurche zwischen den beiden Striae longitudinales Lancisii, auf der oberen Fläche des Corpus callosum im Gehirn, als Rhaphe cerebri. Die Schädel-

1) Da wir so viel mit Barbarismen beschäftigt sind, sollen auch ein Paar Verwechslungen von Rhaphe scroti, mit Worten anderen Sinnes, nicht iibergangen werden. Diese sind Tramis, Taurus, und Orrhos.

1. Tramis der Synonymien war bei den Griechen niemals die Rhaphe scroti, sondern das Mittelfleisch. Es wurde nur von Dichtern gebraucht (Aristophanes, in Thesmophoriazusae, Vers 246).

2. Mit Taurus steht es ebenso. Für die lascive Muse des Aristophanes (Ecclesiazusae, Vers 911), ist Taurus $=$ Penis und Perinaeum, niemals aber Rhaphe scroti. Das griechische ataurota, welches Jungfer bedeutet, wird im Pape, ergötzlicher Weise, als ohne Stier ausgelegt. Im Horaz'schen: nec tauri in venerem ruentis pondus tolerare (valet), steht taurus nicht für penis, sondern für concubitor.

3. Orrhos ("̋̀pos, im Aristophanes), welches in alten und neuen Schriften für Khaphe heruingezerrt wird, ist Steiss und Steissbein. Galen definirt "’p̧os als ultima spinae pars, quo vertebrae desinunt. Man erinnere sich an das Orropygion des Aristoteles, als hervorstehende Feder am Steiss des Vogels. Die Onomastica von Pollux und Stephanus enthalten alles Weitere hierüber. - Das vernünftigste Synonymon für Rhaphe, hat sich in das Syntagma anatomicum J. Veslingi i (Cap. VI, pag. 91) verloren: Linea media scroti, allerdings mit dem Beisatz: tamquam sutura. Die Rhaphe ist wirklich, besonders an einem relaxirten Hodensack, nichts als eine Linie. Wer hat sie je am Mittelfleisch anders, als eine Linie gesehen, welche man sich noch überdiess mehr denken muss, als man sie sehen kann. Von Vesal bis zu Haller, war Linea media und Sutura scroti s. bursae, die gangbarste Benennung der Rhaphe.

Wer in den grossen griechischen Onomastica von Julius Pollux, Hesychius, Suidas, und H. Stephanus, eine kleine Umschan hält, wird sich bald überzeugen, dass die 
nähte wurden mit lateinischen Uebersetzungen anderer griechischer Ausdrücke, oder auch mit neugeschmiedeten, mitunter ganz absurden Namen bedacht. Die Griechen ge-

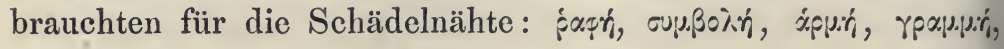

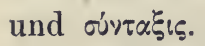

'Pup' hiess die Kleidernaht, und wurde schon von Celsus mit Sutura (suo, nähen) übersetzt. Wir finden bei ihm Sutura als $W$ undnaht (oras vulneris sutur $\hat{\iota}$ comprehendere ${ }^{1}$ ), und als Naht der Hirnschale (raro calvaria solida, et sine suturis est ${ }^{2}$ ). Die Uebersetzer der Araber, wie die guten Lateiner der alten anatomischen Schulen; blieben bei Sutura. Die LatinoBarbari hielten sich an oup.Boikf, und übersetzten es auf wunderliche Weisen: als Commissura und Junctura serratilis ${ }^{3}$ ), im lateinischen Canon, - als Conjunctio und Complexio serratilis, im lateinischen Averroës, - als Complosio und Complosa (statt Complexio) im Haly Abbas, - als Consuitio und Commissio im Vuillichius. - Aoprí drückt überhaupt eine Verbindung und Vereinigung aus, im Galen und Erotianus auch eine Naht.

eben beleuchteten Worte, selbst bei den Griechen, nicht immer dieselbe Bedeutung hatten, und bald als Mittelfleisch, bald als After, bald als männliches Glied, bald als äussere männliche Geschlechtstheile, dienen mussten. So ist Taujpos im Stephanus: pars scroto subjecta (Mittelfleisch), im Suidas die äusseren männlichen Geschlechtsorgane (io xiঠ̀oiov toỉ ¿̀ýpós). Dass Tramis bei den lateinischen Autoren aus der Restaurationsperiode der Anatomie, für Mittelfleisch herhalten musste, scheint sich daraus zu erklären, dass man der grieehischen tpáus, das lateinische trames, Querweg unterschob, und selbes für die quere Hautbrücke zwischen After und Geschlechtstheilen anwendbar erachtete.

1) De.medicina, Lib. VII, Cap. 4.

2) Opus idem, Lib. VIII, in praefatione, und an mehreren anderen Stellen.

3) Serratilis vocatur, quia similis est conjunctioni duarum serrarum, contrario occursu mutuo ingredientium, Gorraeus. 
Wir besitzen ein Andenken an dieses Galenische Wort, in der Harmonia, Fuge, als Zusammenschluss geradeliniger, nicht gezackter Knochenränder, z. B. zwischen den inneren Tafeln

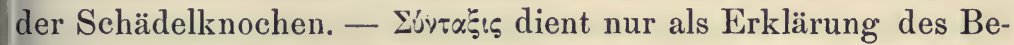
griffes einer Naht, wie: suturam definiunt, syntaxin serrotam ossium calvariae $\left.{ }^{1}\right) .-\Gamma_{p} \alpha$ purir war eigentlich jeder Strich, jede Linie. Da aber das Schachbrett, durch rechtwinkelig gekreuzte Linien, in Felder eingetheilt wird, wie die Hirnschale es durch die Nähte wird, verirrten sich die rpxpup.a! des Julius Pollux, auch in das Gebiet der Anatomie, als Grammata - eine komische Verwechslung von Geschriebenen (Buchstabe und Buch) mit Linien. Nicht viel weiser handelten die Neulateiner, denen die alte Sutura nicht mehr gefiel, und welche ztr Sutèla griffen, ohne zu wissen, dass Sutēla nicht Naht, sondern der Act des Nähens ist, und metaphorisch für Sticheleien und Ränke aller Art gebraucht wird: dolosae astutiae im Festus, und "quando, ob sutelas tuas, te morti misero", im Plautus (Captivi, Act. III, Scena 5). Falsche Nähte vermissen wir bei Griechen und Römern. Erst die Araber (Avicenna), unterschieden die falsche Naht von der wahren, und nannten sie alLarz al-kēdzib, „lügen de Naht". Die Araber, welche, nach dem Gesetz des Koran, keine Anatomie haben durften, waren sehr aufmerksame Beobachter alles dessen, was sich an der OberAäche des Leibes der Lebenden, und an zufällig aufgefundenen Menschenknochen, sehen liess. So gaben sie den Hautvenen hire jetzt noch gebrauchten Namen, und berichtigten mehrere rrige Angaben des Galen über gewisse Knochen, wie Unterkiefer, Brustbein, und Kreuzbein. Die falsche Naht verlanken wir ihnen.

Die Uebersetzer des Avicenna, sagen für falsche Naht: Sutura mendosa, ein Ausdruck, welcher jetzt noch in den Iandbüchern umherirrt. Mendosa soll richtiger mendax heissen, veil mendosus (von mendum, Fehler) fehlerreich bedeutet.

1) Gorraeus, Definitiones medicae, pag. 401. 
Horaz stellt diese beiden Worte, in ihrer ganz verschiedenen Bedeutung, nebeneinander, als Bezeichnung eines schlechten Kerls: mendosus atque mendax. Galen und Celsus wussten es wohl, dass die Schuppennaht nicht den anderen Nähten ähnlich sieht. Sie versahen sie deshalb mit ganz eigenen Namen, wie:

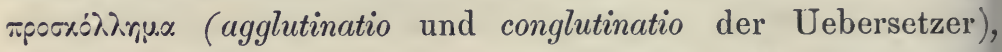

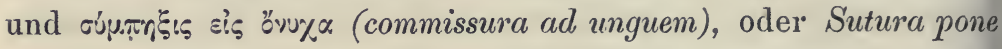
aures und Sutura, quae super aures transversa est. Noch in nachVesalischer Zeit hiess sie Crotaphia, von хpórạ̣os, Schläfe.

\section{Rectum.}

Weil man vom After schneller in den Darmkanal kommt, als von der Mundhöhle her, betrachtete Mundinus und seine Schule, das Rectum als Anfang des Darmes, und behandelten die Abtheilungen des Darmschlauches, in umgekehrter Ordnung als wir, nicht mit dem Duodenum beginnend, sondern mit ihm schliessend. In dieser Beziehung ging schon Hippocrates, mit seinem Beispiele voran, indem er den Mastdarm àp\%ś, Anfang, nannte, aus welchem àpyós (oder aus Łpopos, Steiss), der altdeutsche "Arsz", und der jungdeutsche "Arsch" sich herausbildeten. Diese Zählung der Abtheilungen des Gedärmes vom Rectum an, lässt uns verstehen, wie Julius Pollux den

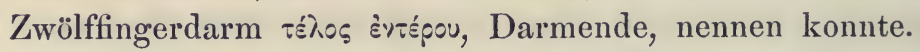

Das Rectum ist kein gerader, sondern ein gekrümmter Darm. Man beschreibt ja an ihm eine Curvatura sacralis und prostatica, zu welchen noch die Curvatura sigmoidea kommt, wenn diese nicht zum Colon gerechnet wird. Warum heisst also dieser dreimal gekrümmte Darm Rectum? Die Antwort auf diese Frage finden wir im Galen. Da er nur Thiere zergliederte, deren Mastdarm bekanntlich keine Krümmungen

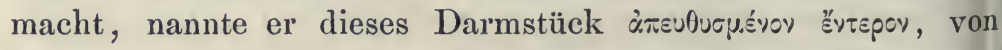
à $\pi$ $\theta_{0} v \omega$, gerade machen. Die Uebersetzer des Galen geben uns ganz correct dafür das Rectum, von dessen allgemein 
gewordener Anwendung, nur die Arabisten eine Ausnahme machten, indem sie dem Rectum, drei barbarische Lieblingsausdrücke vorzogen: Fïcteris, Astale, und Longanon, über welche in HL, §. LXIV, Ausführliches enthalten ist.

Der deutsche Name Mastdarm, von dem nicht mehr gebrïuchlichen mast $=$ fett, erklärt sich aus der reichlichen Ablagerung von Fett, welche bèsonders bei den gemästeten Hausthieren auffältt, - daher Intestinum pingue im Verheyen. Der altdeutsche Grammatiker, Rabanus Maurus, im 9. Jahrhundert Abt zu Fulda, schrieb "Crojdarm", womit nicht, wie die Glossen sagen, grosser Darm gemeint ist, sondern Kreuzdarm, des anliegenden Kreuzbeins wegen. Das norddeutsche Packdarm, erklärt sich aus dem alten Backtharm = von baek oder bak, hinten. Leibesdarm beruht auf der alten Bedentung von Leib als After und Mastdarm, wie in dem Worte Leibstuhl, und in der Phrase: der Leib tritt aus = Mastdarmvorfall. Das englische straight-gut ist eine wörtliche Uebersetzung von Intestinum rectum. Das französische gros boyau bezieht sich eigentlich auf den ganzen Dickdarm, und das holländische aarsdarm ist selbstredend. Sehr anständig für ein so unanständiges Object, lautet das italienische la parte di dietro, und das spanische via comun. Im Culo des gemeinen Volkes in Italien, sowohl für After, als für Mastdarm, erkennt man leicht den Culus des Martial. Eine sehr derbe, aber sehr bezeichnende Benennung, verdankt der Mastdarm dem Arnobius, als stercoris uter, der Kothschlauch.

\section{Restiformis.}

Die Markstränge, welche den hinteren Winkel der Rautengrube des verlängerten Markes begrenzen, und sich in die Hemisphären des kleinen Gehirns einsenken, nannte H. Ridley, Processus restiformes ${ }^{1}$ ). Sie wurden unter diesem

1) Anatomy of the Urain, Lond., 16.95, pag. 78. 
Namen nicht alt, und machten den Pedunculi cerebelli Platz, welche auch Crura oder Processus cerebelli ad medullam oblongatam, statt umgekehrt: Crura s. Processus medullae obl. ad cerebellum, genannt wurden. Da sie sich zum kleinen Gehirn verhalten, wie die Pedunculi cerebri zum grossen, führen sie fast durchgehends den Namen Pedunculi cerebelli. Henle führt sie als Funiculi restiformes an $\left.{ }^{1}\right)$.

Die Lautverwandtschaft von restis mit Rest, scheint die Veranlassung gegeben $\mathrm{zu}$ haben, dass restiformis aufgegeben wurde. Sonst wäre das Wort ganz gut gewesen, in der Bedeutung von strangförmig, denn restis ist Strick, mit welchem Verbrecher gegeisselt (Plautus), oder gehängt wurden (Juvenal).

\section{Retia, und Rete mirabile.}

Die Anatomie ist voll von capillaren Gefässnetzen, und dennoch sind wahre Gefässnetze etwas sehr Seltenes, wenn man den eigentlichen Begriff eines Netzes fest hält. Nur Nervenfäden oder Blutgefässe, welche in Einer Ebene liegen, können durch wechselseitige Anastomosen, Netze bilden. Wahre capillare Gefässnetze werden deshalb nur in sehr dünnen Membranen auftreten, wie in den serösen Häuten, in den Synovialhäuten, in sehr zarten Schleimhäuten, welche die Sinus der Kopfknochen auskleiden, in der Pupillarmembran, in der hinteren Linsenkapselwand des Embryo, in der Retina, an der inneren Oberfläche der Choroidea, und im Trommelfell. Alle parenchymatösen Organe, wohin auch die dicken Schleimhäute zu rechnen sind, alle Muskeln, alle Nerven, das Gehirn, das Rückenmark, die Ganglien, alle drüsigen Organe, haben keine Capillargefässnetze im strengen Sinn des Wortes. Würde man sich aus diesen Organen, Alles wegdenken, was nicht Capillargefäss ist, so würde ein Gefässgebilde zurückbleiben,

1) Nervenlehre, pag. 102. 
welches sicher nicht Netz genannt werden kann. Denn dasselbe besteht aus einem Gewirre von Capillargefässen, welche in allen möglichen Richtungen zu einander stehen und sich untereinander verbinden, so dass sie einem lückenreichen schwammigen Körper gleichen, welchen man vielleicht als ein Gewirre, als ein Durcheinander zahlreicher Netze, aber nicht als cin Netz auffassen kann. Nur an der Oberfläche dieses Körpers, kann, als Grenze des inneren Vernetztseins seiner Capillargefüsse, ein $\mathrm{Netz}$ vor Augen treten. Wenn ich mir eine grosse Anzahl gewöhnlicher Fischernetze, übereinander gelegt, und jedes derselben mit dem darunter und darüber liegenden wieder netzartig verbunden denke, kann ich mir annähernd eine Vorstellung von dem Verhalten der feinsten Blutgefässe in der Substanz eines massigen Organs machen, und diese Vorstellung kann ich nicht mit dem Wort Netz ausdrücken, wohl aber mit Netzgeflecht, Vernetzung, und Plexus reticularis.

Bleiben wir bei einer Art der Gefässnetze länger stehen, bei den sogenannten Wundernetzen, Retia mirabilia.

Schon vor Galen, liessen die Anatomen die Carotis interna, unmittelbar nach ihrem Eintritt in die Schädelhöhle, zwischen dem Keilbein und der harten Hirnhaut, sich in ein dichtes und reiches Geflecht auflösen, welches sie retiformis

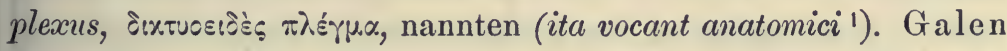
war über den Reichthum dieses Netzgeflechtes so erstaunt,

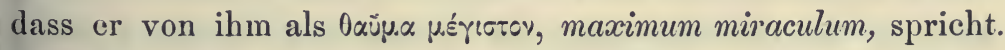
Seine Commentatoren machten deshalb aus dem plexus retiformis ihr Rete mirabile, welches, als Wundernetz, noch in der jetzigen anatomischen Sprache cursirt. Die Stämmchen des Netzgeflechtes, in welches sich die Carotis interna an der Basis der Schädelhöhle auflöst, vereinigen sich wieder zu einem einfachen Stamm, welcher sich nun erst in die Adergeflechte

1) Galen, De usu partium, Liz. IX, Cap. 4. Aıxuosıòn's kommt

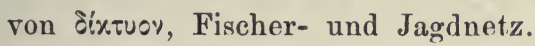

Hyrtl. Onomatologia anatomica. 
des Gehirns auflöst. Der Nutzen des Netzgeflechtes besteht nach Galen'scher Lehre darin, dass der Spiritus vitalis, welchen die Carotis enthält, in diesem Geflecht per subtiliationem, in die Spiritus animales umgewandelt wird, welche in den Hirnhöhlen sich ansammeln, und durch die Nerven den verschiedenen Organen des Leibes zugeführt werden. Dieses Rete mirabile existirt wirklich, aber nicht im Menschen, sondern bei den Katzen, Schweinen, Delphinen, und besonders entwickelt bei den Wiederkäuern, wo es seiner Grösse und seines Reichthums wegen, schon in der Kindheit der Wissenschaft nicht übersehen werden konnte. Durch ein Jahrtausend hielt sich das Rete mirabile der Carotis in den anatomischen Schriften. Berengarius Carpensis hatte der Erste den Muth, seine Existenz zu läugnen, mit den kühnen Worten: istud tamen rete ego nunquam vidi $\left.{ }^{1}\right)$. Aber wo sollte nun der Spiritus vitalis der Carotis sublimirt, und in den Spiritus animalis raffinirt werden, wenn kein Rete mirabile dazu vorhanden ist? Berengarius half sich aus dieser Verlegenheit, indem er die vielen feinen Zweige, welche die Carotis, nachdem sie schon die Dura mater durchbrochen hat, um die Glandula pituitaria und den Hirntrichter herum abgiebt, für das Netz erklärte, in quo subtiliatur spiritus vitalis et fit animalis. Realdus Columbus dagegen, fasst das Rete mirabile, als unseren Plexus choroideus medius auf ${ }^{2}$ ). Jene späteren Nachfolger des Carpus, welche die Autorität des Galen noch aufrecht zu halten bestrebt waren, glaubten das Wundernetz noch in dem netzförmigen Gebälke des Sinus cavernosus retten zu können, und als auch dieses misslang, wurde die später als Circulus arteriosus getaufte Anastomose der Carotiden und Wirbelarterien, als Rete mirabile behandelt. Noeh in 17. Jahrhundert konnte Th. Bartholinus

1) Isagogae breves, in Capitulo: de rete mirabili secundum communem opinionem, versus finem.

2) De re anatomica, Lib. VII, pag. 183, der Venetianer Ausgabe, 1559. 
sagen: rete mirabile in homine dari non negandum est, ut fecit Vesalius $\left.{ }^{1}\right)$.

Heutzutage giebt es noch zwei Arten von Wundernetzen. 1. Das Rete mirabile unipolare. So heisst die fächerförmige Zerspaltung eines Gefässes in viele Aeste. Sie kommt nur an kleinen Gefässen vor, besonders schön an den Schlagadern der Schwimmblase gewisser Fische, an den Verzweigungen der Leberarterien der Scombri, an den Venen der Choroidea (als Vasa vorticosa), und an den Ciliararterien der Choroidea bei den Vögeln und Wiederkäuern. Da die divergirenden Gefässchen dieses Fächers (Gefässwedel, und wenn sie dichter sind: Quasten und Pinsel), sich nicht wieder zu einem einfachen Stämmchen sammeln, verdienen sie den Namen eines Netzes nicht. 2. Rete mirabile bipolare, das eigentliche Wundernetz, dessen Gefässe sich ebenso zu einem einfachen Stamme wieder vereinigen, wie sie aus einem einfachen Stamme hervorgetreten sind. Das arterielle Gefässsystem der Säugethiere und Vögel liefert viele schöne Exemplare dieser Netzform. Im Menschen, und allen Wirbelthieren, kommen kleine Wundernetze dieser Art, und zwar auf Knäuel zusammengeballt, nur an den präcapillaren Zweigen der Nierenschlagadern vor, als Glomeruli oder Corpuscula Malpighii. - Dass in der Anatomie noch Netze existiren, welche keine Netze sind, wird uns, bei der den Anatomen angestammten Leichtfertigkeit in der Wahl ihrer 'Termini, nicht befremden. Das Rete Malpighï, noch schlimmer Rete mucosum, ist die noch nicht verhornte, tiefe Epidermisschicht, - die Substantia reticularis der Knochen, ist kein Rete, sondern ein schwammartiges Knochengefüge, die Retina, die Nervenhaut des Auges, ist keine Netzhaut (sieh' dieses Wort), - und die Netze, Omenta, (Retia und Reticula des Bauhin), sind es ebenfalls nicht.

1) Institutiones anatomicae, Lib. III, Cap. 6. 


\section{Retina,}

Schade um die niedliche und wohlklingende Retina, dass sie für zweifach barbarisch erklärt, und unbarmherzig verurtheilt werden muss. Fiat justitia. Das classische Rom kannte nur Eine Retina. Das war ein kleiner Flecken in Campanien, in der Nähe des Vesuv ${ }^{1}$ ), das heutige Resina. Das griechische prrtivr hat nichts mit dem lateinischen Retina zu thun, denn, als von $\oint^{\prime} s$ (fliessen) abstammend, bedeutet es Harz, weil dieses von selbst aus den Bäumen fliesst (Resina). Das italienische Redina (sicilianisch Retina), aus welchem sich durch Umstellung, das spanische Rienda (französisch Rêne) ergiebt, steht zu unserer Retina in keiner Beziehung, da es von retinere, zurückhalten, geformt wurde, und als Zügel, zum Ersatz für Habena dient, welches mit Avena collidirt, und des den Italienern unbequemen $H$ wegen, in die italienische Sprache nicht aufgenommen wurde.

Retina, als Netzhaut, kann nur im Gedanken an rete gebildet worden sein. Es weiss aber Jedermann, dass dic Netzhaut kein Netz ist. Wie so kam sie also zu diesem absurden Namen. Einzig und allein durch die Schuld des Uebersetzers des Canon Avicennae, welcher in der Bildung neuer Worte gar nicht verlegen war. Das arabische Wort für Netzhaut ist Rescheth, und dieses eine Uebersetzung des griechischen גu. formte ${ }^{2}$ ). Amphiblestron ist in erster Instanz eine $U \mathrm{mh}$ üllung, ein Ueberwurf (von $\dot{\alpha} \mu . \notin \alpha \lambda \lambda \hat{\lambda} \omega$, anziehen), in zweiter Instanz ein Fischernetz, welches die gefangenen Fische umhüllt. Der gebräuchlichere Ausdruck für Fischernetz ist ypirsos. Galen hat gewiss genug Thieraugen zergliedert, und dabei gesehen, dass die Nervenhaut des Auges kein Netz ist, sondern eine

1) Plinius, Epist., VI, 16.

2) De usu partium, Lib. VIII, und Rufi Ephesii Onomasticon. 
nicht durchbrochene, continuirliche, markige Umhüllung des Glaskörpers. Nur in diesem Sinne hat er das Wort Amphiblestron genommen. Nennt doch er selbst, und der spätere

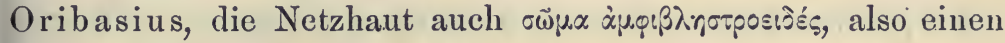
Körper, was ihm nie beigekommen wäre, wenn er die fragliche Membran wirklich für ein Netz gehalten hätte, welches doch sicher kein Körper ist. Das arabische und hebräische Rescheth drückt aber blos retiformis aus, so dass Gerardus Cremonensis noch entschuldigt werden kann, sich statt des Adjectiv retiformis, das Substantiv retina erdacht zu haben. Die Stelle im lateinischen Canon des Gerardus, in welcher die Retina zuerst das Licht des Tages erblickte, lautet: extremitas nervi concavi (so heisst der Opticus, weil er für hohl gehalten wurde) comprehendit vitreum (Glaskörper), sicut rete comprehendit venationem (den Fang), quapropter nominatur

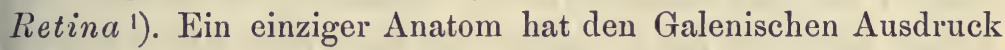

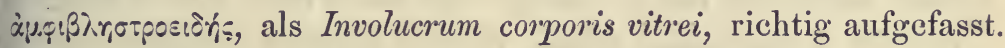
Hätte er dem Involucrum, noch nerveum beigegeben, würden alle sprachkundigen Anatomen diesen Ausdruck angenommen, und die grundfalsche Retina aufgegeben haben. Es war der Todfeind des Galen: der grosse Vesalius. Er sagt: Nervi visorii substantia dilatatur in latum involucrum, posteriori vitrei humoris sedi obductum ${ }^{2}$ ), und später: neque ego scio, quod nomen aptius quam involucrum (huic membranae) indi possit.

Das wäre also der erste Barbarismus in der Retina.

Der zweite besteht in ihrer allgemeinen Pronunciation als Retĩna, während das in ina ausgehende lateinische, oder latein sein sollende Wort, nur als Retīna ausgesprochen werden soll. Die Prosodie aller mir bekannten lateinischen Worte, mit dem Auslaut ina, haben das $i$ lang, wie man sich an folgenden, mir gerade in den Sinn kommenden Beispielen, überzeugen kann: Angīna, Arvīna (Fett), Facelīna (Beiname der Diana),

1) Lib. III, Fen 3, Tract. 1, Cap. 1.

2) De corp. hum. fabrica, Lib. VII, Cap. 14. 
Gallina, Gingrīna (kurze Flöte); Medicīna, Molīna, Officìna, Resīna, Textrīna (Weberei), Tonstrīna (Barbierstube), Urīna, Ustrīna (Verbrennungsstätte der Leichen), Vagīna, u. a. m. Dasselbe gilt von allen weiblichen Adjectiven in ina, wie masculina, feminina, etc. Ich kenne kein lateinisches Wort in ina, in welchem das $i$ kurz tönt. Die einzige Ausnahme dieser Regel, adamantina, ändert an ihrer Giltigkeit nichts. Prosodisch richtig ist:

"Colchis flagrantes adamantinna sub juga tauros "Egit - - -."

und im Lucretius:

\section{Propertius.}

\section{"- - adamantǐna saxa}

"Prima acie constant, ictus contemnere sueta."

Aber die Verse beweisen nur, dass adamantinus, kein römisches,

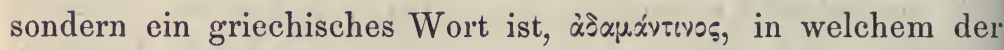
Accent nicht auf das $i$, sondern auf das $a$ fällt, und das kurze $i$, bei der Latinisirung dieses Wortes belassen wurde.

Man hat also, wenn man schon Retina beibehalten, und nicht durch das passende Tunica nervea oculi, oder Involucrum nerveum corporis vitrei ersetzen will, Retīna, nicht aber Retĩna $\mathrm{zu}$ sagen.

Schon Galen und Oribasius hielten die Retina für einen, dem Auge einverleibten Theil des Gehirns, denn wenn die Retina herausgenommen und auf ein Häuflein zusammengelegt wird, tibi plane cerebri quamdam portionem exemptam videberis intueri ${ }^{1}$ ).

\section{Retinaculum.}

Kraft des Stammwortes, retineo, kann jedes Ding, welches dazu verwendet wird, etwas festzuhalten, Retinaculum genannt werden. Die Anwendungen von Retinaculum sind deshalb sehr

1) Oribasius, Anatomica ex Galeno, pag. 33. 
vielseitig. Wir finden Retinaculum als Zügel, Hacken, Binde, Klammer, Schiffstau, und Seil, bei den Classikern. Selbst der Lebensfaden hiess so: vitae retinaculum, im Plinius.

Die Anatomie verwendet Retinaculum auf zweifache Weise: 1. als anatomisches Werkzeug zum Aufheben und Festhalten von Weichtheilen, beim Präpariren. Ly ser ${ }^{1}$ ) belegte mit diesem Namen, die anatomischen Hacken, welche zu den unentbehrlichen Geräthschaften jedes Zergliederers gehören. In Mundinischer Zeit, wo der Hacken und die Pincette, noch nicht gebräuchlich waren, bediente man sich der Finger, um ein Weichgebilde, z. B. einen Muskel, zu umgreifen, und aufzuheben, worauf er durch parallele Schnitte mit einem grossen Messer (Novacula), von seinen Adhärenzen getrennt.wurde, welche Operation Excarnare hiess. Mundinus erwähnt den Hacken nie. Seine Nachfolger aber sprechen von ihm als Uncus und Hamus (nicht Hamulus). Ihre Hacken müssen also ebenso plump gewesen sein, wie ihre Messer. Auf den schönen Holzschnitten, welche die Titelblätter der Werke alter anatomischer Meister bilden, findet man einfache und doppelte Hacken abgebildet. Nur Realdus Columbus wird noch mit den Fingern arbeitend dargestellt. Sehr praktisch sind die Adjutoria der Engländer, welche aus einem kleinen Metallring bestehen, von welchem drei dünne Kettchen auslaufen, deren jedes am Ende einen Hacken trägt. Diese Hacken benöthigen bei ihrer Anwendung, keine fassende oder ziehende Hand. Dient der einfache oder doppelte Hacken mit Griff, wie er in unseren Seciretouis enthalten ist, nur zum Aufheben oder Spannen von Weichtheilen durch die Hand eines Gehilfen, so wird jeder Anatom zugeben, dass sich die Finger viel besser für diese Verwendung eignen, da sie niemals ausreissen können, wie der Hacken. - 2. Die zweite Anwendung von Retinaculum, liegt in fibrösen Gebilden, welche andere festhalten, damit sie nicht aus der Lage weichen. Wir haben in der Gegenwart nur ein

1) Culter anatomicus in prooemio, Art. 2, Num. 4. 
solehes Retinaculum: das Retinaculum tendimum peronceorum, welches die Sehnen des langen und kurzen Peronaeus, in der Furche des äusseren Knöehels überbrïckt, und ihı Ausweichen verhindert. Dasselbe ist, genau genommen, kein Retinaculum. Denn ein Retinaculum muss sich an den Gegenstand, welchen es festhält, ansetzen, was das Retinaculum tendinum peronaeorum nicht thut, da es, wie ein Ligamentum transversum, nur über diese Sehnen hinübergespannt ist. Die Retinacula ossis brachii, worunter Loder die fibrösen, scharfrandigen, an den Hals des Oberarmbeins sich inserirenden Fortsätze der "Kapsel des Schultergelenkes verstand 1), sind nach Verdienst in Vergessenheit gerathen. Sie konnten ja niemals leisten, was ihr Name ausdiüekt.

\section{Risorius.}

Der Ernst der anatomischen Wissensehaft verschmäht auch Heiteres nicht. Die Myologie führt uns sogar einen lächerlichen Muskel vor, - den Risorius Santorini. - Er ist jener dünne Muskelstreif, welcher von der die Parotis deckenden Fascie entspringt, und quer zum Mundwinkel tritt. Santorini, welcher ihn zuerst beschrieb ${ }^{2}$ ), gab ihm den Namen Risorius novus, in der Absicht, mit diesem Worte seine Betheiligung beim Lachen auszudrücken. Der Muskel wird schon lange nicht mehr als ein selbstständiger betrachtet. Albin ${ }^{3}$ ) erklärte ihn für einen Antheil des Subcutaneus colli (Platysma myoides Galeni), und Henle für einen queren Kopf des Triangularis anguli oris, an dessen oberen Rand er sich zuweilen ganz genau ansehmiegt.

An der Benennung Risorius ist auszustellen, dass sie nicht den Sinn eines Lachmuskels, sondern eines lächer-

1) Tabulae anat., Tab. XIX, Fig. 4, Num. 6.

2) Observationes anatomicae, Venet., 1724, Cap. 1, §. 34.

$\left.{ }^{3}\right)$ Historia musculorum hominis, Leidae, 1734, Lib. III, Cap. 35. 
lichen Muskels ausdrüickt. Lachmuskel hätte mit Risor gegeben werden sollen, denn das der basse latinité angehörige, und nicht mehr als einmal, in der Mythologia des Fulgentius Placiades (6. Jahrhundert) anzutreffende Risorius, ist $=$ ridiculus, wie aus honores risorii et citius fugitivi des genannten Schriftstellers zu ersehen (Lib. II, Cap. 17). Die reichsten lateinischen Lexica, und der Thesaurus linguae et eruditionis Romanae, von Matth. Gesner, kümmern sich um Risorius gar nicht, und verweilen nur bei Ridiculus und Ridibundus.

Der Zusatz novus ist ïberflüssig, da es keinen Risorius antiquus giebt.

\section{Rostrum cochleare.}

Das Ende des Canalis oder Semicanalis tensoris tympani, aus welchem die Sehne des Tensor tympani hervortritt, um sich nach auswärts zum Hammer hin zu krümmen, an welchem sie sich einpflanzt, heisst allgemein Rostrum cochlear'e '). Die Sache sieht wirklich einem Löffel gleich, oder vielmehr, wie Winslow sagt, dem Schnabel einer Löffelgans, dessen Ränder man sich aber aufgebogen denken muss. Der Uebersetzer des Winslow, wollte vermuthlich durch cochleare, als Adjectiv zu Rostrum, die Aehnlichkeit mit einem Löffel ausdrïicken. Aber cochleare ist leider ein Substantiv. Es giebt kein Adjectiv cochlearis, - der Löffel selbst heisst cochleare, als Nebenform von cochlear. Man hat also Rostrum cochleariforme, nicht cochleare zu sagen.

\section{Sacrum und Kreutzbein.}

Ueber das Os sacrum, und seinen, auf ein Missverstehen des Galen'schen ispòv brơjy beruhenden Namen, habe ich in meiner descriptiven Anatomie (\$. 124), Alles erschöpft, was

1) Winslow, Expos. anat., Tractatus de ossibus, §. 400. 
sich zur Erklärung und Begründung dieses Namens vorbringen lässt. Auf sie verweise ich den Leser. Die Namensgeschichte dieses Knochens bei den Arabern und im Mittelalter, findet sich in HL, $\S . X I I$, und $\S . X X I I$, so wie in der Note zu letzteren, pag. 276. Eine zutreffende Stelle im Caelius Aurelianus, sagt: majora omnia, vulgus sacra vocat (de morbis acutis, Lib. I, Cap. 4).

Warum das Os sacrum im Deutschen Kreutzbein heisst, ergiebt sich aus der alten Bedeutung von $\mathrm{Kreutz}=$ Erhabenheit. Dieses alte $\mathrm{Kreutz}$, niedersächsisch $\mathrm{Krütz}$, ist nämlich die sehr ansehnliche Erhabenheit am Ende des Pferderückens, zwischen den beiden Hüften, - das französische crouppe. Das nach hinten convexe Os sacrum des Menschen, mahnt an diese Erhabenheit am Hintertheil des Pferdes, und erhielt deshalb auch seinen Namen Kreuzbein. Mit dem Symbol des Christenthums, hat dieses $\mathrm{Kreuz}$ nichts gemein. Das christliche Kreuz $\uparrow$, sogenanntes Andreaskreuz, zeigt ïbrigens nicht die Gestalt des Kreuzes, an welches die Römer ihre Verbrecher schlugen. Dieses Kreuz war T-förmig (Antoniuskreuz), oder Y-förmig, jetzt noch als Schächerkreuz bekannt. Auf altbyzantinischen Gemälden, welche den Versöhnungstod Christi darstellen, sieht man nur diese beiden letzteren Kreuzformen. Bei den Buchdruckern heisst die Krücke (Querholz mit langem Stiel), mit welcher sie die feuchten Druckbogen zum Trocknen an Schnüren aufhängen, das Kreutz.

\section{Salvatella.}

Für ein feines $\mathrm{Ohr}$, klingt ein arabischer Accord aus diesem barbarischen Worte. Eine in ihrer Lage sehr variable Vene am Handrücken, heisst Salvatella. Ihre Lagc entspricht meistens dem Zwischenraum zwischen kleinem Finger und Ringfinger, oder Ring- und Mittelfinger. In diesem Falle bildet sie die Wurzel der Basilica. Entspricht aber ihre Lage dem 
Zwischenraum zwischen Mittel- und Zeigefinger, oder zwischen Zeigefinger und Daumen, bildet sie die Wurzel der Cephalica. Im Avicenna erscheint diese Vene als Al-usailim, im Rases als Osailemon. Aus beiden hört man das Sceilem des Avicenna $=$ Cephalica heraus. Andreas Alpagus, welcher die Randnoten zur Uebersetzung des Canon von Gerardus schrieb, behandelt das Al-usailim als Alaseilem. Petrus Aponus formirte daraus sein Salaseilem, welches durch Albertus Magnus zur Salacella, und durch erneuerte Schreibfehler zu Salvatella wurde. Dieses ist der wahre Stammbaum der Salvatella; nicht, wie Rolfink meinte, "quia salvat illa"1), da die Aderlässe aus ihr, für sehr heilsam gehalten wurde. Uebrigens bedeutet auch das arabische Wort Osailemon, nach Golius (Arab. Lex. pag. 1207) so viel als Vena salutis: ad arabicae vocis immitationem, quae a salute, quam ex hujus venae sectione sperant medici, indita fuit.

Mehr über Salvatella in HL, $\S . X C$.

\section{Saphena.}

Saphena ist, wie ich gezeigt habe, kein griechisches, sondern ein arabisches Wort ${ }^{2}$ ). Was wir heutzutage Saphena nennen, war bei den Griechen immer nur sp̣pirins ộśu, die Vene am Knöchel, im Celsus: vena ad malleolos. Das Adjectiv oxọrís steht für deutlich, manifestus. Man glaubte also, mit aller Ueberzeugung, dass diese Vene, deren Varicositäten sich durch die Haut hindurch, als blaue Geschwülste kundgeben, ebendeshalb von den Griechen oxṕns oder oxprivis genannt worden sei. Dem ist nicht so. Kein griechischer Arzt oder Anatom hat je von

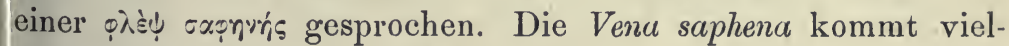

1) Dissertationes anat., Lib. V, Cap. 39.

2) HL, §. XCI, Saphena. 
mehr aus dem Canon Avicennae ${ }^{1}$, wo sie al-săfin heisst, mit vulgärer Aussprache al-sāfen. Dieses arabische sāfen bedeutet verborgen, also gerade das Gegentheil von dem griechischen oag̣is. Wie erklärt sich das? Sehr leicht durch Folgendes. Die Araber waren grosse Freunde vom Aderlassen, und kannten die schon im gesunden Zustande leicht zu sehenden Hautvenen des menschlichen Leibes sehr gut, welche sie zu eröffnen pflegten. Die Saphena sieht man, während ihres ganzen Verlaufes vom Schenkelbug bis zum Knöchel, nicht durch die Haut hindurch. Die Araber kümmerten sich deshalb wenig um sie, da sie aus ihr nicht zur Ader lassen konnten, und nannten sie sofort al-säfen, die Verborgene. Erst am Knöchel wird sie durch die Haut hindurch sichtbar, und dort eröffneten sie dieselbe auch bei verschiedenen Unterleibsleiden. Dort hiess sie ihnen auch: Vena ad cavillas (cavilla = malleolus im lateinischen Canon). Von Varicositäten dieser Vene bei Frauen wussten sie nichts, da Frauen in der Regel nicht von Aerzten, sondern von den mulieres medicae, wie sie im lateinischen Abul-Kasem genannt werden, behandelt wurden.

Die Ueberzeugung, dass Saphena griechisch ist, war bei unseren Voreltern so tief eingewurzelt, dass sie dieselbe oft als Saphaena schrieben (Spigelius), oder als saphsía (Jac. Sylvius), in der Meinung, dass das Adjectiv oxpris, das femi-

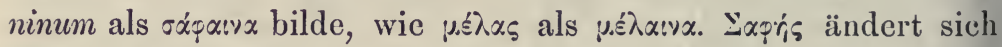
aber, wie $\dot{\alpha} \lambda \hat{r} 0 \dot{r}_{s}$, in der weiblichen Geschlechtsform nicht, und bleibt oxş่s.

\section{Scala tympani und Scala vestibuli.}

Ohne Stufen giebt es keine 'Treppen, Scalae. Die Scalcue der Schnecke, haben keine Stufen, und sind somit auch keine Scalae, im eigentlichen Sinne des Wortes. Das Unrichtige in

1) Lib. I, Fen 1, Doctr. 5, Summa 5, Cap. 5. 
diesem Ausdruck, scheinen auch Andere schon eingesehen zu haben, denn man ersetzte die Scalae und Treppen, durch Ductus oder. Canales spirales (Duvernoy), auch durch Gyri (Scharrschmidt), und Gänge der Schnecke (Sömmerring). Nur die, bei vertical gehaltener Schnecke, schief aufsteigende Richtung ihrer, wie eine Wendeltreppe spiral gewundenen Gänge, konnte J. M. Valsalva veranlasst haben, diesen unpassenden Namen zu wählen. Besser würde Scala auf die Lamina spiralis passen, da sie ebenfalls schief aufsteigt, und durch ihr radiärgefasertes Ansehen im frischen Zustande (besonders schön bei den grossen Säugethieren), etwas, den Sprossen einer Leiter Aehnliches vorspiegelt. Schiffsleitern und Sturmleitern hiessen bei den Römern Scalae. - Die sogenannten Treppen der Schnecke, sollten also füglich durch spirale Schneckenkanäle oder Gänge ersetzt, und nur die Lamina spiralis, Schneckentreppe genannt werden.

Die beiden Scalae, als Scala vestibuli und Scala tympani von einander zu unterscheiden, verdient ebenfalls gerügt $\mathrm{zu}$ werden, da diese Scalae nicht dem Vestibulum und Tympanum angehören, sondern der Cochlea. Das würde sich leicht durch Scala ex vestibulo, und Scala ex tympano corrigiren lassen.

Scala kommt von scandere, steigen, wie Stiege (Steige) von steigen. An Treppe von trappen (treten), máhnt das polnische Drab und Drabina, Leiter, und in der Jägersprache die Trappe des Wildes = Fährte, womit wieder das französische attraper, erwischen, die italienische trappola, eine Falle zum Fangen des Wildes und der Mäuse, zusammenhängt. Ein sehr pfiffiges Kartenspiel, welches die spanischen und italienischen Hilfstruppen im dreissigjährigen Kriege, nach Deutschland brachten, und welches jetzt noch beim Volke sehr beliebt ist, heisst la trappola, und wird mit eigenen Karten gespielt, den sogenannten Trapulirkarten. 


\section{Scaleni,}

Ausonius setzte dem gleichschenkeligen und dem gleichseitigen Dreieck (isosceles und isopleuros), das skalene entgegen (scalenos 1). Die Lexica definiren oxxinqvós, als triangulus, cujus omnia latera, inter se sunt inaequalia. Die Wurzel von oxaingrys ist $\sigma \% \alpha \not \zeta \omega$, hinken. Nimmt man jene Muskeln her, welche Scaleni heissen, und welche von Sömmerring als „ungleich dreiseitige Muskeln" beschrieben werden, so findet man, dass keiner derselben ungleich dreiseitig (scalenus) ist. Jeder von ihnen ist vielmehr ein langer, von oben bis unten gleichbreiter, bandförmiger Muskel. Wie sind sie also zu dem Namen Scaleni gekommen. Betrachtet man diese Muskeln nicht einzeln, sondern alle zusammen, so bilden sie eine dreieckige Fleischmasse, mit ungleichen Seitenrändern. Sie entspringen sämmtlich von der Seitengegend der Halswirbelsäule, divergiren im Herablaufen, und setzen sich theils mehr vorn, theils mehr hinten, an der ersten und zweiten Rippe fest. Diese Divergenz derselben bedingt eben die ungleich dreiseitige Gestalt ihres Gesammtfleisches. Es ist deshalb unrichtig, mehrere Scaleni (bis fünf nach Albinus) aufzuführen, da keiner derselben ein Scalenus ist. Der Name Scalenus wurde auch von Riolan, welcher ihn als Muskelnamen in die anatomische Welt einführte, nur der Gesammtheit dieser 'Muskeln verliehen $\left.{ }^{2}\right)$. Von den einzelnen redet er gar nicht. Die Worte: Scalenus perforatur, ut venis, arteriis, et nervis, in brachium distribuendis, viam praebeat, sagen klar und deutlich, dass er nur Einen Scalenus vor sich zu haben überzeugt war. Schon Spigelius redet nur von Einem Triangularis cervicis ${ }^{3}$ ), und die Onomatologia medica completa kennt ebenfalls nur Einen, aber in mehrere Portionen

1) Epistola praefixa, Idyll. XIII.

2) Anthropographia, Lib. V, Cap. 21, Musculi colli.

3) Op. cit., Lib.IV, Cap. 7. 
getheilten Scalenus. - Unser vorderer, mittlerer, hinterer Scalenus, und unsere accessorischen Scaleni, welche selbstständig gewordene Fascikel dieser drei Muskeln sind, sollten deshalb anders genannt werden, und könnten es auch, da passende Benennungen bereits vorliegen, wie $\mathrm{Rippenheber}$ von Meckel, Trachelo-costales von Dumas, und Costo-tracheliens von Chaussier. Es liesse sich auch sagen: Portio s. Pars anterior, media, und posterior Scaleni, wie Winslow, Morgagni, u. A. diese Sache auffassten.

Uebrigens tritt das Wort exxinyvóg, nicht zuerst als Muskelname, in scenam anatomicam ein. Schon im Hippocrates

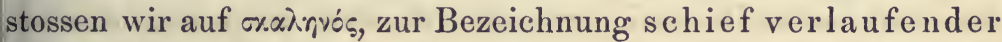
Kanäle und Venen $\left.{ }^{1}\right)$.

\section{Scaphoideus.}

Sieh' die Artikel: Cotyle und Pronaus.

\section{Scapula, Spathula, Scoptula.}

Nicht Ein Beispiel ist bekannt, dass Scapula, von den Classikern, je im Singular gebraucht wurde. Sie bringen inmer nur den Plural Scapulae, für Rücken, im Gegensatz zu Pectus, B rust. So der Sclave im Plautus, welcher die Ruthen fürchtet: nulla salus scapulis, und dudum scapulae gestibant mihi, der Rücken juckte mir, und scapulas praebere verberibus im Terenz. Celsus kennt die Scapulae nur als Rücken. Für Schulterblatt gebraucht er Os latum scapularum, der breite Knochen des Rückens ( $\dot{\omega} \mu \sigma \pi \lambda \dot{\alpha} \tau$ im Aristoteles und Galen). Wir erfahren aus Celsus zugleich, dass die Römer das Schulterblatt Scutulum opertum nannten, „das bedeckte Schildchen", seiner Breite und fleischigen Auflagen wegen.

I) In dem unechten Buch de resectione, Lib. II, Cap. 5 und 8. 
Eine nur dem Caelius Aurelianus eigene Nomenclatur für Schulterblatt ist Palla (Grabscheit, Schaufel) wodurch die flache Krümmung des Knochens ausgedrückt werden soll ').

Im Mittelalter war Scapula verpönt. Man bediente sich nur der Spathula. Dieses Wort ist kein Barbarismus. Es ist im Gegentheil richtiger als Spatula, da es von $\sigma \pi \dot{0} 0 \mathrm{r}_{\text {a }}$ abgeleitet wurde, worunter verschiedene breite Gegenstände verstanden wurden, wie die Schaufel des Ruders, ein breites Stück Holz zum Umrühren (Spatel), das vordere breitere Ende der Rippen (Hippocrates)', das breite Schwert der Leibgardisten der griechischen Kaiser (Spatharii), und das Schulterblatt (Med.). Bei den Latino-Barbari gerathen wir, statt des echt römischen Scutulum opertum, auf Scoptula operta. Wie dieser Ausdruck in's Dasein kam, lässt sich nur vermuthen. Bei den Opfern

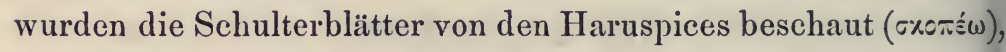
und die Zukunft, aus dem verknöcherten oder nicht verknöcherten Zustand ihres unteren Winkels vorhergesagt ${ }^{2}$ ).

Die Scoptula und Spathula hielten sich nicht länger, als bis in die Vesal'sche Zeit, mit welcher die Alleinherrschaft der Scapula beginnt. Riolan deducirt Scapula bei den Haaren, von $\sigma \alpha \dot{\alpha} \pi \tau \omega$, graben, „ob concavitatem“, während er zum scopulus, Riff, viel näher gehabt hätte, denn die Spina scapulae, der Grat des Schulterblattes, steht bei mageren Personen wie ein Riff am Rücken hervor. Von $\pi \lambda \dot{\alpha} \tau_{r}$ (Platte) $=\sigma \pi \dot{x} 0 r_{r}$, stammen die curiosen Homines platonici der älteren Medicin, Männer mit breiten Schultern, im Gegensatz zu den Homines alati, mit schmalen und vorspringenden Schultern „qui sigmum tabis futurae secum circum ferunt ${ }^{3}$ ).

Eine reiche Auswahl älterer, und nicht mehr gebräuchlicher Benennungen des Schulterblattes, findet sich in HL, §. XCVII.

1) De morbis acutis, Lib. II, Cap. 35 und 185.

2) Hyrtl, Antiquitates anat. rariores, §. 16, pag. 29.

3) Rolfink, Dissertationes anat., Lib. II, Cap. 43. 


\section{Schindylesis.}

Schindylesis wurde in einem obscuren anatomischen Leitfaden für Anfänger aufgejagt 1 ). Es wird damit jene Art fester Knochenverbindung ausgedrückt, wo der scharfe Rand des einen Knochens, zwischen den gespaltenen Lefzen eines anderen steckt, wie eine Schindel in der anderen. Ich fand diese Bezeichnung so treffend, dass ich sie in meinen Schriften adoptirte. Das Wort ist Galenisch: $\sigma \%$ เvơ ùinoเ = Spaltung in kleinere Stücke, von $\left.\sigma_{i}(v \delta \partial\rangle\right)^{\varepsilon} \omega=\sigma_{i} i \xi \omega$, spalten, das lateinische scindo. Hievon $\sigma \gamma i o ̛ \eta$ und $\sigma \chi: v \delta \alpha \lambda \mu \delta \delta$, gespaltenes, d. i. eingeschnittenes Holz, Schindel. Aus dem Schidacedum der alten Chirurgen $=$ Längenbruch eines Knochens, klingt das griechische $\sigma \chi 100$ xnóov heraus, welches Galen für Fractura longitudinalis und Fissura gebraucht ${ }^{2}$ ), zum Unterschied von Cauledon (xavinjobv), als einen Querbruch ohne Splitter, wie ein Stengel (caulis) in der Quere bricht. Paulus A egineta bedient sich dafür der Worte

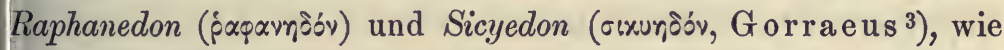

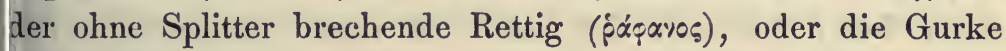
(orxus). Im Hippocrates und Dioscorides wird Schidacedon als Längenbruch, durch Schindalmos vertreten. Alles mit $\sigma \chi i \zeta \omega$ verwandt.

\section{Sclera oder Sclerotica?}

Wo bei den griechischen Aerzten von der Sklerotika

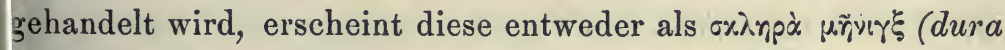

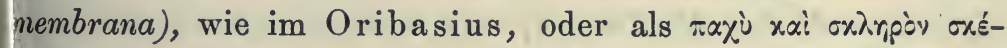

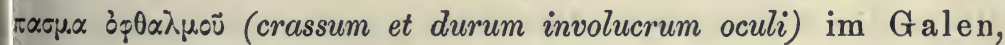

1) Christoph Heinrich Keil, Anatomisches Handbüchlein, Leipzig, 1730 , Cap. 5, §. 3.

2) Methodus medendi, Lib. VI, Cap. 5.

$\left.{ }^{3}\right)$ Definitiones medicae, $R$. und $S$.

Hy rt. Onomatologia anatomica. 


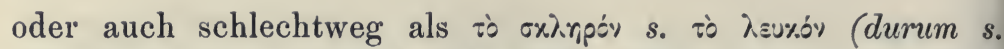
album) im Rufus, Pollux, u. A. Von einer Sclerotica schweigen sie alle. Sclerotica ist ein Barbarismus, dessen erstes Auftreten in den lateinischen Uebersetzungen des Rases und Avicenna gefunden wird. Von dem Zeitwort oxisrpów, hart machen, und dem Adjectiv oxinnós, hat die medicinische Sprache sich nur Eine Ableitung angeeignet: Scleroma (Verhärtung). ¿xirpostrós konnte nur von Sprachbarbaren erfunden werden, wie die Arabisten waren. Sie entstellten das Unding noch mehr durch neugriechische Aussprache, als Sclirotica, Sclyrotica, und Schlyrotica, welche im Mundinus, Carpus, und Gentilis zu finden sind. Nur selten wenden sie das arabische Wort Alnocha an. Nach dem to $\lambda$ suxóv des Rufus, wurde ein zweites barbarisches Wort für die Sklerotika geschaffen: Albuginea oculi ${ }^{1}$ ), auch Albamentum s. Album oculi. Beide sind nicht ganz identisch. Denn Albuginea heisst die ganze Sklerotika, Album oculi nur der vordere Abschnitt derselben, welcher durch die Lidspalte hindurch gesehen wird. So im Gerardus, Rasarius, und Alpagus. Mit diesem Album oculi wurde viel Verwirrung angerichtet, da auch die, mit dem vorderen Abschnitt der Sklerotika verwachsene Conjunctiva, als Album oculi und Albuginea behandelt wurde.' Sieh' die betreffenden Artikel, und $\mathrm{HL}, \S . X X X$.

Dem Gesagten zu Folge, giebt es keine Wahl zwischen Sclerotica und Sclera. Nur Sclera kann bestehen. Der erste Anatom, welcher Sclera statt Sclerotica schrieb, war der alte Salomon Albertus, Professor der Anatomie in Wittenberg ${ }^{2}$ ). Die Tunica oculi dura des Vesal, die Crassa des Vesling, die Extima oculi des F. Leber, die Cornea opaca des Van Diemerbroek, werden, obwohl sie verständigen Sinnes sind, sehr wenig oder gar nicht gebraucht, höchstens als Synonyme.

1) Wird auch als Albuminea angetroffen.

$\left.{ }^{2}\right)$ Historia plerarumque partium corp. hum., 1585, pag. 21. 


\section{Scortum oder Scrotum?}

Keine eitle Frage, denn beide Worte standen, als Hodensack, durch Jahrhunderte nebeneinander in Verwendung. Sie sind auch sprachlich identisch. Das alte Scortum, giebt per metathesin zweier Buchstaben scrotum. Scortum ist Haut, pellis. Pellem antiqui scortum dicebant, lese ich im Varro 1), und im Festus ${ }^{2}$ ): omnia ex pellibus facta, scortea appellantur. Die Hodensäcke der Böcke, hiessen Scortes ${ }^{3}$ ). Somit können auch die menschlichen Hodensäcke, Scorta genannt werden, welche durch Versetzung des $r$, Scrota geben. Das Etymon ist und bleibt: sacculus ex pelle. Wie wir jetzt noch jene Hodensäcke der Böcke zu Tabak- und Geldbeuteln verwenden, war auch im Alterthum, Scortum $=$ Marsupium $=$ Beutel. Ein Oberkleid aus Fellen, stösst uns im Martial, als Paenula scortea auf $\left.{ }^{4}\right)$. Die Huren, welche nach Forcellini (IV, pag. 53), lederne Oberkleider tragen mussten, erhielten „a veste scortea, qua indutae erant istae feminae", den Namen Scorta - welches Wort, als Ausdruck schimpflicher Verachtung, nur im Munde gemeiner Leute und von der gemeinsten Sorte dieser Dirnen geführt wurde: scorta, meretrices appellantur, ex consuetudine rusticorum. Das Scortum triobulare (Dreipfennighure), und die Moecha bustuaria, welche, ohne ein Quartier zu haben, hinter Grabsteinen (busta) sub Jove ihr Handwerk trieb, sind die schlechtesten der schlechten.

Im Mittelalter war Scortum, als Hodensack, für besser als Scrotum angesehen: Involucrum cutaneum testium, a.quibusdam scrotum vocatur, a quibusdam vero, qui se latinius

1) De lingua latina, Lib. VI, Cap. 5.

2) De verborum significatione, Edit. Müller, pag. 330 .

3) Festus, ibid.

4) Epigram. Lib. XIV, 130 . 
loqui existimant, scortum dicitur '). Celsus in classischer Zeit, wusste wohl ob Scortum oder Scrotum besser ist. Er hält es nur mit Scrotum: inciditur interdum inguen, interdum scrotum ${ }^{2}$ ). Wenn Scrotum und Scortum, vi nominis, einen (häutigen) Beutel anzeigen, darf es uns nicht überraschen, dass alle Synonyma für Beutel, als Benennungen des Hodensackes dienen mussten. Es sind ihrer mehrere:

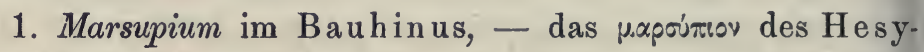
chius, ein lederner Beutel.

2. Bursa; Byrsa, und Bursula, bei den Latino-Barbari (vom griechischen Búpoc, Fell), mit der Erklärung, quia crumena ex corio est, "weil sie ein Beutel aus Haut ist". Bursa diente fast ausschliesslich zur Bezeichnung einer Geld-Börse, une bourse, deren Plural: les bourses, im Französischen ausschliesslich für Hodensack gebraucht wird. Bursa, als Geldbeutel, gab auch der Börse ihre Entstehung, wo Leute Geldgeschäfte machen. Bursae waren einst Stiftungshäuser, in welchen viele Studenten, nach Landsmannschaften eingetheilt, zusammenlebten. Diese Bursen entarteten bald zu Studentencasernen, wo allerlei grober Unfug getrieben wurde. Man hob sie also auf, aber die, der Bursa entsprossenen Burschen und Burschenschaften gedeihen noch.

3. Crumena, von mir nur im Alpagus, als Hodensack angetroffen, ist das Lederbeutelchen für Kleingeld, welches die Römer an einer Schnur um den Hals trugen (crumena plena assium, im Aulus Gellius).

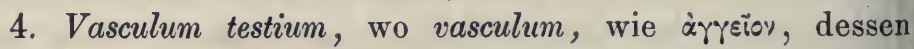
Uebersetzung es ist, überhaupt für ein $\mathrm{B}$ ehältniss gebraucht wird.

5. Pera, entweder das griechische $\pi$ ripa, Sack und Ränzel,

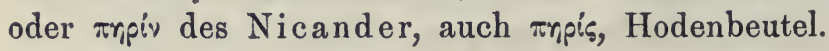

6. Saccus coriaceus im Bauhinus, Hautsack.

1) Vesalius, Op. cit., Lib. V, Cap. 13.

2) De medicina, Lib. VII, Cap. 19. 
7. Claudit agmen: Oscheus. Das altehrwürdige Wort des

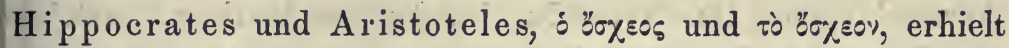
sich bis auf unsere Tage, jedoch nur in einigen Zusammensetzungen neueren Datums, wie Oscheocele, Oscheocarcinoma, Oschoedema, u. m. a. Im Zerbis wurde es zum Orcheum, da er diesen Barbarismus mit Orchis, Hode, in Verbindung brachte, bei anderen Arabisten sogar zu Oseus und Oseum!

Die Bedeutung von Scrotum als Beutel, tritt auch in der sonderbaren Benennung Scrotum cordis für Herzbeutel hervor. Sie taucht bei den Arabisten nicht eben selten auf. Ich fand sie zuerst in den Commentarien zum Canon Avicennae, von Jacobus de Partibus.

\section{Scrobiculus cordis und Praecordia.}

Ueber Scrobiculus cordis, Herzgrube, sieh' HL, pag. 257. Ich habe blos hinzuzufügen, dass Scrobiculus das Diminutiv von Scrobis oder Scrobs ist, welches im Allgemeinen jede Grube, auch das Grab bedeutet:

\section{"Jam scrobe, jam lecto, jam pollinctore parato."}

$$
\text { (Martial, Epigr., X, N. 97.) }
$$

Meistens wird es aber für Gruben zum Pflanzen von allerlei Gewächsen und Bäumen gebraucht (Columella, Varro). Im Arnobius überrascht uns Scrobs, als Schamspalte. Bei Gelegenheit, als er von der Pertunda spricht, einer Göttin, welche die Entjungferung unter ihre specielle Aufsicht genommen hatte (von pertundere, durchbrechen), gedenkt er ihrer Mission mit den Worten: quae in cubiculis praesto est, virginalem scrobem effodientibus maritis 1 ).

Scrobiculus cordis entspricht nicht den Praecordiis der Classiker. Diese wussten selbst nicht, was es mit den Praecordiis

1) Adversus gentes, Lib. IV, C'up. 131. 
eigentlich für eine Bewandtniss hat. So vieldeutig sind deren Anwendungen. Das 'Avtixápòtov im Julius Pollux, welches als Praecordia übersetzt wird, ist vi nominis, Alles, was vor dem Herzen liegt, also die vordere Brustwand, nicht die Herzgrube ${ }^{1}$ ). Im Plinius sind die Praecordia $=$ Zwerchfell: mem. branam, quam Graeci ppévas appellaverunt, praecordia nominamus, quia cordi praetenditur ${ }^{2}$ ). Gleich darauf widerspricht er sich aber selbst, und nennt alle Brusteingeweide Praecordia: praecordia vocamus uno nomine exta (Brusteingeweide) in homine. Dem Celsus sind die Praecordia $=$ den Hypochondrien ${ }^{3}$ ).

Den Anatomen braucht nicht erst gesagt zu werden, dass der Scrobiculus cordis nur an Leuten zu sehen ist, in welchen die Knorpel der letzten wahren Rippen, über den Schwertknorpel hervorragen, oder der Schwertknorpel eine etwas aufgebogene Spitze hat. Der Schwertknorpel hat aber den linken Leberlappen hinter sich. Man könnte, um die Trias seiner deutschen Benennungen vollständig ' zu machen, der Herzgrube, und der Magengrube, noch eine Lebergrube zur Gesellschaft geben. Ich sage dieses nur, um ersichtlich zu machen, wie vag der Begriff der Herzgrube ist.

\section{Scyphus Vieussenii,}

Ray mond Vieussens erkannte es zuerst, dass die beiden Scalae der Schnecke, in der Schneckenkuppel, in einen trichterförmigen, durch die Lamina modioli umschriebenen Raum einmünden, welchen er la coupe du nerf auditif nannte ${ }^{4}$ Becher des Gehörnerven. Während Fr. Cassebohm, Winslow's Schüler, und Professor in Halle, dieses Raumes

1) Sieh' HL, pag. 257, Note 2.

2) Hist:nat:, Lib: IF, Cap. 37, Sect. 77.

3) De medicina, Lib. II, Cap. 3 und 7.

$\left.{ }^{4}\right)$ Traité de la structure de l'oreille, Toulouse; 1714, pag. 72. 
nur als Communicatio scalarum cochleae und Canalis communis scalarum gedenkt, wurde er von Späteren als Scyphus latinisirt, und mit dem Zusatz Vieussenii, zu einem stehenden Terminus der Gehöranatomie erhoben ${ }^{1}$ ).

Scyphus ist das griechische oxúpos, Trinkbecher, Pokal inter scyphos, bei einem Glas Wein, im Cicero. Der römische Scyphus (abgebildet in Anthony Rich, pag. 55), war eigentlich eine ziemlich grosse, weite, und nach unten sich zuspitzende Schale mit Henkeln, wie die Oberstassen unserer Kaffeeservice, aber bedeutend grösser, weshalb er besonders bei Trinkgelagen, wo viel Wein getrunken wurde, in Gebrauch stand:

„Capaciores affer puer scyphos, "Et Chia vina, aut Lesbia,"

(Horatii Epodon, IX, 33, 34).

und :

"Natis in usum laetitiae scyphis."

(Carminum, Lib. 1, Od. 27.)

\section{Sebaceus.}

Sebum, Talg (von dem altsächsischen talgan, schmieren), durch Austausch des $b$, gegen das verwandte $v$, auch Sevum (italienisch sevo und sego), ist alles spisse, thierische Fett, während das weiche, Adeps hiess. Plinius nannte nur das Fett der Wiederkäuer, Sevum, jenes der Digitaten dagegen "Adeps: corrigera sevo pinguescunt, "non corrigera adipe 2): : Dás Sebum hatte keine medicinische Anwendung, und wurde nur zu Talglichtern, taedae und lucernae sebaceae (A pul.), gebraucht.

Sebum giebt, als Adjective, sebosus und sebaceus. Das zweite hat sich in der Anatomie, in den Glandulis sebaceis, niedergelassen. Wenn argillaceus, cretaceus, farinaceus, membranaceus,

1) Blumenbach, Geschichte und Beschreibung der Knochen, pag. 161.

2) Hist. nat., Iiz. II, Cap. 37. 
und viele ähnliche, besagen, dass ein Gegenstand aus Thon, Kreide, Mehl, Haut, u. s. w., gemacht ist, so besagt auch Glandula sebacea, eine aus Talg gemachte Drüse. Die Glandulae sebaceae bestehen aber nicht aus Talg, sondern bereiten ihn, und sollten deshalb Glandulae sebiparae, keineswegs sebaceae genannt werden. Das Wort sebaceus ist gut, aber bei seiner Anwendung in der Anatomie, im Sinne von talgbereitend, muss es für einen Barbarismus erklärt werden.

\section{Secundinae.}

Die Secundinae (Nachgeburt) tragen den Barbarismus an der Stirn. Secundinus ist uns nur aus Inschriften bekannt, als Beiname einiger römischer Geschlechter, wie Aelius Secundinus, und Petilia Secundina. Die Nachgeburt hiess Secundae, nicht Secundinae. Der Pluralis femininus ergiebt sich daraus, dass man unter Nachgeburt die Häute des Embryo verstand, quae, quia secundo quasi partu eduntur, secundae membranae, vocabantur. So finden wir die Secundae in unseren beiden besten Gewährsmännern Celsus und Plinius. Medicus trahere debet umbilicum (Nabelstrang ${ }^{1}$ ), usque ad eas membranas, quas secundas vocant, quod velamentum infantis intus fuit, heisst es im Celsus ${ }^{2}$ ), und im Plinius: morantes secundas extrahere ${ }^{3}$ ). Im Avicennat) besteht die Secundina aus drei Panniculi (Chorion, Amnios, und Allantois). Alexander Benedictus definirt die Secundae als Umbilicus cum involucro, Nabelstrang

1) Noch in den Annotationes anatomicae von Albinus, sehen wir Umbilicus als Nabelstrang.

2) De medicina, Lib. VII, Cap. 29, f.

3) Hist. nat., Lib. XXVI, Cap. 15, Sect. 90, und an anderen Stellen: Secundas trahere, Secundas pellere, evocare, purgare, sedare.

4) Canon, Lib. III, Fen 21, Tract. 1, de generatione embryonis. 
und Eihaut 1). Im Singular, als Secunda, erscheint, unrichtiger Weise, die Nachgeburt im Vesal und Columbus. Auf die Membranae foetus, können sich nur die Secundae beziehen.

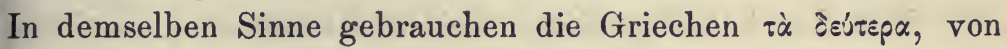

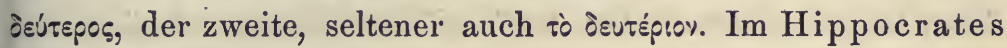
finden wir die Nachgeburt als $\tau \dot{\alpha}$ ü $\tau \varepsilon \rho \alpha^{2}$ ) (das hinterher kommende), und $\left.\tau \dot{\alpha} \% \omega \dot{\omega} ! \alpha^{3}\right)$ erwähnt, im Galen jedoch immer nur als to \%opioy, da das Chorion, und die mit ihm innigst verbundene Placenta, den Hauptbestandtheil der Nachgeburt bildet. So im Lib. VI, de Hippocratis et Platonis decretis, Cap.6,

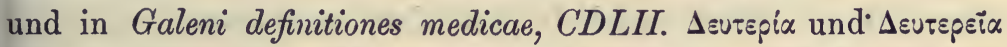
hiess auch eine schlechte Gattung Wein, welche durch ein

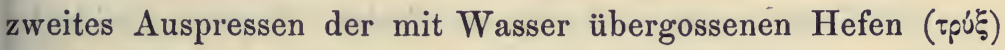
gewonnen wurde.

Der Ausdruck Angion im Moschion ${ }^{4}$ ), kann nicht befremden, da ày̧siov nicht nur Gefäss (Blutgefäss), sondern überhaupt einen Behälter ausdrückt, wie denn selbst die Wohnhäuser im Xenophon, angeia heissen, und ein solches Wohnhaus für den Embryo, bilden seine häutigen Hüllen.

Das französische arrière-faix, entspricht der gesammten Nachgeburt, - gateau aber nur der Placenta. Faix stammt ohne Zweifel von Fascis, Bündel, welches Bündel als Bürde, sich in der Hand oder auf dem Rücken bequem tragen lässt. Arrière-faix ist somit $=$ dem altdeutschen Wort Afterbürde für Nachgeburt, wie das englische After-birth. Das englische after, nach, hinter, und das deutsche After, sind identisch.

1) Anatomice, Lib. II, Cap. 24.

$\left.{ }^{2}\right)$ Aphorism. V, 49.

3) Hippocratis Aphorismi, et Galeni in eos Commentarii, XXXV.

4) De mulierum passionibus, citirt im Pierer, V, pag. 545. 


\section{Semimembranosus und Semitendinosus.}

Nur das Auffällige dieser beiden Muskelnamen, sicherte ihren langen Bestand. Der Semitendinosus kann noch hingehen, da seine schlanke Sehne, so lang ist wie sein fleischiger Bauch. Als man noch an der alten Bedeutung von nervus, als Sehne, Gefallen hatte, hiess dieser Muskel Seminervosus. So noch im Riolan 1), und im Kulmus ${ }^{2}$ ). Cowper führte die Benennung Semitendinosus ein, welche seit Albin, der ausschliessliche Name dieses Muskels blieb. Da aber tendinosus, reich an Sehnen heisst, wäre tendineus vorzuziehen.

Semimembranosus ist in zweifacher Hinsicht schlecht. Denn erstens muss statt Semimembranosus, richtig Semimembranaceus oder Semimembraneus gesagt werden, wie es im Spigelius geschieht ${ }^{3}$ ), und zweitens darf die breite und starke Ursprungs- und Endsehne dieses Muskels, gar nicht Membrana genannt werden, da nur zarte und dünne Häute, wie jene des Auges und des Gehirns, von Celsus, als Membranae, aufgeführt werden, und sehnige Häute in der Anatomie nie Membranae schlechtweg, sondern Membranae fibrosae heissen. Nur der Umstand, dass die beiden Sehnen dieses Muskels, breiter als irgend eine andere sind, konnte Riolan bewogen haben, diesen Muskel Semimembranosus zu nennen, eine Benennung, welche auch Albinus beibehielt, und sie dadurch zur allgemeinen: Geltung brachte. Da der Muskel doch im Grunde ein Semitendineus ist, könnte er von dem eigentlichen Semitendineus, welcher schlank und spindelförmig ist, als Semitendineus crassus unterschieden werden.

1) Anthropographia, Lib. V, Cap. 41.

2) Anatomische Tabellen, Tab. 28.

3) Op. cit. Lib. IV, Cap. 23. 


\section{Sesamoideus.}

Ich habe anderswo bewiesen, dass Sesamos, von welchem die Ossicula sesamoidea ihren Namen erhielten, ein arabisches Wort ist ${ }^{1}$ ). Die Pflanze, welche wir als Sesamum orientale Linn. kennen, war ursprünglich in Aegypten und Arabien zu Hause, und hiess dort Semsem (Sempsem). Als Genuss- und Heilpflanze, kam sie nach Kleinasien, und brachte ihren heimischen Namen mit, welchen die Griechen, euphoniae causa,

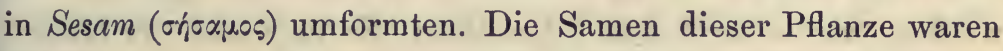
den Aerzten sehr wohl bekannt, da sie dieselben in allerlei Zubereitungen, als Emolliens, Antiphlogisticum und Antibiliosum priesen: Galen bemerkte die Aehnlichkeit, welche zwischen diesen oblongen Samen, und gewissen kleinen Knöchelchen an den Zehen der Thiere obwaltet, und nannte letztere deshalb

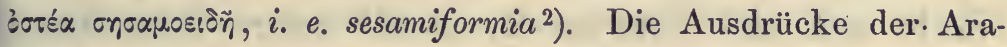
bisten, Simsimania und Semsamania, stehen dem semitischen Stammwort, Semsem, viel näher, als das griechisch-lateinische Sesamina, mit neugriechischer Aussprache Sisamina, welches noch zu Vesal's Zeiten ausschliesslich gebraucht wurde, bis Bauhin die von der gesammten anatomischen Nachkommenschaft bewahrten Ossicula sesamoidea wieder herstellte ${ }^{3}$ ). "Die Deutschen, welche mehr auf die Sache, als auf die Aehnlichkeit gehen, erfanden sich ganz richtig ihre Gelenk-oder: Gleichbeine, wie ihre Rollknochen und Sehnenrollen. Sesambeinchen zu sagen, konnten sie sich lange nicht entschliessen. Erst durch BIumenbach wurde das Beispiel dazu grègeben 4 ).

i) HL, §. XCIII.

2) De ossibus ad tirones, Cap. 25, ad finem.

3) Theatrum anat., Lib. IV, Cap: 29.:

1) Geschichte und Beschreibung : der Knochen, \$. 431. 


\section{Sigmoideus und semilunaris.}

Von der Regel, dass die Namen der griechischen Buchstaben indeclinabel sind, macht das Sigma eine Ausnahme. Es hat einen Genitiv oivuatoc. Man sieht dieses an seiner Verbindung mit sî̀os (Gestalt). Eữos wird nur dem Genitiv des vorhergehenden Hauptwortes angehängt, wie wir aus pterygoideus, allantoideus, coracoideus, odontoideus, und anderen, ersehen. Deshalb soll sigmatoideus, statt sigmoideus geschrieben werden, wie es im Rufus ${ }^{1}$ ) geschieht. Es liegt aber im Galen und Oribasius, welche die halbmondförmigen Klappen der

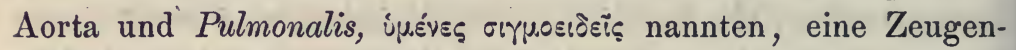
schaft vor, dass man auch sigmoideus schreiben und sagen darf, welche Schreibart in der heutigen Anatomie die allein angenommene ist. Sigmoideus ist $=$ semilunaris ${ }^{2}$ ). Das Sigma bezieht sich also nicht auf $\Sigma$, als die neuere Form dieses Buchstabens, sondern auf die ältere: C. - A pulejus nennt deshalb das Sigma: litera semirotunda. Als der viereckige Speisetisch bei den Römern ausser Gebrauch kam, und nur in den Casernen belassen wurde, bediente man sich runder Tische (orbes), um welche halbrunde Sopha's gestellt wurden. Auch diese Sopha's, welche Apulejus: suggesta semirotunda nennt, hiessen, gleich wie die in den Bädern angebrachten. halbmondförmigen Sitzbänke Sigmáta:

\section{"Accipe lunata scriptum testudine sigma."}

(Martial, Epigr. Lib. XIV, N. 87.)

Mit dem Worte sind wir also im Reinen. Nun zu seinen anatomischen Anwendungen. Die Plicae oder Valvulae sigmoideae im Colon und Rectum, die Cavitas sigmoidea ulnae major et

1) De partibus hominis, pag. 69.

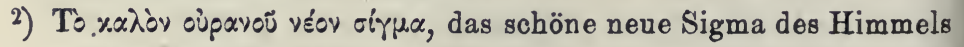
= Neumond (Aeschrion). 
minor (auch Cavitas lunata), die Cartilagines sigmoideae der Luftröhre, die Incisura sigmoidea (semilunaris) am oberen Rande des Unterkieferastes, die Fossa sigmoidea an der inneren Fläche der Pars mastoidea und petrosa des Schläfebeins, der Processus sigmoideus scapulae (alte Diction für Processus coracoideus), sind sattsam bekannt. Es werden aber, in der neueren anatomischen Sprache, mehrere Dinge sigmoid genannt, wo weder das griechische $\Sigma$, noch das $C$, sondern nur das lateinische $S$ gemeint sein kann. Denken wir 1. an die Curvatura sigmoidea recti (das S. Romanum Winslovii), welche von Einigen, mit gutem Grund, noch zum Colon geschlagen wird, da ein Intestinum rectum, gerader Darm, doch keine S-förmige Krüm: mung machen kann, - 2. an die Curvatura sigmoidea der Carotis interna, - und 3. an die nicht mehr gebräuchlichen Curvaturae sigmoideae der Muttertrompeten.

Sigmoeides wird allgemein mit semilunaris übersetzt. Dieses, der Anatomie unentbehrlich gewordene Wort, ist, wie das ebenso oft verwendete semicircularis, ein Italicismus. Die Römer kannten diese beiden Worte nicht. Ihnen war nur semicirculatus und semilunaticus bekannt, letzteres $=$ halbverrückt. Lange dauerte es bis die Klappen in der Wurzel der Aorta und Arteria pulmonalis, mit dem Beinamen semilunaris beglückt wurden. Im Mundinus hiessen sie einfach Hostiola ${ }^{1}$ ); im Berengar aber Pelliculae similes vacuitati, quae est in litera $C$. Heister führte semilunaris ein, und Morgagni wollte, dass nur die Klappen der Aorta diesen Namen führen, jene der Arteria pulmonalis aber sigmoideae genannt werden sollen. Warum? sagt er nicht. Beide Worte sind gleichbedeutend.

1) Ostium ist Thüröffnung und Thüre, Ostiolum kleine Thüre, und Ostiola kleine Thürflügel, mit welchen die Klappen verglichen wurden. Hostiola zu sagen, ist ein bei den Italienern jener Zeit allgemein $\mathrm{zu}$ findender Barbarismus. 


\section{Sinus.}

Die sehr verschiedenartigen Verwendungen von Sinus bei den Römern, lassen sich alle auf den Begriff einer Ver tiefung oder einer Biegung zurückführen. Was wir Sinus durae matris nennen, ist weder Biegung noch Vertiefung, sondern ein bluthältiger Kanal oder Gang, auf welchen das Galenische $\alpha \gamma \omega \gamma \delta \varsigma$, ductus (von $\not{\alpha} \gamma \omega$, führen, leiten, die agogae des Plinius ${ }^{1}$ ), viel besser passen würde, als Sinus. Die deutsche Sprache hat allein das Richtige getroffen, mit ihren Blutleitern und Blutbehältern.

Lassen wir es uns von den Classikern beweisen, dass es fehlerhaft ist, einen geschlossenen Hohlraum in der harten Hirnhaut, Sinus zu nennen. Wir kennen Sinus als Krümmung der Schlange im Cicero, des Winzermessers im Columella, der Haarlocke im Ovid, des windgeschwellten Segels im Virgil, und der Schlachtreihe im Tacitus. Wir kennen ferner Sinus 1. als die Vertiefung der um den linken Arm geschlagenen, und von ihm zusammengefalteten Toga, aus welcher Regulus den Carthagern Krieg oder Friede hervorholte (sinum ex toga facere, Livius), - 2. als Busen und Schoss (in sinu est meo, er ist mein Schosskind, und in sinu amici deflere, am Busen des Freundes weinen, Cicero), - 3. als Bucht der Meeresküste (naves ex porto sinuque abducere, Jul. Ca e sar), 4. als Schlund und Schlucht in der Erde (terra in ingentem sinum consedit, Livius), - 5. als Tasche (praedam in sinum deferre, und aurum in sinu invenire, Propert.), - 6. als grossen, bauchigen Napf für Milch (Varro), - 7. als Trinkgefäss für Wein (Plautus), - und 8. als Gelenksgruben, und halbmondförmige Ausschnitte gewisser Knochen, sowie auch als Vertiefungen zwischen langen Nahtzacken (daher Sutura sinuosa, für Sutura vera, im Loder). Von Sinus, als einem langen, geschlossenen

1) Hist. nait., Lib. XXXIII, Cap. 4, Sect. 21. 
Gang, wie es eine Blutleiter ist, liest man nirgends. Erst mit Vesal tauchten die Sinus durae matris ${ }^{1}$ ) auf. Das Wort wurde nicht glücklich gewählt. Die Sanguiductus meningei des Fallopia, oder die Cavernae venosae des Ruysch, wären vorzuziehen. Aber Sinus hat den Vorzug der Kürze, und ist in das Fleisch und Blut der Anatomen so allgemein übergegangen, dass man es nicht leicht wieder aufgeben wird, obwohl seine Anwendung als eine falsche anerkannt werden muss.

Da ein einmal begangener Sprachfehler, andere zur Folge hat, wurde das Wort Sinus auch auf Höhlen überhaupt angewendet. So entstanden die Sinus frontales, sphenoidales und maxillares, welche weit besser Antra zu nennen wären, - die Sinus cordis und cerebri, bereits durch Atria cordis und Ventriculi cerebri verdrängt, - der nur am Skelet leere, sonst aber mit Bandmasse ausgefüllte Sinus tarsi, und der Sinus renis (Vesal'scher Name für Nierenbecken). Alle Aus- und Einbuchtungen dagegen, können recte als Sinus bezeichnet werden, wie die Gelenksgruben, die Sinus im Kehlkopf (Ventriculi Galeni s. Morgagni), der Sinus coxae = Acetabulum, die Sinus coli = Haustra, die Sinus Morgagni im Mastdarm, die Sinus oculi (alter Name der Augenwinkel), der Sinus coecus linguae = Foramen coecum, die drei Sinus Valsalvae, als Ausbuchtungen des Aortenrohres über den Halbmondklappen, der Sinus urogenitalis Mülleri des Embryo, der Sinus mammarum (die Vertiefung zwischen den weiblichen Brüsten - der Busen), und die ausgebuchteten Seitenränder weiblicher Harnblasen, als Sinus vesicae.

\section{Smegma,}

Smegma, als Talg, Schmiere, oder Salbe, kennt die Anatomie im Smegma cutaneum, und Smegma praeputii. Das Smegma articulorum hat aufgehört zu existiren, seit Paracelsus mit

1) Op. cit., Lib. III, Cap. 14. 
seiner Synovia auftrat. Nun ist leider das griechische op.riץp. keine Salbe, sondern der Act des Schmierens. Es kommt von $\sigma \mu \dot{\alpha} \omega$, reiben, streichen, schmieren, und abwischen, und wird deshalb auch als ou. r. u. in den besten Autoren gefunden. Nur in den Compositis ist smegma als Seife und Salbe enthalten, wie in Smegmatopōles und Smegmatophoreion, Seifenhändler und Salbenbüchse.

Die alten medicinischen Lexica setzen Smegma = Sapo, Seife 1) (Sapo smegmatis genus est). Plinius erzählt uns von der Seife, dass sie eine Erfindung der Gallier war, welche mit einer Mischung von Talg (sebum caprinum), und Buchenasche (cinis faginus), ihre Haare röthlich $\mathrm{zu}$ färben pflegten (rutilandis capillis ${ }^{2}$ ). Diese Seife der Gallier wurde in Kugelform in den Handel gebracht. Der Hauptstappelplatz für diese Toilettenwaare, war Mattiacum (Wiesbaden). Daher: Accipe Mattiacas, quo tibi calva, pilas, im Martial. Die Vorliebe der römischen Damen für rothes Haar, consumirte viel von diesem Artikel, welcher als Unguentum cineris im Serenus Sammonicus, und, mit Wasser angerührt, als Spuma caustica im Martial mehrmals erwähnt wird. - Der Sapo, war als $\sigma \alpha ́ \pi \omega y$, schon dem Galen bekannt ${ }^{3}$ ), und wird von ihm als ein Abstergens potentissimum gerühmt. Smegma und Sapo unterscheiden sich nur durch den Alcaligehalt des letzteren. Das Constituens von beiden bildet Adeps, oder Sebum. Sebum ist trockenes, compactes, bei gelinder Wärme nicht zerfliessendes Fett, welches die Griechen oréxp nannten. Deshalb sind Seborrhoea und Seborrhagia der modernen Pathologen, ganz widersinnig, nicht etwa als hybride Worte, sondern weil Sebum, als starres Fett, nicht fliessen kann, und rhagia, wie in Haemorrhagia, einen förmlichen Strom oder Sturz einer Flüssigkeit ausdrückt, wie ihn die winzigen Talgdrüsen

1) Barthol. Castelli Lex. medicum, Editio P. Brunonis, pag. 650.

2) Hist. nat., Lib. XXVIII, Cap. 12, S. 51.

3) Methodus medendi, Lib. VIII, Cap. 4, gegen Ende dieses langen Capitels. 
doch nicht bringen können. Adeps umfasst alle Arten thierischen Fettes, vom spissen Schaf- und Menschenfett, bis zum weichen Schweinschmalz.

\section{Soleus, Sohlenmuskel.}

Die älteren Benennungen des Musculus soleus waren: Quartus pedem moventium, im Vesal, Quartus tibiae, im R. CoI umbus, Gastrocnemius internus, im Spigelius und Cowperus. Den Namen Soleus erhielt er durch J. Riolan ') (Soleus latus st crassus). Riolan entlehnte diesen Namen aus dem Paraeus, welcher, da er Bader war, und nicht Latein kannte, in seiner inatomischén Schrift: Briève collection de l'administration anatomique, Paris, $1549^{2}$ ), den Muskel als le solaire bezeichnet hat, welches Wort durch Winslow zu le soléaire corrigirt wurde ${ }^{3}$ ). Nicht von solea, als Fusssohle, sondern von solea, als Plattfisch (Pleuronectes solea Linn., Solea vulgaris Cuv.), zonnte dieser Muskelname abgeleitet worden sein. Joh. Vesing, ein Deutscher, und einer der besten Anatomen an der veltberühmten Schule zu Padua ( $† 1649)$, sagt ganz entschieden: :oleus, a figura piscis denominatus ${ }^{4}$ ). Der Muskel kommt gar hicht in die Fusssohle (solea) hinab, sondern tritt ganz und far an die Achillessehne, an deren Bildung er mehr Antheil at, als der Gastrocnemius. Die deutsche Benennung des Soleus, Is Sohlenmuskel, welche Schaarschmidt einführte ${ }^{5}$ ), und Meckel zum bösen Beispiel für andere deutschschreibende Anatomen annahm, kann nicht scharf genug gerügt werden.

1) Anthropographia, Lib. V, Cap. 42.

2) Vermehrt und verbessert durch J. Bostaing, und mit dem Titel: Anatomie universelle, wiederaufgelegt, Paris, 1561.

3) Exposition anatomique, Traité des muscles, §. 584, 1126, und 1130.

4) Syntagma anatomicum, Cap. XIX.

5) Myologische Tabellen, Tab. 22.

Hyrt1. Onomatologia anatomica. 
Schollenmuskel muss er heissen, da der Fisch Solea (sfoglia der Italiener), im Deutschen als Scholle bekannt ist. Solaeus zu schreiben ist grob gefehlt, wie Cruraeus und Fibulaeus (sieh' den Artikel aeus und eus in diesem Buche). Ebenso absurd ist Solaris - der Sonnenmuskel.

Verweilen wir etwas länger bei Solea, als Plattfuss, denn ich befürchte Widerspruch, welcher sich darauf stützen könnte, dass der Muskel seinen Namen nicht von seiner Fischgestalt, sondern von einer Schuhsohle erhielt, welcher seine Contour ähnelt. Solea, Sandale, war bei den Römern, wie das ox́vòx.iov oder ímínnux bei den Griechen, ein nach der Gestalt der Fusssohle zugeschnittenes Stück Leder, welches mittelst eines Bandes oder Riemens, über den Span des Fusses befestigt wurde. Die Barfüssermönche tragen jetzt noch solche Sandalen. Ant. Rich bildet eine Sandale $a b^{1}$ ), nach einem Pompejanischen Gemälde. Diese Sohle hat bei Leibe nicht die Gestalt des Schollenmuskels - ein längliches Oval, sondern ist geigenförmig (pandurceformis), da, wegen Einwärtsbiegung ihrer beiden Ränder, die geringste Breite derselben, in ihre Mitte fällt. So sieht der Soleus wahrlich nicht aus. Wir müssen also schon bei der Scholle bleiben. Noch weniger lässt sich an jene solea denken, welche den Beinamen spartea führte, weil sie aus den Reisern von spartum, Pfriemengras, geflochten wurde. Sie war gar keine Sohle, sondern eine Art von Schuh, mit welcher nur die Füsse von Rindern und Saumthieren bekleidet wurden, wenn sie wund waren ${ }^{2}$ ). Die Japanesen bedienen sich heut zu Tage ähnlicher Soleae, aber nur für die Pferde, deren Hufe sich zu erweichen beginnen.

1) Römische Alterthümer, pag. 574.

2) Columella, De re rustica, Lib. VI, Cap. 12: solea spartea pes bovis induitur. 


\section{Sphenoideus oder Sphecoideus?}

An das $O s$ sphecoideum, W espenbein, welches sich unter den Synonymen des Keilbeins, in den Osteologien von Monro ind Walter, bemerklich machte, dachte heut zu Tage Niemand nehr. Henle trat in neuester Zeit mit dem Wespenbein wieder auf, und gebraucht es fast ausschliesslich für Keilbein. Unter den Anatomen des vorigen Jahrhunderts, lassen nur Loder, und der Wiener Professor F. Leber, etwas vom Wespenbein hören. Da das Keilbein von jeher mit einem liegenden Insect verglichen wurde, und auf diesen Vergleich seine Eintheilung in Körper und Flügel beruht, kann der Knochen, wenn man das Insect näher als Vespa, oథ̣r eeichnet, immerhin sich mit diesem Namen abfinden. Das Wort ist aber entschieden neueren Ursprungs, denn es findet sich, bei den Alten, nirgends erwähnt. Unter den vielen AusArücken, welche Galen für das Keilbein gebrauchte, war ihm der geläufigste: Os sphenoideum, von ợív, Keil, weil es, oiov ọ̣ìv

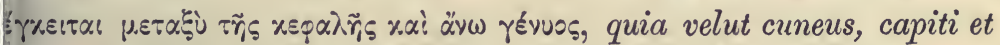
maxillae superiori interjacet. Eine andere Galenische Benennung les Os sphenoides, als Os azygos, taugt nichts, da auch das Atirnbein und das Hinterhauptsbein, unpaare Knochen sind.

Alle übrigen Synonyme des Keilbeins - und sie sind ingemein zahlreich - finden sich im Pierer und Schreger vollzählig versammelt. Sie beziehen sich fast durchgehends unf die Gestalt dieses Knochens. Da Sphenoideus und Sphecoileus einander uti ovum ovo, ähnlich sehen, liegt die Möglichzeit sehr nahe, dass beim Copiren der griechischen Codices, ich Sphecoideus als Schreibfehler, schon sehr frühzeitig einpeschlichen haben mag. Die griechischen Adjective opryosıòng and ợrixwòn૬, wurden nur zur Bezeichnung von Menschen mit pesonders schlanker Taille, angewendet.

Ueber die Benennungen des Keilbeins bei den Arabisten, 1andelt umständlich $\mathrm{HL}, \S$. XLVI, Cavilla, Os paxillare. 


\section{Sphincter.}

Die Schliessmuskeln des Mundes, der Lidspalte, des Speiseröhrenanfangs (unser Cricopharyngeus), des Magenausganges, des Afters, und der Harnblase, waren dem Galen bekannt 1). Er nannte sie Sphincteres (von oథ̣! $\gamma \gamma(\omega)$ schnüren, würgen, und zusammenziehen ${ }^{2}$ ). Sie wurden als Constrictores und Adstrictores (im lateinischen Rufus), ihrer kreisrunden Form wegen, auch als Orbiculares übersetzt. $\mathrm{Zu}$ den Galenischen Sphincteren oder Constrictoren, sind noch einige neuere, mehr oder minder berechtigte hinzugekommen, wie Sphincter cardiae, Sphincter foraminis ovalis (Isthmus Vieussenii), Sphincter ilei (in der Valvula Bauhini), Sphincter vaginae = Constrictor cunni, Spincter ani internus, Sphincter pupillae, und die Constrictores pharyngis.

Sphincter hat einen berüchtigten Verwandten in der bekannten Sphinx, jenem Thebanischen Monstrum, welches die Dichter besingen, als:

"Sphinx volucris pennis, pedibus leo, fronte puella,"

wobei sie den Drachenschwanz, den hochgewölbten Busen, die Mädchenhand, und die menschliche Stimme ausgelassen haben. Das Ungeheuer hauste auf einem Felsen bei Thebae, und zerstreute sich in seiner Einsamkeit damit, dass es den Passanten Räthsel aufgab, aber zugleich die Unart hatte, dass es die Unglücklichen, welche sie nicht lösen konnten, erwürgte

1) C. Hoffmann lässt sich über dieselben weitläufig aus, in seinem Comment. in Galeni librum de usu partium, Num. 257, und 297.

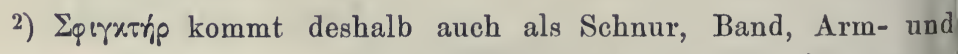

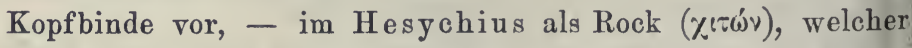
mit einer Schnur zusammengebunden wird, und die Volkstracht der Tarentiner bildete. 
und zerriss. Nur Oedipus war so glücklich, das ihm aufgegebene Aenigma: welches Thier in der Früh auf vier, Mittags auf zwei, und Abends auf drei Füssen geht, mit Mensch zu lösen, weil dieser als Kind auf allen Vieren kriecht, als Mann auf zwei, als Greis auf drei Füssen geht, deren einer der Stab ist. Die Sphinx konnte hierauf nichts Vernünftigeres thun, als den Helden seiner Wege ziehen zu lassen, und sich selbst, durch Herabstürzen von ihrem Felsen, den Tod zu geben. Sie lebt aber jetzt noch in der Zoologie als Affe fort: Cynocephalus Sphinx, mit unbehaartem vollem Busen, ad feminarum similitudinem. In Wahrheit war aber die Sphinx, wie der Scholiast des Euripides darlegt, eine Thebanische Priesterin, welche sich mit Orakelsprüchen abgab, deren Unverständlichkeit sie als besonders werthvoll erscheinen liess.

Eine im ersten Mittelalter allgemein gewordene Entstellung von Sphincter, ist Ficteris. Ueber die Verwendung dieses Wortes als After, und dessen Schliessmuskel, wie auch als Mastdarm und Unterleib, sieh' HL, §. LXIV. pag. 134.

\section{Spina dorsi.}

Wie gelangte das Rückgrat zu dem Namen Spina dorsi? Wir müssen zuerst bemerken, dass dieser Name classisch ist. Celsus sagt: caput spina excipit, quae viginti quatuor vertebris constat, und Plinius: cervix (Genick) spinae adnectitur, spina lumbis. Das Kreuzbein tritt im Suetonius als spina sacra auf, worüber Isidorus Hispalensis die Erklärung giebt: quia a gentilibus (Heiden) ex hostia primum Diis dabatur ${ }^{1}$ ). Um den Namen zu begründen, darf man nicht an Dorn oder Stachel denken, sondern an die Einrichtung eines römischen Circus. Dieser war durch eine lange, zwanzig Fuss breite, und sechs

1) Originum Lib. II, Cap. 1. Num. 96. 
Fuss hohe Mauer, welche sich in der Mittellinie der Rennbahn, etwa in drei Vierteln ihrer Länge hinzog, unvollkommen in zwei gleiche Theile getheilt. An den beiden Enden dieser Mauer standen die Metae (Grenzsteine), um welche herum die Wagen von der einen Hälfte des Circus in die andere umlenkten. Die Mauer war mit Obelisken, Altären, und Statuen der Götter geschmückt, und hiess Spina $\left.{ }^{1}\right)$. Da das Rückgrat den Rücken ebenso in zwei gleiche Theile theilt, wie die Spina den Circus, ging der Name auch auf das Rückgrat über. Woher wollte man ihn sonst ableiten? Sicher nicht von Spina als Dorn, noch weniger von Spina in der Bedeutung als Igelstachel, Fischgräte, Nadel, zugespitzter Federkiel, oder Zahnstocher im Petronius (Spina argentea). Die Spinae der Aloen werden jetzt noch bei den Beduinen als Nadeln zum Nähen verwendet, wie einst bei den Germanen starke Dornen statt der Heftnadeln dienten: spinis conserere, im Tacitus. Auch Spina, als Zahnstocher, hat die Zeit nicht ganz vergessen. In Frankreich, Italien, und Spanien, bediente man sich eines citherähnlichen Saiteninstrumentes, welches mit einem zugespitzten Federkiel (Zahnstocher, spina) gespielt wird, und deshalb spinetta (épinette) heisst. Dasselbe ist nunmehr nur selten in Gebrauch. Der Spinat (épinard, spanisch espinaca, wallachisch spenae), erhielt diesen Namen wegen der spitzigen Zacken seiner krausen Blätter.

Ueber die griechische $\alpha^{2} \times x y \theta \alpha$ (von $\dot{\alpha} \times \nvdash$, Spitze), lässt sich Folgendes sagen: Sie kommt als Stachel, als Dorn, als Distel,

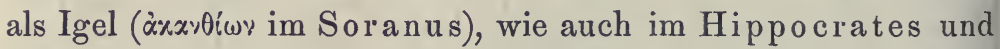
Galenus²) als Rückgrat vor. Nicht blos die Wirbelsäule, auch die Fortsätze der Wirbel, erhielten den Namen $\alpha^{2} \times \alpha, \theta \alpha$ : quia aculeo vel spinae non dissimiles sunt (Gorraeus).

1) Cassiodorus, Variarum epist. Lib. III, 51. Abbildung davon nach einem geschnittenen Stein, in Anthony Rich, Römische Alterthümer, pag. 579.

2) De usu partium, Lib. XII, Cap. 15. 
Die griechische $\alpha^{\prime} x a y \theta \alpha$ ist heutzutage gänzlich verschollen. Zwei andere Worte drängten sich an ihre Stelle, und behauptet sich eines derselben jetzt noch in der Medicin. Sie

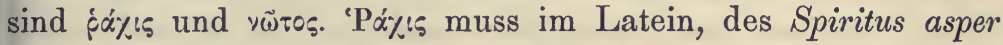
wegen, Rhachis, nicht Rachis geschrieben werden, wie denn auch die englische Krankheit, welche sich durch Verkrümmung des Rückgrats kund giebt, Rhachitis, nicht wie es allgemein gefällig ist, Rachitis, zu lauten hat. Die Anatomie kennt Rhachis im Bulbus rhachidicus') (Medulla oblongata), im Canalis rhachidicus, und im Rhachiotom. Die Medicin hat mehrere aus Rhachis gebildete Composita, leider alle ohne $H$ (Rachiodynie und Rachialgie, Rachiorheuma, Rachiomyelitis, etc. - Rhachis kommt uns im Griechischen auch als mediale Trennungslinie

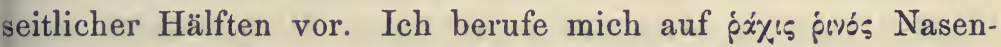

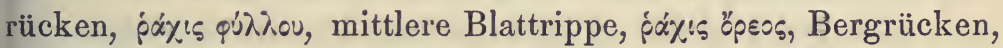
von welchem die seitlichen Abhänge abfallen.

Von vผ̈тоร und vய̈т0\% hört und sieht man nichts mehr.

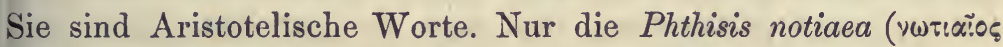
und $\left.\omega^{\prime} \tau 0_{5}\right)$ Rückendarre, hat einen verklingenden Nachlaut davon 2). Im Homer, Aristoteles, und allen griechischen Autoren, steht vש̈тo६ nur für Rücken, nicht für Rückgrat. Dass etwas Breites, nicht etwas Langes damit gemeint ist, beweist uns, dass $\tau \grave{\alpha} \nu{ }^{\prime} \tau \tau$ auf jede breite Fläche überhaupt, Land, Meer, und Himmelsgewölbe, angewendet wurde. Aus

1) Man hat sich nicht gehütet, rachiticus statt rachidicus zu schreiben. Beide Worte sind neu. Aber rachiticus wird nur im pathologischen Sinne gebraucht. Es giebt wohl rhachitische Kinder, aber keine rhachitischen Bulbi.

2) Die neue Notiomyelitis im krit. etym. Lexicon von $\mathrm{Kraus,} \mathrm{ist}$ ein Barbarismus, für Notomyelitis. Gegen den Notencephalus des Ge offroy Saint-Hilaire, eine Missgeburt, deren Gehirn in den nach hinten offenen Nackenwirbeln liegt, haben wir nichts einzuwenden, vorausgesetzt dass wir v心̈тos als Rückgrat gelten lassen wollen. 
den Synonymen für Rückgrat (Pierer, Choulant, Schreger), sollte es allen Ernstes ausgewiesen werden, da es gar nicht dahin gehört.

\section{Spina scapulae.}

An der hinteren Fläche des Schulterblattes ragt das als Gräthe, Gräte, oder Grath, bekannte Knochenriff heraus, welches die Fossa supra- und infraspinata von einander abmarkt, und nach aussen und oben, in das Acromion auslauft. Das Riff heisst Spina scapulae. Der deutsche Name Gräte, scheint aus der Bedeutung von Spina, als Fischgräte, nicht als Dorn oder Stachel, hervorgegangen zu sein, obwohl diese Spina ebensowenig einer Fischgräte, als einem Dorn ähnlich sieht.

Der unglückliche Einfall, von einer Spina scapulae zu reden, mag wohl auf folgende Weise entstanden sein. Die hintere, etwas convexe Fläche des Schulterblattes hiess bei den Griechen: Chelonium, weil man sie mit dem flach convexen Rückenschild einer Seeschildkröte ( $\left.\psi_{\varepsilon}\right\rangle(\omega) \eta \eta$, Chelonia midas) verglich. Petrus Paaw konnte nur aus diesem Grunde seine Testudo für diese hintere Schulterblattsfläche anbringen ${ }^{1}$ ). Andere nannten sie einfach Dorsum scapulae. Da nun das Dorsum des Stammes, eine Spina hat, als Rückgrat, glaubte man auch das Riff auf:dem Dorsum scapulae, eine Spina nennen zu müssen, obgleich man unberücksichtigt liess, dass die Spina dorsi vertical steht, und den Rücken in zwei gleiche Theile theilt, während die Spina scapulae schief nach aus- und aufwärts strebt, und die hintere Schulterblattfläche in zwei ungleiche Hälften theilt. Wer figürlich redet, iiberlegt nicht viel.

Die deutsche Benennung der Spina scapulae als Gräte ist.albern, weil es auch keine Rückengräte, wohl aber cinen Rückengrat oder Rückgrat giebt. Blumenbach schreibt zuerst und ganz richtig, Grath des Schulterblattes. Grath

1) Primitiae anatomicae de ossibus, Lugd., 1615, pag. 136. 
heisst im Ober- und Niederdeutschen jede scharfe Kante eines Dinges. Unsere Sprache führt deshalb Grathsparren (Dachfirst), Grathhobel, Grathbohrer (nicht mit spiraler, sondern mit geradeliniger Schneide versehener Tischlerbohrer), Grathsäge, Gratheisen (bei Bindern, zum Ausschneiden der Fassreife), Graththier (Gemse, weil sie auf hohen Gebirgskämmen sich aufhält, welche in der Schweiz Grätli und Grütli heissen), und die Kupferstecher nennen allgemein den zu beiden Seiten des arbeitenden Grabstichels sich aufwerfenden Saum weichen Kupfers: den Gràt, welcher mit einem scharfen Messerchen (Gratmesser), abgetragen werden muss, um den Druck nicht grob und patzig ausfallen zu lassen. So muss denn auch die Spina scapulae hinfüro nicht Gräthe, sondern Grat oder Grath genannt werden, und man ist vor jeder Missdeutung sicher.

Dass man auch scharfe Kämme und Leisten an verschiedenen Knochen, in der Anatomie Spinae nennt, beweist die Spina tuberculi majoris und minoris des Oberarmbeins, die Spina tibiae (vordere, scharfe Kante dieses Knochens), die Spina acustica am Grunde des Meatus auditorius internus, und die ohnediess schon zumeist aufgegebene Spina ossis frontalis und occipitalis. Sie sind Cristae, d. i. Kämme, und sollen auch Cristae bleiben.

\section{Spinosus,}

Wir treffen in anatomicis häufig mit dem Beiwort spinosus, und einer ganzen Reihe von Composita desselben zusammen. Ich erwähne die Processus spinosi der Wirbel, den Processus spinosus des Keilbeins (seit Sömmerring richtiger Spina angularis), den Processus spinosus mallei (seit Meckel Processus longus mallei), das Foramen spinosum des Keilbeins, wie auch das Tuberculum spinosum an der äusseren Fläche des grossen Keilbeinflügels (Crista transversalis), die Arteria und Vena spinosa (meningea media), das Ligamentum spinoso-sacrum, die Musculi spinoso-coccygei, spinoso-costales (serrati postici), spinoso- 
scapulares (rhomboidei), spinoso-transversales (multifidus), und die interspinosi (interspinales). Vielleicht sind noch einige Beispiele übergangen. - Das Beiwort spinosus will in allen diesen Fällen sagen, dass es sich entweder um etwas dornähnliches, oder in einem Dorne befindliches, oder von einem Dorn entspringendes handelt. Dazu aber ist spinosus nicht zu brauchen. Spinosus war zu allen Zeiten dornenreich, spinis abundans

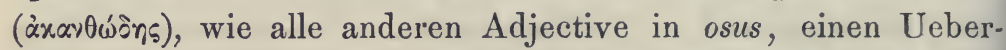
fluss an einer Sache ausdrücken (sieh' Tuberositas). Herbae spinosae, Folia und Loca spinosa, Cortex und Caulis spinosus, Animalia spinosa (Igel und Stachelschwein), und Fragmenta spinosa, als spitzige Knochensplitter im Celsus, die metaphorische Oratio spinosa des Cicero, Stichelrede, die Quaestio spinosa des Macrobius, heiklige Frage, und die Curae spinosissimae des Catullus, quälende, marternde Sorgen, sprechen laut für diese Bedeutung. Die genannten anatomischen Objecte sind nicht stachelig oder dornig; sollen also auch nicht so heissen.

Alles Spinose muss aus der Anatomie hinaus. Und das kann leicht geschehen, wenn man kurzweg Spina vertebrae, Spina mallei, Spina ossis sphenoidei, Foramen in spina, Tuberculum spiniforme, Ligamenta spino-sacralia, Musculi spino-coccygei, interspinales, etc. sagt. Wir wünschen sehnlich, dass es bald geschehen möge.

Was die Anatomie Spina heisst, ist es in der Regel nicht. Man kann eine Śpina ossis ischii, eine Spina nasalis anterior und posterior, und eine Spina nasalis des Stirnbeins, gestatten; - die Spina tibiae aber (als Ansatzstelle des Extensor. cruris quadriceps), und die Spinae des Darmbeins, sind wahrlich nur Prótuberantiae oder Tubercula. Der einzige Knochen. fortsatz, welcher das meiste Anrecht hätte, Spina genannt zu werden, ist der Griffelfortsatz des Schläfebeins, während andererseits die sogenannten Griffelfortsätze des Radius und der Ulna, keine Griffel oder Stachel sind, und besserer Benennungen harren. Werden sie sie erhalten? 


\section{Splenius.}

Der Name Musculus splenius ist viel älter, als Albin, welchem er zugeschrieben wird. Schon vor Spigelius musste der Muskel diesen Namen geführt haben, da Spigelius, welcher die zwei Splenii, den Splenius capitis und Splenius colli, noch nicht als selbstständige Muskeln auffasste, sondern beide zusammen, als Triangularis beschreibt, hinzusetzt: aliis splenius (par splenium) dictus ${ }^{1}$ ). So hat z. B. Ambrosius Paraeus, welcher um ein Jahrhunder't älter ist, als Spigelius, unseren Muskel splenique und splenitique genannt ${ }^{2}$ ), woraus sein Landsmann Riolan, seinen Splenius bildete. Weder Jene, welche nur Einen Splenius gelten lassen, noch die Vertheidiger von zweien, sagen, woher der Name Splenius geholt wurde. Er kann von Splenium, oder von Splen hergeleitet werden. Es frägt sich nur, welche Ableitung die naturgemässe ist. Splenium (o $\pi \lambda$ rivooy) ist im Plinius der Name einer Pflanze, quae medetur lienibus, aber auch ein Pflasterstreifen, wie im mentum spleniatum, und ein Schönheitspflästerchen. In letzterer Bedeutung kommt Splenium im Martial (Epigr. II, 29) vor:

„Et numerosa linunt stellantia splenia frontem."

Die Schönheitspflästerchen der Römer waren nicht rund, wie die mouches der Franzosen, sondern stern- oder halbmondförmig, daher obiges stellantia. - Der lange, breite, und dünne Musculus splenius capitis, und der schmale Splenius colli, konnten wohl mit einem Pflasterfleck, oder einem Pflasterstreifen verglichen worden sein.

In der Chirurgie wird Splenium = Compresse gehalten, ein mehrfach zusammengelegtes, breites Leinwandstück, welches,

1) Op. cit., Lib. IV., Cap. 7 .

2) Schreger, Synonymik, pag. 125. Splenitique, als Muskelname, kann man dem alten Franzosen nachsehen. Spleniticus und Spleneticus, heisst im Plinius ein Milzkranker. 
auf Wunden gelegt, die darüber anzubringenden Verbände, nicht zu viel drücken oder einschneiden lässt. Auch mit Splenium in diesem Verstande, ist ein Vergleich mit dem breiten und flachen Splenius, nicht widersinnig. Für Compressen sagen die Deutschen: Bauschen. Der Splenius konnte also von Meckel und Sömmerring mit Fug und Recht, der Kopfbauschmuskel genannt werden. Als Riemen kenne ich Splenium nicht, und finde deshalb den riemenförmigen Muskel des Kulmus und Hildebrandt nicht zu entschuldigen.

Milzähnlicher Muskel, wie uns der Splenius zuerst im Schaarschmidt's Myologischen Tabellen (Tab. IX), und später in den meisten deutschen anatomischen Handbüchern entgegentritt, ist ganz missrathen, da die Gestalt der bohnenförmigen, dicken, und saftreichen Milz, mit den fraglichen Muskeln, welche einst den Namen Triangularis führten, nichts gemein hat. Splenius und Bauschmuskel, sollen somit allein gebraucht werden. Albin begründete die Trennung des Splenius, in einen Splenius capitis und Splenius colli' ${ }^{1}$, welche allgemein acceptirt wurden. Ein deutscher Anatom würde, wenn schon ein alter Muskel, mit einem neuen griechischen Namen aufgeputzt werden soll, statt Dorso-trachélien des Chaussier,

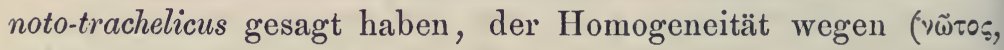

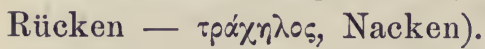

In der Bedeutung als Bauschen, dient Splenium auch zur Bezeichnung des hinteren, dicken und gewulsteten Randes des Corpus callosum. Dieser Rand heisst: Splenium corporis callosi, der aufgesetzte Wulst.

\section{Stapes.}

Stapes, stapedis, nur im Vesal: stapidis, bildet das letzte Glied in der Kette der Gehörknöchelchen. Dieses artige Ding

1) Historia musculorum hominis, pag. 354 und 356. 
entdeckt zu haben, schrieben sich nicht weniger als fünf Anatomen zu: Ingrassias ${ }^{1}$ ), Eustachius ${ }^{2}$ ), Columbus ${ }^{3}$ ), Petrus Ximenes ${ }^{4}$ ), und Ludovicus Collado ${ }^{5}$ ), die beiden letzteren Schüler des Vesal, und Professoren der Anatomie in Valencia. Die Stimmen der geschichtskundigen Anatomen älterer Zeit, vereinigen sich alle darin, dem berühmten sicilianischen Arzt, Philippus Ingrassias, welchen seine dankbaren Zeitgenossen Hippocrates Siculus nannten, den Ruhm dieser schönen Entdeckung zuzuschreiben. Er demonstrirte den Stapes in Neapel, schon 1546, während die Opuscula anatomica des Eustachius, welcher auch eine Partei für sich hat, erst 1564 erschienen. Die übrigen drei kommen mit ihren ehrgeizigen Ansprüchen viel zu spät. Von Columbus lässt sich nur sagen, dass er Stapha statt Stapes gebraucht. Casserius verstieg sich sogar zu Staffa, wie die Deutschen zum Stegreif und Steigereif (Kulmus), "Stegfrayfï" im Schwabenspiegel. Im mittelalterlichen Latein, kommt Stapia und Stapeda für Steigbügel vor. Nicht ganz auf die krummen Schenkel des menschlichen Steigbügels, wohl aber auf den dreieckigen vieler Thiere, passt der Tropus im Eustachius: Deltois.

Die Römer und Griechen hatten keine Sättel. Sie ritten auf Decken, welche über dem Rücken der Pferde befestigt wurden,

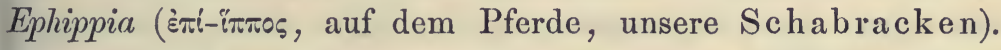
Es ist deshalb ganz unhaltbar, die obere, sattelförmig gehölte Fläche des Keilbeinkörpers, Ephippium zu nennen. Die Sella turcica-des Adrianus Spigelius drückt die wahre Gestalt dieser concaven Fläche besser aus, als die Sella equina des Fallopia. Die Lehne des Sattels am Keilbein, Dorsum ephippii ist sehr hoch. Nur an den Sätteln der Türken und Beduinen

1) Comment. in Galeni librum de ossibus, pag. 7 und 8.

2) De auditus organo, pag. 131.

3) De re anatomica, Lib. I, Cap. 7.

4) Dialogo de anatomia, Valencia, 1549, pag. 20.

5) In Galeni librum de ossibus, Valent., 1555, pag. 30. 
trifft man hohe Lehnen. Sie reichen bis an die Lenden hinauf, und dienen dem Reiter wirklich zum Anlehnen seines Leibes. Sättel und Steigbügel, welche an den Sätteln hängen, kamen erst im 4. Jahrhundert nach Christus auf. Damals hiessen die Steigbügel scalae ${ }^{1}$, und die Sättel: Sellae equestres. Das Wort Stapes war gänzlich unbekannt, - es gehört zu den neueren Erfindungen. Die Sättel dieser Zeit, welche wir von der Säule des Theodosius kennen, sahen ganz den jetzt gebrauchten gleich, waren aber viel plumper und schwerer, und bestanden, wie diese, aus einem gepolsterten, mit Leder überzogenen Holzgestell, mit Sattelknopf fulcrum, und halbkreisförmiger, niedriger Sattellehne, dorsum ${ }^{2}$ ). Ein Rescript des Kaiser Theodosius vom Jahre 385, verordnete, dass der Sattel eines Postpferdes, nicht über sechzig Pfund wiegen soll ${ }^{3}$ )!

Was mag wohl der Grund gewesen sein, dass die ersten Steigbügel, Scalae, Treppen, genannt wurden? Ich kann hierüber nur folgende Gedanken äussern. Junge Bursche 'und kräftige Leute, mögen wohl bei den Römern, frei und ohne Behelf auf das Pferd gesprungen sein, wie in Ritterszeiten. Ein dicker und bequemer Herr aber, welcher einen Spazierritt machen wollte, sprang gewiss nicht auf das Ephippium, sondern liess sich entweder von seinen Sclaven hinaufheben, oder bediente sich hiezu eines Schemmels mit mehreren Stufen, vielleicht auch einer breitsprossigen Leiter, welche an den Leib des Pferdes angelehnt wurde. Treppen und Leitern hiessen aber Scalae, welches Wort man dem später erfundenen Steigbügel liess, der gleichen Verwendung wegen. Ich kann meine Vermuthung auf kein einziges antikes Zeugniss basiren 4). Aber plausibel dürfte sie auch Anderen, ausser mir erscheinen.

1) Mauricius, Ars militaris, Edit. Scheffer, pag. 22 und 64.

2) Ginzroth, Wagen und Fuhrwerk, Tab. 80.

3) Anthony Rich, Römische Alterthümer, pag. 559.

4) Im Lexicon von Suidas, T. I, pag. 318, finde ich das Wort Anaboleus ( $\left.\alpha \alpha \beta 0 \lambda_{\varepsilon} \varepsilon_{5}\right)$, mit der Erklärung: qui in equum levat, 


\section{Sternum,}

Das otépvov der Dichter, und das Sternum der Anatomen, sind zwei verschiedene Dinge. Etéprov ist im Homer immer

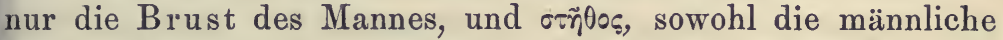
als die weibliche Brust (pectus). Im Hippocrates finden wir

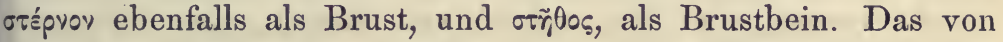
Laennec erfundene Stethoscop, sollte richtig Stetheoscopeion heissen, obwohl es nicht zum Sehen (oxoréw) dient. Galen, welcher die Brust Thorax nennt, verwendet orépyoy nur als Brustbein, und dabei blieb es in allen nachfolgenden Zeiten.

Das Wort Sternum davon abzuleiten, quia hoc os cartilaginibus costarum insternitur (Lex. med.), war nur Jenen möglich, welche nicht wussten, dass Sternum ein griechisches

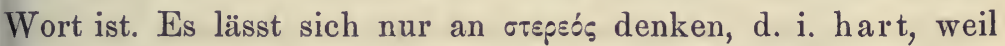
die Gegend des Brustbeins, wegen Mangels fleischiger Auflagen, sich hart anfühlt.

Die reiche ältere Synonymik von Sternum, mit dem Cassum der Araber, enthält HL, $\S$. XLV.

\section{Stomachus.}

Ueber Bedeutung und Etymologie von Stomachus, verweise ich auf HL, $\S . L X X V I I$.

ein Sclave also, welcher seinem Herrn, beim Aufsteigen behülflich war. Die Stelle lautet: Massinissa senex, equum

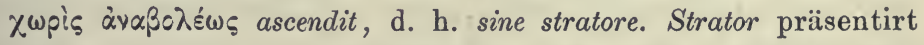
sich im Ammianus als Reitknecht. An einem anderen Orte

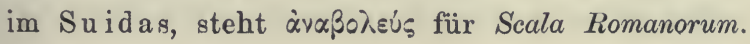




\section{Stria und striatus.}

Ist ein Körper an seiner Oberfläche mit Streifen oder erhabenen Linien gezeichnet, so kann er Corpus striatum genannt werden. Es giebt eine längsgestreifte Säule Columna

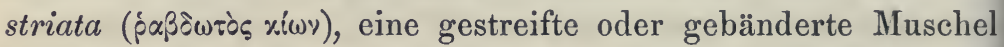
Concha striata (zum Unterschied von laevis), eine gerunzelte Stirn frons striata, eine aloe striata, und auch ein lilium striatum im Plinius. Statt striatus, tritt auch virgatus auf, wenn die Streifen nicht erhaben sind, z. B. virgato corpore tigris im Silius Italicus, und virgatis lucent sagulis im Maro. Erscheint aber nicht die Oberfläche, sondern der Durchschnitt eines Körpers gestreift, und zwar parallel gestreift, so kann der betreffende Körper nicht mehr Corpus striatum genannt werden, sondern muss ex stratis compositum heissen, weil die parallelen Streifen der Durchschnittsebene, den verschieden gefärbten Schichten desselben entsprechen. So verhält es sich mit dem vordersten Hügel in der Seitenkammer des Gehirns, welchen die Alten keines Namens würdigten. Er erhielt ihn erst durch Thomas Willis, als Corpus striatum 1). Das Corpus striatum wurde von ihm für den Sitz des Bewusstseins (perceptio) gehalten. Wohl mag der Name den Anatomen anfangs nicht gefallen haben, da ein Körper von einfach grauer Oberfläche, nicht als gestreift erscheinen kann. Vieussens, ein, wie Haller sagt, infelix in nominibus vir, erfand sich deshalb einen anderen, welcher aber nur ihm besser als der alte zu sein schien, weil er, nach seiner Meinung, das gestreifte $A \mathrm{n}$ sehen des Durchschnittes ausdrückt. Seine Corpora striata interiora $^{2}$ ) sagen aber nicht, dass die Streifenhügel inwendig gestreift sind, was nur mit intus oder interne striata, hätte gegeben werden können, sondern dass sie nach innen gelegen

1) Anatome cerebri, Lond., 1664, Cap. 13.

2) Neurographia universalis, Lyon, 1685, Tab. XIV, lit. B, B. 
sind, somit Corpora striata externa vorhanden sein müssten, welche nicht da sind. Würde das Corpus striatum in Ganglion cerebri anterius umgewandelt, wie es von Meckel 1) geschah, und diese Benennung allgemein eingeführt, zählte die Anatomie um einen ungereimten Ausdruck weniger.

Deutsche Anatomen haben den grauen Kolben von Sömmerring ${ }^{2}$ ) angenommen. Ganz verwerflich ist das Corps cannelé der französischen Anatomen, denn cannelé drückt die longitudinale Furchung, die Auskehlung einer Oberfläche aus, wie sie an den Schäften der Dorischen Säulen des Parthenon angebracht wurde.

Die Stria der Classiker ist bald ein einfachè Streifen, bald ein erhabener Saum, bald eine Furche (z. B. stria vomeris im Varro). Von allen diesen Bedeutungen finden sich Anwendungen in der Anatomie. Als Streifen: die Corpora striata und die Substantia striata renum, - als erhabener Saum: Striae longitudinales Lancisii und transversales Willisii, - 3. wird die zwischen den beiden Striae longitudinales Lancisii liegende Furche, zuweilen Stria media corporis callosi genannt - besser Rhaphe.

\section{Stroma.}

Stroma hat sich erst in neuester Zeit, ganz unbeachtet, in der Anatomie eingestellt. Möge es, ebenso unbemerkt, aus derselben wieder verschwinden. Die Histologie hat uns dieses Wort gebracht, und die beschreibende Anatomie hat es, als allgemeinen Ausdruck für bindegewebige Grundlage, in Umlauf gesetzt. Alle Anatomen halten das Stroma für etwas Unentbehrliches. Und doch ist Stroma etwas ganz anderes, als

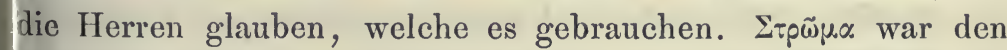
Griechen alles, was als Unterlage oder als Decke gebraucht

1) Handbuch der menschlichen Anatomie, Bd. III, §. 1774.

2) Hirn- und Nervenlehre, §. 47.

Hyrtl. Onomatologia anatomica. 
wird. Bett-, Tisch- und Pferdedecken hiessen Stromata. Da man die buntfarbigen liebte, gab man auch Büchern bunten Inhalts,

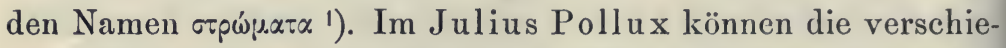

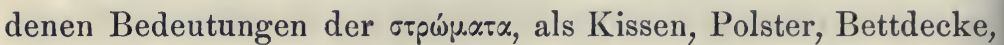
Matratze, aufgelesen werden ${ }^{2}$ ). Auf die Anatomie bezogen, könnte das Bindegewebe, auf welchem ein Organ liegt, oder mit dem es bedeckt ist, consequenter Weise Stroma genannt werden. Aber das Bindegewebe im Inneren eines Organes, Stroma zu nennen, vermag nur der, welcher den Sinn dieses Wortes nicht kennt. Die Nieren und Nebennieren, die Speichelund Thränendrüsen, die Lymphdrüsen, der Augapfel, die Thymus, die Ganglien, die Blutgefässe, u. s. w., sind im Bindegewebe eingebettet, und dieses darf Stroma heissen. Aber das Bindegewebe im Inneren der Eierstöcke, der Schilddrüse, aller anderen zusammengesetzten Drüsen, der Häute, etc. muss, eben weil es nicht a uf den Organen liegt, sondern im Inneren derselben, als Bindungsmittel ihrer Bestandtheile vorkommt, einen anderen Namen erhalten, zu welchem sich Stratum und Fundamentum cellulare viel besser eignet, als Stroma. Bindegewebshülle, mit oder ohne Fettablagerung, und somit von grösserer oder geringerer Dicke, heisst von je her Capsula für rundliche, und Vagina für langgestreckte Organe. Wir brauchen also Stroma nicht.

1) So die noch existirenden $\sigma \tau p \omega ́ \mu \alpha \tau \alpha$ des Clemens Alexandrinus.

2) Onomasticon, Lib. VII, Cap. 19 und 23, Lib. X, Cap. 8 und 12. Auch lateinische Schriftsteller gebrauchen Stroma als Unterlage, wie auch als Kissen und Matratze. So z. B. Julius Capitolinus (Ver. $4, f)$ : trahens coenam in noctem, et in toro convivali condormiens, ita ut levatus cum stromatibus, in cubiculum perferretur. 


\section{Stylus oder Stilus?}

Alle lateinischen Sprachautoritäten schreiben Stilus, alle Anatomen Stylus. Die Italiener kennen nur stilo, die Engländer stile und style, aber in verschiedener Bedeutung, ersteres als Wagebalken, letzteres als Styl. Der Processus styloideus wird nie stiloideus geschrieben. Galen führte diesen Namen

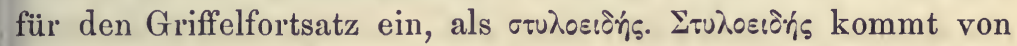

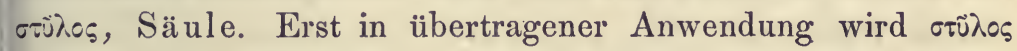
Griffel zum Schreiben, und vieles Andere, wie Schaft, Nadel, Uhrzeiger, Sonde, und Spitze. Galen benannte seinen Processus styloideus, nicht nach $\sigma \tau \tilde{j} \lambda_{0}$ als Griffel, sondern als Säule: a columnae similitudine sic appellatus ${ }^{1}$ ). Er bedient sich aber auch der Worte graphioideus (von rpapis, Griffel zum Schreiben), und belonoideus (von Beìóvr, Spitze und Nadel), welche als Os calamo simile (barbarisch calaminum) und Acus ossea übersetzt wurden (Fallopia). Sieh' über die alten Synonyme des Griffelfortsatzes HL, $\S$. XXI, Alhiliri.

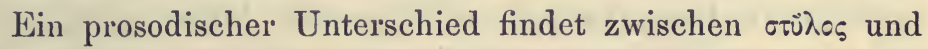
stylus statt, wesshalb beide nicht ejusdem originis sein können. Im griechischen Wort ist das $v$ lang, im lateinischen kurz, wie aus dem Horazischen Hexameter erhellt:

\section{„Saepe sty̆lum vertas, iterum quae digna legi sunt "Scripturus - - -."}

Auch behalten alle aus dem Griechischen in das Lateinische aufgenommenen Worte, ihr $y$ unverändert, wie gyrus, lyra, scyphus, typus, tyrannus, u. v. a. Warum sollte also gerade der griechische stylus bei den Classikern seines $y$ verlustig, und dafür mit einem $i$ ausgestattet worden sein? Ich glaube,

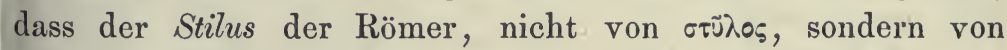
$\sigma \tau \varepsilon \lambda \varepsilon \delta$ s, Stiel, verwandt mit $\sigma \tau \hat{\varepsilon} \lambda \varepsilon \% \circ \varsigma$, Sta m m, abgeleitet wurde.

1) Oribasius, Anatomica ex Galeno, pag. 139. 
Dann ist sicher Stilus die richtige Sehreibart. Da wir aber unseren Griffelfortsatz von einem Griechen, nicht von einem Römer ererbt haben, ist es für uns ziemlicher, styloideus, statt stiloideus zu schreiben.

Der Bauhin'sche Ausdruck Calcar capitis, ist eine Uebersetzung des Aristotelischen $\pi \lambda \tilde{r}$ y.rpov $=$ Sporn des Hahnes, bei Anderen der Griffel aus Elfenbein, mit welchem die Saiten der Zither geschlagen wurden. Das Wort ging unter, da wohl von Sporen im Schädel, aber nicht von Sporen a $\mathrm{m}$ Schädel geredet wird.

\section{Sublimis.}

Was erhaben ist an Gesinnung oder an Gestalt und äusserer Erscheinung, heisst Sublimis. Kommen dem Flexor digitorum sublimis solche Vorzüge zu? Gewiss nicht. Was hoch in die Luft hinauf ragt, was dem Himmel zustrebt, oder in den Lüften schwebt, heisst sublimis (man erinnere sich des deutschen sublimiren), zum Gegensatz dessen, was auf der Erde (humus) liegt, als humilis. Sublime ferri, fliegen, sonus sublime fertur, und sublimi feriam sidera vertice, sind allbekannte Beispiele. In geistiger Hinsicht giebt es eine mens sublimis, hochstrebend, eine oratio sublimis, herrliche und gedankenreiche Rede, eine virtus sublimis, hehre Tugend. Einen Muskel am Vorderarm Sublimis zu nennen, weil ein anderer unter ihm liegt, ist gut gemeint, aber zugleich ein Verstoss gegen des Wortes eigentlichen Sinn. Andreas Laurentius beging ihn, als er Sublimis und Profundus auf den hoch- und tiefliegenden Fingerbeuger bezog: digitos ergo quatuor flectunt tres musculi: palmaris, sublimis, et profundus $\left.{ }^{1}\right)$. Es ist wahrlich zu wundern, dass eine so ungereimte Benennung allgemein Eingang fand, wo doch Besseres zu Gebote stand, wie Flexor secundi internodii

1) Historia anat. corporis humani, Lib. V, Cap. 28. 
(Spigelius '), oder Flexor perforatus (Cowper). Zwei übereinander liegende Muskeln gleicher Wirkung, können nur als superior und inferior unterschieden werden; - superficialis und profundus wäre bei weitem nicht so gut, da der superficialis nicht an der Superficies, sondern in der zweiten Schichte der Vorderarmmuskeln liegt, also schon ein profundus ist. Profundus bedeutet übrigens nicht tiefliegend, sondern unergrïndlich tief. Vesal gebraucht Primus et secundus digitos flectentium.

\section{Supra- et infraspinatus.}

Die Anatomie hat sich mit aller Macht gegen diesen Barbarismus zu wehren. Er gehört in das anatomische Sündenregister des J. Riolan ${ }^{2}$ ), und verdrängte den bisher geführten Namen Circumagens humerum primus et secundus, welchen Spigelius diesen beiden Drehmuskeln des Oberarms angewiesen hatte ${ }^{3}$ ). Die Myographen W. Cowper und J. Douglas, welche alle missrathenen Muskelnamen des Riolan annahmen, vervielfältigten auch diesen groben Fehler, welcher seither in allen anatomischen Schriften paradirt, selbst in den französischen und italienischen, als sur (sus)- und sous-épineux, und

1) Seiner Anheftung am zweiten Fingergliede wegen, während der profundus, welcher sich an dritten Glied ansetzt, Flexor tertii internodii von $\mathrm{Spigelius} \mathrm{genannt} \mathrm{wurde} \mathrm{(Op.} \mathrm{cit.,}$ Lib. IV, Cap. 19). An dem Spigelischen Flexor internodii tertii ist aber auch das Internodium tertium nicht ganz tadellos. Die Phalangen Internodia zu nennen, wie Gaza, der Interpretator des Aristoteles, das Beispiel gab, ist nur für die erste und zweite Phalanx richtig, für die dritte aber nicht, denn sie liegt, als die letzte, nicht mehr zwischen zwei Fingergelenken: nodi. Hätte der Mensch vier Fingerglieder, würde das dritte ein Internodium sein, was es bei drei Gliedern nicht sein kann.

2) Anthropographia, Lib. V, Cap. 24.

3) De hum. corp. fabrica, Lib. IV, Cap. 14. 
supra- ed infraspinato. - Will man sagen, dass der eine dieser beiden Muskeln über, der andere unter der Spina scapulae liegt, so war nur Ein Ausdruck richtig: musculus supra et infra spinam, was die deutsche Anatomie schon lange in ihrem Ober- und Untergrätenmuskel (Sömmerring), eingesehen zu haben scheint, als Ersatz für den kläglichen Ober-und Unterstachelmuskel, wie der Uebersetzer des Winslow (Bd. II, Seite 94), diese Muskeln verdeutschte.

Dieselbe Bewandtniss, wie mit dem Musculus supra- et infraspinatus, hat es mit der Fossa supra- et infraspinata scapulae. Der Kamm auf der hinteren Fläche des Schulterblattes, heisst Spina (sieh' dieses Wort), und die 'Theilflächen ober und unter ihm: Fossa s. Cavitas supra- et infraspinata, welche in Fossa supra et infra spinam umzutaufen wären. Wer ein Schulterblatt ansieht, wird zugeben, dass die Fossa supra spinam eine Grube ist. Die dreieckige, mässig convexe Fläche aber, welche unter der Spina liegt, kann nemo emunctae naris, eine Grube nennen.

Ein älterer Ausdruck, verwirrten Sinnes, für Fossa supraet infraspinata, ist Interscapulium s. Interscapilium ${ }^{1}$ ) superius et inferius. Er tritt uns zuerst im Spigelius entgegen: spina

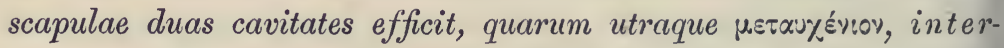
scapulium dicitur ${ }^{2}$ ). Dem Unbefangenen kann Interscapulium, nur die Gegend zwischen den beiden Schulterblättern sein. So nahm Vesalius die Sache, als er die Rückenwirbel Vertebrae interscapilii nannte ${ }^{3}$ ). Schon Caelius Aurelianus nennt die Rückengegend Interscapulas $\left.{ }^{4}\right)$ : cucurbitulae apponendae inter-

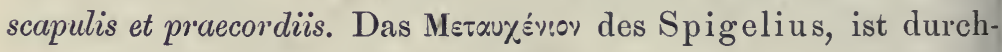

1) Die Sehulterblätter werden von den Arabisten häufig Scapilia genannt. Als Varianten kommen auch Interscapulum und Interscapulo vor.

2) De hum. corp. fabrica, Lib. II, Cap. 17.

3) De corp. hum. fabrica, Lib. I, Cap. 42, Varia ossium nomina.

4) De morbis chronicis, Lib. I, Cap. 4 und 6 . 
aus nicht Interscapulium, sondern Regio infra cervicem ( $\mu \varepsilon \tau \alpha$, nach, und $\alpha \dot{y} \%$, Nacken, Genick), also Tergum, Rücken. Was an der Rückenfläche die Gleichförmigkeit ihrer Wölbung beeinträchtigt, sind die schiefen Joche der beiden sicht- und fühlbaren Spinae scapulae. Pollux, welcher weder Anatom, noch Arzt, sondern Rhetor war, übertrug ganz willkürlich Metauchenion auf diese beiden Spinae: obliquae partes scapularum metauchenia ${ }^{1}$ ). Apulejus und Isidorus bekannten sich zur selben Auffassung der Schultergräten als Metauchenia. Da nun hiedurch die Metauchenia zu Spinae scapulae wurden, war der Fehler leicht, auch die Fossa supra- et infraspinata: Interscapulium zu nennen. Dabei bleibt Interscapulium immer noch eine unerträgliche Wortfratze, da nicht die Gruben des Schulterblattes zwischen der Spina, sondern die Spina zwischen den Gruben liegt. Dass die Alten, und viele von den Neueren (bis in das 18. Jahrhundert), welche dieses Wort festhalten, nur mittelmässige Lateiner waren, beweist uns zur Genüge der Zusatz infernum, statt inferius. Die Unterwelt der Heiden, und die Hölle der Christen, heisst Infernum; - der Plural Inferna, bedeutet Unterleib, wie im Plinius: helleborus purgat per inferna.

\section{Sura und suralis,}

Etliche, an der Wade gelegene Gebilde, participiren an der lateinischen Sura. Sie sind die Fascia surae, der Nervus suralis, der Gemellus surae = Gastrocnemius, und der zuweilen sogenannte Musculus biceps surae = Gastrocnemius. Die Sura der Römer war theils Wade, theils Unterschenkel, theils Wadenbein. Als Wade finden wir Sura im Plinius, wo er der fleischigen Waden, als ein Prärogativ des Menschengeschlechtes erwähnt: surae homini tantum, et crura carnosa. Sura als Unterschenkel treffen wir im Virgil: alte suras vincire

1) Onomasticon, Liz. II, Cap. 4, Num. 177. 
cothurno, und im Gratianus: tegat imas fascia suras. Sura als zweiten, kleineren Knochen des Unterschenkels, giebt uns Celsus: alterum os cruris, brevius, tenuius, ad talos intumescens, quod ipsum Sura recte nominetur ' $)$. Diese Celsische Sura hat sich aber nie in der Anatomie festsetzen können, da ihr Fïbula und Perŏne immer vorgezogen wurde. Nur die deutsche Benennung der Fibula als Wadenbein, beruht auf der Sura des Celsus, welche in dem fleischigen Theile des Unterschenkels, Wade genannt, weit weniger inbegriffen wird, als das Schienbein. Das italienische mollame (auch polpaccio), und das französische mollet, drücken die mollities surae aus. Das englische calf, bedeutet ebenso Kalb, wie Tölpel, und Wade.

Um dem wunderlichen spanischen Wort für Wade, las pantorrillas, auf den Grund zu kommen, liefert uns das lateinische Pantex einen Anhaltspunkt. Pantex steht im Plautus und Martial für Wanst. Auf diese Wurzel lässt sich das spanische Wort zurückführen. Noch genauer drückt der Catalane die Wade aus, mit Ventrell de la cama, das Bäuchlein des Unterschenkels.

Die griechische xиnu', hat wie Sura, drei Bedeutungen: 1. Unterschenkel, 2. Wade, und.3. Schienbein. Die zweite Bedeutung tritt im Gastrocnemius hervor.

Vergleiche über "Wade", auch den Artikel: Fibula.

\section{Suspensorius.}

Das Beiwort suspensorius, gehört nicht in den Thesaurus purae latinitatis. Es ist ein anatomisches Machwerk. Von den vielen sogenannten Aufhängebändern, verdienen nur zwei den Namen Ligamenta suspensoria: das Ligamentum suspensorium des Penis und der Clitoris. Durch sie werden diese Organe wirklich an der Schamfuge aufgehängt. Alle iibrigen Bänder

1) De medicina, Lib. VIII, Cap. 1, f. 
dieses Namens, wie das Ligamentum suspensorium hepatis, lienis, processus odontoidei, capitis femoris, und mehrere andere, hängen die betreffenden Organe nicht auf, tragen sie auch nicht, weil sie nie in die Lage kommen, durch ihre Last angespannt zu werden. Alle Bauchfellfalten, welche als Ligamenta suspensoria beschrieben werden, haben keine freien Flächen, wie ein vertical stehendes Band haben muss, sondern schmiegen ihre Flächen den beiden Organen genau an, welche sie miteinander verbinden. Wenn z. B. das Ligamentum suspensorium hepatis vertical stünde, und zwei freie Flächen hätte, müsste zwischen der Leber und dem Zwerchfell ein leerer Raum sich finden, welcher im Lebenden, der Bauchpresse wegen, nicht entstehen kann, und nur an der Leiche mit geöffnetem Unterleib zum Vorschein kommt, weil dann die Leber factisch an ihrem Ligamentum suspensorium hängt. Diese Aufhängebänder können immerhin als Ligamenta verbleiben, da sie wirklich zwei Organe verbinden, aber statt suspensorium, muss ein Adjectiv gebildet werden, welches jene beiden Organe nennt, z. B. Ligamentum phreno-hepaticum (nicht phrenico-hepaticum) für Ligamentum suspensorium hepatis. Das Aufhängeband des Schenkelkopfes wurde schon durch Ligamentum teres s. triquetrum ersetzt, und könnte besser Ligamentum intracapsulare capituli femoris heissen, so wie das Ligamentum suspensorium processus odontoidei, viel richtiger als Ligamentum medium oder interalare zu bezeichnen wäre. Das Ligamentum suspensorium hepatis, kennt Galen und

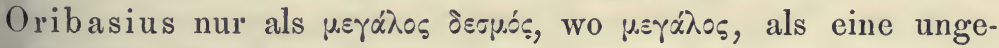

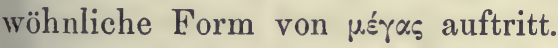

\section{Sutura arcualis und arcuata,}

Wie im nächsten Abschnitt gezeigt wird, verdient der Ausdruck Sutura arcuata, den Vorzug vor Sutura coronaria. Die Benennung der Stirnnaht, als Sutura arcualis, schreibt sich von Haly Abbas her. Er bediente sich derselben in 
seinem, dem Buiden-Sultan, Adad Addaula, gewidmeten Werke, welches wir als Almaleki, d. i. Liber regius, noch besitzen. Haly und der spätere Avicenna, welcher die Stirnnaht ebenfalls Sutura arcualis nennt, waren Perser. Die gefürchtetste Nationalwaffe der Perser, war der Bogen, dessen sich auch die Parther und Mauritanier bedienten. Die Maurischen Aerzte Spaniens, Abul Kasem, und Avenzoar, adoptirten gerne die Benennung der Kranznaht nach der Lieblingswaffe ihres Volkes ${ }^{1}$ ), deren schon die Muse des Horaz gedenkt:

\section{„Non eget Mauri jaculis, nec arcu,} „Nec venenatis gravida sagittis, "Fusce pharetra."

Der Maurische Bogen sah ganz anders aus, als der griechische, welcher eigentlich kein Bogen war, da er aus einem geraden Mittelstück (Griff), und zwei daran befestigten Antilopenhörnern bestand, an deren Enden die Schnur befestigt war. An letzteren konnte, seiner flachen Krümmung wegen ${ }^{2}$ ), bei der Einführung der Sutura arcualis, nicht gedacht worden sein. Dieser griechische Bogen, war nur in Homerischer Zeit eine Kriegswaffe. Später haben weder Griechen noch Römer sich desselben zu anderen Zwecken, als zur Jagd, und zum Scheibenschiessen bedient. Er war offenbar für den Kriegsdienst zu schwach. Ungleich stärker war der Persische und Arabische Bogen. Er wurde beim Spannen, gegen seine Krümmung zurückgebogen, was seine Schnellkraft verdoppelte. Die Gestalt desselben glich dem Segment eines Kreisbogens, ohngefähr drei Viertel einer Kreisperipherie ${ }^{3}$ ). Diese Gestalt

1) Sie verwendeten sie aber nicht ausschliesslich, da auch aldarz al ikל̌ $\bar{\imath}$ bei ihnen gefunden wird, d. i. Sutura coronalis.

2) Daher Arcus patulus im Ovid (Metamorph., VIII, 30).

3) Im Ovid (Metamorphoses, VIII, 380), wird seiner als Arcus sinuosus gedacht. 
hat auch die Kranznaht. Sie erhielt sonach von den Arabern den Namen Bogennaht.

Wenn der Vergleich der Stirnnaht mit der Waffe des Bogens, dem kriegerischen Volk der Araber näher lag als Kranz und Krone, so hätten doch die Uebersetzer ein besseres Wort als arcualis anwenden sollen, denn von arcualis weiss die lateinische Sprache nichts. Sie kennt nur arcuatus, welches auch arquatus geschrieben wurde (arquato coelum curvamine signans Iris ${ }^{1}$ ). Arcuaria, wie Coronaria, zu brauchen, war ebenso unstatthaft, da Arcuarius nur als Bogenschütz, oder als Bogenmacher, vorkommt ${ }^{2}$ ).

Als Sutura puppis begegnen wir der Stirnnaht bei den Arabisten, welche das Schädeldach, und die ganze Hirnschale, mit einem Kahne verglichen, dessen schmaler Vordertheil puppis, dessen breiterer Hintertheil prora heisst (daher Sutura prorae für Hinterhauptnaht). Sie waren aber so sorglos in der Unterscheidung von puppis und prora, dass sie beide öfter miteinander verwechselten, und der Eine Sutura prorae nennt, was der Andere Sutura puppis hiess.

\section{Sutura coronalis und coronaria.}

Die Sutura coronalis, Kranznaht, kennt Jedermann. Weniger bekannt dürfte es sein, dass dieser Name ungereimt und widersinnig ist. Ein Kranz auf dem Haupte, liegt nicht in der Richtung der Sutura coronaria. Eine Ebene, welche durch diese Naht gelegt wird, steht vertical. Sie schneidet den Schädel nicht in eine obere und untere Hälfte, wie es die Ebene eines Kranzes thut, sondern in eine vordere und hintere. Ein Kranz, in dieser Ebene liegend, umgiebt nicht die Hirnschale, sondern umrahmt das Gesicht. Der Name der Kranznaht, kann also

1) Ovid, Metamorphoses, II, 589.

2) Vegetius, de re militari, Lib. II, Cap. 11. 
mit einem Kranze in keiner Beziehung stehen. Wie ist er also entstanden? Zur Zeit, als das unechte Buch des Hippocrates,

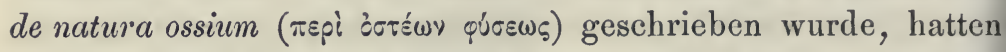
die Nähte der Hirnschale noch keine eigenen Namen erhalten. Wir erfahren aus Rufus Ephesius ${ }^{1}$ ), dass sie dieselben erst durch die ägyptischen Aerzte erhielten, welche in der grie-

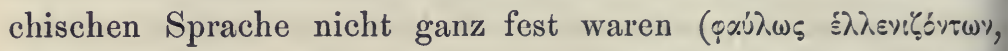
graecam linguam male doctorum, wie die lateinischen Uebersetzer sich ausdrücken). Galen, welcher während seines Aufenthaltes in Alexandrien, diese Namen kennen lernte, nahm dieselben an, und wir werden mit ihnen nur durch seine Schriften bekannt. Die Naht, welche das Stirnbein umsäumt, sozusagen

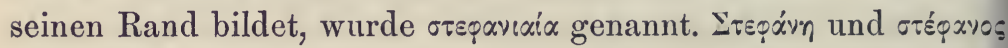
heisst aber in erster Instanz Rand, Umgebung, oder Einfassung, und in zweiter Instanz, weiblicher Hauptschmuck, als Kranz von Blumen oder von falschen Haaren (Julius Pollux). Aber auch der vordere Begrenzungsrand der Kopf-

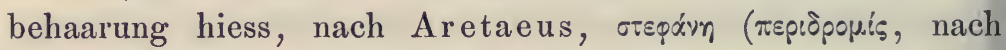
Vesal). Mit diesem vorderen Rande des Haarbodens, stimmt die sogenannte Kranznaht durch Richtung und Lage überein,

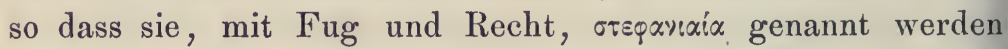
konnte. Das lateinische Wort für $\sigma \tau \varepsilon \varphi^{\alpha} y \eta$, ist Corona, welches dieselbe Doppelbedeutung hat: als Rand und kranzförmiger Hauptschmuck. Im ersteren Verstande, gab es eine Corona muri, Rand einer Mauer, Corona agri, Rand (Grenze) eines Feldes, Corona montium, Gebirgsrand, Corona theatri, Rand des

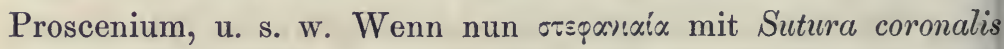
oder coronaria übersetzt wurde; so ist dieses nicht des Kranzes oder der Krone wegen geschehen, sondern aus der Vorstellung einer Begrenzungsnaht des Stirnbeins entsprungen ${ }^{2}$ ). Grenznaht des Stirnbeins, sollte also statt Kranznaht gesagt

1) De partibus corporis humani. Edit. Clinch, pag. 34 .

2) Sehr richtig wird von Gorraeus bemerkt: dicitur Stephaniaea, quia frontem in orbem cingit. 
werden. Kranznaht wäre noch besser als Kronennaht. Denn Kronen, im jetzigen Sinne, als Zeichen königlicher Würde, gab es bei Griechen und Römern nicht, - sie kannten nur Diademe.

So viel über den Sinn von Sutura coronaria. Nun auch zum Wort selbst. Coronarius, in anatomischer Anwendung, ist ein Barbarismus, weil es in gewöhnlicher Sprachweise, als zu Kränzen dienlich oder Kränze erzeugend, behandelt wird. Im Plinius heisst ein Kranzflechter: Coronarius, und ein Mädchen, welches Kränze bindet: Coronaria. Coronalis verfällt demselben Urtheil, nach dem, was im Plinius ${ }^{1}$ ) hierüber gesagt wird.

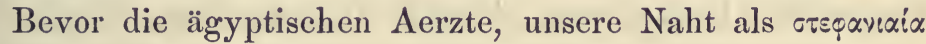
benannten, hiess sie bei den griechischen Aerzten und Ana-

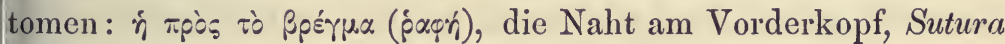
sincipitis.

Die Vasa coronaria des Herzens, des Magens, und der Lippen, unterliegen keiner Beanständigung, da sie wirkliche Kränze bilden. Das Ligamentum coronarium hepatis widerspricht seinem Namen, durch die ihm eigene Gestalt eines Doppelflügels (Ligamentum alare dextrum et sinistrum).

\section{Sutura lambdoidea, nicht lamdoidea.}

Die Sutura lambdoidea stammt aus dem Galen: òtót tò

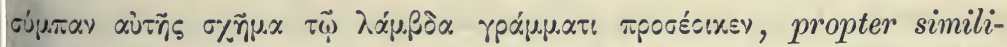
tudinem, quam habet cum litera $\Lambda^{2}$ ). Die Theilungsstelle der Aorta und Vena cava auf dem vierten Lendenwirbel, und das Zungenbein, wird auch lambdoeides genannt, ob similem rationem. Ich habe nichts hinzuzufügen, als dass die oft anzutreffende Schreibart lamdoeides uncorrect, und labdoeides barbarisch ist.

1) Hist. nat., II, 105 und 109.

2) Oribasius, Op. cit., pag. 133. 
Letztere entstand aus der Unachtsamkeit der Abschreiber der alten Texte, indem sie das Circumflex $\sim$ über dem $a$, mit welchem das $m$ im Schnellschreiben ausgedrückt wurde (läbdoeides ${ }^{1}$ ), wegliessen. Es giebt übrigens auch ein echtes lateinisches Wort labda. Wir finden es in den Epigrammen von Ausonius. Es hat aber keine anatomische, sondern eine höchst obscöne Bedeutung = irrumator (qui fascinum in os alterius inserit).

Die Arabisten schrieben Sutura lambdae oder lamdae, woraus die Sutura laude der Mundinisten hervorging. Die Sutura hypsili in den Vesal'schen Synonymen, ist eine entstellte Sutura ypsiloides $=$ lambdoides, da $\mathrm{Y}$ und $\Lambda$ einander, bis auf die Umkehrung, ziemlich ähnlich sehen.

\section{Sutura sagittalis,}

Der Pfeil gehört zum Bogen. Die Araber, welche die Stirnnaht Bogennaht nannten, nannten die geradlinige Verbindungsnaht beider Seitenwandbeine: al-darz al-sahm̄̄ (sahm, Pfeil), was im Mönchslatein mit Sutura sagittalis übersetzt wurde, quia stat, ut sagitta ad arcum (Gerardus). Sagittalis ist zwar latein, aber nicht gut latein. Die Römer hatten nur ein einziges, aus Sagitta gebildetes Adjectiv: sagittarius. Sagittarius wurde genannt, was sich auf Pfeile bezieht: miles sagittarius (Bogenschütz, im Sallustius und Curtius), calamus sagittarius (Rohr für den Pfeilschaft, im Plinius), faber sagittarius (Pfeilmacher, im Aurelius), u. m. a. Sagittalis kann

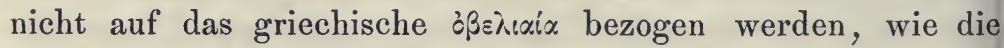
Pfeilnaht im Galen ${ }^{2}$ ) heisst, denn oßßsiós ist in der Odyssee und Ilias "Bratspiess", und giebt im Lateinischen das

1) Forcellini (Lexicon totius latinitatis) meint, dass auch die alten Griechen, euphoniae causa, statt lambda, labda sagten.

2) De usu partium, Lib. IX, Cap. 17. 
bekannte veru, woraus die Arabisten ihre häufig zu begegnende Sutura veruculata bildeten, womit sie eigentlich spiessige oder zackige Naht sagen wollten, was die Sutura sagittalis oft im höheren Grade ist, als die Kranznaht. V'eruculata scheint mir aber auch nicht ganz richtig gewählt zu sein, da es eigentlich vericulata lauten müsste, weil das Diminutiv von veru, nicht veruculum, sondern vericulum ist, wie von genu geniculum, von

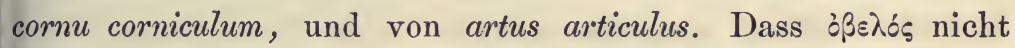
Pfeil, sondern Spiess oder Spitze ist, bezeugt uns auch der Name obeliscus, für die aus Einem Stück Syenitischen Marmor gehauenen, schlanken, und spitzig zulaufenden, dem Sonnengott geheiligten Säulen, zum Unterschied von Pyramis, welche viel stumpfer, breiter, und höher war, und aus Steinen aufgebaut wurde (structilis). Obeliscus wurde, als Diminutiv von Obelos, Spiess, von den Deutschen mit $\mathrm{Nadel}$ übersetzt. Dadurch kam der aus Aegypten nach England gebrachte, vortrefflich erhaltene Obelisk, zu dem Namen: Nadel der Cleopatra. Eine eigene Nadel das. Sie wiegt nur 4000 Zentner! Aus Obelos entstand Obulus, die kleinste griechische Münze, den sechsten Theil einer Drachme werth (10 Pfenninge). Sie hatte wahrscheinlich einen Spiess in ihrer Prägung, oder war selbst ursprünglich von länglich spitziger Gestalt. Es hatte ja auch dreieckige und viereckige Münzen gegeben.

Der griechische Name ṡ drückt aus, dass die Pfeilnaht entweder die Stirn- mit der Hinterhauptsnaht verbindet, oder beide Seitenwandbeine untereinander. Am besten wäre durch Sutura interparietalis für die richtige Benennung dieser Naht gesorgt.

\section{Sutura squamosa.}

Als Sutura temporalis und squamaeformis führt Vesal die Schuppennaht des Schläfebeins auf - Bauhin als squamosa agglutinatio, - Spigelius als sutura mendosa, squamosas 
combinationes referens. Geradeheraus Sutura squamosa zu sagen, wagte erst Bartholin ${ }^{1}$ ). Es war wirklich ein Wagniss, einen solchen Barbarismus in die anatomische Welt zu tragen. Squamosus ist schuppenreich, schuppig. Squamoso corpore pisces, lesen wir im $\mathrm{C}$ icero. Die fragliche Naht ist nicht schuppig, sondern verbindet die Schuppe des Schläfebeins mit dem unteren Rande des Seitenwandbeins, welcher ebenso barbarisch Margo squamosus genannt wird. Kein Anatom hat sich noch von dieser widersinnigen Sutura squamosa losgemacht, - alle huldigen ihr, ohne zu ahnen, welche anatomische Unwahrheit sie im Munde führen. Die Sutur kann Superpositio oder Agglutinatio squamaeformis genannt werden, wie das

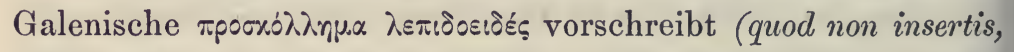
sed squamarum modo cohaerentibus ossium marginibus fiat), oder spuria s. mendax schlechtweg, weil keine andere spuria von solcher Ausdehnung, am Schädel vorhanden ist, aber nie und nimmer squamosa, da sie blos die Verbindung einer einfachen squama mit einem anderen zugeschärften Knochenrand darstellt. Conglutinatio, Proscollema (Zusammenlöthung), Sympexis ad unguem (nagelartige Zusammenfügung, ihrer bogenförmigen Krümmung, und der Dünnheit der Schuppe wegen), sind die alten und guten Benennungen dieser falschen Naht, an welcher selbst der jetzige Name falsch ist. Mit Sutura temporo-parietalis wäre dem Uebel leicht abgeholfen.

\section{Suturae verae et spuriae.}

Das Wort Sutura, Naht (von suere, nähen), entlehnte die Anatomie aus dem Celsus. Die chirurgische Naht, und die Nahtverbindung zweier Schädelknochen, heisst bei ihm Sutura. Die betreffende, sehr curiose Stelle lautet: raro calvaria sine suturis est, in locis tamen aestuosis facilius invenitur, et tale caput

1) Institutiones anat., Lib. IV, Cap. 6. 
firmissimum, atque a dolore tutissimum est, ex caeteris, quo suturae pauciores sunt, eo commodior capitis valetudo est; neque numerus, neque locus suturarum certus est! ') Lange Zeit blieben die Suturae des Celsus vergessen. Bis zu Vesal, hiessen sie: Juncturae serratiles oder Commissurae serratae. Vesal restituirte sie als Suturae: ob rerum consutarum similitudinem. Die älteren französischen Anatomen ersetzen suture häufig durch cuiture und couture, wie die Italiener durch cucitura, - beide Worte vom italienischen cucire $=$ consuere, zusammennähen.

Wahre und falsche Nähte gab es bei den Griechen und Römern nicht. Diese Unterscheidung verdankt die Anatomie dem Avicenna ${ }^{2}$ ). Weil der Wahrheit die Lüge gegenübersteht, nannte er die falsche Naht: al-darz al-kādzib, d. i. lügende Naht. Gerardus, der Uebersetzer des Avicenna, gab den arabischen Ausdruck als Junctura mendosa. Ihm folgten alle Arabisten, wodurch die Suturae mendosae entstanden, welche jetzt noch sich in der Anatomie, neben Suturae spuriae, blicken lassen. Man wollte eigentlich mendaces sagen, und vergriff sich blos mit einem ähnlich lautenden, aber nicht gleichwerthigen Wort. Sieh' Rhaphe, pag. 446. Besser als S. mendax ist Mon ro's S. falsa. Das Uebereinanderschieben der in einer falschen Naht sich begegnenden Knochenränder, drückt die Holländische Schub-naad aus. Die französische Suture écailleuse und die engliche Scaly suture sind ebenso widersinnig, wie die $S$. squamosa. Der alte Name Sutura corticalis für Schuppennaht, entstand daraus, dass squama, wie das italienische scaglia, nicht blos Schuppe, sondern auch Hülse und Rinde bedeutet (Plinius). Die Griechen behandelten die falsche Naht gar nicht als pa甲’n. Für sie war die Sutura spuria, ein $\pi \rho \circ \sigma x \delta \lambda_{\lambda \eta \eta \mu \alpha}$

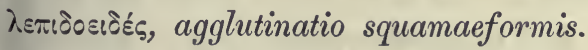

Die Archäologie der Nähte sieh' in $\mathrm{HL}, \S . V$.

1) De medicina, Lib. VIII, Cap. 1.

2) Canon, Lib. I, Fen 1, Doctr. 5, Summa 1, Cap. 11. 


\section{Sympathicus.}

Galen hatte dem Nervus sympathicus noch keinen besonderen Namen gegeben, da er ihn nur sehr unvollständig kannte, und für einen Theil seiner Conjugatio sexta, unseres Vagus hielt, zu welchem sich auch ein Zweig der Conjugatio tertia gesellt 1). Der sehr ansehnliche Verbindungsast zwischen dem Vagus und dem Ganglion cervicale primum sympathici, welcher dem Galen nicht entgehen konnte, mag die Ursache sein, dass er den Sympathicus in eine abhängige Stellung zum Vagus setzte. Die Conjugatio tertia des Galen entspricht einigen Zweigen des zweiten und dritten Astes des Trigeminus und dem Abducens. Galen sagt: dass diese Conjugatio tertia, durch dasselbe Loch, durch welches die Carotis in die Schädelhöhle eintritt, einen Ast nach abwärts sendet, welcher durch den Hals und durch die Brust in die Bauchhöhle gelangt, und sich auf diesem langen Wege mit den Aesten der Conjugatio sexta (Vagus), und

1) Galen zählte nur sieben Hirnnerrenpaare, Syzygiae, Conju-

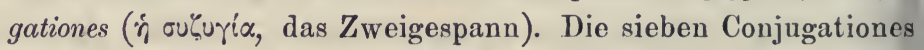
waren : prima $=$ Opticus, - secunda = Oculomotorius, - tertia und quarta = gewissen Zweigen des Trigeminus, + Abducens, quinta $=$ Acusticus und Communicans faciei, - sexta = Vagus, - septima = Hypoglossus. Durch Aufnahme des Olfactorius unter die Hirnnerven, wuchs ihre Zahl auf acht, und durch die Entdeckung des Nervus trochlearis auf neun, welche bis Sömmerring andauerte, dann aber durch die Trennung des Communicans rom Acusticus auf zehn, und durch die Unabhängigkeitserklärung des Glossopharyngeus und Accessorius Willisii, welcher bisher als Bestandtheil des Vagus angesehen wurde, auf zwölf stieg. Diese zwölf werden hoffentlich nicht mehr vermehrt werden, da man einsehen lernte, dass auch die dem Glossopharyngeus und Accessorius ausgestellte Freibeitsacte, keine Nothwendigkeit war. 
mit den Spinalnerven in Verbindúng setzt ${ }^{1}$ ). Dass er damit den Sympathicus gemeint hat, wird aus zwei Stellen seines Buches de usu partium klar. Die eine lautet: descendunt hi nervi usque ad os latum (Kreuzbein, $\pi \lambda \alpha$ ¿ cotéov) in omnia fere

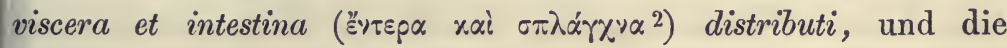
andere: ipsa igitur substantia, quae similis est ganglio, nervos crassescere contingit ${ }^{3}$ ), welche ganglienförmige Intumescenz sich am Halse, in der Brust, und im Unterleib wiederholt, w.o diese Nerven an den Wirbeln anliegen (spinae dorsi accumbunt, oder ad radices costarum feruntur). Im neunten Capitel des Galenischen Buches de dissectione nervorum, sind weitere Belege dafür enthalten, dass Galen den Sympathicus, nur als einen Theil seines dritten und sechsten Nervenpaares (Abducens und Vagus) kannte.

So lange die Autorität des Galen in der Anatomie anerkannt war, selbst noch ein Jahrhundert nach Vesal, welcher sie stürte, war der Sympathicus namenlos, und galt nicht als selbstständiges Nervensystem. Vesalius, welcher bei den sieben Hirnnerven des Galenus blieb, kannte nur Theile des Sympathicus, als Zweige des Par sextum (Vagus), welche an der" Wirbelsäule bis zur Harnblase und zum Uterus hinablaufen $\left.{ }^{4}\right)$. Spigelius kennt vom Sympathicus nichts, als die Nodi (Ganglien) der Plexus, welche das Par sextum mit anderen

1) Dieser vermeintliche Ast des Abducens wurde, seit Willis, für eine Wurzel des Sympathicus gehalten, und als solche noch in der berühmten Schrift Meckel's des Aelteren: de quinto pare nervorum, aufgeführt. Jetzt sind wir besser informirt, und wissen, dass diese Wurzel des Sympathicus, vielmehr ein Ast des ersten Halsganglions ist, welcher sich an den Abducens während seines Laufes durch den Sinus cavernosus, dort anschliesst, wo dieser Nerv an der äusseren Fläche der Carotis cerebralis anliegt.

2) De usu partium, Lib. IX, Cap. 11.

3) Idem opus, Lib. XVI, Cap. 5.

4) Op. cit., Lib. IV, Cap. 9. 
„concurrentes nervorum propagines" bildet "). Fallopia ${ }^{2}$ ) und Vidus Vidius ${ }^{3}$ ), welcher die erste Abbildung des Ganglion cervicale primum ${ }^{4}$ ) giebt ${ }^{5}$ ), kennen gleichfalls nur Parthien des Sympathicus, als Abzweigungen des sechsten Paares. Als man daran zu denken anfing, dem Sympathicus, seiner immer mehr und mehr bekannt werdenden Beziehungen $\mathrm{zu}$ allen Eingeweiden wegen, eine gewisse Autonomie zuzugestehen, führte man ihn als Par octavum in die Gesellschaft der Hirnnerven ein; - die sieben anderen Paare waren die sieben Hirnnerven des Galen. Th. Willis gebührt die Ehre, den Sympathicus vom Vagus losgerissen $\mathrm{zu}$ haben ${ }^{6}$ ). Er leitete seinen Ursprung aus dem fünften und sechsten Hirnnervenpaare (nach jetziger Zählung) ab. Hiemit war der erste Schritt zur Selbstständigkeitserklärung dieses Nerven gegeben, welche theils durch Bidloo ${ }^{7}$ ) (als Nervus intercostalis), besonders aber durch Winslow ${ }^{8}$ ) definitiv sichergestellt wurde. Winslow schmückte unseren Nerv auch mit dem sentimentalen Titel Sympathicus, welchen er bis zur Stunde führt, und welchen

1) Op. cit., Lib. VII, Cap. 2, de nervis cerebri.

2) Observationes anat., pag. 152 und 153.

3) De anatome corporis humani, Lib. III, Cap. 2.

4) Als Wälschmann vergleicht Vidius (Guidi) dieses Ganglion mit der Frucht des Oelbaumes, und nennt es Olea (Oelbeere).

5) Tab. XIX, Fig. 1, Lit. u und Tab. LXXV, Fig. 12, Lit. D, $E$, und $F$.

6) Cerebri anatome, Lond., 1664, pag. 340.

7) Anatome corporis humani. Explic. Tab. XI, Fig. 1, Die durch und durch widersinnige Benennung, als Nervus intercostatis grassirt noch vor unseren Augen in den anatomischen Lehrbüchern. Nur was zwischen den Rippen liegt (inter costas); kann intercostal genannt werden, wie die Musculi und Nervi intercostales. Der Sympathicus geräth nur in seinem Brustsegment, in nähere locale Beziehung zu den Rippenköpfen,.aber nie zu den Intercostalräumen.

8) Expos. anat., Traité des nerfs, §. 361. 
selbst der klägliche Trisplanchnicus des Chaussier, in Deutschland wenigstens nicht in seiner Alleinherrschaft beschränken konnte. Der Sympatheticus maximus des W risberg, der Nervus magnus harmonicus des Ander s ch, und der Nervus consensualis magnus des Mayer, klingen voller, aber sicher nicht besser als Sympathicus. Das Censorsamt, welches ich mir angemasst habe, nöthigt mich aber auch zu sagen, dass weder Sympathicus, noch Sympatheticus, gute griechische Worte

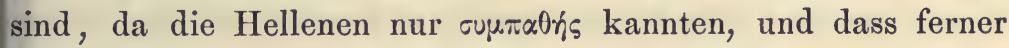
der Name Sympathicus, auf dem supponirten Vermögen dieses Nerven basirt wurde, den Consensus und die Mitleidenschaft der Organe zu bedingen. Wir wissen jetzt, dass die Sympathien, oftmals nur Reflexerscheinungen sind, welche durch Gehirn- und Rückenmarksnerven vermittelt werden, und häufig durch Nerveneinfluss gar nicht erklärt werden können, wie die Sympathie zwischen Gebärmutter und Brüsten, zwischen Herz und Gelenken, zwischen Hoden und Parotis, zwischen der Fusssohle und dem Darmkanal, etc. Consentientia et conspirantia omnia, sagt Hippocrates.

\section{Symphysis.}

$V i$ nominis drückt Symphysis jede Verwachsung aus, von oupqúw, zusammenwachsen. G a le n, dem anderthalb Jahrtausende ihre anatomische Weisheit abborgten, beschränkte das Wort auf jene Knochenverbindungen, welche weder Gelenke noch Nähte sind. Er unterschied drei Arten seiner oúuøusı: 1. Synchondrosis, wie die Schamfuge, 2. Synneurosis (veũpov, als Band), wie zwischen Zungenbein und Griffelfortsatz, zwischen Kniescheibe und Schienbein, zwischen Sitzbein und Kreuzbein, u. m. a., 3. Syssarcosis, eine durch Fleisch bewerkstelligte Verbindung zweier Knochen, wohin Galen die Fixirung der Zähne durch das Zahnfleisch, und die Verbindung des Zungenbeins mit dem Schulterblatt durch den Omohyoideus, und mit 
dem Unterkiefer durch die Mylo- und Geniohyoidei rechnet, obwohl im Grunde jeder Muskel, welcher von Knochen zu Knochen geht, der Vermittler einer Syssarcosis wird. Die Anatomen verstehen gegenwärtig unter Symphysis eine bleibende knorpelige Verbindung zweier Knochen (Symphysis pubis und sacro-iliaca), unter Synchondrosis dagegen die transitorische knorpelige Verlöthung zweier Knochenstücke, als Vorläufer der Synostosis.

\section{Synciput und Occiput.}

Synciput findet in den lateinischen Schriften, als Stirn und Vordertheil der Hirnschale, oftmalige Verwendung. Die Schreibart ist unorthographisch. Das $y$ liesse den Gedanken an eine Zusammensetzung aus oóv und caput zu. Es wäre aber unmöglich, mit dieser, gegen die Gesetze der Wortbildung verstossenden Etymologie, einen Sinn zu verbinden. Mit $i$ statt $y$ geschrieben, ist Sinciput so viel als Semicaput, Kopfhälfte.

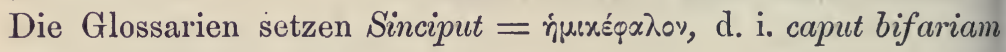
dissectum. Es war nämlich Sitte, die Köpfe der geschlachteten Schweine und Hammel, mitten durch die Ohren vertical durchzuschneiden, und die beiden Hälften zu räuchern, um sie durch längere Zeit aufbewahren zu können. Solche geräucherte Schweins- und Hammelköpfe waren ein beliebtes Gericht bei den Griechen und Römern (fissa fumosum sinciput aure, heisst es im Persius, VI, 69). Ebenso im Juvenal, XIII, 84. Die Dichter geben, per synecdochen, Sinciput für den ganzen Kopf sammt Gehirn. So z. B. Plautus:

$$
\text { „Sanum est, adolescens, sinciput, ut intelligo." }
$$

und :

(Menaechmi, Act. III, Sc. 2, Vers 40,41.)

„Dissicit ancipiti miserabile sinciput ense."

(A pollinaris, Carm. $V, 418$.) 
Wenn das Lexicum medicum St. Blancardi, Sinciput $=\beta p \varepsilon ́ \gamma \mu \alpha$ annimmt, und darunter partem anteriorem cranii, a fronte usque ad suturam coronalem, versteht, so kann ich dieser Interpretation nicht beistimmen, weil sich der den Seitenwandbeinen beigelegte Name: Ossa sincipitis, nicht mit ihr vereinbaren

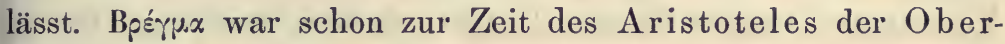
schädel, welcher, weil er bei Kindern und Erwachsenen die Unreinigkeiten des Gehirns, durch seine Nähte durchschwitzen

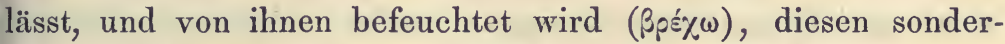
baren Namen davontrug. Die Borken und Krusten, welche sich am Schädel von Säuglingen bilden, wurden für solche

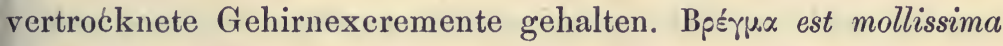
et humidissima cranii pars, praesertim in infantibus, heisst es in den Definitiones medicae von Gorraeus, pag. 80.

Man hat also Sinciput, nicht Synciput zu schreiben, und darunter die vordere Partie der Hirnschale zu verstehen, durchaus nicht die Stirn allein. Ihm steht dann Occiput (ob $\left.{ }^{1}\right)$ und caput) gegenüber, welches hingehen mag, obgleich es im genuinen Latein, sich nicht heimisch machen konnte. Dieses hält sich immer nur an Occipitium, wie z. B.: cucurbitulas fronti et occipitio admovere, im Cornelius Celsus (Lib. IV, Cap. 2), und locustarum vox ab occipitio proficisci videtur, im Plinius (Lib. XI, Cap. 29).

\section{Syndesmos oder Desmos.}

Ein naseweiser Momus anatomicus ${ }^{2}$ ), tadelte es, dass die Bänderlehre, Syndesmologia heisse, und glaubte, es wäre Desmo-

1) Die Präposition ob behauptet ihre Bedeutung, als entgegen und gegenüber, in sehr vielen Compositis, wie opponere, obvertere, objicere, und in den Redensarten Cicero's: ob oculos versari, ob oculos habere.

2) Dieser war ich selbst, als ich die ersten Auflagen meines anatomischen Lehrbuches besorgte, bevor ich mit den griechischen Meistern der Anatomie näher vertraut wurde. 
logia besser, da seøpós allein, schon Band bedeutet, - Syndesmologia also ein Pleonasmus ist. Richtig. $\Delta s \sigma \mu c ́ s$ ist zuweilen Band. Weit öfter aber ist es Riemen, Ankertau, Fessel, und im Plural: Gefängniss, während oúvoิsqu.s schon im Hippocrates als Verbindung dient, und im Galen als Band zur Vereinigung zweier Knochen, sehr oft sich vorfindet. Dieses oúv hat auszudrücken, dass es sich um eine Verbindung zweier

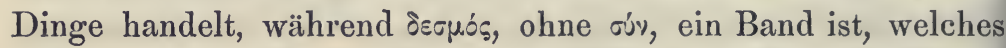
nicht zwei Gegenstände zusammenbindet, sondern nur Einem angehört. So wäre z. B. das Strumpfband, ein ঠ̇øuós, dic

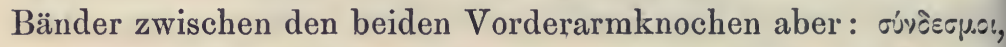
wie sie auch im Galen gebraucht werden: radius et cubitus

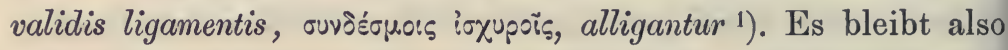
bei der Syndesmologia, worüber erfreut sein werden die Manen Josias Weitbrechts, des Verfassers des Fundamentalwerkes über Bänderlehre: Syndesmologia, Petropoli, 1742.

\section{Synhymensis,}

Am schwersten hat sich die Anatomie gegen Regel und Gebrauch griechischer Wortbildung, durch das fürchterliche Synhymensis versündigt. Adrianus Spigelius wollte damit die häutige Verbindung ( jury, membrana) der Hirnschalknochen des Embryo und Neugebornen ausdrücken. Er sagt: Synhy. mensis fit ope membranae, qua ratione in recens natis ossa syncipitis cum osse frontis junguntur $\left.{ }^{2}\right)$. Die Classificationen der Knochenverbindungen, haben auch in neuester Zeit, auf die Synhymensis nicht vergessen. Man hielt sich zu dieser Onomatopoe berechtigt, da für alle Arten von Knochenverbindungen, schon von altersher, besondere Ausdrücke gang und gebe waren: wie Synchondrosis, Syssarcosis (Verbindung durch Muskeln),

1) Oribasius, Op. cit., pag. 159.

2) De hum. corp. fabrica, Lib. II, Cap. 3. 
Synneurosis $=$ Syndesmosis (Bandverbindung, weil neuron $=$ desmos). Nur hätte man den neuerfundenen Namen besser schmieden, und etwa Synhymenosis sagen sollen, statt des unleidlichen Synhymensis, da ein Zeitwort ip.єvó(), mit der Bedeutung umhäuten, im Hippocrates vorliegt. Aus den grie. chischen Zeitwörtern in $\varepsilon \omega$ und ow, wurden sehr oft Hauptwörter in esis und osis gebildet. Es giebt aber leider kein Zeit-

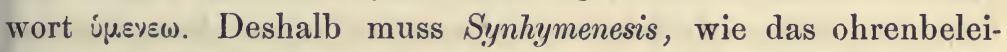
digende Synhymensis, als eine sprachliche Unmöglichkeit verurtheilt werden. Uebrigens war die Erschaffung eines neuen Wortes, für die sogenannte häutige Verbindung der kindlichen Schädelknochen, gar nicht nöthig. Das Verbindungsmittel ist ja mehr Knorpel als Haut, und hätte Synchondrosis mollior s. laxior völlig ausgereicht.

Unbegreiflich ist es, dass das kritisch-etymologische Lexicon von G. A. Kraus, diesen Wechselbalg in Schutz nehmen konnte. Es wird nur die Verbesserung in Synymensis gewünscht, welche schon lange vor $\mathrm{Kraus,}$, in der Onomatologia medica completa (1756) auftauchte. Der gute Homer schläft auch zuweilen.

\section{Synovia.}

Mit einem besonderen Talent, neue Worte zu erfinden, waren Van Helmont und Paracelsus begabt. Ihre Erfindungen gingen aber sämmtlich unter, bis auf zwei, welche in allen gebildeten Sprachen der Welt das Exequatur erhielten. Sie sind das Gas des Helmont, und die Synovia (Synophia) des Paracelsus.

Synovia und Gas gehören gar keiner Sprache an. Synovia verdankt seinen, in der Medicin allgemein gewordenen Gebrauch, nur seinem griechisch-lateinischen Exterieur, und seiner Euphonie. Die reichsten Glossarien ignoriren Synovia gänzlich. Das Lexicon medicum Stephani Blancardi, mit den trefflichen sprachlichen Erörterungen von C. G. Kühn, sagt nichts 
über die Abstammung von Synovia. Nur das kritisch-medicinische Lexicon von L. A. Kraus, hält es aus ouv und ovum hervorgegangen, gleichsam als gesammelter Eistoff. Heisst denn Eistoff ovum? und ist unter diesem Eistoff nicht das albumen gemeint, welches griechisch Leucoma heisst? so dass, wenn es sich wirklich um die Erschaffung eines neuen griechischen Wortes gehandelt hätte, welches die Aehnlichkeit zwischen Eiweiss und Gelenkschmiere ausdrückt, man auf Arthroleucoma, nicht aber auf Synovia hätte verfallen müssen. Dass Paracelsus nicht an ovum dachte, ersehen wir daraus, dass er sehr oft Synophia statt Synovia schreibt.

Woher ist also Synovia gekommen? Es kam von einem Manne, welcher, der griechischen Sprache vollkommen unkundig, doch schon von der modernen Manie, unnöthiger Weise für bekannte Dinge neue Worte zu schmieden, besessen war. Theophrastus Paracelsus, der Auctor vocabuli, hätte uns selbst nicht sagen können, welcher Sprache seine Erfindung angehört. Der griechischen sicher nicht. Paracelsus verstand unter seiner Synovia, nicht die Gelenkschmiere, sondern den Ernährungssaft der Organe (nutrimenta omnia digeruntur in synoviam ${ }^{1}$ ). Weil man aber damals, die Gelenkschmiere für den Ernährungsstoff der Gelenkbänder hielt, ist auch auf sie der Name Synovia übertragen worden. Der

1) Paragraphorum Lib. VI, Cap. 1. In den Scholiis zu diesem Buche heisst es weiter: Synophia est causa, unde pars nutritur, und später: Synophia est in omnibus membris. Im Tractatus de origine et causis (Opp. omnia, T. I, pag. 612) steht Synovia für Podagra: genuinum podagrae nomen Synovia est. - Paracelsus giebt seiner Synophia oder Synovia, als Nahrungssaft der Organe, dieselbe Farbe, welche die Organe selbst haben. In den Knochen und Gelenken, lässt er sie weiss oder wasserklar sein. Letzterer Umstand scheint die Anatomen veranlasst zu haben, das Wort Synovia, nicht wie alle anderen Paracelsischen Termini wegzuwerfen, sondern für die Gelenkschmiere beizubehalten. 
phantastische Paracelsus trug sich mit dem grossen Gedanken, nicht blos die Medicin, sondern auch ihre Sprache zu renoviren. Deshalb ersann er eine Unzahl neuer Worte, welche, da der medicinische Arabismus, zu seinen Lebzeiten, im grössten Flor stand, meistens einen arabischen Anstrich haben. In Bartholomaei Castelli Lexicon medicum, Genevae, 1746, findet man die meisten derselben verzeichnet. Die Synovia hat zwar keinen arabischen Anstrich, und will man ihren Laut für griechelnd halten, ist $\mathrm{Paracelsus}$ wahrlich ganz unschuldig daran, denn er verstand weder griechisch noch lateinisch. Synovia ist und bleibt somit eine Neubildung allen Sprachen fremd. Im Lexicon alchem. von Martin Ruland, Francof., 1612, wurde Synovia zu Sinonia und sogar zu Simonia.

Wie hat denn die Synovia vor Paracelsus geheissen? Es fehlte wahrlich an Namen nicht, um einen neuen nothwendig erscheinen zu lassen. Bei den griechischen Aerzten stossen wir auf die Gelenkschmiere, theils als Phlegma, theils als Hydor der Gelenke. Pierer und Choulant, wie auch Schreger, reihen ihren Synonymieen für Synovia, auch Melicera und Meliceria ein. Das ist ein gewaltiger Irrthum, denn $\mu \varepsilon \lambda$ :krpís findet sich im Julius Pollux als Balggeschwulst am Kopf oder an einem Gelenk (unser Ganglion) angeführt, und wird nur dann gebraucht, wenn der Inhalt des alten Ganglion, schon Farbe und Consistenz des Honigs ( $\mu^{\prime} \hat{\lambda}_{l}$ ) angenommen hat ${ }^{1}$ ). Celsus kennt Melicera, nur als eine von den drei Arten des Eiters, die zwei anderen heissen Ichor und Elaiodes

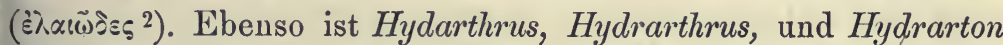
dieser Herren, als Gelenkwasser ganz unstatthaft. Denn diese Worte, welche sämmtlich Neubildungen sind, wurden in keinem griechischen Autor aufgelesen, und könnten, wenn man sie ja gelten lassen wollte, nur Gelenkwassersucht, nicht aber Synovia bedeuten, welche kein Wasser ist. Die Neuheit dieser

1) Onomasticon, Lib. I, Cap. 15, und Lib. IV, Cap. 25.

$\left.{ }^{2}\right)$ De medicina, Lib. V, Cap. 26, de sanguine, sanie et pure. 
Ausdrücke verräth sich schon darin, dass ein Compositum'von äpopor, nicht in die masculine Endsilbe us auslauten kann. Alle sonst noch bekannten Benennungen der Synovia, wie Axungia articularis und Smegma (Sömmerring), Mucilago juncturarum (Schnaper), Gluten articulorum, und Humor glarealis (V an Helmont), Unguen (Haase), Liquidum Haversianum (Leber), drücken nur die viscide, schleimige Beschaffenheit dieser Flüssigkeit aus, welche kein Absonderungsproduct der Glandulae Haversianae sein kann (wie Leber und Andere vor ihm glaubten), da diese Drüsen, keine Drüsen, sondern Fettläppchen sind.

\section{Talus,}

Kein Knochen des menschlichen Körpers gebietet über eine so stattliche Menge gleichwerthiger Benennungen, wie der Talus, das Sprungbein. Im Pierer sind zweiundzwanzig Namen des Sprungbeins versammelt, und doch fehlen noch sechs: Os talare im Zacutus Lusitanus, Choragus ossium pedis im Villanovanus, und Allachius der Latino-Barbari, Cä̈b, Cahab, und Alchaab des Mundinus und seiner Schüler. Die arabischen Worte, und die meisten der lateinischen und griechischen Synonyme, sind nichtswürdig, weil sie auf das menschliche Sprungbein gar nicht passen, oder auf Verwechslung mit anderen Knochen beruhen. Hieher sind zu zählen: Astragalus $\left.{ }^{1}\right)$, Talus (abgekürzt für Taxillus ${ }^{2}$ ), Tetroros ${ }^{3}$ ), Quadrilaterum ${ }^{4}$ ), Quaternio

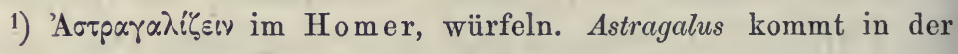
Ilias als Wirbel, und zwar als Halswirbel vor (XIV, Vers 465). Die Körper der Halswirbel (ohne Bögen) ähneln, durch ihre queroblonge Form, dem Sprungbein der Wiederkäuer, und können, wie dieses, als Würfel gedient haben.

2) Ludere talis, im Cicero, = würfeln.

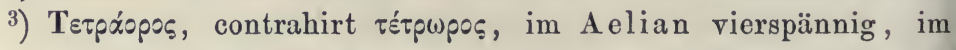
Oribasius Sprungbein.

4) Lateinische Uebersetzung von tétน 
und Quartio 1), Astris und Astrion $\left.{ }^{2}\right)$, Os tesserae) ${ }^{3}$, Clavicula, Cavilla, und Malleolus der Latino-Barbari. Mit den figürlichen Benennungen kann man sich abfinden. Nur das Sprungbein der Säugethiere mit gespaltenen und ungespaltenen Hufen, hat die Gestalt eines Würfels (lateinisch Talus oder Tessera, grie-

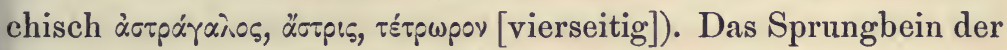
Schafe und Ziegen diente, seiner wenn auch nicht ganz cubischen Gestalt wegen, in ältester Zeit, als Würfel. Nur vier Flächen dieses Sprungbeins sind plan, zwei aber convex, auf welche der Würfel nicht fallen, oder darauf liegen bleiben konnte. Die alten Knochenwürfel waren deshalb nur auf vier Seiten mit Augen versehen. Cubische Würfel wurden erst später aus Holz oder Elfenbein verfertigt, mit sechs planen Flächen, deren jede mit Augen gezeichnet wurde, wie es bei unseren Würfeln geschieht. Das menschliche Sprungbein, und jenes der Digitaten, hat einen Hals und Kopf - sicher kein Attribut eines Würfels. Alle oben angeführten Namen, von Talus bis Os tesserae, taugen deshalb nichts. Nur eine einzige lateinische Benennung des Sprungbeins, nimmt auf den Körper, Hals, und Kopf dieses Knochens Bedacht. Sie ist: Os balistae des Gabriel Zerbis ${ }^{4}$ ). Die römische Baliste kennen wir zwar nicht, trotz der Beschreibungen, welche uns Ammianus und Vitruvius von ihr hinterlassen haben. Es handelt sich auch nicht um die römische Balista, sondern um die bekannte Schiesswaffe des Mittelalters - die Armbrust, welche im Mönchslatein Arcubalista und Arbalista (Bogenwurf) hiess. In einem viereckigen Loch des Schaftes der Armbrust, bewegt sich-ein verticaler Bügel um eine Querachse. Das obere Ende dieses Bügels bildet einen runden Knopf, welcher die Sehne der Armbrust in einer

1) Vesal'sche Ausdrücke für tétpwpos.

2) "Aørpls, im Callimachus, Sprungbein.

3) Tessera = Würfel, im Cicero und Ovid.

4) Opus praeclarum anathomiae, Venet., 1533, Fol. 181: per similitudinem nodi balistae. 
526 363. Tarsus und Metatarsus des Fusses, - Tarsus als Augenlidknorpel.

Vertiefung an seiner Hinterseite aufnimmt und festhält. Durch Fingerdruck auf das untere Ende des Bügels, wird die Sehne losschnellen gemacht. Das obere kopfähnliche Ende des Bügels, hiess die Nuss, Nux oder Nucleus balistae. Die Nuss hat auf den ersten Blick auffallende Achnlichkeit mit dem Kopf des Sprungbeins, und so ist denn Os balistae wirklich die beste Benennung, welche das Sprungbein (ausser seinem deutschen Namen) erhalten hat. Der ehrliche Schylhans sagt: "2litra= galus, in arabifher jung cahab, if ain armbroft 1)." Die Armbrust kam durch die Feuergewehre aus dem Gebrauch, und findet sich nur mehr in den Rüstkammern. Auch der Talus und Astragalus werden in der Rumpelkammer der anatomischen Sprache sorgfältig gehütet werden, um das Os primum tarsi, durchaus mit einem widersinnigen Namen, statt des einzig tadellosen Os balistae, ausgestattet zu sehen. Bei den Classikern, Dichtern und Prosaikern, wird mit Talus die Ferse gemeint, z. B.

„Candidus, et talos, a vertice pulcher ad imos"

(Horatii Ep. II, 2, 4.)

und im Cicero: purpura ad talos demissa. Von Talus, als Fer'se, entstanden das italienische tallone, das französische talon, und das deutsche Talar, ein bis auf die Ferse reichendes Gewand.

Ueber die Namen, welche das Sprungbein bei den Arabisten führte, sieh' HL, $\S$. XLIII, Cäb und Cahab.

\section{Tarsus und Metatarsus des Fusses, - Tarsus als Augenlidknorpel.}

I. Tarsus, als Fusswurzel.

Dass zwei so disparate anatomische Objecte, wie Fusswurzel und Knorpel der Augenlider, denselben Namen, Tarsus,

1) felotbud der wundarjtney, Fol. 15, Seite 6 . 
führen, wird Manchen schon befremdet haben. Ich halte eine

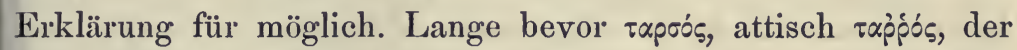
technisch-anatomische Ausdruck für Fusswurzel wurde, führten verschiedene, breite und flache Gebrauchsgegenstände des täglichen Lebens diesen Namen ${ }^{1}$ ), wie der ausgespreitete Flügel

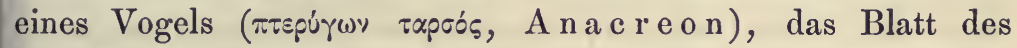

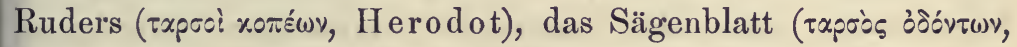
Oppianus), die Hürde zum Trockneu von Obst, Käse, und

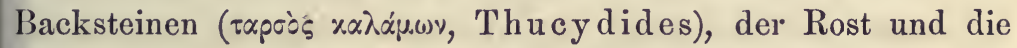
Egge (tapppiov, Craticula, und Crates dentata des Plinius), das Rohrgeflecht und was daraus bereitet wurde, z. B. Korb aller Art - der calathus, Fruchtkorb des Virgil. So wurde denn auch der breite Theil des Fusses und der Hand (ohne Zehen und Finger) rapoós genannt, wie uns Hesychius²), die tapoo!

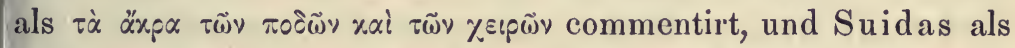
planta pedis, und summa par's manus ${ }^{3}$ ), ganz ohne osteologischen Hintergedanken, sondern conform mit der Handwurzel- und Mittelhandgegend, und mit der Fusswurzel- und Mittelfussgegend der topographischen Anatomie vorführt ${ }^{4}$ ). Der osteologische Sinn von Tarsus kam erst im Galen zum vollen Ausdruck,

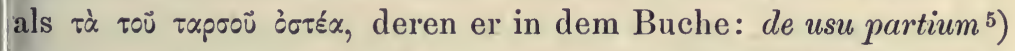
nur vier zählt (die drei Keilbeine und das Würfelbein ${ }^{6}$ ), worin

1) Tarsus vocatur omne id, quod dilatatum est, giebt das Lexicon med. Edit. Brunonis, Genevae, 1746, T. Der Ausdruck $\tau \varepsilon \tau \alpha \rho \sigma \omega-$ p.évos im Dioscorides, von breiten oder gefiederten Blättern, wird daraus verständlich.

2) Lex. Edit. Lugd., Joh. Alberti, T. II, lit. T.

$\left.{ }^{3}\right)$ Suidae Lex. Edit. Hal. Godofr. Bernardy, T. II.

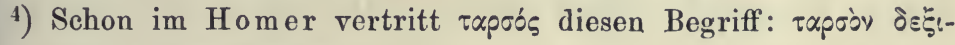

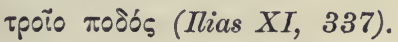

5) Lib. III, Cap. 8, sub initio.

$\left.{ }^{6}\right)$ Das Sprungbein, das Fersenbein, und das Kahnbein, werden als selbstständige Knochen, nicht als Bestandtheile des Tarsus, abgehandelt. 
ihm die Araber mit ihrer Rasceta pedis folgten, während er im Commentarius II. in Hippocratis librum de fracturis ${ }^{1}$ ), die Fusswurzel aus acht Knochen bestehen lässt: in manu ossa octo primam palmae partem constituunt, in pede autem ea pars, quae inter talos (der Plural = Knöchel) et plantam (pedium, unser Metatarsus) sita est, cum calce ac talo (der Singular = Sprungbein), quae omnia ossibus octo continentur. Galen lässt sich sonst nirgends auf solchen Widersprüchen ertappen. Es ist daraus mit Sicherheit zu schliessen, dass der angeführte Commentarius in Hippocratis librum de fracturis, nicht $\mathrm{zu}$ den echten, sondern zu den unterschobenen Büchern des Galenus gehört, wofür auch die Verschiedenheit des Styles spricht, welche selbst einem flüchtigen Leser nicht unbeachtet bleiben kann. Diese acht Knochen des Tarsus kehren im Rufus Ephesius wieder: Tarsus ex octo ossiculis, inaequalibus angulis instruitur ${ }^{2}$ ). Weder Galen, noch Rufus, führen die acht Tarsusknochen namentlich auf, und lässt sich deshalb nicht sagen, welchen Knochen sie für den achten hielten, da wir doch nur deren sieben von ihnen kennen.

$\mathrm{Rufus}$ spricht auch von unserem Metacarpus als txpés: lata et compacta pars, post brachiale (Handwurzel), Metacarpion Tarsusque nominata ${ }^{3}$ ). Da ein aus parallelen Eisenstäben gebildeter Rost, rapoiov (craticula) hiess, wird es erklärlich, dass der Name Tarsus, auch auf die fünf parallelen Röhrenknochen der Mittelhand applicirt werden konnte. Merkwürdiger Weise hat die im Anthony Rich enthaltene Abbildung einer Craticula $\left(\tau \alpha\right.$ popiov $\left.^{4}\right)$, fünf parallele Stäbe, und da auch der Mittelfuss aus fünf langen Röhrenknochen besteht, erklärt es sich leicht, warum das Fussgerüst vom Sprunggelenk bis zu den Zehen, denselben Namen erhielt. Seit Celsus die Handwurzel

1) Num. XVIII, pes hominis.

2) De partibus hominis, pag. 71.

3) Op. cit., pag. 29.

4) Römische Alterthümer, pag. 196. 
Carpus, als prima palmae pars definirte, folgten auch die Mönchsärzte des Mittelalters ${ }^{1}$ ) seinem Beispiel, nannten den Tarsus: prima plantae pars, und dabei blieb es für lange Zeit. Tarsus ist seitdem nicht mehr der ganze Fuss bis zu den Zehen, sondern nur seine erste Abtheilung, die Fusswurzel. Ein Metatarsus kommt im ganzen Galen nicht vor ${ }^{2}$ ). Das Wort ist neu, und wurde von Andreas Laurentius zuerst angewendet ${ }^{3}$ ). Ebenso neu, und überdiess noch der Sache nicht entsprechend, ist das Metapedium des Spigelius $\left.{ }^{4}\right)$. Den deutschen Namen Fusswurzel, erhielt der Tarsus schon im 17. Jahrhundert, durch den Uebersetzer des Bartholinus, Namens Dr. Elias Wallner, Kreisphysikus in Baden bei Wien (Bartholini verbesserte Zerleging des menschlichen Leibes, Nürnberg, 1677). Früher hiess sie "Rephenbein", (propter seriem ossium), wie im Spigel der $\mathfrak{U}_{\text {natomey. }}$

\section{Tarsus, als Knorpel des Augenlides.}

So wie die fünfknochige Mittelhand, und der Mittelfuss,

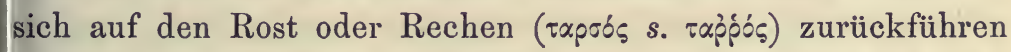
lassen, so gab eine andere Bedeutung von tapoós, jene des Flügels, die Veranlassung, dass auch die breiten und wie Flügel beweglichen Deckel der Augen, rapooi genannt wurden, obwohl sie für gewöhnlich $\beta \lambda$ śpapa hiessen. Galen restringirte aber zapobs auf den freien Rand der Augenlider: partes, quibus palpebrae invicem committuntur, tarsi nominantur ${ }^{5}$ ), und $\mathrm{R}$ ufus blos auf die Behaarung dieses Randes: pili, a palpebris prodeuntes, Tarsi s. Blepharides vocantur $\left.{ }^{6}\right)$. Die oben erwähnte

1) Celsus wurde in der Physica der Klosterschulen gelesen und commentirt.

2) Was wir Metatarsus nennen, findet sich im Juliụs Pollux nur als $\pi \varepsilon \delta$ iov.

3) Historia anatomica corp. hum., Lib. II, Cap. 37.

4) De corp. hum. fabrica, Lib. I, Cap. 6.

5) Introductio s. Medicus, Cap. 10.

6) Op. cit., pag. 24.

Hyrtl. Onomatologia anatomica. 
Introductio Galeni ist aber, erwiesener Massen, ein liber spurius. Das echte Galenische Buch: de usu partium ${ }^{1}$ ), erwähnt als

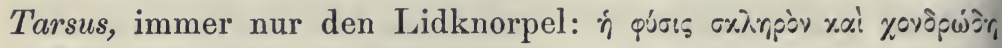

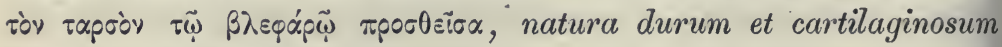
tarsum ipsi palpebrae apponens.

Die Hippocratische Benennung der Augenlider als \%.я,úp$\mu \alpha \tau \alpha$, beruht auf $x_{\alpha} \lambda \dot{u} \pi \tau \omega$, verhüllen und bedecken. Aus ihr sind die Opercula und Tegumenta oculorum des Spigelius und Veslingius hervorgegangen.

Das deutsche Augenlid (unrichtig Augenlied), zeigt nicht, wie Adelung meint, auf das altdeutsche Lid hin, ein Gelenk, sondern auf das angelsächsische hlid, Deckel, von hlidan, bedecken.

Der Grammatiker Nonius, zu Ende des 2. Jahrhunderts nach Christus, beruft sich darauf, dass Palpebrum suo tempore, häufiger als Palpebra gesprochen wurde ${ }^{2}$ ). Im Caelius Aurelianus finde ich ebenfalls: palpebrum superius, paralysi vitiatum, latius fit, und item inferius palpebrum intrinsecus flectitur (Entropium ${ }^{3}$ ).

\section{Tela.}

Tela ist Gewebe. Quod texitur, texela est, et haec in telam contrahitur, heisst es im Forcellini. Tela steht also zu texere, weben, in demselben Verhältniss, wie medela zu medeor, loquela zu loquor, tutela zu tutor, und candela zu candeo (glänzen, leuchten). In der Anatomie wird tela weit weniger gebraucht, als in der Hauswirthschaft (Leinwand). Wir haben nur Haller's Tela cellulosa, als Zellgewebe, und Meckel's Tela choroidea, als mittleres Adergeflecht des Gehirns, - eine Uebersetzung der toile choroidienne von Vicq d'Azyr. Toile, Tischtuch und

1) Lib. X, Cap. 9.

2) De varia significatione verborum, III, 164.

3) Morbi chron., Lib. II, Cap. 1. 
Serviette, finden wir in der französischen Volkssprache, für Omentum majus, welches die alten Anatomen aus der Schule von Montpellier, wie auch Vesal, Mappa ventris nannten. Den mit dem schneeweissen Tischtuch überzogenen Putztisch der Damen, kennen wir hinlänglich als toilette.

\section{Tendo Achillis.}

Achilles wurde als Kind, von seiner Mutter Thetis, in die Fluthen des Styx getaucht, um ihn unverwundbar zu machen. Die Ferse, an welcher er bei dieser Taufe gehalten wurde, blieb natürlich unbenetzt, und war deshalb verwundbar. Bekanntlich starb Achilles an einen Pfeilschuss in die Ferse. So kam es, dass, in figürlicher Rede, die schwache und angreifbare Seite irgend eines Gegenstandes, dessen Achillesferse genannt wird. Darnach schuf auch die Anatomie ihre Tendo Achillis, für die mächtige Endsehne des Gastrocnemius und Soleus. Philippus Verheyen, Professor der Anatomie in Löwen, spricht der Erste von der Achillessehne, nicht als Tendo, sondern als Chorda Achillis ${ }^{1}$ ). Dem Verheyen musste ein Fuss amputirt werden, welchen er später selbst secirte, und dabei auf den erwähnten dichterischen Einfall gerieth. Heister verwandelte Chorda in Tendo, und hinterliess uns seinen Tendo Achillis, omnium fortissimus ${ }^{2}$ ). Gerardus Cremonensis, der Uebersetzer des Avicenna, bediente sich des Ausdrucks: Chorda magna Hippocratis ${ }^{3}$ ). Hippocrates hielt bekanntlich die Wunden und Quetschungen der Achillessehne

1) Sein classisches Compendium, welches jenes des Thom. Bartholinus verdrängte, wurde zuerst 1693 in Löwen (Lovanium) aufgelegt, und enthält in Lib. I, Tract. 6, Cap, 13, die Chorda Hippocratis.

$\left.{ }^{2}\right)$ Compendium anatomicum, Num. 174.

3) Canon, Lib. IV, Fen. 4, Tr. 4, Cap. 1. 
für sehr gefährlich : contusus hic tendo, et sectus, febres acutissimas movet, singultus excitat, mentem perturbat, tandemque mortem accersit. Dieser Glaube erhielt sich sehr lange, und war die Ursache des späten Aufkommens der Tenotomie (sprachrichtig nur Ten on to to mie). Die Achillessehne selbst wurde von Hip pocrates veüp $\alpha \mu \varepsilon \gamma \alpha \dot{\lambda} \lambda \alpha$, genannt - im Plural wahrscheinlich deshalb, weil diese Sehne mehreren Muskeln zugleich angehört. Im Galen ${ }^{1}$ ) lesen wir: os calcis nervis (Sehnen) conjungitur, quos Hippocrates vocat Ė $\pi$ ixaipovङ, wozu der Uebersetzer hinzufügt: i. e. grandiores. Das ist aber unrichtig. Hippocrates gebraucht

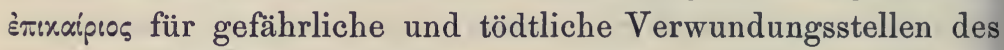

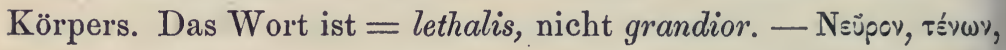
Tendo, und Chorda, sind in der alten anatomischen Terminologie ganz synonym ${ }^{2}$ ). Der Nervus latus und Nervus crassus der Mundinischen Zeit, wird uns deshalb nicht besonders auffallen. Der Nervus crassus kommt auch im alten Testament, aber für Hüftnerv vor. Als Tendo latus erscheint die Achillessehne im Vesal und seinen Schülern, als Teido validissimus im Bartholinus. Die Erklärung, welche ich eingangs über den Ursprung des Namens: Achillessehne gegeben habe, ist richtiger als die ältere, welche sich auf jenen Vers im Homer bezieht, wo gesagt wird, dass Achilles dem getödteten Hector, die Riemen unter der Sehne der Ferse durchzog, um den Leichnam an seinen Siegeswagen zu binden, und dreimal um Troja's Mauern zu schleifen:

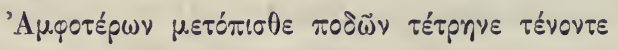

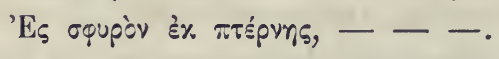

$$
\begin{aligned}
& \text { (Ilias, XXII, 396, und 397). }
\end{aligned}
$$

Diese Operation wurde an Hector, nicht an Achilles vorgenommen. Wäre sie mit der Strecksehne des Fusses in Verbindung zu bringen, so hätte diese Tendo Hectoris genannt werden müssen.

1) Comment. II. in Hippocratis librum de fracturis, N. 17.

') Sieh' den Artikel: Chorda. 


\section{Teres.}

Einige anatomische Anwendungen von teres, lassen sich grammatikalisch nicht verfechten. Das Ligamentum teres hepatis und uteri sind tadelfrei, aber der Teres major et minor, der Pronator teres, und das Ligamentum teres capituli femoris, bedürfen einer Correctur. Teres definiren die Lexica als: quidquid oblongum et cylindricum (Gesner), und Forcellini setzt hinzu cum laevitate, d. i. mit glatter Oberfläche, weil das Etymon von teres, tero ist $=$ reiben. Festus sagt: in longitudine rotundatum. In diesem Sinne finden wir Digiti teretes, Surae teretes, und Collum teres im Ovid, und Membra teretia im Suetonius. Ein Cylinder, ein Baumstamm, eine Säule, kann teres genannt werden, weil ihr Querschnitt ein Kreis ist. Die drei oben genannten Muskeln sind, wie Albin sagt, latiores quam crassi, geben im Querschnitt flache Ellipsen, sind also keine Cylinder, und somit auch nicht Teretes. Cow per brachte ihnen diese Namen auf, während Riolan sie als rotundi abhandelt. Dass teres und rotundus nicht synonym sind, bezeugt der Horazische Vers vom weisen Manne:

\section{"Fortis et in se ipso totus, teres atque rotundus."}

$$
\text { (Satyra II, 7, 85.) }
$$

Horaz würde sich einer Tautologie nicht schuldig gemacht haben. Teres und rotundus stehen hier in figürlicher Anwendung als glatt und rund, d. h. minime scaber aut angulosus, ut nulla labes, nullum vitium, sapienti adhaerere possit, wie die Commentaria sich vernehmen lassen. Hunderte von Muskeln könnten teretes genannt werden, wenn man einmal vom Cylinder absieht, mit Recht aber nur die conischen, wie der Psoas, weil sie den Querschnitt von Cylindern haben. Chaussier's Benennung des Teres major als Anguli-scapulo-huméral, und jene von Dumas für den Teres minor als: Margini-sus-scapulo- 
trochitérien, sind horrend. Haben sich diese Herren je denken können, dass solche monströse Compositionen, die alten und einfachen anatomischen Muskelnamen verdrängen, und es sich an ihrer Stelle durch allgemeinen Consensus bequemer machen werden? Wollen wir uns, solcher Kleinigkeit willen, nicht ereifern. Desto dringender muss das Ligamentum teres femoris, ohne alle Wortstürmerei aus der Anatomie ausgewiesen werden. Denn erstens ist es kein Band, hält den Schenkelkopf nicht, und trägt ihn nicht, greift in keine einzige Bewegung im Hüftgelenk hemmend ein, und gehört den gefässreichen Synovialfalten an 1), welche für nichts anderes, als für die Absonderung der Gelenksfeuchtigkeit zu sorgen haben. Zweitens ist es, seiner Gestalt nach, keineswegs teres, sondern dreiseitig prismatisch, mit zwei scharfen, und einer sehr stumpfen Kante - gerade der Gegensatz von teres. Wenn auch das Ligamentum bleiben darf, weil ich nicht weiss, welchen anderen kurzen Ausdruck man wählen könnte, so muss doch, wie alle Welt zugeben wird, das teres in triquetrum oder prismaticum umgeformt werden, was sporadisch bereits geschah. Auch das Ligamentum privatum capitis femoris ${ }^{2}$ ) wäre annehmbar, wie das Ligamentum acetabuli internum des Thomas Schwenke ${ }^{3}$ ), und das Ligamentum interarticulare von A. F. Walthe ${ }^{4}$ ) (igament renfermé des Winslow ${ }^{5}$ ). Das Ligamentum neurocartilagineum des Riolan, und Böhmer's Ligamentum suspensorium femoris, sind Absurditäten. Der Ausdruck Ligamentum teres, ist übrigens nur eine wörtliche Uebersetzung von évydsqu.os

1) Henle, Bänderlehre, 1. Aufl., pag. 124.

2) Andreas Laurentius, Hist. anat. hum. corporis, Lib. III, Cap. 21.

3) De acetabuli ligamento interno, in dessen Haematologia, Hagae, $1743,8$.

4) De articulamentis et musculis hominis, etc., Lips., 1728, pag. 22. Ich habe, pag. 505, Ligamentum intracapsulare vorgeschlagen.

5) Exposition anat., Traité des os, §. 127, 144 und 145. 
oтporrúios im Galen ${ }^{1}$ ), welcher somit die erste Schuld dieser anatomischen Unrichtigkeit auf sich hat. Eтporrǜos ist = cylindricus.

\section{Testa,}

Neue Worte mussten in der Anatomie, für neu entdeckte Gegenstände, gefunden werden. Aber auch alte Worte gingen unter, und verschwanden spurlos aus unserer Sprache. Hieher gehört Testa, für Kopf. Calvaria apparet, testa ab antiquis dicta, lese ich im A. Benedictus ${ }^{2}$ ), und im Carpus: Testa etiam caput dicitur, quia sensus in eo originem capiunt ${ }^{3}$ ). Testa ist eine vox aequivoca. Alles gebrannte Thongeschirr, hiess bei den Römern testa. Man meint, dass testa für tosta steht, von torreo, rösten, backen. Töpfe, Schalen, Schüsseln, Krüge, u. s. w., gehörten zu den Testae, z. B.:

„Qua semel est imbuta recens, servabit odorem „Testa diu - - - .

und :

(Horatii, Ep. I, 2, 69.)

"Accipiat manes, parvula testa meos."

(Propertius, II, 10, 33.)

Testae hiessen auch die Scherben der Geschirre, und die Fragmente der Ziegel (testae tegularum), wie im Ovid, wo er den kürzeren Fuss eines wackeligen Tisches, eine solche Scherbe unterlegt:

$$
\begin{aligned}
& \text { "Testa parem fecit - - mensae sed erat pes tertius impar, } \\
& \text { (Metamorph. VIII, 666.) }
\end{aligned}
$$

Im Gemein-Wienerischen heisst der Topf, besonders der Nachttopf: "Scherm", oder "Scherberl", und "alter Scherm"

1) De usu partium, Lib. XII, Cap. 5.

2) Hist. corp. hum., Lib. IV, Cap. 7.

3) Isagogae, Cap. 1. 
ein abgetragener Hut, ein baufälliges Haus, selbst ein altes Weib, u. v. a.

Die medicinischen Autoritäten Rom's, führen Testae als Knochenfragmente und als Zahnsplitter auf: dens per testas excidit, und labans ossis testa (loses Knochenstück) im Celsus. Die harte Schale des Eies, die Schale des Krebses, der Schildkröte, der Auster, und anderer Conchylien, heisst im Plinius: Testa, woher die Testacea, Schalthiere stammen. Im Aristoteles heisst sie öørpaxov ${ }^{1}$ ), unde Ostracismos, das Gericht in Athen, dessen Mitglieder durch einen, auf einer Austernschale, oder

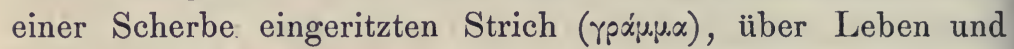
Tod, oder Verbannung eines Bürgers, aburtheilten. Im figürlichen Sinne, als Schale des Gehirns; erscheint Testa erst zu Ende des 4. Jahrhunderts, im Ausonius, einem gelehrten Grammatiker, Rhetor, und Dichter:

„Abjecta in triviis, inhumati glabra jacebat, "Testa hominis - - - ."

(Epigr. 72.)

Der gleichzeitige römische Arzt, Caelius Aurelianus, schleppte das Wort in die medicinische Sprache ein: anatresis testae (Anbohrung des Schädels) jam dudum explosa ${ }^{2}$ ). Durch das ganze Mittelalter erhielt sich die Testa um so leichter, als die Aerzte Italiens, Testa, als Kopf, auch in ihrer Nationalsprache enthalten fanden. Die meisten Arabisten hielten streng an testa fest. Da die ursprüngliche Bedeutung derselben Topf und Schale ist, haben wir diese testa im Deutschen als Hirnschale aufgenommen, statt des barbarischen "Gyprntopfes"

1) Ein solches Thier mit harter Schale, nannte Aristoteles: Ostracodermon, im Plural Ostracoderma, nicht Ostracodermata, wie ein in der Sprache der Zoologie und bei den besten Autoren stabil gewordener Sprachfehler sich vernehmen lässt. Es sind ja mit diesem Worte nicht harte Häute, sondern Thiere mit harter Leibesbedeckung gemeint.

2) Morborum chron. Lib. II, Cap. 1, Num. 59. 
und "Gaubthaven" (Haven statt Hafen = Hefen und Heferl der Wiener), im Vocabularius des Schylhans. In der anatomischen Sprache der nach-Vesal'schen Zeit, ist nichts mehr von Testa zu finden. Die Italiener aber haben testa und teschio, und die Franzosen tête, bis auf unsere Tage bewahrt. Das altspanische tiesto wurde schon frühzeitig durch cabeza verdrängt, welches aus Caput hervorging, dessen verstümmelter Rest, im wallachischen Cap sich erhalten hat, mit der ursprünglichen Bedeutung als Kopf, während das französische cap, das englische cape, und das spanische cabo, nur als vorspringender Theil des Festlandes, als Vorge birge, gebraucht werden.

\section{Textus cellularis, Textura, und Structura.}

Aus Zellen lässt sich nichts weben. Weben lassen sich nur Fäden. Es kann also auch kein Zellengewebe, Textus cellulosus oder cellularis, geben. Textus heisst so viel als Textura. Textura aber ist Gewebe, und Textura cellulosa ein Gewebe von Zellen, also etwas Unmögliches. Haller mochte das Widersinnige des Ausdrucks gefühlt haben. Er verliess ihn deshalb, und erfand die Metapher: Tela cellulosa, = eine Metapher, weil Tela, Webestuhl1) ist, und nur als Tropus zum Gewebe werden kann (telam texere, im Terenz, und tela, Leinwand, toile).

Als der Textus cellularis im vorigen Jahrhundert aufkam, verband man mit Zelle freilich einen ganz anderen Begriff, als heutzutage. Zellen wurden von Haller die Lücken und Räume im Bindegewebe genannt, in welchen sich das Fett ablagert ${ }^{2}$ ). Die von ihm noch gebrauchten Ausdrücke: Caver-

1) Telam exercere braucht Cicero für weben.

2) Primae lineae physiologiae, §. 25. Diese ohne alle Regel, in einem wahren Durcheinander, zusammengehäuften Lücken, wurden 
nulae, Areolae, Spatia, und Intervalla cellularia, beruhen auf dieser Idee. Aber auch diese Zellen liegen nur neben- und übereinander. Miteinander verwebt sind sie nicht, weil sie es nicht sein können, und widerspricht somit Textus cellularis, auch im alten Begriff der Zelle, einem Gewebe. Die Zelle, im histologischen Sinn, als Elementargebilde, eignet sich ebensowenig zu einem Gewebe. Elementarzellen können nur zusammengehäuft oder aneinandergereiht werden. Geschieht diese Anhäufung in einer gewissen Ordnung, wie das Zusammenfügen der Ziegel oder der Pflastersteine, so heisst dieses Structura, welches Wort in der Anatomie mit Textura gleichbedeutend gehalten wird, während die Römer beide sehr scharf von einander unterschieden. Textura war ihnen alles Gewebte, Structura alles aus gleichartigen Theilen Zusammengesetzte. So hatten sie eine Structura muri, eine Structura pavimenti, eine Structura domus und navis, selbst eine Structura verborum (Cicero), als Verbindung der Worte zur Rede. Was in der Anatomie aus Elementarzellen besteht, besitzt Structur, was aus Fasern, Gefässen, und Nerven zusammengewebt ist, hat Textur. Hieraus ist es klar, dass man von einer Structur, nicht von einer Textur, der Horngebilde, der Haare, der Oberhaut, des Zahnschmelzes, der Epithelien, der Krystalllinse zu reden hat, von einer Textur der Zellen aber, d. i. von einem Zellengewebe, durchaus nicht reden darf, wenn man sprachrichtig reden will.

Das deutsche Bindegewebe ist dem Zellgewebe unbedingt vorzuziehen. Selbst die Franzosen haben uns die Ehre angethan, ihr tissu conjonctif darnach zu bilden.

mit jenem eines Schwammes verglichen, und deshalb auch Substantia spongiosa und porosa genannt (E. Stahl). 


\section{Thalami nervorum opticorum.}

Im Griechischen und Lateinischen hat Thalamus eine ganz gleiche Bedeutung. Es wird damit immer ein Raum ausgedrückt, zu verschiedenster Verwendung : wie Wohnzimmer, Schlafzimmer, Brautgemach, Vorrathskammer, im Griechischen insbesondere noch: Schiffsraum, für die untersten Ruderknechte der Trieren (Tprippns, Kriegsfahrzeug mit drei Reihen von Ruderbänken), welche deshalb $\theta \alpha \lambda$ a.üral hiessen, dann noch Bienenzelle, und in christlicher Zeit, Tabernakel für das Allerheiligste, nach Aelianus 1). Die Dichter gebrauchen Thalamus für ein ganzes Wohnhaus, wie Virgil2): ferrei Eumenidum thalami, und:

"Hic thalamum invasit natae, vetitosque hymenaeos,"

und im Ovid: thalami jam limina tangit, jamque foras aperit. Das Palais, welches der ägyptische Apis bewohnte, hiess ebenfalls Thalamus ${ }^{3}$ ). Selbst die Anatomen in vor-Vesal'scher Zeit, nennen die Herzkammern Thalami cordis, die cavernösen Körper der Ruthe Thalami penis, sogar den Herzbeutel Thalamus regalis, weil das Herz Amt und Namen eines Viscus regens führte ${ }^{4}$ ). In der Botanik wird mit Thalamus der unterste Raum des Calyx ausgedrückt.

Wie ist es also gekommen, dass man einen Markhügel im Gehirn, welcher keine Höhle enthält, Thalamus opticus nannte? Die Geschichte der Anatomie beantwortet uns diese Frage. Galen liess die Sehnerven aus dem vordersten Winkel

1) Animalium historia, $X I, 10$.

2) Aeneis, Lib. VI, Versus 280 und 623.

3) Plinius, Hist. naturalis, Lib. VIII, Cap. 46.

4) J. Valverda, Anatomia corp. humani, Romae, 1560, Lib. I, Cap. 4. und E. Hebenstreit, de homine sano et aegro, Lips., 1753, P. I, Cap. 5, §. 4. 
der Seitenkammer, nicht aus den Sehhügeln hervorgehen. Ein Ausläufer dieses Winkels setzt sich in den Sehnerven fort, welcher hohl ist und einen Kanal enthält ${ }^{1}$ ). Seine Worte hierüber können nicht missverstanden und anders gedeutet werden. Sie sagen: $u b i$ anterior ventriculus cerebri desinit, illinc nervi optici oriuntur, qui cavi sunt, ut spiritum reciperent ${ }^{2}$ ). Dieser vordere Winkel der Seitenkammer wird $\theta \alpha \lambda \alpha_{\mu} i_{i}^{3}$ ) genannt. Als später die Galenische Lehre verlassen wurde, und man die Sehnerven, nicht aus den Hirnkammern, sondern aus jenen soliden Markhügeln derselben, welche Gal en Glutia (Hinterbacken) nannte, entstehen liess, behielt man doch den Ausdruck $\theta \alpha \lambda \alpha \dot{u}$.r bei, und machte Thalamus daraus. So entstand der Thalamus nervi optici, welcher, richtig übersetzt, noch immer Sehnervenkammer lauten würde. Seit Riolan und Willis, ist der Thalamus, als Sehnervenhügel, nicht als Vorderhorn der Seitenkammer, allgemein eingeführt, und zugleich der alte Name der beiden neubenannten Hügel: glutia s. nates (bei dem Arabisten Berengarius: anchae ${ }^{4}$ ), auf das vordere Paar des Vier-

1) Der Sehnerv wurde schon von Herophilus für einen Kanal gehalten und deshalb Iópos genannt. Im Oribasius wird ebenfalls von exigui meatus nervorum, a cerebro ad oculos descendentium, gesprochen. Diese Meatus vereinigen sich im Chiasma zu einem einfachen Kanal, damit die zwei Augen nur einen einfachen Gesichtseindruck im Gehirn erzeugen können.

2) De usu partium, Lib. XVI, Cap. 3.

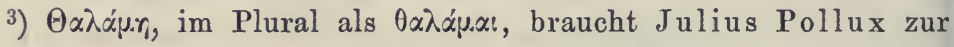
Bezeichnung zweier Oeffnungen und zweier Höhlen: vordere Nasenöffnungen, und innere Nasenhöhlen (Onomasticon, Lib. II, Cap. 4). Nur Ein Anatom folgt seinem Beispiel. Es war Alessandro Benedetti: foramina narium, unde pituita destillat,

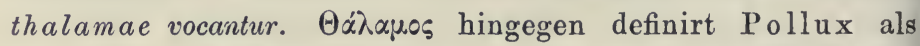

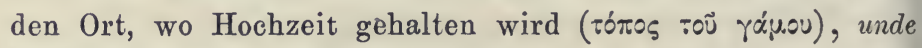
Epithalamium, ein Hochzeitsgedicht.

4) Im Th. Bartholin heissen die Sehhügel: Magnae cerebri eminentice, - im Vieussens: Corpora striata posteriora, - im 
370. Thenar, Hypothenar, Mesothenar, Opisthenar, und Parathenar. 541

hügels übertragen worden. Nur in Pierer und Choulant's Realwörterbuch, stösst man noch auf Sehnervenkammern, unter den Synonymen der Sehnervenhügel.

Die Anatomie wird den Thalamus, als Sehhügel, nicht mehr los werden. Sie hat sich durch Jahrhunderte in ihn hineingelebt. Um ihn einigermassen mit Ehren fortbestehen zu lassen, möge man ihn als Tropus auffassen. Tropisch kann Lager für Schlafgemach gesetzt werden, wodurch der Thalamus zum Lager der Sehnerven würde, was man immerhin sagen kann.

\section{Thenar, Hypothenar, Mesothenar, Opisthenar, und Parathenar.}

Die neuere Anatomie befindet sich ausser Stand, festzustellen, was Thenar, Hypothenar, Mesothenar, Opisthenar, und Parathenar, eigentlich zu bedeuten hat. Die alten Anatomen und Aerzte wussten es auch nicht ganz genau, denn ihre Angaben über" diese Worte sind widersprechend. Stammt Thenar von $\theta$ sivw, schlagen, ab, so kann nur die flache Hand damit gemeint sein, da man mit ihr schlägt. Die deutschen Anatomen des vorigen Jahrhunderts nannten deshalb den Thenar: Klopfer ${ }^{1}$ ). Als Flachhand finden wir Thenar im Homer:

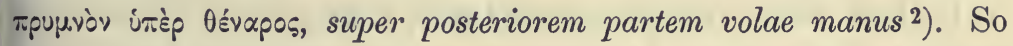
fasst auch Aristoteles das Thenar auf: ea manus pars, quae est a carpo, usque ad digitos. Er unterscheidet am Thenar eine innere, weiche und fleischige Fläche, als Thenar sarcodes, und eine äussere, harte, welche keinen besonderen Namen führt, und erst von späteren Autoren, Opisthenar genannt wurde.

Ridley: Capita medullae oblongatae, - im Haller: Colliculi nervorum opticorum.

1) Leber, Vorlesungen über Zergliederungskunst, pag. 242.

2) Mias, V, 339. 
542 370. Thenar, Hypothenar, Mesothenar, Opisthenar, und Parathenar.

Auch im Galen ist Thenar die hohle Hand '): quae manuum partes prominent, eas volas, 0śvapo, a percutiendo ( $\theta$ sivs:v) nominant. Die Flachhand zeigt aber eine mittlere Vertiefung. Die Vertiefung auf dem Opferherd, in welche das Brandopfer gelegt wurde, heisst im Pindarus ${ }^{2}$ ): 0śvap. Wäre es nicht gerathener, das Thenar mit dieser Grube in Verbindung zu bringen? Ich glaube wohl, da Thenar im Hippocrates, auch für Hohlkehle des Fusses (Planta) gebraucht wird ${ }^{3}$ ), mit welcher man nicht schlägt. Rufus Ephesius beschränkte das Thenar, auf den Ballen des Daumens: spatium carnosum inter indicem pollicemque, sub quo manus in cavum subsidet, Hypothenar vero, quod sub quatuor digitis est ${ }^{4}$ ). Oribasius kennt Thenar gar nicht, und Julius Pollux, eine hohe Autorität in der richtigen Auslegung zweifelhaften Wortsinnes, schlägt sich ganz auf seine Seite: carnea et interna manus pars, a pollice ad indicem, vocatur Thenar, exterior autem pars Opisthenar (ỏnıốvap, nicht Opistothenar, wie die neuere Schreibart lautet); pars vero ab indice ad minimum digitum Hypothenar; nonnulli vero omnem anteriorem pugni partem, Thenar dici autumant $\left.{ }^{5}\right)$. Man sieht aus all' diesem, dass auch bei den Griechen, Thenar kein ganz genau präcisirter Begriff war, als Hohlhand aber, und als Daumenballen, am meisten gebraucht wurde.

Die Confusion, welche die Anatomen der neueren Zeit mit Thenar anrichteten, begann mit Riolan, und wurde von Winslow weiter gefördert. Winslow fasste als Thenar die kleinen Muskeln des Daumens zusammen, welche das Fleisch des Daumenballens bilden ${ }^{6}$ ), und die unter Haller's Aegide

1) Commentarius in Hippocratis librum de fracturis, $X X$.

2) Pythiae, I, 206.

3) De morbis mulierum, Lib. II, Cap. 19.

4) De partibus hominis, Edit. Clinch, pag. 30.

5) Onomasticon, Lib. II, Cap. 4, Seite 143 und 144.

$\left.{ }^{6}\right)$ Auch der Abductor und kurze Flexor der grossen Zehe, wurden als Thenar zusammengefasst. 
erschienene Onomatologia medica, beschränkt Thenar blos auf den kurzen Abzieher des Daumens. Hypothenar nannte Winslow $\left.{ }^{1}\right)$ die den Ballen des kleinen Fingers bildenden Muskeln: Abductor und Adductor digiti minimi, während Riolan nur den letzteren der beiden, als Hypothenar gelten lässt. Parathenar, ein den Griechen unbekanntes Wort, wurde von Winslow an den Abductor und kurzen Beuger der kleinen Zehe verliehen ${ }^{2}$ ), wie das ebenso neue Mesothenar, an den Adductor pollicis und den inneren Kopf des kurzen Beugers des Daumens. Antithenar, ein von Riolan erfundenes Wort, gehört dem äusseren Kopf des kurzen Flexor pollicis. Wer sich für diese längst verklungenen Muskelnamen interessirt, findet im dritten Buch von Albin's Historia musculorum, wo die Synonyme der Muskeln zusammengestellt sind, Befriedigung seiner Neugierde. Auch in Schreger's Anatomischer Synonymik, trifft er hierüber reiches Material auf pag. 170, 171, 172, und 195. In der Jetztzeit werden nur Thenar und Hypothenar, als Daumen- und Kleinfingerballen der Hand, geduldet. Thenar, als Muskelname, musste, schon der Verwirrung wegen, welche durch Hypo-, Meso-, Para-, und Opisthenar heraufbeschworen wurde, verstummen. Die jetzige, vernünftige, weil naturgemässe Nomenclatur der kleinen Handmuskeln, braucht solchen altmodischen gelehrten Aufputz nicht.

\section{Thorax.}

Thorax hat, wie Sternum, mit seiner Aufnahme in die anatomische Sprache, seinen primitiven Begriff eingebüsst. Ө $\omega_{p} \alpha \xi$ ist im Homer immer nur eine Rüstung, welche die Brust und den Bauch bedeckt. Hippocrates und Aristoteles verstehen unter Thorax, Brust und Unterleib zusammen. Sie lassen die Leber im Thorax liegen. Im Plato wird $\theta \omega \omega_{p} \alpha_{\text {G }}$ auf

1) Exposition anat., T. II, Traité des muscles, §. 307 und 511.

2) Op. cit., §. 548 . 
die Brust beschränkt '), und durch Gale n dieser Begriff dauernd in der Anatomie festgestellt. Dass $\theta \omega \dot{p} p \alpha \xi$ von $\theta_{0 p \varepsilon ́(\omega)}=\theta_{p} \omega \sigma \% \omega$, hüpfen, herstammt, lässt sich vermuthen, quia cor in pectore saltat.

\section{Thymus,}

Dieses seit Jahrtausenden der Anatomie angestammte Wort zu erklären, fällt sehr schwer, da dasselbe sich auf kein bekanntes Etymon bei den Alten zurückführen lässt. Man hat sich, leichtfertiger Weise, allerlei Unmögliches über die Abstammung von Thymus eingeredet, ohne je auf die rechte Fährte gekommen zu sein. Wir können nur über die verschiedenen Anwendungen des Wortes in der Medicin Auskunft geben, und abstrahiren gänzlich von dem, was Dichter und Philosophen unter Oupós verstanden haben. 1. Im Hippocratẹs ist Thymus = inanis tussiendi pruritus, in quo nihil excernitur $\left.{ }^{2}\right)$, was in Norddeutschland der Blasehusten, bei den Wienern das Stecken heisst. 2. Ist Thymus eine sehr bekannte, starkriechende Pflanze, Oúp.os, auch Oúp.ov (Thymian, Quendel), aus der Familie der Labiaten, von welcher eine Species: Thymus vulgaris (und Thymus serpillum?) in den medicinischen Arzneischatz aufgenommen wurde, als ein Nervinum, Anticatarrhale, Diureticum, u. s. f. 3. Eine Hautkrankheit, welche von Galen als aspera extuberatio, thymis esculentis similis, circa genitale ac sedem (After) definirt wird ${ }^{3}$ ), sonst aber auch jede schnell aufschiessende, juckende und brennende Hitzblatter. Swediaur ${ }^{4}$ ) machte daraus seine Thymiosis, welche er an die Stelle der

1) Timaeus, LXIX, e.

2) Foësius, Oeconom. Hipp., pag. 275, und Galenus, Commentarius II. in Hipp. Prognosticon, Cap. 3.

3) Definitiones medicae, Num. CDII, schon im Hippocrates enthalten (de aliment, $I V, 10$ ).

4) Novum nosologiae systema, T. II, pag. 179. 
barbarischen Framboësia setzte, und als excrescentiae tuberculosae, fungosae v. durae, fructibus mori v. rubi idaei (französisch framboises) similes, dolentes, ichorem foetidum exsudantes, etc. beschrieb. Thymioma wäre eigentlich zu sagen gewesen, da die Substantiva verbalia in osis und esis, den Act des Machens oder Erzeugens, nicht aber das Gemachte und Erzeugte ausdrücken, was nur Hauptwörter in oma $(\omega \mu \alpha)$ thun. 4. Endlich, die bekannte, aber hinsichtlich ihrer Leistung gänzlich unbekannte Thymusdrüse.

Giebt es zwischen diesen Anwendungen von 0jpos, einen Zusammenhang, welcher im Stande wäre, die Etymologie der Thymusdrüse aufzuhellen? Ich vermuthe ja.

Gehen wir von 0úpos, als Pflanze, aus. Sie deutet auf óv hin $=$ "opfern", und "das Opfer verbrennen". Das Reisig der Thymuspflanze wurde, des Wohlgeruches wegen, welchen es beim Verbrennen ausströmt, bei den Brandopfern verwendet ${ }^{1}$ ). Dass auch die Blüthenquirle und Fruchtbüschel dieser Pflanze zügleich mit dem Reisig verbrannt wurden, um die Würze des Geruches zu steigern, kann angenommen werden. Das körnige Ansehen der Thymusdrüse, hat etwas mit diesen Blüthenköpfchen und Fruchtbüscheln (Capitula s. Corymbi) gemein, und mag der Name der Pflanze, auf die Drüse übergewandert sein, welche beim Zerlegen und Verspeisen der geopferten Thiere (meist junger Kälber, Schafe, und Ziegen), ihres gekörnten Wesens wegen, auffallen musste. Diese Ableitung von Thymus erscheint mir berechtigter, als jene, welche Rufus Ephesius giebt: a thymi folii similitudine, denn die Blätter des Thymuskrautes, sind klein und schmal, die Thymusdrüse breit, zweilappig, und bei den genannten Thieren, nach oben in zwei Hörner verlängert, welche sich bis über die Schilddrüsenlappen hinauf erstrecken. Mit dieser Etymologie von Thymus verträgt sich auch die gleichnamige Hautkrankheit, als höckerige oder warzige, maulbeerähnliche Excrescenz.

1) Philoch. Schol. Sophocles, Oed., Col., 100, in Pape's griechischem Handwörterbuch, T. I, pag. 1112.

Hy rtl. Onomatologia anatomica. 
Es wäre noch ein zweiter Versuch zu wagen, den Namen der anatomischen 'Thymus zu erklären, indem wir auf Oup.ós (nicht Oúp.os) zurückblicken. Oưuós ist nicht blos Seele und $\mathrm{L}$ ebenskraft, sondern auch Gemüth, und dessen verschiedene Erregungen durch Begierden, Leidenschaften und Affecte. Der Sitz dieser Aufregungen war nicht das kalte und feuchte Hirn, sondern das trockene und heisse Herz (Aristoteles). Auf dem Herzen und seinen grossen Gefässen, liegt unsere Drüse auf, und konnte in jener Zeit, wo die primae lineae der anatomischen Sprache entworfen wurden, mit dem im Herzen hausenden tupós, in einen, wenn auch nicht klar eingesehenen Nexus gebracht werden, welcher durch den Namen sich ausspricht ${ }^{1}$ ). Diesem $\theta u \mu o ́ s$, würde dann auch der früher erwähnte Hippocratische Thymus, als ein Erregungszustand, nicht sehr ferne stehen. So hat auch Riolan, das Wort Thymus aufgefasst: corpus glandosum, molle, esu jucundissimum,

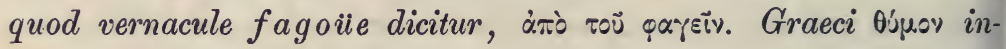
digitarunt, sive quod is locus caedi admodum opportunus sit ${ }^{2}$, sive quod in perturbationibus animi, sanguis et spiritus, ad eum locum, supra glandem illam, tamquam in scatebra (Wassersprudel) ebulliant ac effervescant ${ }^{3}$ ).

Galen schrieb seiner Thymus eine rein mechanische Verwendung $\mathrm{zu}$, wie dem Pancreas. Sie hatte nur die grossen Blutgefässe hinter dem Brustbein und über dem Herzen zu

1) Sehr beachtenswerth erscheint in dieser Hinsicht die $\alpha \delta \dot{\gamma} \nu$ Qupoü, im kritisch-etymologischen Lexicon von Kraus, 3. Aufl., pag. 1050.

2) Oúw heisst nicht blos opfern, sondern auch "morden" und "tödten" überhaupt. Die Opferthiere wurden, nachdem sie durch einen Schlag auf den Kopf mit dem Malleus betäubt waren, vom Cultrarius durch einen Stich oder Schnitt in das Jugulum getödtet. Die Gefährlichkeit, und der schnell tödtliche Erfolg von Stichen und Schnitten in regione furculae sterni, ist bekannt.

3) Anthropographia, Lib. III, Cap. 12, de thymo. 
schützen, und in ihrer Lage zu halten: natura hanc glandulam, maximam simul et mollissimam, partibus retro sternum subjecit, ne os ipsum venam cavam attingeret, simulque omnes ipsius propagines, quae hoc in loco sunt quam plurimae, fultae stabiliventur; id enim naturae est perpetuum, ut, quoties vas sublime dividit, ibi mediam glandulam ( $\mu$ ścov àòśv $\alpha$ ) divisionem ipsam oppleturam interponat ').

Ueber Lactes, als lateinisches Synonym von Thymus, sieh' HI, §. LVIII, Eucharus, und über das Glandium des Plautus giebt der Artikel: Glandula in diesem Buche Näheres. - Das Corpus thymianum der Restauratoren der Anatomie, hat verdienter Weise ausgelebt.

\section{Thyreoidea,}

Unter den anatomischen Gebilden, welche das Epitheton thyreoideus, in allen drei Geschlechtern führen, verdient dasselbe nur ein einziges: die Cartilago thyreoidea. Oupsós kennen wir aus der Odyssee, als eine grosse viereckige Steinplatte, zum Verschluss der Eingangsöffnung einer bewohnten Höhle. Als man Häuser zu bauen lernte, verschloss man die Oeffnung derselben-durch fest zusammengefügte Bretter, als Thür (Ojpa). Die Thüren der Häuser dienten unstreitig anfangs auch als Schilder, um den ganzen Leib des Kriegers zu decken. So erklärt sich die Lautverwandtschaft zwischen ópa, Thür, und Qupsós, Schild. Der grosse viereckige, griechische Schild, wurde schon frühzeitig bei den römischen Legionen, statt des runden und kleineren Clypeus eingeführt, und hiess Scutum. Er bestand aus vernieteten Brettern, mit einem Ueberzug von rohem Leder, welches an der Peripherie des Schildes, mit einem metallenen Rahmen festgehalten wurde. Das Scutum war vier Fuss lang, dritthalb Fuss breit, und im Halbkreis gebogen,

1) De usu partium, Lib. VI, Cap. 4. 
so dass es seinen Mann vortrefflich zu schützen im Stande war $\left.{ }^{1}\right)$. Der viereckige Knorpel des Kehlkopfes erhielt durch Galen, von Oupsós, seinen Namen: thyroeides, lateinisch scutiformis. Alle anderen, von späteren Anatomen, statt scutiformis, angewendeten Synonyme, wie peltalis, parmalis, und clypealis, sind fehlerhaft, weil pelta, parma, und clypeus, runde Schilder waren ${ }^{2}$ ).

Die Glandula thyreoidea, die Arterien, Venen, und Nerven dieser Drüse, die Ligamente und Muskeln, welche am Schildknorpel sich ansetzen, führen sehr ungeschickte Namen. (Vergleiche den Abschnitt ideus, als Ausgang von Muskelnamen). Die Schilddrüse hat eine halbmondförmige Gestalt, mit abgerundeten Spitzen. Sie ist nicht viereckig, sieht keinem Schild gleich, liegt aber neben einem viereckigen und schildähnlichen Knorpel. Apo- oder Parathyreon, allenfalls auch Parathyrium, könnte sie genannt werden, aber nie und nimmer Glandula thyreoidea. Die Gefässe und Nerven der Schilddrüse würden füglich mit Vasa parathyrea und Nervi parathyrei zufrieden sein können, und die Muskeln und Bänder der Cartilago thyreoidea, müssen, aus demselben Grunde, anstatt Ligamenta thyreoidea und Musculi thyreoidei (schildförmig, was sie nicht sind), in Ligamenta und Musculi cartilaginis thyreoideae umgeschrieben werden.

Was über die mit thyreoideus zusammengesetzten Worte soeben bemerkt wurde, gilt auch für die Composita mit hyoideus und arytaenoideus.

Der Name Glandula thyreoidea, rührt nicht von Galen her, wie Cartilago thyreoidea. Die Griechen hatten ein viel zu feines und richtiges Gefühl, um in solche Sprachfehler zu verfallen. Dieses überliessen sie dem ersten Bearbeiter der Drüsen des menschlichen Körpers: Thomas Wharton, welcher in seiner Adenographia, Londini, 1646, Cap. 18, pag. 107, die

1) Livius, I, 43, und VIII, 8. Auch Vegetius, II, 18.

2) Sieh' Das Arabische und Hebräische in der Anatomie, §. LXXI, Haugena, Larynx. 
Schuld auf sich geladen hat, der Erfinder des Namens: Glandula thyreoidea zu sein. Vor Wharton wurde die Schilddrüse, sonderbarer Weise zusammt den Mandeln, als Glandulae laryngi appositae, adstantes, oder adjacentes, zusammengefasist (Vesal, Bauhin, Th. Bartholin). Die Latino-Barbari erdachten sich für die Schilddrüse, das unenträthselbare Botium oder Bocium, worunter aber oft nur der Kropf gemeint ist. Paracelsus belehnte auch andere Tumores, z. B. die Condylome, mit dem Namen Botium '). Ich vermuthe, dass Botium, das latinisirte arabische Bothor (بثَ, batsr, plur. بثر, butsūr) ist, welches im Rases und Avicenna dreifachen Sinn hat: 1. als entzündliche Geschwulst und Abscess, 2. als Geschwulst ohne Entzündung ('Tumor), und 3. als pustulöses oder papulöses Exanthem. Näheres darüber giebt Fallopia ${ }^{2}$ ).

\section{Tibia.}

Eine Pfeife, mit einem Mundstück, welches zwischen die Lippen genommen wurde, und mit Löchern an ihrem Schaft, hiess Tibia (aìós), - das Mundstück: Lingula, Ligula, Glottis. Bevor man sich Pfeifen aus Holz, Horn, Elfenbein, oder Metall, zu bereiten lernte, mussten die Röhrenknochen der Thiere, insbesonders die langen Schienbeine der Haussäugethiere, der Hirsche, und der Stelzfüsservögel (Kraniche, nach Forcellini) zu dieser Verwendung herhalten, wie denn noch in unserer Zeit, die Wilden Neuhollands und Neuguineas, sich ihre Pfeifen, aus solchen Knochen verfertigen, sie aber nicht mit dem Munde, sondern mit der Nase blasen. Rohrpfeifen ohne Seitenlöcher, einzeln, oder mehrere in abnehmender Länge nebeneinander gestellt, wie in der Panspfeife, in welchen der Ton durch schiefes Anblasen (wie bei unseren Flöten) hervor-

1) De natura et cura morbi Gallici, Lib. VIII, Cap. 1.

2) De tumoribus, T. I, Cap. 2. 
gebracht wurde, hiessen Fistulae und Syringes ${ }^{1}$ ). Der Name Tibia ging auf die Schienbeine über, und verblieb ihnen seit Celsus: alterum os cruris, a priori parte positum, longius et in superiori parte plenius, quod solum cum femoris osse committitur, tibia ${ }^{2}$ ) est. Von den Schienbeinen wurde der Name Tibia, auf den ganzen Unterschenkel übertragen, wie z. B. von Plinius, welcher die untere Gliedmasse in femur, Oberschenkel, tibia, Unterschenkel, und talus, Fuss, eintheilt. Die vom Knie bis zum Knöchel reichenden Gamaschen, welche Soldaten und Jäger, als Schutzwehr gegen Waffen und Dornen, und verweichlichte Menschen aus diätetischer Vorsicht trugen, hiessen Tibialia (Pericnemides der Griechen), wie wir aus Suetonius ersehen, welcher den Augustus, zur Winterszeit feminalia und tibialia tragen lässt.

Im Galen begegnen wir dem Schienbein, und zugleich dem ganzen Unterschenkel, als xvripr: pars inter femur et talos, vocatur xvinun, eodemque nomine os grandius cruris appellatur ${ }^{3}$ ). Die scharfe vordere Kante des Schienbeins, nicht das Schienbein

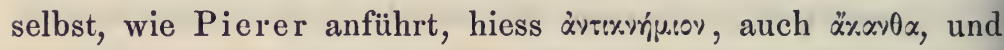
die Beinschienen, mit welchen die Griechen im Kriege ihre

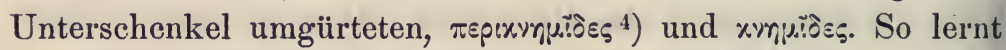

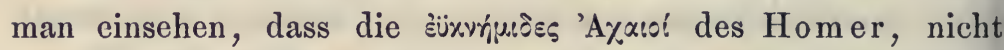
auf die dicken Waden; sondern auf die künstlich gearbeiteten metallenen Beinschienen der Helden vor Troja absehen. Das deutsche Schienbein kann, da dieser Knochen in seiner ganzen Länge, durch die Haut hindurch gefühlt wird, von dem alten deutschen Wort Schin (englisch skin) = Haut (daher

1) Virgilius, Eclogae, II, 36, und Tibulli, Carm. II, 5, 31.

2) De medicina, Lib. VIII, Cap. 1.

3) Oribasius, Op. cit., pag. 165.

4) Pericnemion hat das Schienbein niemals geheissen, obgleich es von Pierer unter diesem Namen angeführt wird. Wie soll auch ein Knochen, welcher im Inneren der Wade («vri $\mu_{i}$ ) liegt, zu einem solchen Namen kommen. IIspi heisst ja herum. 
schinden und Schinder), gebildet worden sein, und wäre dann $=$ Hautbein.

Ueber \%ripn kann noch der Artikel: Gastrocnemius nachgesehen werden. Ueber die arabischen und hebräischen Namen des Schienbeins, welche, wie die mittelalterliche Canna und Arundo cruris major, und Loder's Schienbeinlöhre, auf den langgedehnten Markiaum des Knochens zurückzuführen sind, sieh' HL, §. XXXV, Assetum, und §. LXXXVIII, Rigil.

\section{Tonsillae.}

Die Mandeln - Amygdalae der Arabisten, Spongiae,

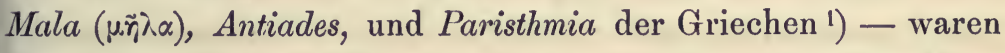
den Römern nur als Tonsillae bekannt. Sie borgten das Wort aus der Schiffersprache, in welcher Tonsa, ein Ruder, und Tonsilla einen Pflock bezeichnet, an welchem die Schiffe festgebunden wurden. Wie dieses Wort auf die Mandeln im Halse, als ausschliessliche Bezeichnung derselben, übertragen werden konnte, weiss kein Sprachkundiger zu erklären. Ci cero, Plinius, unser Celsus, und der Grammatiker Festus, welcher sich auf die sehr alten Zeugnisse des Accius, Pacuvius, und Verrius stützt, sprechen von den Mandeln, als Tonsillae. Dass die Radix des Wortes tondeo, scheeren oder kratzen ist, giebt Festus zu. Sollte nicht in dem kratzenden Gefühl, welches der Bissen, bei entzündeten oder geschwollenen Mandeln, im Halse hervorruft, die Ursache liegen, dass diese Drüsen Tonsillae genannt wurden? Denn mit Bootshacken, Rudern, und Schiffspflöcken, kommt man bei einem Erklärungsversuch nicht aus.

1) Sieh' die Artikel: Amygdalae und Isthmus. 


\section{Torcular Herophili.}

Ein uraltes, und trotz seiner vagen Bedeutung, in der Anatomie aller Zeiten, sorgfältig gehütetes Wort, ist das Torcular Herophili - die Aderpresse. Die zwei Stellen im Galen, welche vom Torcular handeln, sind deutlich genug, dass man nicht zweifeln kann, welcher Sinus der harten Hirnhaut mit diesem auffälligen Namen belegt wurde. Da nicht alle Uebersetzer und Ausleger des Galen, sich hierüber klar geworden sind, wollen wir diese Stellen reproduciren. Sie lauten: scalpellum adigere conaberis adusque verticem, ubi venae duae invicem congrediuntur, quam regionem Herophilus torcular ( $\lambda$ nvós) nominavit ${ }^{1}$ ), und: coeuntes autem in vertice capitis meningis duplicaturae (unsere Processus durae matris) in locum quemdam

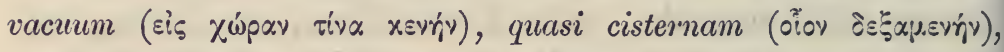

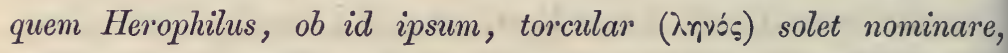
inde velut ab arce quadam, omnibus subjectis partibus rivos mittunt ${ }^{2}$ ). Diese Worte können nicht anders verstanden werden, als dass das Torcular, dem Zusammenfluss des Sinus falciformis, mit den beiden Transversi, und dem Sinus perpendicularis, in der Mitte des hinteren Randes des Hirnzeltes, entspricht. Dieser Zusammenfluss mehrerer Sinuse, wird auch Sinus confluens, richtiger Confluens sinuum genannt. Auf den Sinus perpendicularis allein, wie es von Winslow, Haller und Mayer ${ }^{3}$ ) angenommen wurde, passen diese Worte durchaus nicht, noch weniger auf die Vena magna Galeni, wie sie Rosen$\mathrm{m} \ddot{\text { üller }}{ }^{4}$ ) auslegte. Selbst das allein anstössige: in vertice, verschwindet, wenn man bedenkt, dass Galen nur die Gehirne von Thieren untersuchte, bei welchen diese Vereinigungsstelle

1) Administrationes anat., Lib. IX, Cap. 1, ad finem.

2) De usu partium, Lib. IX, Cap. 6.

3) Beschreibung der Blutgefässe, pag. 204.

4) Compendium anat., pag. 198. 
der Blutleiter, weit mehr gegen die Scheitelgegend des Kopfes gerückt erscheint, als es beim Menschen der Fall ist, denn das kleine Gehirn der Thiere liegt nicht unter, sondern hinter dem grossen, und heisst deshalb bei Galen:, Parencephalis. Beim Menschen müsste es Hypencephalis genannt worden sein. Von der leidigen Sucht der Anatomen, die Organe des menschlichen Körpers mit figürlichen Namen zu schmücken, war schon Herophilus, dreihundert Jahre vor Christus, befallen. Seinem Calamus scriptorius, seinem Dodecadactylon, seiner Prostata, reiht sich auch der inyós an. Um einen Hohlraum in der harten Hirnhaut ausdrücken zu können, standen dem Griechen genug andere Worte zu Gebote. Nein, es musste gerade ein kryós gewählt werden, welcher eine Wanne, einen Trog, eine Kufe, einen Sarg, einen Kelter, einen Backtrog, eine Viehtränke, und nach Hesychius auch einen hohlen Kutschensitz bedeutet, und von Herophilus, nur im Sinne von Behälter, angebracht worden sein konnte. An das Pressen der Trauben im Kelter, konnte Herophilus

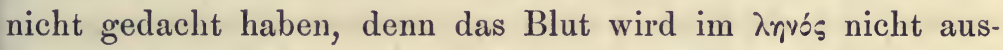
gepresst, sondern nur, wie in einem Behälter (locus vacuus) angesammelt, um von ihm aus, nach Galen's Lehre, der Pia

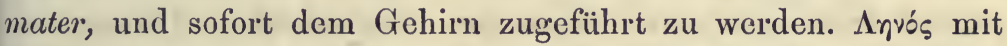
Aderpresse zu übersetzen, statt mit Behälter, ist deshalb ganz absurd. Obstupui, steteruntque comae, als ich auch mit einer Aderschraube zusammenstiess, im Heuermann, weil eine Weinpresse mit Schrauben getrieben wird! was auch im lateinischen Torcular ${ }^{1}$ ) liegt, von torqueo, drehen.

1) Torcular, auch Torculum, hiess nach Varro und Plinius, die Wein- und Oelpresse. Sie presste durch einen gewaltigen, mittelst Zuschrauben erzeugten Druck, allen Saft aus, welcher in den Bälgen und Stielen der Trauben (pes vinaceorum), und in dem Fleisch der Oliven (samsa) zurückblieb, nachdem dieselben durch die vorhergehende Operation des Austretens, ihres flïssigen Inhaltes entledigt waren. Ausführliches über 
Das griechische $\lambda$ ryós wurde von R. Columbus zu Linon entstellt. Das im Pierer, aus dem Galen angeführte $\lambda r_{i} / \gamma_{\gamma} v \varepsilon เ{ }^{\prime} \%$, kennt weder Galen, noch ein anderer griechischer Anatom. Pierer's anatomische Mitarbeiter waren durch die Bank, keine sprachkundigen Griechen. Sie liessen alle Accente weg, selbst jene, welche Buchstaben vertreten. Wahrscheinlich ist

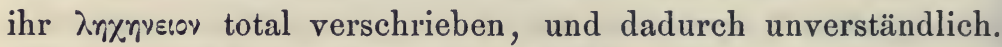

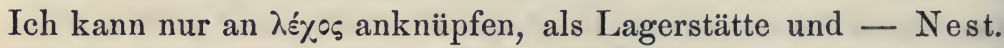

Das Torcular war, nach den Ansichten der alten Aerzte, ein viel bedeutsamerer Sinus, als alle anderen, welche deshalb auch keine besonderen Namen erhielten. Das Torcular, als ein median gelegener, und unpaarer Sinus, hatte das Blut aufzunehmen, welches die beiden Venae jugulares internae in den Schädel brachten, wo es durch die beiden Sinus transversi in das Torcular, als Hauptdepot, geschafft, und von ihm aus, durch die übrigen Sinus; und die aus ihnen hervorgehenden Venen, dem Gehirn und seinen Häuten überantwortet wurde. So lautet die Galenische Lehre. Was wir Sinus durae matris nennen, kannte Galen nur als Rivi oder Ductus sanguinis

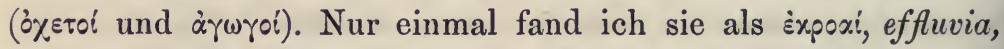
angeführt. Die Latino-Barbari übersetzten diese Worte mit Plateae (Strassen), und dem ganz barbarischen Palmentum, worunter Pavimentum (als gepflasterte Strasse) steckt.

\section{Trabs cerebri.}

Sieh' den Artikel: Corpus callosum.

die Construction der Torcularia, mit Abbildungen, in Anthon y Rich, Römische Alterthümer, pag. 636 bis 640 . 


\section{Trachea}

Die Anatomen fragen, ob sie Trachēa oder Trachĕa zu sagen haben. Die Philologen antworten: keines von beiden, sondern Trachīa. Die letzteren sind beim Recht, aus folgendem Grunde. Arteria hiess bei den Griechen ursprünglich nur die

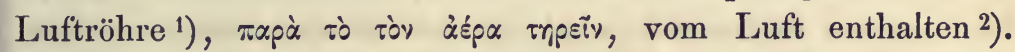
Arzneimittel gegen die Krankheiten der Luftröhre, wurden noch in später Zeit Arteriaca genannt ${ }^{3}$ ). Als Aristoteles den Blutgefässen, welche wir Schlagadern nennen, auch den Namen Arteriae gab, weil sie nach damaligen Ansichten kein Blut, sondern einen luftigen Geist enthalten, mussten, um keine Verwechslung zuzulassen, beide Arten von Arteria, durch ein Adjectivum distinctivum von einander unterschieden werden. Man nannte die Schlagader, ihrer glatten Oberfläche wegen, àprnpia $\left.\lambda \varepsilon i \alpha^{4}\right)$ (die glatte), die Luftröhre aber, ihres durch die Knorpel bedungenen quergeringelten, also unebenen Ansehens

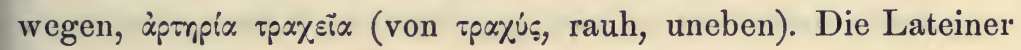
iibersetzten dieses mit Aspera arteria, ein jetzt noch vielseitig gebrauchter Ausdruck, die trachée artère der Franzosen, und die traquiarteria der Spanier. Der Kürze wegen liess man das

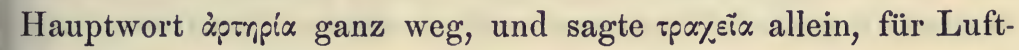
röhre. Nimmt die lateinische Sprache, die griechische $\tau \rho \alpha \gamma \varepsilon i \alpha$. an, so darf sie dieselbe nur als Trachia, nicht als Trachea zulassen, welche vom Schlendrian eingeführt wurde. Das $i$ in Trachia, ist der Diphthong st, muss also lang betont werden.

1) Galenus, de Hipp. et Plat. decretis, Lib. VI, Cap. 8.

2) Die Etymologen lassen deshalb auch Aeroteria (àspotnpía), statt Arteria vernehmen.

3) C. Celsus lehrt uns die Zusammensetzung einer Arteriace, in De medicina, Lib. V, Cap. 25. Sieh' auch C. Hoffmann, Institutiones med., Lib. II, Cap. 13, §. 2.

4) Galenus, de usu partium, Lib. VII, Cap. 8 und 9. 
Darum bieten uns auch die besten Lexica nur Trachīa, niemals Trachea, und berufen sich, ganz überflüssiger Weise, auf Macrobius ${ }^{1}$ ). Alle anderen römischen Autoren, bedienen sich ausschliesslich des Ausdruckes Aspera arteria, welchen Cicero ${ }^{2}$ ) und Celsus ${ }^{3}$ ) gebrauchten.

Von den vielen Synonymen der Luftröhre, welche in Schreger's anatomischer Synonymik, und in Pierer's und Choulant's anatomisch-physiologischem Realwörterbuch nachgesehen werden können, will ich nur die Uebersetzungen der arabischen Worte Mazamar und Zumara, als Canna und Fistula aeris s. pulmonis, anführen, welche bei den Arabisten immer die Trachea vertreten. Aus diesen beiden Worten leitèt die deutsche Luftröhre ihre Entstehung her. Die Uebersetzung der griechischen oder der lateinischen Arteria aspera, hätte das rauhe Luftenthaltende lauten müssen. In del Volkssprache der Wiener, hört man vom "unrechten Schlund" für Luftröhre, besonders wenn Speisentheile auf diesen Abweg gerathen.

Noch haben wir eines altgriechischen Namens der Luftröhre zu gedenken: Bpóryos $\left.{ }^{4}\right)$. Sein Andenken hat sich bis heute erhalten, da der Luftröhrenschnitt Bronchotomia hẹisst,

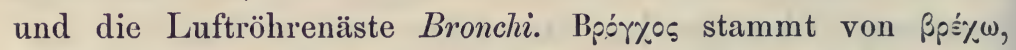
befeuchten, im Athenaeus auch trinken. Plato liess noch die Getränke nicht in den Oesophagus, sondern in die Luftröhre gelangen, welche von ihnen befeuchtet wird. Langes und Breites hierüber bietet uns Macrobius ${ }^{5}$ ). Die Luftröhren-

1) Saturnalia, Lib. VII, Cap. 15.

2) De natura Deorum, II, 54: Aspera arteria (sic medici vocant) ostium habet adjunctum linguae radicibus.

3) De medicina, Lib. IV, Cap. 1.

4) Rufus Ephesius, Onomasticon, Edit. Clinch, pag. 37, 50, 57.

5) Das fünfzehnte Capitel des siebenten Buches der Saturnalia, führt die Aufschrift: An recte a Platone scriptum sit, cibum per

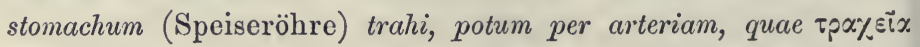
dicitur. 
äste hiessen bei den römischen Aerzten Celsus und Aurelianus niemals Bronchi, sondern Bronchia, -orum. Die schon ihrer Knorpelfassung verlustig gewordenen Aestchen der Bronchia, führen durch E. Schultz'), den passenden Namen:

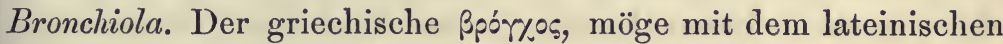
Bronchus nicht für identisch gehalten werden. Der lateinische Bronchus, als variante Schreibart für Brocchus, bezieht sich auf vorstehende Zähne, wie sie Bullenbeisser haben. Zuweilen stehen auch bei Menschen die oberen Schneidezähne so weit hervor, dass sie von den Lippen nicht mehr bedeckt werden. Thiere und Menschen mit solchen Zähnen, heissen im Varro und Lucilius: Brocchi s. Bronchi. Ein römisches Geschlecht erhielt von dieser Eigenschaft den Namen Brocchus (Titus und Lucius Furius Brocchus). Ob Bronchus mit Branchus (Heiserkeit), in Verbindung gebracht werden kann, will ich weder behaupten noch verneinen. Die Verwandtschaft beider kann sich nur auf die Lautähnlichkeit stützen, und auf den Sitz der Heiserkeit im Bronchus. Branchus vox rauca est, gravis, et dissonans, heisst es in den Lexicis. Ein alter Gedächtnissvers in St. Blancardi Lex. medicum ${ }^{2}$ ) lautet:

"Si fluat ad pectus, dicatur rheuma catarrhus, "Ad fauces branchus, ad nares esto coryza."

\section{Tractus,}

Diese rara avis in terris anatomicis, lässt sich nur zweimal blicken, als Tractus digestorius, Darmkanal, und als Tractus foraminulentus, auf dem Grunde des inneren Gehörganges. In der ersten Anwendung bedeutet Tractus den Zug, den Verlauf des Darmkanals, wähirend Canalis und Tubus digestorius,

1) De structura canalium aeriferorum, Dorpat, 1850.

2) T. I, pag. 316 . 
sowie das veraltete primae viae nutrimenti, den Darm als Schlauch auffassen. In der zweiten Anwendung steht Tractus nicht für Zug, sondern für Gegend, wie im Virgil'schen coeli tractus, Himmelsgegend, und Tractus Laurens im Livius, die Gegend zwischen Lavinium und Ostia. Das foraminulentus jedoch, ist ein Monstrum ingens et informe! Wenn dieser spirale Tractus am Grunde des inneren Gehörgangs, mit vielen Löchern durchbohrt erscheint, welche in den Modiolus der Schnecke führen, so war er nicht anders als foraminosus oder foraminatus zu nennen, beide Worte Spätlatein. Perforatus wäre noch schicklicher. Foraminulentus hat noch kein Schriftsteller gebraucht, ausser Rosenmüller ${ }^{1}$ ), welcher es erfand. Wie die Anatomie von jeher bereit war, alle ungereimten und unmöglichen Worte sich anzueignen, so auch den Tractus spiralis foraminulentus, welcher nichts Gutes an sich hat, als seine Verständlichkeit.

\section{Tragus und Antitragus.}

Rufus Ephesius versichert uns, dass die Griechen, zur Zeit des Aristoteles, für die verschiedenen Erhabenheiten und Vertiefungen des äusseren Ohres, noch keine bestimmten Namen hatten. Nur die ganze Ohrmuschel, wenn ich den Ausdruck tò Ėxpspuśs, das Schwebende, Hängende, als Ohr-

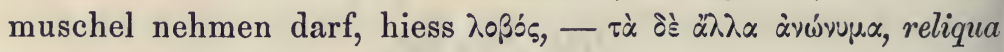

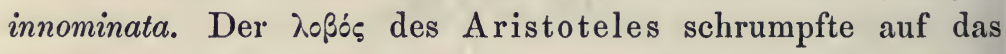
Ohrläppchen, Lobulus auriculae, zusammen, seit die einzelnen Formbestandtheile der Ohrmuschel zu besonderen Namen gekommen sind, deren Verzeichniss Julius Pollux ${ }^{2}$ ) uns hinterliess. Hier finden wir den Tpáros als pars, quae sub termino temporum, ad interiora assurgit, und den 'Avtitpayos als sein

1) Compendium anatomicum, 29.

2) Onomasticon, Lib. II, Cap. 4, Sect. 81, de auribus, et quae aurium sunt. 
vis-à-vis. Ganz auf gleiche Weise werden auch die beiden Erhabenheiten im $\mathrm{Rufus}$ Ephesius definirt, als conchae, prope temporis finem elatio, et huicce opposita. Die Anatomen glaubten, den трáyos nur als tragus schreiben zu sollen, um dasselbe $\mathrm{zu}$ sagen. Und wirklich finden wir Tragus. und Antitragus, Bock und Gegenbock, in allen Anatomien! Dagegen muss ich bemerken, dass die Römer Tragus und Tragum nie als Bock

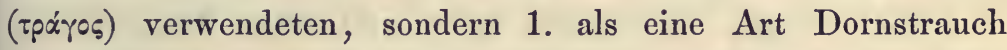
(vepres), über welche Plinius viel $\mathrm{zu}$ sagen weiss ${ }^{1}$ ); 2. als eine schlechte Sorte des Badeschwamms, nach Plinius und Dioscorides; 3. als eine Art eines nicht näher zu bestimmenden Seefisches: rapidique lupi (marini), percaeque, tragique, im Ovid; 4. als scharfer Geruch des Achselhöhlenschweisses, wie in: inde tragus celeresque pili, mirandaque matris barba, im Martial; und 5. als eine Gattung griesähnlicher Mehlspeise (cibus frumentaceus), aus Zea oder Olyra (wahrscheinlich 'Triticum monococcum Linn.), welche von Celsus: inter cibos boni succi (euchymos) gezählt wird ${ }^{2}$ ). Als Bock (Capra hircus Linn.), lässt sich Tragus nirgends sehen, wohl aber die lateinische Uebersetzung von tpáros, als Hircus. Es soll hiemit den Anatomen das Recht nicht bestritten werden, den Bock des Ohres, Tragus, zu nennen. Nur anschaulich machen wollte ich es, dass Hircus besser wäre. Warum aber тpáyos, tragus, und hircus, alle drei als Böcke, an eine vorspringende Ecke des Ohrknorpels geknüpft wurden, mag sich daraus erklären, dass, wie es in St. Blancardi Lex. medicum, Edit. Kühnii, T. II, pag. 1486, heisst: haec auris eminentia, pilis aliquot hispida, in quibusdam vero densam hirci barbulam exprimit. Ist nun Tragus, als Bock des Ohres, nicht viel werth, so ist es der Musculus tragicus des Valsalva noch weniger, welcher den Bock nach vorn bewegen, und dadurch den Eingang des Porus

1) Hist. nat., Lib. XIII, Cap. 21, Sect. 37, und Lib. XXVII, Cap. 13, Sect. 116.

2) De medicina, Lib. II, Cap. 20. 
acusticus erweitern soll. Tragicus war nie etwas anderes, als tragisch (tragicus poëta, tragica ar's, tragicus cothornus, tragicum carmen), - einen tragischen Muskel zu besitzen, kann sich nur das $\mathrm{Ohr}$ rühmen. Soll er verbessert werden, kann es durch Musculus hirci geschehen. Einige gute Lateiner unter den Anatomen, wie Bartholinus und Kulmus, haben immer statt Tragus, das richtige Hircus gesetzt.

Bei einigen tauchenden oder grabenden Säugethieren, z. B. Ornithorrhynchus und Sorex, kann der äussere Gehörgang durch den Bock oder Gegenbock, wie durch eine Klappe verschlossen werden. Professor Bock hat deshalb den Bock: Ohrklappe genannt ${ }^{1}$ ). Ecke und Gegenecke (Meckel) sind den Böcken vorzuziehen. Die Franzosen haben ihre boutons (Knöpfe) dafür.

\section{Trapezius.}

Der erste Muskel unter der Haut des Rückens wurde von Vesalius: Secundus scapulam moventium genannt; - der primus war unser Serratus anticus major. Realdus Columbus gab ihm den Namen Cucullaris: nam is, cum suo pari simul consideratus, monachorum cucullae percommode comparari potest, aut panno, quem viduae nostrae Cremonenses, super humeros gestant $\left.{ }^{2}\right)$. J. Riolanus führte für ihn die uncorrecte Benennung Trapesius ein ${ }^{3}$ ), vielleicht zum Andenken an das Trapezion, mit welchem Galenus die obere, ihm allein bekannte Parthie dieses Muskels vergleicht $\left.{ }^{4}\right)$. Cowper corrigirte

1) Handbuch der praktischen Anatomie, Bd. I, Seite 111.

2) De re anatomica, Lib. V, Cap. 15.

3) Anthropographia, Lib. V, Cap. 22.

4) Die vicr Seiten des Trapezion, waren der kurze Occipitalursprung des Muskels, die Spina scapulae, der Ursprung an der Wirbelsäule, und der äussere freic Rand des Muskels. Was von diesem Muskel unterhalb der Spina scapulae liegt, scheint Galen gar nicht gekannt zu haben. 
Trapesius zu Trapezius ${ }^{1}$ ), welcher Name, neben Cucullaris, jetzt noch allgemein cursirt.

Würde der Muskel mit einer Spitze am Hinterhaupt entspringen, so hätte er drei ungleiche Ränder, und würde, wenn man den Muskel der anderen Seite, mit ihm zusammengewachsen denkt, aus beiden ungleichseitigen Dreiecken, ein ungleichseitiges Viereck, ein Trapezion, entstehen. Da aber unser Muskel, nicht mit einer Spitze, sondern in einer längeren Linie, am Occiput seinen Ursprung nimmt, so hat er schon für sich allein vier Ränder, welche unter einander sehr ungleich sind, und ein Trapez, im Sinne des Aristoteles bilden, so dass der Name Trapezius, nicht blos auf die beiden zusammengerückten Muskeln, sondern auf jeden einzelnen passt, während Cucullaris nur der Summe des rechten und linken Trapezius entspricht. Im Julius Pollux erscheint die breite Fläche des Rückens, als тр $\alpha \pi \varepsilon \zeta \alpha$ :

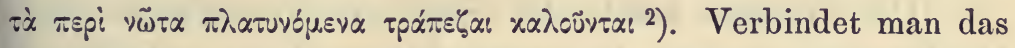
Hinterhaupt, die beiden Schulterhöhen, und die Lende, dur'ch vier Linien, so umschreiben diese in der That den Contour eines Vierecks, mit zwei oberen kurzen, und zwei unteren langen Rändern, dessen Diagonale der Wirbelsäule entspricht. Dieses Viereck ist aber kein verschobenes, sondern ein symmetrisches. Albucasis und seine Nachfolger nannten diese Fläche Almeidah, welches die Uebersetzer als Tabula s. Mensa interpretirten, weil auch ein Tisch eine breite Fläche hat. Hieraus entstand der Name Musculus mensalis für Trapezius, welcher in der lateinischen Uebersetzung von Winslow's Exposition anatomique, und deutsch, als Tischmuskel, in Schaarschmidt's anatomischen Tabellen (Tab. 15) enthalten ist. Nicht des verschobenen Vierecks, sondern der breiten Fläche wegen, kann der Musculus Trapezius diesen Namen behalten, da auch die breiten Kronen der Mahlzähne, welche doch keine verschobenen Vierecke sind, im Rufus Ephesius

1) Myotomia reformata, Lond., 1694, Cap. 20.

2) Onomasticon, Lib. II, 177.

Hy rl. Onomatologia anatomica. 
$\tau \rho \alpha^{\prime} \pi \varepsilon \zeta_{\alpha}{ }^{1}$ ) heissen (mensae und mensales bei den Uebersetzern ${ }^{2}$ ), wie auch die flache Hand, als breitester Theil der oberen Gliedmasse, bei den Chiromanten als Trapeza s. Mensa auftritt, und deshalb die Handlinie, welche die Basen der drei letzten Finger umgreift, jetzt noch in der Anatomie die T'ischlinie, Linea mensalis heisst.

Aus dem Gesagten ergiebt sich, dass der Name Trapezius nur auf Einen, der Name Cucullaris aber nur auf beide Muskeln zusammengenommen passt. Trapezius wäre übrigens dringend in das richtige Trapezoides umzuwandeln.

\section{Triangulus, trigōnus, und triquetrus.}

Die Anatomie macht sich öfter mit Triangulus zu thun. Das Dreieck heisst bei den besten Autoren (Cicero, Plinius), immer nur Triangulum. Triangulus dagegen ist im classischen Latein, ein Adjectiv = dreieckig, welches nur einmal, im Martial, durch triangularis ersetzt wird, während die Anatomie über eine erkleckliche Anzahl von triangulären Muskeln und Bändern verfügt. Statt des Adjectivs triangulus, kann trigōnus oder triquetrus gebraucht werden, jedoch nimmermehr triqueter, weil dieses nicht existirt. Von Trigōnus, als Adjectiv, haben wir eine Anwendung im Corpus trigonum Lieutaudii der Harnblase, und von triquetrus, in dem Ossiculum triquetrum Wormii (Fontanellknochen am Hinterhaupt). Trigōnum als Hauptwort zu verwenden, wie im Trigonum colli sup. et inf., und in Bergmann's Trigonum molle s. pensile $=$ Commissura posterior, und

1) De partibus corp. hum., Edit. Clinch, pag. 49: latae molarium dentium summitates mensae ( $\left.\tau \rho \alpha \dot{\pi} \pi \zeta \alpha_{\ell}\right)$ vocantur.

2) Also sicher nicht deshalb, quia super illas, veluti supra mensam collocantur cibi, wie die naive Erklärung des Fallopia lautet (De ossibus, Cap. 16).

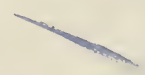


desselben Autors Trigonum durum zwischen den beiden vorderen Erhabenheiten des Corpus quadrigeminum, wird insofern gestattet, als das griechische tpíyvov = Dreieck ist, und im Varro ein Trigonum, als Dreieck, wirklich existirt. Andere schrieben aber nur Trigonium. Trigon, trigonis, hiess bei den Römern, ein dreieckiges Local, in welchem sich drei Personen mit dem Ballspiel unterhielten:

„Seu lentum ceroma teris, tepidumve trigona."

(Martial, Epigr., Lib. IV, 19.)

Die Nahtknochen der Hirnschale, mit Blumenbach Ossicula triquetra s. triangularia zu nennen, ist allgemeiner Brauch geworden. Man möge ihn bald aufgeben, denn nur ein einziger Schaltknochen, und zwar jener, welcher die Stelle der einstmaligen Hinterhauptsfontanelle einnimmt, ist dreieckig. Die Gestalt der übrigen ist entweder rundlich, oder oblong, oder polygonal, oder rhombisch, oder rectangulär (wie die grossen Schaltknochen in der Lambdanaht). Sie Ossicula Wormii zu nennen, ist ebenfalls unrichtig, da diese Knochen lange vor Olaus Worm schon bekannt waren, und von Guintherus Andernacensis (Winther von Andernach), Professor in Paris und königlichem Leibarzt, in seinen Institutiones anat., Basil, 1536, erwähnt werden. Riolan nennt diese Knochen deshalb: Ossicula Andernaci. Die Benennung Ossicula intercalaria oder epactalia (Schaltknochen, von غ̇ंaxtéৎ, hinzugefügt), lässt sich nicht auf alle diese Knochen anwenden,.da mehrere derselben nicht als Einschübe, sondern als Zerfallen eines regulären Schädelknochen aufzufassen sind. Ein in neuerer Zeit durch C. G. Jung aufgestellter Name: Ossicula raphogeminantia ${ }^{1}$ ) (richtiger rhaphogeminantia), Nahtdoppler, würde allen anderen vorzuziehen sein, wenn er nicht eine vox hybrida

1) Animadversiones de ossibus, Basil, 1827. 
wäre. Die deutschen Ausdrücke Nahtknochen und Schaltknochen sind gut - Zwickelbeine aber nur auf die dreieckige Form anwendbar.

\section{Tricuspidalis,}

Die Valvulae tricuspidales am Orificium venosum der rechten Herzkammer, gehören zu den radicalsten Barbarismen. Denn 1. geht der lateinischen Sprache, ein Adjectiv tricuspidalis vollständig ab, indem sie für etwas dreispitziges, wie der Dreizack des Neptun, nur das Beiwort tricuspis kennt, und 2. haben die drei sogenannten dreispitzigen Klappen nur zusammen drei Spitzen, da jede einzelne nur Eine Spitze besitzt. Jede dieser Klappen bildet ein Dreieck, dessen freie Spitze nach abwärts sieht, während die Basis desselben, und also auch die Basalwinkel- oder Spitzen, mit dem Rande des Orificium venosum verwachsen sind, und nicht als Spitzen hervorstehen. Die Griechen

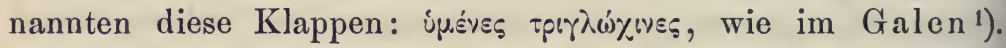

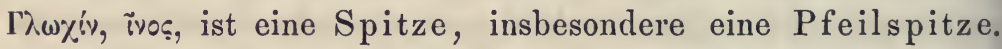
Sie kann, weil sie drei Zacken hat, von welchen nur die eine stechend verwundet, die beiden anderen als Widerhacken die

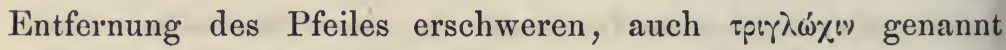
werden, wie im $\mathrm{Homer}^{2}$ ). Es war jedoch nicht gut, jede ein-

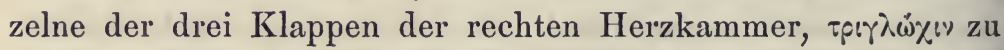
nennen; wohl aber können alle drei zusammen, so genannt werden, weil sie zusammen nur drei freie Spitzen haben. Man soll also an dem genannten Ostium der rechten Herzkammer, nur Eine Valvula tricuspis, nicht aber drei Valvulae tricuspidales existiren lassen, welche neun Spitzen geben. Dass die Valvulae tricuspidales nicht auf drei separirte Klappen, sondern nur auf Eine bezogen werden müssen, welche drei Zacken hat, beweist

1) De administrationibus anat., Lib. VII, Cap. 9.

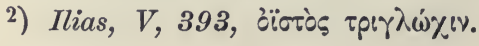


die neuere Auffassung dieser Klappen, als einfacher Annulus valvulosus, welcher von seinem freien Rande, durch drei Winkelausschnitte, in drei Zacken zerfällt, und deshalb als dreizackige und dreizipfelige Klappe im Sömmering aufgeführt wird. Wenn die Uebersetzer des Galen und Ori-

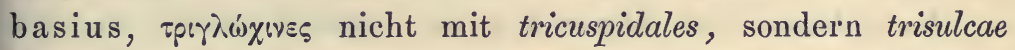
geben, so thun sie ganz recht daran, denn trisulcus steht gleich dem trifidus, triquetrus, tridens, und tricuspis. Im Virgil finden wir eine lingua trisulca, dreispitzige Schlangenzunge, im Varro: fores trisulcae, dreitheilige Thür, und im Claudian, die Sicilia trisulca $=$ Trinacria (پ̈火pos, spitzig), a tribus promontoriis ita vocata. Der gelehrte Grammatiker Nonius Marcellus, sagt es ausdrücklich, dass sulcus, nicht blos die durch die Pflugschaar aufgewühlte Furche, sondern auch ein scharfer, spitziger Gegenstand ist: omne, quod in longitudine aculeatum est, veterum auctoritate doctornm, sulcus dici potest ${ }^{1}$ ).

Bei den Vätern der Anatomie im Beginn des 14. Jahrhunderts, führten die Zipfe der Valvula tricuspis, den Namen Hostiola (Mundinus), und Ostiola (Berengarius²). Den stabilen Namen Valvula, erhielten die Klappen des Herzens erst zu Ende des 15. Jahrhunderts, durch Alexander Benedictus. In der Stelle, welche von dem Specus cordis dexter (rechte Kammer) handelt, heisst es: in orificio venae magnae (unser Ostium venosum ventriculi dextri), ternae valvulae, de industria a natura positae sunt, quasi claustra quaedam mobilia ${ }^{3}$ ). Vesalius spricht von den Klappen des Herzens immer nur als Membranulae ${ }^{4}$ ), wie schon vor ihm, Berengarius sie als Pelliculae, Andere als Panniculi aufführen, - lauter verschiedene Versionen der Galenischen ipuéves.

1) De proprietate sermonis inter auctores, VI, 2.

2) Sieh' den Artikel: Valvulae.

3) Anatomice, Lib. III, Cap. 14.

4) Op. cit. Lib. VI, Cap. 13, de undecim membranulis quatuor orificiorum cordis. 


\section{Trigeminus und Trifacialis.}

Unter allen Hirnnerven, wurde das fünfte Paar am reichlichsten mit Synonymen versehen. Eines derselben, welches zur Hauptbenennung dieses Nerven erhoben wurde, stammt von Winslow her. Der französische Text der Exposition anatomique, edit. 1732, T. III, N. 28, weist für das fünfte Nervenpaar, den Namen trijumeau auf. Die lateinischen Uebersetzungen dieses Werkes '), enthalten für trijumeau ganz richtig: Nervus trigeminus (trigemini, poet. tergemini, Drillinge), während früher schon Hebenstreit ${ }^{2}$ ), das nicht weiter beachtete, ganz verfehlte trimellus erfand, welches nicht einmal als Diminutiv von trimulus zulässlich wäre, da trimulus und trimus dreijährig heisst. Von dem Nervus divisus des Rosenmüller, dem Nervus mixtus des Gall, dem Nervus sympatheticus s. sympathicus medius des Wrisberg, dem Nervus consensorius des Andersch, dem Nervus anonymus des E. König, dem Par gustatorium des Heister, und dem Par balneare von Mayer ${ }^{3}$ ), spricht kein Mensch mehr; - nur der Trigeminus (dreigetheilter Hirnnerv), und brevitatis causa, auch Quintus, herrschen jetzt allein. Wozu hat also Chaussier es nöthig gehabt, seinen Trifacial der Anatomie aufzubürden. Hat der Nerv drei Gesichter? - Ein lateinisches Adjectiv facialis, sucht man in

1) Argentorati, 1753, und Venetiis, 1758.

2) De basi calvariae, Lips., 1738, pag. 11.

$\left.{ }^{3}\right)$ Diese auffällige und sonderbare Benennung des fünften Nervenpaares, hat sich in L. A. Mayer's Beschreibung des menschlichen Körpers verirrt (Bd. VII, pag. 71). Sie basirt auf einem anatomischen Irrthum. Der noch ungetheilte Stamm des Quintus, wird zwar von einer, zwischen den Blättern der harten Hirnhaut befindlichen Höhle aufgenommen (Cavum Meckelii), aber in der Höhle des Sinus cavernosus liegt er nicht, so dass er vom Blute desselben gebadet werden könnte, wie die Carotis interna. 
den Wörterbüchern vergeblich. Würde es eines geben, so könnte es nur zum Gesicht gehörig bedeuten, wie ähnliche Worte in alis, z. B. dorsalis, ventralis, abdominalis, immer eine Zugehörigkeit ausdrücken. Aber das tri dem facialis vorgesetzt, taugt gar nichts, da, wenn der Nerv einmal zum Gesicht gehört, er nicht dreimal dorthin zu gehören braucht.

\section{Trochanter, Trochiter, und Trochantin.}

Niemanden kann es verwehrt werden, einem neuen, von ihm entdeckten oder erfundenen Ding, auch einen neuen Namen zu geben. Nur wünscht man, dass, wenn der neue Name aus dem Griechischen geholt wird, er auch den Regeln der Wortbildung in dieser Sprache nicht zuwiderlaufe. Alte, längstbekannte Dinge, mit neuen Namen auszustatten, kann nur dann erlaubt sein, wenn die alte Benennung schlecht ist, wie so oft in der Anatomie, und ein neuer, richtiger und bezeichnender Name gewünscht wird. Für die Trochanteren des Oberschenkels sind die alten Namen Trochanter major und minor vollkommen entsprechend. Jedermann weiss, was diese Ausdrücke zu sagen haben. Sie sind, als Dictiones Galenicae ${ }^{1}$ ) so gut, dass sie selbst auf die homonymen Tubercula des Oberarmbeins übertragen wurden, welche; wie die Trochanteren des Schenkelbeins,

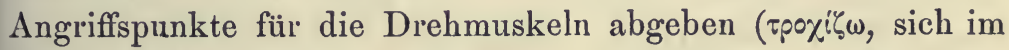
Kreise drehen), und deshalb von den Deutschen, seit Mayer ${ }^{2}$ ), Rollhügel genannt werden. Nicht das Gebot der Nothwendigkeit, sondern die Sucht des Namengebens, welche Herrn Chaussier keine Ruhe liess, dichtete Trochiter für den grossen, und das noch schlimmere Trochantin für den kleinen Trochanter, von welchen beiden Worten, nur die erste Silbe, einen

1) Administrationes anat., Lib. III, Cap. 10.

2) Beschreibung des menschlichen Körpers, Bd. II, Seite 316. 
schwachen Wiederhall von dem Galenischen тpo\% nehmen lässt.

Sonderbarer Weise wurden gerade den Trochanteren, zu verschiedenen Zeiten verschiedene neue Namen angedichtet. Sie beziehen sich meistens nur auf den grossen; - der kleine wurde durch lange Zeit keines besonderen Namens werth gehalten, weil er, unter Muskeln verborgen, am lebenden Menschen, weder gesehen noch gefühlt werden kann, wie der grosse. Der älteste und ehrwürdigste, dessen sich schon Hippocrates bediente, ist rioutós ${ }^{1}$ ). Dieser wurde von Vesal mit Natis (Hinterbacke) übersetzt, wohl nur in dem Gedanken, dass die grössten, am grossen Trochanter angreifenden Muskeln, vom Gesäss (nates) herkommen, wie denn auch riouvós, vom Trochanter auf das Gesäss übersiedelte, und dort allein verblieb. Hippocrates nennt auch den Gelenkskopf des

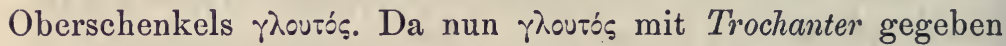
wird, erklärt es sich, wieso Bartholinus dem Oberschenkel drei Trochanteres zuschreiben konnte, deren einer offenbar das Caput femoris ist. Der Cotyledon des Julius Pollux, blieb der Sprache der Osteologie für immer fremd, da das Wort schon an $\mathrm{zu}$ viel andere Dinge verliehen war, insbesondere an alle napfförmigen Vertiefungen, als Pfanne des Hüftbeins, Uterinaldrüsen der Wiederkäuer, Saugnäpfe der Tintenfische, u. v. a. Hierauf erschien Tharuca und Carchametra in den Randnoten des lateinischen Canon Avicennae von Gerardus Cremonensis 2). Paracelsus verunstaltete Carchametra $\mathrm{zu}$ Trachametra, womit die Trias dreier gänzlich unerklärbarer Benennungen der Trochanteren abschliesst. Ich kann über die Genealogie dieser räthselhaften Worte nicht einmal eine Vermuthung hegen. Sie sind nicht arabisch, nicht griechisch, nicht lateinisch, nicht romanisch, und können nur für Curiositäten sinnloser Wortbildung gehalten werden. Dann kam das Malum granatum der

1) Galenus, de ossibus, Cap. 21.

2) Lib. I, Fen 1, Doctr. 5, Summa 2, Cap. 27. 
Arabisten, mit dem Zusatz testiculorum, worüber in $\S . C$ meiner Schrift: Das Arabische und Hebräische in der Anatomie, das Nähere gesagt wird.

Vesal, welcher die griechischen Worte aus der anatomischen Terminologie gänzlich auszumerzen, unablässlich und mit bestem Erfolg bemüht war, übersetzt Trochanter mit Rotator. Es ist das erste und zugleich das letzte Mal, dass ich den grossen Reformator unserer Wissenschaft, und den besten Lateiner des 16. Jahrhunderts, auf einem Irrthum ertappe. Rotator ist ein Umdreher. Der Trochanter dreht nicht um, sondern er wird umgedreht, oder vielmehr im Kreisbogen bewegt. Er ist somit kein Rotator, sondern ein ens rotandum. Noch schlimmer ging es dem Rolfink mit seinen Cursores ${ }^{1}$ ).

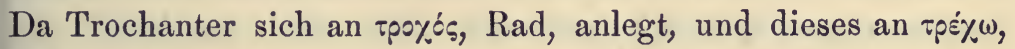
laufen, glaubte der ehrliche Jenenser Professor, Trochanter mit Cursor übersetzen zu sollen, welcher Ausdruck selbst zu Lebszeiten Rolfink's nicht Stand halten konnte, sondern seinem Herrn entlaufen ist, so dass dieser nolens volens wieder zum alten Trochanter zu greifen für gut fand. Ebenso ging es den Apophyses cursoriae des Gorraeus. Da nun alle neueren Namen der Rollhügel nicht brauchbarer oder bequemer sind als Trochanter, wollen wir auch treu bei dem letzteren aushalten.

\section{Trochlea, Musculus und Nervus trochlearis.}

Zur allbekannten und uralten Trochlea des Oberarmbeins, sind in der neueren Anatomie, durch Loder und Walter, noch die Trochleae der Finger- und Zehenglieder, und die Trochlea des oberen schiefen Augenmuskels (Trochlearis) hinzugekommen. Zwei Gelenkshöcker mit Zwischenincisur, alles zusammen mit einem continuirlichen Knorpelüberzug, heissen

1) Dissertationes anat., Lib. II, Cap. 49. 
Trochlea, Rolle. Trochlea ist kein griechisches, wohl aber ein gut lateinisches Wort. Die Griechen drückten eine Rolle, durch $\tau p \circ \% \alpha \lambda i x$ und $\tau p \circ \%$ ! $\lambda i \alpha$ aus, welchen die lateinische Trochlea nachgebildet wurde. Die griechische Wurzel ist $\tau \rho \varepsilon \xi \omega$, laufen, woher $\tau p \circ \%$ s, Rad. Trochalia, Trochilia, und die Trochlea der römischen Autoren (Vitruvius, Cato, u. A.), drehen sich um eine horizontale Queraxe. Die anatomische Trochlea dreht sich nicht, sondern bildet einen festen Punkt, eine Angel, um welche sich ein anderer Knochen, nur in Einer Ebene, auf und nieder, bewegen kann. Die Trochlea des Oberarmbeins, hat also nicht die drehende Bewegung, sondern nur die Gestalt einer Rolle. Ebenso die Trochleae der Phalangen, welche jedoch blos Segmente von Rollen sind. Ein Stück einer wahren, sich um ihre eigene Queraxe drehenden Rolle, bildet nur der Körper des Sprungbeins. Galen nannte deshalb die Rolle des Ober-

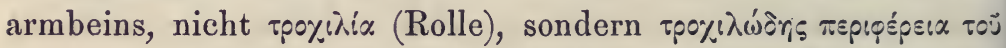
Bpayiovos, trochleae similis orbita brachii $\left.{ }^{\prime}\right)$. Dieses Adjectiv rpo-

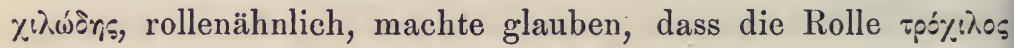
heissen müsse. Und so wurde wirklich das Rollengelenk, von einigen Aelteren und Neueren, wie von meinem Lehrer, Trochilus, genannt. Diese Herren waren im Griechischen nicht wohl bewandert, sonst hätten sie wissen müssen, dass Trochilus im Herodot (II, 68), der Strandläufer, und im Linnéischen System der Colibri ist. - Die Vervielfältigung der bewegenden Kraft in einem Flaschenzug, in welchem der Strick über mehrere Rollen läuft, war seit Archimedes bekannt, welcher mit diesem Apparat die Erde aus ihren Angeln heben zu können versicherte, wenn nur der feste Punkt gegeben wäre, an welchen er seinen Flaschenzug befestigen könnte. Der Flaschenzug hiess ebenfalls Trochatia, und zwar der gewöhnliche mit drei Rollen Trochalia trispastos, - der com-

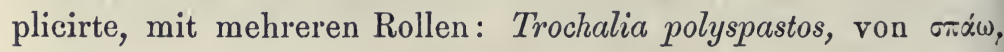
ziehen.

1) Oribasius, Op. cit., pag. 158. 
Die Trochlea des oberen schiefen Augenmuskels, erhielt ihren Namen erst durch Arantius 1): Obliquus ille musculus, qui per trochleam fertur. Man wusste zwar schon lange, dass die Sehne dieses Muskels eine Schlinge passirt, jenseits welcher sie gegen den Augapfel hin ablenkt: in ligamento, cartilagineum quid ostendente, continetur, et in illo, velut habena in annulo retorquetur ${ }^{2}$ ). Auch Riolan sagt bestimmt: tendo obliqui superioris, velut funis per trochleam contorquetur $\left.{ }^{3}\right)^{*}$, und bemerkt, dass diese knorpelige Rolle, zuweilen verknöchert (cartilago interdum ossea). Von dieser Trochlea, erhielt der Musculus obliquus sup. oculi, von Casserius den Namen Musculus trochlearis $\left.{ }^{4}\right)$. Der Nerv, welcher diesen Muskel versorgt, wurde zuerst von Guilielmus Molins, einem englischen Wundarzt, welcher eine Myotomia herausgab (Londini, 1670), Nervus trochlearis genannt. Dieser Nerv war schon dem Achillinus und Vesalius bekannt, als radix gracilior tertii paris (unser Trigeminus). Fallopia erklärte ihn zuerst für einen selbstständigen Hirnnerv. - Eine ganz widersinnige Anwendung von Trochlea, fällt dem A. Laurentius zur Last. Er nannte die Schnecke des Gehörorgans : Trochlea ${ }^{5}$ ).

\section{Tuba Eustachii.}

Die Eustachische Ohrtrompete hat mehr Recht, eine Tuba genannt zu werden, als die Tuba Fallopiae, denn sie ist geradelinig, und dadurch der römischen Tuba, mit welcher das Signal zum Angriff gegeben wurde, ganz ähnlich. Ich

1) Observationes anat., Venet., 1587, Cap. 19.

2) Vesalius, Examen observationum Fallopiae, in Opp. omn., Edit. Lugd., T. II, pag. 781.

3) Anthropotomia, Lib. V, Cap. 11.

4) Pentaestheseion, Lib. V, Sect. 1, Cap. 18.

5) Anatomia corp. humani, Li飞. XI, Cap. 13. 
finde aber, dass Eustachius sie nicht als Tuba benannte, sondern von ihr nur als von einem Kanal: "de coni genere" spricht. - Dass die Ohrtrompete schon dem Aristoteles bekannt war, lässt sich aus seinen Schriften beweisen: regio intima auris (Trommelhöhle), meatum nullum ad cerebrum, sed in palatum oris habet ${ }^{1}$ ). Der griechische Philosoph, Alcmaeon von Croton, welcher die ersten Zergliederungen an Ziegen unternommen haben soll, musste eine Vorstellung von diesem, die Trommelhöhle mit der Rachenhöhle verbindenden Kanal gehabt haben, da er die Behauptung aufstellte, dass die Ziegen durch die Ohren athmen ${ }^{2}$ ). Aristoteles widerlegte ihn. Galen wusste nichts von diesem Gang. Er spricht zwar von der Syrinx, und ouppry ist $=$ tuba. Aber die Syrinx des Galen, war ein Instrument, ein Rohr zum Aufblasen, dessen er sich bei seinen anatomischen Untersuchungen über die Gehirnkammern bediente ${ }^{3}$ ). Wohl hatten Vesal, F. Plater, und Ph. Ingrassias4), eine Kenntniss von dem Verkehr der Trommelhöhle mit dem Rachen, aber dem B. Eustachius war es vorbehalten, die Anatomie des betreffenden Ganges festzustellen ${ }^{5}$ ), und sich dadurch ein Anrecht auf die Bezeichnung desselben mit seinem hochgeachteten Namen zu erwerben. Nur die leidige Neuerungssucht konnte der Tuba andere Benennungen andichten, von welchen keine Stich gehalten hat. Am leidlichsten ist noch die Tuba acustica von unserem alten Leber ${ }^{6}$ ), weil sie wirklich mit einem Hörrohr Aehnlichkeit hat. Am schlechtesten nimmt sich der ganz unsinnige Aquaeductus Fallopiae oder Eustachii aus, wie die Tuba von Duverney,

1) Historia animalium, Lib. I, Cap. 9 (vulgo Cap. 11).

2) Petersen, historisch-philologische Studien, Hamburg, 1832, 1. Heft, und Kühn, Opuscula academica, T. I, 69.

3) De administrationibus anat., Lib. IX, Cap. 2.

4) Comment. in Galen., Lib. VIII, Cap. 1, pag. 97.

5) Examen organi auditus, pag. 162.

$\left.{ }^{6}\right)$ Praelectiones anat., Vindobonae, 1778, pay. 27. 
Dionis, und Morgagni genannt wurde. Fallopia bezeichnet nur jenen Kanal des Schläfebeins, durch welchen sein fünftes Nervenpaar (unser Communicans faciei) verläuft, mit diesem unpassenden Namen, und Eustachius hat in seiner Beschreibung der Tuba, eines Aquaeductus mit keiner Sylbe erwähnt. Der lange Ductus palatinus tympani Winslow ${ }^{1}$ ), konnte gegen die kurze Tuba, auch nicht aufkommen.

Die Anatomie erfreut sich auch eines Kanals, welcher Trompeten macht. Der knöcherne Kanal am vorderen Rande der Pyramide des Schläfebeins, heisst, weil er die Fortsetzung der knorpeligen Tuba Eustachii bildet, Canalis tubarius (musculotubarius). Alle Lexica kennen tubarius nur als vir qui tubas

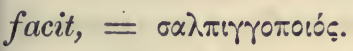

\section{Tubae Fallopianae.}

Bis zu Ende des 17. Jahrhunderts hielten einige Anatomen vom alten Schlag, an der Lehre fest, dass die Ligamenta ovarii, die eigentlichen Ausführungsgefässe des in den Ovarien bereiteten weiblichen Samens seien. Da diese Bänder die Eierstöcke unmittelbar mit dem Grunde der Gebärmutter verbinden, schrieb man ihnen diese Leistung zu. Die Tubae Fallopianae, welche mit den Eierstöcken nicht zusammenhängen, hielt man solcher Verrichtung nicht fähig, sah in ihnen blos die Wiederholungen des Uterus bicornis der Säugethiere, und gab ihnen sofort auch den Namen Cornua uteri. Ob die Ligamenta ovariorum hohl sind oder nicht, und wo sie in die Höhle der Gebärmutter einmünden, untersuchte man nicht näher. Ja man liess von ihnen noch einen Gang auslaufen, welcher an den Seiten der Gebärmutter, zwischen den Blättern des Ligamentum uteri latum herabsteigt, um sich in die Scheide zu öffnen, damit auch Weiber, welche schwanger sind, ihren

1) Expositio anat., T. IV, §. 501. 
Samen bei der Begattung in die Scheide ausleeren können, da er in die Uterushöhle nicht mehr gelangen kann. A. Laurentius, Highmorus, Varolius, und fast alle Anatomen des 15. und 16. Jahrhunderts; glaubten an diese Gänge, bis man durch Regnerus de Graaf darauf geführt wurde, dass sie nur der Ramus vaginalis der Arteria uterina sind. Fallopia entsetzte die Ligamenta ovarii ihres Amtes als Ausführungsgänge der Eierstöcke, und betraute die Tubae damit. Er nannte sie deshalb Meatus seminarii s. Vasa deferentia, und verglich ihr trichterförmiges Ostium abdominale mit einer Trompete: extremum foramen amplum habet, quod semper clausum jacet concidentibus fimbriis, quae tamen si diligenter aperiantur ac dilatentur, tubae cujusdam aeneae extremum finem caprimunt $\left.{ }^{1}\right)$. Also nicht die ganze Röhre, sondern nur ihr trichterförmiges Ende, soll Tuba genannt werden. Der geschlängelte und gewundene Verlauf der Röhre selbst (capreoli modo crispatus, Fallopia), gestattet mit einer Trompete keinen Vergleich ${ }^{2}$ ). Nichtsdestoweniger heisst die ganze Röhre, nicht blos ihr trichterförmiges Ende, bei allen Anatomen Tuba. Regnerus de Graaf, welcher zeigte, dass in den Eierstöcken kein Same, sondern Eier gebildet werden, verwarf den Namen Meatus seminarii, und acceptirte die Tuben des Fallopia als Oviductus, welche sich so sehr erweitern, dass sie ein ganzes Ovulum Graafianum in das Cavum uteri überführen können,

1) Observationes anatomicae in Vesalii Opp. omnia, T. II, pag. 751.

2) Die römische Tuba war lang und ganz gerade. Wir kennen sie, nach der Abbildung auf einem Triumphbogen des Titus. Sie war, ihres dröhnenden Tones wegen, nur zu militärischen Signalen gebraucht:

"At tuba terribili sonitu, taratantara dixit."

Ennius.

Ihre unbequeme Länge veranlasste erst in späterer Zeit, sie im Bogen zu krümmen, woraus das Waldhorn und die Trompete entstand. 
wo es dann ausgebrütet wird, wie das Ei im Nest ${ }^{1}$ ). Auf den Einwurf, welchen die selbst zu Graaf's Zeiten noch nicht gänzlich ausgestorbenen Anhänger der alten Lehre erhoben, dass das Graaf'sche Ei (unsere Vesicula Graafii), viel zu gross sei, als dass es durch die enge Oeffnung der Tuba in den Uterus gelangen könnte, erwiderte Graaf ganz treffend, dass auch das Kind viel grösser ist als das Ostium uteri, durch welches es geboren werden müsse ${ }^{2}$ ).

Mit den Tubae Fallopianae ${ }^{3}$ ) und den Oviductus Graafi, hat der Strom der Zeit alle älteren Benennungen derselben

1) De mulierum organis, in Operibus omnibus, Cap. XIV.

2) Op. cit., pag. 268.

3) Ueber den Eigennamen des hochberühmten Canonicus und Professor, Fallopia, haben wir etwas zu erwähnen. Nicht weniger als sechs Variationen desselben, irren in den anatomischen Büchern, und auf den Titelblättern der zahlreichen Auflagen seiner Werke herum: Fallopia und Fallopius, Faloppia und Faloppius, Falloppia und Falloppius. Wie hat nun der Mann eigentlich geheissen?

Die meisten anatomischen Geschichtsschreiber, wie auch die durch Correctheit ihrer historischen Angaben ausgezeichnete Bibliotheca anatomica Halleri, nennen ihn Fallopius, der gelehrte Sprengel aber Faloppia, nach Tassoni, Secchia rapita, Cent. 2, Num. 2, wo es heisst:

Andar gli ambasciatori ad onorare

Alessandro Faloppia e Gaspar Prato,

$E$ li condusser, per diritta strada

Alla sala, dove il Duca or tien la biada.

Sprengel konnte natürlich nicht gewusst haben, ob dieser Alessandro Faloppia, ein Verwandter des grossen Anatomen, Gabriel Fallopia, war. Wenn er es nicht war, ist die Schreibart Faloppia für unsere Frage ganz werthlos. Die Venetianer Auflagen seiner Schriften führen auf dem Titel: G. Falloppius, ebenso jene von Frankfurt, und der Leydner Edition der Opera omnia Vesalii, sind die Observa- 
fortgeschwemmt, wie Cornua, Cirrhi, Ductus varicosi, Processus laterales, Canales tubarii coeci ${ }^{1}$ ), u. m. a. Der Oviductus Graafii ist jedenfalls besser als die Tuba Fallopiae, da er auf die ganze Länge dieses Kanals passt, dessen physiologische Bedeutung er klar und verständlich ausspricht.

tiones anatomicae des Falloppius beigegeben. Die Unsitte der damaligen Zeit, die Consonanten, besonders die labiales und linguales, zu verdoppeln, scheint mir auch dieses doppelte $p$ im Falloppius erzeugt zu haben. Der italienische Name muss Fallopia gewesen sein, da ich ihn bei etlichen Zeitgenossen unseres Altmeisters so erwähnt finde. In lateinischen Schriften wurde, durch die Umwandlung des terminalen italienischen $a$ in das lateinische us, Fallopius daraus, obwohl auch römische Eigennamen ein $a$ am Ende aufweisen, wie Sulla, Catilina, Cinna, Scaevola, Valerius Agricola, u. m. a. Mag man also den Fallopia so oder so schreiben, man kann immer etwas Gedrucktes zu seiner Rechtfertigung finden. - Juan Valverda, ein Spanier, Schüler und Freund des oftgenannten Realdus Columbus, schrieb in seiner Muttersprache eine Anatomie, deren lateinische Uebersetzung 1589 in Venedig erschien. Auf dem Titelblatte derselben sehen wir ebenfalls den Valverda zum Valverdus latinisirt.

1) So nannte Highmor die Tuben, vermuthlich weil er ihre sehr enge Oeffnung in den Uterus nicht auffinden konnte (Disquisitio anat. corporis humani, pag. 91). Dieses angenommene Geschlossensein der Tuba, veranlasste auch in jener Zeit, wo die Tuba noch als Meatus seminalis galt, die Ansicht, dass sich der weibliche Same nicht in die Höhle, sondern in die Substanz der Gebärmutter ergiesse, - ein Irrthum, in welchen auch Harvey befangen gewesen. Regnerus de Graaf, Opera omnia, pag. 257: Semen muliebre non in uteri cavitatem, sed in solidam ejus substantiam derivari, autoritate Clarissimi Harvei seducti credidimus. 


\section{Tuber, Tuberculum; Tuberositas.}

Die Anatomie macht keinen Unterschied zwischen Tuber und Tuberositas, obgleich beide sprachlich verschieden sind. Sie nennt einen und denselben Höcker, bald Tuber, bald Tuberositas, z. B. den Sitzbein- und Fersenbeinhöcker. Nur mit Tuberculum geht sie etwas vorsichtiger um, und vergiebt dässelbe blos an kleine Höcker.

Tuber, von tumeo, kann jede Erhöhung auf einer Fläche genannt werden, wenn ihr Umfang rundlich, und ihre Oberfläche glatt ist, wie z. B. bei einer entzündlichen Geschwulst, oder einer Beule. Die Maulwurfshügel, die Höcker des Kamels, die Knorren an Baumstämmen, und die Wurzelknollen gewisser Pflanzen, hiessen ebenfalls Tubera. Niedrig und glatt muss ein anatomischer Hügel sein, um Tuber zu heissen. Man denke an die flachen und glatten Tubera frontalia und parietalia, welche niemals Tuberositates genannt wurden. Denn Tuberositas kommt zunächst von tuberosus. Alle Adjective in osus sind cumulativ, und drücken $a$ ) eine Fülle, eine grośse Menge von Etwas aus, $b$ ) seltener eine in besonderem Grade entwickelte Eigenschaft. Beispiel zu a: spinosus, ramosus, pilosus, nivosus, nebulosus, etc. - zu $b$ : nervosus, tendinosus, musculosus, cellulosus, letztere meist neugebildete Worte. Tuberosus, ein gutes lateinisches Wort ${ }^{1}$ ), wäre somit: reich an tubera, - das deutsche höckerig, und Tuberositas = höckeriger (nicht glatter) Höcker. Der Höcker des Sitzbeins, des Darmbeins, des Fersenbeins, des Oberkiefers, des Kahnbeins der Fusswurzel, können nur Tuberositates heissen, - die glatten Höcker an den Rippen, am Radiushals, an der Tibia (sogenannte Spina tibiae), am Würfelbein, am Stirn- und Seitenwandbein, sind nach ihrem Grössenmass Tubera oder Tubercula, aber keine Tuberositates,

1) Wir finden einen campus tuberosus im Varro, und eine frons tuberosissima im Petronius.

Hyrtl. Onomatologia anatomica. 
obwohl sie gemeinhin so benannt werden. Will man also der Grammatik Einsprache in die anatomische Terminologie zugestehen, so dürfen grosse, flache, und glatte Hügel nur als Tubera, kleinere als Tubercula, alle rauhen Hügel, gross oder klein, als Tuberositates benannt werden. Wer diese Unterschiede unberücksichtig lässt, verfährt schleuderisch, und wird hierin leider viele Mitschuldige haben.

Tuber und Tuberculum geniessen blos das anatomische Gastrecht. Ursprünglich wurden diese Worte, nur auf pathologische Zustände, auf Beulen, Abscesse, und weiche Auswüchse bezogen, welche bei den griechischen Aerzten, Galen und Paulus von-Aegina, qúuara hiessen ${ }^{1}$ ). Im Plinius und Celsus können zahlreiche Belege für diese Bedeutung von Tuber und Tuberculum aufgelesen werden. Ich erwähne nur zwei : tubera anserino adipe molliuntur (Plinius), und : in gingivis

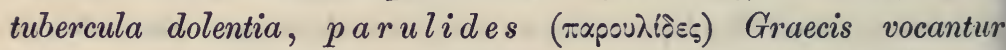
(Celsus). - Die deutsche Sprache nimmt bei diesen Dingen, auch auf ihre Consistenz Rücksicht, und nennt weiche Tubera Knollen, harte aber Knorren. Sie findet deshalb in der Osteologie keine Knollen vor, sondern nur Knorren. Schon das doppelte $r$ klingt hart.

Ein Hauptwort Excrescentia, - ae, dessen sich das anatomische und medicinische Latein sehr oft bedient, giebt es in der römischen Sprache nicht, und das ebenso oft vorkommende Elevatio, war bei den Römern nur eine ironische Redefigur, qua rem aliquam, dum videmur attollere, deprimimus et irridemus (Forcellini). Cicero gebraucht für Erhabenheit, nur $E x-$ stantia und Prominentia.

1) Tubera vocantur tumores et abscessus, e corpore in rotundum erumpentes. Tubercula antrosa sind Pestbeulen, und syphilitische Bubonen im Forestus und Vinarius. 


\section{Tympanum und Membrana tympani.}

Bis zum Anfang des 16. Jahrhunderts war die Existenz des Gehörlabyrinthes in das tiefste Dunkel gehüllt. Man sucht in den Schriften der Restauratores anatomiae, vergebens nach einer Andeutung, dass sie von dem Vorhandensein dieses wundervollen Organs, eine Ahnung gehabt hätten. Das Trommelfell war ihnen der eigentliche Sitz der Gehörwahrnehmungen. Mundinus spricht von ihm als panniculus subtilis, contextus ex villis (Fasern) nervorum auditus $\left.{ }^{1}\right)$. Berengarius kennt das Trommelfell als Meninx auris (Haut des Ohres), in qua nervus auditivus dilatatur ${ }^{2}$ ), und Alessandro Benedetti sagt noch bestimmter: in imo anfractu (äusserer Gehörgang) posita membrana, quam meninga vocant, '́ cerebro est ${ }^{3}$ ). Die Trommelhöhle kannten diese Männer sehr wenig, erwähnen sie nur obenhin als cavernositas oder concavitas ossis petrosi (Mundinus), als certa quaedam vacuitas (Berengarius), oder schweigen gänzlich von ihr, wie Benedetti. Fallopia benannte die Trommelhöhle, zusammen mit der Trommelhaut, als Tympanum, „a similitudine cum tympano" 4). Wenn man von der höchst unregelmässigen Gestalt der Trommelhöhle absieht, welche weder mit einer Paucke, noch mit einer Trommel Aehnlichkeit hat, kann man doch das Tympanum, des darübergespannten Häutchens wegen, als Paucke oder Trommel acceptiren. Tympanum

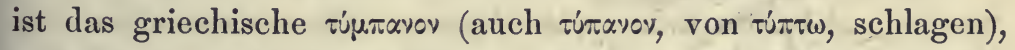
war eine besonders beim Dienste der Cybele gebrauchte Handtrommel, mit halbrund gewölbtem Schallboden. Haller unterschied das Trommelfell, als. Membrana tympani, von der eigentlichen knöchernen Trommel, Cavum s. Cavitas tympani. Die

1) Anathomia emendata, in Cap. de anathomia auris.

2) Isagogae breves, Cap. de auribus.

3) Anatomice, Lib. IV, Cap. 28.

4) Observationes anat., pag. 24, b. 
Synonyme, welche Pierer für das Týmpanum anführt, als Concha, Cochlea, Antrum, Caverna, Cavitas buccinata, und Pelvis, sind längst ausser Cours gesetzt. Sie waren nur den Arabisten geläufig. Einige von ihnen, wie Concha, Cochlea, und Buccina, wurden irrthümlich auch auf die Schnecke bezogen, obgleich dieses Organ, in der Blüthezeit der Anatomie des Avicenna und Rases, noch nicht auf der Welt war. Die Benennungen der Trommelhöhle als Concha, Cochlea, und Buccina (Muschel) entstanden daher, dass in jenen Zeiten, wo die menschliche Anatomie im Todesschlummer lag, und nur Thiere zergliedert werden konnten, das blasig aufgetriebene, oder muschelartig eingerollte Os tympanicum, mit dem Namen einer bauchigen Muschelschale belegt wurde, und dieser Name, als die menschliche Anatomie wieder auflebte, auch der menschlichen Trommelhöhle eine Zeitlang belassen wurde. Sehr passend nannte R. Columbus die Trommelhöhle: Sinus auditorius $\left.{ }^{1}\right)$.

Nicht blos bei den Latino-Barbari, auch bei guten lateinischen Anatomen, z. B. Fallopia, fällt uns die Trommelhaut als Myrinx und Myringa auf, worüber ich folgende Auskunft geben kann. Man leitete damals die Trommelhaut von der Pia mater ab. Diese hiess bekanntlich im Aristoteles $\mu \tilde{n} \eta \gamma_{\gamma} \xi$. Mit neugriechischer Aussprache des $\eta$ als !, entsteht Mininx. Das $i$, wird nach einer damals allgemeinen üblen Gewohnheit, als $y$ geschrieben, wie wir in Yleum, Yris, Ysophagus, Hypocrates, Galyenus, - in dyxit und scrypsit der Salernitaner, u. v. a. sehen. So kam es zu Myninx. Die Abschreiber substituirten fast ebenso häufig dem $n$ das ähnliche $r$, und so wurde aus $\mu . \tilde{\eta} v \gamma^{\prime} \xi$ endlich myrinx.

Vergleiche den Artikel: Cochlea und Meninx.

1) De re anatomica, Lib. I, Cap. 7. 


\section{Ulna,}

Ulna ist, wie Cubitus, ein doppelsinniges Wort. Wir finden es als Vorderarm, und als Ellbogenbein. Sein griechisches Synonym : $\pi \tilde{r}$ ivs, theilt dasselbe Schicksal: id totum, quod inter brachium et carpum est, ejusdemque partis majus os, ulna ( $\pi \tilde{\eta} \mathbf{v}_{\mathrm{s}}$ )

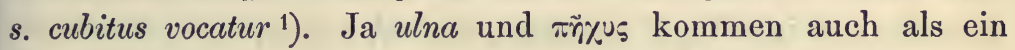
Längenmass vor, $=$ der deutschen Elle, d. i. der Abstand der Spitze des Mittelfingers vom Ellbogen, ungefähr 11/2 Fuss. Elle, das spanische alna und ana, und das französische aune, sind intime Verwandte der lateinischen Ulna. Im Plinius begegnen wir der Ulna, als Klafter, = dem Abstand, welcher mit beiden ausgespreiteten Armen gemessen wird. Denn der Ulna bedienen sich die Dichter, auch für den ganzen Arm: ulnis amplecti, in ulnas attollere, und maternis in ulnis, im Ovid.

Die lateinische Ulna ist eine Tochter der griechischen

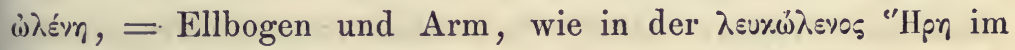
Homer, weissarmige Juno.

Die mittelalterlichen Benennungen der Ulna, als Canna, Arundo, und Focile, theilt die Ulna mit dem Radius und der Tibia. Sieh' diese Artikel, wie auch Cubitus und Olecranon.

\section{Umbo und Umbilicus.}

Mit dem Umbo, welchen wir nur ein einziges Mal in der Anatomie enthalten finden, hat eine kleine Verwechslung stattgefunden. In der Meinung, dass Umbo eine Vertiefung ist, nennen die meisten neueren Anatomen, duce Hallero ${ }^{2}$ ), die

1) Oribasius, Op. cit., pag. 159.

2) Elementa physiol., T. V, Lib. 15, pag. 200: in umbonis speciem, extrorsum cavi; das erste Mal, dass ein Umbo, als Concavität zum Vorschein kommt! 
tiefste Stelle der Concavität des Trommelfells, welche dem unteren Ende des Hammerstieles entspricht, den Umbo mem-

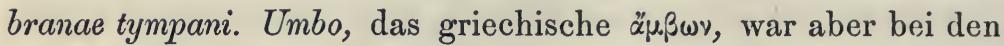
Classikern immer nur etwas Erhabenes, auf einer Fläche Hervorragendes. So hiess z. B. der Knopf oder Kegel, welcher sich in der Mitte eines Schildes erhebt: Umbo. Durch ihn wurden die aus der Ferne geschleuderten Geschosse abgelenkt, wie im Virgil (Aeneis, II, 544, seqq.):

\section{"- - - telumque imbelle sine ictu,}

„Conjecit, rauco quod protinus aere repulsum, „In summo clypei nequidquam umbone pependit."

Im Handgemenge diente der spitze Umbo des Schildes, auch als Angriffswaffe 1). Die grossen, abgerundeten, am Rande eines Trottoirs aufgestellten Steine, welche den Fussweg vom Fahrweg trennten, werden als Umbones, im Anthony Rich erwähnt ${ }^{2}$ ). Der erhabenste Punkt eines geschliffenen Edelsteins, heisst im Plinius: $U m b o^{3}$ ). So hätten wir denn Belege genug dafür, dass nicht die tiefste Stelle der concaven Trommelfellsebene, sondern jene Erhabenheit am oberen Rande dieser Membran, welche durch das Anstemmen des kurzen Fortsatzes des Hammer's hervorgebracht wird, Umbo genannt werden soll, wie es in Hildebrandt's Anatomie geschieht ${ }^{4}$ ).

Der dem Umbo nahe verwandte Umbilicus, hat, wie der

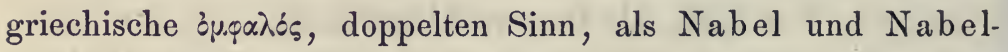
strang. Diese zweifache Bedeutung von óp.q $\alpha \lambda o_{s}$ finden wir bei allen griechischen Aerzten. Ich citire nur den Rufus:

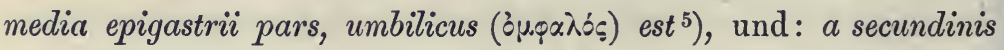

1) Livius, $I V, 19$.

2) Römische Alterthümer, pag. 669, wo die von Herculanum nach Pompeji führende Chaussée abgebildet ist.

3) Hist. nat., Lib. XXXVII, Cap. 6, Sect. 23.

4) Vierte Aufl., Bd.IV, pag. 17.

5) De partibus hominis, pag. 31. 
(Placenta gemeint), umbilicus oritur, ex duabus arteriis totidemque venis, et ex urinaculo (uracho) compositus ${ }^{1}$ ). Nach dem griechischen Vorbild, bedienten sich auch die Uebersetzer des Galen, Rufus, und Oribasius, des Wortes Umbilicus für Nabel und Nabelstrang, wie es schon Celsus gethan ${ }^{2}$ ). Im weitesten Sinne ist Umbilicus, die Mitte irgend eines Gegenstandes. So spricht Cicer ${ }^{3}$ ) von einem Umbilicus Siciliae, als medius insulae locus, und bei einer anderen Gelegenheit, von einem Umbilicus terrarum, worunter Delphi gemeint ist ${ }^{4}$ ). Livius hat umbilicus diei, für Mittag. Dass der Nabel nicht die Mitte des'Leibes bildet, wissen wir Alle. - Umbilicus lebt fort im italienischen ombelico (gekürzt bellico und bilico), im spanischen ombligo, im portugiesischen umbigo, und im französischen nombril, wo das $n$ den Artikel $l$ vertritt, wie aus dem catalanischen llombrigol geschlossen werden darf. Unser Nabel, im Rabanus Maurus: Navelo, ist das angelsächsische navel, durch das Sanscrit verwandt mit dem persischen Naf.

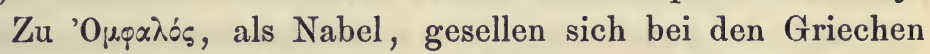
noch einige Nebenbezeichnungen, als Acromphalon, Mesomphalon,

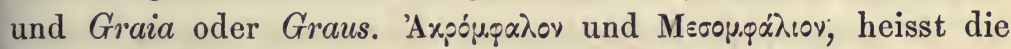
Mitte des Nabels, $\Gamma_{p \alpha i \alpha}$ oder $\Gamma_{p} x u ̈ s$ (altes Weib) die gefaltete Hauteinfassung des Nabels, quoniam corrugata, senectutem significat $^{5}$ ). So versteht sich auch die Vetula der alten Anatomen, als gerunzelte Haut des Nabels. Die Uebersetzer der Araber, geben uns Vetula für After, und sofort für Steissbein, weil auch der arabische Ausdruck für Steissbein (Adschūz), After und altes Weib bedeutet, der Runzeln wegen ${ }^{6}$ ). -

1) Op. cit., pag. 45.

2) De medicina, Lib. VIII, Cap. 29: sinistra manu leniter trahere umbilicum, ne abrumpas.

3) Orat. in Verr., II, 4, 48.

4) De divinatione, $I I, 56$.

5) Rufus, Op. cit., pag. 30 und 31 .

6) Näheres hierüber in HL, §. XII, §. XXII, und pag. $276 \mathrm{der}$ Nachträge. 


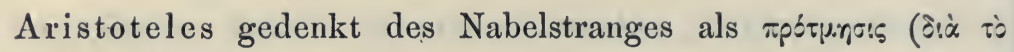

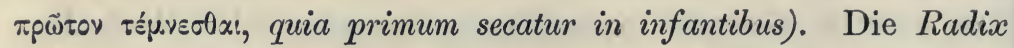
ventris im A. Laurentius für Nabelstrang, beachten wir nur

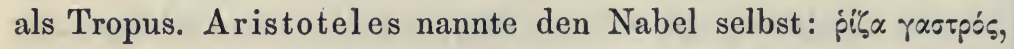
radix abdominis.

\section{Urachus.}

Der Urachus, Harnstrang, Harnschnur, war als oupajss und ojparós, den Griechen sehr wohl bekannt. Sie wussten von ihm, dass er die Harnblase des Embryo mit der Allantois verbindet, und konnten diese Wahrnehmung sehr leicht bei Thierembryonen machen, an welchen der Urachus, und seine Beziehung zur Allantois, viel deutlicher zu sehen ist, als beim Menschen, wo, wegen des frühzeitigen Eingehens der Allantois, dieser Zusammenhang nur bei sehr jungen Leibesfrüchten erkannt werden kann. Das Wort ojpayós leiten die Meisten von oưpov und \%ह̂́ $\omega$, giessen, ab, da es im Rufus heisst: per urachum, humorem quemdam (urinam) in secundinas transfundi cognovimus. Andere, auf oùpajós sich stützend, setzen $\not ̈ \gamma \omega$ (führen, leiten), statt $\chi^{\hat{s} \omega}(\mathrm{K} u ̈ \mathrm{hn})$. Wie dem immer sei, Urachus ist die fast ausschliesslich gebrauchte Form. Oupx geben, war nur dem lateinischen Barbaren möglich, welcher den Rufus übersetzte. Urinaculum kennt Niemand. Und dennoch lesen wir es noch im Fabricius ab Aquapendente, im 17. Jahrhundert. Der Name Blasenband, ligament de la vessie, welchen Lieutaud zuerst vorführte, drückt nur den, noch im Leibe des Erwachsenen vorfindlichen Rest des Urachus aus das Ligamentum vesico-umbilicale medium s. suspensorium vesicae der Autoren, obwohl es zur Befestigung der vollen Blase in situ gar nichts beitragen kann, da es bei dem Aufsteigen des Scheitels einer vollen Blase, relaxirt wird, und in diesem $\mathrm{Zu}$ stande nichts halten oder tragen kann. 


\section{Urethra und Ureteres.}

Nicht um sie zu tadeln, führe ich diese Worte an. Nur um ihre Entstellungen zu rügen, halte ich mich bei ihnen auf. Oipritopa ist ein Hippocratisches Wort 1), und muss Urethra, nicht Uretra geschrieben werden. Im Celsus erscheint sie als Fistula urinaria, welche der gute Oesterreicher Wallner, zu Anfang des vorigen Jahrhunderts, in der deutschen Herausgabe der Anatomie des Bartholinus, mit Harnpfeife übersetzt. Dass die Latino-Barbari zuweilen Uretra schrieben, war von Barbaren zu erwarten. Iter urinae, Meatus und Ductus urinarius, entsprechen dem Begriff der Urethra nicht. Die Worte sind Versionen des Galenischen Tópos oupprisxós, unter welchem Galen zwar auch die Harnröhre, gewöhnlich aber nur den Harnleiter versteht. Ueber Collum und Cervix vesicae, wie die Harnröhre von den Uebersetzern der Araber gewöhnlich genannt wird, sieh' HL, Nachträge zu $\S . X L I I I$, pag. 259, seqq. In dem unechten Buch des Galen: Introductio s. Medicus, wird nur die Oeffnung der Harnröhre an der Eichel oippritop genannt.

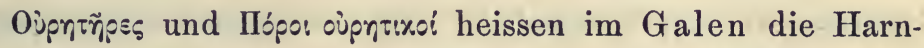
leiter, wahrscheinlich von oũpov, Harn, und tnpéw, bewahren. Von oùprrappal und oupoxval, welche Schreger anführt, ist, weder im Galen, noch in anderen Griechen, etwas zu finden. Die griechischen Ureteres, wurden im Vesal zu Meatus urinarii, im Bartholin zu Ductores urinae, und im deutschen zu Harnleitern - alles gut und richtig. Dass man Urêthra, nicht aber urěthra zu sagen hat, zeigt uns das lange $\eta$ in der griechischen ojprípos.

1) Aphorismorum Lib.IV, aphor. 82. 


\section{Urocystis,}

Ueber Urocystis sieh' den Artikel: Choledochus und Cholecystis. Hier bemerke ich blos, dass der Ausdruck Vesica urinaria, nicht zum guten Latein gehört, indem ein Beiwort urinarius, bei keinem römischen Schriftsteller, selbst bei den Spätlateinern nicht, vorliegt. Sie brauchen alle nur urinalis, wie Caelius Aurelianus mit seinen Viae urinales, und Vegetius mit seiner Fistula urinalis.

\section{Uterus.}

Wenn man die menschliche Gebärmutter Uterus nennt, begeht man eigentlich eine Unart gegen das schöne Geschlecht. Uterus kommt von Uter, "Schlauch" 1). Der menschliche Uterus ist kein Schlauch. Wohl aber können die Hörner eines trächtigen, thierischen Uterus bicornis, ihrer Länge und Dicke wegen, mit Schläuchen verglichen werden. Das hat man auch gethan, als man bei den Opfern, der mächtigen Uterusschläuche trächtiger Hausthiere zuerst ansichtig wurde. Dazu fehlte es im Alterthum an Gelegenheit nicht, denn gewissen Gottheiten, welche als Symbole und Ideale der Fruchtbarkeit verehrt wurden, wie Ceres und Pomona, durften nur trächtige Thiere geopfert werden. Uterus passt also, genau genommen, nicht auf den ledigen, sondern auf den geschwängerten Zustand dieses Organs. So oft im Plinius das Wort Uterus unterkommt, ist immer von trächtigen oder gebärenden Thieren die Rede. Da man später doch auch für die menschliche Gebärmutter einen Namen brauchte, wurde der thierische dazu benützt, und von den Schriftstellern wiedergegeben, wenn von der Schwangerschaft oder Geburt die Rede ist, z. B. puellae utero

1) Nonius Marcellus, de varia significatione verborum, Cap. 2, pay. 915. 
laborantes (gebärende Mädchen) im Horaz, diva potens uteri (Beiname der Lucina, als Beschützerin der Schwangeren und Gebärenden) im Ovid, uterus felix (fruchtbar) im Vellejus Paterculus, Fratres uterini, Brüder von derselben Mutter, aber nicht von demselben Vater erzeugt, während Brüder, von demselben Vater, aber nicht von Einer Mutter erzeugt, Consanguinei hiessen, u. v. a. Stammt doch selbst das Wort Uterus, nach Forcellini, von dem veralteten oderos, welches selbst

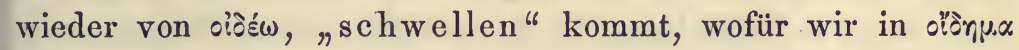
(oedema) einen Hippokratischen Zeugen haben 1). - Ueber den menschlichen Uterus hatte man, bis lange nach Galen, eine klägliche Vorstellung. Man hielt ihn dem thierischen ähnlich. Der thierische Name war also gut genug für ihn. Erst Soranus, ein griechischer Arzt zur Zeit Kaiser Hadrians, giebt seine Form bestimmter an, indem er sie mit einem Schröpfkopf vergleicht. Èr nennt ihn nicht mehr zweihörnig, wie seine Vorgänger thaten, sondern theilt ihn in Fundus, Corpus, und Collum ein, welche Eintheilung jetzt noch beibehalten wird "). Ein Schröpfkopf ist von einem Schlauche sehr verschieden, - ein Beweis mehr, dass der birnförmige menschliche Uterus einen seiner Gestalt widersprechenden Namen führt.

Wir finden Uterus noch als Unterleib im Celsus: Septum transversum a praecordiis uterum diducit, "das Zwerchfell trennt den Bauch von der Brust", und im Virgil heisst es vom Trojanischen Pferd, als der Unheil ahnende Laocoon, ihm den Speer in den Bauch stiess:

$$
\text { ¡- - - uteroque recusso }
$$

„Insonuere cavae, gemitumque dedere cavernae."

1) Oedema ist im Hippocrates, nicht blos die wässerige Anschwellung, wofür wir es einzig und allein gebrauchen, sondern jede Geschwulst, was immer für einer Natur (tumor cujuscumque generis im Gorraeus, Definitiones med., pag. 325).

2) IIspi prítpas xai yuvalxsiou aiòoíou, latein von Rasarius in der Uebersetzung des Oribasius, pag. 693. 
Columella spricht von einem uterus dolii, bauchiges Fass, Tacitus von naves lato utero, bauchige Schiffe, und die alte Chemie von einem Uterus spagyricus, Sublimirofen ${ }^{1}$ ).

Das Stammwort von Uterus: Uter, Nebenform Utris, bezeichnet die im Ganzen (d. h. ohne der Länge nach aufgeschnitten $\mathrm{zu}$ sein) abgezogene Haut eines Thieres, welche als Schlauch für Oel und Wein verwendet wurde, und jetzt noch in allen südlichen Ländern Europas, zu diesem Zweck, wie auch bei den Caravanen zur Aufbewahrung des Wassers verwendet wird. Das griechische Wort dafür, war às\%ós, schon im Homer enthalten. Dasselbe lebt noch fort in der Medicin, als Ascites, Bauchwassersucht. Die Araber aber, von welchen Plinius ${ }^{2}$ ) erzählt, dass sie Ascitae hiessen, weil sie auf aufgeblasenen Schläuchen von Rinderhäuten (bubuli utres), welche mit Brettern überdeckt wurden, Seeräuberei trieben, sind längst schon ausgestorben. Kleinere solche Schläuche hiessen Uterculi und Utriculi. Sie dienten nebenher als Blasebälge für ein sehr bekanntes musikalisches Instrument. Im Sallustius wird Nero, welchen die Eitelkeit plagte, in verschiedenen freien Künsten für einen Meister zu gelten, wie als Flötist (choraules), und Wasserorgelspieler (Hydraules), auch als Utricularius „Dudelsackpfeifer" erwähnt. Die Glandulae utriculares der Gebärmutterschleimhaut, sind nach den Utriculi (kleine Schläuche) benannt.

\section{Uvea und Iris.}

Uvea ist eine barbarische Uebersetzung ${ }^{3}$ ) des Galen is chen

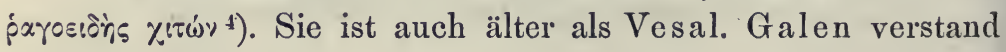

1) Mart. Ruland, Lexicon chemicum, wo dieser Ofen auch als Athanor benannt wird.

2) Hist. nat., Lib. VI, Cap. 29, Sect. 35.

3) Von uva ist kein Adjectiv uveus bekannt, somit auch keine Tunica oder Membrana uvea.

4) Oribasii Anatomica ex Galeno, pag. 40. 
unter seinem Chiton rhagoides, die Choroidea und die Iris zusammen, weil beide miteinander dem Balge einer Weinbeere ( $\left.\hat{\alpha}^{\prime} \xi \xi, u v a\right)$ vergleichbar sind, deren ausgerissener Stengel, ein Loch - die Pupille, xópn - zurückgelassen hat ${ }^{1}$ ). Aus diesem Grunde wird in den ältesten lateinischen Anatomien, für Uvea, auch Tunica uviformis, aciniformis, und acinalis, gefunden (von acinus, Weinbeere).

Galen bediente sich ferner des Wortes Iris, um jenen

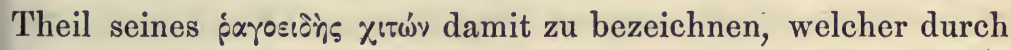
die Cornea hindurch gesehen wird: medium candidi oculi (die Mitte des Weissen am Auge) iris, circulus coloribus varius, occupat, unde et a similitudine, quam cum coelesti Iride habet, nomen accepit ${ }^{2}$ ). In einem anderen Galenischen Buch, wird die

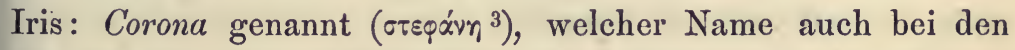
Restauratoren der Anatomie noch bekannt und gebraucht war. Von dieser Corona muss der Circulus unterschieden werden, dessen Galen bei der Anatomie des Auges öfters erwähnt. Er hat offenbar, unter dem Worte xúx入os (Circulus), die Grenze zwischen Sclerotica und Cornea, zwischen Choroidea und Iris, zwischen Retina und Linse verstanden. Seine Worte lauten: Circulus, terminus utrisque (den genannten Häuten) communis, ligamentumque his ipsis. Was Oribasius mit seinen septem circulis will, kann ich aus seinem Texte nicht entnehmen: ad mediam usque humoris crystallini regionem, septem circulos, sibi ipsis incumbentes ac cohaerentes, maxime admiraberis $\left.{ }^{4}\right)$. Vielleicht hat er die farbigen Ringe der Iris damit gemeint. Die Ueber-

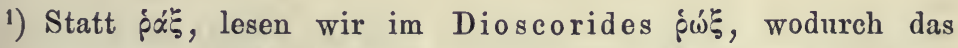
Synonymon für Uvea: Rhox (im Pierer und Choulant) sich aufklärt.

2) Introductio s. Medicus, Cap. 10. Das Buch wird für unecht gehalten.

3) Methodus medendi, Lib. XIV, Cap. 19, versus finem; ferner De usu partium, Lib. X, Cap. 2.

4) Anatomica ex Galeno, pag. 39. 
setzungen, selbst die beste, von Rasarius, sind ebenso undeutlich, wie das Original. Noch sei hier erwähnt, dass man, noch in Vesalischer Zeit, die Uvea sich am Pupillarrand umschlagen, und zum Corpus ciliare zurücklaufen, und die Iris somit aus zwei Blättern bestehen liess, welche mit einander verlöthet sind. Ich wollte diese Bemerkung nicht weglassen, da sie uns erklärt, warum die Iris in damaliger Zeit, auch Duplata choroides genannt wurde, z. B. im Jac. Sylvius ${ }^{1}$ ). Rufus Ephesius trennte die Uvea in, zwei Häute: rhagoides und choroides. Rhagoides $=$ Iris, und Choroides $=$ unserer Choroidea ${ }^{2}$ ). Diese Trennung wurde nicht mehr aufgegeben, aber statt Rhagoides: Iris gesetzt. Die Iris erscheint bei den Latino-Barbari, auch als Membrana coronoides und foraminalis, quia est perforata sicut corona ${ }^{3}$ ).

Der hintere, grössere Abschnitt der Uvea, welcher an die Sclerotica anliegt, erhielt seinen Namen, Choroidea, von \%opostòis

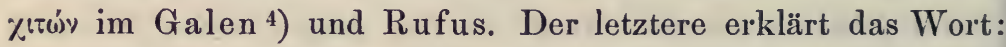
choroides vocatur, quoniam venulis referta (gefässreich), secundinas foetui circumdatas (i. e. Chorion) repraesentat ${ }^{5}$ ). Die Ausdrücke Chorion und Choroidea stehen zu dem Gefässreichthum der Häute, welche ihn führen, in keiner Beziehung, denn Chorion hiess bei den Griechen jede beliebige Haut, Thierfell, und Leder, wie sein lateinischer Verwandter: corium.

Der Uebersetzer des Avicenna, Gerardus Cremonensis, nannte die zweite Haut des Auges: Secundina, theils weil er dieselbe von der Secundina cerebri (weiche Hirnhaut) ableitete, theils weil er ihr dieselbe Ernährungsbeziehung

1) Isagogae in libros Hippocratis et Galeni, Lib. I, pag. 21.

2) De partibus hominis, pag. 36 .

3) Berengarius, Isagogae breves, Caput de anatomia oculorum.

4) De usu partium, Lib. X.

5) De partibus hominis, pag. 36. Georgius Valla glaubte deshalb das Wort choroides mit Tunica sanguinolenta übersetzen zu müssen. 
zum Auge zuschrieb, wie sie die Secundina des schwangeren Uterus (Chorion), zum Embryo hat. - Die Uvea der Arabisten, als Choroidea + Iris, erfreute sich keines langen Bestandes. Seit ihr hinterer grösserer Abschnitt, als selbstständige Choroidea installirt wurde, blieb nur die Iris als Uvea zurück. Beide Namen vertreten sich wechselseitig bei einem und demselben Autor, z. B. Haller. Aber auch dieser Besitz wurde ihr geschmälert, denn heutzutage versteht man unter Uvea, nur die hintere Pigmentlamelle der Iris. Es liesse sich dafür auch ein Grund finden, wenn man das Irispigment, mit dem schwarzen, sammtähnlichen Häutchen an der inneren Oberfläche des Balges einer blauen Weinbeere vergleicht.

\section{Uvula und Uva.}

Wenn der lateinische Avicenna, und das Heer der Arabisten, vom Zäpfchen reden, behandeln sie dasselbe als Uva, nicht als Uvula. Uva hat den Celsus zum Patron, und wurde deshalb populär ${ }^{1}$ ).

Wir müssen jedoch bemerken, dass $U v a$ eigentlich ein pathologischer Terminus ist. Die Griechen nannten das gesunde

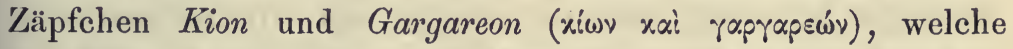
Worte im Lateinischen zu Columna und Gurgulio werden ${ }^{2}$ ). Aristoteles nannte aber nur das durch Entzündung angeschwollene Zäpfchen Staphyle (d. i. Uva, Weintraube), und den entzündeten weichen Gaumen: Staphylophoron ${ }^{3}$ ). Rufus äussert

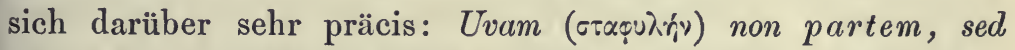
affectum ( $\pi \dot{\alpha} \theta \eta n \alpha)$ nominari oportet $\left.{ }^{4}\right)$. Vesalius enthält sich deshalb der Uva, und bleibt bei der Columella, worin er unter

1) De medicina, Lib. VI, Cap. 14, de uvae morbis.

2) Rufus Ephesius, de partibus hominis, pag. 28.

3) Historia animalium, Lib. I, Cap. 11.

4) Toidem. 
geschichtskundigen Anatomen, deren es seiner Zeit mehr als jetzt gab, Anhänger fand. Erst die neuere Zeit erfand das Diminutiv von $U v a$, als $U v u l a^{1}$ ), für welche wir vergebens nach einem classischen Gewährsmann gesucht haben, und sie deshalb für einen Barbarismus erklären müssen, jedoch avec des circonstances atténuantes. Der Vesal'schen Columella, kann eine anständige Abkunft nicht abgesprochen werden, denn sie ist die wörtliche Uebersetzung von xovis, dem von $R u f u s^{2}$ )

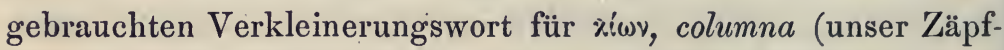
chen). Die im Pierer anzutreffende Livitula für Uvula, lässt sich in keinem Wörterbuch, ausser jenem von Du Cange, ertappen. Papias, der Verfasser des ersten lateinischen Lexicon (Elementarium), soll sich desselben bedient haben, wie im Glossarium des Du Cange gesagt wird. Das Wort wird aber dort nicht als Livitula, sondern als Livitila geschrieben, und dem Sublinquium des Papias (Zäpfchen) gleichgestellt. Ich halte Livitula und Livitila für Schreibfehler. Es giebt ein Adjectiv lividulus, als "neidisch":

$$
\text { "- - - quibus invides, si lividulus sis." }
$$

$$
\text { (Juvenal, Sat. X.) }
$$

Lividulus hat aber auch den Werth von bläulich (lividus, racemi lividi, im Horaz, blaue Trauben). Da nun Staphyle und Uvula sich auf das durch Congestion angeschwollene und bläuliche Zäpfchen beziehen, mag wohl auch die livitula = lividula, durch die Copisten des Papias, zu einer ganz unberechtigten Existenz in der anatomischen Sprache gekommen sein, wo sie übrigens nur als Rarität bekannt ist, an deren

1) J. Veslingii Syntagma anatomicum, Edit. B lasii, 1695, pag. 274. Der Westphale Ves ling, geboren $1598, \dagger 1649$, studierte und lebte in Italien, wo er eine Zeitlang, Professor der Anatomie in Padua war, und zwar einer der geachtetsten.

2) Op. cit., pag. 56 . 
etymologische Deutung sich noch Niemand gewagt hat. Die barbarischen Worte: Sublingua, Sublinguium, und Sublingium, entstanden verkehrter Weise, aus der i $\pi \circ \gamma \lambda \omega \sigma \sigma i c$ des

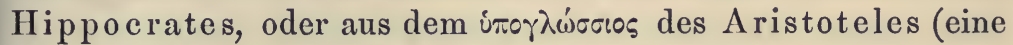
Geschwulst unter der Zunge). Von den, im Pierer und Choulant zusammengetragenen zahlreichen Synonymen für Uvula, haben Sibilus, Tintinnabulum, und Plectrum, Beziehung auf die uralte Vorstellung, dass das Zäpfchen bei der Stimmbildung mitthue, ein schon zu Rufus Zeiten verworfener Irrthum: nullam, magni faciendam utilitatem (zpsiav) afferens, unde fit, ut ea recisa, nulla corporis actio vitietur $\left.{ }^{1}\right)$. Galen hielt es noch

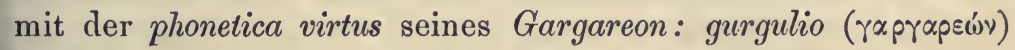
ad vocis magnitudinem et elegantiam facit, aër enim ingrediens, ab ipso prius inciditur, et impetus ipsius vehementia frangitur, et $o b$ id, etiam vis frigoris retunditur; proinde nonnulli, quibus ad basin usque fuerat amputatus, non modo noxam in voce perspicue senserunt, verum etiam frigidiorem inspirationem, ex quibus plerique aut pulmone, aut thorace refrigerato perierunt $\left.{ }^{2}\right)$. Er trug, aus diesem Grunde, das Zäpfchen, nie bis zu seiner Basis ab.

Während die italienische und englische Sprache, der lateinischen Uvula treu blieben, die erstere sich nur erlaubte, das comaskische uga für uva, auch in ugola statt uvola, zu verwenden, haben die Franzosen und die Spanier, neue Namen dem Zäpfchen angedichtet. Die französische luette lässt uns, wenn wir das provençalische lavouletto berücksichtigen, aus welchem sie hervorging, noch einen Anklang an die lateinische Uvula aus sich heraushören. Aber das spanische Gallillo und Galluelo, hat mit Uvula nichts mehr gemein, und leitet auf agallas hin. Las agallas heissen die Amygdalae, weil die Spanier sie nicht mit Mandeln, sondern mit Galläpfeln vergleichen. Das zwischen den Agallas hängende Zäpfchen, erborgte von ihnen seinen Namen: el galluelo, contrahirt: gallillo.

1) Op. cit., pag. 56 .

2) Oribasii Anatomica ex Galeno, pag. 67.

Hyrtl. Onomatologia anatomica. 
Die Luette vesicale der Franzosen, als vorderer, etwas verdickter, und in die Pars prostatica urethrae hineinragender Winkel des Corpus trigonum Lieutaudii, fand auch bei uns allgemeinen Anklang als Uvula vesicae.

$\Sigma \tau \alpha \varphi v \lambda \gamma_{\text {ist }}$ und war immer nur Z $\mathrm{Z}$ a f chen, niemals weicher Gaumen. Deshalb sind die für die Levatores palati mollis beliebt gewordenen Spheno- und Petro-salpingo-staphylini, und der Substitut des Constrictor isthmi faucium, als Glossostaphylinus, aus der Anatomie zu verbannen, da sie sprachlich unrichtig sind. Dagegen darf der Azygos uvulae, sub forma des Palatostaphylinus (Fallopia), noch fortdauern, da er wirklich im Zäpfchen aufgeht.

Sprachliches über Uvula und Gargareon, sieh' in \$. LXIII, meiner oft citirten Abhandlung HL.

\section{Vacuolen.}

Die Sprache, welcher dieses Wort angehört, ist noch nicht erfunden worden. Die Histologen verstehen unter Vacuolen kleine Hohlräume im Gewebe verschiedener Gebilde. Vacuus mag ihrem Geiste vorgeschwebt haben.

\section{Vagus.}

Unseren anatomischen Vorfahren, welche mit Galen nur sechs Hirnnervenpaare kannten, war der Vagus, das Par sextum (Vesal und Fallopia). Durch die Constituirung des Olfactorius und Trochlearis als autonome Hirnnerven, wurde er zum Par octavum (Willis), durch die Auflösung des alten Par quintum in einen Acusticus und Communicans faciei, zum Par nonum, und durch die von Sömmerring durchgesetzte Loslösung des Glossopharyngeus vom Vagus, zum Par decimum, was er heute noch ist. Der Nervus accessorius Willisii bildet das Par 
undecimum, und der Hypoglossus das Par duodecimum, womit die zwölf Hirnapostel vollzählig wurden.

Allen alten Anatomen fiel es auf, dass, während die Gehirnnerven entweder nur an Ein einziges Organ treten (Geruchorgan, Sehorgan, Auge, Zunge), oder sich in einer kleinen Gruppe von Organen auflösen, nur das sechste Paar (Vagus), einer Menge von Organen angehört, welche, vom Kopf bịs zum Becken hinab, in ununterbrochener Reihe aufeinanderfolgen. An allen diesen Organen zieht der Vagus vorbei, und sendet ihnen seine Aeste zu. Daher sein Name Vagus s. Ambulatorius: quia non determinatur ad aliquam specialem partem, sed per omnia viscera vagatur ${ }^{1}$ ). Das Wort Vagus, hat also in der Anatomie einen anderen Sinn erhalten, als es bei den Römern hatte. Diesen war vagus etwas Hin- und Herstreifendes ${ }^{2}$ ), Unstätes, und Abschweifendes. Der anatomische Vagus vagirt aber gar nicht. Er geht schnurgerade, und weicht von dem Anfang seiner Bahn, bis zu ihrem Ende, von seiner absteigenden Richtung nirgends ab. Der anatomische Beiname vagus bezieht sich also nicht auf die Richtung des Nerven, sondern auf die varia organa, welchen er während seines geraden Verlaufes begegnet. In diesem Sinne durfte Haller auch den Nervus facialis, einen Nervus multivagus nennen ${ }^{3}$ ). Der deutsche Name umherschweifender Nerv ist also auf den Vagus gar nicht anwendbar. Winslow nannte ihn, eben der vielen, von ihm versorgten Organe wegen: Sympathicus medius ${ }^{4}$ ), zum Unterschied vom grand und petit Sympathique (unser eigentlicher Sympathicus und Communicans faciei). Sömmerring's Stimmnerve ${ }^{5}$ ) steht dem Vagus nicht gut an, wohl aber seinem Ramus

1) Guernerus Rolfink, dissertationes anat, pag. 742.

2) Aves vagae und pisces vagi, - vaga multitudo, - ritu ferarum per silvas vagi homines.

3) Elem. physiol., T. 1V, pag. 228.

4) Tractatus de nervis, Num. 104.

5) Hirn- und Nervenlehre, pag. 244. 
laryngeus recurrens, dessen Durchschneidung, wie schon Galen wusste, die Stimme aufhebt. Meckels Lungen-Magennerv ${ }^{1}$ ) drückt die zwei Hauptorgane aus, denen die Ramificationen des Vagus angehören. Der Name ist so gut gewählt, dass Chaussier darnach seinen nerf pneumogastrique bildete, welcher nur an einem kleinen Gebrechen leidet, da sein Vorname nicht pneumo sein kann, sondern pneumono sein muss. Nichtsdestoweniger wird bei uns Deutschen, weder der Nervus pneumono-gastricus, noch der Lungen-Magennerve je zu so allgemeinem Gebrauch kommen, wie der Vagus, da dieser der kürzere, und somit bequemer ist.

\section{Valvulae.}

Ausser den Herzklappen, waren den Griechen und Römern keine Klappen im thierischen Leibe bekannt. Sie wurden nicht als Klappen aufgefasst, sondern nur als Häutchen, úuévę,

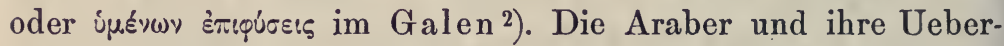
setzer, blieben bei den Häutchen. Die Arabisten kennen keinen anderen Ausdruck für Klappen, als pelliculae und panniculi, als zwei verschiedene Uebersetzungen der íú́ves Galeni. Als die gute Zeit der Anatomie mit Vesalius herankam, wurden die pelliculae und panniculi durch membranae und membranulae verdrängt: ea cordis corpora membranas vocamus, quae vasorum radicibus adnata, prorsus membranae existunt ${ }^{3}$ ). Die Klappen waren dem Vesal das einzige am Herzen, was nicht fleischig ist, und deshalb bevorzugte er den Ausdruck membranae. Auf Valvulae verfiel zuerst Benedictus ${ }^{4}$ ), von welchem sie Bauhin übernahm ${ }^{5}$ ). Spigelius bediente sich

1) Handbuch der Anatomie, III. Bd., §. 1835.

2) De usu partium, Lib. VI, Cap. 14.

3) De corp. hum. fabrica, Lib. VI, Cap. 13.

4) Anatomice, Lib. III, Cap. 14.

5) Theatrum anat., Lib. II, Cap. 22. 
fortan dieses Namens, und gedenkt auch der Benennung Ostiola: membranae cordis (Herzklappen) a recentioribus, ab usu, Valvulae s. Ostiola (kleine Thürflügel) vocantur. Fabricius ab Aquapendente, welcher die Klappen in den Venen zuerst einer genaueren Untersuchung würdigte, und ihr reiches Vorkommen in den subcutanen Venen darlegte, schrieb über sie ein eigenes Werk: De venarum ostiolis, Patavii, 1603, dessen Titel, ohne folgendem, nicht verständlich ist. Valvulae ') weisen auf Valvae hin, deren Verkleinerung sie sind. Valvae heissen die zwei Schotenklappen einer Hülsenfrucht, und die Doppelflügel einer Thüre: valvae aedium et templorum, und Valvae oder Valvolae, nicht Valvulae fabarum et lentium (Columella). Per tropum kann man sich des Wortes Ostiola, statt Valvolae bedienen, wenn das zu Verschliessende (Ostium), für das Verschliessende substituirt wird. So drängten sich die Ostiola, anstatt der Valvolae, schon bei den Latino-Barbari in die anatomische Sprache ein, wurden aber von ihnen nicht Ostiola, sondern, durch ihre Vorliebe für ein übel angebrachtes $H$, Hostiola geschrieben, wie Prohoemiun, Hysophagus, und Herisipilas, statt Prooemium, Oesophagus, und Erysipelas. Dass aus den correcten Valvolae, uncorrecte Valvulae entstanden, haben gleichfalls die Latino-Barbari auf ihrem Gewissen. Niemand wehrte sich 'gegen die Valvulae, und so sind sie denn zu einem Allerwelts-Barbarismus geworden, welchen man nur durch den Klang ähnlicher Verkleinerungsworte, wie flammula, furcula, habenula, schedula, sphaerula, campanula, etc. entschuldigen kann.

Ein ärgerer Fehler als in der Verwechslung des o mit $u$, liegt im Singular: Valvula. Valvolae, als Thürflügel oder Schotenklappen, waren immer zwei. Der Singular: Valvola, wurde noch niemals erlebt. Einer Einzelklappe, wie die Valvula Eustachii, die Valvula Thebesii, die Valvula pylori, wäre

1) Im Festus seltsamer Weise: Valvoli (de verborum significatione, Edit. Müller, pag. 374). 
eine andere lateinische Benennung zuzuweisen, etwa Plica. Es können und dürfen also nur die pa arigen Venenklappen Valvolae genannt werden. Drei gleichgeformte Klappen, wie die Semilunares der Aorta und Pulmonalis, und die Tricuspidales im rechten Ventrikel, sind keine Valvolae, da weder dreiflügelige Thüren, noch dreiflügelige Schoten existiren. Vielleicht zu rigorös! Eine einfache Thüre, hiess nicht Valvola, sondern Janua. Wir finden deshalb im J. C. Arantius, welcher ein guter Lateiner war, für Valvola auch Janitrix ${ }^{1}$ ). Bei den treuherzigen deutschen Uebersetzern des Bauhin und Vesling, heissen die Herzklappen: "Thürlein" oder "Fallen". Isidorus, welcher die weibliche Scham Vulva nennt, während alle Alten, unter Vulva nur den Uterus verstehen, erklärt seine Abweichung vom Herkömmlichen dadurch, dass er die paarigen grossen Schamlefzen, mit Valvae vergleicht, als Thürflügel an der Geschlechtsöffnung.

Drei Arten anatomischer Valvulae: die Valvula magna cerebri, die Valvulae conniventes Kerkringii, und die Valvula Bauhini sind einer besonderen Betrachtung werth.

\section{Valvula cerebri magna.}

Jede Valvula muss einen freien Rand haben. Hat sie diesen nicht, so ist sie keine Klappe. Die in einem viereckigen, durch Vierhügel, Bindearme und Wurm des kleinen Gehirns gebildeten Rahmen ausgespannte Valvula cerebri magna, verdiente also einen besseren Namen. Diesen hat ihr Reil mit seinem grossen Marksegel zu geben vermeint ${ }^{2}$ ). Tegmen cinereum würde dem Verhältniss dieser Klappe zur vierten Gehirnkammer am besten entsprechen. Die hinteren Marksegel, welche sich zwischen Flocke und Malacarnischen Knoten

1) Observationes anat., Venetiis, 1587, Cap. 33.

2) Archiv für Physiologie, VIII. Bd., pag. 15. 
des kleinen Gehirns befinden, können ihre Namen als Valvulae cerebelli schon fortbehalten, da sie einen freien, halbmondförmigen, nach vorn gekehrten Rand haben.

\section{Valvulae conniventes Kerkringii,}

Indem die Anatomie vielen Organen des menschlichen Leibes, die Namen ihrer vermeintlichen Entdecker beilegt, begeht sie manches harte Unrecht. Die Valvulae conniventes Kerkringii gehören hieher. Zwar hat sie nicht die Anatomie, sondern Kerkring selbst: conniventes genannt, und sie für eine neue Entdeckung gehalten: alia erat novitas, valvulae nimirum per jejunum et colon dispositae, quas ego, si verbis audacia detur, nominare non reformidem: valvulas conniventes $\left.{ }^{1}\right)$. Kerkring nimmt also auch die Valvulae sigmoideae des Dickdarms (colon) unter seine conniventes auf. Die kurze Beschreibung, welche er von ihnen giebt, ist ebenso ungenau, wie der Name unrichtig. Denn connivere heisst: sich zusammenneigen, und schliessen. Diese Klappen, welche einander nicht gegenüberstehen, schliessen sich nie, und neigen sich nicht zusammen, wie die beiden Augenlider, von deren Blinzen und Schliessen, connivere fast ausschliesslich gebraucht wird, sondern decken sich dachziegelförmig, wenn sie breit sind, wie im oberen Bereich des Dünndarms. Dem Vermeinen des Kerkring: „quod hactenus observatae hae valvulae non fuerint", muss ich entgegenstellen, dass Fallopia ${ }^{2}$ ) diese Klappen gesehen hat. Dass sie auch Vidus Vidius kannte, lässt sich aus dem Texte ${ }^{3}$ ), wo nur von fibrae, nicht von plicae intestinorum gesprochen wird, nicht mit Sicherheit entnehmen. Die ivş des Galen, auf welche

1) Spicilegium anat., Amstel. 1670, Obs. 39.

2) Observationes anat., in Halleri Bibliotheca anat., T. I, pag. 219.

3) De anatome corp. hum., Lib. V, Cap. 5. 
Assmann, im Vol. XX, pag. 631, der Opera Galeni (Edit. Kiihnii) hinweist, sind ganz gewiss nicht die Falten, sondern die Muskelfasern des Gedärms. Galen konnte mit den Valvulae conniventes schon deshalb nicht bekannt gewesen sein, weil er keine menschlichen Leichen zergliederte, die fraglichen Falten aber bei Thieren, ausser den Cetaceen und dem Ornithorrhynchus, nicht vorkommen.

\section{Valvula Bauhini, Tulpii, oder Fallopiae?}

Sieben Städte Griechenlands stritten sich um die Ehre, der Geburtsort des Homer gewesen zu sein:

"Smyrna, Rhodus, Colophon, Salamis, Chios, Argos, Athenae."

Ebenso viele Anatomen wurden der Ehre theilhaftig, für die Entdecker der Valvula coli gehalten zu werden. Sie sollen sich in chronologischer Ordnung nacheinander präsentiren.

1. Joh. Posthius, Professor zu Heidelberg, und Leibarzt des Pfalzgrafen. Ein Schüler des berühmten Rondelet in Montpellier, scheint er von diesem die Kenntniss dieser Klappe übernommen zu haben (quam putes a Rondeletio habuisse, Haller). Er erwähnt sie ganz kurz in seinen Observationes anatomicae, pag. 502, welche zugleich mit der Res anatomica des Realdus Columbus, in Frankfurt, 1590, aufgelegt wurden. Da Rondelet im Jahre 1566 starb, muss die Entdeckung der Klappe, vor dieses Jahr gesetzt werden.

2. Vidus Vidius, ein Florentiner, kurze Zeit Professor der Anatomie in Paris, und Leibarzt König Franz I., starb 1567. Sein Werk: Ars medicinalis, dessen T. III, die anatome corporis humani enthält, wurde lange nach seinem Tode in Venedig zuerst in Druck gelegt (1611). Ich besitze besondere Ausgaben der Anatome, welche in Florenz, und später in Frankfurt erschienen sind. In dieser Anatome, wird einer Falte der Darmschleimhaut erwähnt, welche die Fäcalmasse 
verhindert: sursum reverti. $\mathrm{Haller}$ hält diese Angabe für älter, als jene des Posthius ').

3. Constantius Varolius, Professor in Bologna, starb 1578. Sein Opus posthumum: de resolutione corporis humani, Francof. 1591, enthält in Lib. III, Cap. 3, eine kurze Hindeutung auf unsere Klappe, welche er als eine Invagination des Ileum in das Coecum auffasste, und Operculum ilei nannte. Riolan führt deshalb die.Klappe, als Valvula Varolii ${ }^{2}$ ) auf.

4. Caspar Bauhin, Professor in Basel, beschrieb die von ihm im Jahre 1579 in Paris entdeckte Klappe, zuerst in der durch ihm veranstalteten lateinischen Ausgabe von Fr. Rousset's Hysterotomotokie (de sectione caesarea), Basil., 1588. Ausführlich befasste er sich mit ihr in seinem Theatrum anatomicum (1621), Lib. I, pag. 63 und 64. Er wusste von den eben angeführten Vorläufern nichts, und war sehr gerührt darüber, dass Andreas Laurentius (Dulaurens), Casserius, Fabricius ab Aquapendente, und Bartholinus, ihm die Ehre der Entdeckung zuerkannten, und die Klappe mit seinem Namen schmückten, welcher noch jetzt in omnium ore circulirt.

5. Nicolaus Tulpius, Arzt und Bürgermeister in Amsterdam, welches er, 1672, von der Besetzung durch die Franzosen rettete, giebt sich in seinen Observationes medicae, Amstel., 1652, Lib. III, Cap. 21, nicht für den Entdecker der Valvula Tulpii aus, nennt selbst die Klappe, wie sie Varolius nannte: ilei operculum, fügt auch über ihre Verwendung nicht mehr hinzu, als Bauhin wusste, beachtete aber ihre beiden Retinacula, deren er als exiles membranulae und Vincula, zur Fixirung der Klappe Erwähnung macht.

6. und 7. werden auch Salomon Alberti, Professor in Wittenberg ${ }^{3}$ ), und Archangelus Piccolhomini ${ }^{4}$ ), theils mit

1) Elem. physiol., T.VII, pag. 132.

2) Anthropographia, Pariser Edit., 1626, Lib. II, Cap. 14.

3) Historia plerarumque partium corp. hum., Wittebergae, 1585.

4) Praelectiones anatomicae, Romae, 1586. 
der Entdeckung, theils mit der richtigeren Auffassung und Beschreibung der Klappe, in Verbindung gebracht.

Dennoch ist keiner von den sieben genannten Weisen, der wahre Entdecker der Valvula coli. Dieser war vielmehr der grosse Fallopia. Nicht in seinen berühmten Observationes anatomicae hat er von dieser Klappe gehandelt, sondern in einer nicht gedruckten Handschrift: Anatomia simiae, welche in der Göttinger Bibliothek enthalten ist ${ }^{1}$ ). Bei dem Bericht über eine Section und Demonstration, am 22. Februar, 1553, stehen folgende Worte: si in rectum aqua aut flatus immittatur, perveniet in coecum, non transgreditur autem crassa. At si superius immittatur, pertransiet. Ratio est, quia ad insertionem ilei, plicae sunt duae, quae in inflatione et repletione comprimuntur, et prohibent regressum. Der früher genannte Vidus Vidius, war ein Schüler des Fallopia. Er konnte die Kenntniss der Klappe, wohl von seinem Lehrer erhalten haben.

Will man also die Valvula coli, nach ihrem Entdecker benennen, so kann sie nur Valvula Fallopiae heissen. Alle übrigen Benennungen nach Anatomen, sind historische Unrichtigkeiten. Um ihnen ganz aus dem Wege zu gehen, wollen wir, mit Haller, der Valvula coli treu bleiben, oder, den Franzosen folgend, der Valvula ileo-coecalis.

\section{Vasa vorticosa Stenonis.}

Die Vasa vorticosa Stenonis, sind eigentlich unipolare Wundernetze der Choroidealvenen (sieh' den Artikel: Retia), mit stark divergenten, und bogenförmig geschwungenen Zweigen, ähnlich dem Zerfahren des Hauptstrahles eines Springbrunnens, in viele, bogenförmig zur Erde fallende Strömchen. Mit einem Wirbel oder Strudel (vortex), sind sie kaum zu vergleichen. Alle Beiwörter in osus drücken ein Uebermass an Menge oder

1) Blumenbach, Medicinische Bibliothck, Bd. I, pag. 372, und dessen Institutiones physiologicae, §. 419. 
Grösse eines Gegenstandes aus. Vorticosus wäre demnach reich an Wirbeln, wie die Charybdis vorticosa im Sallust, der amnis vorticosus im Livius, und der Turbo vorticosus (Sturmwind) im Seneca. Die Vasa Stenonis sind nicht reich an Wirbeln, wohl aber bilden sie in ihrer Anordnung Figuren von bogenförmig geschwungenen Strahlen, welche nur hyperbolisch Vortices genannt werden können. Vortex ist übrigens die alte Schreibart für Vertex. Vorto und Verto bedeuten drehen, und Vortex oder Vertex das im Kreise Gedrehte, oder sich Drehende. Vasa palmata würde auf die fraglichen Gefässe viel besser passen. Aus Achtung vor Nicolaus Stenson, kann man aber auch die Vasa vorticosa noch passiren lassen. Stenson erwähnt die Vasa vorticosa in seiner Schrift: Myologiae specimen, Florent., 1665. Die Schrift hat einen Anhang: Carchariae dissectum caput (Anatomie eines Haifischkopfes). In diesem Anhang lesen wir auf pag. 83, die vasa vorticosa choroideae. Zinn bildete sie in seiner Descriptio oculi humani sehr schön ab (Tab. IV), so schön, dass alle Abbildungen der Vasa vorticosa in den verschiedensten illustrirten Anatomien, und anatomischen Kupfertafeln, dieser Zinn'schen Figur auf ein Haar gleichen! Dass Zinn diese Vasa vorticosa mit dem Namen ihres Entdeckers ziert, ist billig und schön. Im $\mathrm{Haller}$ finden wir sie als Venae ciliares posteriores, von den sehr feinen Venis ciliaribus anticis unterschieden ${ }^{1}$ ).

Nimmt man Vertex und Vortex nicht als Wirbel und Strudel, sondern als Scheitel, wie in Cicero's a talo ad verticem, von der Sohle bis zum Scheitel, so lässt sich die Benennung der Vasa vorticosa insofern auch etymologisch gut heissen, als die vielen bogenförmig geschwungenen Venen eines Wirbels, in einen Scheitelpunkt zusammenlaufen, welcher der Anfang des einfachen, abführenden, venösen Stämmchens des betreffenden Wirbels ist.

Vergleiche den Artikel: Vertebra.

1) Elem. physiol., T. V, Lib. 16, Sect. 2, §. 37 . 


\section{Vastus.}

Vier Muskeln, welche die vordere Peripherie des Oberschenkels einnehmen, und mittelst ihrer gemeinschaftlichen, an die Spina tibiae implantirten Endsehne, das gebogene Knie wieder ausstrecken, wurden von mir als Extensor cruris quadriceps zusammengefasst. Ihre früher gebrauchten Einzelnamen waren: Rectus femoris, Vastus externus und internus, und Musculus cruralis. Um die beiden Vasti handelt es sich hier.

Der Name Vasti, wurde zuerst von Joh. Riolan ') diesen Muskeln beigelegt, von Spigelius adoptirt, und sofort von allen Myologen (Cowper, Douglas, Winslow) festgehalten. Früher hiessen sie, nach Galenischer Weise, Septimus und Octavus tibiam moventes. Der Vastus externus ist in der That eine gewaltige Fleischmasse, welche selbst jene des Soleus überbietet. Aber der Vastus internus und der Cruralis, welchen ich als Vastus medius, dem externus und internus beiordnete, haben gar nichts Vastes an sich, und widersprechen somit ihrem Namen, welcher überdiess nicht glücklich gewählt wurde. Denn Vastus ist, in erster Linie, öde und leer (man denke an Devastiren), und in zweiter Linie unermesslich und ungeheuer gross, weil jede grosse, räumliche Ausdehnung, ohne Abwechslung, einförmig erscheint, und den Eindruck des Leeren und Oeden auf uns macht, wie die Wüste, das Meer, unbewohnte und uncultivirte Landstrecken (Desertum vastum, Mare vastum, Provincia vasta, niemals aber Coelum vastum, da er von den Gestirnen belebt und bevölkert wird). Unser Vastus internus und medius sind aber weder leer, noch unermesslich, im Gegentheil kleiner und schwächẹ als andere Muskeln, welche nicht Vasti heissen. Nur dem Vastus externus könnte man insofern seinen Namen erlauben, als Cicero von homines vasti et agrestes redet, worunter er plumpe Leute

1) Anthropographia, Lib. V, Cap. 42. 
versteht. Zart ist der Vastus externus nicht, also mag er plump heissen. Die Franzosen (Dumas) nennen ihn le massif. Bei den deutschen Anatomen, erscheinen die Vasti, seit Sömmerring, als dicke Schenkelmuskeln. Man möge darnach die Vasti in Crassi umwandeln. Doch wozu das Gerede? Es leuchtet ja Jedem von selbst ein, dass, wenn die anatomische Nomenclatur dereinst eine vernünftige Reformation erleben sollte, der Rectus femoris als langer Kopf, die drei Vasti aber: äusserer, innerer, und mittlerer kurzer Kopf des Extensor cruris guadriceps benannt werden müssen.

\section{Vena portae oder Vena portarum?}

Beide Redensarten finden sich bei den alten lateinischen Anatomen, bei den neueren ausschliesslich Vena portae.

Nie wird man bei einem griechischen Arzte oder Anatomen, eine $\pi \dot{j} \lambda \eta$ der Leber ausfindig machen können; - sie reden alle nur von ai $\pi^{j} \lambda \alpha$, wie Plato ${ }^{1}$ ) Aus diesem Grunde allein, wäre die Vena portarum, der Vena portae vorzuziehen. Was sind die $\pi \dot{\lambda} \lambda \alpha_{t}$ der Leber? Wenn ich, wie ich mir zutrauen darf, den Galen richtig verstanden habe, so waren die

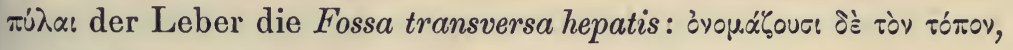

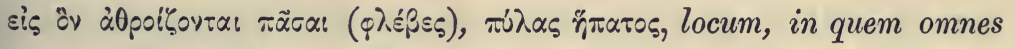
venae colligantur, portas jecoris vocant ${ }^{2}$ ). Hiemit stimmt auch Julius Pollux überein: portae hepatis dicuntur, per quas sanguis suscipitur, ut ab unica vena, in omnes ramos deducatur ${ }^{3}$ ). Bedenkt man ferner, dass die griechischen Classiker, wie Homer und

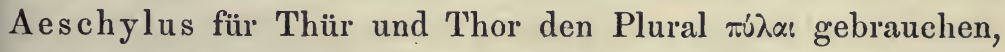
so kann kein Zweifel mehr obwalten, dass Vena portarum, der

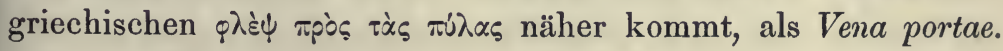

1) Timaeus, 71, c.

$\left.{ }^{2}\right)$ Oribasius, Anatomica ex Galeno, pag. 114.

3) Onomasticon, Lib. II, Cap. 4, Sect. 215. 
Der Plural $\pi \dot{\lambda} \lambda a$ erklärt sich daraus, dass die Fossa transversa mit anderen Gruben der Leber zusammenhängt, in welche sich die Aeste der Pfortader hineinlegen. Die Leberlappen, welche diese Furchen begrenzen, schliessen sich zuweilen über den Furchen zusammen, verwandeln sie in Gänge, deren Oeffnungen, füglich $\pi \dot{\jmath} \lambda \alpha_{l}$, Thore, genannt werden können. Die Scholiasten des Galen, dehnten den Begriff der $\pi \dot{\lambda} \lambda \alpha_{\ell}$ viel weiter aus, und verstanden darunter die ganze concave Leberfläche (sima jecoris pars ${ }^{1}$ ), während andere die Pfortader selbst als Vena porta, nicht Vena portae, gelten lassen. Sie haben den Rufus Ephesius für sich, welcher ganz bestimmt erklärt:

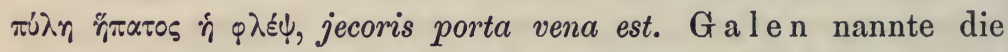

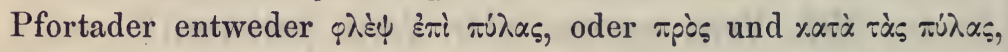
und soll somit die Pfortader richtig Vena ad portas, wie May er ${ }^{2}$ ) allein gethan, nicht Vena portarum genannt werden. Mit den beiden genannten Ausdrücken intercurrirt im Galen auch

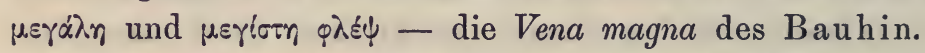

Inzwischen hat aber, bei den Neueren, die Vena portae entschieden mehr Anhänger gefunden als die Vena portarum, und zwar erst seit der Mitte des vorigen Jahrhunderts, wo die Exercitatio anatomica von A. F. W alter, De vena portae, Lips., 1739, ihr die Bahn eröffnete. Den auffallenden Namen: Vena lactea, führt die Pfortader bei den Uebersetzern der Araber, da man damals keinen anderen Weg des Chylus in das Blut kannte, als durch die Venae mesaraicae in die Pfortader. Vena stelechiaea liegt blos in den lateinischen Uebersetzungen des Galen vor, und bei einigen Latino-Barbari als Stilicha. Sie ist die $\sigma \tau \varepsilon \lambda \varepsilon \chi\llcorner$ ¿i $\alpha$ des Galen ${ }^{3}$ ), ein Synonym für die Pfortader, und zwar nur für ihren Hauptstamm, von $\sigma \tau \varepsilon \dot{\lambda} \varepsilon \chi \circ \varsigma$, Stamm. Komisch klingt die Erklärung, welche Garengeot von seiner Veine-porte giebt: parce qu'elle porte le sang dans le foie. - Die Vena ostiaria

1) Gorraeus, Definitiones medicae, pag. 396.

2) Beschreibung des menschlichen Körpers, Bd. IV, Seite 445.

3) De locis affectis, Lib. VI, Cap. 4. 
des Bartholin, und die Vena janitrix des Bauhin sind Tautologien für Pfortader. Die Vena arteriosa im Sömmerring ${ }^{1}$ ) hat nur auszudrücken, dass die Pfortader sich in der Leber wie eine Arterie verzweigt. Den Namen Vena arteriosa führt im Galen, und im ganzen Alterthum, blos die Arteria pulmonalis, weil sie venöses Blut führt, wie die Venen überhaupt, aber die Wanddicke einer Arterie zeigt. J. Ch. Bianchi's ${ }^{2}$ ) semiarteria ist eịn unglücklicher Einfall gewesen, welcher die Verzweigung der Pfortader nach Art einer Arterie, mit ihrem Wesen als Blutader ausgleichen sollte. Als Manus hepatis präsentirt uns A. Spigelius die Pfortader: quod per eam, tamquam per manum, hepar alimentum ex intestinis attrahat ${ }^{3}$ ). Manus hepatis (Plural) werden von den Arabisten zuweilen auch die Leberlappen genannt, insbesondere der linke, weil er die ventrale Fläche des Magens umgreift oder deckt.

Wenn ich mir in meinem Lehrbuch der Anatomie erlaubte, die Einschnitte anderer Organe, in welchen die Gefässe derselben wechseln, Portae zu nennen (Porta pulmonis, Porta lienis, Porta renis ${ }^{4}$ ), so geschah dieses mit weit mehr Recht, als Rolfink ${ }^{5}$ ) die weibliche Schamspalte Porta nennen konnte. Die Schamspalte ist kein Stappelplatz für Gefässe, wie die Pforte der Lunge, der Milz, und der Niere.

\section{Vermis cerebri vor Alters, und jetzt.}

Die Adergeflechte des Gehirns kannte Galenus ganz

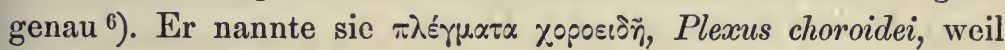

1) Gefässlehre, pag. 273.

2) Historia hepatica, Taurin., 1711, pag. 23.

3) De corp. hum. fabrica, Lib. V, Cap. 4.

4) Welche, als Portae renis schon im Fallopia vorkommt.

5) De partibus genitalibus, P. II, Cap. 33 .

6) Opera omnia, Edit. Kühnii, T. II, pag. 719, T. III, pag. 657. T. IV, pag. 101, T. V, pag. 606. 
ihr Reichthum an Blutgefässen, jenem des Chorion entspricht: nomine, a chorio membrana deducto, quae foetum extrinsecus ambit ${ }^{1}$ ). Im Oribasius dagegen werden nur unsere Tela choroidea, und der mit ihr verbundene Plexus choroideus medius,

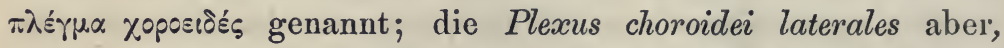
als Auswüchse des medius, mit dem Namen Apophyses scolecoideae belegt, welchen Ausdruck ich nur einmal im Galen

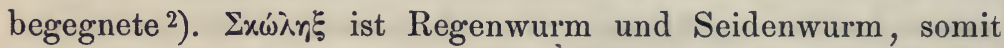

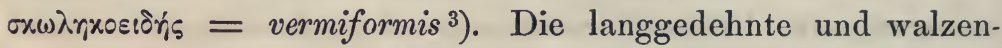
runde Form der Plexus choroidei laterales, rechtfertigt diese Benennung. So wurde denn $\sigma x \omega \dot{\lambda} \eta \xi \xi$ von Avicenna, mit Dud (Wurm), und von den Uebersetzern der Araber, mit Vermis gegeben. Der erste Wurm im Gehirn war also das seitliche Adergeflecht. Entsprechend ihrem Namen, sollten diese Würmer, welche sich bogenförmig über die Sehnervenhügel (glutia) hinüberlegen, und mit ihnen Adhärenzen eingehen, sich bald verkürzen, bald verlängern. Ihre Verkürzung bedingte eine Annäherung beider Sehnervenhügel, bis zum Zusammenschluss, - ihre Verlängerung eine Entfernung derselben von einander. Dadurch wird die dritte Gehirnkammer, welche man nicht als Kammer, sondern als Verbindungskanal zwischen der vorderen und hinteren Gehirnkammer gelten lassen wollte ${ }^{4}$ ), bald verengt und geschlossen, bald aufgethan und erweitert 5), je nachdem Eindrücke, aus der vorderen Hirnkammer (unsere Ventriculi laterales), in die hintere geschafft, oder von ihr ausgeschlossen werden sollen. Die hintere Hirnkammer war der Sitz des

1) Administrationes anat., Lib. IX, Cap. 3.

2) De usu partium, Lib. VIII, Cap. 12.

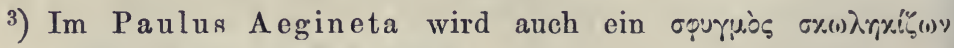
(pulsus vermicularis) erwähnt.

4) Die dritte Kammer wird auch als Via perforata im Constantinus Africanus erwähnt.

5) Substantia rubea, vermis dicta, motum habet, aperiens et claudens meatum (ventriculum) voluntarie, im Berengarius. Isagogae breves, in Cap. de medulla cerebri. 
Gedächtnisses (Cellula memorialis im Magister Richardus). Das Offen- oder Verschlossensein des Verbindungsganges zwischen der vorderen und hinteren Gehirnkammer, bedingte also das Behalten, oder das Vergessenwerden der Eindrücke.

Als die Vermes des Oribasius, in nach-Vesal'scher Zeit, durchgehends zu Plexus choroidei laterales wurden, liess man doch das Wort Vermis nicht gänzlich fallen, sondern übertrug es auf die Commissur der beiden Hemisphären des kleinen Gehirns, welche, ihrer Zusammensetzung aus vielen, kleinen, transversalen Randwülstchen wegen, an den geringelten Leib einer Raupe erinnert. So metamorphosirten sich die zwei Vermes cerebri des Oribasius, zum einfachen Vermis oder Processus vermiformis cerebelli, welche Namensübertragung zuerst von Vesal 1), dann von Bartholinus und Th. Willis ${ }^{2}$ ) vorgenommen, und von $\mathrm{Haller}^{3}$ ) als stehender Begriff in der Anatomie des kleinen Gehirns sanctionirt wurde. Häufig führt, in älteren Schriften, der Vermis cerebelli, den Zusatz bombycinus. Man wollte den generellen Ausdruck: Wurm, als Seidenw urm specialisiren. Allerdings ist bombyx $=$ Seidenwurm. Aber bombycinus hatte nie eine andere Bedeutung, als aus Seide gemacht, wie in den Classikern zum Ueberfluss bestätigt wird. Vermis bombycinus würde also seidener $\mathrm{Wurm}$, nicht aber Seidenwurm sein. Dazu hätte Bombyx allein genügt. Es liegt gar nichts daran, welcher Anatom dem kleinen Gehirn, zuierst einen seidenen Wurm aufgedrungen hat. Unsere Aufgabe ist: dicere de vitiis, parcere personis.

Der Vermis hat sich auch in die Pathologie eingebohrt. Das pestartige ungarische Lagerfieber, Febris hungarica theriodes (bösartig), s. Lues pannonica, wird als Vermis cerebri von C. G. Kühn erwähnt ${ }^{4}$ ).

1) Op. cit., Lib. VII, Cap. 10.

2) Anatomia cerebri, Cap. 3.

3) Elem. physiol., T. IV, Lib. 10, Sect. 2, §. 2.

4) Lexicon medicum St. Blancardi, T. I, pag. 625 .

Hyrtl. Onomatologia anatomica. 


\section{Vernix caseosa.}

Der in grösserer oder geringerer Menge anzutreffende, schmierige Hautbeleg neugeborner Kinder, heisst bei den Geburtshelfern und Anatomen: Vernix caseosa. Der Name entstand erst gegen Ende des vorigen Jahrhunderts, und stammt von J. G. Schulz her, dessen in Helmstadt, 1788, aufgelegte Inauguralis, den Titel führt: De.ortu et usu caseosae vernicis. Bevor Schulz diesen Namen populär machte, sprach man nur von sordes cutis embryonis, oder einem Excrementum cutis crassum et unctuosum nach Spigelius ${ }^{1}$ ), oder von einer crassa, alba, et pinguis sordities, corpori embryonis adhaerens, nach $\mathrm{Fabricius}$ ab Aquapendente 2). Die Hebammen bedienten sich der Ausdrücke Kindsschleim, Kindsschmiere, oder käsige Rinde, von welcher letzteren zur Vernix caseosa, non è, che un breve passo. Aber bedenken möge man, dass Vernix kein lateinisches Wort ist. Welcher Nationalität es angehört, lässt sich mit Bestimmtheit nicht angeben. In allen Sprachen klingt Vernix mit verschiedenem Accord: Bspovicry und Bsprikx, (im Spätgriechischen $=$ resina splendens), im spanischen berniz, im provençalischen vernitz, im französischen vernis, im italienischen vernice, im englischen varnish, im dänischen fernis, im deutschen Firniss, im ezechischen fermez. Dietz schliesst sich der Ansicht an, dass das mittellateinische vitrinire, glasiren (vitrinus = vitreus), die Mutter des romanischen vernis ist. Aus vernis ergiebt sich von selbst das Vernisium des Van Helmont ${ }^{3}$ ), für Sandaraca s. Gummi juniperinum, zwei Stoffe zum Firnissbereiten. Vernisium kürzte man zu Vernix ab, und Linné sanctionirte dieses Wort in seinem Rhus vernix (Giftbaum, Giftesche), ein in Japan heimischer Baum, welcher ein giftiges

1) De formato foetu, Cap. 8.

2) De formato foetu, Pars II, Cap. 7.

$\left.{ }^{3}\right)$ Tractatus de lith., Cap. 3, Num. 7. 
Harz ausschwitzt. Wie nun immer sei, ein Firniss kann nicht käseartig sein, sonst glänzt er nicht, und ein Käse kann nicht aus Epithelialzellen und Fettmolekülen bestehen, wie die Vernix caseosa. Die schmierige Beschaffenheit der Vernix caseosa, lässt sich weit besser durch unctuosa und mollis ausdrücken, als durch caseus, welcher in der Regel härtliche Consistenz hat. Da der schmierige Hautbeleg des Embryo doch nichts anderes als Sebum cutaneum ist, welches, in so reichlicher Menge abgesondert, die Haut des Embryo gegen die macerirende Wirkung des Liquor amnii in Schutz nimmt, wäre bei Stratum oder Indumentum sebosum embryonis zu verbleiben. Die Franzosen haben ohnediess schon ihr induit cutané du fétus.

Hätten unsere Vorfahren es verstanden, die Vernix caseosa microscopisch $\mathrm{zu}$ untersuchen, sie würden sie nie für einen Niederschlag aus dem Liquor amnii gehalten haben.

\section{Verpa und Verpus.}

Jene, welche den Synonymen für Penis, auch Verpus eingereiht haben, mögen wissen, dass Verpus ein Beschnittener, auch ein $\mathrm{Jude}$ ist:

$$
\text { "Delapsa est misero fibula, verpus erat," }
$$

und :

$$
\text { (Martial, VII, 82.) }
$$

"Quaesitum ad fontem solos deducere verpos,"

(Juvenal, $X I V$, 104.)

Verpa dagegen ist männliches Glied, kommt aber nur bei Dichtern als Tropus ${ }^{1}$ ), nie in der prosaischen Anatomie vor: „Incipit in medios mejere verpa pedes,“

(Martial, $X I, 46$.

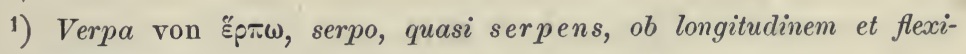
bilitatem. 
Verbus im Lexicon Blancardi, kann nur ein Schreibfehler sein, welchen Kühn übersehen hat. Ebenso unbrauchbar ist der von Pierer und Choulant verzeichnete Vepenis, welches Wort = pusillus, nur für puerulus verwendbar wäre, gleichsam "noch ohne brauchbaren Penis", wo ve die Abgängigkeit, oder den schlechten Zustand zu bezeichnen hätte, wie in vecors und vesanus.

\section{Vertebra.}

Vertebra, Wirbel, war ursprünglich etwas anderes, als die Anatomen daraus gemacht haben. Von vertere, drehen, abstammend, war Vertebra und Verticula, das Bewegliche ein Gelenk. Noch im Plinius erscheint Vertebra, als Gelenk: in vertebra ligatus talus, "das im Gelenk festgehaltene Sprungbein", und im Seneca: podagra et chiragra, et omnis vertebrarum dolor, ,jeglicher Schmerz der Gelenke“. Auch die Leibessegmente der Articulaten, heissen im Plinius vertebrae. Erst durch Celsus ging Vertebra an die Wirbel über: Spina constat ex vertebris quatuor et viginti $\left.{ }^{1}\right)$, quarum beneficio homo se vertere et flectere potest.

Die griechischen Aerzte bedienten sich für Wirbel, nul des Wortes $\sigma \pi \delta$ vồ $0 \xi$, - Homer ein einziges Mal auch des Wortes $\left.\dot{\alpha} \sigma \rho \alpha \dot{\gamma} \gamma \alpha \lambda\rangle_{\varsigma}{ }^{2}\right)$, für den ersten Halswirbel, Ilias, $X I V$, 465 und 466 :

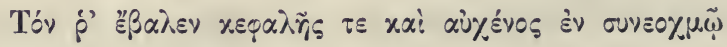

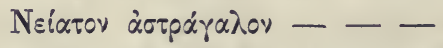

„Diesem flog das Geschoss, wo Haupt und Nacken sich füget,

"Oben am Wirbel hinein - - - ."

1) Celsus, De medicina, Lib. VIII, Cap. 1.

2) Vergleiche über Astragalos, HL, §. XLIII, Caib und Cahab. 


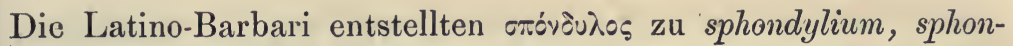

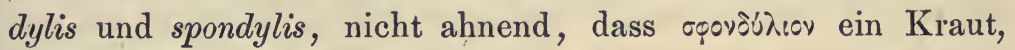

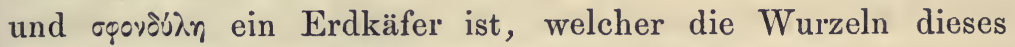
Krautes abfrisst (Aristophanes). Sie können sich allerdings

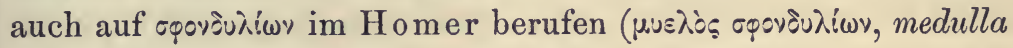

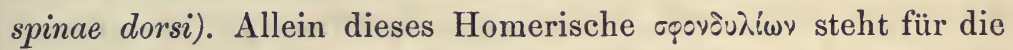
ganze Wirbelsäule, nicht für einen einzelnen Wirbel. Ossa fusi und Verticuli, um welche Niemand mehr frägt, treffen wir im Vesal, unter den Synonymen der Wirbel ${ }^{1}$ ). Ebenso Cubi, als Uebersetzung von \%oßßos im Julius Pollux. Auf Vertebrum - ein fürchterliches Wort - gerieth ich nur im Z erbis. Dass man es auch dem Caelius Aurelianus zuschreibt, dazu hat man eigentlich kein Recht, da im Caelius nur Vertebris, als Dativ des Plurals vorkommt ${ }^{2}$ ), dem man es nicht ankennt, ob sein Nominativus Singularis, Vertebrum oder Vertebra ${ }^{3}$ ) ist. Caelius bedient sich auch des Wortes Vertebrum oder Vertebra, nicht für Wirbel, sondern für Hüftbein (Ischium), in dessen Pfanne sich der Schenkelkopf dreht; vielleicht ist auch der Schenkelkopf selbst damit gemeint.

Die Wirbelbeine der deutschen Sprache hängen ebenso mit wirbeln (im Kreise drehen) zusammen, wie vertebra mit vertere. Deshalb giebt es bei uns Wasserwirbel, Rauchwirbel, Haarwirbel (Scheitel, um welchen die Haare in Kreisen stehen),

1) Op. cit. ad finem Lib. I. Im Caelius Aurelianus wird die Darmverschlingung (Chordapsus) durch Verticula intestinorum interpretirt. Morbi acuti, Lib. III, Cap. 17.

2) Morbi acuti, Lib. I, Cap. 10 und 11 .

3) Nachträglich fand ich aber in den Morbis chronicis des Caelius, zwei Stellen, am Anfang des ersten Capitels des fünften Buches, welche beweisen, dass das mir als zweifelhaft erscheinende Wort, nicht Vertebra, sondern wirklich das horrende Vertebrum ist. Sie lauten: Vertebrorum summitas ipsorum initio terminatur, graeci ischia vocaverunt (ein unklarer Satz), und: Sequitur ischiadicos dolor vertebrorum, quam passionem multi duplicem ischiada vocaverunt. 
und in vertraulicher Rede, auch einen Wirbel per excellentiam, $=$ Rausch.

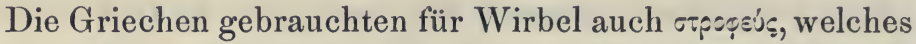
von orpśṣ, drehen, kommt, wie vertebra von vertere ${ }^{1)}$. Hieraus wird es verständlich, warum der erste Halswirbel (Atlas)

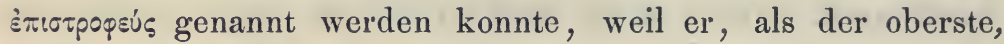
auf den iibrigen Wirbeln aufliegt.

\section{Veru montanum.}

Veru montanum - ein bergiger, oder auf einem Berge stehender Spiess! Man erschrickt förmlich über einen so colossalen Unsinn. Dennoch hält er sich fortan dem Caput gallinaginis zur Seite. Vor Haller wird dieses Unding nie erwähnt. Man begnügte sich mit Caput gallinaceum, nach Eustachius, oder mit Caruncula urethrae, nach Bauhin, oder mit Eminentia rostriformis, Verruca, Monticulus carnosus, nach Riolan, und Caput gallinaginis, nach Regnerus de Graaf ${ }^{2}$ ). Im Haller taucht das Veru montanum zuerst ${ }^{3}$ ) auf. Haller scheint aber den Ausdruck blos zu reproduciren. Ihn erfunden zu haben, getraue ich mir einem so gewandten Lateiner nicht zuzumuthen. Den wahren Auctor vocabuli zu eruiren, gelang mir bisher nicht.

Veru ist Spiess, und zwar Wurf- und Bratspiess ${ }^{4}$ ); montanus, was sich auf Bergen befindet, und poetisch auch gebirgig, wie die Dalmatia montana in Ovid's Briefen ex Ponto. Die fragliche Erhabenheit in der Pars prostatica urethrae,

1) Julius Pollux, Onomasticon, Lib. II, Cap. 4, Num. 130.

2) De virorum organis, Tab. VI, lit. J.

3) Elem. physiol., T. VII, Sect. 1, §. 26.

4) "Subjiciunt verubus prunas, et viscera torquent",

(Virg. Aen. V, 163.) 
ist aber ein langer Kamm, mit einer rundlichen Anschwellung an einem Ende, auf welcher die Ductus ejaculatorii und der Sinus prostaticus münden. Die rundliche Anschwellung kann man Monticulus nennen, wie Plazzonus that. Aber das von diesem Monticulus auslaufende Veru, ist kein Spiess, sondern ein Kamm, Crista. Ein Spiess ist von allen Seiten frei, - eine Crista ist in ihrer ganzen Länge auf einer Fläche angewachsen, also nur ein linearer Aufwurf derselben. Kein vernünftiger Mensch kann eine Crista mit einer rundlichen Anschwellung am Ende, ein Veru montanum nennen. Einen Tropus zu wittern, gebricht es an allen Anhaltspunkten. Crista urethralis ist und bleibt für immer das Entsprechendste. Das populäre Caput gallinaginis des R. de Graaf, ist nur ein verbessertes Caput gallinaceum des Eustachius. Der Kopf eines Scolopax gallinago, Schnepfe, hat einen sehr langen, der Kopf einer Gallina dagegen einen viel kürzeren Schnabel. Die Länge der Crista urethralis mit ihrem rundlichen Ende, verträgt sich also besser mit Schnepfenkopf, als mit Hahnenkopf.

\section{Vesiculae seminales.}

Wie konnte man einen vier bis sechs Zoll langen, mit Divertikeln besetzten, und auf einen Ḱnäuel zusammengeballten Kanal, eine Vesicula nennen? Rondelet und Fallopia, die Erfinder dieser Benennung, kannten nur die äussere Gestalt dieses zusammengeballten Schlauches, welche allerdings den Eindruck einer länglichen und abgeplatteten Blase macht. Diese Blase wurde jedoch erst durch Entfernung ihres Ueberzuges, welcher die Krümmungen und Divertikeln des Schlauches zusammenhält, als ein langer, zusammengeknäuelter Schlauch erkannt, behielt aber seinen alten Namen Vesicula bei, welchen wir ihm auch lassen wollen. Das zellige Ansehen der Durchschnittsfläche der nicht entfalteten Vesicula seminalis, verglich Bartholin mit den Fächern im Inneren der Granatäpfel: 
cavitas granorum mali Punici cellulas, ordine et figura eleganter aemulatur 1$)$.

Es sind die Artikel: Prostata und Parastata, wie auch Epididymis und Plexus pampiniformis nachzusehen.

\section{Vestibulum.}

Vestibulum wurde theils ein offener Raum vor einem grossen Wohnhaus, theils in ältester Zeit das erste Zimmer im Hause selbst (Vorzimmer) genannt, in welchem der Eintretende das Oberkleid der Toga ablegte, um sich blos in der Tunica, in das zweite, eigentliche, vom Rauch des Herdes geschwärzte Wohnzimmer (atrium), zu begeben. Ich halte Vestibulum für ein Derivat von Vestis, Kleid. Das Vestibulum,

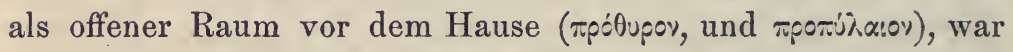
vierseitig. Zwei Seiten desselben bildeten die Nebengebäude des Hauses, die dritte war die Front des Hauses selbst, und die vierte war gegen die Gasse zu offen. Vestibula in diesem Sinne, befanden sich bei allen Pallästen, Tempeln, Curien, und öffentlichen Gebäuden. In der Anatomie tritt uns ein solcher Vorplatz, nur in Meckel's Vestibulum oris, (vordere Mundhöhle, bei geöffnetem Munde), und im Vestibulum vaginae entgegen. Letzteres wurde von dem gelehrten Göttinger Professor, Jac. Huber, in seiner trefflichen Dissertatio de hymene, Gött., 1742, pag. 6, zuerst genannt, als Raum zwischen Scheidenöffnung, kleinen Schamlippen, und Clitoris, - Scheidenvorhof. Alle Anatomen haben diesen Ausdruck angenommen. Sieh' den Artikel: Pronaus.

Als geschlossener und bedeckter Raum oder Vorhalle, wurde Vestibulum für den Vorsaal oder Vorhof des Gehörlabyrinths, von Fallopia eingeführt, und verblieb bei der Anatomie für immer. Vergleiche den Artikel: Atria und Auriculae.

1) Op. cit., Lib. I, Cap. 23. 


\section{Vibrissae.}

Vibrissae, Nasenhaare, sind, ausser der Anatomie, eine inusitata vox. Die Griechen hatten keinen besonderen Namen für sie, und sprechen nur von tpíxes ṕıvós (Glossar. Philoxeni), welche sich den Haaren des Hyporhinion (Oberlippe) anschliessen, und mit ihnen den Mystax (im Athenaeus Bystax) bilden. Für Vibrissae lässt sich kein classischer Zeuge namhaft machen, weshalb auch ihre Schreibart variirt, als Vibrissi (im A. Spigelius ${ }^{1}$ ), und Vibrisci (im Blasius ${ }^{2}$ ). Ueber die Etymologie des Wortes, sagt Festus: ita dicti, quod his evulsis, caput vibretur. Da man bei den Katzen von Schnurrhaaren spricht, schnurren aber $=$ vibrare ist, liegt die Conjectur nahe, dass die Vibrissae eigentlich den Katzen gehören, und figürlich auf den Menschen übersiedelten, an dessen Schnurrbart (nicht Schnurbart) sie Antheil nehmen. Schnurren, die dumpfere Form von Schnarren, wird auf den schwirrenden und brummenden Ton angewendet, welchen die Katzen, die Maikäfer, und die Spinnräder erzeugen. Da man das Schnurren der ersteren, für ein Tremuliren der Lippen hielt, heisst die Schnauze bei den Sachsen, auch Schnurre.

\section{Villi alt und neu.}

In der alten Anatomie galt Villus nur als Faser, insbesondere als Muskelfaser. Von Mundinus, bis zum Beginn des 16. Jahrhunderts, wurde Villus nur in diesem Sinne gebraucht. Selbst im 17. Jahrhundert hielten einzelne Anatomen,

1) De hum. corp. fabrica, Lib. 1, pag. 3 (vibrissae s. vibrissi, pili in narium antro crescentes).

2) Medicina univers. prolegomena, pag. 2 und 157. 
z. B. Laur. Bellini'), an diesem alten Usus fest. Villus ist verwandt mit Pilus, und bedeutet bei den Classikern das Wollhaar der Thiere, auch zottiges Haar, und Moos der Bäume. Das faserige Ansehen dieser Gegenstände, verursachte die Uebertragung von Villus auf Faser und Muskelfaser. Jetzt sind die Villi nur als Darmzotten in Verwendung, und villosus für das feinzottige Ansehen gewisser Häute, bei den Botanikern auch für wollige Blätter und Stängel.

Sieh' den Artikel: Papilla.

\section{Vomer.}

Das Geschichtliche über diesen interessanten Knochen, welchen Oken die Wirbelsäule des Kopfes nannte, lässt sich kurz fassen. Vom Vorner schweigt das griechische und lateinische Alterthum. Er wurde mit den Nasenmuscheln, den Thränenbeinen, den Siebbeinslabyrinthen und ihren Deckplatten (Laminae papyraceue ${ }^{2}$ ), in Bausch und Bogen, als Ossa, quae sunt infra basilare, zusammengeworfen. Vesal hielt ihn für einen Bestandtheil des Siebbeins, und Vidus Vidius für einen Appendix des Keilbeins ${ }^{3}$ ). Fallopia und Columbus proclamirten den Vomer als einen selbstständigen Knochen des

1) De urinis et pulsibus, Bonon., 1683, in praefatione.

2) Eine dünne Knochenplatte papyracea zu nennen, ist ein sehr übel ausgefallener Tropus. Papyraceus war nie papierdick, sondern immer etwas, aus dem Holz oder aus dem Bast der Papyrusstaude Gemachtes.

3) Diese Ansichten haben insofern etwas für sich, als der Vomer schon frühzeitig mit der senkrechten Platte des Siebbeins, und mit dem Rostrum des Keilbeins verwächst, weshalb auch spätere Anatomen, wie Santórini und Lieutaud, die Selbstständigkeit dieses Knoches, nicht zugeben wollten (Blumenbach, Geschichte und Beschreibung der Knochen, pag, 230). 
Oberkiefergerüstes, als undecimum maxillae superioris os, und letzterer gab ihm auch seinen Namen: ejus formam aratri vomer. imitatur 1). Bartholin und Vesling thaten nicht gut, das Pflugscharbein Aratrum oder Os aratro simile zu heissen. Der Knochen hat keine Aehnlichkeit mit einem Pfluge, sondern nur mit dem Eisen eines Pfluges, - der Pflugschar, und zwar nicht mit dem Eisen eines alten römischen Pfluges, welches dreieckig war, wie ein Haifischzahn, und deshalb auch Dens s. Dentale ${ }^{2}$ hiess. Dieses Eisen machte im Boden nur Furchen, während die grosse deutsche Pflugschar, tief in den Boden eingreift, und denselben nicht blos aufreisst, sondern auch wie eine krumme Schaufel umlegt. Da das Pflugscharbein in der Regel nach der einen oder anderen Seite ausgebogen erscheint, fällt die Aehnlichkeit mit diesem breiten und krummen Pflugeisen um so mehr in die Augen.

Dass das Wort Vomer von vomere, sich erbrechen, abstammt, wird Manchen überraschen. Das alte römische Pflugeisen warf die aufgewühlte Erde zu seinen beiden Seiten aus: terram erutam utrimque vomit, heisst es im Varro. - Der älteste und einfachste Pflug war, nach einer in Arezzo aufgefundenen etruskischen Bronze, ein krummer Baumast, dessen eines Ende zugespitzt wurde, um in die Erde besser einzudringen. Der schnellen Abnützung wegen, beschlug man später dieses Ende mit einem Spitz von Eisen ${ }^{3}$ ), welcher noch später, um mehr zu leisten, zu einer dreieckigen, spitzig zulaufenden Platte, ausgehämmert wurde.

Im Griechischen heisst die Pflugschar Uvvı und Uvi६. Plutarch deducirt dieses Wort von üs, sus, Schwein, weil der

1) De re anat., Edit. Veneta, pag. 31.

2) Dens, quod eo mordetur terra, Varro, de lingua latina, V. 135.

3) Daher schreibt es sich, dass auch der Griffel zum Schreiben, Vomer genannt wurde (Isidorus), und Lucretius sich erlauben konnte, das männliche Glied ebenso zu nennen (De rerum natura, IV, 1266). 
Rüssel des erdwühlenden Schweines, zur Erfindung des nützlichsten aller Werkzeuge, den ersten Anlass gab. Das deutsche "Scheidebein" im Sömmerring, lese ich als ein abgekürztes Seheidewandbein, denn der Vomer bildet den unteren grösseren Theil des Septum narium osseum. Wenn die deutschen Anatomen Pflugschaar schreiben, beweisen sie, dass sie sich im Adelung nicht umgesehen haben. Jene aber welche Pflugscharre brauchen, mögen wissen; was jeder Bauer weiss; dass die Pflugscharre ein langer, eisenbeschlagener Stecken ist, mit welchem der Pflüger, die feuchte und fette Erde, welche an die Pflugschar anklebt, wegstösst. Mit diesem Ding, lässt sich unser Knochen nicht vergleichen.

\section{Vulva, Cunnus, und deren Synonyme.}

Die im gewöhnlichen Sprachverkehr verzeihliche Verwechslung der Begriffe: äussere Geschlechtstheile, und Geschlechtstheile überhaupt (als System), trägt die Schuld an der Verwirrung, welche in der Benennung beider herrscht. Die Mehrzahl der alten Anatomen hat für die Gebärmutter nur Ein Wort, die Vulva des Celsus 1), und für die Scheide: Collum vulvae. Nach Plinius war ursprünglich unter Vulva, nur der Uterus der Thiere gemeint: uterus in homine, in reliquis animalibus vulva ${ }^{2}$ ). Besonders war es die Gebärmutter eines zum ersten Mal trächtigen Schweines, welche unter diesem Namen, als Leckerbissen von den Feinschmeckern gerühmt wurde (primiparae suis optima, contra effetis (Plinius, ibid.). Die Schreibart Volva ist nicht ganz veraltet. Volva, von volvere, bezieht sich auf die Eihäute, besonder's das Chorion ${ }^{3}$ ). Die

1) De medicina, Lib. IV, Cap. 1 und 20, Lib. V, Cap. 21, Lib. VI, Cap. 29.

2) Hist. nat., Lib. XI, Cap. 37, Sect. 84 .

3) Varro, de re rustica, Lib. II, Cap. 1. 
Botaniker verstehen unter Volva auch den Calyx membranaceus der Schwämme ${ }^{1}$ ), und Scribonius Largus die Schale der Aepfel und Birnen. Mehrere mit vul beginnende lateinische Worte, theilen das Schicksal der Volva, und werden auch mit der Anfangssylbe vol geschrieben, z. B. Volsella für Vulsella, Pinzette, - Volgus für Vulgus, Volnus für Vulnus, im Plautus, Volcanus für Vulcanus, auf alten Inschriften, Volscus statt Vulscus, im Properz, Volpes für Vulpes, und Volturnus für Vulturnus, ein Fluss in Campanien.

Als das Wort Uterus, die Vulva als Gebärmutter verdrängte, verblieb dieselbe doch dem äusseren weiblichen Genitale - der Scham. Isidorus giebt eine Erklärung für diese Anwendung der Vulva, indem er die beiden grossen Schamlippen, mit Thürflügeln vergleicht, Valvae. Der Vergleich mag insofern hingehen, als die Schamspalte, nicht immer als Rima pudendi, sondern auch als Porta auftritt ${ }^{2}$ ), zu welcher die grossen Schamlefzen dic Thorflügel bilden: pudendum muliebre poëtis Cunnus, communiter Vulva appellatur, quia propter longam fissuram, qua labia genitalium disparantur, valvas aemuletur ${ }^{3}$ ). Valvae, Thürflügel, werden aber niemals vulvae geschrieben, somit kann auch vulva nicht mit valvae in Verbindung gebracht werden, um so weniger, als valvae, immer nur im Plural vorkommen, da ihrer zwei sind, die vulva aber niemals im Plural, da sie nur einmal vorhanden ist. Risum teneatis, wenn Regnerus de Graaf ${ }^{4}$ ) anführt, dass Vulva von volo, ich will, abstammen kann, quia insatiabiliter coitum velit atque desideret, und sich auf den Schrifttext beruft: tria sunt insatiabilia, infernus, os vulvae, et terra. - Cunnus, für äussere Scham, steht im ausschliesslichen Besitz der Dichter, und zwar nur der frivolen:

1) Kühn, im Lex. med. Steph. Blancardi, T. II, pag. 1558.

2) Wie noch in späterer Zeit bei Rolfink, de partibus genitalibus, Lib. II, Cap. 33.

3) Adr. Spigelius, de corp. hum. fabrica, Lib. I, Cap. 4.

4) Op. cit., Cap. II. pag. 218. 
und :

\title{
„Jam fuit ante Helenam cunnus deterrima belli "Causa - - -."
}

\author{
(Horaz, Sat. I.)
}

"Si tibi tam gratus, Baetice, cunnus erat."

$$
\text { (Martial, III, 81.) }
$$

Von diesem Cunnus ${ }^{1}$ ) der Dichter hat die Anatomie ein Andenken im Constrictor cunni bewahrt.

Die grossen Schamlefzen sind die xpnuyoi des Galen (Ränder, auch Geschwürsränder), und die $\gamma_{\varepsilon}(\hat{\imath} \wedge \varepsilon \alpha$ (Lefzen) des Erotianus. Aus letzteren entstanden Haller's Labia majora, und die deutschen Schamlippen oder Schamlefzen. Die zwischen den grossen Schamlippen befindliche Schamspalte, nannten erst die späten Griechen, wie Rufus Ephesius, Schisma (von $\%_{i} \zeta \omega$, spalten), was die Latino-Barbari mit Scissura, und Fissura, die besseren Lateiner mit Rima und Sinus pudendi, auch mit Os genitale (Benedetti), übersetzten. - Die von den Arabisten eingeschleppten Worte: Rupes und Hortus sind erklärbar. Rupes ist eine verunglückte Uebersetzung des Galenischen xppuvós, welches Uferrand und überhaupt etwas Abschüssiges und Steiles, aber auch eine schroffe Felsenmauer (rupes) ausdrückt. Hortus betrifft die äussere Scham nur insofern, als sie mit Haaren bewachsen ist ${ }^{2}$ ). Die Navis der Carmina Priapeia ist $=$ Sinus muliebris. Ein Ueberbleibsel von ihr, erhielt sich in der Fossa navicularis am unteren Schamspaltenwinkel.

Der Saltus des Plautus ${ }^{3}$ ) erweist sich als ein trivialer Tropus: enge Schlucht (Saltus Pyrenaei und Saltus Thermopy-

1) Man will das Wort von xisw, turgere, herleiten, quia inde mulieres gravidae fiunt (Forcellini). Andere versuchen es mit xúolos, Höhlung, im Aristophanes auch weibliche Scham.

2) $\mathrm{K} \tilde{r} \pi \circ \varsigma$, ein Homerisches Wort, ist Garten, Hortus, und erscheint im Suidas und Hesychius, auch als weibliche Scham, der Behaarung wegen.

3) Casina, Act. V, Sc. 2, Vers 39, „saltum inire". 
larum). Porcus und Porca können dem Varro $\left.{ }^{1}\right)$ nur in Hinsicht auf den Geruch des Organs eingefallen sein, denn die Sitte der Römer, bei Hochzeiten ein Schwein zu schlachten, kann doch nimmermehr dahinter stecken. - Das in der anatomischen Synonymik für Vulva aufgeführte Canis, beruht auf einem Missverständniss. Als Uebersetzung des griechischen xúwv, kann es nur die Bedeutung dieses griechischen Wortes haben. Sie ist sehr vielseitig. Eine davon ist Vorhautbändchen (sonst xuyodéfprov). Canis kann somit höchstens für das Frenulum der Schamlippen verwendet werden. Zum Glück kümmert sich die Anatomie um diesen Kram obsoleter Worte nicht, und überlässt ihn den Philologen. Nur ein einziger griechischer Autor - Eustathius - wendet xíws auf das Pudendum muliebre

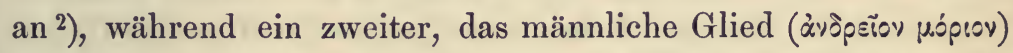
darunter versteht ${ }^{3}$ ). Eines sehr anständigen Ausdruckes für Vulva, bedient sich der Kirchenvater Tertullian: genitalis fovea mulieris.

\section{Xiphoideus.}

Sieh' den Artikel: Manubrium sterni.

\section{Zona orbicularis.}

Jede 'Zona ist kreisrund. Es giebt keine drei- oder viereckigen, oder polygonalen Zonen. Die Zona orbicularis Weberi, der faserknorpelige Aufsatz auf dem kreisrunden Pfannenrand, gehört deshalb zu den Pleonasmen. Zona fibro-cartilaginea wäre das Richtige gewesen. Ligamentum zonale nach Arnold, und Ligamentum orbiculare nach H. Meyer, sind nicht sprachlich,

1) De re rustica, Lib. II, Cap. 4 und 10.

2) Henr. Stephani T'hesaurus linguae graecae, T. II, xúw\%.

3) Joh. Alberti Lexicon Hesychii, T. II, pag. 392. 
sondern anatomisch unrichtig, da die Zona nichts zu verbinden hat. - Da der Randknorpel der Pfanne, den ganz unbescholtenen Namen: Labrum cartilagineum, Limbus cartilagineus, und Margo cartilagineus accessorius, schon seit Jahrhunderten führte, war eine neue Benennung desselben gar nicht nöthig. Supercilium acetabuli, wie $\mathrm{Pi}$ ier anführt, hat er nie geheissen. Blumenbach verstand, unter Supercilium, nur das obere, stark vorspringende Segment des knöchernen Pfannenrandes ${ }^{1}$ ), wie es auch Vesal genommen hat. Cestillus, und das noch ärgere Cesticillus, ebenfalls im Pierer, könnten hingehen, als Diminutive von Cestus (Gürtel), aber der Beisatz cotyloideus müsste wegbleiben, da der Gürtel nicht pfannenförmig ist. Der lateinische Uebersetzer des Winslow, hat den fehlerhaften Ausdruck im Original: bourrelet cotyloidien, auch in der Uebersetzung fortbestehen lassen. Epicotylis würde, wenn man durchaus etwas Neues haben will, allen Anforderungen genügen.

Zona ( $\left.\zeta \omega \vee \eta_{1}\right)$ ist primitiv der Gürtel um den Leib. Jungfrauen mussten ihn tragen. Bei der Hochzeit, eigentlich vor dem Eintritt in das Schlafgemach, wurde die jungfräuliche Zona der Braut, von der Brautführerin, Pronuba, abgenommen, und der Diana, als Keuschheitsgöttin offerirt. Zonam solvere = entjungfern. Die Männer trugen ihr Geld in der Zona, wie Abraham schon im alten Testament, und jetzt noch die Morgenländer auf Reisen. Wir kennen: Zonas plenas, inanes retuli, bin als armer Mann zurückgekommen, im Aulus Gellius, und zonam perdere, verarmen, im Horaz.

Die Himmelszonen, und der im Kreise um den Leib sich

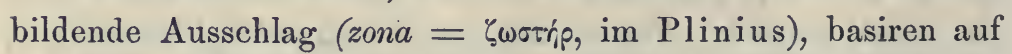
der kreisrunden Zona. Erotianus gedenkt der Zona, als Gegend des Unterleibes unter den Rippen, weil hier der Gürtel getragen wurde. Ebenso Foësius und Gorraeus.

Es ergiebt sich aus dem hier Gesagten zugleich das Urtheil; ob andere anatomische Gegenstände mit Recht oder

1) Geschichte und Beschreibung der Knochen, pag. 336. 
Unrecht Zonae genannt wurden. Die Zona castitatis und virginitatis im Riolan, als Synonym von Hymen, und die Zonula Zinnï, als ringförmiges Haltband der Linsenkapsel sind ganz richtig, während die Zona spiralis Valsalvae ${ }^{1}$ ), als häutiges Spiralblatt der Schnecke, schon lange in die Lamina spiralis umgetauft werden musste, weil eine Spirale kein Kreis ist. Die Zonae nerveae complanatae des Valsalva ${ }^{2}$ ) (häutige Bogengänge), mussten aus demselben Grunde, den Canales semicirculares membranacei Platz machen, gleichwie die Zona cartilaginea tarsi, welche vom Sustentaculum des Fersenbeins zum Höcker des Kahnbeins geht, und der Sehne des Tibialis posticus zur Unterlage dient, schon von Weitbrecht in die richtige Trochlea cartilaginea umgeschrieben wurde.

\section{Zygoma und Zygomaticus.}

Der Jochbogen heisst im Galen: Zygoma ${ }^{3}$ ), weil er durch die Verbindung zweier Knochen, des Schläfebeins und

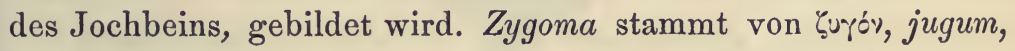

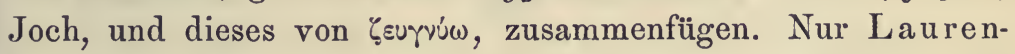
tius hielt das Galen'sche Wort in Ehren*), - alle Anderen gebrauchten Jugum und Jugamentum. Später entstand, und lebt bis zur Stunde, der Arcus s. Pons zygomaticus. Hiemit wurde ein neues, den Griechen unbekanntes Beiwort: zygomaticus eingeweiht, welches Riolan erfand, um den grossen Jochmuskel damit auszustatten ${ }^{5}$ ), und welches seither sehr zahlreiche Anwendungen gefunden hat, da alles, was zum

1) Tractatus de aure humana, Bonon., 1704, Lib. I, Cap. 3.

2) Loco citato.

3) Oribasius, Op. cit., pag. 138.

4) Hist. anat., Lib. II, Cap. 17.

5) Op. cit., Lib. V, Cap. 12.

Hyrtl. Onomatologia anatomica. 
Jochbein, oder zur Jochbrücke in Beziehung steht, zygomaticus genannt wird.

Die Processus zygomatici des Stirnbeins nannten die Araber: Cornua. Bacchus wurde mit kleinen Hörnern dargestellt. Sein griechischer Name ist Dionysos. So wird es uns verständlich, wie im Pierer und Choulant, die Jochfortsätze des Stirnbeins, Dionysisci genannt werden konnten.
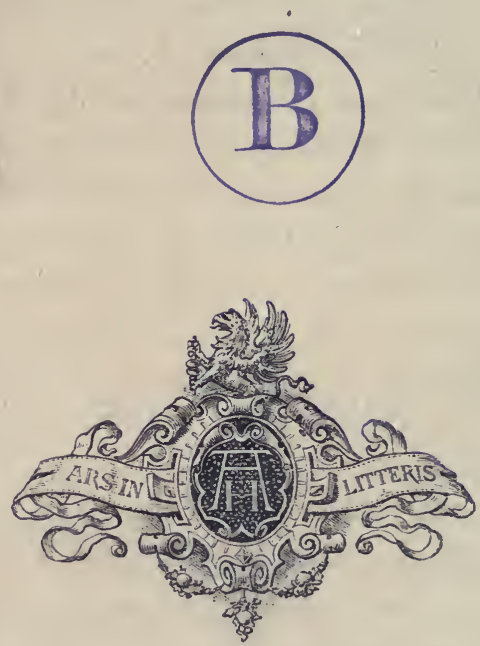

33474 





\title{
H82
}

Hyrt1, Joseph

Onomatologia Anatomica

Biological

\& Medical

\author{
PLEASE DO NOT REMOVE \\ CARDS OR SLIPS FROM THIS POCKET
}

\section{UNIVERSITY OF TORONTO LIBRARY}


